\title{
Die Offenbarung des Johannes
}

\author{
Dr. Ludwig Neidhart
}

(c) Ludwig Neidhart, Athen 1994, Augsburg, 2017

überarbeitete Version: Augsburg, 01. Juni 2022 


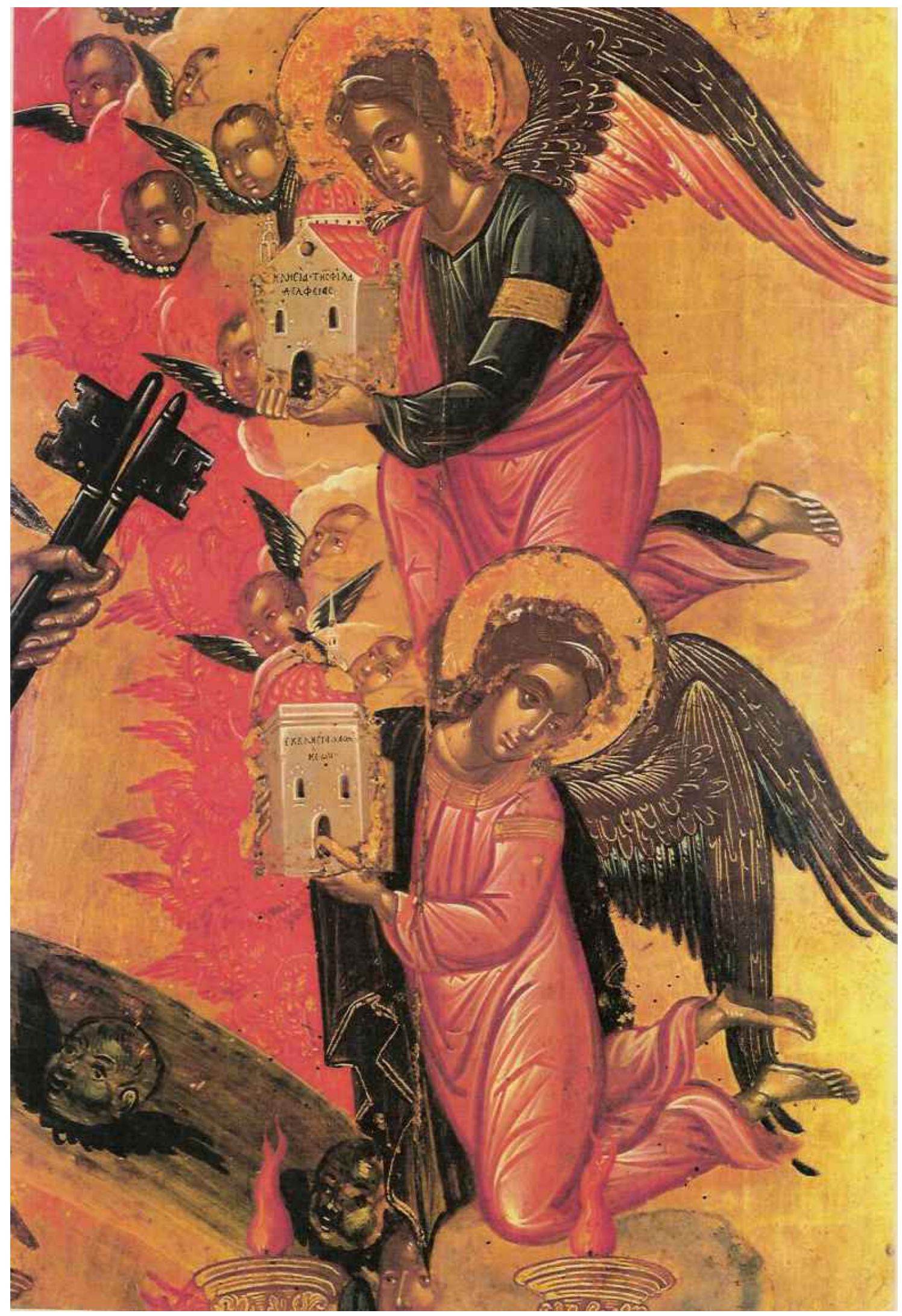

Ikone in der „Höhle der Apokalypse“ auf Patmos (Ausschnitt) 


\section{Inhaltsverzeichnis}

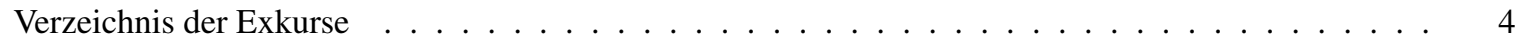

Verzeichnis der Abbildungen, Tabellen und Listen . . . . . . . . . . . . . . . . . . . 5

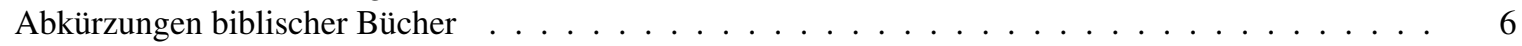

1 Einleitung $\quad 7$

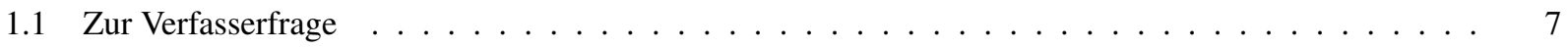

1.2 Wo und wann wurde das Buch geschrieben? . . . . . . . . . . . . . . . . . . . . 8

1.3 Verschiedene Auslegungsrichtungen . . . . . . . . . . . . . . . . . . . . . . . . 8

1.4 Gesamtaufbau . . . . . . . . . . . . . . . . . . . . . . . . 10

2 Auslegung 1

2.1 Apk 1,1-20: Gruß und Eingangsvision . . . . . . . . . . . . . . . . . . . . 11

2.2 Apk 2,1 - 3,22: Die Briefe an die sieben Ortskirchen . . . . . . . . . . . . . . . . . . . . . 24

2.2.1 Apk 2,1-7: Erster Brief (an die Kirche von Ephesus) . . . . . . . . . . . . . . . . . . 25

2.2.2 Apk 2,8-11: Zweiter Brief (an die Kirche von Smyrna) . . . . . . . . . . . . . . . . . . . . . . . 29

2.2.3 Apk 2,12-17: Dritter Brief (an die Kirche von Pergamon) . . . . . . . . . . . . . . . . 31

2.2.4 Apk 2,18-29: Vierter Brief (an die Kirche von Thyatira) . . . . . . . . . . . . . . . . . . 33

2.2.5 Apk 3,1-6: Fünfter Brief (an die Kirche von Sardes) . . . . . . . . . . . . . . . . . . . 36

2.2.6 Apk 3,7-13: Sechster Brief (an die Kirche von Philadelphia) . . . . . . . . . . . . . . . . . 39

2.2.7 Apk 3,14-22: Siebter Brief (an die Kirche von Laodizea) . . . . . . . . . . . . . . . . . . . 43

2.3 Apk 4,1-5,14: Vision des Himmels . . . . . . . . . . . . . . . . . . . . . . . . . . . . . . . . . . . . . . . . . . . . .

2.4 Apk 6,1-8,5: Die Öffnung der sieben Siegel . . . . . . . . . . . . . . . . . . . . . . 6 61

2.4.1 Apk 6,1-2: Erstes Siegel (Der weiße Reiter) . . . . . . . . . . . . . . . . . . . . . . . 62

2.4.2 Apk 6,3-4: Zweites Siegel (Der rote Reiter) . . . . . . . . . . . . . . . . . . . . . . 62

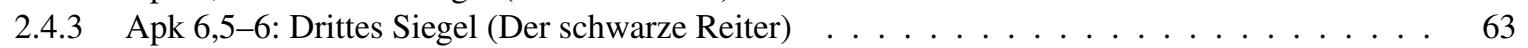

2.4.4 Apk 6,7-8: Viertes Siegel (Der bleiche Reiter) . . . . . . . . . . . . . . . . . . . . . 65

2.4.5 Apk 6,9-11: Fünftes Siegel (die Märtyrer unter dem Altar) . . . . . . . . . . . . . . . . . . 67

2.4.6 Apk 6,12-17: Sechstes Siegel, Teil 1 (allgemeine Beschreibung der Strafgerichte) . . . . . . . 69

2.4.7 Apk 7,1-8: Sechstes Siegel, Teil 2 (Bewahrung von 144000 vor dem ersten Gericht) . . . . . 71

2.4.8 Apk 7,9-17: Sechstes Siegel, Teil 3 (Rettung Unzähliger aus dem letzten Gericht) . . . . . . . 74

2.4.9 Apk 8,1-5: Siebtes Siegel (Vorbereitung auf das Blasen der Posaunen) . . . . . . . . . . . . 77

2.5 Apk 8,6 - 11,19: Das Blasen der sieben Posaunen . . . . . . . . . . . . . . . . . . . . . 79

2.5.1 Apk 8,6-9: Erste und zweite Posaune (jüdische Aufstände 115-135) . . . . . . . . . . . . . 80

2.5.2 Apk 8,10-11: Dritte Posaune (Bar Kochba 135) . . . . . . . . . . . . . . . . . . . 82

2.5.3 Apk 8,12: Vierte Posaune (Verdunkelung Christi nach 135) . . . . . . . . . . . . . . . 83

2.5.4 Apk 8,13: Zwischenruf als Einleitung zu den letzten drei Posaunen . . . . . . . . . . . . . . . . 84

2.5.5 Apk 9,1-12: Fünfte Posaune (die Sekte Theodots 190 bis 268) . . . . . . . . . . . . . . . 86

2.5.6 Apk 9,13-21: Sechste Posaune, Teil 1 (Barbareneinfall ins Reich ab 250) . . . . . . . . . . . 93

2.5.7 Apk 10,1-11: Sechste Posaune, Teil 2 (Vorbereitung auf weitere Weissagungen) . . . . . . . 97

2.5.8 Apk 11,1-14: Sechste Posaune, Teil 3 (Plagen durch verfolgte Christen, 303-312) . . . . . . 101

2.5.9 Apk 11,15-19: Siebte Posaune (Signal für den Sieg über Rom, 312) . . . . . . . . . . . . . 112

2.6 Apk 12,1-8: Der Drache und die Frau . . . . . . . . . . . . . . . . . . . . . . . . . 115

2.7 Apk 13,1-18: Die zwei Tiere . . . . . . . . . . . . . . . . . . . . . . . . . 128

2.8 Apk 14,1-5: Das Lamm und die 144.000 . . . . . . . . . . . . . . . . . . . . . . . . . 160

2.9 Apk 14,6-20: Vorankündigung des Gerichts . . . . . . . . . . . . . . . . . . . . . . . 162

2.10 Apk 15,1 - 16,21: Die Ausgießung der sieben Schalen . . . . . . . . . . . . . . . . . . 171

2.10.1 Apk 15,1 - 16,1: Vorbereitung der Schalenausgießung . . . . . . . . . . . . . . . 171 
2.10 .2 Apk 16,2: Erste Schale (Geschwür) … . . . . . . . . . . . . . . . . . . . . . . . 173

2.10.3 Apk 16,3: Zweite Schale (das Meer wird zu Blut) . . . . . . . . . . . . . . . . . . 174

2.10.4 Apk 16,4-7: Dritte Schale (Flüsse und Quellen werden zu Blut) … . . . . . . . . . . . 174

2.10 .5 Apk 16,8-9: Vierte Schale (Sonnenhitze) … . . . . . . . . . . . . . . . . . . 175

2.10.6 Apk 16,10-11: Fünfte Schale (Finsternis) … . . . . . . . . . . . . . . . . . . . . 175

2.10.7 Apk 16,12-16: Sechste Schale (Vorbereitung zur Schlacht) . . . . . . . . . . . . . . 176

2.10 .8 Apk 16,17-21: Siebte Schale (Erdbeben) … . . . . . . . . . . . . . . . . . . 177

2.11 Apk 17,1 - 19,10: Das Gericht über die Stadt … . . . . . . . . . . . . . . . . . . 179

2.12 Apk 19,11-21: Das Gericht über die beiden Tiere . . . . . . . . . . . . . . . . . . . . . 201

2.13 Apk 20,1-6: Das Tausendjährige Reich (Millenium) . . . . . . . . . . . . . . . . . . . 204

2.14 Apk 20,7-15: Das Endgericht . . . . . . . . . . . . . . . . . . . . . . 213

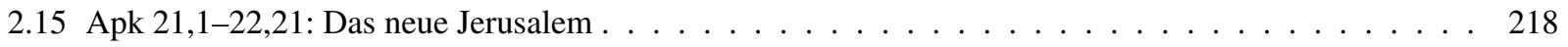

$\begin{array}{ll}\text { Literaturverzeichnis } & 241\end{array}$

$\begin{array}{lll}\text { Index } & 243\end{array}$

\section{Verzeichnis der Exkurse}

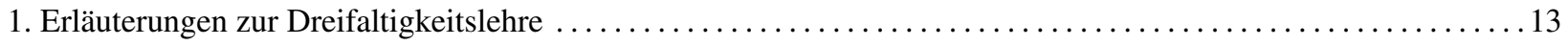

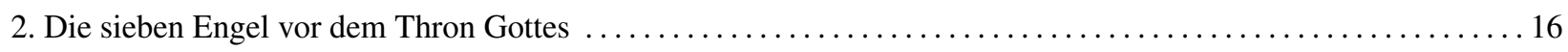

3. Paradies, Himmel, Hades, Hölle, Fegfeuer und Limbus in der Bibel $\ldots \ldots \ldots \ldots \ldots \ldots \ldots \ldots \ldots \ldots \ldots \ldots \ldots$

4. Die Symbolik der Zahlen drei, vier, zwölf und vierundzwanzig $\ldots \ldots \ldots \ldots \ldots \ldots \ldots \ldots \ldots \ldots \ldots \ldots \ldots \ldots$

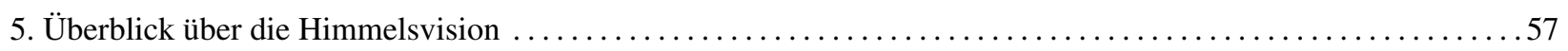

6. Überblick über die in Kapitel 11 und 12 angesprochenen Zeitphasen und Ereignisse $\ldots \ldots \ldots \ldots \ldots \ldots \ldots \ldots$

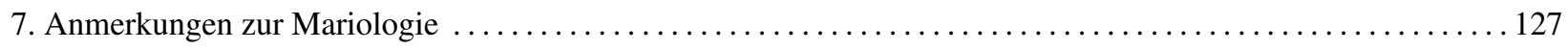

8. Gibt es im Neuen Testament ein absolutes Tötungsverbot? ................................ 134

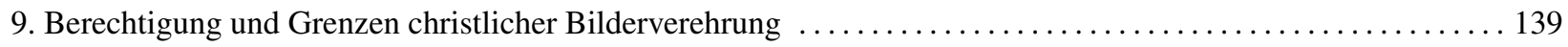

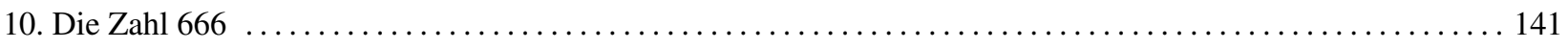

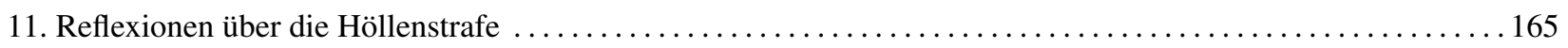

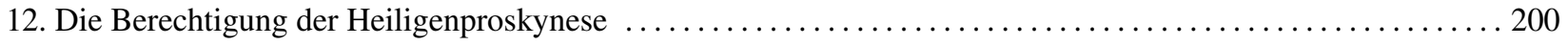




\section{Verzeichnis der Abbildungen, Tabellen und Listen}

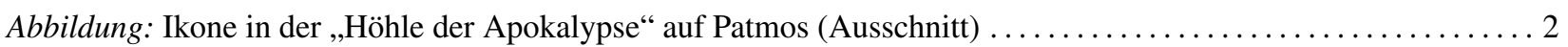

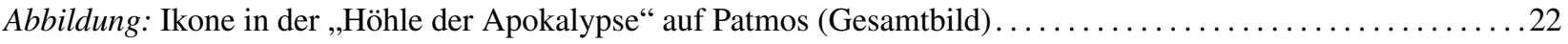

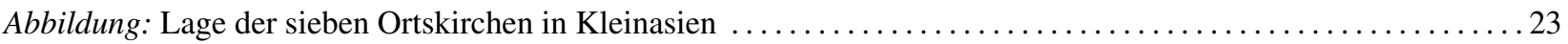

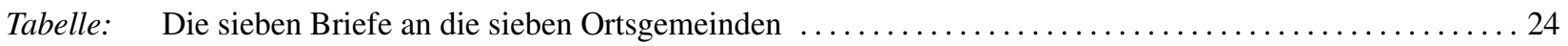

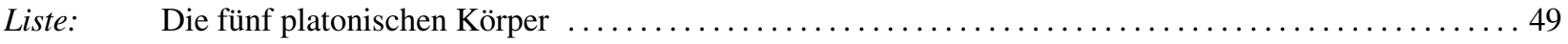

Liste: $\quad$ die zehn großen Verfolgungsphasen im Römischen Reich von 64 bis 312 n.Chr. ............6 63

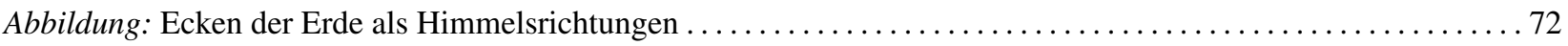

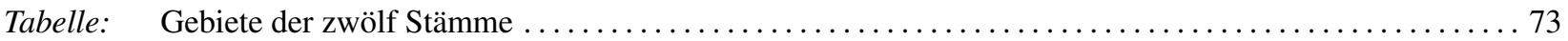

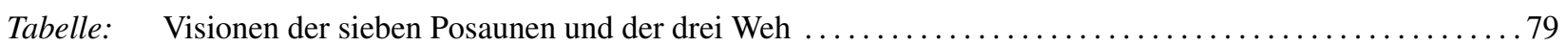

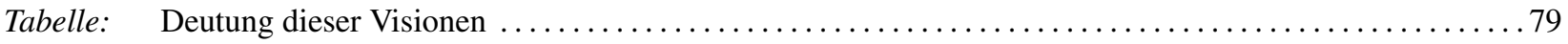

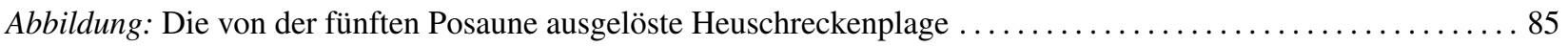

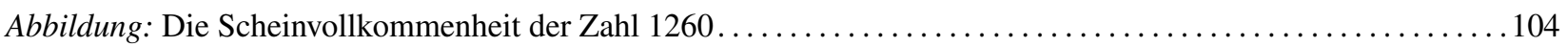

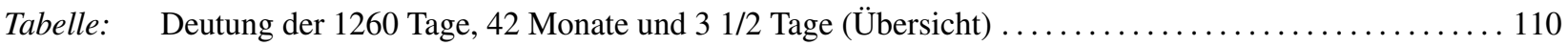

Tabelle: $\quad$ Deutung der 1260 Tage, 42 Monate und $31 / 2$ Tage (im Detail) $\ldots \ldots \ldots \ldots \ldots \ldots \ldots \ldots \ldots$

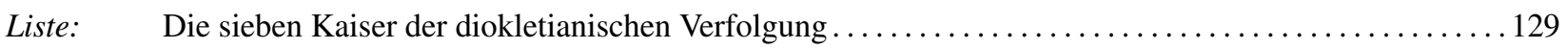

Tabelle: Zahlenwerte der hebräischen, griechischen und lateinischen Buchstaben .................

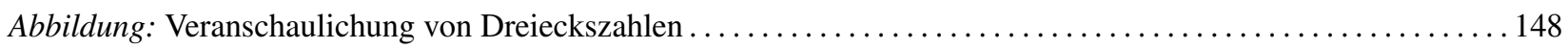

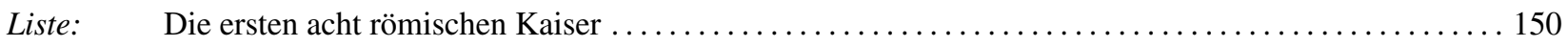

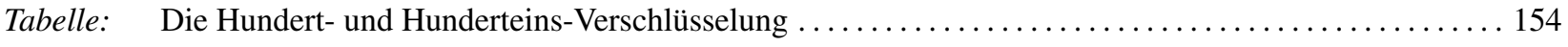

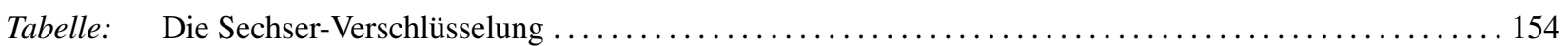

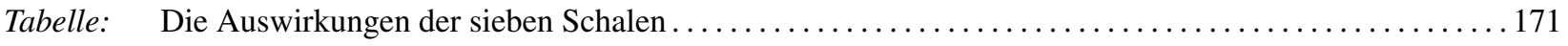

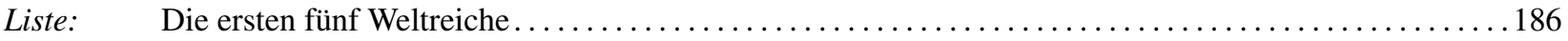

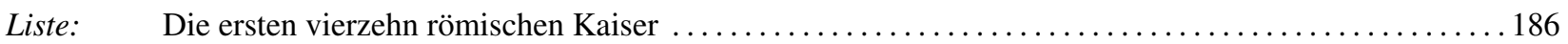

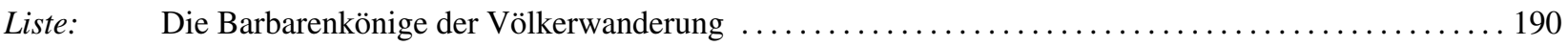

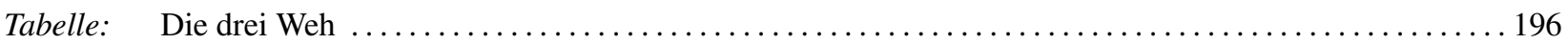




\section{Abkürzungen biblischer Bücher}

\begin{tabular}{|c|c|c|c|}
\hline & ALTES TESTAMENT & & NEUES TESTAMENT \\
\hline Gen & $\begin{array}{l}\text { 1. Buch Mose } \\
\text { (oder Genesis) }\end{array}$ & $\begin{array}{l}\text { Mt } \\
\mathrm{Mk}\end{array}$ & $\begin{array}{l}\text { Evangelium nach Matthäus } \\
\text { Evangelium nach Markus }\end{array}$ \\
\hline Ex & $\begin{array}{l}\text { 2. Buch Mose } \\
\text { (oder Exodus) }\end{array}$ & $\begin{array}{l}\text { Lk } \\
\text { Joh }\end{array}$ & $\begin{array}{l}\text { Evangelium nach Lukas } \\
\text { Evangelium nach Johannes }\end{array}$ \\
\hline Lev & $\begin{array}{l}\text { 3. Buch Mose } \\
\text { (oder Levitikus) }\end{array}$ & $\begin{array}{l}\text { Apg } \\
\text { Röm }\end{array}$ & $\begin{array}{l}\text { Apostelgeschichte } \\
\text { Paulusbrief }\end{array}$ \\
\hline Num & $\begin{array}{l}\text { 4. Buch Mose } \\
\text { (oder Numeri) }\end{array}$ & 1 Kor & $\begin{array}{l}\text { an die Römer } \\
\text { Paulusbrief }\end{array}$ \\
\hline Dt & $\begin{array}{l}\text { 5. Buch Mose } \\
\text { (oder Deuteronomium) }\end{array}$ & 2 Kor & $\begin{array}{l}\text { an die Korinther } \\
\text { Paulusbrief }\end{array}$ \\
\hline Jos & Buch Josua & & an die Korinther \\
\hline $\mathrm{Ri}$ & Buch der Richter & Gal & Paulusbrief \\
\hline Rut & Buch Rut & & an die Galaler \\
\hline $1 \mathrm{Sam}$ & 1. Buch Samuel & Eph & Paulusbrief \\
\hline $2 \mathrm{Sam}$ & 2. Buch Samuel & an die Epheser & \\
\hline 1 Kön & 1. Buch der Könige & Phil & Paulusbrief \\
\hline 2 Kön & 2. Buch der Könige & & an die Philipper \\
\hline $1 \mathrm{Chr}$ & 1. Buch der Chronik & Kol & Paulusbrief \\
\hline $2 \mathrm{Chr}$ & 2. Buch der Chronik & & an die Kolosser \\
\hline Esra & Buch Esra & 1 Thess & 1. Paulusbrief \\
\hline Neh & Buch Nehemia & & an die Thessalonicher \\
\hline Tob & Buch Tobit & 2 Thess & 2. Paulusbrief \\
\hline Jdt & Buch Judit & & an die Thessalonicher \\
\hline Est & Buch Esther & $1 \mathrm{Tim}$ & 1. Paulusbrief \\
\hline 1 Makk & 1. Buch der Makkabäer & & an Timotheus \\
\hline 2 Makk & 2. Buch der Makkabäer & $2 \mathrm{Tim}$ & 2. Paulusbrief \\
\hline Job & Buch Job (oder Hiob) & & an Timotheus \\
\hline Ps & Buch der Psalmen & Tit & Paulusbrief \\
\hline Spr & Buch der Sprichwörter & & an Titus \\
\hline Koh & Buch Kohelet (Prediger) & Phlm & Paulusbrief \\
\hline Hld & Hoheslied & & an Philemon \\
\hline Weish & Buch der Weisheit & Hebr & Paulusbrief (?) \\
\hline Sir & Buch Jesus Sirach & an die Hebräer & \\
\hline Jes & Buch des Propheten Jesaja & Jak & Jakobusbrief \\
\hline Jer & Buch des Propheten Jeremia & 1 Petr & 1. Petrusbrief \\
\hline $\mathrm{Klgl}$ & Buch der Klagelieder & 2 Petr & 2. Petrusbrief \\
\hline Bar & Buch des Baruch & $1 \mathrm{Joh}$ & 1. Johannesbrief \\
\hline $\mathrm{Ez}$ & Buch des Propheten Ezechiel & $2 \mathrm{Joh}$ & 2. Johannesbrief \\
\hline Dan & Buch des Propheten Daniel & $3 \mathrm{Joh}$ & 3. Johannesbrief \\
\hline Hos & Buch des Propheten Hosea & Jud & Judasbrief \\
\hline Joel & Buch des Propheten Joel & Apk / Offb & Apokalypse / Offenbarung des Johannes \\
\hline Am & Buch des Propheten Amos & & \\
\hline Obd & Buch des Propheten Obadja & & \\
\hline Jona & Buch des Propheten Obadja & & \\
\hline $\mathrm{Mi}$ & Buch des Propheten Micha & & \\
\hline Nah & Buch des Propheten Nahum & & \\
\hline $\mathrm{Hab}$ & Buch des Propheten Habakuk & & \\
\hline Zef & Buch des Propheten Zefanja & & \\
\hline Hag & Buch des Propheten Haggai & & \\
\hline Sach & Buch des Propheten Sacharja & & \\
\hline Mal & Buch des Propheten Maleachi & & \\
\hline
\end{tabular}




\section{Einleitung}

\subsection{Zur Verfasserfrage}

Das im Neuen Testament an letzter Stelle stehende Buch beginnt im griechischen Urtext mit dem Titel „Apokalypse“ (deutsch: „Offenbarung“) und wird gewöhnlich als Apokalypse des Johannes (Abkürzung Apk) oder Offenbarung des Johannes (Abkürzung Offb) oder auch Geheime Offenbarung des Johannes bezeichnet, denn der Verfasser nennt im Text an vier Stellen seinen Namen JoHANnES $(1,1 ; 1,4 ; 1,9 ; 22,8)$.

Dabei handelt es sich aller Wahrscheinlichkeit nach um den Apostel JoHANNES, einen der zwölf engsten Jünger Jesu. Dies beweisen die ältesten Quellen, die wir zur Frage des Verfassers der Apokalypse heranziehen können:

- Die älteste Quelle ist die Schrift „Dialog mit Tryphon“ (Kap. 81,4) des christlichen Philosophen und Märtyrers JUSTIN, die vor dem Jahre 160 abgefasst wurde. „Johannes, einer der Apostel Christi“, so schreibt JustiN, habe „,aufgrund einer Offenbarung ... prophezeit“. JUSTIN ist Anfang des 2. Jahrhunderts in Palästina geboren, so dass er in unmittelbarer zeitlicher und örtlicher Nähe zur jüdischen Urkirche stand. Außerdem hielt sich JUSTIN öfter in Ephesus auf, wo er sich auch (um 135 n. Chr.) zum Christentum bekehrte. Ephesus war aber die Stadt, wo der Apostel JoHANneS nach einhelliger Aussage der Tradition gegen Ende seines Lebens gewirkt hat und gestorben ist. Somit könnte JUSTIN seine Informationen direkt von den Bewohnern von Ephesus erhalten haben, von denen damals noch viele JOHANNES gekannt haben müssen.

- Ebenso wichtig wie das Zeugnis JUSTINs ist das Zeugnis des Bischofs IRENÄUS VON LYON, der in seiner Schrift „Adversus Haereses“ (um 180-185) als Verfasser der Apokalypse JOHANNES, ,den Jünger des Herrn“ nennt, ${ }^{1}$ ein Ausdruck, der bei IrenäUs den Apostel Johannes meint (vgl. 2. Buch, Kap. 22,5). Das Zeugnis des IRENÄUS ist vor allem deshalb von großem Wert, weil IRENÄUS ein Schüler von POLYKARP war, der seinerseits noch persönlich mit dem Apostel JOHANNES zusammengetroffen ist. Dies geht hervor aus einem Brief des IRENÄUS an FLORINUS, wo er von seinen Jugenderinnerungen spricht: „Ich kann auch noch den Ort angeben, wo der selige Polykarp saß, wenn er sprach, auch die Plätze, wo er aus- und einging, auch seine Lebensweise, seine körperliche Gestalt, seine Reden vor dem Volke, seine Erzählung über den Verkehr mit Johannes und den anderen Personen, die den Herrn noch gesehen haben, seinen Bericht über ihre Lehren, ferner das, was er von diesen über den Herrn, seine Wunder und seine Lehre gehört hatte. “2

Die Autorenschaft des Apostels JoHANnes wurde im Altertum wohl nur deshalb von einigen Kirchenlehrern bestritten, ${ }^{3}$ weil die Apokalypse wegen ihrer Auslegungsschwierigkeiten von gewissen Irrlehrern falsch gedeutet wurde. Als diese Irrlehren überwunden waren, setzte sich die ursprüngliche Überzeugung wieder durch, dass der Apostel JOHANNES der Verfasser sei.

In der modernen Bibelwissenschaft ist jedoch der Verfasser umstritten. Nach wie vor treten zahlreiche Bibelwissenschaftler für den Apostel als Verfasser ein (z.B. Beckwith, Hadorn, Albertz, Feine-Behm, Guthrie, HarRiSON, HöPfl-Gut, MARIANi, Michaelis, POHL, RoHR, DE ZWAAN und vor allem Allo mit seiner ausführlichen Untersuchung der Verfasserfrage). Weitaus mehr Gehör und Beifall findet heute jedoch die Meinung, dass die Apokalypse von irgendeinem unbekannten Johannes geschrieben wurde. Der Grund für die weit verbreitete Ablehnung der Autorenschaft des Apostels scheint mir jedoch nicht eine klare Widerlegung der traditionellen Auffassung zu sein, sondern die Geisteshaltung des modernen Menschen, dem klare Feststellungen und Identifizierungen missfallen, weil er durch solche Feststellungen seine Freiheit bedroht sieht, die er im Nebel der Ungewissheit und in der darauf beruhenden Beliebigkeit des Denkens, Meinens und Handelns zu finden meint. Dies wäre ein Thema für sich, auf das ich hier jedoch nicht näher eingehen kann.

\footnotetext{
Vgl. Adversus Haereses 5. Buch, Kap. 26,1.

Zitiert nach EUSEBIUS, Kirchengeschichte 5,20,6).

Namentlich bestritten dies die Bischöfe Dionysius von ALEXANDRIEN (†264) und EusEBIUS VON CAESAREA $(† 337 / 41)$.
} 
Die meistgebrauchten Argumente gegen den Apostel als Verfasser sind, dass der Verfasser andere Gedanken vorträgt und einen anderen Sprachstil benutzt als der Verfasser des Johannesevangeliums, welches dem Apostel JOHANNES, wie man teilweise glaubt, näher steht als die Apokalypse (obgleich meist auch das Evangelium dem Apostel abgestritten wird). Was zunächst die verschiedene Gedankenwelt angeht, so sagt man z. B., das Evangelium sei am irdischen Leben Jesu interessiert, aber die Apokalypse erwähne nur seinen Tod (W. G. KÜMMEL). Oder: das Evangelium sei nur an der Jetztzeit interessiert, in der Apokalypse werde dagegen ,eine Folge endzeitlicher Geschehnisse dargestellt, die abrollen muss“ (E. LOHSE). Aber wen wundert dies eigentlich? Dass die Apokalypse nach Inhalt und Form vom Evangelium abweichen muss, ist eigentlich selbstverständlich, wenn man die verschiedene Themenstellung der beiden Bücher bedenkt. Im übrigen aber finden wir in beiden Schriften sehr ähnliche Gedanken, z. B. wird Jesus bezeichnet als „Zeuge“ für die Wahrheit (Joh 18,37, Apk 1,5), als „Lamm“ (Joh 1,36, Apk 5,5-6), als „Wort Gottes“ (Joh 1,1, Apk 19,13), als ,der Wahrhaftige“ (1 Joh 5,10, Joh 1,9, 6,32, 15,1, Apk 3,7) und als Lebensspender (Joh 11,25, Apk 1,18). In beiden Schriften erfolgt der Hinweis auf die Durchbohrung Christi am Kreuz unter Zitierung der alttestamentlichen Sacharja-Weissagung (Joh 19,37; Apk 1,7) usw.

Was sodann die Differenzen im Sprachstil betrifft, so ist festzustellen, dass der griechische Stil des Evangeliums besser sei als der ziemlich grobe und dem Hebräischen bzw. Aramäischen sehr nahe Stil der Apokalypse. Aber dies beweist nichts. Denn in Patmos, wo JoHANNEs in der Verbannung lebte, hatte er höchstwahrscheinlich keinen griechischen Sekretär, der ihn hätte stilistisch verbessern können; wir haben hier deshalb die ungehobelte Ausdrucksweise des Nichtgriechen JoHANnes vor uns. Das Evangelium dagegen, das JoHANnES gemäß der Tradition nach seiner Heimkehr aus Patmos geschrieben hat, ist sehr wahrscheinlich von einem Sekretär stilistisch revidiert und mit einem Anhang (Kap. 22) versehen worden. Das bessere Griechisch des Evangeliums kann also problemlos „durch eine literarische Beihilfe erklärt werden“ (M. MEINERTZ).

Ein drittes Argument, das oft gegen den Apostel als Verfasser angeführt wird ist, dass der Verfasser in einer Vision die Namen der 12 Apostel auf den Grundsteinen des neuen Jerusalem sieht $(21,14)$, aber mit keinem Hinweis andeutet, dass er selber dazugehört. Aber auch dieses Argument überzeugt nicht. Denn wieso hätte der Apostel JOHANNES sein Dabeisein unter den Aposteln extra betonen müssen? Hätte das nicht hochmütig und eines Jüngers Jesu unwürdig geklungen: „Ich sah die Namen der 12 Apostel und darunter auch meinen eigenen?“

\subsection{Wo und wann wurde das Buch geschrieben?}

Abfassungsort ist die Insel Patmos, wie aus der Apokalypse selbst hervorgeht: „Ich, Johannes, euer Bruder und Teilhaber an der Bedrängnis ... kam auf die Insel, die Patmos genannt wird ... Ich wurde vom Geist entrückt am Herrentag (= Sonntag) und hörte hinter mir eine laute Stimme .... Was du siehst, schreibe in ein Buch“ (Apk 1,9-11).

JOHANNES befand sich also auf der griechischen Insel Patmos und schrieb das Buch aufgrund einer Vision, die er dort an einem Sonntag hatte. JOHANNES spricht von einer Bedrängnis, offenbar einer Christenverfolgung, während derer er nach Patmos geflüchtet ist oder verbannt worden war. In Frage käme die erste Christenverfolgung unter NERO (64-68) oder die zweite unter DoMiTiAn (ca. 94-96). Aber die neronische Verfolgung wütete anscheinend nur in Rom und Umgebung, so dass sehr wahrscheinlich an die Verfolgung Domitians, in dessen letzten Regierungsjahren gemeint ist, die partiell auch im Osten des Reiches wütete. Dass die Apokalypse tatsächlich in den letzten Jahren des Kaisers DOMITIAN verfasst wurde, bezeugt in verlässlicher Weise wieder IRENÄUS $†$ 202), der Schüler eines Schülers des JOHANNES, welcher der früheste altkirchliche Zeuge ist, der überhaupt etwas über die Entstehungszeit der Apokalypse berichtet. IRENÄUS schreibt im 5. Buch seiner Schrift „Adversus Haereses“ im 30. Kapitel, dass die Apokalypse „nicht vor langer Zeit geschaut wurde, nämlich fast in unserer Generation, am Ende der Herrschaft des Domitian“. Der älteste Kirchengeschichtsschreiber, EusEBIUS von Caesarea († zwischen 337 und 341) vermerkt in seiner „Chronik“ noch genauer, dass die Apokalypse im 14. Jahr der Regierung Domitians geschrieben wurde, d. h. 95 n. Chr.

\subsection{Verschiedene Auslegungsrichtungen}

1. Das Buch wird oft als geheimnisvolle Prophetie betrachtet, die fast ausschließlich von den letzten Jahren der Menschheitsgeschichte handelt (endgeschichtliche Auslegung). So legen es meist die Sekten, aber auch viele katholische, evangelische und orthodoxe Ausleger aus (J. Gagnaeus, F. De Ribera, R. Bellarmin, Cornelius a Lapide, R. Cornely, L. C. Fillion, J. Sickenberger, evangelischerseits Th. Zahn). Die ausführlichste Auslegung dieser Art ist wohl die des flämischen Jesuiten CoRnelius A LAPIDE (1625). Aber während CoRNELIUS A LAPIDE 
eine ziemlich wörtliche endgeschichtliche Auslegung vertritt, sehen die Sekten in der Apokalypse meist die neuesten politischen Ereignisse der Gegenwart vorhergesagt (symbolische endgeschichtliche Auslegung), so dass sie ihre Auslegung immer wieder ändern und dem tatsächlichen Verlauf der Ereignisse anpassen müssen. Daher ist ihre Auslegung meist mehrdeutig und sehr anpassungsfähig.

Meines Erachtens ist jedoch eine in allem wörtliche und damit für jedermann sofort einsichtige Erfüllung der Prophetie unwahrscheinlich. Sobald die Menschen nämlich sehen würden, dass die ersten Prophezeiungen beginnen, sich zu wörtlich erfüllen, würden sie, wie mir scheint, nicht mehr nach dem prophezeiten Muster handeln: Z. B. würde dann wohl auch der Antichrist aus Angst vor der prophezeiten Strafe in sich gehen und aufhören, die Christen in der angegebenen Weise zu verfolgen.

Aber auch die ,symbolische endgeschichtlichen Auslegung“, wonach die Apokalypse in detaillierter, aber verschlüsselter und damit nicht hundertprozentig eindeutiger Form die Ereignisse unmittelbar vor dem Ende der Geschichte beschreibt, scheint unangemessen zu sein. Denn dann wäre das Buch der Apokalypse allein für die letzte Generation der Menschen von Wert, während die übrigen immer wieder prüfen müssten, ob sich die Prophetie irgendwie auf die aktuellen Ereignisse übertragen lässt, und dabei fast notwendigerweise immer wieder einen „falschen Alarm“ auslösen müssen. Vor allem aber spricht gegen diese Auslegung das, was JESUS am Ende des Buches zu JOHANNES sagt: „Versiegle die Worte der Prophetie dieses Buches nicht! Denn die Zeit ist nahe.“ $(22,10)$. Wenn auch die „Nähe“ der Erfüllungszeit der Apokalypse ein dehnbarer Begriff ist, so zeigt doch die Aufforderung, dass JOHANNES das Buch nicht versiegeln, $\mathrm{d}$. h. nicht geheim halten soll, dass tatsächlich die Prophetie etwas sagen muss, was alle Christen angeht und daher auch für alle Generationen von Wert sein muss.

2. Eine andere Art der Auslegung ist die kirchengeschichtliche (oder universalgeschichtliche) Auslegung, wonach die Apokalypse in ihrem größten Teil die Periode zwischen der ersten und der zweiten Ankunft Christi beschreibt. Jedoch gibt es auch hier wieder zwei grundlegende Auslegungs-Varianten:

Die abstrakte kirchengeschichtliche Auslegung sieht in der Apokalypse nicht einmalige Ereignisse vorhergesagt, sondern geschichtliche Prozesse, die sich oftmals wiederholen: Verfolgung der Christen, Krieg, Hunger, Pest, Irrlehren, Untergang antichristlicher Reiche und wunderbare Befreiung der Kirche. Diese Prozesse laufen zum Teil nebeneinander ab: Die Reihenfolge der Visionen wäre dann also nicht immer zeitlich zu verstehen. Diese Deutung hat besonders Ernest-Bernard ALLO (1920) ausführlich begründet. Jedoch stößt auch diese Ansicht auf Schwierigkeiten. Wenn sie richtig ist, kann man kaum noch von einer „Prophezeiung“ sprechen, da dann kaum etwas vorausgesagt wäre, was nicht ohnehin jedem Menschen klar ist, der die Logik der sich immer wieder wiederholenden Geschichtsabläufe begriffen hat (abgesehen von der immer wieder eintretenden Errettung der Kirche und einigen weiteren Einzelheiten, die keineswegs selbstverständlich sind). Dieser Auslegung gerät also mit der Tatsache in Konflikt, dass der Text sich als prophetisch ausgibt $(1,3 ; 10,11 ; 19,10 ; 22,7 ; 22,9-10 ; 22,18-19)$, und zwar ,prophetisch“ durchaus im Sinne von konkreter Weissagung für die Zukunft. So steht schon zu Beginn der Visionen über den Weltablauf, dass JOHANNES sehen soll, „was danach geschehen muss“ $(4,1)$. Und nach der Beschreibung einer Plage, die das ,erste Wehe“ genannt wird, heißt es: ,das erste ,Wehe“ ist vergangen: siehe, es kommen noch zwei ,Wehe“ danach“ $(9,12)$.

So kommen wir zur zweiten Variante der kirchengeschichtlichen Auslegung, der konkreten kirchengeschichtlichen Auslegung, wonach die Apokalypse viele detaillierte Beschreibungen innergeschichtlicher Epochen enthält. Diese Auslegung, die LUTHER und vielen ältere Protestanten, aber auch Katholiken wie Bartholomäus HOLZHAUSER, LAFONT DE SENTENAC, P. DRACH und F. GUTJAHR vertreten haben, macht aber oft einen recht willkürlichen Eindruck.

3. Die dritte große Auslegungsrichtung ist die zeitgeschichtliche Auslegung, wonach sich die Apokalypse schwerpunktmäßig auf die Zeitepoche des JOHANNES und eventuell die ersten Jahrhunderte unmittelbar danach bezieht. Auch bei dieser Auslegung gibt es zwei Varianten.

Die eine Variante, vertreten durch die meisten modernen Bibelgelehrten, ist die kritisch-zeitgeschichtliche Auslegung. Ihr zufolge handelt die Apokalypse gänzlich von der Zeit des Verfassers: Sie beschreibt größtenteils damals schon bekannte Ereignisse und gibt sich dabei als prophetisch aus (sog. vaticinium ex eventu). Wirklich vorausgesagt wären dann allenfalls Ereignisse, die man bei einigermaßen klugen politischen Verstand voraussehen konnte. Manche Ausleger scheuen sich auch nicht, zu sagen, dass der Verfasser sich in der Vorhersage mancher Dinge geirrt habe. Er habe vor allem die irrtümliche Ansicht verbreitet, dass CHRISTUS in kurzer Zeit wiederkommen würde, um der jetzigen Menschheitsgeschichte ein Ende zu bereiten und ein tausendjähriges paradiesisches Gottesreich auf Erden zu errichten (vgl. Apk 20,1-6). Doch wird sich zeigen, dass diese Behauptungen unhaltbar sind.

Nach der anderen Variante, der antik-geschichtlichen Auslegung (unter den Katholiken u. a. vertreten von Luis DE Alcazar, J. B. Bossuet, A. Calmet, F. M. Wouters, F. Allioli, J. Schäfer - M. Meinertz, L. Billot) 
handelt der größte Teil der Apokalypse (bis einschließlich Kap. 19) symbolisch von der Entwicklung des Christentums in den ersten Jahrhunderten, angefangen von der Zeit des JOHANNES bis zur Überwindung der ersten großen Feinde des Christentums: des nichtchristlichen Judentums und des Heidentums in Gestalt des christenverfolgenden römischen Reiches. Erst in den letzten drei Kapiteln erfolgt ein Ausblick auf den weiteren Verlauf der Weltgeschichte nach dem Sturz Roms: Zunächst erfolgt die Periode des Siegeszuges des Christentums durch die Welt (symbolisch als ,Tausendjähriges Reich“ beschrieben), dann ein katastrophales Weltende und das letzte Gericht, nach welchem die Welt ihren ewigen Endzustand erreicht.

Diese Auslegung, die vor allem Jacques-Bénigne Bossuet (1689) in vorbildlicher Weise ausgearbeitet hat, scheint der Wahrheit am nächsten zu kommen. Denn dies ergibt einen guten Sinn: Die Christen der ersten Jahrhunderte konnten die Apokalypse mit Recht unmittelbar auf ihre Zeit anwenden, und alle nachfolgenden Generationen können nun auf die Apokalypse als auf eine größtenteils bereits erfüllte Prophetie zurückblicken, die ihren Glauben an Gott stärken kann, ähnlich wie die erfüllten Prophezeiungen des Alten Testaments. Mit dieser Auslegung stimmt auch die heute fast allgemein anerkannte Tatsache überein, dass das „siebenköpfige Ungeheuer“ in der Apokalypse das heidnischrömische Reich darstellt, das bereits zur Zeit des JOHANNES dabei war, die Christen zu verfolgen (siehe Auslegung zu Kap. 13 und 17). Schließlich erklärt diese Auslegung auch sehr gut den acht mal vorkommenden Hinweis, dass die Erfüllung der Prophetie „,nahe“ ist bzw. „,bald“ geschehen wird $(1,1 ; 1,3 ; 3,11 ; 22,6 ; 22,7 ; 22,10 ; 22,12 ; 22,20)$. Denn die „kurze Zeit“ bis zum tausendjährigen Reich bezieht sich offenbar auf die relativ kurze Periode bis zum Untergang des römischen Reiches, und das darauf folgende Tausendjahrreich verläuft innerhalb der jetzigen Menschheitsgeschichte, die mit einem einmaligen Endgericht abschließen wird. So zeigt sich, dass JOHANNES keineswegs irrtümlich von einer kurzen Zeit bis zum Endgericht ausging, sondern ganz im Gegenteil voraussah, dass dieses noch mindestens „tausend Jahre“ (Symbol einer unübersehbar langen Zeit) in der Zukunft lag.

So scheint es das Vernünftigste zu sein, der zeitgeschichtlichen Auslegung im Sinne von BossuET (d. h. der antikgeschichtlichen Auslegung) zu folgen, welche wohl den in erster Linie gemeinten Sinn der Apokalypse, den Literalsinn, treffend wiedergibt. Zugleich ist aber zu beachten, dass die inspirierten Schriften der Bibel oftmals in ein und demselben Satz noch andere, hinter dem Literalsinn verborgene Dinge bezeichnen, so dass eine mehrdimensionale Auslegung berechtigt erscheinen kann. Gerade bei einem so geheimnisvollen Buch wie der Apokalypse dürfte dies vielfach zutreffen. Somit dürfen die Ergebnisse der ,endgeschichtlichen“ und „kirchengeschichtlichen“ Auslegung keineswegs als wertlos erachtet werden. Ich werde im Folgenden vor allem das herauszustellen, was meines Erachtens der in erster Linie gemeinte Literalsinn ist, weise aber gelegentlich auch auf andere Auslegungen hin, die vielleicht einen verborgenen Sinn des Textes enthüllen.

\subsection{Gesamtaufbau}

Nach einer Einleitung nach Art eines Briefes (1,1-8), beschreibt JoHANnES eine Christusvision, die er in Patmos hatte (1,9-20), bei der JESUS ihm sieben Briefe an sieben Ortskirchen Kleinasiens diktierte (Apk 2-3). JOHANNES wird sodann in den himmlischen Tempel entrückt (4-5; vgl. 6,9; 7,9-15;8,1-5;9,13;11,19), wo er die Öffnung der sieben Siegel $(6,1-8,1)$ und das Blasen der SIEBEN POSAUNEN $(8,2-12,17)$ erlebt. Johannes befindet sich nach dem Erschallen der siebten Posaune offenbar wieder auf der Erde (12,1), genauer am Strand des Meeres (12,18), wo er das antichristliche Tier sieht und den Kampf mit ihm verfolgt (13,1-14,20). Vom Strand aus sieht er erneut den himmlischen Tempel (15,1-8), und verfolgt die Ausgießung der sieben Zornesschalen (16,1-21). Daraufhin wird JOHANNES in die Wüste entrückt und sieht das Gericht über das Tier (17,1-19,21), das Tausendjahrreich und das Endgericht (20,1-15) sowie die Welterneuerung (21,1-8). Schließlich wird JOHANNES wird auf einem hohen Berg entrückt und sieht dort das neue Jerusalem (21,9-22,20a). Das Buch schließt mit den Schlussworten des JoHANNES, wieder nach Art eines Briefes (22,20b-21). 


\section{Auslegung}

\subsection{Apk 1,1-20: Gruß und Eingangsvision}

\section{Text}

1,1 Offenbarung Jesu Christi, die ihm Gott gegeben hat, um seinen Knechten zu zeigen, was bald geschehen muss.

Und er hat es kundgetan, indem er seinen Engel seinem Knecht Johannes sandte,

1,2 der das Wort Gottes bezeugt hat und das Zeugnis Jesu Christi:

alles, was er gesehen hat.

1,3 Selig (ist), wer die Worte der Prophetie vorliest und wer sie hört und das in ihr Aufgeschriebene bewahrt, denn die Zeit ist nahe.

1,4 Johannes an die sieben (Orts-)Kirchen in Asien: Gnade und Friede von dem „, der ist und der war und der kommt“ und von den sieben Geistern vor seinem Thron

1,5 und von Jesus Christus, welcher ist der Zeuge, der Glaubwürdige, der Erstgeborene der Toten und der Herrscher der Könige der Erde. Ihm, der uns liebt und uns erlöst hat von unseren Sünden durch sein Blut,

1,6 und der uns zu einem Königreich und zu Priestern gemacht hat für Gott, seinen Vater: Ihm sei die Ehre und die Macht in alle Ewigkeit. Amen.

1,7 Siehe, er kommt mit den Wolken, und sehen wird ihn jedes Auge, und die, welche ihn durchbohrt haben. Und es werden sich an die Brust schlagen wegen ihm alle Stämme der Erde. Ja, Amen.

1,8 Ich bin das Alpha und das Omega, sagt Gott, der Herr, der ist und der war und der kommt, der Allmächtige.

1,9 Ich, Johannes, euer Bruder und Mitgenosse an der Bedrängnis und an der Königsherrschaft und am geduldigen Ausharren in Jesus:

Ich fand mich auf der Insel ein, die Patmos heißt, wegen des Wortes Gottes und des Zeugnisses von Jesus.

1,10 Ich wurde im Geist [entrückt] am Herrentag.

1,11 Und ich hörte hinter mir eine laute Stimme wie von einer Posaune. (Die Stimme) sagte: Was du siehst, schreibe in ein Buch und schick es den sieben (Orts-)Kirchen, nach Ephesus und nach Smyrna und nach Pergamon und nach Thyatira und nach Sardes und nach Philadelphia und nach Laodizea.

1,12 Und ich wandte mich um, um die Stimme zu sehen, die mit mir redete. Und als ich mich umgewandt hatte, sah ich sieben goldene Leuchter.

1,13 Und in der Mitte der Leuchter (sah ich) einen, der aussah wie ein Menschensohn. (Er war) bekleidet mit einem bis auf die Füße reichendem Gewand und um die Brust gegürtet mit einem goldenen Gürtel.

1,14 Sein Kopf und seine Haare waren weiß wie weiße Wolle: wie Schnee. Und seine Augen waren wie eine Flamme von Feuer.

1,15 Und seine Füße glichen dem im Schmelzofen glühend gemachten Golderz. Und seine Stimme war wie die Stimme vieler Wasser. 
1,16 Und in seiner Hand hatte er sieben Sterne.

Und aus seinem Mund kam ein zweischneidiges Schwert heraus.

Und sein Gesicht war, wie wenn die Sonne in ihrer Kraft erstrahlt.

1,17 Als ich ihn sah, fiel ich ihm wie ein Toter zu Füßen.

Und er legte seine rechte Hand auf mich und sagte: Fürchte dich nicht!

Ich bin der Erste und der Letzte.

1,18 Und ich bin der Lebendige, und ich war tot, und siehe, lebendig bin ich in alle Ewigkeit. Und ich habe die Schlüssel des Todes und des Hades.

1,19 Schreibe also, was du gesehen hast, und was ist und was danach geschehen wird.

1,20 Das Geheimnis der sieben Sterne, die du gesehen hast in meiner rechten Hand, und (das Geheimnis der) sieben goldenen Leuchter (ist folgendes):

Die sieben Sterne sind (die) Engel der sieben (Orts-)Kirchen , und die Leuchter sind die sieben (Orts-)Kirchen .

Auslegung

1,1a Offenbarung Jesu Christi,

Der Inhalt des Buches wurde von JESUs CHRISTUS offenbart.

1,1b die ihm Gott gegeben hat,

Gott GAB diese Offenbarung Christus, und Christus brachte sie den Menschen. Wie konnte Gott aber die Offenbarung CHRISTUS ,geben“? Ist CHRISTUS nicht selber Gott?

Darauf ist zu antworten: CHRISTUS hat zugleich eine menschliche und eine göttliche Natur. In seiner göttlichen Natur ist er „eins“ mit Gott dem Vater (Joh 10,30), aber in seiner menschlichen Natur ist er geringer als der Vater (Joh 14,28) und empfängt von ihm den Auftrag, die Offenbarung den Menschen zu enthüllen. Mit „Christus“ ist hier also CHRISTUS allein in seiner menschlichen Natur angesprochen, und mit „Gott“ ist hier allein der Vater gemeint.

Zum genauen Verständnis der Verhältnisses Christi zum Vater, zu den beiden Naturen in CHRISTUS und zur Dreifaltigkeit vergleiche den Exkurs nach dem Kommentar zu 1,4b.

1,1c um seinen Knechten zu zeigen, was bald geschehen muss.

BALD: Das Hauptziel der Apokalypse ist es also, etwas über die nahe Zukunft zu enthüllen.

1,1d Und er hat es kundgetan, indem er seinen Engel seinem Knecht Johannes sandte,

$1,2 \quad$ der das Wort Gottes bezeugt hat und das Zeugnis Jesu Christi:

alles, was er gesehen hat.

Die Offenbarung kommt also von GotT zu CHRISTUs (1,1b), von CHRISTUS zum EnGEL, und vom ENGEL zu JOHANNES.

1,3 Selig (ist), wer die Worte dieser Prophetie vorliest

und wer sie hört und das in ihr Aufgeschriebene bewahrt, denn die Zeit ist nahe.

Die ZeIT IST NAHE: „Bald“ (vgl. 1,1c) sollte die Erfüllung der Prophetie beginnen: Einiges erfüllte sich bereits im 2. Jahrhundert, das meiste in den ersten Jahrhunderten, und nur ein kleiner Teil wird sich erst am Ende der Weltgeschichte erfüllen. 
1,4a Johannes an die sieben (Orts-)Kirchen in Asien.

Wie wir in Vers 11 erfahren, sind die ORTSKIRCHEN von sieben Orten in Kleinasien gemeint: nämlich die Ortskirchen von Ephesus, Smyrna, Pergamon, Thyatira, Sardes, Philadelphia und LAODIZEA. Zu ihrer Lage in Kleinasien siehe das Schaubild auf S. 23.

Das hier mit ORTSKIRCHE übersetzte griechische Wort lautet EKKLESIA ( $\varepsilon \varkappa \chi \lambda \eta \sigma i \alpha)$ und ist von EK ( $\dot{\varepsilon} x=$ heraus) und KALEO $(\varkappa \alpha \lambda \varepsilon \omega=$ rufen) abgeleitet. Es wird meist mit Kirche, Gemeinde oder Versammlung übersetzt. Im damaligen weltlichen Sprachgebrauch bezeichnet es eine beliebige Volksversammlung (so auch in Apg 19,32 und 19,39), es eignet sich aber in besonderer Weise für die Bezeichnung der christlichen Gemeinschaft (Kirche), weil sich diese als eine (von Gott durch Christus aus der Welt) herausgerufene, erwählte Schar versteht. Ekklesia kann sowohl die weltweite christliche Gemeinschaft oder Weltkirche bezeichnen (so vor allem in Mt 16,18) als auch die Kirchengemeinde oder Ortskirche einem am bestimmten Ort, wie es offenbar hier der Fall ist.

1,4b Gnade und Friede von dem, „der ist und der war und der kommt“

„Der ist“ oder „der Seiende“ (hebr. „Jahwe“) ist der Name Gottes, der dem MosE geoffenbart wurde (Ex 3,13-15). Dieser Name, der die zeitlos-ewige Existenz Gottes ausdrückt, begegnet uns hier in der erweiterten Form „DER IST UND DER WAR UND DER KOMMT“.

Wenn es heißt, dass Gott „kommt“ (statt: „,sein wird“), so wird betont, dass es keine Zukunft Gottes gibt außer in Bezug auf seine kommenden Taten, durch die er in die Menschheitsgeschichte eingreift. Das ist das Thema des vorliegenden Buches.

\section{Exkurs 1: Erläuterungen zur Dreifaltigkeitslehre}

1. „Jahwe“ bzw. „,der Seiende“ ist nicht nur Bezeichnung für Gott den Vater, sondern auch für seien Sohn Jesus Christus und den Heiligen Geist, also insgesamt für den einen Gott in drei Personen, den dreifaltigen Gott. Auch CHRISTUS ist nämlich der zeitlos „Seiende“, der im Johannesevangelium $(8,58)$ sagen kann: „bevor Abraham war, bin ich“ (siehe auch Joh 8,24; 8,28; 13,9 und Hebr 1,8-12; 13,8), und auch im vorliegenden Buch zeigt sich deutlich, dass CHRISTUS (in seiner göttlichen Natur) mit Gott dem Vater ,eins“ ist. Man sieht dies sofort, wenn man folgende Stellen vergleicht:

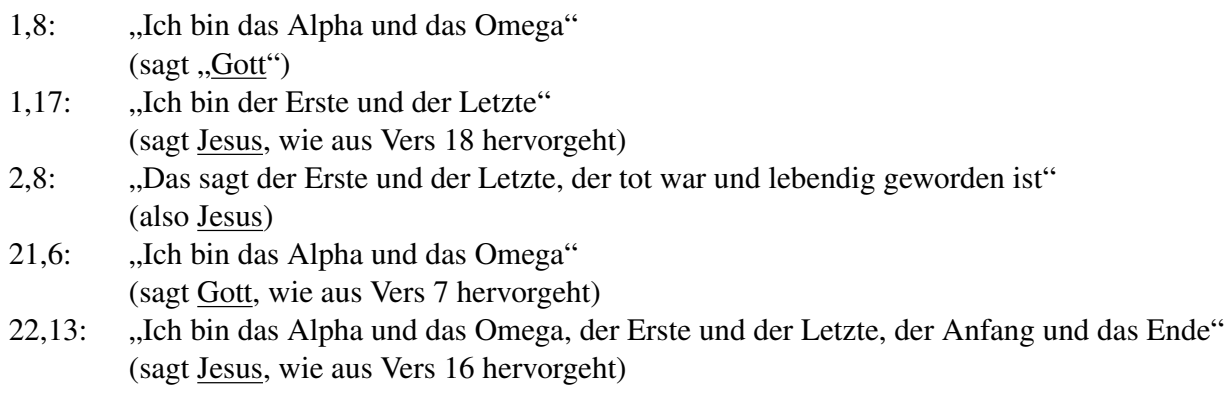

Die Eigenschaft, Erster und Letzter zu sein, wird also sowohl Gott als auch CHRISTUS zugeschrieben. Es ist aber unmöglich, dass zwei Personen beide „,der Erste“ (oder „,der Letzte“) sind, es sei denn, sie sind so tief vereint, dass sie eine Wesenseinheit bilden, d. h. eine so tiefe Einheit, dass sie als ein und dasselbe Wesen angesprochen werden können. Dieses eine göttliche Wesen, zu dem Vater und Sohn vereint sind, muss nun weiterhin mit Jahwe identifiziert werden, denn der Propheten Jesaja sagt:

Jes 44,6: „So spricht Jahwe (= der Herr, der Seiende):

Ich bin der Erste, ich bin der Letzte, und außer mir gibt es keinen Gott". 
Dadurch, dass in der Apokalypse dieses Wort Jahwes (in welchem Jahwe sich als der einzige wahre Gott zu erkennen gibt!) auf Jesus übertragen wird, zeigt sich nun aufs Deutlichste, dass Jesus (wohlgemerkt: in seiner göttlichen, nicht in seiner menschlichen Natur) gleichzusetzen ist mit Jahwe, dem „Seienden“, dem einzigen wahren Gott.

2. Dass auch der Heilige Geist eines Wesens mit dem Vater und dem Sohn ist, ist ebenfalls in der Apokalypse klar bezeugt. So werden die sieben Briefe (Kap. 2-3) dem Johannes von der ihm erscheinenden Gestalt (1,9-20) diktiert, die offenbar Jesus ist (denn in 1,13 wird sie als „Menschensohn“, und in 1,18 als von den Toten erweckt bezeichnet), und dennoch heißt es am Ende eines jeden Briefes, der „Geist“ habe zu den Gemeinen gesprochen $(2,7.11 .17 .29 ; 3,6.13 .22)$. Somit muss der Geist mit Jesus eines Wesens sein. ${ }^{1}$ Ein weiteres klares Argument für die Gottheit des Geistes lässt sich dem Johannesevangelium entnehmen. Denn dort wird der Heilige Geist als „Beistand“ der Gläubigen (Joh 14,26) bezeichnet, der anstelle Jesu kommen wird (Joh 16,7), um Jesu Werk weiterzuführen und zu vollenden (Joh 16,13). Der Vollender des göttlichen Heilswerkes kann nun nicht geringer sein als der, der es begonnen hat. Also muss auch der Geist letztlich Gott selber sein.

3. Johannes geht also von einer Wesenseinheit der drei göttlichen Personen Vater, Sohn und Geist aus: Diese drei sind nur ein Wesen. Das bedeutet aber nicht, dass alle drei nur eine einzige Person, d. h. ein einziges „Ich“ sind. Vielmehr stehen sich die Personen einander gegenüber wie drei verschiedene Subjekte (z. B. Joh 16,13-15; vgl. auch Apk $2,28 ; 22,17)$. Wie ist das mit ihrer Wesenseinheit zu vereinbaren? Den Schlüssel dazu gibt uns JoHANNES in seinem 1. Brief, wo er sagt: „Gott ist die Liebe“ (1 Joh 4,8). Liebe ist eine vereinigende Beziehung zwischen verschiedenen Personen. Es muss also, wenn Gottes Wesen die Liebe ist, in Gott verschiedene göttliche Personen geben, die sich lieben. Aber Liebe vereint, sie vermag aus vielen Personen „ein Herz und eine Seele“ zu machen. Da nun die Liebe der drei göttlichen Personen unendlich stark und unvergleichlich anders als die irdisch-menschliche Liebe sein muss, kann man sich vorstellen, dass diese göttliche Liebe die drei Personen unendlich miteinander vereint und auf diese Weise zu einem einzigen Wesen macht. Dies jedoch so, dass immer noch eine Gegenüberstellung und Ich-Du-Beziehung der drei übrig bleibt - denn wäre nur noch eine Person da, so sonst auch die einende Liebe selber wieder aufgehoben. Man kann also sagen: Es gibt nur einen Gott, aber seine Einheit ist keine einsame Einerleiheit, sondern eine unendliche Vereinigung von drei an sich verschiedenen Personen. Keine Eigenschaften unterscheiden diese drei Personen mehr voneinander bis auf jene, die ein Ich-Du-Verhältnis möglich machen: Der Vater ist nicht der Sohn, weil der Sohn aus dem Vater gezeugt ist (Joh 8,42; Hebr 1,5) und nicht umgekehrt. Ebenso ist der Geist weder der Vater noch der Sohn, weil er aus dem Vater und Sohn hervorgeht (Joh 15,26 und 16,15) und nicht umgekehrt.

4. Dieses Zeugen und Hervorgehen der göttlichen Personen kann aber kein zeitlicher Ablauf sein, der irgendwann im Zustand des Werdens war, denn das stünde im Widerspruch zur vollkommenen Unveränderlichkeit des göttlichen Wesens (Jak 1,17). Also muss man das Hervorgehen des Sohnes aus dem Vater und das Hervorgehen des Geistes aus dem Vater und dem Sohn als ein immer schon da-seiendes Ursprungsverhältnis ansehen. Man kann sich ein solches Verhältnis veranschaulichen, wenn man an eine Kugel denkt, die auf einem Kissen liegt und dort eine Verformung des Kissens verursacht (dieses Beispiel stammt von KANT). Auch wenn Kugel und Kissen schon seit Ewigkeit da wären und niemals eine Bewegung stattgefunden hätte, könnte man mit Recht sagen, dass die Form des Kissens auf den Einfluss der Kugel zurückgeht. Ebenso geht der Sohn seit Ewigkeit aus dem Vater hervor, und der Geist aus dem Vater und dem Sohn, obwohl alle drei Personen schon seit Ewigkeit existieren.

5. Da der Vater der Ursprung sowohl des Sohnes als auch des Geistes ist, und daher „Ursprung der ganzen Dreifaltigkeit“ genannt werden kann, gebührt ihm (nicht im Sinne einer wesensmäßigen Überordnung, sondern im Sinne einer natürlichen Reihenfolge) innerhalb der Dreifaltigkeit der erste Platz. Den zweiten Platz hat der Sohn (weil dieser zu-

$1 \quad$ Ein beeindruckendes Beispiel für ein Zitat, das in der Bibel sowohl als Wort Jahwes, als auch des Sohnes und des Geistes bezeichnet wird - wodurch sich die Wesenseinheit von Vater, Sohn und Geist deutlich zeigt - ist das Folgende. Jesaja berichtet (Jes 6,8): „Da hörte ich die Stimme Jahwes: ,geh und sag diesem Volk: Hören sollt ist, hören, aber nicht verstehen. Sehen sollt ihr, sehen, aber nicht erkennen. Verhärte das Herz dieses Volkes, verstopfe ihre Ohren, verkleb ihm die Augen, damit es mit seinen Augen nicht sieht, und mit seinen Ohren nicht hört, damit sein Herz nicht zur Einsicht kommt und es sich nicht bekehrt, und nicht geheilt wird“. - Nach Paulus (Apg 28,35-37) hat diese Worte der Heilige Geist zu Jesaja gesprochen. „Treffend hat der Heilige Geist durch den Propheten Jesaja gesagt: „Geht zu diesem Volk und sprich: Hören sollt ihr, aber nicht verstehen“. - Nach Johannes war der Sprechende schließlich der Jesus, der Sohn Gottes (Joh 12,40-41). 
sammen mit dem Vater der Ursprung des Geistes ist), und den dritten Platz hat der Heilige Geist (weil er nicht mehr Ursprung einer weiteren göttlichen Person ist). Weil der Vater in diesem Sinn den ersten Platz hat, kann das Wort „Gott“" in der Schrift manchmal allein den Vater bezeichnen (vgl. 1 Kor 8,6). Das ist wohl auch in Apk 1,1 der Fall.

6. Darüber hinaus ist seit der Menschwerdung des Sohnes noch eine andere Unterscheidung zwischen dem Sohn und dem Vater möglich geworden. In der Menschwerdung bekam der Sohn zusätzlich zu seiner göttlichen Natur, die er mit dem Vater und dem Geist seit Ewigkeit gemeinsam besaß, eine menschliche Natur (vgl. Joh 1,14; Phil 2,6-7; 2 Kor 8,9). Seitdem lebt die eine Person des Sohnes, also die zweite göttliche Person, in zwei Naturen, also als wahrer Gott und wahrer Mensch zugleich. Christus steht dem Vater nicht nur gegenüber wegen des Ich-Du-Verhältnisses, sondern auch wegen eines Unterordnungsverhältnisses, so dass er in der Nacht vor seinem Leiden sagen konnte: „Der Vater ist größer als ich“ (Joh 14,28). Denn es besteht ein unendlicher Größenunterschied zwischen seiner menschlichen Natur und der göttlichen Natur des Vaters. Nicht, dass er aufgehört hätte, an der göttlichen Natur des Vaters Anteil zu haben. Aber seine Gottheit war, solange die Menschen ihn nur in seiner leidensfähigen menschlichen Natur sahen, verhüllt und unerkannt (vgl. Joh 14,9; Kor 2,8). Sie sollte erst nach seinem Heimgang zum Vater den Menschen aufstrahlen (2 Kor 4,6). Daher sagt er in der Nacht vor seinem Tod: „Wenn ihr mich liebtet, würdet ihr euch freuen, dass ich zum Vater gehe, denn der Vater ist größer als ich“ (Joh 14,28). Der Vater ist, so könnte man Jesu Wort weiter ausführen, größer als ich es in meiner Menschennatur bin, die meine göttliche Natur während meines Erdenlebens so verhüllt, dass ihr meine Einheit mit dem Vater nicht recht erfassen könnt (vgl. Joh 14,9-10). Deshalb freut euch, dass ich ,zum Vater gehe“, d. h., dass ich durch Tod, Auferstehung und Himmelfahrt meine Gottheit erweisen werde, denn so werdet ihr erkennen, dass ich als Gott ebenso groß bin wie der Vater.

7. Der Sohn weist nun durch seine menschliche Natur in gewisser Weise sogar eine Verschiedenheit zur ganzen dreifaltigen Gottheit auf, welcher er zwar einerseits (aufgrund seiner göttlichen Natur) weiterhin angehört, über die er aber andererseits (aufgrund seiner menschlichen Natur) ,hinausgewachsen“ ist, oder besser gesagt: unter die sie sich erniedrigt hat. Deshalb kann CHRISTUS (in seiner menschlichen Natur) auch dem ganzen dreifaltigen Gott gegenübergestellt werden. Vgl. dazu den Kommentar zu Apk 5,6a. -

\section{1,4c $\quad$ und von den sieben Geistern, die vor seinem Thron sind}

Von diesen sieben Geistern ist auch 3,1 und 5,6 die Rede. Wahrscheinlich sind dieselben auch 4,5 (sieben Fackeln) gemeint. Vergleiche auch den siebenarmigen Leuchter im Tempel (Ex 25,37 und Sach 4,2) und den geheimnisvollen Stein mit sieben (eingravierten?) Augen darauf (Sach 3,9), welche in Sach 4,10 gedeutet werden als die „Augen Jahwes,,, die ,,auf der ganzen Erde umherstreifen“; dies wird in Apg 5,6 aufgenommen, wo Johannes ein Lamm mit sieben Hörnern und sieben Augen sieht, und die sieben Augen gedeutet werden als ,die sieben Geister Gottes, die in die ganze Welt ausgesandt sind“. Worum also handelt es sich bei den sieben Geistern? Meines Erachtens sind es die sieben höchsten Botenengel. Nach einer zweiten Auslegung sind die „sieben Geister“ der Heilige Geist, die dritte göttliche Person.

Die erste Auslegung besagt also: bei den „sieben Geistern“ handelt es sich um eine Gruppe hoher Engel. Denn:

1. Die Bezeichnung von Engeln als „Geister“ ist auch anderswo in der Bibel bezeugt, z. B. Hebr 1,1314: „Zu welchem von den Engeln hat Gott jemals gesagt: setz’ dich zu meiner Rechten? ... Sind sie nicht alle dienende Geister ...?"

2. JoHANnes spricht hier von den „sieben Geistern vor dem Thron Gottes“. Der Heilige Geist aber müsste als dritte göttliche Person auf dem Thron Gottes sitzen. Somit können die „,sieben Geister“ kaum der Heilige Geist sein.

3. Schon das Alte Testament nennt sieben Engel, die vor Gott stehen: „Ich bin Raphael, einer von den sieben heiligen Engeln, die das Gebet der Heiligen emportragen und mit ihm vor die Majestät des heiligen Gottes treten.“( Tob 12,15). 
4. Den entscheidenden Hinweis gibt uns JoHAnNeS in 8,2: „und ich sah die sieben Engel, die vor Gott stehen“, wobei der Ausdruck ,die sieben Engel“ zeigt, dass es sich um bereits bekannte und (wahrscheinlich auch) zuvor genannte Wesen handelt - und die Beschreibung „die vor Gott stehen“ verweist den Leser zurück auf unsere Stelle, wo von den ,sieben Geistern vor dem Geister mit den sieben Engeln identisch zu sein.

Warum nennt JOHANNES in seinem Gruß 1,4c jene sieben Engel und nicht die höheren ,vier Wesen“? Vielleicht deshalb, weil die sieben Botenengel seinen Lesern vertrauter sind als jene vier Wesen, die nur noch sehr indirekt mit dieser Welt zu tun haben. Oder weil die sieben es sind, welche persönlich von Gott ausgesendet werden, um den Grußwunsch „Gnade und Friede“ in der Welt durchzusetzen. Werfen wir noch einen Blick auf die zweite Auslegung der ,sieben Geister“:

Die zweite Auslegung besagt, dass mit den „,sieben Geistern“ der Heilige Geist gemeint ist, der dem Wesen nach zwar nur einer ist, aber wegen seinen Wirkungen siebenfach genannt werden kann (vgl. die sieben Gaben des Hl. Geistes in Jes 11,2). Die Vertreter dieser Ansicht argumentieren wie folgt:

1. Die Platzierung der ,,sieben Geister“ zwischen dem Vater (,der ist und der war und der kommt“) und CHRISTUS (Vers 5) zeige, dass die sieben Geister wie der Vater und CHRISTUS zur göttlichen Dreifaltigkeit gehören.

Aber wir haben bereits gesehen (Kommentar zu 1,4b), dass mit dem, ,der ist und der war und der kommt", wohl kaum der Vater allein, sondern bereits die ganze göttliche Dreifaltigkeit gemeint ist. Dann sollte man aber eher erwarten, dass die ,sieben Geister“ nicht mehr zur Dreifaltigkeit gehören. Dass aber nach der Erwähnung der ,sieben Geister“ CHRISTUS erwähnt wird, ist nicht unpassend: JoHANnES nennt zuerst Gott und dann die Engel, um die obersten Personen des himmlischen Bereichs zu nennen, und dann geht er zu CHRISTUS über, weil dieser in seiner menschlichen Natur das Verbindungsglied zwischen Himmel und Erde ist. Daher wird CHRISTUS in der Folge (Vers 5) auch als Erlöser beschrieben.

2. Die sieben Geister werden in 5,6 mit den Hörnern und Augen des „Lammes“ (= Jesus) gleichgesetzt, und werden zugleich bezeichnet als ,sieben Geister Gottes, die in die ganze Welt ausgesandt sind“ (vgl. auch Sach 4,10). Die sieben Geister gehören also eng zu Jesus und Gott dem Vater, und sie werden von beiden ,ausgesandt“. Dies trifft auf den Heiligen Geist zu (Joh 14,26; 16,7).

Aber dass die sieben Geister Hörner und Augen Jesu (und Gottes) sind, lässt sich ebenso gut erklären, wenn man sie als hohe Engel auffasst: Diese können „Augen“ Jesu sein, weil sie in Jesu Auftrag das Weltgeschehen überwachen, und „Hörner“, weil sie gegen Gottes Feinde (die Dämonen, die bösen Gedanken usw.) ankämpfen.

3. „Gnade und Friede“ dürfe, so sagt man, nur von Gott erbeten werden.

Aber in der Apokalypse ist mehrfach vom Mittlerdienst der Engel und Heiligen im Himmel die Rede (5,8; 8,3-4; vgl. 6,10-1; 20,4-6). Überall bezeugt das Buch außerdem, dass Engel in diese Welt eingreifen, um Gottes Befehle auszuführen. Was liegt also näher, als dass JOHANNES auch „Gnade und Friede“ zwar zunächst von Gott selbst erwartet, dann aber auch die Engel als Vermittler von Gottes Gnade und Friede erwähnt, die Gottes diesbezügliche Anordnungen ausführen?

4. Es gibt in der Schrift kein anderes Beispiel dafür, dass man „Gnade und Friede“ von den Engeln erbeten hätte.

Aber dem kann man entgegenhalten: Auch sonst bietet die Apokalypse vieles, was anderswo nicht gesagt wird. Im übrigen aber wäre auch die Bezeichnung des Heiligen Geistes als „,sieben Geister vor dem Thron Gottes“ eine nirgendwo sonst in den biblischen Schriften bezeugte Einmaligkeit. Wir bleiben also dabei, dass die ,sieben Geister“ Engel sind.

\section{Exkurs 2: Die sieben Engel vor dem Thron Gottes}

Von den sieben Engeln sind uns durch die biblischen Schriften drei namentlich bekannt. Außer dem schon genannten RAPHAEL (Tob 12,15) sind es GABRIEL (Lk 1,19: „Ich bin Gabriel, der vor Gott steht“) und MiCHAEL, der nach Dan 
10,13 „einer der ersten unter den (Engel)Fürsten“ ist und nach Apk 12,7 das Heer der guten Engel im Kampf gegen Satan und dessen Engel leitet. Michael dürfte zu den sieben Engeln gehören, da diese nach 5,6 ,in die ganze Welt ausgesendet" werden, um als Augen (= Aufseher) und Hörner (= Kämpfer) Jesu aufzutreten. Als Anführer des Engelheeres Jesu (Apk 12,7) muss Michael dann der höchste der sieben Engel sein. Da die Zahl „sieben“ oft eine heilige Gesamtheit symbolisiert (siehe Kommentar zu 13,18), kann man fragen, ob die Zahl der sieben Engel hier wörtlich genommen werden muss oder ob sie vielleicht rein symbolisch für eine zahlenmäßig nicht feststehende, große Anzahl von Engeln steht. Meiner Meinung nach ist die Zahl wörtlich zu nehmen, denn von 8,6 an sieht JOHANNES diese sieben Engel nacheinander eine Posaune blasen, woraufhin stets ein bestimmtes geschichtliches Ereignis beginnt. Da also jedem der Engel das „Anblasen“ eines konkreten Geschichtsereignisses zugeschrieben wird, dürften es einzelne Individuen sein. Außer MiCHAEL, GABRIEL und RAPHAEL nennt eine im ausgehenden Mittelalter verbreitete Tradition die folgenden Namen der übrigen vier anderen Engel: URIEL (der schon im ersten Jahrhundert erwähnt wird), SEALTIEL, ,JEHUDIEL und BARACHIEL. Die Überlieferung von den ,sieben Engeln vor dem Thron Gottes“ könnte übrigens den König der Perser dazu bewogen haben, sich sieben weise Ratgeber auszusuchen, die Zugang zu seinem Thron hatten (Est 1,14). Dieselbe Überlieferung mag auch mitgespielt haben, als in der Jerusalemer Urkirche genau sieben Diakone einsetzt wurden (Apg 6,3).

Sind die sieben Engel die allerhöchsten Engel? Da MICHAEL, der höchste der sieben Engel, in Dan 10,13 lediglich als „,einer der ersten unter den (Engel)Fürsten“ bezeichnet wird und nicht als ,,der erste“, scheint es, dass es noch höhere Engel geben muss. Die sieben Engel sind wohl lediglich die höchsten von denjenigen, die ,,in die ganze Welt ausgesendet“ werden (5,6), so dass sie als „,die sieben Hörner und sieben Augen“ Jesu (5,6; siehe oben) bezeichnet werden, d. h. als Jesu oberste Kämpfer und Aufseher, ,vor Ort“. Von ihren Aufträgen zurückkehrend haben sie dann freien Zugang zum Thron Gottes (Tob 12,15), aber nicht, um dort zu bleiben, sondern um von dort aus wieder ausgesandt zu werden. Es sind also die höchsten der sogenannten „Botenengel“. Über diesen stehen die „Thronengel“, die immer in der Nähe Gottes bleiben. In gewisser Weise werden zwar auch diese ausgesendet, da nach Hebr 1,14 alle Engel ,dienstbare Geister sind, die zum Dienst ausgesendet werden“. Der Unterschied ist daher wohl der, dass die Botenengel in eigener Person ausgesendet werden, während die Thronengel nur indirekt gesendet werden, indem sie die Sendungsbefehle Gottes an die Botenengel weiterleiten. Dass es Thronengel gibt, die über den sieben Engeln stehen, wird durch die Vision 4,5-8 bestätigt, wo JOHANNES zuerst die sieben Engel erwähnt (Vers 5) und dann (Vers 6-8) vier andere Wesen beschreibt, die ebenfalls Engel sind (siehe Kommentar). Diese Engel aber sind Thronengel und haben eine größere Nähe zu Gott als die sieben: Denn während die sieben in Gestalt von Feuerfackeln „,vor“ dem Thron Gottes erschienen $(4,5)$, befinden sich die vier ,in der Mitte“ (!) des Throns und rings um ihn“ (4,7).

1,5a und von Jesus Christus, welcher ist der Zeuge, der Glaubwürdige, der Erstgeborene der Toten und der Herrscher der Könige der Erde.

Jesus ist ERSTGEBORENER VON DEN TOTEN, weil er als erster von den Toten zu einem überirdischen Leben auferstanden ist. Dadurch hat er sich als GLAUBWÜRDIGER ZEUGE erwiesen, und HERRSCHT (nun auch in seiner menschlichen Natur) über DIE KÖNIGE DER ERDE, indem er unsichtbar die Geschicke dieser Könige und den Ablauf der Weltgeschichte lenkt.

1,5b Ihm, der uns liebt und uns erlöst hat von unseren Sünden durch sein Blut,

Durch seinen Kreuzestod hat uns Jesus erlöst, insofern er stellvertretend Sühne für die Sünden der ganzen Welt geleistet hat. Diese Erlösung wird dem einzelnen Menschen aber nur dadurch zugewendet, dass er den an der Tür seines Herzens anklopfenden CHRISTUS „einlässt“ (3,20-21).

1,6a und der uns zu einem Königreich und zu Priestern gemacht hat für Gott, seinen Vater:

Die Christen, an denen Jesu Erlösung bereits wirksam geworden ist, sind PRIESTER, indem sie Gott dem Vater dienen. Und sie sind KöNIGE, indem sie andere zum Guten anleiten können. Siehe auch 1,9. Zum Verhältnis von Vater und Sohn siehe den Kommentar zu 1,4. 
1,6b Ihm sei die Ehre und die Macht in alle Ewigkeit. Amen.

Ehre und Macht werden hier wahrscheinlich nicht dem Vater, sondern CHRISTUS zugesprochen, wie die Fortsetzung im nächsten Vers zeigt (,Siehe, er kommt ... und jedes Auge wird ihn sehen“, was nur vom menschgewordenen Herrn Jesus Christus gesagt sein kann).

Da der Artikel („DIE“ Ehre und „DIE“ Macht) auf eine einzigartige und damit höchste Ehrung und Macht hindeutet, wird CHRISTUS hier göttliche Macht und Ehre zugeschrieben.

1,7 Siehe, er kommt mit den Wolken,

und sehen wird ihn jedes Auge, und die, welche ihn durchbohrt haben.

Und es werden sich an die Brust schlagen wegen ihm alle Stämme der Erde. Ja, Amen.

Dieser Vers führt uns das letzte Gericht vor Augen, und verweist damit auf das Ende des Buches: Jesus wird am Ende der Menschheitsgeschichte sichtbar WIEDERKOMMEN, (vgl. 22,12 und 22,20; aber auch Mt 16,27; Mt 24,30; Mk 13,26; Lk 21,27; Apg 1,10-11; 1 Thess 4,16-17; Tit 2,13), und alle Menschen werden dann die wahre Bedeutung Christi erkennen: auch die, welche ihn ans Kreuz genagelt und DURCHBOHRT HABEN, indem sie durch ihre Sünden die Ursache waren, um derentwillen Jesus seinen Sühnetod am Kreuz auf sich nehmen musste.

Aus der Aussage, dass ALlE STÄMME DER ERDE sich an die Brust schlagen werden, folgt, dass sie alle (und nicht nur die Juden) Schuld am Tode Christi haben.

1,8 Ich bin das Alpha und das Omega, sagt Gott, der Herr, der ist und der war und der kommt, der Allmächtige.

Der dreifaltige Gott ist hier gemeint, insbesondere Christus in seiner göttlichen Natur (siehe Exkurs 1), der sich hier als „Alpha“ und „Omega“ (erster und letzter und Buchstabe des griechischen Alphabets), d. h. als Anfang und Ende der menschlichen Geschichte und als ihr allmächtiger Lenker offenbart.

1,9a Ich, Johannes, euer Bruder und Mitgenosse an der Bedrängnis und an der Königsherrschaft und am geduldigen Ausharren in Jesus:

Trotz der BEDRÄNGNIS hat JOHANNES mit den anderen Christen Anteil an der KÖNIGSHERRSCHAFT. Selbst und gerade in der Bedrängnis erweisen sich die Heiligen als „Könige“, d. h. als Vorbilder und Wegweiser für die Menschen. Vgl. 1,6.

1,9b Ich fand mich auf der Insel ein, die Patmos heißt,

wegen des Wortes Gottes und des Zeugnisses von Jesus.

JOHANNES wurde im Zuge der Christenverfolgung unter Kaiser DOMITIAN (94-96 n. Chr.) auf die Insel PATMOS verbannt aufgrund seines ZEUGNIS VON JESUS, d. h. sein christliches Bekenntnis.

1,10 Ich wurde im Geist [entrückt] am Herrentag.

VOM GEIST ERGRIFFEn: Diese Vision geschieht durch eine vom Heiligen Geist bewirkte „Entrückung“ aus dem Bereich der gewöhnlichen Sinneswahrnehmung. Dies geschah am HERRENTAG, genau übersetzt „,zum Herrn gehöriger Tag“ (griech. Kyriake Hemera). Dies ist eine Bezeichnung für den Sonntag, denn da CHRISTUS an einem Sonntag, dem „ersten Tag der Woche“, auferstanden ist (Joh 20,1), feierten die Christen diesen Tag ganz besonders als Tag des Gedächtnisses an den „Herrn“ Jesus. Nach Apg 20,7 kamen sie am Sonntag zusammen, „um Brot zu brechen“, d. h. wahrscheinlich: um das von CHRISTUS für die Feier seines Gedächtnisses eingesetzte Abendmahl zu feiern. In 1 Kor 16,2 sagt Paulus den Korinthern, dass sie ,,jeden Sonntag“ Geld für eine Kollekte zurücklegen sollten. Er sagt nicht „,in jeder Versammlung“, sondern ,,jeden Sonntag“, so dass wir schließen können, dass die Gottesdienstversammlung damals wie heute regelmäßig an jedem Sonntag stattfand. 
So war der Sonntag dem Gedächtnis Christi des HERRN geweiht und wurde darum HERRENTAG genannt; dieser Tag war für die Christen so wichtig, dass er für sie offenbar schon in der Zeit des Neuen Testaments zum Hauptfeier- und Versammlungstag geworden war, der in dieser Funktion den Samstag (Sabbat), den alttestamentlich-jüdischen Ruhetag, ersetzt hatte (siehe auch unten S.139).

Der „Herrentag“ (Kyriake Hemera) ist nicht zu verwechseln mit dem „Tag des Herrn“ (Hemera tou Kyriou), welcher Bezeichnung für den zukünftigen Tag des letzten Gerichts über diese Welt ist.

1,11a Und ich hörte hinter mir eine laute Stimme wie von einer Posaune.

Es ist die Stimme Jesu, der hier machtvoll auftritt (Posaune); denn der Sprechende ist Jesus, wie sich zeigen wird.

1,11b (Die Stimme) sagte: Was du siehst, schreibe in ein Buch und schick es den sieben (Orts-)Kirchen, nach Ephesus und nach Smyrna und nach Pergamon und nach Thyatira und nach Sardes und nach Philadelphia und nach Laodizea.

Das BUCH, das JOHAnNeS schreiben soll, ist das ganze Buch der Apokalypse, die an die sieben Ortskirchen verschickt werden soll, und die darum auch für jede dieser Ortskirchen besondere Ermahnungen enthält (Kap. 2-3).

Die genannten ORTSKIRCHEN befinden sich im Gebiet der heutigen Türkei (siehe die Karte auf S. 23). JOHANNES nennt die sieben Ortskirchen wahrscheinlich in der Reihenfolge, in welcher ein von ihm ausgesendeter Bote ihnen das Buch der Apokalypse überbringen sollte. Denn ein solcher Bote musste von Patmos aus zunächst per Schiff nach EPHESUS kommen, in die Hafenstadt, in der JOHANNES nach der Tradition gewirkt hat und in der er auch begraben wurde. Von Ephesus aus konnte der Bote durch eine nach Norden gehende Straße zuerst SMYRNA (ca. $50 \mathrm{~km}$ von Ephesus entfernte Küstenstadt) und dann PERGAMON erreichen (von Smyrna aus etwa $80 \mathrm{~km}$ nördlich und dann $24 \mathrm{~km}$ landeinwärts). Von hier aus waren durch eine nach Südosten gehende Straße der Reihe nach die übrigen Städte zu erreichen: THYATIRA (ca. $65 \mathrm{~km}$ von Pergamon), SARDES (ca. $50 \mathrm{~km}$ von Thyatira), PHILADELPHIA (50 km von Sardes) und LAODIZEA (ca. $90 \mathrm{~km}$ von Philadelphia). Von Laodizea führte wiederum eine Straße zurück nach Ephesus.

1,12 Und ich wandte mich um, um die Stimme zu sehen, die mit mir redete. Und als ich mich umgewandt hatte, sah ich sieben goldene Leuchter.

Die SIEBEn GOLDENEN LEUCHTER sind Symbole der sieben Ortskirchen, an die JoHANNES schreiben soll (siehe 1,20).

1,13a Und in der Mitte der Leuchter ( (sah ich) einen, der aussah wie ein Menschensohn.

Das ist ChRISTUS in seiner nach der Auferstehung verherrlichten und vergeistigten Menschennatur. Denn Menschensohn ist eine von Jesus gebrauchte Selbstbezeichnung (z. B. Mt 19,28; Joh 3,14), die bereits der Prophet DANIEL für den Messias verwendete (Dan 7,13). Dass es sich bei der Erscheinung um Jesus, den Sohn Gottes handelt, geht mit letzter Klarheit aus dem Vergleich von 1,14 und 2,18 hervor. 
$1,13 \mathrm{~b} \quad$ (Er war) bekleidet mit einem bis auf die Füße reichendem Gewand und um die Brust gegürtet mit einem goldenen Gürtel.

Das BIS ZU DEN FÜSSEN REICHENDE GEWAND (griech. poderes) war ein Priestergewand (Ex 28,4). Es bezeichnet also Jesu priesterliche Würde. Dasselbe bringt die GÜRTUNG UM DIE BRUST (statt um die Hüfte) zum Ausdruck, denn so gürteten sich die Hohenpriester. ${ }^{2}$ Die GOLDENE Farbe des GÜRTELS ist Zeichen der Königswürde. Jesus präsentiert sich also als König und Hoherpriester.

1,14a Sein Kopf und seine Haare waren weiß wie weiße Wolle: wie Schnee.

WeIsses HaAR ist Symbol für hohes Alter. In der Vision DANIELs hat Gott selber weißes Haar und wird als „Alter an Tagen“ bezeichnet (Dan 7,9). Somit ist das weiße Haar Jesu Symbol für seine Präexistenz und seine Identität mit Gott als dem ,Alten an Tagen“. Im weißen Haar ist das ausgedrückt, was Jesus einmal so formuliert hat: „Bevor Abraham gewesen ist, bin ich“ (Joh 8,58).

Auch die WEISSE FARBE SEINES KOPFES will demnach aussagen, dass er eine bereits seit Ewigkeit existierende göttlichen Person ist. Zwar erscheint Jesus hier als Mensch, aber in Verbindung mit seiner verherrlichten Menschennatur strahlt seine Gottheit auf. So konnte Paulus von der „Erkenntnis der Herrlichkeit Gottes im Gesicht Jesu Christi“" sprechen (2 Kor 4,6) und Jesus selbst konnte in der Nacht vor seinen Leiden sagen: „Wer mich sieht, sieht den Vater“ (Joh 14,8).

1,14b Und seine Augen waren wie eine Flamme von Feuer.

Die FeUERAUGEN versinnbilden das durchdringende göttliche Wissen, mit dem JesUs „Herz und Nieren prüft“ (vgl. 2,23), d. h. das Innerste der menschlichen Gedanken und Strebungen erblickt. Dieser Feuerblick ,erleuchtet die Heiligen, verbrennt aber die gottlosen und verbrecherischen Menschen“. 3

1,15a Und seine Füße glichen dem im Schmelzofen glühend gemachten Golderz.

Die GOLDERZ-FÜSSE zeigen die „Standfestigkeit“, d. h. die Unerschütterlichkeit Jesu und seines Reiches an.

1,15b Und seine Stimme war wie die Stimme vieler Wasser.

In 1,11 wurde die STIMME mit dem Klang einer Posaune verglichen, hier gleicht sie einem Wasserfall. Beides unterstreicht die Erhabenheit des Sprechenden.

1,16a Und in seiner Hand hatte er sieben Sterne.

Man kann sich dies am besten so vorstellen, dass Jesus eine Art Rosenkranz in der Hand hielt, der aus sieben an einer Schnur aneinandergebundenen Sternen bestand. Die SIEBEN STERNE versinnbilden die sieben Ortskirchen mit ihren „Engeln“, d. h. Bischöfen (vgl. Vers 20).

1,16b Und aus seinem Mund kam ein zweischneidiges Schwert heraus.

Das ZWEISCHNEIDIGE SCHWERT aus seinem Mund versinnbildet die unwiderstehliche richterliche Macht seines Wortes. Vergleiche Hebr 4,12: „Denn das Wort Gottes ist wirksam und schneidender als jedes zweischneidige Schwert“.

\footnotetext{
2 Vgl. Josephus, Jüdische Altertümer 3,7,2.

3 Andreas von CAESAREA, Ermeneia eis ten Apokalypsin, PG 106 Spalten 229/30.
} 
1,16c Und sein Gesicht war, wie wenn die Sonne in ihrer Kraft erstrahlt.

Der Sonnenglanz im Gesicht Christi erinnert an die „Herrlichkeit Gottes, die im Gesicht Jesu Christi erstrahlt" (vgl. 2 Kor 4,6). Siehe auch Kommentar zu 6,12-17.

1,17 Als ich ihn sah, fiel ich ihm wie ein Toter zu Füßen.

Und er legte seine rechte Hand auf mich und sagte: Fürchte dich nicht!

Ich bin der Erste und der Letzte.

Jesus ist DER ERSTE UND DER LETZTE, d. h. Ursprung und Ziel der Schöpfung und der Geschichte. 


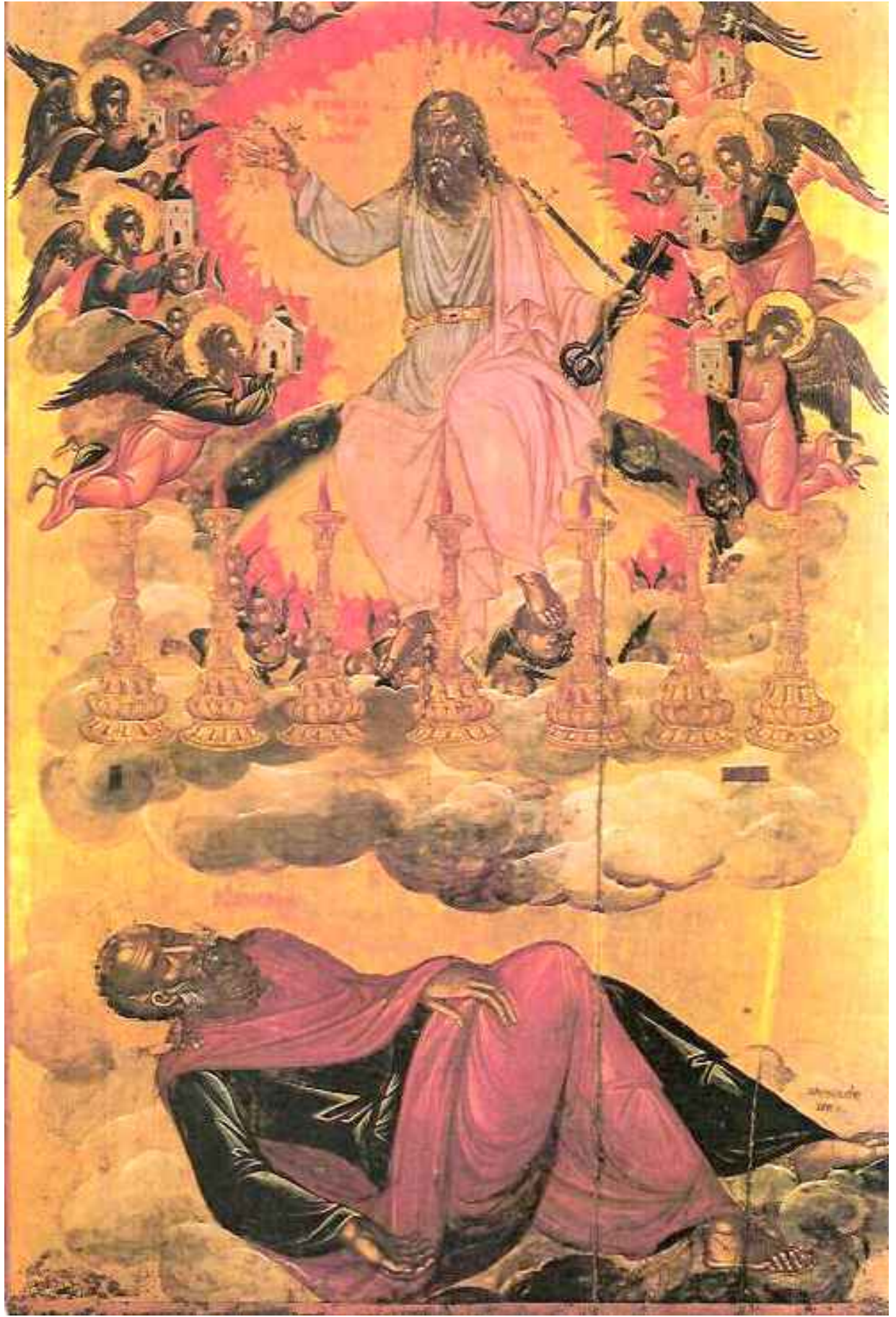

Ikone in der „Höhle der Apokalypse“ auf Patmos

1,18 Und ich bin der Lebendige, und ich war tot, und siehe, lebendig bin ich in alle Ewigkeit.

Und ich habe die Schlüssel des Todes und des Hades.

Jesus ist DER LEBENDIGE, d. h. der lebendige Gott selbst, denn „DER“ Lebendige kann niemand anders als Gott genannt werden, ebenso wie nur er DER Seiende, DER Heilige usw. ist.

Jesus sagt nicht ,ich war tot und wurde lebendig“, sondern ,ich war tot und ich BIN LEBENDIG“, wohl um anzudeuten, dass er, während er in seiner menschlichen Natur am Kreuz gestorben war, dennoch in seiner göttlichen Natur am Leben blieb. 
Jesus hat den Schlüssel Des Todes Und Des HAdes: die Macht, die Toten wieder lebendig zu machen und sie aus dem Hades (siehe Kommentar zu 2,7) herauszuholen. Vgl. hierzu JESU Wort in Joh 11,25: „Ich bin die Auferstehung und das Leben“.

1,19 Schreibe also, was du gesehen hast, und was ist und was danach geschehen wird.

Hier ist das Programm des Buches der Apokalypse: es hat zwei große Anliegen. Erstens die Beschreibung dessen, WAS IST, d. h. die kritische Beleuchtung der gegenwärtigen Zustände der sieben Ortskirchen (Kap. 2-3), und zweitens die Beschreibung dessen, WAS DANACH GESCHEHEN WIRD, d. h. der Ablauf der künftigen Weltgeschichte (Kap. 6-22).

1,20 Das Geheimnis der sieben Sterne, die du gesehen hast in meiner rechten Hand, und (das Geheimnis der) sieben goldenen Leuchter (ist folgendes):

Die sieben Sterne sind (die) Engel der sieben (Orts-)Kirchen, und die Leuchter sind die sieben (Orts-)Kirchen.

Die SIEBEn STERne sind also Symbole für die Engel der sieben Ortskirchen, die ihrerseits durch die LEUCHTER symbolisiert werden. Was hat man aber unter den „Kirchen-Engeln“ oder „GemeindeEngeln“ zu verstehen? Da JoHAnNES im folgenden Kapitel an diese „Engel“ Briefe schreiben soll, handelt es sich höchstwahrscheinlich um Menschen, und zwar um die für die Ortskirchen verantwortlichen Bischöfe. Das Wort „Engel“ bedeutet „Bote“ und kann darum in der Tat den geistlichen Amtsträger bezeichnen, der als ein Gesandter Gottes galt, den „,der Heilige Geist eingesetzt hat, um die Herde Gottes zu weiden“ (Apg 20,28). Vgl. auch Mal 2,7: „Die Lippen des Priesters bewahren die Erkenntnis, aus seinem Mund erwartet man Belehrung, denn er ist der Engel des Herrn“.

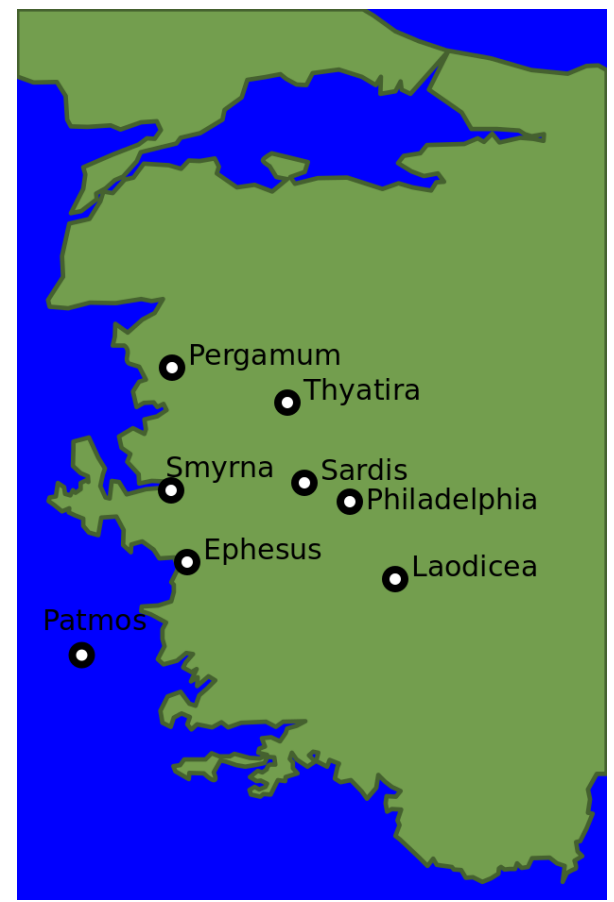

Lage der sieben Ortskirchen in Kleinasien 


\subsection{Apk 2,1 - 3,22: Die Briefe an die sieben Ortskirchen}

Diese Briefe enthalten Ermahnungen mit konkreten Anspielungen auf Geschichte und Topographie der sieben Orte. Hauptgegenstand der Briefe ist also der damalige Zustand der Ortskirchen, wenngleich auch hier bereits Prophezeiungen erfolgen $(2,8-10,2,16,3,10)$. Aus den Briefen können Christen aller Zeiten Nutzen ziehen, da sie zeigen, was Jesus an Bischöfen und Ortskirchen lobt und tadelt:

- Beim Bischof von Ephesus lobt er dessen Eifer gegen Bosheit und Irrglauben, tadelt aber die relative Abnahme dieses Eifers.

- Den Bischof von Smyrna lobt er wegen seines inneren Reichtums trotz äußerer Armut und Bedrängnis.

- Beim Bischof von Pergamon lobt er dessen Standhaftigkeit, tadelt aber, dass es innere Feinde des Glaubens in seiner Kirche gibt.

- Beim Bischof von Thyatira lobt er die Zunahme seines Eifers, tadelt aber, dass er in seiner Kirche Irrlehrer gewähren lässt.

- Den Bischof von Sardes tadelt er wegen seiner Untätigkeit.

- Den Bischof von Philadelphia lobt er wegen seiner Standhaftigkeit trotz seiner geringen äußeren Machtmittel.

- Den Bischof von Laodizea tadelt er wegen seiner eingebildeten Gerechtigkeit und seinem Stolz.

Überblick über die Briefe an die sieben Ortsgemeinden:

\begin{tabular}{|c|c|c|c|c|}
\hline Ort & Charakterbild & Bischof & Lob & Tadel \\
\hline Ephesus & $\begin{array}{l}\text { Hauptstadt } \\
\text { der Provinz Asien } \\
\text { im Eifer erlahmte Kirche }\end{array}$ & Hl. Timotheus & $\sqrt{ }$ & $\sqrt{ }$ \\
\hline Smyrna & $\begin{array}{l}\text { Zentrum des Kaiserkultes } \\
\text { mit starker jüdischer Gemeinde } \\
\text { verfolgte Kirche }\end{array}$ & Hl. Polykarp & $\sqrt{ }$ & - \\
\hline Pergamon & $\begin{array}{l}\text { Zentrum des Götzendienstes } \\
\text { (,Thron Satans“) } \\
\text { Kirche in schwieriger Lage }\end{array}$ & Hl. Karpos? & $\sqrt{ }$ & $\sqrt{ }$ \\
\hline Thyatira & $\begin{array}{l}\text { Handelszentrum mit } \\
\text { weissagender Sibylle } \\
\text { kompromissbereite Kirche }\end{array}$ & Hl. Karpos? & $\sqrt{ }$ & $\sqrt{ }$ \\
\hline Sardes & $\begin{array}{l}\text { sagenhafte „uneinnehmbare“ } \\
\text { Hauptstadt Lydiens } \\
\text { tote Kirche }\end{array}$ & $? ? ?$ & - & $\sqrt{ }$ \\
\hline Philadelphia & $\begin{array}{l}\text { kleine Stadt } \\
\text { in vulkanischer Gegend } \\
\text { Missionskirche }\end{array}$ & Hl. Quadratus? & $\sqrt{ }$ & - \\
\hline Laodizea & $\begin{array}{l}\text { berühmte Industrie-, } \\
\text { Handels- und Ärztestadt } \\
\text { hochmütige Kirche }\end{array}$ & $? ? ?$ & - & $\sqrt{ }$ \\
\hline
\end{tabular}




\subsubsection{Apk 2,1-7: Erster Brief (an die Kirche von Ephesus)}

\section{Text}

2,1 An den Engel der Kirche von Ephesus schreibe:

So spricht der, der die sieben Sterne in seiner rechten Hand hält, der inmitten der sieben goldenen Leuchter umhergeht:

2,2 Ich kenne deine Werke und Mühe und dein geduldiges Ausharren, und (weiß), dass du böse Leute nicht ertragen kannst.

Du hast die geprüft, die sich selbst Apostel nennen und es nicht sind, und du hast sie als Lügner gefunden.

2,3 Du hast geduldiges Ausharren und hast Schweres ertragen wegen meines Namens und bist nicht müde geworden.

2,4 Aber ich habe gegen dich, dass du deine erste Liebe verlassen hast.

2,5 Gedenke also, von welcher Höhe du gefallen bist, bereue und tu (wieder) die ersten Werke! Wenn aber nicht, werde ich zu dir kommen und deinen Leuchter von seiner Stelle rücken, wenn du nicht bereust.

2,6 Aber dies muss man dir lassen:

Du hasst die Werke der Nikolaïten, die auch ich hasse.

2,7 Wer Ohren hat, der höre, was der Geist den Kirchen sagt:

Wer siegt, dem gebe ich zu essen vom Holz (oder: Baum) des Lebens, welcher im Paradies Gottes steht.

\section{Auslegung}

2,1a An den Engel der Kirche von Ephesus schreibe:

Der ENGEL (d. h. Bischof) vON EPHESUs ist wahrscheinlich der Paulus-Schüler TimotheUs. Nach den neutestamentlichen Timotheusbriefen hat nämlich PAULUS den TimoTHEUS in Ephesus als Bischof eingesetzt, ${ }^{4}$ wo er kurz vor dem Tode des PAULUs (zwischen 64 und 68) noch als ,,junger Mann“ amtierte. ${ }^{5}$ Von daher ist es gut möglich, dass Timotheus auch noch 30 Jahre später, als die Apokalypse geschrieben wurde, Bischof in Ephesus war.

Dass dies tatsächlich der Fall war, folgt aus einer Tradition, die erstmals in den Timotheus-Akten, die wahrscheinlich von einem Epheser des 4. Jahrhunderts verfasst wurden, schriftlich greifbar wird. ${ }^{6}$ Demnach wurde Timotheus in Ephesus an einem 22. Januar unter Kaiser NeRVA (der vom 18. Sept. 96 bis 28. Jan. 98 regierte), gesteinigt. Als 22. Januar in NeRVAs Regierungszeit kommen nur der 22. Jan. 97 oder der 22. Jan. 98 in Frage, so dass TiмоTHEUs demnach zur Abfassungszeit der Apokalypse (95) noch Bischof von Ephesus war.

4 Nach 1 Tim 1,3 hat Paulus den Timotheus in Ephesus zurückgelassen, „um gewissen Leuten Einhalt zu gebieten, dass sie keine Irrlehren verbreiten“, also als bevollmächtigten Lehrer der Kirche, der sich „,der Lesung, der Predigt, dem Unterricht“ widmen (1 Tim 4,13) oder kurz „lehren und predigen“ (1 Tim 6,2; vgl. 2 Tim 4,2) soll. Ferner hatte er die Vollmacht, Klagen gegen Presbyter anzunehmen oder abzuweisen (vgl. 1 Tim 5,19); die sich Verfehlenden sollte er „,in Gegenwart aller zurückweisen“ (1 Tim 5,20). Nach diesen Angaben hatte er also in Ephesus die höchste Autorität in Lehre und Leitung. Ferner wurde ihm bei offenbar bei seiner Amtseinführung durch Paulus und die Presbyter die Hände aufgelegt (1 Tim 4,14; 2 Tim 1,6) und er hatte auch selbst die Vollmacht erhalten, durch Handauflegung neue Amtsträger zu weihen (vgl. 1 Tim 5,22). Aus diesen Stellen geht klar hervor, dass Timotheus von Paulus zum Bischof von Ephesus geweiht wurde.

5 Vgl. 1 Tim 4,12: „Niemand soll dich deiner Jugend wegen gering achten“. Die Timotheusbriefe setzen eine Situation voraus, in der Paulus kurz vor seinem Tod stand, vgl. 2 Tim 4,6: „schon bin ich soweit, hingeopfert zu werden, und die Zeit meines Abscheidens steht bevor ... “. Das Martyrium von Petrus und Paulus war nach altkirchlichen Nachrichten unter Nero, wobei der römische Geschichtsschreiber TACITUs (Annalen 15,44) die Verfolgung Neros als Folge des Brandes in Roms im Juli 64 bezeichnet. So ist das Martyrium zwischen 64 und 68 (Tod Neros) zu datieren.

6 Der Text der Timotheus-Akten ist abgedruckt in Johannes Bollandus [Hg], Acta Sanctorum, Januarii Tomus tertius, Paris: Palmé, 1863, S. 180181, vgl. auch die Besprechung des Texts bei Richard Adalbert LIPSIUS, Die apokryphen Apostelgeschichten und Apostellegenden. Ein Beitrag zur altchristlichen Literaturgeschichte, Band 2, 2. Hälfte, Braunschweig: Schwetschke, 1884, S. 372-392. 
EPHeSUS war die Hauptstadt der Provinz Asien. Ihr Artemistempel galt als eines der Sieben Weltwunder. ${ }^{7}$ PAulus, Timotheus und Johannes haben in apostolischer Zeit dort gewirkt.

2,1b So spricht der, der die sieben Sterne in seiner rechten Hand hält, der inmitten der sieben goldenen Leuchter umhergeht:

In jedem der sieben Briefe werden bestimmte Merkmale der einleitenden Jesus-Vision wiederholt, die zu der angeschriebenen Ortskirche passen. Hier ist es das STEHEN IN DER MiTTE DER LEUCHTER, was zu Ephesus als kirchlichem Mittelpunkt der sieben Ortskirchen passt.

2,2 Ich kenne deine Werke und Mühe und dein geduldiges Ausharren, und (weiß), dass du böse Leute nicht ertragen kannst.

Du hast die geprüft, die sich selbst Apostel nennen und es nicht sind, und du hast sie als Lügner gefunden.

2,3 Du hast geduldiges Ausharren und hast Schweres ertragen wegen meines Namens und bist nicht müde geworden.

CHRISTUS lobt hier die bischöfliche Tugend, die im Eifer gegen Sünde (,böse Leute“) und Irrglauben (falsche Apostel) besteht.

2,4 Aber ich habe gegen dich, dass du deine erste Liebe verlassen hast.

Interessanterweise schreibt Paulus in seinem ersten Brief an Timotheus, er solle für den Witwendienst in der Kirche (zu dem man sich offenbar auf den Zölibat verpflichten musste) jüngere Witwen nicht zulassen, weil diese oftmals (im Gegensatz zu ihrem Versprechen) wieder heiraten wollen und dann „die erste Treue“ zu Christus verwerfen. (1 Tim 5,11-12).

2,5a Gedenke also, von welcher Höhe du gefallen bist,

bereue und tu (wieder) die ersten Werke!

Diese Verse zeigen, dass der Bischof von Ephesus zunächst ein eifriger Christ gewesen ist, dessen anfänglicher Eifern (ERSTE LIEBE) aber nachgelassen hat, was gut zu Timotheus passt. Bezeichnenderweise hatte ihn auch schon Paulus gemahnt: „Dein aufrichtiger Glaubenseifer steht bei mir in gutem Andenken ... Aus diesem Grund ermahne ich dich: Entfache die Gnade Gottes wieder ... !“ (2 Tim 1,5-6). Diese Mahnung kommt nun auch von CHRISTUS.

2,5b Wenn aber nicht, werde ich zu dir kommen und deinen Leuchter von seiner Stelle rücken, wenn du nicht bereust.

Wenn der Bischof nicht zu seiner „ersten Liebe“ zurückkehrt, droht Christ mit dem FORTRÜCKEN DES LEuCHTERS, d. h. mit dem Untergang seiner Ortskirche. Timotheus muss sich in der Tat wieder zu einer glühenden Christusliebe bekehrt haben, da er nach der Tradition kurze Zeit später für CHRISTUS das Martyrium durch die Steinigung erlitt, nachdem er eine Predigt gegen heidnische Festsitten der Epheser gehalten hatte. ${ }^{8}$

2,6 Aber dies muss man dir lassen:

Du hasst die Werke der Nikolaïten, die auch ich hasse.

7 zusammen mit der Zeusstatue des Phidias in Olympia, den hängenden Gärten in Babylon, dem Mausoleum von Halikarnassos, dem Leuchtturm von Pharos in Alexandria, den ägyptischen Pyramiden in Gizeh und dem Koloss von Rhodos.

8 So die Timotheus-Akten (siehe Fußnote 6). 
Die NikOlaÏTEN waren eine Sekte, die sich auf NiKOlaUs AUS ANTIOCHIEN berief, einen der ersten sieben von den Aposteln eingesetzten Diakone (Apg 6,5). Einige Kirchenväter (EPIPHANIUS, HiERONymus, IRENÄUS und HiPPOLYT) verurteilen daher Diakon NiKOLAUS als Sektengründer. Andere (KLEMENS vOn AlexAndrien, TheOdoret und Augustinus) versuchen, ihn zu entschuldigen: Er habe die Sekte nicht gegründet, sondern nur durch ein missverständliches Wort zu ihrer Gründung den Anlass gegeben. Wie KLEMENS zu berichten weiß, habe NiKOLAUs die Parole ausgegeben: ,parachresthai dei sarki“", was entweder bedeuten kann: „man muss das Fleisch vernachlässigen“ oder „man muss das Fleisch missbrauchen“. NikOLAUS habe als Asket den Satz im ersten Sinne gemeint, aber nichtnutzige Leute hätten ihn im zweiten Sinne ausgelegt und unter dieser Parole die Sekte der Nikolaïten gegründet, die im Fleischesmissbrauch (Ehebruch, Unzucht) ihr Heil suchten. ${ }^{9}$

Die Nikolaïten trieben im Gebiet der sieben Ortskirchen Zauberei und Unzucht (2,14-15), opferten den Götzen $(2,20)$ und lehrten, dass man die „Tiefen Satans“ kennenlernen müsse (d. h. die Selbsterfahrung des Bösen machen müsse), um das Heil zu erlangen (2,24). Sie nannten sich Apostel $(2,2)$, beriefen sich auf ihre jüdische Abstammung (2,9), waren aber in Wirklichkeit aber Satanisten, nämlich die „Synagoge Satans“ (2,9, 3,9).

\author{
Wer Ohren hat, der höre, was der Geist den Kirchen sagt: \\ Wer siegt, dem gebe ich zu essen vom Holz (oder: Baum) des Lebens, \\ welcher im Paradies Gottes steht.
}

Der GEIST ist hier der Heilige Geist, die dritte göttliche Person, und nicht der prophetisch erleuchtete Geist des JOHANNES, denn dieser kann sich nicht das Werk der jenseitigen Belohnung zuschreiben (,wer siegt, dem gebe ich zu essen vom Baum des Lebens“).

WER SIEGT, d. h. wer bis zu seinem Tod in allen Anfechtungen treu zu CHRISTUS hält, wird ins PARADIES (d. h. in einen Zustand seliger Gottesgemeinschaft) gelangen und dort „vom BAUM DES LEBENS ESSEN“ (d. h. dort ewig leben; siehe auch auch den Kommentar zu 22,2.

\title{
Exkurs 3: Paradies, Himmel, Hades, Hölle, Fegfeuer und Limbus
}

Das Paradies ist zunächst der „Garten Gottes“, welcher in Gen 2,4-3,24 als ein Ort im Osten des (heute nicht mehr eindeutig identifizierbaren) Landes Eden beschrieben wird, wo die ersten Menschen einst in glücklicher Harmonie mit Gott und der Schöpfung lebten, bis sie diesen Ort aufgrund ihrer Sünde verlassen mussten. Doch bezeichnet das Wort Paradies nicht ausschließlich diesen irdischen Ort. Paulus meint mit Paradies offenbar einen himmlischen Ort, wenn er sagt, dass jemand dadurch ins Paradies kam, dass er in den „,dritten Himmel“ entrückt wurde (2 Kor 12,14). An einen himmlischen Ort denken auch die Propheten Ezechiel und Jesaja (Ez 28,13-17, Jes 14,13). Wenn also das Paradies einerseits auf Erden, andererseits im Himmel lokalisiert werden kann, so ist es im eigentlichen Sinne überhaupt kein Ort, sondern muss als symbolischer Ausdruck für eine beglückende Gemeinschaft zwischen Gott und Mensch verstanden werden, unabhängig vom Ort ihrer Verwirklichung. Dies wird durch Lk 23,43 bestätigt, wo Jesus zu dem mitgekreuzigten reumütigen Verbrecher sagte: „Heute noch wirst du mit mir im Paradies sein“. Da Jesus am Tag seiner Kreuzigung noch nicht in den Himmel auffuhr, sondern in das Totenreich (Hades) hinabstieg, muss seine Begegnung mit dem reumütigen Verbrecher im Hades stattgefunden haben. Zur Zeit dieses Hadesaufenthaltes Jesu ist also selbst der Hades zum „Paradies“ geworden!

Auch Himmel und Hades sind allerdings (wenn sie als Aufenthaltsort der Seelen bezeichnet werden) nur symbolische Orte, d. h. Zustände. Der mit Himmel bezeichnete Zustand ist dabei nicht vollkommen mit dem Zustand des „Paradieses“ identisch. Denn während das Wort „Paradies“ nur die Teilhabe am Glück der Gottesgemeinschaft aussagt, bezeichnet „Himmel“ zusätzlich die Teilhabe an der göttlichen Herrschaft über die Erde, d. h. über das Universum. Denn der Himmel ist Sitz des „Thrones“ Gottes (Mt 23,33). Somit ist zwar jeder, der im Himmel ist, auch im Paradies (2 Kor 12,1-4), aber es ist denkbar, dass jemand im Paradies ist, aber noch nicht im Himmel (Lk 23,43).

Klemens von AleXAndrien, Teppiche 3,25-26; siehe auch Eusebius, Kirchengeschichte 3,29. HiERONYMUS stellt den Diakon NiKoLAUS dagegen in seinem Brief an den Mönch Heliodor (Epistula 14 Kap. 9, CSEL Band 54 S. 57-58) dem Verräter Judas an die Seite. 
Der Hades (Totenreich, Unterwelt) umfasst gewissermaßen drei Abteilungen, nämlich Hölle, Fegfeuer und Limbus. Die Hölle (siehe auch Exkurs 11, S. 165-167) kann man symbolisch als den „untersten“, d. h. furchtbarsten „Ort“ der Unterwelt bezeichnen. Es handelt sich um den Zustand einer ewigen schmerzhaften Gottesferne als Folge für die endgültige Verhärtung im Bösen: „,der Rauch ihrer Qual steigt auf in alle Ewigkeit“ (Apk 14,11; vgl. 19,3 und 20,10). Mit dem „Feuer“ der Hölle ist wahrscheinlich der quälende Selbsthass gemeint. Die Möglichkeit des Eintretens in die Hölle sofort nach dem Tod lehrt z. B. Lk 16,19-31, Lk 12,4-5 und (vielleicht auch) Apg 1,25. Vergleiche zur Hölle auch Mt 25,41, 25,46, Apk 20,10 und den Kommentar zu 14,10-11.

Das Fegfeuer liegt, so könnte man symbolisch sagen, ,über“ der Hölle. Es ist ein vorübergehender Zustand schmerzhafter Gottesferne zwecks Reinigung der Seelen, die der Hölle entgehen, weil sie sich der Liebe Gottes nicht völlig verschlossen haben, die aber auch nicht so vollkommen sind, dass sie sofort vor Gottes Angesicht treten können. Das „Feuer“ ist hier wohl Symbol für die reinigende Reue. Alle Seelen des Fegfeuers kommen nach einer kürzeren oder längeren Vorbereitungs- und Reinigungsphase in den Himmel. Da die Existenz des Fegfeuers vielfach bestritten wird, seien zwei Schriftstellen angeführt, die es recht deutlich bezeugen:

1. In 1 Kor 3,12-17 unterscheidet Paulus drei Klassen von Menschen: erstens die Zerstörer des symbolischen Gottestempels, die am Ende selber zerstört werden (Vers 17), zweitens die guten Bauleute, die durch ihr Lebenswerk am Tempel mit Gold, Silber und wertvollen Steinen weiterbauen und am Ende dafür Lohn erhalten (Vers 12a und 14), und drittens die weniger guten, die am Tempel Gottes nur mit Holz, Heu und Stroh bauen. Deren Lebenswerk wird verbrennen, aber sie selbst werden ,,wie durch Feuer hindurch gerettet“ (Verse 12b und 15). Die erste Gruppe umfasst offenbar diejenigen, die in die Hölle kommen, die zweite Gruppe dürfte sofort nach dem Tod in den Himmel kommen (da sie keinerlei Strafe, sondern Lohn verdient), und die dritte dürfte die für das Fegfeuer vorgesehene Gruppe sein. 2. In Lk 12,47-48 spricht Jesus im Zusammenhang mit seinem Kommen zum Gericht (siehe Vers 40) von ,wenigen Schlägen“, die jemand dann bekommen wird, wenn er Entschuldigungsgründe für seine bösen Taten hat, weil er nicht im vollen Wissen gehandelt hat:

„Der Knecht, der den Willen seines Herrn kennt, sich aber nicht darum kümmert und nicht danach handelt, der wird viele Schläge bekommen (VIELE könnte für ,unendlich viele“ stehen und die Höllenstrafe andeuten). Wer aber, ohne den Willen seines Herrn zu kennen, etwas tut, was Schläge verdient, der wird wenig Schläge bekommen (WENIGE scheint eine zeitlich begrenzte Strafe auszusagen, also das Fegfeuer).“

Andeutungen des Fegfeuers könnte man z. B. noch in Mt 5,26 (Gefängnis, aus dem man herauskommt), Mt 18,34 (Folter, bis man die Schuld bezahlt hat), Mt 12,32 (Vergebung in der zukünftigen Welt), Phil 2,10-11 (Christusbekenntnis in der Unterwelt). Andeutungen gibt es auch in der Apokalypse: siehe 5,13 (Gotteslob in der Unterwelt), 20,14 (der Hades wird vom höllischen „Feuersee“ unterschieden) und 21,27 (Notwendigkeit der Reinigung, um vor Gott zu treten).

Den „Limbus der Väter“ kann man symbolisch , über“ dem Fegfeuer ansiedeln, denn er hat mit der eigentlichen Hölle noch weniger zu tun als das Fegfeuer. Der Limbus (deutsch „Schoß“) wird in der Schrift „Schoß Abrahams“ genannt (Lk 16,22). Es handelt sich um einen vorübergehenden Zustand schmerzloser Gottesferne, in dem sich einst die Seelen der alttestamentlichen „Väter“ und allgemeiner der vorchristlichen Gerechten befanden, die bereits persönlich für den Himmel reif waren, die aber deshalb noch im Hades bleiben mussten, weil erst CHRISTUS den Menschen das Tor zum Himmel ,geöffnet“ hat (siehe Joh 3,13, Hebr 9,15; Hebr 11,13-16; Hebr 11,39-40 und Lk 23,43). Seit dem Sündenfall der Stammeltern war den Menschen nämlich der „Weg zum Baum des Lebens“ (d. h. zur vollendeten Seligkeit, zum Paradies) verschlossen (Gen 3,24).

Aber Christi Tod, so heißt es im Hebräerbrief $(9,15)$, hat die Erlösung bewirkt „damit die Berufenen das verheißene Erbe erhalten." Durch Christi Tod wurde also das Paradies wieder eröffnet, und damit stimmt Jesu Wort an den mitgekreuzigten Verbrecher überein: „Heute wirst du mit mir im Paradies sein“ (Lk 23,43). Wie schon festgestellt, muss dieses neu eröffnete Paradies zunächst im Hades verwirklicht worden sein: Denn nach seiner Kreuzigung stieg Jesus mit seiner Seele in den Hades hinab (Apg 2,27-31, Röm 10,7, Mt 12,40, Eph 4,9, 1 Petr 3,19, 1 Petr 4,6), und zwar offenbar nicht in die Hölle oder ins Fegfeuer, sondern in den Limbus. Dort predigte er das Evangelium (1 Petr 3,19 und 4,6) und verwandelte diesen „Ort“ durch seine göttliche Gegenwart in das Paradies. Kurze Zeit später führte er bei seiner Himmelfahrt die bislang im Limbus festgehaltenen Gerechten mit sich in den Himmel (Eph 4,8), d. h. er vervollständigte ihre Seligkeit dadurch, dass er ihnen Anteil an der himmlischen Weltregierung gewährte (siehe die 24 Ältesten in Apk 4,4). Auf diese Befreiung der Gerechten aus dem Limbus spielt auch die Apokalypse an, wenn Jesus sagt, er habe den „Schlüssel zum Hades“ (Apk 1,18). Nach dieser Befreiung existiert der Limbus nicht mehr. Nach dem Weltgericht am Ende der Zeiten wird auch das Fegfeuer aufhören (siehe Kommentar zu 20,14). Dann werden also nur noch Himmel und Hölle übrig bleiben (siehe Mt 25,31-46). 


\subsubsection{Apk 2,8-11: Zweiter Brief (an die Kirche von Smyrna)}

\section{Text}

2,8 Und an den Engel der (Orts-)Kirche von Smyrna schreibe:

So spricht der Erste und der Letzte, der tot war und lebendig wurde:

2,9 Ich kenne deine Bedrängnis und deine Armut - aber du bist reich. Und (ich kenne) die Lästerung vonseiten derer, die sagen, dass sie Juden sind. Aber sie sind es nicht: Sie sind eine Synagoge Satans.

2,10 In keiner Weise fürchte, was du leiden wirst.

Siehe, der Teufel wird einige von euch ins Gefängnis werfen, damit ihr versucht werdet, und ihr werdet eine Bedrängnis von zehn Tagen haben. Sei treu bis in den Tod, und ich werde dir die Krone des Lebens geben.

2,11 Wer Ohren hat, der höre, was der Geist den Kirchen sagt: Wer siegt, der wird nicht Schaden leiden vom zweiten Tod.

\section{Auslegung}

2,8a Und an den Engel der (Orts-)Kirche von Smyrna schreibe:

Dieser ENGEL (d. h. Bischof) VON SMYRNA war wahrscheinlich der heilige Bischof POLYKARP, der 155/156 oder 165/166 (wahrscheinlich am 22. Februar 156) in Smyrna den Märtyrertod starb (fehlgeschlagener Versuch der Verbrennung, dann Hinrichtung mit dem Schwert). Über POLYKARPs Martyrium berichtet das sog. Martyrium Polycarpi: ein bald nach dem Ereignis verfasster Brief der Kirche von Smyrna an die Gemeine von Philomenium, welcher als der früheste echte Augenzeugenbericht über das Sterben eines Märtyrers gilt. Darin ist aufgezeichnet, dass POLYKARP, als man ihn aufforderte, CHRISTUS zu verfluchen, antwortete:

„Sechsundachtzig Jahre diene ich ihm, und nie hat er mir etwas zuleide getan: wie kann ich meinem König, der mich erlöst hat, lästern?“10

Wenn POLYKARP zur Zeit seines Todes bereits 86 Jahre CHRISTUS gedient hat, so könnte er bereits im Amt gewesen sein, als das Buch der Apokalypse geschrieben wurde.

Um 107 schrieb IgNATIUS, der Bischof von Antiochien, an POLYKARP einen Brief, aus dem hervorgeht, dass POLYKARP tatsächlich schon damals Bischof von Smyrna gewesen ist. ${ }^{11}$ Aber er muss noch viel früher dort Bischof gewesen sein, denn sein Schüler IRENÄUS $(† 202)$ bezeugt, dass er die Würde des smyrnensischen Bischofsamtes ,,von den Aposteln“ erhalten habe. ${ }^{12}$ Dies bestätigt auch TERTULLIAN, der um 200 mit Berufung auf die Tradition der Kirche von Smyrna schreibt, dass der Apostel JOHANNES selbst es war, der POLYKARP als Bischof in Smyrna einsetzte. ${ }^{13}$

Außer dem Bischof von Philadelphia ist der von Smyrna der einzige, der nicht getadelt wird.

SMYRNA (heute Izmir) hatte eine berühmte Kaiserkultstätte: Dort war 26. n. Chr. ein Augusteum für Tiberius, Livius und den Senat errichtet worden.

\footnotetext{
10 Martyrium Polycarpi, Kap. 9; griech. Ausgabe in Ausgewählte Märtyrerakten, Neubearbeitung der Knopfschen Ausgabe von Gustav Krüger, 4. Aufl. Tübingen: Mohr, 1965, S. 1-8, hier S. 4. Eine Zusammenfassung des Martyrium Polycarpi bietet auch EusEBIUS in Kirchengeschichte 4,15 .

11 Brief an Polykarp (hrsg. v. Joseph A. Fischer, Die Apostolischen Väter, München: Kösel, 1986, S. 216-225).

12 Adversus Haereses 3,3,4: „Polycarpus ... ab apostolis in Asia in ea quae es Smyrnis ecclesia constitutus episcopus ... “. Vgl. auch EusEBIUS, Kirchengeschichte 3,36,1.

13 De praescriptione haereticorum 32,2: „Smyrnaeorum ecclesia Polycarpum ab Iohanne collocatum refert“
} 
2,8b So spricht der Erste und der Letzte, der tot war und lebendig wurde:

Tod und Auferstehung Christi sollen den Bischof ermutigen, dessen Märtyrertod in diesem Brief vorausgesagt wird.

2,9a Ich kenne deine Bedrängnis und deine Armut - aber du bist reich.

Polykarp war äußerlich arm, aber innerlich reich.

2,9b Und (ich kenne) die Lästerung vonseiten derer, die sagen, dass sie Juden sind. Aber sie sind es nicht: Sie sind eine Synagoge Satans.

Es ist die Rede von JUDEN der Abstammung nach, die aber diesen Ehrennamen nicht verdienten. POLYKARP wurde tatsächlich von Juden ,gelästert“, die dem POLYKARP nach dem Zeugnis des Martyrium Polycarpi besonders feindlich gesinnt waren. ${ }^{14}$

2,10a In keiner Weise fürchte, was du leiden wirst.

Hier ist die klare Voraussage der LEIDEN Polykarps.

2,10b Siehe, der Teufel wird einige von euch ins Gefängnis werfen, damit ihr versucht werdet, und ihr werdet eine Bedrängnis von zehn Tagen haben.

Die ZEHN TAGE sind Symbol für eine kurze Zeit (Zehn ist Symbol für Vollständigkeit, aber auch für eine kleine Summe, die man ,an den Fingern abzählen“ kann). Dem Tod des Polykarp ging in der Tat eine kurze Christenverfolgung voraus (ihre genaue Dauer ist unbekannt). ${ }^{15}$

2,10c Sei treu bis in den Tod, und ich werde dir die Krone des Lebens geben.

Hier ist wieder eine deutliche Anspielung auf das Schicksal Polykarps. Polykarp blieb tatsächlich TREU BIS IN DEN TOD und empfing als Märtyrer die KRONE des ewigen Lebens.

Dass nach der Erwähnung des Todes die „Krone des Lebens“ genannt wird, zeigt andeutungsweise, dass die Märtyrer sofort nach dem Tode mit ihrer Seele in den Himmel eingehen (also nicht, wie manche glauben, erst bis zum Weltende im Zustand eines „Seelentodes“ oder „Seelenschlafes“ warten müssen). Dies wird in 6,11 noch klarer werden; und in 14,13 bezüglich aller Heiligen klar gemacht, nicht nur bezüglich der Märtyrer.

2,11 Wer Ohren hat, der höre, was der Geist den Kirchen sagt: Wer siegt, der wird nicht Schaden leiden vom zweiten Tod.

Der ZWEITE TOD ist die Hölle. Siehe den Kommentar zu 20,5-6.

$14 \quad$ Vgl. Martyrium Polycarpi Kap. 13 und 17-18

15 Vgl. Martyrium Polycarpi Kap. 2-3 und 19. 


\subsubsection{Apk 2,12-17: Dritter Brief (an die Kirche von Pergamon)}

Text

2,12 Und an den Engel der (Orts-)Kirche von Pergamon schreibe:

So spricht der, der das zweischneidige scharfe Schwert hat:

2,13 Ich weiß, wo du wohnst: dort, wo der Thron Satans ist.

Und (dennoch) hälst du meinen Namen fest und hast den Glauben nicht verleugnet,

auch nicht in den Tagen, als Antipas, mein treuer Zeuge, bei euch getötet wurde,

dort, wo der Satan wohnt.

2,14 Aber ich habe auch einiges wenige gegen dich:

Dass du dort einige (Leute) hast, die an der Lehre Bileams festhalten,

welcher den Balak lehrte, die Israeliten dazu zu verführen,

Götzenopferfleisch zu essen und Unzucht zu treiben.

2,15 So hast auch du Leute, die an der Lehre der Nikolaïten festhalten.

2,16 Bereue also! Wenn aber nicht, so werde ich bald zu dir kommen und Krieg mit ihnen führen durch das Schwert meines Mundes.

2,17 Wer Ohren hat, der höre, was der Geist den Gemeinden sagt:

Wer siegt, dem werde ich geben von dem verborgenen Manna.

Und ich werde ihm einen weißen Stein geben.

Und auf dem Stein steht ein neuer Name geschrieben,

den niemand kennt außer dem, der ihn empfängt.

\section{Auslegung}

2,12a Und an den Engel der Gemeinde von Pergamon schreibe:

Bei diesem ENGEL (d. h. Bischof) VON PERGAMON könnte man an den Märtyrerbischof KARPOS denken, der in Pergamon hingerichtet wurde, kurz nachdem Polykarp in Smyrna der Märtyrertod starb, also wahrscheinlich um 155/156 n. Chr. ${ }^{16}$

KARPOS wurde nach den Akten des Karpos, Papylos und Agathonike ${ }^{17}$ auf dem Scheiterhaufen verbrannt (zusammen mit dem Diakon Papylos und dessen Schwester Agathonike), nachdem er zunächst mit den Händen aufgehängt und sein Leib mit eisernen Krallen zerschunden worden war.

Nach einem griechischen Manuskript war KARPOS nach dem Weggang des JOHANNES [= nach seinem Tod oder nach seiner Verbannung?] zum Bischof von Pergamon eingesetzt worden, ${ }^{18}$ nach dem Martyrologium Romanum (Festtag: 13. April) war er allerdings Bischof von Thyatira ${ }^{19}$ und nach der lateinischen Version der Akten Bischof von Gordos. Was richtig ist, bleibt ungewiss, aber es wäre naheliegend, wenn er in jener Stadt Bischof war, in der er hingerichtet wurde: also in Pergamon.

16 Vgl. EusEBIUS, der das Ereignis in Kirchengeschichte 4,15,48 direkt nach dem Bericht über POLYKARPs Martyrium erwähnt.

Nach der lateinischen Version der Akten des Karpos (die später und unglaubwürdiger ist als die griechische; siehe Fußnote 17) fand das Martyrium erst in der Christenverfolgung unter Kaiser DECIUS (249-251) statt. Dies wird auch in einem Manuskript eines griechischen Eulogions behauptete (siehe Fußnote 18).

17 Griechische und lateinische Version in: Ausgewählte Märtyrerakten, Neubearbeitung der Knopfschen Ausgabe von Gustav Krüger, 4. Aufl. Tübingen: Mohr, 1965, S. 8-15. Deutsche Übersetzung der griechischen Version: Frühchristliche Apologeten II (= Bibliothek der Kirchenväter, 1. Reihe, Band 5 = Band 14 in der Reihenfolge des Erscheinens), München 1913, S. 313-317.

18 Es handelt sich um das Manuscriptum Graecum Synaxarium Parisiensis collegii Claromontani Societatis Jesu. Die entsprechende Passage aus diesem Manuskript ist in lateinischer Übersetzung abgedruckt in den ACTA SANCTORUM, Aprilis Tomus Secundus, Paris: Palmé, 1866, S. 122 Nr. 5. Dort wird das Martyrium auf einen 13 Oktober verlegt. Ferner heißt es, Karpos sei ,nach dem Weggang [discessum] Johannes des Theologen und Evangelisten als Bischof von Pergamon eingesetzt worden“. Wenn dies richtig ist, beruht die weitere Behauptung, dass das Martyrium in die Zeit des Decius (249-251) fällt, auf der Übernahme einer fehlerhaften Tradition (siehe Fußnote 16).

Siehe z. B. Ausgabe 1998, S. 86. Aus Thyatira stammte nach den Akten der Diakon Papylos, der mit Karpos starb. 
PERGAMON (heute Bergama) war ein Götzendienstzentrum. Besonders wurde dort Asklepios, der „Gott der Heilkunst“" verehrt, aber außerdem auch Zeus und Dionysios.

2,12b So spricht der, der das zweischneidige scharfe Schwert hat:

Jesus hebt hier seine richterliche Vollmacht hervor, weil Pergamon eine Hochburg des antichristlichen Götzendienstes war, wie aus dem folgenden hervorgeht.

2,13a Ich weiß, wo du wohnst: dort, wo der Thron Satans ist.

Mit dem Thron Satans dürfte der Riesenaltar des in Pergamon verehrten Zeus Asklepios gemeint sein, der sich heute im Pergamon-Museum in Berlin befindet. Denn das Symbol des Gottes Asklepios war die Schlange, die wiederum nach biblischer Auslegungstradition Satan den Teufel symbolisiert (siehe 12,9).

2,13b Und (dennoch) hälst du meinen Namen fest und hast den Glauben nicht verleugnet, auch nicht in den Tagen, als Antipas, mein treuer Zeuge, bei euch getötet wurde, dort, wo der Satan wohnt.

ANTIPAS wurde nach dem Martyrologium Romanum , unter Kaiser Domitian in ein glühendes eisernes Kalb geworfen “. Sein Schädel oder das, was man dafür hält, wird auf der Insel Patmos aufbewahrt. Sein Gedenktag ist der 11. April.

2,14 Aber ich habe auch einiges wenige gegen dich:

Dass du dort einige (Leute) hast, die an der Lehre Bileams festhalten,

welcher den Balak lehrte, die Israeliten dazu zu verführen,

Götzenopferfleisch zu essen und Unzucht zu treiben.

2,15 So hast auch du Leute, die an der Lehre der Nikolaïten festhalten.

Von Bileam und BALAK, dem König von Moab, ist im 4. Buch Mose die Rede.

Beide waren zur Zeit der Wüstenwanderung Israels als Feinde des Volkes Gottes aufgetreten. König Balak von Moab hatte den Zauberer Bileam aus Mesopotamien rufen lassen, damit dieser die Israeliten verfluchen sollte (Num 22,5-6), und Bileam gab den Rat, die Israeliten durch moabitische (oder midianitische) Frauen zum Götzendienst und zur Unzucht zu verführen (Num 25,1-2 und 31,16). Nach dem Rat Bileams handelten auch die NikOLAÏTEN (siehe Kommentar zu 2,6), welche die Christen zu Götzendienst und Unzucht verführen wollten.

Es gibt nun eine interessante Beziehung zwischen den Namen Bileam und Nikolaus: NiKOLAUS ist Griechisch und bedeutet „Sieg des Volkes“, BILEAM ist Hebräisch und bedeutet „Verderben des Volkes“. So liegt eine feinsinnige Ironie darin, dass Jesus diejenigen, die sich als „Nikolaïten“ bezeichneten, als „Bileamiten“ bloßstellt.

2,16 Bereue also! Wenn aber nicht, so werde ich bald zu dir kommen und Krieg mit ihnen führen durch das Schwert meines Mundes.

Die Nikolaïten werden also auf jeden Fall BALD besiegt werden, sei es, dass der Bischof gegen sie vorgeht, sei es, dass CHRISTUS sie bekämpft. Diese Prophezeiung ging in Erfüllung. Die Nikolaïten waren zur Zeit des Kaisers Trajan (98-117) zwar noch vorhanden, sind dann aber, wie der Kirchengeschichtsschreiber EUSEBIUS feststellen musste, ,schneller, als man beschreiben kann, völlig verschwunden“. 20

20 EUSEBIUS, Kirchengeschichte 3,29,4. 
2,17a Wer Ohren hat, der höre, was der Geist den (Orts-)Kirchen sagt:

Wer siegt, dem werde ich geben von dem verborgenen Manna.

Das MANNA war die geheimnisvolle Speise der Israeliten auf ihrer Wüstenwanderung und symbolisiert das eucharistische Abendmahlsbrot, das Jesus seinen Jüngern gab (Joh 6,48-51). Mit dem VERBORGENEN Manna ist aber nicht bloß der äußere Empfang des eucharistischen Brotes gemeint (das ja auch Sünder empfangen), sondern die mit dem gläubigen und würdigen Empfang verbundene innere Gnadenkraft, die zum ewigen Leben führt (vgl. Joh 6,53-58). Diese Stärkung kann auch denen zuteil werden, die nur geistig an der Eucharistie teilnehmen, weil sie am körperlichen Empfang gehindert sind. Dem SIEGER, dem standhaft Gläubigen, gibt Jesus dieses verborgene Manna, d. h. er stärkt ihn mit seiner Gnade und macht ihn würdig, das ewige Leben zu erlangen.

2,17b Und ich werde ihm einen weißen Stein geben.

WEISSE STEINE wurden damals den freigesprochenen Angeklagten gereicht und dienten außerdem als Eintrittskarten für verschiedene Veranstaltungen. Daher ist der weiße Stein hier Symbol für die Gnade des Freispruchs von den Sünden, die zugleich „Eintrittskarte“ für den Himmel ist.

2,17c Und auf dem Stein steht ein neuer Name geschrieben, den niemand kennt außer dem, der ihn empfängt.

Da der NAME ursprünglich die Eigenart bzw. das Wesen einer Person beschreibt, bedeutet das Wort „Name“ an vielen Schriftstellen dasselbe wie das Wort „Wesen“.

Eine Änderung des Namens bedeutet daher eine innere Erneuerung des Wesens einer Person. Siehe z. B. die Namensänderungen bei Abraham, Jakob und Petrus (Gen 17,5, 32,29, Joh 1,42, Mt 16,18). Der hier gemeinte NEUE NAME bedeutet daher eine innere Erneuerung durch den Heiligen Geist, welche die Sündenvergebung und ein Leben mit sich bringt. Diesen ,neuen Namen“ KENNEN NUR DIE, DIE IHN EMPFANGEN, d. h. nur die Glaubenden, weil es sich um eine innere Wirklichkeit handelt, die den Nichtglaubenden in keiner Weise begreiflich gemacht werden kann.

\subsubsection{Apk 2,18-29: Vierter Brief (an die Kirche von Thyatira)}

2,18 Und an den Engel der (Orts-)Kirche von Thyatira schreibe:

So spricht der Sohn Gottes, dessen Augen wie Feuerflammen sind und dessen Füße dem Golderz gleichen:

2,19 Ich kenne deine Werke und deine Liebe und deinen Glauben und deinen Dienst und dein geduldiges Ausharren. Und deine letzten Werke sind größer als die ersten.

2,20 Aber ich habe gegen dich, dass du das Weib Isebel gewähren lässt, die sich eine Prophetin nennt.

Und sie lehrt und verführt meine Knechte,

Unzucht zu treiben und Götzenopferfleisch zu essen.

2,21 Und ich habe ihr eine Zeit gegeben, damit sie bereut, und sie will nicht bereuen und ablassen von ihrer Unzucht.

2,22 Siehe, ich werfe sie aufs Krankenlager und bringe die, die mit ihr Ehebruch begehen mit ihr in große Bedrängnis, wenn sie sich nicht abkehren von ihren Werken. 
2,23 Und ihre Kinder werde ich töten mit dem Tod (= mit tödlicher Krankheit).

Und alle (Orts-)Kirchen werden erkennen, dass ich es bin, der Herz und Nieren prüft.

Und ich werde einem jeden von euch vergelten nach euren Werken.

2,24 Euch aber, den übrigen in Thyatira, welche nicht diese Lehre haben und welche nicht ,,die Tiefen Satans erkannt haben“, wie sie sagen: (Euch) lege ich keine andere Last auf.

2,25 Haltet nur fest, was ihr (bisher errungen) habt, bis ich komme.

2,26 Wer siegt und bis zum Ende an meinen Werken festhält, dem werde ich Macht über die Völker geben.

2,27 Und er wird sie weiden mit eisernem Stab, wie Tongefäße wird er sie zerschlagen,

2,28 so wie auch ich (Macht) erhalten habe von meinem Vater. Und ich werde ihm (dem Sieger) den Morgenstern geben.

2,29 Wer Ohren hat, der höre, was der Geist den (Orts-)Kirchen sagt.

\section{Auslegung}

2,18a Und an den Engel der(Orts-)Kirche von Thyatira schreibe:

Es könnte sich bei diesem ENGEL (d. h. Bischof) VON THYATIRA um den heiligen KARPOS handeln, aber es ist nicht sicher ist, ob dieser Bischof von Thyatira, Gordos oder Pergamon war (siehe Kommentar zu 2,12).

THYATIRA (heute: Akhissar) war eine bedeutende Handelsstadt, die ein berühmtes SambetheHeiligtum besaß, in dem eine orientalische Sibylle weissagte.

2,18b So spricht der Sohn Gottes, dessen Augen wie Feuerflammen sind und dessen Füße dem Golderz gleichen:

Die flammenden AUGEN stehen für das profunde Wissen Jesu, das hier besonders betont werden muss, weil sich die Nikolaïten in Thyatira eines tiefen Wissens um die Geheimnisse Satans rühmten (Vers 24), wohingegen nur Jesus das Innere des Menschen (,Herz und Nieren“) durchschaut (Vers 23).

Die FÜSSE AUS GOLDERZ passen dazu, dass dieses Erz in jener Gegend hergestellt wurde.

2,19 Ich kenne deine Werke und deine Liebe und deinen Glauben

und deinen Dienst und dein geduldiges Ausharren.

Und deine letzten Werke sind größer als die ersten.

Ein großes Lob, das gut zu einem heiligen Bekennerbischof wie KARPOS passen würde.

2,20 Aber ich habe gegen dich, dass du das Weib Isebel gewähren lässt,

die sich eine Prophetin nennt.

Und sie lehrt und verführt meine Knechte,

Unzucht zu treiben und Götzenopferfleisch zu essen.

IsEBEL, die Frau des Königs AHAB, wird im Alten Testament als Zauberin und unzüchtige Götzendienerin beschrieben (1 Kön 18,19, 2 Kön 9,22, 9,30-37). In Thyatira hatte sich offenbar eine prophetisch begabte Frau die Haltung und den Geist der verrufenen Königin ISEBEL angeeignet. Vielleicht nannte sie sich aus diesem Grund auch selbst „Isebel“. 
Da es in Thyatira eine weissagende Sibylle gab, könnte diese Sibylle gemeint sein. Aber dies ist unwahrscheinlich, da die Sibylle eine heidnische Frau war, während „Isebel“ anscheinend zur Kirchengemeinde gehörte, denn andernfalls könnte Jesus dem Bischof wohl kaum vorwerfen, dass er sie GEWÄHREN LÄSST. Dennoch hat Isebel vielleicht etwas mit der Sibylle zu tun: Schon der Name „Isebel“ klingt ähnlich wie „Sibylle“. Isebel könnte also eine christliche Prophetin gewesen sein, welche die heidnische Sibylle nachzuahmen versuchte.

Etwas ähnliches geschah ein halbes Jahrhundert später, als in Phrygien und somit in der Nähe von Thyatira der Irrlehrer MONTANUS eine Bewegung gründete, in der weissagende Frauen eine hervorragende Rolle spielten. Diese Bewegung verbreitete sich in ganz Kleinasien, und in Thyatira ging sogar die ganze Kirchengemeinde zu ihr über. ${ }^{21}$

Dass IsEBEL die Christen zu UnZUCHT und GÖTZENOPFERFLEISCH verführt, hat sie mit den Nikolaïten von Pergamon gemeinsam, die dem Zauberer BILEAM nacheiferten (2,14-15), so dass auch ISEBEL zur Nikolaïtensekte gehören dürfte.

2,21 Und ich habe ihr eine Zeit gegeben, damit sie bereut, und sie will nicht bereuen und ablassen von ihrer Unzucht.

Gott gibt den Sündern Zeit zur Umkehr. Daher greift er nicht immer sofort strafend ein.

2,22 Siehe, ich werfe sie aufs Krankenlager

und bringe die, die mit ihr Ehebruch begehen, mit ihr in große Bedrängnis, wenn sie sich nicht abkehren von ihren Werken.

2,23a Und ihre Kinder werde ich töten mit dem Tod (= mit tödlicher Krankheit).

Das Wort TOD kann hier nicht seine gewöhnliche Bedeutung haben, sondern muss ein Mittel bezeichnen, mit dem man zu Tode kommen kann (sonst wäre ,töten mit dem Tod“ unsinnig). Es dürfte eine todbringende Krankheit gemeint sein: vermutlich die Pest, die im Mittelalter „der Schwarze Tod“ genannt wurde, und die auch in 6,7-8 mit dem ,Tod“ gemeint sein dürfte.

Zur hier angedrohten TÖTUNG ist zu bemerken, dass das Gebot „du sollst nicht töten“ nur für Menschen Gültigkeit hat, nicht aber Gott. Denn Gott ist der Herr über Leben und Tod, dem es zusteht, zu entscheiden, wann und wie das menschliche Leben enden soll. Gerade deshalb hat der Mensch nicht das Recht, einen Menschen zu töten, außer er hat dazu eine besondere Erlaubnis Gottes. Eine solche Erlaubnis hat Gott aber keiner Privatperson gegeben, sondern nur dem Staat, der als „Diener Gottes“ nötigenfalls das „Schwert“ gebrauchen darf, um die Guten zu beschützen und die Bösen zu bestrafen (vgl. Röm 4,1-4 und Exkurs 8).

2,23b Und alle (Orts-)Kirchen werden erkennen, dass ich es bin, der Herz und Nieren prüft. Und ich werde einem jeden von euch vergelten nach euren Werken.

HERZ UND NIEREN für die innere Gesinnung. Hier wird wieder deutlich, dass Jesus mit Jahwe gleichgesetzt werden muss. Denn beim Propheten Jeremia $(23,10)$ heißt es: „Ich, Jahwe, erforsche das Herz und prüfe die Nieren, um jedem zu vergelten, wie es sein Verhalten verdient, entsprechend der Frucht seiner Taten.“ Dieser ganze Ausspruch Jahwes wird hier auf Jesus, den „Sohn Gottes“ $(2,18)$ übertragen. Zur VERGELTUNG NACH DEN WERKEN siehe auch 14,13, 20,12-13 und 22,12.

2,24 Euch aber, den übrigen in Thyatira, welche nicht diese Lehre haben und welche nicht „,die Tiefen Satans erkannt haben “, wie sie sagen: (Euch) lege ich keine andere Last auf.

21 Vgl. Epiphanius, Adersus Haereses 51,33 (PG 41 Sp. 947-948). 
Die Anhänger IsEBELs behaupteten also, dass man die TIEFEN SATANS KENNENLERnEN müsse, $d . h$. dass man die Selbsterfahrung des Bösen machen müsse, um das Heil zu erlangen. Darum praktizierten sie bewusst das Böse (vor allem Unzucht und Götzendienst), ähnlich wie die heutigen Satanisten.

2,25 Haltet nur fest, was ihr (bisher errungen) habt, bis ich komme.

2,26 Wer siegt und bis zum Ende an meinen Werken festhält, dem werde ich Macht über die Völker geben.

Will man in diesen Versen keine falsche Andeutung eines nahen Weltendes sehen, dann muss man sagen, dass das ENDE, von dem hier die Rede ist, der Tod des Einzelnen ist. Beim Tod erfolgt insofern ein Kommen Christi, als die Seele sofort nach dem Tod CHRISTUs begegnet.

Die MACHT, welche die SIEGER (die im Stand der Heiligkeit sterbenden Christen) erhalten, ist die Teilhabe an der göttlichen Weltregierung. Tatsächlich wird sich in 3,21, in 20,1-6 und besonders in 4,4 zeigen, dass die Heiligen im Himmel zusammen mit den Engeln schon jetzt an der göttlichen Weltregierung beteiligt werden.

2,27 Und er wird sie weiden mit eisernem Stab, wie Tongefäße wird er sie zerschlagen,

ER ist hier nicht CHRISTUS, sondern der Sieger, d. h. der bis zum Ende treue Christ, der als Heiliger bei Christus im Himmel weilt. Das WeIDEN der Völker bedeutet, sie mit dem Wort Gottes zu ernähren und auf das ewige Leben vorzubereiten. Dies tun die Heiligen, indem sie sich fürbittend für die Bekehrung und für den geistlichen Fortschritt der Völker einsetzen.

Dass dieses „Weiden“ MIT EISERNEM STAB geschieht, bedeutet, dass die Fürbitte der Heiligen ,durchschlagend" ist, d. h. ihre Wirkung nicht verfehlt.

Das ZERSCHLAGEN DER VÖLKER WIE TONGEFÄSSE bedeutet demnach die Zerschlagung der bösen, über die Völker herrschenden Mächte, die sie an ihrer Bekehrung zu Gott hindern.

2,28a so wie auch ich (Macht) erhalten habe von meinem Vater.

Jesus hat als Mensch nach seiner Auferstehung und Himmelfahrt vom Vater jene MACHT ERHALTEN, die er als Gott immer schon gemeinsam mit dem Vater hatte (vgl. Exkurs 1).

2,28b Und ich werde ihm (dem Sieger) den Morgenstern geben.

2,29 Wer Ohren hat, der höre, was der Geist den (Orts-)Kirche sagt.

In 22,16 sagt Jesus: „Ich bin ... der lichte Morgenstern.“ Der „Sieger“ bekommt also den „Morgenstern“ Jesus zum Geschenk, d. h. er bekommt Anteil an Jesu Herrlichkeit.

\subsubsection{Apk 3,1-6: Fünfter Brief (an die Kirche von Sardes)}

3,1 Und an den Engel der (Orts-)Kirche von Sardes schreibe: So spricht der, der die sieben Geister Gottes hat und die sieben Sterne: Ich kenne deine Werke.

Du hast einen Namen (der ausdrückt) dass du lebst, aber dennoch bist du tot.

3,2 Wach also auf und stärke das übrige, was im Begriff war, zu sterben. Denn ich habe deine Werke nicht als vollkommen gefunden vor meinem Gott. 
3,3 Gedenke also, was du empfangen und gehört hast, und bewahre es und bereue! Wenn du aber nicht wachst, werde ich kommen wie ein Dieb, und du weißt nicht, zu welcher Stunde ich über dich kommen werde.

3,4 Aber du hast einige wenige Namen in Sardes, die ihre Kleider nicht befleckt haben. Und sie werden wandeln mit mir in weißen Kleidern, weil sie würdig sind.

3,5 Wer siegt, der wird bekleidet mit weißen Kleidern. Und ich werde seinen Namen nicht auslöschen aus dem Buch des Lebens und ich werde seinen Namen bekennen vor meinem Vater und vor seinen Engeln. Wer Ohren hat, der höre, was der Geist den (Orts-)Kirchen sagt.

\section{Auslegung}

3,1a Und an den Engel der (Orts-)Kirche von Sardes schreibe:

Wer der damalige ENGEL (d. h. Bischof) VON SARDES war, ist völlig unbekannt. Es wird als durchweg schlechter Bischof geschildert. Abgesehen vom Bischof von Laodizea ist er der einzige, der nur getadelt wird. SARDES (heute Sart) war eine Stadt mit großer Vergangenheit. Im 6. Jahrhundert vor Christus war sie Hauptstadt des Königreiches Lydien und Sitz des Königs KRÖSUS gewesen. Sardes lag auf einem Hügel und war nur vom Süden her erreichbar, so dass sie uneinnehmbar zu sein schien. Dennoch nahm der Perserkönig Kyros II. die Stadt in seinem Krieg gegen KRÖsUS ein, ebenso wie drei Jahrhunderte später Antiochus Der Grosse. Beide Male hatte der Feind die Stadt, die sich zu sehr auf ihre geschützte Lage verlassen hatte, überraschend überfallen ,wie ein Dieb in der Nacht“. Darauf spielt Jesus in Vers 3 an.

3,1b So spricht der, der die sieben Geister Gottes hat und die sieben Sterne:

Die SIEBEn GeIster GotTES sind die höchsten Botenengel (siehe Kommentar zu 1,4c). Die SIEBEN STERNE sind dagegen die Bischöfe der sieben Ortskirchen (siehe Kommentar zu 2,20). Somit wird hier gesagt, dass Engel und Bischöfe in der Hand Jesu sind, dem alles im Himmel und auf Erden unterworfen ist und der folglich über die Engel erhoben ist (vgl. auch Hebr 1,5-14), wie es seiner wahren Gottheit entspricht.

Jesu Macht über die himmlischen Engel wird hier wohl deshalb erwähnt, um seine Macht über die „,irdischen Engel“, die Bischöfe, noch zu unterstreichen. Damit will CHRISTUS offenbar den Bischof von Sardes einschüchtern und zur Besinnung rufen, der aufgrund seiner Trägheit bereits geistig tot war (siehe Vers 1c).

3,1c Ich kenne deine Werke.

Du hast einen Namen (der ausdrückt) dass du lebst, aber dennoch bist du tot.

Der Bischof hatte wohl einen Namen, in dem das Wort LEBEN enthalten war (griech. „Zoe“, Wortwurzel „Zo-“). Er könnte also Zosimos, Zosimas, ZoTiKos oder ähnlich geheißen haben. Doch trotz dieses Namens war er nicht geistig lebendig, sondern TOT. Wie die Fortsetzung zeigt, hatte er nämlich seine Kirchengemeinde vernachlässigt, so dass auch diese im Absterben begriffen war.

3,2a Wach also auf und stärke das übrige, was im Begriff war, zu sterben.

Die Mahnung zur geistigen Wachsamkeit passt besonders gut zu Sardes, wie sich aus den überraschenden Überfällen in ihrer Geschichte ergibt (siehe Kommentar zu Vers 1a). 
Wenn Jesus sagt VOR MEINEM GOTT, so spricht er offenbar als Mensch, obgleich er seine Rede als Gott begonnen hatte (als Herrscher über die Engel, siehe 3,1b). Dies zeigt, dass Jesus immer zugleich Gott und Mensch ist, und dass seine beiden Naturen in ihm untrennbar verbunden sind. Aus den Reden Jesu leuchten fast immer beide Naturen mehr oder weniger deutlich hervor.

3,3 Gedenke also, was du empfangen und gehört hast, und bewahre es und bereue!

Wenn du aber nicht wachst, werde ich kommen wie ein Dieb,

und du weißt nicht, zu welcher Stunde ich über dich kommen werde.

Mit dem Kommen Jesu ist hier entweder die Begegnung mit ihm nach dem Tod gemeint (siehe Kommentar zu 2,25) oder ein erneutes geschichtliches Unglück, das die Stadt ereilen könnte wie in den Tagen des Kyros und des ANTIOCHUS.

3,4 Aber du hast einige wenige Namen in Sardes, die ihre Kleider nicht befleckt haben. Und sie werden wandeln mit mir in weißen Kleidern, weil sie würdig sind.

3,5a Wer siegt, der wird bekleidet mit weißen Kleidern.

NAMEN, DIE IHRE KLEIDER NICHT BEFLECKT HABEN: Wir haben schon gesehen, dass ein „Name“ im biblischen Sprachgebrauch keineswegs immer bloß eine Personenbezeichnung ist: In 2,17 war mit dem „Namen“ das Wesen und die Eigenart einer Person gemeint. Der vorliegende Vers ist nun ein Beispiel dafür, dass „Name“ auch genau dasselbe wie Person meinen kann: denn die „Namen“, die ihre Kleider nicht befleckt haben, sind natürlich Personen. Diese Bedeutung hat der Ausdruck „Name“ übrigens auch in der ersten Bitte des Vaterunsers: „Dein Name werde geheiligt““

Das KLEID ist die Beschaffenheit der Seele: ihr sittlicher Charakter und der Grad ihrer Gottesnähe. Jeder Mensch hat in diesem Sinne ein Kleid, und dieses ist entweder BEFLECKT (böser, gottloser Charakter) oder WEISS (guter, christusähnlicher Charakter). In der Taufe erhält der Mensch durch Sündenvergebung und innere Heiligung (Apg 2,18, 22,16, Röm 6,3-7, 1 Kor 6,11, Tit 3,5) ein weißes Kleid (vgl. den Ritus der Übergabe eines weißen Kleides an die Neugetauften).

Wer sein Kleid in diesem Leben nicht befleckt (Vers 4), wird mit einem neuen weißen Kleid bekleidet werden (Vers 5a). Das Streben nach Reinheit in diesem Leben (= das Nichtbeflecken des Kleides Vers 4) wird also mit einer noch vollkommeneren Christusähnlichkeit im anderen Leben belohnt (= das weiße Kleid in Vers 5a). Siehe auch 3,18, 6,11, 7,14, 19,8, 22,14.

3,5b Und ich werde seinen Namen nicht auslöschen aus dem Buch des Lebens und ich werde seinen Namen bekennen vor meinem Vater und vor seinen Engeln.

3,6 Wer Ohren hat, der höre, was der Geist den (Orts-)Kirchen sagt.

In der Apokalypse kommen mehrere geheimnisvolle Bücher vor:

- das Buch mit den sieben Siegeln, das künftige Geschichtsereignisse enthält (Kap. 5)

- die Bücher, welche die Taten der Menschen enthalten, nach denen sie gerichtet werden (20,12, vgl. Dan 7,10)

- das Buch des Lebens, in dem die zum ewigen Leben Berufenen und die dazu Auserwählten aufgelistet sind; dieses wird hier und 13,8, 17,8, 20,12, 20,15, 21,27 erwähnt, vgl. auch 2 Mose 32,32-33, Dan 12,1, Mal 3,16 und Ps 69,29.

Das erste Buch ist Gottes „Vorsehung“, welche seine von Ewigkeit her feststehenden Beschlüsse und Zulassungen hinsichtlich der Weltgeschichte umfasst.

Unter einem Buch, das die Taten eines Menschen enthält, ist sodann derjenige Teil des göttlichen Vorauswissens zu verstehen, welcher das Leben dieses Menschen umfasst. 
Schwer zu erklären ist aber das Buch des Lebens, von dem der vorliegende Vers spricht. Ein Teil dieses Buches enthält die Namen der „Auserwählten“, d. h. der Menschen, die einst das Heil erlangen werden. Diese sind die einzigen, die am Ende der Weltgeschichte noch in dem Buch enthalten sind $(20,15,21,27)$ und die bereits am Anfang der Zeiten (,seit Grundlegung der Welt“) darin verzeichnet waren $(13,8,17,8)$.

Ein zweiter Teil des Buches muss die Namen der Menschen enthalten, die sich zwar irgendwann auf den Weg des Heiles begeben (z. B. durch Taufe, Glaube, gute Werke), die dann aber wieder vom rechten Weg abkommen und letztendlich verlorengehen. Anscheinend werden die Namen dieser Personen zum Zeitpunkt ihrer Bekehrung in das Buch eingeschrieben, und zum Zeitpunkt ihrer Abwendung von Gott wieder aus dem Buch GESTRICHEN. ${ }^{22}$

Der erste Teil des Buches könnte also das seit Ewigkeit feststehende Vorauswissen Gottes über die Auserwählten sein. Der zweite Teil aber muss sich außerhalb des Vorauswissens Gottes befinden, da dieses Wissen völlig irrtumsfrei ist und daher keine Streichung oder Änderung zulässt. Am besten erklärt man meines Erachtens den zweiten Teil des Buches als das Wissen der heiligen Engel über die Menge der gegenwärtig ihrer Heilsberufung folgenden Menschen. Die Engel wissen vermutlich nicht, wer letztendlich das ewige Heil erlangen wird und wer nicht, aber sie wissen, wer von den Menschen zum gegenwärtigen Zeitpunkt auf dem richtigen Weg ist. Dieses Wissen haben sie von CHRISTUS, der hier sagt, dass er die Namen der Würdigen VOR SEINEM VATER UND DESSEN ENGELN bekennen wird. Sobald sich allerdings ein Mensch durch schwere Sünden von CHRISTUS abwendet, STREICHT Christus ihn aus dem Buch, d. h. vielleicht: Er lässt die Engel wissen, dass dieser Mensch den Weg des Heiles verlassen hat.

Insgesamt ist also das „Buch des Lebens“ ein Symbol für das Vorauswissen Gottes über die Auserwählten, verbunden mit dem aktuellen Wissen der Engel über die ihrer Heilsberufung folgenden Menschen. Dieses Buch mit den „seit Grundlegung der Welt“ darin verzeichneten Auserwählten ist ein hervorragendes Schriftzeugnis für Gottes absolute Allwissenheit und deren erstaunlichste Dimension: das Vorherwissen zukünftiger freier Handlungen.

\subsubsection{Apk 3,7-13: Sechster Brief (an die Kirche von Philadelphia)}

3,7 Und dem Engel der (Orts-)Kirche von Philadelphia schreibe:

So spricht der Heilige, der Wahrhaftige, der den Schlüssel Davids hat, der schließt, und niemand kann öffnen, und der öffnet, und niemand kann schließen:

3,8 Ich kenne deine Werke. Siehe, ich habe vor dir eine Tür geöffnet.

Denn du hast eine kleine Kraft und hast doch festgehalten an meinem Wort und meinen Namen nicht verleugnet.

3,9 Siehe, ich gebe (dir) einige von den Leuten aus der Synagoge Satans, die sagen, dass sie Juden seien, es aber nicht sind. Und ich werde sie dazu bringen, dass sie kommen und niederfallen zu deinen Füßen. Und sie werden erkennen, dass ich dich geliebt habe.

3,10 Weil du mein Wort vom geduldigen Ausharren bewahrt (= befolgt) hast, werde auch ich dich bewahren vor der Stunde der Versuchung, die über die ganze Welt kommen soll, um die Bewohner der Erde zu versuchen.

3,11 Ich komme bald: halte fest, was du hast, damit dir niemand deinen (Sieges)kranz nimmt.

\footnotetext{
22 Vgl. auch den Ausspruch Gottes in Ex 32,33: „Ich will den aus meinem Buch streichen, der an mir sündigt“.
} 
3,12 Wer siegt, den werde ich zu einer Säule im Tempel meines Gottes machen, und er wird nicht mehr hinaus gehen.

Und ich werde auf ihn schreiben den Namen meines Gottes

und den Namen der Stadt meines Gottes, des neuen Jerusalem,

das aus dem Himmel von meinem Gott herabkommt,

und meinen neuen Namen.

3,13 Wer Ohren hat, der höre, was der Geist den (Orts-)Kirchen sagt.

Auslegung

3,7a Und dem Engel der (Orts-)Kirche von Philadelphia schreibe:

Der Engel (d. h. Bischof) von PhILAdelphia könnte der Prophet QUADRATUS gewesen sein, der nach dem Zeugnis des EusEBIUS Anfang des 2. Jahrhunderts in Philadelphia aufgetreten ist. ${ }^{23} \mathrm{Er}$ dürfte mit dem „Schüler der Apostel“ QUADRATUS identisch sein, der 125 n. Chr. eine christliche Verteidigungsschrift verfasste und dem Kaiser Hadrian überreichte. ${ }^{24}$ So könnte er schon zur Abfassungszeit der Apokalypse als Prophet oder reisender Bischof in der Gegend von Philadelphia aufgetreten sein. Jedenfalls war der Engel von Philadelphia ein hervorragender Bischof: Außer dem Bischof von Smyrna ist er der einzige, der keinen Tadel erhält.

PhiladelPhia (heute Alacheher oder Alasehir) war eine kleine Stadt in einer vulkanischen Gegend, in der es laufend Erdbeben gab. ${ }^{25}$ Nach einem Erdbeben im Jahre 17 n. Chr. mussten die Leute außerhalb der Stadtmauern übernachten. Durch die Freigebigkeit des Kaisers TIBERIUS wurde der Wiederaufbau der Stadt ermöglicht, und aus Dank für diese kaiserliche Unterstützung nannte sie sich seitdem auch „Neocaesarea“ (neue Kaiserstadt). Auf diese Geschichte wird in den Versen 12-13 angespielt.

3,7b So spricht der Heilige, der Wahrhaftige, der den Schlüssel Davids hat, der schließt, und niemand kann öffnen, und der öffnet, und niemand kann schließen:

Der HeILIGE ist eine Gottesbezeichnung (z. B. Jes 43,3, vgl. Apk 15,5: ,du allein bist heilig“), ebenso wie Der WAHrhaftige ist ebenfalls Gottesbezeichnung (1 Joh 5,20). Die Kombination DER HeILIGE UND WAHRHAFTIGE bezieht sich schließlich auch in 6,10 eindeutig auf Gott. Somit bezeugt dieser Titel wieder sehr klar die Gottheit Christi.

Die Aussage über den Schlüssel DAVIDS erinnert an den Schlüssel zum Palast des Königs David (Jes 22,20-22). Jesus meint hier mit dem „Schlüssel Davids“ den geistigen „Schlüssel“ zu den Herzen der ihm treu ergebenen Menschen, die sein geistiger „Palast“ sind.

NIEMAND KANN SCHLIESSEN, WENN JESUS ÖFFNET - das bedeutet: Niemand kann einem Menschen die Möglichkeit zur Bekehrung nehmen, wenn Jesus in einer Gnadenstunde sein Herz aufschließt: Allerdings könnte der betreffende Mensch sich weigern, die aufgeschlossene Tür zu öffnen und Jesus hineinzulassen (vgl. 3,20).

EusEBIUS, Kirchengeschichte 5,17,4 und 3,37,1.

24 Vgl. EusEBIUS, Kirchengeschichte 4,3,1. Zumindest EuSEBIUS dürfte von der Identität ausgehen: Dafür spricht die unmittelbare Nähe der Stelle 4,3,1 zu dem einige Seiten vorher (in 3,27,1) genannten kleinasiatischen Propheten, an der der Leser an der Stelle 4,3,1, unwillkürlichen zurückdenken muss. Den Apologeten erwähnt EuSEBIUS noch in der Chronik zum 9. Jahr Kaiser Hadrians (= 125) (siehe GCS 20 S. 220 und GCS 47 S. 199), und sagt dort, „Quadratus, der Schüler der Apostel und Aristides, der Athener“ hätten dem nach Athen gereisten Kaiser Hadrian eine Apologie überreicht. Quadratus ist hier im Gegensatz zu Aristides nicht als Athener bezeichnet, er war also kein gebürtiger Athener, aber er scheint dennoch dort später Bischof geworden zu sein (vgl. Kirchengeschichte 4,23,3 und HIERONYMUS, De viris illustribus 19). Aus all diesen Nachrichten wird man den Schluss ziehen dürfen, dass Quadratus vor 125 in Pergamon und Umgebung als ,Schüler der Apostel", Prophet und eine Art reisender Bischof wirkte, im Jahre 125 aber nach Athen kam später das reguläre Bischofsamt in der dortigen Ortskirche übernahm

25 Vgl. Strabo, Geographia $12,8,18$ und 13,4,10 
NIEMAND KANN ÖFFNEN, WENN JESUS SCHLIESST - das könnte bedeuten: Wenn Jesus sich im Herzen eines Menschen befindet, der ihn bereits hereingelassen hat, und dann die „Tür“ dieses Herzens von innen abschließt (d. h. wenn Jesus diesem Menschen die Gnade der Beharrlichkeit im Guten schenkt), so kann niemand dieses Herz wieder öffnen, um durch schlechte Einflüsse Christi Gnade wieder zunichte zu machen.

Jesus betont also in diesem Brief seine Gottheit und seine gnadenbringende Herrschaft und Macht über die Herzen der Menschen, weil er die kleine missionarische Ortskirche, die nur wenig äußere Kraft hatte $(3,8 b)$ trösten will: Sie kann sich darauf verlassen, dass er sie in ihrem Missionswerk mit seiner göttlichen Gnadenkraft unterstützt.

3,8a Ich kenne deine Werke.

Siehe, ich habe vor dir eine Tür geöffnet.

Jesus hat die Herzen der Menschen im Missionsgebiet von Philadelphia aufgeschlossen.

3,8b Denn du hast eine kleine Kraft

und hast doch festgehalten an meinem Wort und meinen Namen nicht verleugnet.

Die Stadt und folglich auch die Kirchengemeinde war nur klein. Dennoch hat sie vorbildlich am Glauben festgehalten.

3,9a Siehe, ich gebe (dir) einige von den Leuten aus der Synagoge Satans, die sagen, dass sie Juden seien, es aber nicht sind.

Leute der Satanssynagoge, d. h. Nikolaïten, die trotz ihrer jüdischen Abstammung den Ehrennamen „Juden“ nicht verdienen (vgl. 2,9), wird Jesus dem Bischof von Philadelphia „geben“: d. h. er wird sie zu Christen machen.

3,9b Und ich werde sie dazu bringen, dass sie kommen und niederfallen zu deinen Füßen.

Und sie werden erkennen, dass ich dich geliebt habe.

Die Bemerkung, dass die ehemaligen Christenfeinde nach ihrer Bekehrung ZU FÜSSEN des Bischofs von Philadelphia NIEDERFALLEN werden (eine sog. Proskynese, kniefällige Verehrung, ausüben), ist ein Zeugnis für die Berechtigung einer Verehrung des Bischofsamtes. Diese Verehrung gilt nicht dem Bischof als Person, sondern seinem heiligen Amt. Zur kniefälligen Verehrung (Proskynese) vergleiche auch den Kommentar zu 19,10.

3,10 Weil du mein Wort vom geduldigen Ausharren bewahrt (= befolgt) hast, werde auch ich dich bewahren vor der Stunde der Versuchung, die über die ganze Welt kommen soll, um die Bewohner der Erde zu versuchen.

3,11 Ich komme bald: halte fest, was du hast, damit dir niemand deinen (Sieges)kranz nimmt.

Hier ist erstmals die Rede von einer BaLdigen weltweiten Versuchung. Damit dürfte die Christenverfolgung gemeint sein, die kurz nach der Abfassung der Apokalypse, nämlich unter Kaiser Trajan (98-117), ,weltweite“ Ausmaße annahm, indem sie auf das ganze römische Reich ausgedehnt wurde, das unter Trajan seine größte Ausdehnung erreichte. DIE GANZE WELT ist also ein Ausdruck für das Gebiet des damals herrschenden römischen Weltreiches, weil dieses in der Tat fast die ganze dem JoHAnNES bekannte Welt umfasste.

Das Kommen Christi bedeutet hier die Zulassung dieser Christenverfolgung: In ihr „kommt“ CHRISTUS als Richter, um die Standfestigkeit der Christen zu erproben. Eine ähnliche Bedeutung hatte das Kommen Christi in 3,3. 
CHRISTUS verspricht, dass der Bischof vor dieser Versuchung bewahrt werden wird: Er wird so gefestigt sein, dass die Verfolgung für ihn nicht zur Versuchung werden wird, den Glauben aufzugeben.

3,12a Wer siegt, den werde ich zu einer Säule im Tempel meines Gottes machen, und er wird nicht mehr hinaus gehen.

Das Bild von der feststehenden SÄULE muss die Philadelphier besonders angesprochen haben: Man denke an jenes Erdbeben, das ihre Stadt einst zum Einsturz brachte (siehe Kommentar zu 3,7a). Der Satz „ER WIRD NICHT MEHR HINAUS GEHEN“ erinnert ebenfalls an das Erdbeben, bei dem die Bewohner ihre Stadt verlassen mussten. Der TEMPEL ist hier ein symbolischer Tempel: die Gemeinschaft der Kirche. Zum Ausdruck TeMPEL Meines GotTES siehe den folgenden Halbvers.

\section{3,12b Und ich werde auf ihn schreiben den Namen meines Gottes}

Der Ausdruck Name meines GotTes ist (ebenso wie Tempel meines GotTes im vorherigen Halbvers) ein Beispiel dafür, dass Jesus mitunter den himmlischen Vater seinen „Gott“ nannte (vgl. auch Joh 20,17). Es spricht also hier als Mensch, obgleich er am Anfang des Briefes als Gott sprach (vgl. zu diesem Wechsel den Kommentar zu 3,2b). Dadurch wird hier die untrennbare Verbindung seiner beiden Naturen, Gottheit und Menschheit, deutlich.

Hier wird an den Namen JAHWE (,der Seiende“) zu denken sein, oder eventuell an die Namen ,der ist und der war und der kommt“", den JOHANNES eingangs benutzte.

Mit dem Schreiben des Namens Gottes auf die Philadelphier ist ein unsichtbarer Vorgang gemeint: die Festigung ihrer Zugehörigkeit zu Gott.

3,12c und den Namen der Stadt meines Gottes, des neuen Jerusalem, das aus dem Himmel von meinem Gott herabkommt

Außer der Zugehörigkeit zu Gott wird auch die Zugehörigkeit zum „neuen Jerusalem“ besiegelt. Das Neue Jerus alem, DAS AUS DEM Himmel Herab KOMMt, ist die Kirche der Heiligen im Himmel, die am Ende der Zeiten ,vom Himmel herabkommen“ und sich dann auch auf die „Erde“, d. h. auf das ganze Universum erstrecken wird (siehe Kap. 21-22 und Hebr 12,22-23).

Passenderweise werden die Philadelphier, die seit dem großen Erdbeben (siehe Kommentar zu 3,7a) ihre Stadt „,neue Kaiserstadt“ nannten, auf das ,neue Jerusalem“ hingewiesen: Nicht nur Bewohner der „neuen Kaiserstadt“, sondern auch des „,neuen Jerusalem“ sollen sie sein.

Im Ezechielbuch (48,35), das ebenfalls eine Vision des neuen Jerusalem enthält, heißt es: „Dann soll die Stadt genannt werden: JAHWE IST HIER“. Dieser Satz, der die Gegenwart Gottes unter den Menschen ausdrückt, ist also der neue NAME DER STADT. Darauf wird auch in Apk 21,2-3 angespielt, wo das neue Jerusalem „Zelt Gottes bei den Menschen“ genannt wird.

$3,12 \mathrm{~d} \quad$ und meinen neuen Namen.

3,13 Wer Ohren hat, der höre, was der Geist den (Orts-)Kirchen sagt.

Der NeUE NAmE Jesu ist wahrscheinlich der Name Immanuel, zu deutsch: GotT Mit Uns. In Jes 7,14 und Mt 1,23 war prophezeit worden, dass man Jesus so nennen würde, aber in seinem Erdenleben ist er nie so genannt worden. Es könnte also der zukünftige, ,neue“ Name Jesu zu sein. Eine Stütze erhält diese Hypothese in 21,3, wo über die Bewohner des „,neuen Jerusalem“ gesagt wird: „Er selbst, GOTT MIT IHNEN, wird ihr Gott sein“. 


\subsubsection{Apk 3,14-22: Siebter Brief (an die Kirche von Laodizea)}

Text

3,14 Und an dem Engel der (Orts-)Kirche von Laodizea schreibe: So spricht der „Amen“, der treue und wahrhaftige Zeuge, der Anfang der Schöpfung Gottes:

3,15 Ich kenne deine Werke, dass du weder kalt noch heiß bist. Wärest du doch kalt oder heiß!

3,16 Weil du aber lauwarm bis, und weder heiß noch kalt, bin ich im Begriff, dich auszuspeien aus meinem Munde.

3,17 Du sagst: Ich bin reich und zu Reichtum gekommen, und ich habe nichts nötig. Und du weißt nicht, dass du der Elende und Erbärmliche und Arme und Blinde und Nackte bist.

3,18 Ich rate dir, von mir Gold zu kaufen, das im Feuer geläutert ist, damit du reich wirst, und weiße Kleider, damit du sie anziehst und nicht die Hässlichkeit deiner Nacktheit offenbar wird, und Augensalbe (Kollyrion), damit du deine Augen einsalbst und sehen kannst.

3,19 Wen ich liebe, den weise ich zurecht und züchtige ihn. Sei also eifrig und bereue!

3,20 Siehe, ich stehe an der Tür und klopfe: Wenn jemand meine Stimme hört und die Tür öffnet, werde ich zu ihm hineingehen und mit ihm Mahl halten, und er mit mir.

3,21 Wer siegt, dem werde ich gewähren, mit mir auf dem Thron zu sitzen, so wie ich gesiegt habe und mich auf den Thron meines Vaters gesetzt habe.

3,22 Wer Ohren hat, der höre, was der Geist den (Orts-)Kirchen sagt.

\section{Auslegung}

3,14a Und an dem Engel der (Orts-)Kirche von Laodizea schreibe:

Es ist völlig unbekannt, wer der ENGEL (d. h. Bischof) vON LAODIZEA war. Die Apokalypse beschreibt ihn, ähnlich wie den Bischof von Sardes, als sehr schlechten Bischof.

LAODIZEA (heute nur noch Ruinen) war eine berühmte Ärztestadt und eine reiche Industrie- und Handelsmetropole. Die Stadt lag in einem Tal am Fuß eines Berges, auf dem die Stadt Hierapolis erbaut war. Oben in Hierapolis entsprangen heiße Thermalquellen, deren Wasser nach Laodizea hinabfloss, wo es jedoch in einem lauwarmen Zustand ankam. Die Namen berühmter laodizenischer Ärzte sind bereits zur Zeit des Augustus auf lokalen Münzen zu finden. Es scheint, dass diese Ärzte vor allem Augenleiden behandelten. Dazu benutzen sie die berühmte Augensalbe, „Kollyrion“ genannt, die man aus dem Pulver herstellte, das man durch Zerreiben eines besonderen Steins gewann. ${ }^{26}$ Außer dem Kollyrion wurde in Laodizea eine glänzende schwarze Wolle hergestellt, die man zu verschiedenen kostbaren Kleidungsstücken verarbeitete. Laodizea war voll von Banken und überall blühte der Handel. Der Reichtum der Bewohner war so groß, dass die Stadt nach einem Erdbeben im Jahre 60 n. Chr. ohne fremde Hilfe wiederaufgebaut werden konnte. ${ }^{27}$

\footnotetext{
26 Galenus, De Sanitate tuenda 6,12 (C. G. Kühn, Claudii Galeni Opera Omnia Band 6 S. 438-439, Leipzig 1823, Nachdruck Hildesheim: Olms, 1965)

27 Vgl. TACITUS, Annalen 14,27.
} 
Von den sieben Briefen enthält der vorliegende die meisten Anspielungen an das Charakterbild dieser Stadt: ihr lauwarmes Wasser (15-16), ihre Augensalbe (18c), ihre schwarze Wolle (18b), ihren Reichtum und ihr Gold (17a, 18a), und ihren Wiederaufbau aus eigener Kraft (17a).

3,14b So spricht der „Amen“, der treue und wahrhaftige Zeuge, der Anfang der Schöpfung Gottes:

CHRISTUS ist der „AMEN“ (deutsch: wahrlich), d. h. die entschiedene Bestätigung des Heils, im Gegensatz zum Bischof von Laodizea, der ,,weder heiß noch kalt“ ist $(3,15)$. Der Titel „Amen“ weist auch auf Christi Gottheit hin, denn beim Propheten Jesaja $(65,16)$ ist vom „wahrhaftigen Gott“ die Rede, wörtlich: vom „Gott Amen“.

Christus ist auch DER ANFANG Der Schöpfung GotTes. Die Arianer und Zeugen Jehovas legen dies so aus, dass CHRISTUS das erste Geschöpf, also der ersterschaffene Engel Gottes ist. Nach katholischer Auslegung ist dagegen CHRISTUS DER ANFANG der Schöpfung Gottes in demselben Sinn, wie er zusammen mit Gott, dem Vater ,der erste und der letzte, das Alpha und das Omega, der Anfang und das Ende“ ist (21,6, vgl. Exkurs 1). Das heißt: Er ist als Schöpfer (nicht als Geschöpf) der Ausgangspunkt und das Ziel für alle Schöpfung. So sagt JOHANNES auch in seinem Evangelium, dass CHRISTUS ,im Anfang war“ (nicht: im Anfang wurde), und dass ,alles, was geworden ist, durch ihn geworden ist" (Joh 1,1-2).

Paulus schreibt im Kolosserbrief (1,16), CHRISTUS sei der „Erstgeborene aller Schöpfung, denn in ihm ist alles erschaffen worden im Himmel und auf Erden“. Auch dies verstehen Arianer und Zeugen Jehovas so, dass Christus das erste Geschöpf ist. Aber wenn, wie Paulus hier lehrt, die gesamte Schöpfung von CHRISTUS erschaffen wurde, so muss CHRISTUS bereits vor aller Schöpfung existiert haben und über allen Geschöpfen stehen. CHRISTUS ist „Erstgeborener aller Schöpfung“ in dem Sinn, dass er bereits vor der gesamten Schöpfung aus dem Vater geboren ist (weil er schon seit Ewigkeit aus dem Vater hervorgeht: siehe Exkurs 1).

CHRISTUS kann auch in einem zweiten Sinn „Anfang der Schöpfung Gottes“ genannt werden, weil er nämlich auch der Ausgangspunkt der neuen Schöpfung Gottes (= des Reiches Gottes, der Kirche) ist, die mit Jesu Menschwerdung, Tod und Auferstehung begann. Im diesem Sinn sagt Paulus im Kolosserbrief $(1,18)$, dass CHRISTUS ,der Anfang, der Erstgeborene von den Toten“ ist.

Die entscheidenden Parallelen zu unserer Stelle stehen also im Kolosserbrief, und es ist wohl kein Zufall, dass Paulus die Kolosser auffordert, diesen Brief auch in Laodizea bekannt zu machen $(4,16)$. Die Apokalypse knüpft also bei den Laodizenern an bereits Bekanntes an.

Das Prädikat „Anfang der Schöpfung Gottes“ ist ebenso wie „Amen“ ein göttliches Prädikat. CHRISTUS weist in den beiden beklagenswertesten Ortskirchen, Laodizea und Sardes, auf seine göttliche Macht hin, um den Bischof zu einem dringend notwendigen Umdenken zu bringen.

3,15 Ich kenne deine Werke, dass du weder kalt noch heiß bist. Wärest du doch kalt oder heiß!

3,16 Weil du aber lauwarm bist, und weder heiß noch kalt,

bin ich im Begriff, dich auszuspeien aus meinem Munde.

Dass der Bischof und seine Kirche WEDER HEISST NOCH KALT ist, ist eine Anspielung auf die lauwarme Temperatur des Wassers in Laodizea.

CHRISTUS vergleicht hier die guten Christen mit heißem oder kaltem Wasser: beides ist brauchbar, denn es ist jeweils in seiner Art von guter Qualität. „Heiße“ und „kalte“ Christen sind also solche, die sich in bestimmter Weise für das Reich Gottes qualifiziert haben.

Die ,lauwarmen“ Christen sind dagegen nicht etwa die mäßig guten, wie man oft glaubt (diese müsste man als mäßig warme oder mäßig kalte ansehen), sondern die vollkommen trägen und gleichgültigen, die ,geistig tot“" und daher für CHRISTUS unbrauchbar sind. 
3,17a Du sagst: Ich bin reich und zu Reichtum gekommen, und ich habe nichts nötig.

Hier ist auf Wiederaufbau Laodizeas nach dem Erdbeben im Jahr 60 angespielt (siehe Kommentar zu 3,14a), der ohne fremde Hilfe gelang.

3,17b Und du weißt nicht,

dass du der Elende und Erbärmliche und Arme und Blinde und Nackte bist.

JESUS erklärt dem Bischof, dass er derjenige Bischof ist, der am meisten geistige Hilfe nötig hat.

3,18a Ich rate dir, von mir Gold zu kaufen, das im Feuer geläutert ist, damit du reich wirst,

Dem Bischof dieser Handelsmetropole möchte Jesus seine Gnade in einer ihm bekannten Sprache als sinnbildliches GOLD ,verkaufen“. Das IM FEUER GELÄUTERTE GOLD bedeutet die in Not und Bedrängnis bewährte und darum standhafte Liebe.

3,18b und weiße Kleider, damit du sie anziehst und nicht die Hässlichkeit deiner Nacktheit offenbar wird,

Wohl im bewussten Gegensatz zu der schwarzen Wolle, die in Laodizea hergestellt wurde, spricht Jesus hier von WEISSEN KLEIDERN. Die weißen Kleider stehen für die Reinheit der Seele, die man bei CHRISTUS „kaufen“ kann und ohne die sich der Mensch schämen muss wie ein körperlich NACKTER. Die NACKTHEIT bedeutet hier offenbar dasselbe wie das befleckte Kleid in 3,4.

3,18c und Augensalbe (Kollyrion), damit du deine Augen einsalbst und sehen kannst.

In Anlehnung an die in Laodizea hergestellte Augensalbe möchte CHRISTUS dem Bischof seine Gnade als geistige Augensalbe ,verkaufen“, damit er die Wahrheit erkennt und einsieht, in welch erbärmlicher Lage er sich befindet.

3,19 Wen ich liebe, den weise ich zurecht und züchtige ihn. Sei also eifrig und bereue!

Es gibt noch Hoffnung: Die angedrohte „Ausspeiung“ (Vers 16) ist noch nicht endgültig beschlossen.

3,20 Siehe, ich stehe an der Tür und klopfe:

Wenn jemand meine Stimme hört und die Tür öffnet,

werde ich zu ihm hineingehen und mit ihm Mahl halten, und er mit mir.

Die TÜR ist die Tür des Herzens (siehe Kommentar zu 3,7-8). Jesus KLOPFT durch innere Inspiration an, und wer ÖFFNET, d. h. ihn und seine Gnade hereinlässt, wird mit ihm MAHL HALTEN, d. h. eine glückbringende Gemeinschaft mit ihm haben, in diesem und im anderen Leben (Mt 8,11, 26,29).

3,21 Wer siegt, dem werde ich gewähren, mit mir auf dem Thron zu sitzen so wie ich gesiegt habe und mich auf den Thron meines Vaters gesetzt habe.

3,22 Wer Ohren hat, der höre, was der Geist den (Orts-)Kirchen sagt.

Als Mensch hat sich Jesus nach seiner Auferstehung AUF DEN THRON gesetzt. Wer SIEGT, d. h. bis zum Ende seines Lebens standhaft bleibt, darf sich ebenfalls AUF DEN THRON SETZEN und mit Christus herrschen. Siehe auch 20,4. 


\subsection{Apk 4,1 - 5,14: Vision des Himmels}

JESUS hatte in 1,9 zu JOHANNES gesagt: „Schreibe auf ... was ist, und was danach geschehen soll.“ (1,19). In Kap. 2-3 hat sich gezeigt, was genauer mit dem, ,was ist“, gemeint war: der gegenwärtige Zustand der sieben Ortskirchen. Nun beginnt der zweite, im eigentlichen Sinn prophetische Teil: die Offenbarung über das, ,was danach geschehen soll“ (4,1). Dieser Teil beginnt mit einer längeren Einleitung, nämlich einer Himmelsvision (Kap. 4-5).

text

4,1 Danach schaute ich, und siehe eine geöffnete Tür im Himmel.

Und die erste Stimme, die ich wie eine Posaune mit mir sprechen gehört hatte, sagte:

Steige hier herauf, und ich werde dir zeigen, was danach geschehen soll.

4,2 Und siehe, ein Thron stand im Himmel, und auf dem Thron saß einer.

4,3 Und der, der auf dem Thron saß,

glich in der Vision dem Stein Jaspis und dem Sarder.

Und ein Regenbogen war rund um seinen Thron,

der glich in der Vision einem Smaragd.

4,4 Und rings um den Thron (sah ich) vierundzwanzig Throne,

und auf den Thronen saßen vierundzwanzig Älteste.

Sie waren bekleidet mit weißen Kleidern.

Und auf ihren Häuptern hatten sie goldene Kronen.

4,5 Und von dem Thron gehen aus Blitze und Stimmen und Donner.

Und sieben Feuerfackeln brennen vor dem Thron: das sind die sieben Geister Gottes.

4,6 Und vor dem Thron war etwas wie ein gläsernes Meer gleich einem Kristall.

Und in der Mitte des Thrones und im Kreis um den Thron waren vier Lebewesen, die voll waren von Augen vorn und hinten.

4,7 Und das erste Lebewesen glich einem Löwen und das zweite Lebewesen glich einem Stier und das dritte Lebewesen hatte das Gesicht eines Menschen und das vierte Lebewesen glich einem fliegenden Adler.

4,8 Und jedes der vier Lebewesen hatte je sechs Flügel,

die ringsum und innen voll mit Augen waren.

Und sie haben keine Ruhe Tag und Nacht und singen:

heilig, heilig, heilig ist der Herr,

der Gott, der Allmächtige, der war und der ist und der kommt.

4,9 Und jedes Mal, wenn die Wesen Preis und Ehre und Dank dem darbringen, der auf dem Thron sitzt und in Ewigkeit lebt,

4,10 fallen die vierundzwanzig Ältesten vor dem, der auf dem Thron sitzt, nieder und beten den an, der in alle Ewigkeit lebt, und legen ihre Kronen nieder und sagen:

4,11 Würdig bist du, unser Herr und Gott,

zu empfangen die Herrlichkeit und die Ehre und die Macht,

weil du das All erschaffen hast:

Durch deinen Willen waren alle Dinge und und wurden sie erschaffen.

5,1 Und ich sah in der Rechten dessen, der auf dem Thron sitzt, ein Buch, beschrieben innen und außen, versiegelt mit sieben Siegeln.

5,2 Und ich sah einen starken Engel, der verkündete mit lauter Stimme:

Wer ist würdig, das Buch zu öffnen und seine Siegel zu lösen?

5,3 Und niemand im Himmel, auf der Erde, oder unter der Erde konnte das Buch öffnen oder in es hineinsehen.

5,4 Und ich weinte viel, weil niemand als würdig erfunden wurde, das Buch zu öffnen und in es hineinzusehen. 
5,5 Und einer von den Ältesten sagt(e) zu mir: Weine nicht!

Siehe, gesiegt hat der Löwe aus dem Stamm Juda, die Wurzel Davids,

um das Buch zu öffnen und seine sieben Siegel.

5,6 Und ich sah in der Mitte des Thrones und der vier Wesen und in der Mitte der Ältesten ein Lamm stehen wie ein Geschlachtetes. Es hatte sieben Hörner und sieben Augen: Das sind die sieben Geister Gottes, die in die ganze Welt ausgesandt sind.

5,7 Das Lamm trat heran und empfing das Buch aus der rechten Hand dessen, der auf dem Thron saß.

5,8 Als es das Buch empfangen hatte,

fielen die vier Wesen und die vierundzwanzig Ältesten vor dem Lamm nieder.

Alle trugen Harfen und goldene Schalen voll mit Weihrauch:

Das sind die Gebete der Heiligen.

5,9 Und sie singen ein neues Lied und sprechen:

Würdig bist du, das Buch zu nehmen und seine Siegel zu öffnen,

weil du geschlachtet worden bist und Menschen erkauft hast für Gott durch dein Blut aus jedem Stamm und jeder Zunge und jedem Volk und jeder Nation

5,10 und du hast sie für unseren Gott zu einem Königreich und zu Priestern gemacht.

Und sie werden auf der Erde herrschen.

5,11 Und ich sah und hörte eine Stimme vieler Engel im Kreis um den Thron und die Wesen und die Ältesten.

Und ihre Zahl war zehntausende von Zehntausenden und tausende von Tausenden.

5,12 Sie sprachen mit lauter Stimme:

Würdig ist das Lamm, das geschlachtet wurde, die Macht zu erhalten

und Reichtum und Weisheit und Stärke und Ehre und Herrlichkeit und Lob.

5,13 Und jedes Geschöpf im Himmel und auf der Erde und unter der Erde und auf dem Meer - alles in diesen (Lebensbereichen) hörte ich sagen:

Dem, der auf dem Thron sitzt und dem Lamm gebührt das Lob und die Ehre und die Herrlichkeit und die Macht in alle Ewigkeit.

5,14 Und die vier Wesen sagten: Amen. Und die Ältesten fielen nieder und beteten an.

Auslegung

4,1 Danach schaute ich, und siehe eine geöffnete Tür im Himmel.

Und die erste Stimme, die ich wie eine Posaune mit mir sprechen gehört hatte, sagte:

Steige hier herauf, und ich werde dir zeigen, was danach geschehen soll.

Und sogleich wurde ich vom Geist ergriffen.

JOHANNES wird in den HIMMEL versetzt, d. h. in die unmittelbare Gegenwart Gottes (vgl. Exkurs 3). WAS DANACH GESCHEHEN SOLL ist das hauptsächliche Thema des Buches. JOHANNES wurde VoM GEIST ERGRIFFEN: siehe Kommentar zu 1,10.

4,2 Und siehe, ein Thron stand im Himmel, und auf dem Thron saß einer.

4,3 Und der, der auf dem Thron saß,

glich in der Vision dem Stein Jaspis und dem Sarder.

Und ein Regenbogen war rund um seinen Thron,

der glich in der Vision einem Smaragd. 
Der AUF DEM HIMMLISCHEN THRON SITZENDE ist (bzw. symbolisiert) Gott. Selbstverständlich wurde nicht Gott selbst geschaut, denn das göttliche Wesen ist unkörperlich. Zu sehen waren vielmehr körperliche Figuren und Gestalten, die Gott symbolisierten.

So dürfte der JASPIS, ein grüner Edelstein (siehe den Kommentar zu 21,19), Gott als Schöpfer und Lebensspender symbolisieren, denn grün ist als Farbe der Pflanzen die Farbe des Lebens.

Gott glich auch einem SARDER, einem roten Edelstein (siehe Kommentar zu 21,20). Dieser Edelstein könnte für Gott als strafenden Richter stehen, denn Rot ist die Farbe des Feuers.

Über Gottes Thron sah Johannes einen REGEnBogen, das Zeichen des Friedensbundes zwischen Gott und allen Lebewesen (siehe das Ende der Sintflutgeschichte, Gen 9,13-15). Der Regenbogen glich einem SMARAGD (einem durchsichtig-grünen Edelstein), d. h. in diesem Regenbogen war das Grün, die Farbe des Lebens, deutlicher zu sehen als die anderen Farben. Dadurch wird die biblische Symbolik des Regenbogens noch unterstrichen.

Die ganze Vision kann so gedeutet werden: Gott ist sowohl Schöpfer (Jaspis) als auch Richter (Sarder), aber über diesen beiden Eigenschaften steht als zusammenfassendes Glied der grüne Regenbogen, d. $h$. Gott ist vor allem der milde und versöhnliche Beschützer des Lebens.

4,4 Und rings um den Thron (sah ich) vierundzwanzig Throne, und auf den Thronen saßen vierundzwanzig Älteste. Sie waren bekleidet mit weißen Kleidern. Und auf ihren Häuptern hatten sie goldene Kronen.

Auf jeden Fall sind die VIERUndzWAnZIG ÄLTESTEN eng mit Gott verbundene Geschöpfe. Manche glauben, dass es sich um eine besondere Klasse von Engeln handelt, und zwar um jene Klasse hoher Engel, die Paulus „Throne“ nennt (Kol 1,16). Aber die 24 Ältesten sitzen auf Thronen, sie sind also keine Throne. Dass es sich nicht um Engel, sondern um Menschen handeln muss, bezeugt m. E. der Titel „Älteste“, der in der Schrift sonst immer nur auf Menschen angewendet wird. Es handelt sich also bei den vierundzwanzig Ältesten wahrscheinlich um verstorbene und bereits mit ihrer Seele in den Himmel eingegangene Heilige.

Ist die Zahl 24 hier wörtlich zu nehmen oder könnte sie die Gesamtheit aller Heiligen oder aller hervorragenden Heiligen symbolisieren? Zunächst ist zu beachten, dass die Zahl eine starke symbolische Ausdruckskraft hat, die sich vor allem daraus ergibt, dass sie das Doppelte der Zahl 12 ist, die wiederum als Produkt von drei und vier teilweise auf der Symbolik dieser beiden Zahlen beruht. In einem Exkurs gehe ich daher hier zunächst auf die Zahlen, drei, vier, zwölf und vierundzwanzig ein. ${ }^{28}$

\section{Exkurs 4: Die Symbolik der Zahlen 3, 4, 12, 24 und 144}

Die Zahlen drei, und vier, gelten zunächst deshalb als „,vollkommene Zahlen“, weil Dreieck und Viereck die einfachsten geometrischen Figuren sind. Die drei gilt auch deshalb als vollkommen, weil sie die ,Zahl von Raum und Zeit“" ist: der Raum hat die drei Dimensionen Länge, Breite, Höhe, während die Zeit in Gegenwart, Vergangenheit und Zukunft eingeteilt ist. Auch ist die Zahl drei „Zahl der nachdrücklichen Wiederholung“ sowie die „Zahl der Mitte zwischen zwei Extremen“ und „Zahl der Überwindung von Gegensätzen“, letzteres, weil sie die Zahl zwei, die den Gegensatz, Zwiespalt und Zweifel anzeigt, durch das ,,verbindende Dritte“ überbietet (es steht die Zahl eins für eine These oder Bejahung, die Zahl zwei für die zugehörige Antithese oder Verneinung, so die Zahl drei für die Synthese, die Überwindung der Gegensätze zu einer höheren Einheit). Als Überwinderin des Zweifels kann die drei auch „Zahl des Glaubens“ genannt werden. Dadurch deutet sich schon an, dass die drei die Zahl der Übernatur ist, was eine Bestätigung durch die Anzahl der göttlichen Personen (Vater, Sohn und Heiliger Geist) sowie durch die Anzahl der ,übernatürlichen“ Tugenden (Glaube, Hoffnung und Liebe) findet. Die Zahl vier ist dagegen die „Zahl der Natur“, unter anderem wegen

Außerdem ist in der Apokalypse noch die Symbolik der Zahlen 1/3, 3 1/2, fünf, sechs, sieben, acht, zehn, 42, 666, 1000,1260 und 144000 wichtig; siehe hierzu S. 143-148 (zu 6,7,8), S. 207 (zu 1000), S. 81-82 (zu 1/3), S. 73 (zu 144000), S. 91 (zu 5) und S. $103-104$ (zu 3 1/2). 
der Vierzahl der Himmelsrichtungen, Jahreszeiten, irdisch-materiellen Seinsstufen, Gliedmaßen höherer Lebewesen und der Vierzahl der „natürlichen“ Tugenden (Klugheit, Gerechtigkeit, Tapferkeit und Mäßigkeit); siehe weiteres zur Vierzahl auf S. 53-54 im Kommentar zu 4,6b-8). Die zwölf ist ebenfalls bei zahlreichen Völkern eine Vollkommenheitszahl, und dies aus mehreren Gründen. Einer von diesen dürfte sein, dass man mit einer einzigen Hand nicht nur bis fünf, sondern bis zwölf zählen kann. Dazu berührt man mit dem Daumen an jedem der vier anderen Finger derselben Hand nacheinander die drei durch Gelenke deutlich getrennte Fingerteile (tatsächlich ist diese Zählweise bei Völkern im nahen und fernen Osten verbreitet, etwa in der Türkei, im Irak, in Indien und Indochina): Man berührt mit dem Daumen der rechten Hand zuerst den oberen, dann den mittleren, dann den unteren Teil des kleinen Fingers, dann in derselben Reihenfolge die Teile des Ringfingers, dann des Mittelfingers und schließlich des Zeigefingers. Auf diese Weise berührt man zwölf Stellen und kann auf diese Weise bis zwölf zählen und die Zahlen von eins bis zwölf durch je eine eigene Handstellung repräsentieren. Macht man mit der linken Hand dasselbe, kommt man folglich bis vierundzwanzig, so dass auch die vierundzwanzig eine Vollkommenheit besonderer Art (nämlich eine solche mit zwei vollkommenen Teilen) versinnbildet (siehe auch unten). Von daher lag es vielleicht nahe, den Tag in zwölf Stunden und die Nacht ebenfalls in zwölf Stunden (die gesamte Einheit von Tag und Nacht also in vierundzwanzig Stunden einzuteilen). Man kann aber auch mit dem Daumen der linken Hand, während man mit der mit der Rechten in beschriebener Weise immer wieder bis zwölf zählt, jedesmal einen der anderen der zwölf Teile der Finger der linken Hand berühren, und kann auf diese Weise bis 144 (d.h. bis zwölf mal zwölf) zählen. So symbolisiert hundertvierundvierzig eine Vollkommenheit höherer Ordnung und absolute Vollständigkeit.

Ein weiterer wichtiger Grund für die Vollkommenheit der Zahl Zwölf ist geometrischer Art: Es gibt fünf Körper, deren Flächen regelmäßige Vielecke sind. Dies sind die sogenannten fünf platonischen Körper:

$\begin{array}{lll}\text { 1. der Tetraeder } & \text { mit } 4 \text { Flächen (Dreiecken), } \\ \text { 2. der Würfel (= Hexaeder) } & \text { mit } 6 \text { Flächen (Quadraten), } \\ \text { 3. der Oktaeder } & \text { mit } 8 \text { Flächen (Dreiecken), } \\ \text { 4. der Dodekaeder } & \text { mit } 12 \text { Flächen (Fünfecken), } \\ \text { 5. der Ikosaeder } & \text { mit 20 Flächen (Dreiecken). }\end{array}$

Von diesen Körpern hat der Dokedaeder mit seinen zwölf Flächen bei gleicher Kantenlänge den größten Rauminhalt und die vollkommenste Gestalt: Denn er gleicht am meisten einer Kugel. Ein dritter Grund für die Vollkommenheit der zwölf dürfte sein, dass die Zeit eines gesamten Sonnenjahres zwölf Monate (d. h. zwölf Mondumläufe) umfasst. Ein vierter Grund ist schließlich, dass zwölf das Produkt der vollkommenen Zahlen drei und vier ist. Als drei mal vier“ ist die zwölf auch ein Symbol für die Verbindung der Natur mit der Übernatur und bezeichnet eine „Gesamtheit von Heiligen, die durch die vier natürlichen und die drei übernatürlichen Tugenden ausgezeichnet sind“ oder eine „Gesamtheit von Heiligen, die aus den vier Himmelsrichtungen kommend durch den Glauben an die Dreifaltigkeit geeint sind“. So taucht die zwölf wohl nicht zufällig oft in Verbindung mit einem in sich geschlossenen Kreis vollkommener Menschen auf: vgl. die zwölf Richter Israels, die zwölf Söhne Jakobs, die zwölf „kleinen“ Schriftpropheten, die zwölf Apostel. Da schon die zwölf eine „Gesamtheit von Heiligen“ symbolisierten kann, kann die Zahl vierundzwanzig, also zweimal die zwölf, die Summe zweier vollkommener Gruppen bezeichnen: z. B. die Heiligen der vor- und nachchristlichen Zeit oder die Heiligen des alten und des neuen Gottesvolkes. Beachtlich sind in diesem Zusammenhang für die Symbolik der 24 noch die folgende Tatsachen:

- Wie schon oben erwähnt, kann man mit einer Hand bequem bis zwölf, und folglich mit zwei Händen bis 24 zählen; so bildet die 24 eine übergeordnete Gesamtheit zweier gleich großer, in sich bereits vollkommener Hälften.

- 24 ist die Anzahl der beweglichen Wirbel der menschlichen Wirbelsäule sowie die Anzahl der Rippen. So könnte die Zahl die Heiligen symbolisieren, welche das „Rückrad“ und Herz der Kirche sind.

- 24 Stunden machen einen Tag aus. Auch darum kann die Zahl eine vollendete Gesamtheit darstellen.

- 24 war die Zahl der Priesterklassen nach 1 Chr 24,1-9. So könnte die Zahl für eine Gesamtheit von Priestern stehen.

Nun zurück zur Deutung der „vierundzwanzig Ältesten“ in Vers 4,4. Wie der Exkurs gezeigt hat, verdient die Symbolkraft der Zahl 24 ohne Zweifel, hervorgehoben zu werden. Jedoch beweist sie keineswegs, dass die 24 Ältesten 
für die Gesamtheit aller Heiligen stehen: die Symbolik würde genauso passend sein, wenn es sich um eine besonders herausragende Gruppe von Heiligen handelt. Dafür, dass dies der Fall ist, sprechen folgende Argumente:

- Der Begriff „Älteste“ zeichnet die 24 gegenüber anderen Heiligen aus und deutet an, dass sie der älteren Zeit angehören. Es muss sich um die „Väter“ der Heilsgeschichte handeln, welche das „Fundament" der Kirche bilden.

- In der Vision 7,9-17 steht den 24 Ältesten unzählige andere himmlische Heiligen gegenüber.

- Dass im übrigen ein einzelner von den 24 JOHANNES trösten $(5,5)$ und sich mit ihm unterhalten konnte (7,13-14), spricht für die Individualität jedes einzelnen dieser Ältesten. Die Ältesten sind also ein Gremium, das die 24 höchsten und bedeutendsten „Väter“ der Heilsgeschichte umfassen muss.

Welche sind dies? Manche denken an die 24 Stammväter der 24 Priesterklassen Israels (1 Chr 24,1-9). Dafür spricht das Wort „Älteste“ (griech. Presbyter), welches in apostolischer Zeit eine Bezeichnung für das (u. a. priesterliche Funktionen wahrnehmende) Amt des Leiters einer Ortskirche war. Außerdem handeln die Ältesten priesterlich, wenn sie dem Lamm (= Jesus) Räucherwerk (= die Gebete der Heiligen) darbringen $(5,8)$. Gegen die 24 Stammväter der Priesterklassen spricht jedoch, dass diese persönlich so unbedeutend waren, dass die Schrift lediglich ihre Namen überliefert hat.

Im alttestamentlichen Buch Jesus Sirach (Kap. 44-50) werden nacheinander genau 24 Väter der Heilsgeschichte namentlich gelobt (abgesehen von den nur unter dem Gruppennamen „Richter“ und ,zwölf Propheten“ zusammengefassten Personen, von Salomon, der mehr getadelt als gelobt wird, von den im Nachtrag Sir 49,14-16 genannten Personen und von dem danach noch abschließend genannten Hohenpriester Simon). Die von Sirach gelobten 24 Väter sind: Henoch, Noah, Abraham, Isaak, Jakob, Mose, Aharon, Pinchas, Josua, Kaleb, Samuel, Natan, David, Elija, Elischa, Hiskija, Jesaja, Joschija, Jeremia, Ezechiel, Hiob, Serubbabel, Jeschua und Nehemia. Dass Sirach gerade 24 Heilige erwähnt, könnte seinen Grund darin haben, dass die 24 als Zahl der Stunden eines vollen Tages eine Ganzheit bezeichnet, und dass, wie die Sonne in 24 Stunden ihren (scheinbaren) Lauf um die Erde vollendet und den ganzen Erdkreis erleuchtet, so auch die 24 Väter das Volk Israel nacheinander erleuchteten, jeder in seiner Epoche.

Meines Erachtens sind aber die 24 Ältesten nicht die von Sirach gelobten Väter und auch keine andere auf das Alte Testament beschränkte Auswahl von Heiligen: Denn es wäre unverständlich, wenn auf den himmlischen Thronen die ZWÖLF APOSTEL (mit MATTHIAS als Ersatz für den Verräter JUDAS) fehlen würden, denen Jesus ja verheißen hat, dass sie ,,auf 12 Thronen sitzen und die 12 Stämme Israels richten“ würden (Mt 19,28, vgl. Lk 22,30), und die als Fundamente der Kirche beschrieben werden (Eph 2,20, Apk 21,14).

Als eine Schwierigkeit für diese Deutung führt man an, dass JOHANNES dann selber zu den 24 Ältesten gehören würde, ihnen also kaum als Seher gegenüberstehen könne. Aber bei einer zumindest teilweise symbolischen Auffassung der Ältesten wäre es durchaus möglich, dass JOHANNES sich selbst in die Schar der himmlischen Apostel eingereiht sieht. Wenn man jedoch darauf besteht, dass JOHANNES in den Ältesten Heiligen begegnet ist, die damals schon im Himmel waren, könnte der „dreizehnte“ Apostel PAUlus in der Vision den Platz des JoHANNES eingenommen haben.

Eine zweite Schwierigkeit wäre, dass MARIA, Jesu Mutter, offenbar eine größere heilsgeschichtliche Rolle spielt als die Apostel. Müsste sie dann nicht ebenfalls in der Himmelsvision vorkommen? Marias einzigartig bevorzugte Rolle wird jedoch in der Apokalypse dadurch Rechnung getragen, dass sie nicht unter die 24 Ältesten eingereiht ist, sondern mit der gesamten, umfassenden himmlischen Stadt gleichgesetzt wird (siehe 21,9-10 und Kommentar zu 21,15-17).

So wird man in 12 von den 24 Ältesten die Apostel Christi sehen dürfen. Die übrigen 12 werden dann zur vorchristlichen Zeit zu rechnen sein. Dies würde der Symbolik der Zahl 24 als einer ,doppelten Summe von Heiligen“ am besten entsprechen, es würde auch zur Symbolik des 24-Stunden-Tages gut passen, der (nach jüdischer Sitte) mit 12 Nachtstunden beginnt (Symbol für die vorchristliche Zeit) und mit 12 Tagesstunden endet (Symbol für die nachchristliche Zeit). 
Wer sind die 12 zur vorchristlichen Zeit gehörigen Heiligen? Man könnte an die zwölf Söhne Jakobs denken (Gen 29,32-30,24): Wie die zwölf Söhne Jakobs die leiblichen Väter der zwölf Stämme des alten Gottesvolkes sind, so sind die zwölf Apostel die geistigen Stammväter des neuen, christlichen Gottesvolkes, und so wären die 24 , Ältesten“ die Fundamente des Gottesvolkes der alten und der neuen Zeit. Aber: Die Stammväter Israels sind nicht die bedeutendsten der Heiligen Väter des Alten Testaments; größere Bedeutung haben etwa Abraham, Isaak, Jakob, Mose und David.

Meiner Meinung nach hat daher CORNELIUS A LAPIDE recht, wenn er sagt, dass die 12 vorchristlichen Ältesten einfach die 12 bedeutendsten Heiligen der vorchristlichen Zeit sind. Konkret schlägt er vor: Abel, Noah, Abraham, IsaAK, Jakob, Moses, Samuel, David und die vier großen Schriftpropheten JeSAJA, JeRAmia, DANiEl und Ezechiel. Ohne in dieser Sache etwas mit Sicherheit behaupten zu wollen, würde ich in dieser Liste zwei Heilige (etwa Abel und Samuel) durch Johannes Den TÄUfer und Josef, den Pflegevater Jesu ersetzen. Denn JeSUS selber stellte JoHANNES DEM TÄUFER das Zeugnis aus, dass kein vorchristlicher Heiliger größer war als er (vgl. Mt 11,11), und JOSEF dürfte wegen seiner unvergleichlichen Nähe zu JESUS und MARIA denselben Rang wie JOHANNES DER TÄUFER einnehmen.

4,5a Und von dem Thron gehen aus Blitze und Stimmen und Donner.

Donner, STIMMEN und BLITZE sind Symbole für die göttliche Gegenwart in ihrem furchterregenden Aspekt (vgl. 4,5, 11,19, 16,18, Ex 19,16).

4,5b Und sieben Feuerfackeln brennen vor dem Thron: das sind die sieben Geister Gottes.

DiE SIEBEn GEISTER sind die hervorragendsten Botenengel (siehe Kommentar zu 1,4c).

4,6a Und vor dem Thron war etwas wie ein gläsernes Meer gleich einem Kristall.

$\mathrm{Zu}$ diesem MEER ${ }^{29}$ gibt es viele Deutungen:

- Im Hof des Jerusalemer Tempel stand ein Waschbecken, das für kultische Reinigungen gebraucht wurde. Dieses Becken wurde als „Meer“ bezeichnet (1 Kön 7,23-26). Da JOHANNES sich im himmlischen Tempel befindet (wie sich später herausstellen wird, vgl. 6,9, 8,3 und 11,19), könnte das hier gemeinte MEER das himmlische Urbild dieses Kultgerätes sein.

- Mit dem MEER könnte auf das Wasser der Taufe angespielt sein, durch das man „Zugang“ zum Thron Gottes erlangt.

- Mit dem MeER könnte die Ruhe und unendliche Weite des Friedens vor Gott beschrieben sein, denn da das Meer „gläsern“ ist, ist es ein von allen Wogen geglättetes, beruhigtes Meer.

- Es könnte mit dem MEER einfach Gottes Unzugänglichkeit beschrieben sein: Gott „wohnt in unzugänglichem Licht“ (1 Tim 6,16), d. h. sein Wohnsitz ist von der uns bekannten Welt getrennt und gleicht insofern einer Insel in den Weiten des Ozeans.

- Mit dem MeER könnte die Menge der Gott umstehenden Engel gemeint sein. Die Durchsichtigkeit des Meeres würde dann die Unkörperlichkeit der Engel bezeichnen.

- Das MeEr könnte das Menschengeschlecht aller Zeiten bezeichnen, denn in Apk 17,15 heißt es, dass Gewässer „Völker und Menschenmassen, Nationen und Sprachen“ bedeuten. Das könnte auch hier die Bedeutung des Wassers sein. Das Wasser könnte dann deshalb als durchsichtig wie Glas und Kristall beschrieben sein, weil vor Gott alle Gedanken und Strebungen der Menschen offenliegen, d. h. weil Gott in uns Menschen hineinblickt und uns bis auf den Grund unseres Herzens durchschaut.

29 Vgl. hierzu auch das „gläserne Meer“ in 15,2 sowie das „Wasser über dem Himmel“ in Gen 1,7 und Gottes Wohnung „über den Wassern“ in Ps 104,3 . 
Mir scheint, dass das MEER alle diese Deutungen zugleich umfassen könnte: JOHANNES schaut wohl eine unendlich weite glas- und kristallklare Wasserfläche, die im himmlischen Tempel dort beginnt, wo im Salomonischen Tempel das kultische „Waschbecken“ stand. Dieses Meer symbolisiert sowohl das Wasser der Taufe als auch die Ruhe und den Frieden vor Gott, als auch Gottes Unzugänglichkeit, als auch die vor Gott stehenden unkörperlichen Engel als auch die für den Blick Gottes ,durchsichtigen“ Menschen der gesamten Weltgeschichte.

4,6b Und in der Mitte des Thrones und im Kreis um den Thron waren vier Lebewesen, die voll waren von Augen vorn und hinten.

4,7 Und das erste Lebewesen glich einem Löwen und das zweite Lebewesen glich einem Stier und das dritte Lebewesen hatte das Gesicht eines Menschen und das vierte Lebewesen glich einem fliegenden Adler.

4,8 Und jedes der vier Lebewesen hatte je sechs Flügel, die ringsum und innen voll mit Augen waren.

Und sie haben keine Ruhe Tag und Nacht und singen: heilig, heilig, heilig ist der Herr, der Gott, der Allmächtige, der war und der ist und der kommt.

Die vier Wesen waren sowohl IN DER MITTE des Thrones als auch RUND UM IHN HERUM - das kann man sich am ehesten so vorstellen, dass sie sich als Träger des Throns an dessen vier Ecken befanden und sich mit ihren Flügeln unterhalb des Throns in dessen Mitte berührten. Ihre Gesichter waren wohl nach außen gekehrt, so dass JOHANNES das Gesicht des eines Lebewesens von vorn, das Gesicht eines anderen von hinten und die Gesichter der beiden anderen von der Seite sah. Er konnte auf diese Weise sehen, dass die Gesichter und Flügel sowohl vorn und hinten bzw. innen als auch außen ,,voll mit Augen" waren.

Worum handelt es sich bei diesen VIER WESEN? Im eigentlichen Sinn dürften es die höchsten Engel sein. Nach einer anderen Auslegung handelt es sich um Symbole der vier Evangelien. Nach einer dritten Auslegung sind es personifizierte Eigenschaften Christi oder Gottes. Ich gehe näher auf diese Deutungen ein.

1. Auslegung: Nach der meines Erachtens am ehesten zutreffenden Auslegung handelt sich um die vier höchsten Engel. Der Prophet EzECHIEL sah nämlich in einer Vision (Ez 1,5-11) ebenfalls vier Wesen, die den hier genannten sehr ähnlich waren. Die einzigen Unterschiede sind, dass bei EzECHIEL jedes der vier Wesen je vier Gesichter hatte (jeweils Löwen-, Stier-, Menschen- und Adlergesicht), während in der Apokalypse jedes Lebewesen nur eines dieser vier Gesichter hat, und dass Ezechiels Wesen vier Flügel hatten, aber die Wesen in der Apokalypse sechs. EZECHIEL nennt die von ihm geschauten Wesen Kerubim (Ez 10,1), was eine Gattung sehr hoher Engeln bezeichnen muss, da die Kerubim als Träger des Thronwagens Gottes erscheinen (Ez 1,26, 10,1), ebenso wie auch die hier genannten Wesen den himmlischen Thron tragen. Dass die Wesen in der Apokalypse sechs Flügel haben und dass sie das „heilig, heilig, heilig“ singen, verbindet sie jedoch mit einer anderen Engelvision: Der Prophet JESAJA sah ebenfalls sechsflüglige Engel mit nur einem Angesicht, die das Dreimalheilig sangen und ebenfalls den Thron Gottes umgaben (Jes 6,1-3). JESAJA nannte diese Engel SERAPHIM. Die Seraphim sind offenbar höhere Engel als die Kerubim: denn dass sie ein Flügelpaar mehr haben, deutet an, dass sie sich in höhere Geisteshöhen erheben können, und dass sie nur ein Angesicht haben, deutet auf eine stärker ausgeprägte Individualität hin.

JOHANNES sieht hier also vier Seraphim, die den Thron Gottes im Himmel tragen. Dass bei EZECHIEL vier Kerubim, also niedrigere Engel, den Thron Gottes trugen, hier aber vier Seraphim, darf nicht verwundern: Denn EzECHIEL wurde nicht in den Himmel entrückt und sah nicht den himmlischen Thron Gottes, sondern einen beweglichen Thronwagen Gottes, der von den Kerubim auf die Erde getragen wurde. Als Träger dieses Thronwagens dienten vier Engel der zweithöchsten Klasse, während den himmlischen Thron, der anscheinend auch dem Jesaja erschien, nur die Engel der höchsten Ordnung tragen dürfen. Die von JOHANNES geschauten Seraphim sind also die höchsten Engel überhaupt. 
Die Einzelheiten der Vision können nun wie folgt ausgelegt werden:

- Engel haben keinen Körper, sie sind „Geister“ (Hebr 1,14). Ihre „Flügel“ sind daher Symbole für ihre Geisteskraft, mit der sie sich zu Gott emporschwingen können. Die Sechszahl führt zur Vorstellung von drei Flügelpaaren (wie in Jes 6,2 ausdrücklich gesagt wird), was eine nachdrückliche Betonung der hochfliegenden Gedankenkraft dieser Wesen ist, denn die Zahl drei, ist die Zahl des Nachdrücklichen Betonens (vgl. das dreimalige ,heilig“ in Vers 8).

- Die vielen Augen der Wesen deuten an, dass sie ständig Gottes Angesicht schauen (vgl. Mt 18,10). Die Augen sind auf der Innen- und Außenseite der Flügel, weil sie den allgegenwärtigen Gott sowohl in ihrem eigenen Inneren als auch in dem sie umgebenden Universum erkennen und sich durch diese Erkenntnis zu Gott erheben.

- Das Tragen des Thrones symbolisiert, dass sie in unmittelbarer Verbindung mit Gott stehen und an seiner Herrschaft über die Erde teilnehmen.

- Ihre Gestalt als Löwe, Stier, Mensch und Adler sagt aus, dass sie das höchste sind, was Gott geschaffen hat, denn die genannten Lebewesen stellen das Höchste dar, was in der sichtbaren Natur auf Erden existiert: Der Löwe ist das stärkste Tier, der Stier das edelste (nach den Opfervorschriften Israels das geeignetste Opfertier), der Mensch ist auf Erden das weiseste Lebewesen und der Adler ist das am höchsten hinaufstrebende sowie das schnellste Tier.

Man könnte die vier Gestalten auch durch eine interessante Beziehung zwischen den Tierkreissternbildern Löwe, Stier, Pegasus (= Pferd mit Flügeln) und Skorpion (eigentlich: Skorpionmensch) erklären. Diese vier Sternbilder folgen am Himmel in jeweils 90 Grad Abstand aufeinander: Sie teilen also den ganzen Himmelskreis in vier gleiche Teile ein. Wenn die Gestalten der vier Wesen tatsächlich auf diese Sternbilder anspielen sollen, dann würde dies bedeuten, dass der Thron Gottes den ganzen Himmelskreis ausfüllt, so dass die Engel, die den Thron tragen, sich über den ganzen Himmel verteilen müssen. Die vier Engel wären dann als Mitherrscher über die irdischen Naturkräfte auch dadurch gekennzeichnet, dass sie gewissermaßen über den ,,vier Ecken der Erde“ am Himmel stünden. Selbstverständlich kann man aus einer solchen Auslegung nicht den Schluss zu ziehen, dass Gott im materiellen Sternhimmel bzw. im Weltraum seinen Wohnsitz hat, sondern dieser materielle Himmel müsste als ein Symbol für höhere, rein geistigen Wirklichkeiten verstanden werden.

Wenn die vier Wesen Engel sind, fragt sich noch, ob die Vierzahl wörtlich zu nehmen ist. Die Zahl vier ist nämlich eine wichtige Symbolzahl, die den gesamten Kosmos (die vollständige geschaffene Naturordnung) versinnbildet, denn es gibt nach antiker Anschauung (welche die Natur nicht entsprechend heutiger Naturwissenschaft, sondern entsprechend dem Augenschein wiedergibt - eine Sicht, die für die Symbolsprache die einzig geeignete ist):

- „vier Himmelsrichtungen bzw. Winde“, nämlich Nordwind, Südwind, Ostwind, Westwind, über die nach Apk 7,1 jeweils ein Engel zu befehlen hat,

- „vier Elemente“, nämlich Erde, Wasser, Luft, Feuer (wir wissen heute, dass es sich dabei nicht um Elementarstoffe handelt, aber auch die moderne Naturwissenschaft hat etwas diesen „Elementen“ Entsprechendes aufgewiesen, nämlich die vier Aggregatzustände fest, flüssig, gasförmig und plasmatisch; in Apk 14,18 ist die Rede von dem „Engel ..., der Macht hat über das Feuer“, und Apk 16,5 vom „Engel der Gewässer“, so dass anscheinend über jedes der vier Elemente ein Engel gesetzt ist),

- vier Jahreszeiten (Frühling, Sommer, Herbst und Winter) und entsprechend vier Wochen, d. h. „Monatszeiten“ (Mondphasen), die den Monat in vier Teile teilen: Neumond, zunehmender Halbmond, Vollmond, abnehmender Halbmond, und vier Tageszeiten (Morgen, Mittag, Abend, Mitternacht),

- vier Lebensbereiche (Himmel, Erde, Meer und Unterwelt, die Apk 5,13 aufgezählt werden),

- vier irdisch-materielle Seinsstufen, nämlich Unbelebtes, Pflanzen, Tiere, Menschen,

- vier Glieder der höheren Lebewesen (vier Beine bzw. beim Menschen zwei Arme und zwei Beine),

- vier Kardinaltugenden, nämlich Klugheit, Gerechtigkeit, Tapferkeit und Mäßigkeit (Weish 8,7), die das menschliche Verhalten nach allen Seiten hin ausbalancieren, 
- weitere Vierheiten, die jedoch in der Schrift kaum oder keine Beachtung finden, wären z. B. die vier Hautfarben des Menschen, die vier Körpersäfte im menschlichen Körper, nämlich Blut, Schleim, grüne Galle, Schwarzgalle und entsprechend hierzu vier Charaktertypen, nämlich Sanguiniker, Phlegmatiker, Choleriker, Melancholiker. Auch rein mathematisch hat die Vier die einzigartige SymmetrieEigenschaft, dass sowohl $4=2+2$ als auch $4=2 \cdot 2$ als auch $4=2^{2}$.

Die Symbolkraft der Vierzahl ist nun jedoch noch kein Beweis dafür, dass es sich nicht wirklich um vier Engel handelt: Mag es auch unzählige Seraphim geben, so sind doch die hier genannten meines Erachtens genau vier einzelne Seraphim. Dafür spricht, dass JOHANNES einzelne dieser vier Wesen konkret tätig werden sieht: Beispielsweise öffnen in Kap. 6,1-7 alle vier Wesen nacheinander je ein Siegel. Die Vierzahl der Wesen unterstreicht aber wegen ihres Symbolgehaltes auf jeden Fall die Tatsache, dass es sich um Engel handelt, die von Gott als Mitherrscher über denn Kosmos eingesetzt sind: es sind sozusagen seine obersten „Minister“ für die Leitung verschiedener Bereiche der irdischen Natur. Für diese Aufgaben sind den vier Wesen wahrscheinlich noch weitere Engel zu ihrer Unterstützung beigegeben: Dazu dürften die in 7,1 genannten ,vier Engel der vier Winde“ gehören, ebenso wie der „Engel des Feuers“ in 14,8 und der „Engel der Gewässer“ in 16,5.

Insgesamt beschreibt JOHANNES somit die höchsten Vertreter von drei himmlischen Klassen:

- die 24 höchsten ,heiligen Väter“ $(4,4)$,

- die 7 höchsten Botenengel $(4,5)$,

- die 4 höchsten Thronengel (4,6-8).

Manche Autoren behaupten jedoch, dass es sich bei den vier Wesen nicht um Engel handeln könne, weil in 7,11 die 24 Ältesten, die vier Wesen und die Engel gesondert aufgezählt werden, und weil es 5,11 heißt: ,,alle Engel standen rings um den Thron und die Ältesten und die 4 Wesen“. Doch die Trennung der vier Wesen von den Engeln bzw. sogar von ,allen Engeln“ in den Versen 5,11 und 7,11 kann dadurch erklärt werden, dass das Wort „Engel“ dort möglicherweise nicht alle Geistwesen (Engel im weiteren Sinn) meint, sondern nur eine untere Klasse von Geistwesen (Engel im engsten Sinn). Siehe Röm 8,38: „Weder Engel noch Fürsten ... können uns scheiden von der Liebe Christi“, wo die „Engel“ von den „Fürsten“, einer höheren Klasse von Geistwesen, unterschieden werden.

2. Auslegung: Nach der Lehre vieler altkirchlicher Väter (z. B. IRENÄUS, ATHANASIUS, HIERONYMUS, AUGUSTINUS, GREGOR DER GROSSE) handelt es sich bei den vier Wesen um die vier Evangelisten oder Evangelien (MATTHÄUS-, MARKUS-, LUKAS- und JOHANNESevangelium). Die vier Evangelien sind Thronträger Gottes, weil sie das Wort Gottes in sich tragen. Sie sind voll Augen, weil sie Gottes Weisheit betrachten. Sie haben ihre Augen vorn und hinten, weil sie sowohl die vergangene Heilsgeschichte betrachten als auch die Zukunft voraussehen. Sie haben sechs Flügel wie die Seraphim-Engel bei JESAJA (Jes 6,2), weil sie den Menschen geistige Flügel verleihen, so dass diese sich zu Gott emporschwingen können. Ihre Flügel haben Augen innen und außen, weil die Evangelien sowohl die offensichtlichen wie die verborgenen Geheimnisse Gottes enthalten, durch deren Betrachtung die Menschen zu Gott emporgehoben werden.

Konkret wird die Zuschreibung der Wesen zu den einzelnen Evangelien verschieden vorgenommen, etwa wie folgt:

- Das Wesen, das dem LöWEN glich, ist das Evangelium nach MARKUS, weil dieses Evangelium mit der Bußpredigt JOHANNES’ DES TÄUfERS beginnt, die als „Stimme des Rufers in der Wüste“ tituliert wird und damit an das Brüllen des Löwen erinnert.

- Das Wesen, das dem STIER glich, ist das Evangelium nach LUKAS, weil dieses mit dem Opfer des Zacharias beginnt, der Stier aber als nobelstes Opfertier gilt.

- Das Wesen, das einem Menschen glich, ist das Evangelium nach MATthäUs, weil dieses mit den menschlichen Vorfahren Jesu beginnt.

- Das Wesen, das einem Fliegenden AdLER glich, ist das Evangelium nach JoHANnes, weil dieses mit dem himmlischen, vorweltlichen Dasein Jesu beginnt, welches der hoch am Himmel fliegende Adler symbolisiert. 
Diese Auslegung stellt einen mystischen Nebensinn dar, nicht aber die Hauptbedeutung. Denn nur von Engeln kann es im eigentlichen Sinne wahr sein, dass sie Gott anbeten, Befehle erteilen, Schalen austeilen usw., wie es JOHANNES über die vier Wesen sagt $(5,8 ; 6,1 ; 6,3 ; 6,5 ; 6,7 ; 15,7)$.

3. Auslegung: Die Wesen sind 4 Attribute Christi: Christus ist König (Löwe), Priester (Stier), Gott (Adler) und Mensch. Oder vier Eigenschaften Gottes, z. B. Stärke (Löwe), Geduld (Stier), Weisheit (Adler), Liebe (Mensch). Aber diese Deutungen scheinen mir ungenügend zu sein, unter anderem deshalb, weil dann viele Details (z. B. die Augen innen und außen) kaum erklärt werden können.

4,9 Und jedes Mal, wenn die Wesen Preis und Ehre und Dank dem darbringen, der auf dem Thron sitzt und in alle Ewigkeit lebt,

4,10 fallen die vierundzwanzig Ältesten vor dem, der auf dem Thron sitzt, nieder und beten den an, der in alle Ewigkeit lebt, und legen ihre Kronen nieder und sagen:

4,11 Würdig bist du, unser Herr und Gott, zu empfangen die Herrlichkeit und die Ehre und die Macht, weil du das All erschaffen hast:

Durch deinen Willen waren alle Dinge und wurden sie erschaffen.

Dieser himmlische Lobpreis gilt dem, den die Ältesten als „UNSER HERR UND GOTT“ anreden. Vergleiche dazu Joh 10,28, wo THOMAS den auferstandenen JESUS anredet als: „mein Herr und mein Gott!“ Hier haben wir einen Hinweis darauf, dass unter dem „der auf dem Thron sitzt“, nicht allein der Vater zu verstehen ist, sondern der dreifaltige Gott.

5,1 Und ich sah in der Rechten dessen, der auf dem Thron sitzt, ein Buch, beschrieben innen und außen, versiegelt mit sieben Siegeln.

Ein Buch bestand in damaliger Zeit aus einem Streifen aneinandergehefteter Papyrusblätter, den man zylinderförmig zusammenrollte (vgl. 6,14: „der Himmel wich zurück wie ein Buch, das zusammengerollt wird“). Nur bei einer solchen Papyrusrolle hat es Sinn zu sagen, das Buch sei ,innen und außen“ (d. h. beidseitig) beschrieben, und nur bei einer solchen Rolle konnte JOHANNES auch sehen, dass sie innen und außen beschrieben war.

Dieses BUCH ist ein Symbol des Vorherwissens und der bereits beschlossenen Willensbefehle Gottes bezüglich der zukünftigen Weltentwicklung, die in den folgenden Visionen der Apokalypse enthüllt werden wird. Das Buch ist AUF VORDER- UND RÜCKSEITE BESCHRIEBEN:

- entweder weil es geheime Teile enthält, die nicht enthüllt werden (Rückseite),

- oder weil die eine Seite die positiven, die andere die negativen Ereignisse enthält (so wie Kaufleute auf die Vorderseite der Papyrusblätter die Einnahmen und auf der Rückseite die Ausgaben zu verbuchen pflegten),

- oder einfach wegen des großen Umfangs seines Inhalts.

Da 7 eine Zahl der Vollkommenheit ist (siehe Kommentar zu 13,18) und da königliche Siegel dazu dienen, ein Geheimnis zu bewahren und zugleich die Öffnung des Geheimgehaltenen einer entsprechend würdigen Person vorzubehalten, bezeichnen die SIEBEN SIEGEL die vollkommene Verborgenheit der im Buch vorgezeichneten Ratschlüsse Gottes, und die hohe Würde, die erforderlich ist, um diese Ratschlüsse zu verlesen. Diese Siegel werden geöffnet werden durch den gekreuzigten, auferstandenen und in den Himmel aufgefahrenen CHRISTUS (Vers 5-7), welcher das „Wort Gottes“ (Joh 1,1; Apk 19,13) ist, also derjenige, von dem wir Aufschluss über die Geheimnisse Gottes erwarten können (vgl. Joh 1,18; 14,8-9). 
5,2 Und ich sah einen starken Engel, der verkündete mit lauter Stimme:

Wer ist würdig, das Buch zu öffnen und seine Siegel zu lösen?

Es steht außer Frage, dass Gott selber das Buch öffnen kann bzw. dass er es gar nicht zu öffnen braucht, weil es ja einen Teil seiner eigenen Gedanken und Befehle darstellt. Gesucht ist also eine außerhalb des Bereichs der göttlichen Natur befindliche Person.

DAS BUCH ÖFFNEN und daraus vorzulesen bedeutet, die Verwirklichung der in ihm enthaltenen Gedanken einzuleiten und dadurch den Inhalt des Buches bekannt zu machen. Denn bei der „Verlesung“ des Buches $(a b 8,6)$ scheinen sogleich die in ihm enthaltenen Gedanken verwirklicht worden zu sein.

5,3 Und niemand im Himmel, auf der Erde, oder unter der Erde konnte das Buch öffnen oder in es hineinsehen.

Die Frage des ,starken Engels“ umfasste offenbar drei Teilfragen:

1. Kann einer von uns Himmlischen, die wir dem JOHANNES erschienen sind, das Buch öffnen?

2. Kann einer der noch auf der Erde lebenden Menschen das Buch öffnen?

3. Kann jemand ,unter der Erde“, d. h. im Hades (vgl. Kommentar zu 2,7) das Buch öffnen?

Auf jede dieser Fragen wird er vom Thron her die gleiche Antwort bekommen haben: Nein.

Freilich konnte CHRISTUS das Buch öffnen (Vers 5). Dieser war jedoch bisher noch nicht in Erscheinung getreten. Darum sagt JOHANNES: ,niemand im Himmel (nämlich von denen, die sichtbar zugegen waren) ... konnte das Buch öffnen“".

5,4 Und ich weinte viel, weil niemand als wïrdig erfunden wurde, das Buch zu öffnen und in es hineinzusehen.

JOHANNES weint, weil er sich in seiner Gottesliebe nach Erkenntnis und Verwirklichung der Gedanken Gottes sehnt.

5,5 Und einer von den Ältesten sagt(e) zu mir: Weine nicht!

Siehe, gesiegt hat der Löwe aus dem Stamm Juda, die Wurzel Davids, um das Buch zu öffnen und seine sieben Siegel.

Der Löwe aus dem Stamm Juda ist Jesus Christus. Denn Christus gehörte zum Stamm Juda (Hebr 7,14) und Jakob, der Stammvater Israels, hatte einst über CHRISTUS, prophezeit: „Ein junger Löwe ist Juda. ... Nie weicht von Juda das Zepter, der Herrscherstab von seinen Füßen, bis der kommt, ... dem der Gehorsam der Völker gebührt." (Gen 49,9-10).

„Der Löwe aus dem Stamm Juda hat GESIEGT“ bedeutet also: CHRISTUS hat durch Tod und Auferstehung sein Heilswerk vollendet und ist in die Herrlichkeit des Himmels aufgestiegen, um dort als König über die Völker zu herrschen.

Auch „WURZEL DAVIDS“ ist eine Bezeichnung für Jesus Christus, die auf einen Prophetenspruch anspielt. PAULUS weist in Röm 15,12 auf folgende Prophezeiung JESAJAs hin: „Und Jesaja sagt (Jes 11,10): Kommen wird der Spross aus der Wurzel Isais, er wird sich erheben, um über die Heiden zu herrschen. Auf ihn werden die Heiden hoffen.“

ISAI war der Vater des Königs DAVID; ein „Spross aus der Wurzel Isais“ bedeutet darum: ein Nachkomme von ISAI bzw. von DAVID. JESUS ist also „Wurzel Davids“ bzw. eigentlich: Spross aus der Wurzel DAVIDs oder der Wurzel IsAIs, insofern er Nachkomme des Königs DAVID war (Mt 1,1). Weiteres zum Ausdruck „Wurzel Davids“ siehe im Kommentar zu 22,16.

Der Ausdruck „Wurzel Davids“ beschreibt also ebenso wie der Ausdruck „Löwe aus dem Stamm Juda“ JESUs ChRistus. Dieser ist es also, der DAS BUCH ÖFFNEN kann: Er ist der einzige, der (wenigstens teilweise, nämlich durch seine Menschennatur) dem Bereich der Geschöpfe angehört und dennoch würdig ist, das Buch zu verlesen. 
5,6a Und ich sah in der Mitte des Thrones und der vier Wesen und in der Mitte der Ältesten ein Lamm stehen wie ein Geschlachtetes.

In diesem LAMM erscheint nun der Gesuchte: Jesus CHRISTUS, den JOHANNES DER TÄUfER im Johannesevangelium als „Lamm Gottes“ bezeichnet. CHRISTUS wird hier (wie in Joh 1,29 und prophetisch bereits in Jes 53,7) als „Lamm“ bezeichnet, weil er am Kreuz wie ein Opferlamm das Sühnopfer für die Sünden der Welt geworden ist. Deshalb tritt er in der Vision auch als GESCHLACHTETES Lamm auf, d. h. er erscheint als ein zwar lebendiges Lamm, an dem jedoch Wunden bzw. Spuren einer „Schlachtung“ zu sehen sind. Man vergleiche dazu die im Johannesevangelium berichtete Erscheinung des auferstandenen CHRISTUS, der als Zeichen seiner Identität mit dem Gekreuzigten die verklärten Wundmale an seinen Händen und an seiner Seite aufwies (Joh 20,24-29).

Sehr wirkungsvoll ist der Kontrast, der hier aufgebaut wird: Während CHRISTUS als ,,siegreicher Löwe“ angekündigt worden war (Vers 5), erscheint er als ein ,geschlachtetes Lamm“. Denn paradoxerweise hat CHRISTUS gerade am Kreuz gesiegt und sich als Löwe erwiesen.

Das Lamm erschien nicht auf dem Thron (denn es heißt in Vers 7, dass es „hinging“ und das Buch aus der Hand dessen, der auf dem Thron saß, in Empfang nahm); es erschien IN DER MITTE DES Thrones und Der VIER Wesen, d. h. unter dem Thron in dessen Mitte und in der Mitte der vier Wesen, die den Thron trugen, und sich zuvor in der Mitte unter dem Thron sich berührt hatten $(4,6)$.

Das Lamm stellt CHRISTUS in seiner verherrlichten Menschennatur dar, die über alle anderen Geschöpfe erhöht ist (Eph 1,20-22), aber - als geschaffene Natur - dennoch unter dem dreifaltigen Gott steht: Daher ist das Lamm nicht auf, sondern unter dem Thron. CHRISTUS ist als Mensch der „Mittler zwischen Gott und den Menschen“(1 Tim 2,5), was seiner hier beschriebenen Position entspricht.

\section{Exkurs 5: Überblick über die Himmelsvision}

Insgesamt bietet sich dem JoHAnnes nun folgender Anblick. In der Mitte sieht er den Thron, darunter in der Mitte das Lamm, und rings um das Lamm die vier Wesen als Träger des Throns. Vor dem Thron und außerhalb des Kreises der vier Wesen stehen die sieben Feuerfackeln. Thron, Lamm, Wesen und Fackeln sind umgeben vom Kreis der vierundzwanzig Ältesten, und außerhalb des Kreises der Ältesten steht schließlich, wie in Vers 11 hinzugefügt werden wird, eine unzählige Schar von Engeln, und zwar anscheinend auf dem „gläsernen Meer“. Weitere Details kommen im Folgenden zum Vorschein: Der Thron mit den Wesen, Fackeln und Ältesten befindet sich in einem durchsichtigen Tempel $(7,15 ; 14,15 ; 15,5)$, der das Urbild des Jerusalemer Tempels ist. Insbesondere befindet sich im Vorhof dieses Tempels, also außerhalb des Kreises der Ältesten, der große Brandopferaltar und innerhalb des Tempels vor dem Thron (wohl neben den sieben Fackeln) der kleine goldene Rauchopferaltar (siehe Verse 6,9; 8,3; 9,13). Der Thron selber hat die Position der Bundeslade, ist geheimnisvoll verhüllt und wird von Zeit zu Zeit (besser) sichtbar (11,19). Außerdem wird sich zeigen, dass JoHANNES vom Himmel aus auch Erde, Meer und Unterwelt modellartig überblickt $(5,13 ; 7,1)$.

5,6b Es (das Lamm) hatte sieben Hörner und sieben Augen:

Das sind die sieben Geister Gottes, die in die ganze Welt ausgesandt sind.

HöRnER sind ein Symbol der Macht, besonders der Kriegsmacht. AUGEN sind ein Symbol der Erkenntnis und der Aufsicht. Die Augen (und wohl ebenfalls die Hörner) werden hier als die SIEBEN GEISTER gedeutet, welche nach unserem Kommentar zu 1,4c die sieben höchsten Botenengel Gottes sind. Diese „Geister Gottes“ sind zugleich Geister Christi, die im Auftrage Christi in die ganze Welt gesandt werden als Aufseher (Augen) und Kämpfer (Hörner) Christi. Da die sieben Engel in eigener Person bereits im Form der sieben Feuerfackeln $(4,5)$ auftreten, stellen die Hörner und Augen natürlich nicht die Personen der sieben Engel dar, sondern sie sind Symbole für die Eigenschaft Christi, Herr und Befehlshaber dieser Engel zu sein (vgl. Hebr 1,5-14), wie es seiner wahren Gottheit entspricht. 
Das Lamm trat heran und empfing das Buch aus der rechten Hand dessen, der auf dem Thron saß.

5,8 Als es das Buch empfangen hatte, fielen die vier Wesen und die vierundzwanzig Ältesten vor dem Lamm nieder. Alle trugen Harfen und goldene Schalen voll mit Weihrauch: Das sind die Gebete der Heiligen.

Die vier Wesen und die vierundzwanzig Ältesten bringen Christus die Gebete DER HeILIGEN (symbolisiert durch den WeIHRAUCH) dar. Mit den HEILIGEN sind hier nicht die himmlischen Heiligen gemeint, sondern die Gläubigen auf Erden, so wie es einem weitverbreiteten Sprachgebrauch im Neuen Testament entspricht (vgl. die Anfänge der Paulusbriefe). Somit ist hier bezeugt, dass die Engel und die bereits verherrlichten Heiligen im Himmel die Gebete der irdischen Gläubigen an CHRISTUS weiterleiten (vgl. auch 8,3-4). In diesem Weiterleiten kann man eine unterstützende Fürbitte für die Anliegen der Gläubigen sehen.

5,9 Und sie singen ein neues Lied und sprechen:

Würdig bist du, das Buch zu nehmen und seine Siegel zu öffnen, weil du geschlachtet worden bist und Menschen erkauft hast für Gott durch dein Blut aus jedem Stamm und jeder Zunge und jedem Volk und jeder Nation.

5,10 Und du hast sie für unseren Gott zu einem Königreich und zu Priestern gemacht. Und sie werden auf der Erde herrschen.

Dieser Lobpreis ist ein NEUES LIED im Himmel, weil es erst seit Christi Kreuzestod erklingen konnte. Denn CHRIstus hat erst durch sein am Kreuz vergossenes Blut einen neuen, ewigen, und nicht mehr auf das Volk Israel beschränkten Bund zwischen Gott und den Menschen geschlossen (Eph 2,12-16), so dass von nun an Menschen aus allen Völkern zu Gottes neuem Volk zusammenkommen und seine „königliche Priesterschaft“ bilden (1 Petr 1,9-10).

Inwiefern werden die Christen AUf DER ERDE HERRSCHEN? Bereits im irdischen Leben herrschen sie, indem sie andere zum Guten anleiten (vgl. 1,9). Vollkommener aber wird ihre Herrschaft erst, wenn sie nach ihrem Tod vom Himmel aus zusammen mit CHRISTUS auf der (= über die) Erde herrschen. Im Himmel erhalten sie nämlich wie die Engel Anteil an der göttlichen Weltlenkung, an der sie sich durch ihre Fürbitte (Vers 8) und durch ihren Einsatz für „Gnade und Friede“ in der Welt beteiligen (vgl. 1,4: „Gnade und Friede ... von den sieben Geistern“). Sie sind im Himmel auch Beisitzer des göttlichen Gerichtshofes (siehe die 24 Ältesten).

Diese Herrschaft der Heiligen hatte zur Zeit des JOHANNES schon begonnen, und sie konnte sich nach dem Gericht am heidnischen Rom in einer für die Weltöffentlichkeit klarer sichtbaren Weise durchsetzen (siehe Kommentar zu 20,4). Aber erst am Ende der Zeiten werden die Heiligen im eigentlichen Sinne ÜBER DIE ERDE HERRSCHEN, denn dann wird der „Himmel“ in Gestalt des „himmlischen Jerusalem" auf die Erde herabkommen (siehe Kommentar zu 22,5).

5,11 Und ich sah und hörte eine Stimme vieler Engel im Kreis um den Thron und die Wesen und die Ältesten, und ihre Zahl war zehntausende von Zehntausenden und tausende von Tausenden.

Diese ENGEL stehen in der Vision außerhalb des engsten Kreises der 4 Wesen, 7 Geister und 24 Ältesten. Es ist das unzählbare Heer der Engel gemeint, Botenengel und Thronengel, deren höchste Vertreter die „,ieben Geister“ und die „vier Wesen“ sind. Vergleiche die Kommentare zu 1,4c und zu 4,6-8. Die hier genannte immense ZAHL der Engel (die auch Dan 7,10 genannt wird) will wohl nichts anderes aussagen, als dass es unüberschaubar viele waren. 
5,12 Sie sprachen mit lauter Stimme:

Würdig ist das Lamm, das geschlachtet wurde, die Macht zu erhalten

und Reichtum und Weisheit und Stärke und Ehre und Herrlichkeit und Lob.

Macht, Weisheit usw. erhält CHRISTUS DAS LAMM dadurch, dass er nach seiner Auferstehung und Himmelfahrt von den Menschen als mächtig, weise usw. verehrt wird, die erst jetzt seine wahre Größe erkennen und anerkennen.

DIE MACHT ist wegen des Artikels Macht in ihrer höchsten Ausprägung, d. h. göttliche Macht.

Jesus Christus erhält die Macht, die er in seiner göttlichen Natur immer schon mit dem Vater besessen hat, nun auch in seiner menschlichen Natur (als LAMM, DAS GESCHLACHTET WAR) zugesprochen. Da Jesus in den Himmel aufgestiegen und ,zum Vater gegangen“ ist, steht seine menschliche Natur in den Augen der Menschen nicht mehr im scheinbaren Widerspruch zu seiner Gottheit, und es wird offenbar, dass es „,der Herr der Herrlichkeit“ war, der gekreuzigt worden ist (1 Kor 2,8).

Somit wird nun „das Lamm, das geschlachtet wurde“ (= Jesus in seiner menschlichen Natur) als der gekreuzigte „Herr der Herrlichkeit“ bewundert und erhält göttliche Ehrungen. ${ }^{30}$

5,13 Und jedes Geschöpf im Himmel und auf der Erde und unter der Erde und auf dem Meer - alles in diesen (Lebensbereichen) hörte ich sagen: dem, der auf dem Thron sitzt und dem Lamm gebührt das Lob und die Ehre und die Herrlichkeit und die Macht in alle Ewigkeit.

Der Artikel vor LOB, Ehre, HerRlichKeIT und MACHT zeigt, dass es sich um die höchst denkbaren Ehrungen handelt. Sie werden dem Lamm dargebracht, was die schon im vorherigen Vers erklärte Einbeziehung der Menschennatur Christi in das göttliche Lob unterstreicht.

Die ganze Natur (in ihren vier Lebensbereichen: Himmel, ERde, MEer und UnTERwelt) lobt hier in einem einzigen Anbetungsakt den Vater und den Sohn: er wird dargebracht ,,dem, der auf dem Thron sitzt UND dem Lamm“.

Wie konnte nun dieser Lobpreis „ALLER GESCHÖPFE“ im Himmel, auf der Erde und unter der Erde zustande kommen? Im eigentlichen Sinne können Gott nur die vernunftbegabten Geschöpfe, d. h. die Engel und Menschen lobpreisen. Also sprechen die Engel und Menschen dieses Lob stellvertretend auch für die unvernünftigen Geschöpfe aus. IM HiMmEL also hörte JOHANNES dieses Lob aus dem Mund aller Engel und Heiligen.

Aber AUf DER ERde und AUf DEM MeER - wann konnte Johannes dort alle Menschen Gott loben hören? Immer gab und gibt es auf Erden Menschen, die nicht an Gott denken oder die ihn sogar hassen und verfluchen. Wir müssen also sagen: das Lob, das JOHANNES von der Erde her hörte, stammte nicht direkt aus dem Mund aller Menschen, sondern es war das Lob, das aus den Versammlungen der Christen aller Orte ertönte, das die über die Erde und Meere verstreuten Beter zu Gott emporsandten, wo immer sie sich gerade befanden. Ebenso wie die vernünftigen Geschöpfe stellvertretend für die unvernünftigen sangen, so sangen diese Christen stellvertretend für alle anderen Menschen. Da Gott der Zeit enthoben ist, könnte Johannes hier überdies den Lobpreis nicht nur der damaligen Christen, sondern aller Erlösten aller Orte und Zeiten überhaupt vernommen haben, insbesondere den zukünftigen Lobpreis der vollendeten Schöpfung nach dem Ende ihrer vergänglichen, noch durch die Sünde geprägten Phase.

30 Das bedeutet nicht, dass hier die menschliche Natur Christi, die ja etwas Geschaffenes ist, mit seiner göttlichen Natur vermengt wird. Die rechte Verehrung Christi zielt nämlich letztlich nicht auf eine der beiden Naturen Christi, sondern immer auf die eine Person Christi, welche die zweite göttliche Person ist. Diese Person aber existiert seit der Menschwerdung in zwei Naturen, so dass wir beide Naturen, auch die menschliche, vor Augen haben dürfen, um die zweite göttliche Person darin zu verehren. „Christus auch als Mensch göttliche Ehren darbringen“ kann man auf zwei Weisen, von denen die eine berechtigt ist und die andere eine eine subtile Form verbotener Geschöpfesanbetung wäre. Falsch wäre es, Christi Menschennatur in Gedanken von der Gottheit zu trennen und dieser gedanklich von der Gottheit getrennten Menschennatur göttliche Ehren darzubringen. Richtig aber ist es, die gedanklich mit der Gottheit personal verbundene Menschennatur göttlich zu verehren, denn das bedeutet nichts anderes, als die eine Person Christi, welche die göttliche Person des ewigen Gottessohnes ist, auch in ihrer Eigenschaft als Besitzer einer menschlichen Natur göttlich zu verehren. 
Schließlich hörte JOHANnES noch das Lob der Geschöpfe UNTER DER ERDE. Damit ist der Hades gemeint: Jener Zustand, in den die Seelen der verstorbenen Menschen sich befinden, die nicht im Himmel sind. Zu diesen gehören die „Verdammten“, die Bewohner der Hölle (vgl. Lk 16,23; Lk 12,4-5). Aber diese können Gott nicht loben, weil sie für immer in ihrer Bosheit verhärtet sind. Daher muss es außer den Verdammten noch andere, gute Seelen im Hades geben, die fähig sind, Gott stellvertretend für alle das Lob auszusprechen, so dass der Ausdruck ,alle Geschöpfe ... unter der Erde“ auch hier nur indirekt jedes einzelne Geschöpf meint, insofern wenigstens einige Seelen das Gotteslob stellvertretend für alle darbringen.

Aus vorliegender Schriftstelle kann man (ebenso wie aus der ähnlichen Stelle Phil 2,10) schließen, dass es im Hades außer der Hölle noch eine andere „Abteilung“ geben muss, in der es Gott lobende Geschöpfe gibt. Wie in Exkurs 3 festgestellt wurde, gab es im Hades in vorchristlicher Zeit drei Abteilungen (Hölle, Fegfeuer und Limbus), aber seit Christi Himmelfahrt nur noch zwei (Hölle und Fegfeuer). Somit ist hier von den Seelen im Fegfeuer die Rede. ${ }^{31}$

5,14 Und die vier Wesen sagten: Amen. Und die Ältesten fielen nieder und beteten an.

Das „AMEN“ zu einem solchen die ganze Schöpfung umfassenden Lobpreis können nur die höchsten Geschöpfe sprechen.

31 In Verbindung mit den Schriftstellen, die zeigen, dass seit CHRISTUS der Limbus-Zustand in der Unterwelt nicht mehr existiert (das sind alle Schriftstellen, die zeigen, dass die Heiligen der nachchristlichen Zeit nach ihrem Tod sofort in den Himmel kommen, vgl. Kommentar zu 14,13) deutet die vorliegende Stelle auf die Existenz des Fegfeuers hin. Denn wie in Phil 2,10 zeigt sich auch hier, dass die „Kirche Christi“ als Gemeinschaft der Gott lobenden Geschöpfe gewissermaßen „,drei Stockwerke“ umfasst:

- die „streitende Kirche“ (die Kirche auf Erden),

- die ,triumphierende Kirche“ (die Kirche im Himmel), und

- die „leidende“ Kirche“ (die Kirche im Fegfeuer). 


\subsection{Apk 6,1-8,5: Die Öffnung der sieben Siegel}

In dem geheimen Buch, das nun geöffnet wird, sind vor allem drei göttliche Strafgerichte vorhergesagt. Zuerst sind es die beiden Strafgerichte über das ungläubige Judentum und über das römische Heidentum, die ersten großen Gegner des Christentums (Apg 4,27). Mit dem Schlag gegen das Judentum im Jahre 135 und dem Fall Roms im Jahre 410 erreichten diese Strafgerichte ihren Höhepunkt. Das dritte Strafgericht ist große Gericht am Ende der Menschheitsgeschichte.

Während Christus in Gestalt eines Lammes die sieben Siegel des Buches öffnet, hat JoHAnNES eine Reihe von Visionen. Diese Visionen sind noch keine Inhaltswiedergabe des Buches, denn sein Inhalt kann naturgemäß erst nach der Öffnung des 7. Siegels gelesen und bekannt gemacht werden. Was JOHANNES hier sieht, sind also nur Vorahnungen der in dem Buch enthaltenen Strafgerichte sowie Vorbereitungen zu ihrer Vollstreckung. Ich gebe zunächst einen Überblick über die sieben Siegelvisionen:

1. Der weiße Reiter (Christus)

2. Der rote Reiter (der Krieg)

3. Der schwarze Reiter (der Hunger)

4. Der bleiche Reiter (die Pest) und sein Begleiter

5. Die Märtyrer „unter dem Altar“ bitten um Vergeltung

6. 1.Teil: Vorschau auf den allgemeinen Verlauf der kommenden Gerichte

2. Teil: Schutzmaßnahme zur Bewahrung von 144.000 Israeliten (vor dem ersten Gericht)

3.Teil: Einzug unzähliger Menschen aller Völker in den Himmel (nach dem letzten Gericht)

7. Vorbereitung auf das Blasen der Posaunen

Die geschauten Ereignisse laufen nicht zeitlich nacheinander ab: Denn erstens fragen die Märtyrer in der 5. Vision, wie lange Gott noch mit dem Strafgericht zögert. Also können zu diesem Zeitpunkt die Unheilsbringer der 2. - 4. Vision noch nicht unterwegs sein. Zweitens kann das im 1. Teil der 6. Vision geschaute Strafgericht sinnvollerweise erst nach der Schutzmaßnahme verwirklicht werden, von der im 2. Teil dieser Vision die Rede ist. Drittens heißt es im 2 . Teil der 6. Vision, dass die ,vier Winde“ noch zurückgehalten werden. Diese Winde sind aber die Unheilsbringer der 2. 4. Vision (siehe Kommentar zu 7,1-8), so dass deren Einsatz frühestens nach dem 2. Teil der 6. Vision erfolgen kann.

Die Visionen sind also nicht nach zeitlichem Gesichtspunkt geordnet. Ihre Abfolge erklärt sich wie folgt. In der 1. Siegelvision schaut JOHANNES den Reiter CHRISTUS, dem als dem Herrn der Geschichte der erste Platz gebührt. Dann folgt in der 2. Siegelvision der erste Unheilsreiter, der „Reiter Krieg“, der das Hauptmittel der göttlichen Strafgerechtigkeit ist. Diesem folgt der „Reiter Hunger“, der sich infolge des Krieges regelmäßig einstellt (3. Siegelvision), und diesem wieder der „Reiter Pest“, der oft infolge von Krieg und Hunger auftritt und deren Zerstörungswerk vollendet. Daher führt er den Hades (= das Totenreich) mit sich (4. Siegelvision). Die Unheilsgestalten der 2. - 4. Siegelvision werden bei den Strafgerichten Gottes im Laufe der Geschichte immer wieder auftreten, aber JOHANNES sieht hier noch kein konkretes Eingreifen dieser Reiter, sondern nur ihr Herantreten im Himmel, ihre Zurüstung auf die kommenden Einsätze. Nach den Visionen dieser Reiter sieht JOHANNES in der 5. Siegelvision die Märtyrer, die im Himmel um Vergeltung bitten, was auf ihre Leiden bzw. auf die Christenverfolgungen als den Grund der Strafgerichte Gottes verweist. Dann sieht er im 1. Teil der 6. Siegelvision die Erfüllung der Bitte der Märtyrer: das allgemeine Ereignismuster der Strafgerichte. Diese Vision führt zu der Frage, ob dieses furchtbare Gericht überhaupt jemand heil überstehen wird $(6,17)$. Eine Antwort auf diese Frage erhält JOHAnNES im 2. und 3. Teil der 6. Siegelvision, wo er zuerst 144.000 Israeliten schaut, die durch eine Schutzmaßnahme vor dem ersten der drei Strafgerichte bewahrt werden (2. Teil), und dann eine große Schar aus allen Völkern, die aus der Bedrängnis des letzten Strafgerichts kommen und als Sieger in den Himmel einziehen (3. Teil). Die drei Teile der 6. Vision sind also drei Momentaufnahmen über Verlauf, Anfang und Ende der Strafgerichte. Nach der Öffnung des 7. Siegels aber erfolgt keine Vision, sondern eine gespannte Erwartung und die Vorbereitung auf das Blasen der Posaunen, welche den konkreten Inhalt des Buches verkünden werden.

Das dürfte der eigentliche Sinn der sieben Siegel sein. Die vier Reiter haben aber außerdem wohl noch einen anderen Sinn: Sie bezeichnen vier aufeinander folgende Zeitalter in der Geschichte der Christenheit. Bei dieser ,kirchengeschichtlichen“ Deutung handelt es sich aber meines Erachtens nur um einen mystischen Nebensinn. 


\subsubsection{Apk 6,1-2: Erstes Siegel (Der weiße Reiter)}

Text

6,1 Und ich sah: Als das Lamm eines von den sieben Siegeln öffnete, hörte ich eines von den vier Wesen wie mit einer Donnerstimme sagen: Komm!

6,2 Und ich sah, und siehe, ein weißes Pferd. Und der (,der) auf ihm saß, hatte einen Bogen, und es wurde ihm eine Krone gegeben. Und er zog als Sieger aus, um zu siegen.

\section{Auslegung}

1. Auslegung (Literalsinn): Dieser REITER ist CHRISTUS, denn er wird in 19,13 „das Wort Gottes“ genannt, was bei JOHANNES eine Christusbezeichnung ist (vgl. Joh 1,1-18). Dazu passt die WEISSE FARBE als Farbe der Reinheit und des Lichtes. Die Vorstellung, das CHRISTUS als Bogenschütze für die Gerechtigkeit kämpft, ist hier nicht neu. Auch in Psalm 45,4-7 wird prophetisch von CHRISTUS als einem Bogenschützen gesprochen: „Zieh aus mit Glück, kämpfe für Wahrheit und Recht! Furchtgebietende Taten soll dein rechter Arm dich lehren. Deine Pfeile sind scharf, dir unterliegen die Völker. ... Dein Thron, o Gott, steht fest für immer und ewig." Dass der göttliche Bogenschütze aus Psalm 45 der Sohn Gottes ist, wird in Hebr 1,8 ausdrücklich gesagt, wo es heißt, Gott habe „,vom Sohn“ gesprochen, als er sagte: „Dein Thron, o Gott, steht fest für immer und ewig“.

Gegen die Deutung des Reiters auf CHRISTUS wird zwar eingewendet, dass CHRISTUS bereits als Lamm vor JOHANNES steht, also nicht in ein und derselben Vision auch noch als Reiter auftreten kann. Aber dieser Einwand ist hinfällig, wenn man davon ausgeht, dass dem JOHANNES bei der Öffnung eines jeden Siegels eine neue Vision vor Augen geführt wird, die seine Himmelsvision ,überlagert“.

CHRISTUS ist der Anführer der in den folgenden Versen beschriebenen, unheilbringenden Reiter: Nicht weil er an deren furchtbarem und zumindest teilweise ungerechtem Zerstörungswerk seine Freude hätte, sondern weil er als Gott es versteht, sogar das Böse (dass er nicht will, aber durch die im Missbrauch ihrer Freiheit gegen ihn rebellierenden Geschöpfe geschehen lässt) in seinen Heilsplan einzubeziehen, so dass selbst der Teufel, ohne es zu wollen, zum Diener dieses Planes wird. CHRIstus bedient sich also der drei folgenden Plage-Reiter, damit durch diese die christenfeindlichen Mächte der Geschichte besiegt werden. Dass die Plage-Reiter tatsächlich als Diener des Himmels und nicht als dessen Gegner auftauchen, wird auch darin deutlich, dass sie von den vier himmlischen Wesen „herbeigerufen“werden.

2. Auslegung (kirchengeschichtliche Deutung): Der weiße Reiter symbolisiert das Zeitalter der relativ ungehinderten Ausbreitung der Evangeliums von 30 n. Chr. (Auferstehung Christi) bis 64 n. Chr. (Beginn der ersten römischen Christenverfolgung unter Kaiser Nero). In dieser Zeit zog CHRISTUS siegreich durch die Welt, indem seine Botschaft durch die Apostel und vor allem durch PAULUS überall im römischen Reich verkündigt wurde. Der REITER ist also auch in dieser Deutung Christus. Das WEISSE PFERD aber bezeichnet Gottes Volk, vor allem die Apostel und Verkündiger des Evangeliums (vgl. Sach 10,3). Dazu passt, dass der Reiter vom ERSTEN WESEN herbeigerufen wird: vom Löwen, d. h. mystisch: vom Markusevangelium. Denn Christus ist der Löwe aus dem Stamm Juda (5,5), und das Markusevangelium endet mit der durch Wunder und Zeichen begleiteten Predigt der Apostel.

\subsubsection{Apk 6,3-4: Zweites Siegel (Der rote Reiter)}

\section{Text}

6,3 Und als es (das Lamm) das zweite Siegel öffnete, hörte ich das zweite Wesen sagen: Komm!

6,4 Und es kam ein anderes Pferd heraus, ein feuerrotes.

Und dem, der auf ihm saß, wurde gewährt, den Frieden von der Erde zu nehmen, und dass sie einander hinschlachten. Und es wurde ihm ein großes Schwert gegeben. 


\section{Auslegung}

1. Auslegung (Literalsinn): Dieser ReITER ist der Krieg, denn er NIMMT DEN FRIEDEN VON DER ERDE. Dazu passt die ROTE FARBE als Farbe des Feuers, des Blutes und der Wut. Jesus hatte das Wirken des Kriegsreiters vorhergesagt, als ihn die Jünger gefragt hatten, welches das Zeichen für das Ende der Welt sein würde (Mt 24,3). Unter anderem hatte JESUS geantwortet: ,Ihr werdet von Kriegen hören und Nachrichten über Kriege werden euch beunruhigen. Gebt acht, lasst euch nicht erschrecken! Das muss geschehen, aber es ist noch nicht das Ende. Ein Volk wird sich gegen das andere erheben und ein Reich gegen das andere ... doch das ist alles erst der Anfang der Wehen" (Mt 24,7-8).

Diese Kriege sind also noch nicht die Vollstreckung des Endgerichts, und ebenso wenig handelt es sich um Kriege in der Zeit kurz vor dem Endgericht. Vielmehr ist die Reihe aller Kriege der nachchristlichen Zeit gemeint, die zwischen Christi erstem Kommen und dem Weltende ausbrechen werden. Mit dem „Anfang der Wehen“ ist zwar zweifellos der Beginn der sogenannten „Endzeit“ gemeint, aber diese „Endzeit“ hat nach biblischer Lehre schon mit Christi erstem Kommen begonnen (Apg 2,16-17, Hebr 1,2, 1 Petr 1,20, 1 Joh 2,18). Endzeit bedeutet, dass die Welt in ihr letztes Stadium, in ihr Greisenalter eingetreten ist. Wie nun aber das Greisenalter eines Menschen manchmal alle anderen Lebensperioden (Kindheit, Jugend usw.) an Dauer übertreffen kann, so könnte auch die Endzeit der Welt länger dauern als alle vorhergehenden Geschichtsepochen, worauf schon AUGUSTINUS aufmerksam gemacht hat. Auch PETRUS deutet an, dass der Begriff „Endzeit“ nicht unglaubwürdig wird, selbst wenn diese Zeit tausende von Jahren dauern sollte (2 Petr 3,8-10). Die Vorhersage von Kriegen zwischen Völkern und Reichen kann sich auch deshalb nicht auf die Zeit unmittelbar vor dem Weltende beziehen, weil diese Zeit durch eine weltweite Christenverfolgung gekennzeichnet sein wird, die von einem Weltdiktator ausgeht (20,8-9), und das schließt einem Krieg zwischen Völkern und Reichen aus. Der Plage-Reiter „Krieg“ ist also nicht Werkzeug für das letzte Gericht, sondern für innergeschichtliche Strafen.

2. Auslegung (kirchengeschichtliche Deutung): Nach dem „Zeitalter des weißen Reiters“, der Zeit der ungeheuren Missionserfolge der Urkirche (30-64 n. Chr.), folgt das „Zeitalter des roten Reiters“, die Zeit der Märtyrerkirche im römischen Reich, die zehn großen Verfolgungsphasen von 64-313 umfasste:

1. unter Nero (64-68)

2. unter Domitian (ca. 93-96)

3. unter Trajan (98-117, besonders seit 112)

4. unter Markus Aurel (161-180, besonders seit 176)

5. unter Septimius Severus (ca. 202-208)

6. unter Maximinus Thrax (235-238)

7. unter Decius (249-251)

8. unter Valerian (257-260)

9. unter Aurelian (nur kurz im Jahre 275)

10. unter Diokletian und anderen Kaisern (303-313)

Auch nach 313 gab es zwar Verfolgungen, aber diese haben nie wieder die ganze Christenheit erfasst und mit dem Untergang bedroht, so wie es in den Jahren des ,roten Reiters“ (64-313) der Fall war. Der REITER ist in dieser Deutung der Teufel, und das ROTE PFERD ist die Schar der Christenverfolger. Hierzu passt, dass der Reiter vom ZWEITEN WESEN herbeigerufen wird: vom Stier, d. h. mystisch: vom Lukasevangelium. Denn der Stier erinnert als Schlachtund Opfertier an die christlichen Märtyrer (vgl. 6,9), und das Lukasevangelium endet mit Jesu Verheißung, dass seine Jünger seine „Zeugen“ sein werden (Lk 24,48), wobei für „Zeugen“ im griechischen Text das Wort „Märtyrer“ steht, was bekanntlich sowohl Wort- wie auch Blutzeugen heißen kann (vgl. dazu auch die „Zwei Zeugen“ in Apk 11,3-14).

\subsubsection{Apk 6,5-6: Drittes Siegel (Der schwarze Reiter)}

\section{Text}

6,5 Und als es (das Lamm) das dritte Siegel öffnete, hörte ich das dritte Wesen sagen: Komm! Und ich sah, und siehe, ein schwarzes Pferd. Und der (,der) auf ihm saß, hatte eine Waage in der Hand. 


\section{Auslegung}

1. Auslegung (Literalsinn): Dieser ReITER ist der Hunger, der sich als Folge des Krieges einstellt. Denn seine WAAGE dient offenbar zur Rationierung der Grundnahrungsmittel, die eine akute Lebensmittelknappheit anzeigt. Ein MASS beträgt 1,79 Liter, und der DENAR war der durchschnittliche Tageslohn eines Arbeiters (vgl. Mt 20,2). Da man normalerweise pro Denar zwölf Maß Weizen oder vierundzwanzig Maß Gerste bekam, bedeutet die Preisfestlegung „EIN Mass Weizen pro Denar und drei Mass Gerste Pro Denar" eine gewaltige Teuerung. ${ }^{32}$ Die Ursache der Hungersnot ist also Nahrungsmittelknappheit und Teuerung, wie sie in und nach Kriegszeiten üblich ist.

Von den (auch in 18,13 erwähnten) Waren ÖL und WEIN heißt es hier sonderbarerweise, dass diese NICHT BESCHÄDIGT werden. Manche denken hier an die Belagerung Jerusalems durch Titus im Jahre 70, bei der Titus die Öl- und Weinpflanzungen zugunsten seiner Soldaten zunächst geschont hat. Andere denken an das Jahr 92, in dem Kaiser Domitian befahl, den Weinanbau aufzugeben, was aber aufgrund des großen Widerstands der Bevölkerung nicht in die Tat umgesetzt werden konnte. Am besten deutet man aber diese Aussage auf eine allgemeine Beobachtung, die man immer wieder in Kriegszeiten machen kann: Die korrupte Gesellschaft verwendet ihre wenigen Mittel, statt sie zur Gewinnung der notwendigen Grundnahrungsmittel zu nutzen, zum Anbau und Kauf von Genussmitteln. Das vergrößert die Hungersnot noch.

Jesus nennt den Hunger zusammen mit dem Krieg in seiner Prophezeiung über das „Ende der Welt“ (Mt 24,7, Mk 13,8, Lk 21,11). Wie der Krieg, so bezieht er aber auch den Hunger auf den „Anfang der Wehen“ (Mt 24,7, Mk 13,8), d. h. auf die gesamte nachchristliche Zeit. Siehe 1. Auslegung des 2. Siegels.

2. Auslegung (kirchengeschichtliche Deutung): Nach dem „Zeitalter des roten Pferdes“ (Christenverfolgungen 64313) begann das „Zeitalter des schwarzen Pferdes“, die Epoche der großen Kämpfe gegen die Irrlehren (313-843). Insbesondere gegen die folgenden:

1. Die Arianer, welche die Gottheit Christi leugneten und 325 auf dem Konzil von Nizäa verurteilt wurden.

2. Die Pneumatomachen, welche die Gottheit des Hl. Geistes leugneten und 381 auf dem Konzil von Konstantinopel verurteilt wurden.

3. Die Nestorianer, welche Christus in zwei Personen aufteilten und 431 auf dem Konzil von Ephesus verurteilt wurden.

4. Die Monophysiten, welche die menschliche Natur Christi leugneten und 451 auf dem Konzil von Chalcedon verurteilt wurden.

5. Die Anhänger der „drei Kapitel“, gemäßigte Nestorianer, welche die menschlichen und göttlichen Eigenschaften Christi zu sehr trennten und 553 auf dem zweiten Konzil von Konstantinopel verurteilt wurden.

6. Die Monotheleten, gemäßigte Monophysiten, welche den menschlichen Willen in CHRISTUS leugneten und 680/81 auf dem dritten Konzil von Konstantinopel verurteilt wurden.

7. Die Ikonoklasten (Bilderstürmer), welche die Bilder Christi und der Heiligen bekämpften. Sie hielten CHRISTUS für nicht abbildbar, hatten also wie die Monophysiten und Monotheleten die Menschwerdung Christi, die CHRISTUS abbildbar macht, nicht in letzter Konsequenz verstanden (zur Berechtigung einer christlichen Bilderverehrung siehe Exkurs 9). Diese Irrlehre wurde auf dem zweiten Konzil von Nizäa (787) verurteilt. Nach einer zweite Phase des Bilderstreits wurde dieser 843 endgültig beigelegt, ein Ereignis, das als „,Sieg der Orthodoxie“ noch heute in der Ostkirche jedes Jahr am 1. Fastensonntag (als „Sonntag der Orthodoxie“) gefeiert wird.

32 Flavius Josehus berichtet als Zeitzeuge des Jüdischen Krieges (66-70 n.Chr.), in dessen Verlauf die Juden in dem von den Römern unter ihrem Feldherrn TITUS belagerten Jerusalem unter einer große Hungersnot litten: „Viele der reicheren Bürger gaben heimlich ihr ganzes Vermögen dahin für ein einziges Maß Weizen, ärmere für ein Maß Gerste“ (Jüdischer Krieg 5,10,2). Ein Maß Weizen soll damals sogar für ein ganzes Talent (d.h. in etwa für den Preis eines Segelschiffs!) verkauft worden sein (Jüdischer Krieg 5,13,7). 
In der Zeit von 313 (Ende der Christenverfolgungen) bis 843 (Sieg der Orthodoxie) wurden also durch sieben Konzilien fundamentale Irrlehren besiegt. Diese Konzilien hielten die damals noch geeinte Kirche zusammen und sind daher das gemeinsame Erbe und gemeinsame Glaubensgrundlage der katholischen und der orthodoxen Kirche, während die evangelischen Kirchen in der Regel wenigstens die ersten vier dieser Konzilien aus richtungsweisende Bestätigung des rechten Glaubens anerkennen. Die sieben Konzilien haben den christlichen Glauben in seinen Grundlagen verteidigt und für alle Zeiten gesichert. Zwar gibt es auch nach 843 noch Irrlehren, ebenso wie es nach 313 noch Christenverfolgungen gibt. Aber ähnlich wie die Christenverfolgungen nach 313 nur noch auf einen Teil der Christenheit begrenzt sind, so sind auch die Irrlehren nach 843 nicht mehr so mächtig, dass sie die Mehrheit der Christen für sich gewinnen könnten (so wie es vor 843 mehrfach den Anschein hatte). So kann man zwar sagen, dass das rote und das schwarze Pferd noch immer durch die Welt reiten, dass aber die Epoche ihrer jeweiligen Vorherrschaft längst vorüber ist.

Als Begründung dafür, dass das schwarze Pferd die Epoche der Irrlehren bezeichnet, kann man zunächst die SCHWARZE FARBE anführen: Denn wenn das weiße Pferd das Licht des wahren Glaubens versinnbildet, bezeichnet das schwarze treffend die Finsternis des Irrglaubens. Da außerdem die wahre Lehre in der Schrift mit einer Speise verglichen wird (Mt 24,45, 1 Kor 3,2, 9,7, Hebr 5,12-14, 1 Petr 2,2), haben Irrlehren den Charakter einer geistigen Hungersnot und können durch den Hunger-Reiter versinnbildet werden.

Der REITER ist hier wieder der Teufel, der vom roten Pferd auf das schwarze umgestiegen ist, und das SCHWARZE PFERD ist die Schar der vom Teufel ,gerittenen“ Irrlehrer. Die WAAGE ist Symbol der Gerechtigkeit und könnte hier die eingebildete Gerechtigkeit bezeichnen, welche die Irrlehrer immer wieder sich selbst und ihren Anhängern zuschreiben, indem sie sich und ihre Anhänger als „Kirche der Reinen“ auffassen. Dass die Waage so gesehen für falsche Gerechtigkeit steht, bestätigen die ungerechten, viel zu teuren Preise für die Grundnahrungsmittel GERSTE und WEIZEN, die hier die wahre und nützliche Glaubenslehre symbolisieren. Die Irrlehrer gewichten die christliche Lehre falsch, indem sie die nützlichen Lehren ,unerschwinglich“ machen und den Menschen vorenthalten. Nur Genussmittel wie WEIN und ÖL bieten sie billig an, d. h. „Lehren, die den Ohren schmeicheln“ (2 Tim 4,3).

$\mathrm{Zu}$ dieser Deutung des schwarzen Pferdes passt, dass der Reiter vom DRITTEN WESEN herbeigerufen wird: vom Menschen, d. h. mystisch: vom Matthäusevangelium. Das Symbol „Mensch“ lässt sich in diesem Zusammenhang möglicherweise so ausdeuten, dass die Irrlehrer die wahre Kirche stets als Menschenwerk verachten, während sie ihre eigene Lehre als etwas „Göttliches“ betrachten. Das Matthäusevangelium ist außerdem das „kirchliche Evangelium“, das am meisten von den Kirchenvätern zur Widerlegung der Irrlehrer verwendet wurde, und das mit dem Befehl Christi endet, alle Völker zu seinen Jüngern zu machen.

\subsubsection{Apk 6,7-8: Viertes Siegel (Der bleiche Reiter)}

\section{Text}

6,7 Und als es (das Lamm) das vierte Siegel öffnete, hörte ich die Stimme des vierten Wesens sagen: Komm!

6,8 Und ich sah, und siehe, ein grünbleiches Pferd. Und der (,der) auf ihm saß, hieß ,,der Tod“.

Und der Hades folgte ihm nach.

Und es wurde ihnen Macht gegeben über den vierten Teil der Erde, um zu töten mit dem Schwert und mit dem Hunger und mit dem Tod und durch die Tiere der Erde.

\footnotetext{
Auslegung
}

1. Auslegung (Literalsinn): Dieser REITER ist die Pest, die sich als letzte und furchtbarste Folge von Krieg und Hunger einzustellen pflegt. Dazu passt die GRÜnbleICHE FARbE des Pferdes, die Farbe der Verwesung. Der Reiter hat zwar den Namen DER TOD, aber er kann nicht den Tod generell darstellen, denn dann wäre er überflüssig (weil ja auch die anderen Reiter schon todbringend sind). Das Wort „Tod“ ist also hier (wie in 2,23a) eine Bezeichnung für eine todbringende Krankheit, besonders für die Pest, weil die Pest von ihrer Erscheinungsweise her als eine Art „Tod am noch Lebenden“ aufgefasst werden kann. Der Pestreiter ist außerdem im Gegensatz zu den anderen beiden Unheilsreitern 
unmittelbar todbringend, und er hat deshalb auch als unmittelbaren Begleiter den HADES, in welchem das Strafgericht Gottes nach dem Tod seine jenseitige Fortsetzung findet. Den Hades sieht JoHANNES offenbar als eine Person, die hinter dem grünbleichen „Reiter Tod“ hinterherläuft, um einige der Opfer, die dieser Reiter erschlägt, zu verschlingen. Zusammen mit Krieg und Hunger nennt Jesus in seiner Rede über das „Ende der Welt“ auch die Pest (Lk 21,9-11). Wie Hunger und Krieg ist hier wahrscheinlich auch die Pest nur zu den Vorzeichen des eigentlichen Weltendes zu rechnen. Sie prägt daher die gesamte nachchristliche Zeit (vgl. 1. Auslegung des 2. Siegels).

In Vers $8 \mathrm{~b}$ wird das Wirken aller Plagereiter zusammengefasst: das TÖTEN MIT DEM SCHWERT ist das Werk des ersten Reitens, und das Töten mit DEM Hunger das Werk des zweiten, und folglich muss das TÖTEN MIT DEM TOD das Werk des dritten sein. Die Formulierung „Töten mit dem Tod“ macht ganz deutlich, dass das Wort „Tod“ hier nicht die allgemeine Bedeutung des Todes hat, sondern eine spezielle Todesart ausdrückt, nämlich (wie die Farbe des Reitens zeigt) die Pest. Nun bleibt aber noch das Töten DURCH DIE TIERE DER ERDE übrig, welches wohl das Werk des Begleiters des dritten Plagereiters, also des Hades, sein muss. Der Hades verschlingt also seine Opfer, wie ein wildes Tier Menschen verschlingt. Das Gefressenwerden von Tieren und der Einzug wilder Tiere in verwüstete Orte ist in biblischer Sprache eine typische Beschreibung für die völlige Verwüstung und Entvölkerung von Orten (Dt 7,22, Jes 13,21-22, 34,10-17, Apk 19,17-21) sowie für die Verunehrung eines Toten (1 Kön 21,23-24).

Wenn nun also am Ende gesagt wird, dass jede der vier Plagegestalten (drei Plage-Reiter plus personifizierter Hades) die Macht über EIN VIERTEL der Erde bekommt, so ist mit dieser Zahl anscheinend gemeint, dass die vier Plagegestalten sich die Erde so aufteilen, dass jeder ein Viertel bekommt, so dass alle vier zusammen auf der ganzen Erde wüten.

2. Auslegung (kirchengeschichtliche Deutung): Das grünbleiche Pferd bezeichnet auf einer mystischen Ebene das letzte Zeitalter der Kirche vom Ende der großen Auseinandersetzungen um den wahren Glauben ( $843 \mathrm{n}$. Chr.) bis zum Endgericht. Diese Zeit ist durch die immer größer werdende Gleichgültigkeit geprägt, die man als geistige Pest oder geistigen Tod bezeichnen kann (vgl. 3,1-2). Und in der Tat: Während man in der Zeit der Verfolgungen und der Irrlehren eifrig um die Bewahrung des Glaubens gerungen hatte, wurde dieser nun zur Selbstverständlichkeit, und das Glaubensleben erstarrte zur Gleichgültigkeit. Dass diese Haltung am Ende der Zeiten vorherrschen wird, hat CHRISTUS in seiner Endzeitrede vorausgesagt: „Die Liebe vieler wird erkalten“ (Mt 24,12). Die meisten Christen der letzten Generation werden sogenannte „Namenschristen“ sein, die zwar der Kirche äußerlich angehören, aber dennoch den Glauben eigentlich verloren haben. Das deutet CHRISTUs noch an einer anderen Stelle an: „Doch wenn der Menschensohn (= Christus) kommt, wird er dann noch Glauben auf der Erde finden?“" (Lk 18,8).

Der REITER ist wieder der Teufel, der nun vom schwarzen Pferd auf das grünbleiche umgestiegen ist, und das GRÜNBLEICHE PFERD ist die Schar der Namenschristen. Man beachte, dass die Angriffsmethoden des Teufels immer mehr an die Substanz gehen. Zuerst richtete sich der Angriff hauptsächlich auf das äußere: Die Christen sollten körperlich vernichtet werden (rotes Pferd). Dann richtete sich der Angriff auf den Geist: Die Christen sollten vom wahren Glauben abgelenkt und geistig überwunden werden (schwarzes Pferd). Jetzt aber richtet sich der Angriff direkt auf das Herz: Auf den Eifer und die Liebe als den Motor des lebendigen Glaubens. Glaube und Liebe sollen nun nicht mehr so sehr auf falsche Ziele umgelenkt, sondern gänzlich ausgeschaltet werden. Sie wird ersetzt durch Egoismus, Neid und Hass, die geistige Pest. Dadurch erfolgt sogleich der geistige Tod, der den Menschen von Gott abwendet, was weder die körperliche Verfolgung noch die Irrlehre direkt vermag. Daher führt nur der vierte Reiter als BEGLEITER den HADES mit sich, d. h. die Hölle. Zu dieser Deutung passt, dass der Reiter vom VIERTEN WESEn herbeigerufen wird: vom Adler, d. h. mystisch: vom Johannesevangelium. Denn erstens ist der Adler als das schnellste und das am höchsten hinausfliegende Tier ein der geistigen Trägheit entgegengesetztes Symbol. Zweitens hat JOHANNES mehr als die anderen Evangelisten die Liebe verkündigt (Joh 3,16, 31,1, 13,35, 14,21-24, 15,9-17, 17,26 usw.), und er ist höchstwahrscheinlich jener geheimnisvolle „Jünger, den Jesus liebte“ (Joh 13,23, 19,26, 21,7, 21,20). Drittens endet das Johannesevangelium (im 1. Abschlusssatz, 20,31) mit dem Wunsch, der Leser möge „,durch den Glauben das Leben haben“. 


\subsubsection{Apk 6,9-11: Fünftes Siegel (die Märtyrer unter dem Altar)}

\section{Text}

6,9 Und als es (das Lamm) das fünfte Siegel öffnete, sah ich unterhalb des Altars die Seelen derer, die geschlachtet worden waren wegen des Wortes Gottes und wegen des Zeugnisses, das sie festhielten.

6,10 Und sie riefen mit lauter Stimme und sagten: „Bis wann, o Gebieter, o heiliger und wahrhaftiger, richtest und strafst du nicht unser Blut an den Bewohnern der Erde?"

6,11 Und es wurde jedem von ihnen ein weißes Kleid gegeben.

Und es wurde ihnen gesagt, dass sie noch eine kurze Zeit ausruhen (warten) sollten, bis sich erfüllen sollte die Zahl sowohl ihrer Mitknechte als auch ihrer Brüder, die getötet werden sollten wie sie.

\section{Auslegung}

6,9 Und als es (das Lamm) das fünfte Siegel öffnete, sah ich unterhalb des Altars die Seelen derer, die geschlachtet worden waren wegen des Wortes Gottes und wegen des Zeugnisses, das sie festhielten.

Der Altar zeigt, dass sich JOHANNES in einem himmlischen Tempel befindet, der offenbar dem jüdischen Tempel gleicht (vgl. 7,15, 8,3-5, 11,19, 15,5). Ein himmlisches Urbild des jüdischen Tempels erwähnen auch die Stellen Ex 25,8-9, 25,40, 26,30, 27,8, Apg 7,44, Hebr 8,5.

Im jüdischen Tempel gab es zwei Altäre. Außen im Hof stand der große steinerne Brandopferaltar, auf dem Opfertiere dargebracht wurden (Ex 27,1-8, 1 Kön 8,64), und innen befand sich der kleine mit Gold überzogene Rauchopferaltar, auf dem lediglich Weihrauch dargebracht wurde. Von welchem dieser Altäre ist hier die Rede?

Offenbar vom Brandopferaltar, da man sagen kann, dass die Märtyrer ihr Leben „,geopfert“ haben als ein Gott wohlgefälliges Brandopfer. Vergleiche hierzu PAULUS in Phil 2,17: „Wenn ich geopfert werde beim Opfer und Gottesdienst eures Glaubens (oder: für euren Glauben), so freue ich mich“. Ebenso 2 Tim 4,6: „Ich werde schon geopfert, und die Zeit meines Scheidens steht bevor“.

Den Brandopferaltar wird JOHANNES außerhalb des Kreises der vierundzwanzig Ältesten gesehen haben, denn diese waren wohl aufgrund ihrer priesterlichen Tätigkeiten eher im Innenraum des Tempels. JOHANNES konnte offenbar durch die Wände des himmlischen Tempels hindurchblicken, so dass er im Innenraum bei den vierundzwanzig Ältesten stehend $(7,13)$ den Gottesthron (der im jüdischen Tempel durch einen Vorhang vom der großen Tempelhalle abgetrennt war) ebenso sehen konnte wie den Außenaltar im Hof.

Die Seelen der Märtyrer sind Unterhalb Des Altars zu sehen. Dazu muss man wissen, dass nach biblischer Lehre die „Seele im Blut“ ist (Lev 17,14) ${ }^{33}$ und das Blut der Opfertiere am Fuß des Altars ausgegossen werden musste (Lev 4,7). Dazu passend mussten die Seelen der Märtyrer unterhalb des Altars erscheinen. Diese Vision ist übrigens eine Schriftgrundlage für den Brauch, in den Altären christlicher Kirchen die Gebeine von Märtyrern beizusetzen.

\footnotetext{
33 Man beachte, dass die Schrift nicht sagt, dass die Seele ausschließlich im Blut gegenwärtig ist. Die Seele ist nicht nur im Blut, sondern überall im Körper gegenwärtig, da sie dem Körper und allen seinen Teilen Leben verleiht. Jedoch kann das Blut in besonderer Weise als Ort der Seele angesehen werden, weil die Blutzirkulation die deutlichste Lebensäußerung des beseelten Körpers ist.
} 
6,10 Und sie riefen mit lauter Stimme und sagten:

„Bis wann, o Gebieter, o heiliger und wahrhaftiger,

richtest und strafst du nicht unser Blut an den Bewohnern der Erde?"

Hier haben wir ein Beispiel für die Fürbitte der Heiligen im Himmel. Vielen kommt diese Bitte um Vergeltung unchristlich vor. Doch hat bereits der Hl. BEDA VENERABILIS († 735) richtiggestellt, dass die Märtyrer „nicht aus Hass für die Feinde, für die sie in dieser Welt gebetet hatten, (dieses) Gebet verrichten, sondern aus Liebe zur Gerechtigkeit“. ${ }^{34}$

6,11 Und es wurde jedem von ihnen ein weißes Kleid gegeben.

Und es wurde ihnen gesagt, dass sie noch eine kurze Zeit ausruhen (warten) sollten,

bis sich erfüllen sollte die Zahl sowohl ihrer Mitknechte

als auch ihrer Brüder, die getötet werden sollten wie sie.

Den Märtyrern wird gesagt, dass sie nur noch KURZE ZEIT warten müssen, bis das Endgericht kommt. Diese Zeitangabe ist aber nicht nach irdischer Zeit zu bemessen, denn es sind hier die Seelen der Märtyrer im Himmel angesprochen. Was für diese Seelen eine „,kurze Zeit“ bedeutet, wissen wir nicht, aber da sie Gott nahestehen, der in seiner Überzeitlichkeit alle Zeiten in einen einzigen Moment überschaut (vgl. 2 Petr 3,8: ,ein Tag ist beim Herrn wie tausend Jahre und tausend Jahre wie ein Tag“, siehe zu dieser Stelle auch den Kommentar zu 20,2), kann hier ein in unseren Augen längerer, tausende von Jahren umfassender Zeitraum gemeint sein.

Die Märtyrer sollen warten, bis alle heiligen Märtyrer und heiligen Nicht-Märtyrer der Menschheitsgeschichte im Himmel eingetroffen sind. Die hier genannten MITKNECHTE sind nämlich Nicht-Märtyrer, da sie den BRÜDERN, DIE GETÖTET WERDEN SOLLEN, gegenübergestellt werden: Die Märtyrer müssen sowohl auf ihre Mitknechte als auch auf die Brüder, die noch getötet werden, warten (die häufige Übersetzung ,ihre Mitknechte und Brüder“ ist ungenau, denn im griechischen Urtext steht hier , «a ... xal“", „was sowohl ... als auch“ bedeutet und beide Gruppen voneinander trennt). Die von vielen frühchristlichen Autoren vertretene Ansicht, dass nur die Märtyrer sofort nach ihrem Tod in den Himmel kommen und die anderen Heiligen erst beim Endgericht (eine Ansicht, die man auch in der Apokalypse zu finden glaubte), ist mit der gleichberechtigten Erwähnung der Märtyrer und NichtMärtyrer an dieser Stelle kaum vereinbar. Noch klarer wird sich in 14,13 zeigen, dass alle Heiligen der nachchristlichen Zeit sofort nach ihrem Tod in den Himmel kommen.

Das den Märtyrern überreichte WEISSE KLEID ist die vollkommene Reinheit und Christusähnlichkeit ihrer Seele, die sie nun im Himmel als Vervollständigung und Krönung ihres irdischen Bemühens um Reinheit empfangen (vgl. 3,4-5). Nun befähigt Reinheit zur Gottesschau: „Selig, die reinen Herzens sind, denn sie werden Gott schauen“ (Mt 5,8). Und umgekehrt ist es die Gottesschau, die zur Christusähnlichkeit führt: „Wir werden Gott ähnlich sein, denn wir werden ihn sehen, wie er ist“ (1 Joh 3,2). Also sind die WEISSEN KLEIDER untrennbar mit der Gottesschau verknüpft, welche der Hauptlohn des ewigen Lebens ist (Joh 17,3). So kann man sagen, dass die Märtyrer mit den WEISSEN KLEIDERN zugleich ihren persönlichen himmlischen Lohn bekommen.

Diese Beobachtung stimmt mit der Lehre überein, dass sogleich nach dem Tod eines jeden Menschen ein individuelles Gericht stattfindet, das über sein ewiges Schicksal entscheidet und ihn sogleich seiner Strafe bzw. seinem Lohn zuführt (Sir 11,26, Lk 16,22-30, Hebr 9,27). Dieses Gericht ist also zu unterscheiden vom allgemeinen Gericht am Weltende (zu diesem siehe Kommentar zu 20,11-15). Da nun aber das Gebet der Märtyrer zu einem Zeitpunkt stattfinden muss, zu dem sie das weiße Gewand noch nicht haben, zeigt sich, dass Lohn und Strafe nicht in genau demselben Moment einsetzt, in dem man stirbt, sondern dass zwischen Tod und Lohn/Strafe eine kurze „Gerichtszeit“" angesetzt werden muss, in welcher Gott den Verstorbenen das Gute und Böse in ihrem Leben vor Augen führt. Vergleiche hierzu Röm 2,15, wo Paulus über die Heiden sagt: „Ihre Gedanken klagen sich gegenseitig an und verteidigen sich an (jenem) Tag, an dem Gott das, was im Menschen verborgen ist, richten wird.“

34 Beda Venerabilis, Explanatio Apocalysis, Kommentar zu 6,10 (PL 93 Sp. 143). 
Bei einer solchen „Gerichtsverhandlung“ richten offenbar die Märtyrer jenes Gebet „wie lange noch ... “ an Gott. So ergibt sich folgende Reihenfolge der Ereignisse. Sofort nach dem Tod (der „Schlachtung") gelangen die Seelen der Märtyrer (symbolisch) in den Hof des himmlischen Tempels unter den Brandopferaltar. Dort findet ihr persönliches Gericht statt, bei dem sie Gott um Vergeltung bitten. Dann wird ihnen das ,weiße Gewand“ überreicht, das sie zur Gottesschau befähigt. Und nun findet ein (symbolischer) Ortswechsel statt: Vom Brandopferaltar schreiten sie in das Innere des Tempels. Dies folgt aus 7,9-15, wo beschrieben ist, dass jene, ,die aus der großen Bedrängnis kommen“ $(7,14)$, ,in weißen Gewändern vor dem Thron und vor dem Lamm stehen“ $(7,9)$, und zwar „,im Tempel“ (7,15).

Was JOHANNES hier sieht, findet immer wieder statt, wenn auf Erden Märtyrer ,geschlachtet“ werden, ohne dass dadurch bereits „das Maß voll“ ist und die Weltgeschichte an ihr Ende gelangt. Wie die vorhergehenden Siegelvisionen bezieht sich also auch diese (im Literalsinn) nicht auf ein einmaliges Ereignis, sondern auf ein typisches, sich wiederholendes Geschehen.

\subsubsection{Apk 6,12-17: Sechstes Siegel, Teil 1 (allgemeine Beschreibung der Strafgerichte)}

\section{Text}

6,12 Und ich sah: Als es (das Lamm) das sechste Siegel öffnete, geschah ein großes Erdbeben.

Und die Sonne wurde schwarz wie ein Sack aus Haaren.

Und der Mond wurde (rot) wie Blut.

6,13 Und die Sterne fielen auf die Erde, (so) wie ein Feigenbaum seine Spätfeigen abwirft, wenn er von einem starken Wind geschüttelt wird.

6,14 Und der Himmel wich zurück wie ein Buch, das zusammengerollt wird. Und jeder Berg und jede Insel wurden von ihren Orten (weg)bewegt.

6,15 Und die Könige der Erde und die Vornehmen und die Befehlshaber und die Reichen und die Starken und jeder Sklave und Freie verbargen sich in den Höhlen der Felsen der Berge.

6,16 Und sie sagten zu den Bergen und Felsen: Fallt auf uns und verbergt uns vor dem Angesicht dessen, der auf dem Thron sitzt und vor dem Zorn des Lammes.

6,17 Denn gekommen ist der große Tag ihres Zorns: Wer kann da bestehen?

\section{Auslegung}

Die hier genannten kosmischen Katastrophen müssen nicht auf einen buchstäblichen Untergang des gesamten Kosmos bezogen werden, sondern können symbolisch auch partielle Untergänge von Reichen inmitten der Weltgeschichte beschreiben: Denn ,alles scheint unterzugehen für den, der untergeht“ (Bossuet). ${ }^{35}$ Vergleiche hierzu Koh 12,1-7: „Denk an deinen Schöpfer in deinen frühen Jahren, ehe die Tage der Krankheit kommen und die Jahre dich erreichen ..., ehe Sonne und Licht und Mond und Sterne erlöschen ... ehe der Staub (= der Leib) auf die Erde zurückfällt als das, was er vorher war, und die Seele zu Gott zurückkehrt, der sie gegeben hat.“ Die einzelnen Details haben folgende Bedeutung:

Das ERDBEBEN bezeichnet Umstürze, Kriege, Aufstände und geschichtliche Übergangsperioden, in denen Altes und Gewohntes untergeht. In diesem Sinn ist auch beim Auszug der Israeliten aus Ägypten von einem Erdbeben die Rede (Ps 114,1-7, Hebr 12,26).

Die SONNE ist ein häufig gebrauchtes biblisches Symbol für CHRISTUS, und zwar vor allem für seine göttliche Natur. So nennt die Schrift beispielsweise CHRISTUS „Sonne der Gerechtigkeit“ (Mal 3,20), „Aufgang (aufstrahlendes Licht) aus der Höhe“ (Lk 1,87), „Licht, das jeden Menschen erleuchtet“ (Joh 1,9), „Licht der Welt“ (Joh 9,5), „Licht zur

35 Bossuet, Kommentar zu Apk 6,11, SSCC 25, Spalte 1259. 
Offenbarung für die Heiden“ (Lk 2,32). In der Eingangsvision sah JOHANNES JESU Gesicht leuchten, „,wie wenn die Sonne in ihrer Kraft scheint“ $(1,16)$. Auch als CHRISTUS einst mit seinen Jüngern auf einem Berg war, „leuchtete sein Gesicht wie die Sonne“ (Mt 17,2). So ist es kein Wunder, dass die Bewohner des neuen, vom Himmel kommenden Jerusalem keine Sonne mehr nötig haben werden, da CHRISTUS ihre Leuchte sein wird (Apk 21,23). Da die Sonne die Gottheit Christi bezeichnet, war es auch angemessen, dass bei seiner Kreuzigung, als seine Gottheit am tiefsten verhüllt war, „die Sonne verfinstert wurde“ (Lk 23,45). Mit der VERFINSTERUNG DER SONNE könnte also gemeint sein: Die Abnahme des Glaubens an CHRISTUS und dadurch die Zunahme der Finsternis in den Herzen der Menschen, in denen CHRISTUS, das „Licht der Welt““ aufhört, zu leuchten.

Der MOND meint in diesem Zusammenhang wahrscheinlich die Kirche, denn wie der Mond sein Licht von der Sonne bekommt, bekommt die Kirche ihr Gnadenlicht von Christus. Das BLuTiGWERDEN DES Mondes bedeutet demnach eine Kirchenverfolgung.

STERNE können große Lehrer und Vorbilder bezeichnen (vgl. die moderne Bezeichnung „Star“ für einen Menschen, der andere begeistert), denn in Apk 1,20 stehen sieben Sterne für Bischöfe, in Apk 12,1 zwölf Sterne für die Apostel, in einer Vision DANIELs (Dan 8,10) das „Sternenheer“ für das „Volk der Heiligen“ (Dan 8,22-24). In Dan 12,3 heißt es, dass „,diejenigen, die viele zum rechten Tun angeleitet“ auf ewig ,wie die Sterne leuchten“ werden, im Philipperbrief $(2,15)$ spricht Paulus vom ,einer verdorbenen Generation, unter der ihr als Lichter in der Welt leuchtet“" und im Judasbrief (13) werden Irrlehrer ,irrende Sterne“ genannt. Das FALLEN DER STERnE VOM Himmel bedeutet also, dass Lehrer der Kirche vom Glauben abfallen und/oder Irrlehrer werden (vgl. Apk 8,10 und 9,1).

Himmel, Berge und Inseln sind Symbole für alles Feststehende. Denn Inseln stehen fest inmitten des Meeres und Berge sind die standhaftesten Bollwerke der Erde (weshalb das „Berge versetzen Können“ nach Mt 17,20 die übernatürliche Kraft des Glaubens deutlich macht), und das Himmelsgewölbe schließlich ist das, was von allen feststehenden Dingen in der Welt am meisten festzustehen scheint, da er für den Menschen völlig unangreifbar ist. Das WEGRÜCKEN VON HIMMEL, BERGEN und INSELN versinnbildet daher das unerwartete Zerbrechen von Weltbildern und Machtgefügen. So benutzt auch JESAJA im Zusammenhang mit dem Untergang des vorchristlichen Volkes Edom das Sinnbild vom Zus ammenrollen des Himmels (Jes 34,4-5), in Psalm 97,5-8 werden Gottes Strafgerichte in der Geschichte als ein SCHMELZEN VON BERGEN beschrieben und EZECHIEL beschrieb schließlich den Untergang der Stadt Tyrus als eine ERSCHÜTTERUNG VON INSELN (Ez 26,15 und 26,18).

Die KÖNIGE DER ERDE, die sich mitsamt ihren Untertanen vor Gottes Zorn fürchten, sind die Führer der antichristlich eingestellten Menschen. Zu ihnen gehören viele (aber nicht alle!) „Könige“ und Politiker im eigentlichen Sinn, aber auch andere „Stars“ und Idole. Nicht zu ihnen gehören die treuen Christen, die mit CHRISTUS „Könige des Himmels“ genannt werden können (vgl. 1,9, 20,4).

Die ganze Vision bedeutet demnach Folgendes: Es tritt eine Veränderung (Erdbeben) ein, dergestalt, dass der christliche Glaube in den Herzen vieler Menschen verfinstert wird (Verfinsterung der Sonne), so dass sie eine blutige Kirchenverfolgung beginnen (Rotwerden des Mondes), (Fallen der Sterne vom Himmel). Aber plötzlich treten unerwartete Veränderungen ein (Wegrücken von Himmel, Bergen und Inseln), derart, dass die Kirche befreit wird und statt dessen ihre Verfolger (die Könige der Erde usw.) das Fürchten lernen.

Dieses Ereignismuster lässt sich im Prinzip auf alle Christenverfolgungen anwenden. Schon der Prophet JOEL sprach vom Dunkelwerden der Sonne und von der Verwandlung des Mondes in Blut, und der Apostel PETRUS übertrug in seiner Pfingstpredigt diese Prophetie auf seine Zeit: „Jetzt geschieht, was durch den Propheten Joel gesagt worden ist: In den letzten Tagen wird es geschehen, so spricht Gott: ... Die Sonne wird sich in Finsternis verwandeln und der Mond in Blut, ehe der Tag des Herrn kommt, der große und herrliche Tag.“ (Apg 2,16-20) PETRUS spricht hier von den „letzten Tagen“ vor dem „Tag des Herrn“, d. h. vor den Tagen des Endgerichts, die bereits angebrochen sind (,,jetzt geschieht ..."). Diese letzten Tage bezeichnen die Endzeit, worunter die gesamte Zeit von Christi Auferstehung bis zum Endgericht zu verstehen ist (siehe 1. Auslegung zum 2. Siegel). In dieser gesamten Zeit wird also die Kirche immer mehr oder weniger blutig verfolgt werden. Besonders trifft das beschriebene Ereignismuster bei den drei Strafgerichten zu, die später im einzelnen beschrieben werden:

1. Die Vernichtung des antiken Judentums durch die Römer, die zur Zeit des JoHANNEs bereits durch die Zerstörung Jerusalems und seines Tempels im Jahre 70 begonnen hatte, und die in den Jahren 115-135 durch die Niederschlagung zweier jüdischer Aufstände vollendet wurde, bei denen über eine Million Juden starben; am Ende wurden sie aus Jerusalem vertrieben und als Sklaven verkauft. Hierauf ist in der Vision angespielt, denn der verzweifelte Wunsch, von den Hügeln begraben zu werden, wird beim Propheten HoseA (Hos 10,8-10) auf ein Gericht über Israel bezogen, und von JESUS auf ein Gericht über die Stadt Jerusalem: „Ihr Frauen von Jerusalem, weint ... über euch und eure Kinder. 
Denn es kommen Tage, da wird man ... zu den Bergen sagen: ,Fallt auf uns', und zu den Hügeln ,bedeckt uns““ (Lk 23,28-30). Die Katastrophe des Jahres 135 (der jüdische Bar-Kochba-Aufstand) steht auch im Zusammenhang mit einer Christenverfolgung (Verfinsterung der Sonne und Blutigwerden des Mondes), denn die nichtchristlichen Juden verfolgten damals die jüdischen Christen, die sich nicht am Aufstand beteiligen wollten.

2. Der Untergang des heidnischen Rom und verbunden damit der gesamten antiken Weltordnung durch die Barbareneinfälle der Völkerwanderung. Dieser Untergang kann treffend als ein „Wegrücken von Himmel, Bergen und Inseln“ beschrieben werden, denn es handelt sich hier um den schärfsten Einbruch in der bisherigen Geschichte. Die Historiker sind sich einig, dass die zwei größten Veränderungen, die es in der Geschichte gegeben hat, der Übergang von der Antike zum Mittelalter und der Übergang vom Mittelalter zur Neuzeit waren. Aber der Übergang vom Mittelalter zur Neuzeit war kulturell ein Fortschritt, wohingegen der Übergang von der Antike zum Mittelalter ein Rückschritt, ein Rückfall von einer hohen Kulturstufe in die Barbarei war, und somit war dies der deutlichste geschichtliche Einschnitt, dem der Charakter eines Strafgerichtes Gottes zugeschrieben werden kann. Der Untergang Roms erfolgte ebenso wie die Vernichtung des antiken Judentums nach einer Christenverfolgung, d. h. nachdem die Sonne sich verfinstert hatte und der Mond blutig geworden war.

3. Die Vernichtung aller gottfeindlichen Mächte am Ende der Tage. Dies ist im eigentlichen Sinn „DER große Tag des Zorns" (6,17), und erst dieser bringt die vollkommene Erfüllung der Bitte der Märtyrer in der 5. Siegelvision. Tatsächlich wird, wie es die Schrift an mehreren Stellen vorhersagt, unmittelbar vor dem Weltende eine weltweite Christenverfolgung stattfinden (vgl. 20,7-9, Dan 12,1, Mt 24,21-22, Mk 13,19), und nach dieser Verfolgung wird die Weltordnung ihre größte und endgültige Veränderung erfahren. Siehe dazu Jesu Prophezeiung vom Weltende im Matthäusevangelium (24,19, vgl. Mk 13,24-25, Lk 21,25-26): „Sofort nach der Bedrängnis jener Tage (= Christenverfolgung) wird die Sonne finster werden, der Mond wird seinen Schein nicht mehr geben und die Sterne werden vom Himmel fallen, und die Kräfte der Himmel werden erschüttert werden. “"36 Zusammenfassend kann man sagen, dass im 1. Teil des 6. Siegels in allgemeiner Weise der Verlauf und Charakter des göttlichen Strafgerichts beschrieben ist, so wie es sich mehrfach in der Weltgeschichte und dann nochmals in einmaliger Weise deren Ende ereignet.

\subsubsection{Apk 7,1-8: Sechstes Siegel, Teil 2 (Bewahrung von 144000 vor dem ersten Gericht)}

Text

7,1 Danach sah ich vier Engel an den vier Ecken der Erde stehen und die vier Winde der Erde festhalten, damit kein Wind wehe über die Erde noch über das Meer noch gegen einen Baum.

7,2 Und ich sah einen anderen Engel heraufkommen vom Aufgang der Sonne her. Er hatte das Siegel des lebendigen Gottes. Und er rief mit lauter Stimme den vier Engeln zu, welche die Macht hatten, der Erde und dem Meer Schaden zuzufügen:

7,3 Fügt der Erde und dem Meer und den Bäumen keinen Schaden zu, bis wir die Knechte unseres Gottes auf ihrer Stirn mit dem Siegel gekennzeichnet haben.

7,4 Und ich hörte die Zahl der Versiegelten: 144.000 Versiegelte aus jedem Stamm der Söhne Israels.

36 Man beachte aber, dass die in der Prophezeiung JESU beschriebenen Phänomene an Sonne und Mond nicht identisch sind mit der Verfinsterung der Sonne und dem Blutigwerden des Mondes in der Apokalypse, da sie erst nach der Christenverfolgung stattfinden. Als ,,sofort nach“ der Bedrängnis einsetzende Ereignisse kennzeichnen sie deren Ende, und folgerichtig sagt JESUS auch nicht, dass der Mond blutrot wird. Sonne, Mond und Sterne scheinen hier nicht für CHRISTUS, Kirche und Glaubenslehrer zu stehen, sondern sind ebenso wie der Himmel als Symbole für das „Feststehende“ der bis dahin bestehenden Weltordnung gewählt, die nun endgültig ,erschüttert“ werden wird. Was also JOHANNES in der Apokalypse als Wegrücken von Himmel, Bergen und Inseln beschreibt, wird in der von Matthäus aufgeschriebenen Prophezeiung JESU statt dessen als Erschütterung des Himmels samt Verlöschen aller Himmelslichter beschrieben. 
Aus dem Stamm Juda 12.000 Versiegelte, aus dem Stamm Ruben 12.000, aus dem Stamm Gad 12.000, aus dem Stamm Naftali 12.000, aus dem Stamm Manasse 12.000,

\section{Auslegung}

JOHANNES blickt vom Himmel aus auf die damals ihm bekannte ERDE wie auf eine Landkarte herab, die so ausgerichtet ist, dass ihre vier Ecken in die vier Himmelsrichtungen zeigen:

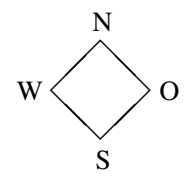

An den VIER ECKEN dieser Landfläche, d. h. an ihrem nördlichsten, südlichsten, östlichsten und westlichsten Punkt, sieht er vier Engel stehen. Diese halten die VIER WINDE, d. h. den Nord-, Süd-, Ost- und Westwind fest.

Diese Engel sind wohl gute Engel, die über die irdische Natur gesetzt sind, also Engel, die den „vier Wesen“ (4,6b8) unterstehen. Die VIER WINDE kommen auch in einer Vision DANIELs vor: „Die vier Winde wühlten das große Meer auf: Da stiegen aus dem Meer vier große Tiere“ (Dan 7,2-3). Diese Tiere sind bei DANIEL gottfeindliche Reiche (vgl. Dan 7,23). Demnach symbolisieren die vier Winde geschichtliches Unheil. Die vier Winde kommen auch beim Propheten SACHARJA (Sach 6,5) vor, wo sie mit Wagen verglichen werden, die von roten, schwarzen, weißen-bleichen und gescheckten Pferden gezogen werden. Diese Pferdegespanne sind, wie die Reihenfolge der Farben beweist, mit den vier Unheilsbringern der ersten vier Siegelvisionen verwandt: mit den Reitern auf dem roten, schwarzen und bleichen Pferd sowie mit dem unheimlichen Begleiter des letzteren, der dem gescheckten Pferd bei SACHARJA entsprechen muss. Diese Unheilsboten (Krieg, Hunger, Pest und Hades) sind also die „vier Winde“, d. h. die Mächte, welche Völker und Reiche ins Unglück stürzen.

Die Schädigung von ERde, MeER und BÄUmen, die hier noch verhindert wird, wird beginnen, wenn die zwei ersten Gerichtsposaunen blasen (in 8,7-8). Wie wir sehen werden, kann man die Schädigung von Erde, Bäumen und Meer mit der Niederschlagung der jüdischen Aufstände von 117-118 n. Chr. und 135 n. Chr. gleichsetzen.

Der ANDERE ENGEL ist wahrscheinlich CHRISTUS. Christus ist zwar kein Engel im eigentlichen Sinn, aber er kann als ENGEL bezeichnet werden, weil das Wort Engel „Bote“ bedeutet, und Christus prophetisch in Mal 3,1 als „Bote des Bundes“ bezeichnet wird. Für diese Deutung spricht zunächst, dass dieser Engel offenbar den Zeitpunkt bestimmt, wann die Winde freigelassen werden dürfen. Er hat also die Oberherrschaft über die vier Winde (= die vier Unheilsgestalten der ersten vier Siegelvisionen) und dürfte darum identisch sein mit dem Reiter auf dem weißen Pferd in der ersten Siegelvision: Das aber war CHRISTUS. Auch die Herkunft des Engels lässt auf ChRISTUS schließen: er kommt vOM AUfGang DeR SONNE, d. h. vom östlichen Aufgangspunkt der Sonne her. CHRISTUS ist nämlich selber symbolisch die Sonne (siehe den Kommentar zu 6,12) und er wird in Lk 1,78 „Aufgang“ genannt (vgl. auch Jes 60,1 und den griech. Text von Sach 3,8). Auch, dass er das SIEGEL GotTeS in der Hand hat, erklärt sich am besten, wenn es sich um CHRISTUS handelt: Denn die Versiegelung bedeutet die (durch die Firmung vollendete) Taufe (siehe unten), und der eigentliche, unsichtbare Spender der Taufe ist Christus (Mt 3,11, Mk 1,8, Lk 3,16, Joh 1,33, Eph 5,25-26). Die Versiegelung auf der Stirn erinnert an die Vision Ezechiels $(9,4)$, in welcher ein Mann den kreuzförmigen Buchstaben Tau auf die Stirn der gottesfürchtigen Israeliten schrieb, wodurch sie vor einem Strafgericht Gottes bewahrt wurden. Dies kann als eine Vorhersage der zukünftigen Rettung durch Christi Kreuz verstanden werden, dessen Kraft durch die Taufe übertragen wird. Das auf die Stirn aufgeprägte SIEGEL ist also der gläubig angenommene und darum das Denken (= die STIRN) prägende Akt der Taufe. Tatsächlich wird die (durch die Firmung vollendete) Taufe auch anderswo in der Schrift als Versiegelung umschrieben (Eph 1,13, 4,30, 2 Kor 1,21-22, 1 Joh 2,20, 2,27, vgl. Röm 3,11). Der ANDERE Engel (Christus) spendet also die Taufe, aber er tut dies nicht allein, wie das WIR in Vers 3 zeigt: Die 
Helfer Christi bei der Taufe sind die Diener der Kirche.

Die Zahl 144.000 lässt sich schreiben als $12 \cdot 12 \cdot 1000$. In Exkurs 4 hat sich gezeigt, dass 12 eine heilige Gesamtheit symbolisiert, also $12 \cdot 12$ eine heilige Gesamtheit höherer Ordnung; in diesem Zusammenhang haben wir auf S. 49 gesehen, dass die Zahl 144 auch deshalb eine absolute Vollständigkeit symbolisiert, weil man bis 144 mit beiden Händen zählen kann. 1000 aber ist die Zahl der unabsehbar große Menge, wie sich im Kommentar zu 20,4 zeigen wird. Die Zahlenangabe der 144.000 Israeliten aus den 12 Stämmen kann also so gedeutet werden, dass aus jedem der 12 Stämme Israels die Zahl von 12 1000 Personen, d. h. eine unabsehbar große (1000), die Vollständigkeit der Heiligen Israels ausmachende (12) Menge versiegelt werden wird; oder dass eine unabsehbar große (1000) absolut vollständige (144) Menge versiegelt sind. Daher muss man nicht unbedingt annehmen, dass genau 144.000 (nicht mehr und nicht weniger) Israeliten vor dem Strafgericht bewahrt werden. Es ist hier die Rede von Israeliten, die vor dem ersten Strafgericht, dass konkret in der Apokalypse vorhergesagt ist, bewahrt werden. Wie wir sehen werden, ist dieses Strafgericht wahrscheinlich die Niederschlagung der jüdischen Aufstände im Jahre 117 und 135 (siehe Kommentar zu 8,6-9), bei denen tatsächlich die getauften Juden verschont blieben, weil sie sich nicht an den Aufständen beteiligten. Demnach sind die hier gemeinten 144.000 leibliche Israeliten, die Ende des 1. und Anfang des 2. Jahrhunderts lebten (tatsächlich lebten im Israel des ersten Jahrhunderts immer noch Angehörige aus allen zwölf Stämmen Israels, vgl. Jak 1,1, Apg 26,7, Mt 4,13, Lk 2,36, Phil 3,5, Röm 11,1). Wie groß die Anzahl der getauften Israeliten damals genau war, wissen wir nicht, aber sie könnte der Zahl 144.000 tatsächlich nahegekommen sein, da schon zu Zeiten des Paulus (um 60 n. Chr.) ,viele Zehntausende“ von Israeliten gläubig geworden waren (Apg 21,20).

Zur AufZÄHLung DER 12 StÄmme. Die Stammväter Israels wurden nach Gen 29,31-30,24 und 35,16-18 in folgender Reihenfolge geboren: Ruben, Simon, LEvi, JudA, DAN, NAFTALI, GAD, Ascher, IsSACHAR, SEBUlON, Josef, Benjamin. Da der Priesterstamm Levi keinen eigenen Landbesitz erhielt, brauchte man einen 13. Stamm, um bei der Gebietsverteilung wieder auf die heilige Zahl 12 zu kommen. Dies wurde durch die Aufteilung des Stammes JOSEF in die Stämme MANASSE und EPHRAIM erreicht (Gen 41,50-52). Die Gebiete der zwölf Stämme waren:

\begin{tabular}{|l|l|}
\hline $\begin{array}{l}\text { westlich des Jordan } \\
\text { von Norden nach Süden: }\end{array}$ & $\begin{array}{l}\text { östlich des Jordan } \\
\text { von Norden nach Süden: }\end{array}$ \\
\hline - DAN & - ein kleiner Teil von MANASSE \\
- ASCHER & - GAD \\
- NAFTALI & - RUBEN \\
- SEBULON & \\
- ISSACHAR & \\
- der größte Teil von MANASSE & \\
- EPHRAIM & \\
- BENJAMIN & \\
- JUDA & \\
- SIMON & \\
\hline
\end{tabular}

Die Aufzählung in der Apokalypse hat nun folgende Besonderheiten:

- Der Stamm DAN wird ausgelassen, wohl deshalb, weil in Gen 49,17 und Jer 8,16-17 angedeutet wird, dass aus DAN einst der Antichrist kommen wird. Außerdem hatten die Israeliten im Gebiet von Dan einst ein goldenes Kalb verehrt (1 Kön 12,29).

- Statt der üblichen Aufzählung der beiden Josef-Stämme MANASSE und EPHRAIM begegnen uns hier die Namen Manasse und Josef, so dass „Josef“ für „Ephraim“ steht. Der Name EPhraim wird wohl deshalb vermieden, weil in der ephraimitischen Stadt Bet-El einst ein goldenes Kalb verehrt worden war (1 Kön 12,29).

So zeigt sich, dass bei der Aufzählung der gute bzw. schlechte Ruf der Namen eine Rolle spielt. Daher muss man nicht annehmen, dass tatsächlich aus jedem der genannten Stämme genau 12.000 Israeliten getauft wurden, aus dem Stamme DAN aber kein einziger. Die Reihenfolge der Namen in der Apokalypse erklärt sich nun vermutlich wie folgt:

- Erster Stamm ist JUDA, weil ihm ChRISTUS entstammt.

- Dann kommt Ruben, weil RubEn der erstgeborene Sohn des Stammvaters JAKOB war. 
- Dann GAD, weil die Stämme GAD und RubEN eine Einheit für sich bilden: Es waren die einzigen vollständig im Ostjordanland angesiedelten Stämme.

- Dann Ascher, Naftali, Manasse, Simon: dies Stämme bilden nämlich eine Reihe von Westjordanstämmen in geographischer Reihenfolge von Norden nach Süden. In dieser Reihe werden ausgelassen: SEBULON, ISSACHAR und BENJAMIN wegen ihrer geringen Größe, DAN und EPHRAIM wegen ihres schlechten Rufes, und JUDA, weil dieser Stamm schon genannt wurde.

- Dann LEVI, weil LEVI unmittelbar nach Simon geboren wurde.

- Zum Schluss Issachar, Sebulon, Josef und Benjamin: die Stämme, deren Stammväter die vier zuletzt geborenen Söhne Jakobs sind, in der Reihenfolge der Geburt dieser Väter.

Sind die 144.000 „Israeliten“, wie manche glauben, ein Symbol für die Christen aller Völker? In diesem Sinn bezeichnet schon Paulus in Gal 6,16 die Gesamtheit aller Christen als „Israel“ (vgl. Gal 3,29, Röm 9,6-8), und auch in 21,12 wird die Christenheit als ein symbolisches Zwölfstämmevolk Israel aufgefasst, wo es heißt, dass auf den Toren des himmlischen Jerusalem, also auf den Toren der allen Christen verheißenen himmlischen Stadt, ,die Namen der zwölf Stämme der Söhne Israels“ geschrieben stehen. Doch dürfte in Apg 7,1-8 von leiblichen Israeliten die Rede sein. Denn JOHANNES schaut unmittelbar nach der Vision von den „144.000 Israeliten“ eine „große Schar, die niemand zählen konnte, aus allen Völkern“ (Vers 9). Diese beiden Gruppen können kaum identisch sein, denn sie werden durch entgegengesetzte Eigenschaften charakterisiert: Die 144.000 sind zählbar (,ich hörte die Zahl der Versiegelten“), wohingegen die große Schar unzählbar ist (,niemand konnte sie zählen“). Außerdem sind die einen „Söhne Israels“ und die anderen eine „Schar aus allen Völkern“. Wenn beide Gruppe Christen aus allen Völkern sind, könnte man zwar den „Mengenunterschied“ zur Not noch so erklären, dass die 144.000 die auf Erden lebenden Christen einer bestimmten Zeitepoche sind, während die unzählbare Schar die im Himmel zusammenkommenden Christen aller Zeiten umfasst. Aber wie will man den doch ebenfalls sehr auffälligen Unterschied zwischen „Söhnen Israels“ und „Schar aus allen Völkern“ erklären? Dieser Unterschied zwingt meines Erachtens, bei den 144.000 an wirkliche Israeliten zu denken. ${ }^{37}$

\subsubsection{Apk 7,9-17: Sechstes Siegel, Teil 3 (Rettung Unzähliger aus dem letzten Gericht)}

7,9 Danach sah ich, und siehe: eine große Schar, die niemand zählen konnte, aus jeder Nation und allen Stämmen und Völkern und Sprachen stand vor dem Thron und vor dem Lamm.

7,10 Und sie rufen mit lauter Stimme und sagen:

Die Rettung liegt bei unserem Gott, der auf dem Thron sitzt, und dem Lamm.

7,11 Und alle Engel standen im Kreis um den Thron und die Ältesten und die vier Wesen und fielen nieder vor dem Thron auf ihre Gesichter und beteten Gott an.

7,12 Und sie sagten: Amen. Das Lob und die Herrlichkeit und die Weisheit und der Dank und die Ehre und die Macht und die Stärke gebühren unserem Gott in alle Ewigkeit. Amen.

7,13 Und es fing an einer der Ältesten und sagte zu mir:

Wer sind diese, die mit weißen Gewändern bekleidet sind, und woher sind sie gekommen?

7,14 Und ich sagte zu ihm: Mein Herr, du weißt es.

Und er sagte zu mir: Das sind die, welche aus der großen Bedrängnis kommen,

und sie haben ihre Gewänder gewaschen und weiß gemacht im Blut des Lammes.

37 In Kap. 14,1-5 ist ebenfalls von einer Gruppe von 144.000 Geretteten die Rede. Wenn man damit ernst macht, dass 144.000 eine Symbolzahl ist, dann müssen beide Gruppen nicht schon aufgrund derselben „Zahlenangabe“identisch sein. In Kap. 14,1-5 ist nicht von „den“ 144.000 die Rede, so dass mit keinem Wort auf eine frühere Erwähnung der gemeinten Gruppe zurückverwiesen wird. Das spricht dafür, dass die 144.000 aus Kap. 14 nicht mit den hiesigen identisch sind. Tatsächlich wird diese Vermutung in Kap. 14 bestätigt werden: Die dortigen 144.000 sind christliche Bekenner des 4. Jahrhunderts, die hiesigen aber jüdische Christen am Anfang des 2. Jahrhunderts (siehe Kommentar zu 8,6-9). 
7,15 Deshalb sind sie vor dem Thron Gottes

und dienen ihm tags und nachts in seinem Tempel.

Und der, der auf dem Thron sitzt, wird über ihnen wohnen.

7,16 Sie werden nicht mehr hungern und dürsten.

Sonne und Hitze werden ihnen nicht mehr schaden.

7,17 Denn das Lamm in der Mitte des Thrones

wird sie führen zu den Quellen der Gewässer des Lebens.

Und Gott wird jede Träne abwischen aus ihren Augen.

\section{Auslegung}

7,9 Danach sah ich, und siehe: eine große Schar, die niemand zählen konnte, aus jeder Nation und allen Stämmen und Völkern und Sprachen stand vor dem Thron und vor dem Lamm.

Hier sieht JOHANNES Gerettete AUS ALLEN VÖLKERn, im Gegensatz zum zweiten Teil der Vision, wo er nur gerettete Israeliten gesehen hatte. Dass diese Schar UNZÄHLBAR ist, verdient hervorgehoben zu werden und muss düsteren Visionen von einer über alle Maßen vollen Hölle entgegengehalten werden (siehe auch die gigantischen Ausmaße des „himmlischen Jerusalem“ in 21,16). Diese Schar steht VOR DEM THRON UND VOR DEM LAMM, d. h. im Himmel.

Die WEISSEN KLEIDER sagen aus, dass die damit Bekleideten eine vollkommene Reinheit der Seele erlangt haben und der Gottesschau teilhaftig geworden sind (siehe Kommentare zu 3,4-5 und 6,9-11). Unter ihnen dürften auch die Märtyrer sein, die unter dem Altar gewesen waren und dort das weiße Gewand erhalten hatten (5. Siegelvision).

Die PalmzWeige sind in der Bibel Zeichen des Sieges und des Jubels (vgl. Neh 8,15, 1 Makk 13,51, 2 Makk 10,7, Joh 12,13). Später bildete man die heiligen Märtyrer mit einer Palme in der Hand ab, und so wurde die Palme speziell das Zeichen des Martyriums. Aber diese Bedeutung dürfte die Palme zur Zeit des JOHANNES noch nicht gehabt haben. Daher handelt es sich hier nicht nur um Märtyrer, wie manche annehmen, sondern um alle Heiligen, die als Sieger über die Sünde im Himmel triumphieren.

7,10 Und sie rufen mit lauter Stimme und sagen:

Die Rettung liegt bei unserem Gott, der auf dem Thron sitzt, und dem Lamm.

7,11 Und alle Engel standen im Kreis um den Thron und die Ältesten und die vier Wesen und fielen nieder vor dem Thron auf ihre Gesichter und beteten Gott an.

7,12 Und sie sagten: Amen. Das Lob und die Herrlichkeit und die Weisheit und der Dank und die Ehre und die Macht und die Stärke gebühren unserem Gott in alle Ewigkeit. Amen.

Dieser Lobpreis erinnert an den Jubelruf „Hosianna“ (Gott rette!), den die Leute einst mit Palmzweigen in den Händen beim Einzug JESU in die Stadt Jerusalem anstimmten (Joh 12,13).

7,13 Und es fing an einer der Ältesten und sagte zu mir:

Wer sind diese, die mit weißen Gewändern bekleidet sind,

und woher sind sie gekommen?

7,14 Und ich sagte zu ihm: Mein Herr, du weißt es.

Und er sagte zu mir: Das sind die, welche aus der großen Bedrängnis kommen.

Und sie haben ihre Gewänder gewaschen und weiß gemacht im Blut des Lammes.

Die Anrede MEIN HERR drückt die Ehrfurcht des Apostels vor einem schon verherrlichten Heiligen aus, was sich als Belegstelle zugunsten einer berechtigten christlichen Heiligenverehrung anführen lässt. Im Lichte dieser Stelle darf 1 Kor 8,5-6 (,es gibt viele Herren, aber wir [Christen] haben ... nur einen Herrn: Jesus Christus“) nicht so ausgelegt werden, wie es manche radikalen Protestanten tun: 
dass man nämlich nur Christus, aber keinen Heiligen und keine andere menschliche Autoritätsperson als „mein Herr“ anreden dürfe. ${ }^{38}$

Die GROSSE BEDRÄNGNIS ist im weiteren Sinne eine Feindschaft vonseiten der Welt, welche die Kirche während der ganzen Zeit ihres Bestehens mehr oder weniger intensiv zu spüren bekommt. Im engeren Sinne aber ist es die letzte Verfolgung, mit der die Menschheitsgeschichte abschließt (vgl. Apk 20,7-9), denn in Dan 12,2 wird diese Verfolgung als die größte von allen beschrieben.

Da es heißt, dass die große Schar aus der Bedrängnis KOMMT (nicht: „,gekommen ist“"), ist die Schar in Bewegung: Sie zieht in einer feierlichen Prozession in den Himmel ein.

Die Schar hat IHRE Kleider Im Blut Des LAmmes Gewaschen, d. h. sie wurde durch Christi Sühnetod von Sünden gereinigt. Das passt nicht nur zu Märtyrern, sondern zu allen Heiligen, die ja alle nach durch Christi Blut ,erkauft“ wurden $(5,9)$.

7,15a Deshalb sind sie vor dem Thron Gottes und dienen ihm tags und nachts in seinem Tempel.

Hier wird erstmals klar von einem himmlischen TEMPEL gesprochen (vgl. 6,9, 8,3, 11,19, 15,5-8). Die große Schar dient Gott TAGS UND NACHTS, d. h. ununterbrochen. Da es aber in Kap. 21-22 heißt, dass es in der Zeit nach dem Endgericht weder einen Tempel $(21,22)$ noch Nacht geben wird $(21,25,22,5)$, muss sich diese Vision immer noch auf die Zeit vor dem Endgericht beziehen: auf die Zeit der ,großen Bedrängnis“, d. h. auf die Jetztzeit zwischen Jesu Auferstehung und dem Weltende, und besonders auf die Zeit der letzten großen Kirchenverfolgung, in der gewisse Heilige schon im Himmel sind.

7,15b Und der, der auf dem Thron sitzt, wird über ihnen wohnen.

7,16 Sie werden nicht mehr hungern und dürsten.

Sonne und Hitze werden ihnen nicht mehr schaden.

7,17 Denn das Lamm in der Mitte des Thrones

wird sie führen zu den Quellen der Gewässer des Lebens.

Und Gott wird jede Träne abwischen aus ihren Augen.

Während bis Vers 15a von der Glückseligkeit der leibfrei im Himmel befindlichen Heiligen die Rede war, zeigt der Übergang zur Zukunftsform hier, dass in Versen 15b-17 von einer späteren Epoche die Rede ist. Die Erwähnung des Fernseins von Hunger, DuRst und HitzE (was für leibfreie Seele ja selbstverständlich ist) dürfte ebenfalls darauf hinweisen, dass hier von der Zeit nach der leiblichen Totenauferstehung am Ende der Weltgeschichte die Rede ist (zur geistigen und leiblichen Auferstehung siehe Kommentar zu 21,4).

\footnotetext{
38 Noch lieber weisen Gegner der Heiligenverehrung auf Jesu Wort Mt 23,8-10 hin, wo Jesus seine Jünger ermahnt, sie sollen sich nicht „Rabbi“, „Vater“ und „Lehrer/Führender“ nennen lassen. Wer dies im Sinne eines absoluten Ehrenbezeugungs-Verbots gegenüber allen Menschen versteht, kennt das Neue Testament nicht wirklich. Es geht Jesus hier darum, solche Ehrentitel in einem absoluten und höchsten Sinn nur Gott und Christus vorzubehalten, nicht aber darum, sie denjenigen Menschen, denen sie in einem relativen Sinn gebühren, völlig abzusprechen. Denn es gibt es zahlreiche Stellen im Neuen Testament, welche zeigen, dass Jesus selbst und die nach dem Evangelium lebenden Apostel und Mitglieder der damaligen Kirche sehr wohl Autoritätspersonen und verehrten Gerechten (wie etwa den Eltern und führenden Persönlichkeiten in der Kirche, aber auch dem Abraham, David, Paulus, Johannes usw.) solche Titel zusprachen, und zwar durchaus auch im Sinne einer religiösen Ehrfurchtsbezeugung: Zur legitimen Anrede „Vater“vgl. etwa Mt 19,19; Lk 2,33; 2,48; Apg 3,13; Apg 4,25; Röm 4,11; Röm 4,16; 1 Kor 4,15; 1 Thess 2,7; 1 Thess 2,11; 1 Tim 5,1; Phlm 10; Jak 2,21; 1 Joh 2,13-14; vgl. Gal 4,19; 1 Tim 1,18; 2 Tim 2,1; 1 Joh 2,1; zum legitimen Gebrauch eines Lehrertitels vgl. Apg 13,1; 1 Kor 12,28-29; Eph 4,11; 1 Tim 2,7; Jak 3,1. Im Hebräerbrief (Kap. 13, Verse 7, 17 und 24 ) ist schließlich von den „Führenden“ in der Kirche die Rede. Siehe zu dieser Thematik auch meine kurze Abhandlung Ist es schriftwidrig, einen Menschen, Vater' zu nennen? auf der Seite http://catholic-church.org/ao/ps/Vater.html.
} 
Das WASSER DES Lebens muss eine lebensspendende Kraft sein, welche die Heiligen erfüllt und bewirkt, dass sie „Gott erkennen“, d. h. persönliche Gemeinschaft mit ihm erleben. Das Lebenswasser steht also für den Heiligen Geist und seine Wirkungen, besonders für das übernatürliche Glorienlicht, das zur Gottesschau befähigt (vgl. Psalm 36,10). Vgl. auch Joh 17,3: „Das ist das ewige LEBEN: dass sie (die Menschen) dich, den einzigen wahren Gott, ERKENNEN" (siehe zum Wasser des Lebens auch die Kommentare zu 21,6 und 22,1). Die Originalquelle dieses Wassers ist Gott (21,6), aber man kann diese Quelle in mehrere QUELLEN einteilen, weil es vieles in Gott zu „schauen“ gibt, und jedes einzelne dieser „Objekte“ der Gottesschau ist ein besonderer Grund zur Freude und macht die Heiligen in besonderer Weise „lebendig“.

CHRISTUS WIRD SIE zu diesen Quellen führen, d. h. er hat es noch nicht getan. Im leibfreien Zustand haben die Heiligen zwar in gewisser Weise schon Anteil am „Wasser des Lebens“, indem sie Gott schauen. Aber sie „leben“ im leibfreien Zustand noch nicht vollständig. In voller Weise haben sie daher erst dann Anteil am „Wasser des Lebens“, wenn sie auch leiblich wieder leben, und die lebensspendende Kraft der Gottesschau von der Seele auch auf ihren wiedererstandenen Körper übergreift.

\subsubsection{Apk 8,1-5: Siebtes Siegel (Vorbereitung auf das Blasen der Posaunen)}

8,1 Und als es (das Lamm) das siebte Siegel öffnete, entstand im Himmel ein Schweigen, ungefähr eine halbe Stunde lang.

8,2 Und ich sah die sieben Engel, die vor Gott stehen. Und es wurden ihnen sieben Posaunen gegeben.

8,3 Und ein anderer Engel kam und stellte sich an den Altar. Er hatte eine goldene Räucherpfanne. Und es wurde ihm viel Weihrauch gegeben, damit er die Gebete aller Heiligen auf dem goldenen Altar vor dem Thron Gottes darbringe.

8,4 Und es stieg der Rauch des Weihrauchs mit den Gebeten der Heiligen aus der Hand des Engels vor Gott auf.

8,5 Und der Engel nahm die Räucherpfanne und füllte sie mit dem Feuer des Altars. Und er warf es auf die Erde.

Und es erfolgten Donner und Stimmen und Blitze und ein Erdbeben.

\section{Auslegung}

8,1 Und als es (das Lamm) das siebte Siegel öffnete, entstand im Himmel ein Schweigen, ungefähr eine halbe Stunde lang.

Beim Öffnen des letzten Siegels hat Johannes keine Vision, die seine Himmelsvision überlagert, so wie es bei den anderen Siegeln der Fall war. Statt dessen herrscht nun eine HALBE StUnde STILLE, d. h. eine Zeit gespannter Erwartung: Denn jetzt ist das Buch offen und kann verlesen werden.

8,2 Und ich sah die sieben Engel, die vor Gott stehen.

Und es wurden ihnen sieben Posaunen gegeben.

Hier beginnen die Vorbereitungen für die Verlesung des Buches, dessen Inhalt durch PosAUnEN bekanntgemacht werden soll. Zur Posaune als Instrument der Gerichtsankündigung und als Untermalung der Stimme Gottes vgl. auch Joel 2,1 und Ex 19,16, 19,19.

Die SIEBEN ENGEL sind die „sieben Geister“ aus 1,4 und die „,sieben Feuerfackeln vor dem Thron Gottes" aus 4,5. 
8,3 Und ein anderer Engel kam und stellte sich an den Altar. Er hatte eine goldene Räucherpfanne. Und es wurde ihm viel Weihrauch gegeben, damit er die Gebete aller Heiligen auf dem goldenen Altar vor dem Thron Gottes darbringe.

8,4 Und es stieg der Rauch des Weihrauchs mit den Gebeten der Heiligen aus der Hand des Engels vor Gott auf.

Der ANDERE ENGEL kann nicht CHRISTUS selber sein, weil dieser ja als Lamm vor JOHANNES steht. Also handelt es sich um einen Engel im eigentlichen Sinne. So zeigt sich hier die Gebetsvermittlung der Engel, welche die GEBETE DER HEILIGEN (der noch auf Erden lebenden Christen) zu Gott tragen. Parallel dazu hat 5,8 gezeigt, dass neben Engeln auch himmlische Heilige, nämlich die 24 Ältesten, diesen Mittlerdienst ausüben.

Bei dem zuerst genannten ALTAR handelt es sich um den Brandopferaltar außerhalb des Tempels, unter dem JoHANNES vorher die Seelen der Märtyrer gesehen hatte $(6,9)$. Von dort nimmt der Engel Weihrauch, und geht dann in den Tempel zum GOLDENEN ALTAR vOR DEM THRON GotTes, der dem Rauchopferaltar des jüdischen Tempels entspricht (siehe Kommentar zu 6,9). Dort bringt er die „Gebete der Heiligen“ dar. Wir sehen hier die Engel als Zelebranten einer priesterlichen Liturgie im Himmel wie schon zuvor in 5,8 und später wieder in 15,5-16,1.

Die vorliegende Schriftstelle ist (zusammen mit 5,8) eine neutestamentlich-christliche Grundlage für die Verwendung von Weihrauch im Gottesdienst. Diesen Brauch hat die Kirche also keineswegs aus dem alttestamentlichen Judentum oder gar aus dem Heidentum entlehnt.

8,5 Und der Engel nahm die Räucherpfanne und füllte sie mit dem Feuer des Altars.

Und er warf es auf die Erde.

Und es erfolgten Donner und Stimmen und Blitze und ein Erdbeben.

Wie der Engel die Gebete der Heiligen nach oben weiterleitet, so leitet er auch den Zorn Gottes nach unten weiter. Er schreitet vom Rauchopferaltar wieder nach außen, hin zum großen Brandopferaltar. Von dort nimmt er FEUER (das Feuer der dort geistig brennenden „Opfertiere“, nämlich der geschlachteten Märtyrer) und wirft es auf die Erde. Das bedeutet, dass nun die Bitte der Märtyrer (6,9-11) in Erfüllung geht, indem das ihnen angetane Unrecht vergolten wird.

Donner, STIMmEn und Blitze untermalen die göttliche Gegenwart in ihrem furchterregenden Aspekt (Kommentar zu 4,5). Das ERDBEBEN ist Symbol der gewaltigen Veränderungen, die durch das nun beginnende göttliche Gericht erfolgen werden. 


\subsection{Apk 8,6 - 11,19: Das Blasen der sieben Posaunen}

Sieben Engel lösen nun durch Posaunenstöße die Verwirklichung der in dem geheimen Buch verzeichneten Ereignisse aus (dabei ist anzunehmen, dass das Lamm ihnen das Buch vorliest, da nach 5,3-9 nur das Lamm die dazu erforderliche Würde hatte). Handelt es sich um

- Ereignisse kurz vor dem Weltende (endgeschichtliche Deutung), oder um

- Ereignisse der gesamten nachchristlichen Zeit (kirchengeschichtliche Deutung), oder um

- Ereignisse, die sich bald nach der Veröffentlichung der Apokalypse abspielen (antik-geschichtliche Deutung)?

Am meisten überzeugend ist meines Erachtens die antik-geschichtliche Deutung. Denn sie kann sich darauf berufen, dass die Apokalypse nach 1,1 hauptsächlich darüber informieren will, ,was bald geschehen muss“, und dass zwischen der letzten Posaune und dem Weltende noch die „tausend Jahre“ von Kap. 20,4-6 vergehen müssen. Gegen die antikgeschichtliche Deutung wird zwar angeführt, dass PAULUS in 1 Kor 15,50 (vgl. 1 Thess 4,15) die ,letzte Posaune“ als das Startzeichen für die allgemeine Totenauferstehung am Ende der Zeiten beschreibt. Aber es gibt keinen zwingenden Grund dafür, dass der „letzte“ Posaunenstoß bei PAULUS mit dem siebten Posaunenstoß der Apokalypse identisch sein muss. Die Posaunen lösen bei JoHANNES folgende Visionen aus:

a) Naturkatastrophen, die indirekt gegen die Menschen gerichtet sind:

1. Posaune: Feuerhagel zerstört $1 / 3$ der Bäume und das Gras

2. Posaune: Feuerberg zerstört $1 / 3$ des Meeres

3. Posaune: Feuerstern zerstört $1 / 3$ der Flüsse

4. Posaune: zerstört $1 / 3$ der Gestirne

a) Katastrophen, die direkt gegen die Menschen gerichtet sind:

5. Posaune $\quad(=1$. Weh): Heuschrecken führen einen geistigen Krieg gegen die Gottlosen

6. Posaune (=2. Weh): Kriegsheer und „,zwei Zeugen“ bereiten den Gottlosen auch körperliche Plagen

7. Posaune $\quad(=3$. Weh $)$ : Sieg über die Gottlosen

Die Zerstörungen werden immer gewaltiger: zuerst fällt Hagel vom Himmel, dann ein ganzer Berg, dann ein ganzer Stern, und schließlich sind sogar die Sterne selber betroffen. Die Zerstörungen haben auch einen immer näheren Bezug zum Menschen. Zuerst werden nur Pflanzen zerstört, die schnell wieder nachwachsen. Schlimmer ist das Verderben des Meeres, noch schlimmer aber das Verderben der Flüsse, da diese den Lebensraum des Menschen noch enger durchziehen als das Meer. Eine weitere Steigerung ist die Verfinsterung des Himmels, die niemand mehr übersehen kann. Den Höhepunkt aber bilden die drei letzten Posaunen (= die drei „Wehe“), deren Plagen sich direkt gegen die Menschen richten. Sind nun diese Visionen

- Symbole für konkrete Ereignisse, die sich einmalig hintereinander abspielen (konkrete geschichtliche Deutung),

- oder Symbole für allgemeine Plagen, die sich in der Geschichte immer wieder wiederholen (abstrakte Deutung)?

Die Schematik spricht zunächst für die abstrakte Deutung, aber es wird sich zeigen, dass die Posaunen sehr gut auf eine ganz konkrete Reihe von Ereignissen bezogen werden können. Das Schema der immer größer werdenden Plagen hat so ebenfalls einen guten Sinn: Die Plagen werden in einen Spannungsbogen eingeordnet, der auf die letzte Plage hinzielt. Tabellarisch lässt sich die im Folgenden begründete Deutung der durch die sieben Posaunen angekündigten Ereignisse so zusammenfassen: 


\begin{tabular}{|lll|}
\hline 1. Posaune: & Feuerhagel & = Niederschlagung des jüdischen Aufstandes 115-117 \\
2. Posaune: & Feuerberg & $=$ Niederschlagung des jüdischen Aufstandes 132-135 \\
3. Posaune: & Feuerstern & $=$ Verbitterung der Juden durch Bar Kochba 135 \\
4. Posaune: & Verdunkelung & $=$ das Licht Christi nimmt im Judentum ab (nach 135) \\
\hline 5. Posaune: & Heuschrecken & $=$ die Sekte Theodots (ca. 190 bis 268) \\
6. Posaune, Teil 1: & Reiterei & $=$ der Barbareneinfall ins römische Reich (ab 250) \\
6. Posaune, Teil 2: & Engel & $=$ die Vorbereitung auf weitere Vorhersagen \\
6. Posaune, Teil 3: & Zwei Zeugen & $=$ die Plagen durch verfolgte Christen (303-312) \\
7. Posaune: & & $=$ das Signal für die völlige Vernichtung des heidnischen Roms (312) \\
\hline
\end{tabular}

Wie sich zeigen wird, leiteten die ersten vier Posaunen das Unheil ein, welches das Judentum heimsuchen wird, während die letzten drei Posaunen (= die drei „Wehe“) gegen das heidnische Römische Reich gerichtete Katastrophen verkünden, und zwar in folgender Abfolge:

(1) die Heuschreckenplage wütet gegen solche Heiden, die den Christen scheinbar nahe standen; diese fielen den Heuschrecken, nämlich einer scheinchristlichen Irrlehre, zum Opfer;

(2) die Plage der Reiterheere und der zwei Zeugen ist gegen Heiden gerichtet, welche die Christen aus politischen Gründen verfolgten, also in einem schärferen Gegensatz zu den Christen standen als die in (1) genannten Heiden;

(3) die Vernichtung Roms schließlich richtet sich gegen Heiden, welch die Christen aus religiöser Überzeugung hassten und deshalb ihre schärfsten Gegner waren.

Insgesamt waren also die Posaunen Signale für die Besiegung der ersten beiden großen Gegner des Christentums: der antichristlichen Mächte im Judentum und im römischen Heidentum der ersten Jahrhunderte.

\subsubsection{Apk 8,6-9: Erste und zweite Posaune (jüdische Aufstände 115-135)}

Text

8,6 Und die sieben Engel, welche die sieben Posaunen haben, machten sich bereit, um in die Posaune zu blasen.

8,7 Und der erste blies in die Posaune.

Und es entstand Hagel und Feuer, gemischt mit Blut, und (dies) wurde geworfen auf die Erde.

Und der dritte Teil der Erde verbrannte.

Und der dritte Teil der Bäume verbrannte.

Und alles grüne Gras verbrannte.

8,8 Und der zweite Engel blies in die Posaune.

Und es wurde etwas wie ein großer Berg, der im Feuer brannte, ins Meer geworfen.

Und es wurde der dritte Teil des Meeres zu Blut.

8,9 Und es starb der dritte Teil der Geschöpfe im Meer, die Seelen haben.

Und der dritte Teil der Schiffe wurde vernichtet.

\section{Auslegung}

Zu den SIEBen Engeln siehe Kommentar zu 1,4c. - Die erste Posaune bringt eine Plage über ERDE und BÄUME, und die zweite bringt Unheil über das MEER. Dass mit diesen Plagen Katastrophen gemeint sind, die über das Volk Israel kamen, lässt sich wie folgt aus dem weiteren Kontext erschließen. In 7,3-4 hatte es geheißen: „Fügt der Erde und dem Meer und den Bäumen keinen Schaden zu, bis wir die Knechte unseres Gottes auf ihrer Stirn mit dem Siegel gekennzeichnet (= getauft) haben. Und ich hörte die Zahl der Versiegelten: 144.000 .. . aus jedem Stamm der Söhne Israels“. Folglich müssen die Plagen über Erde, Bäume und Meer (= erste und zweite Posaune) die Israeliten bedrohen, und zwar die ungetauften, so dass die 144.000 getauften verschont bleiben. 
Zur konkreten geschichtlichen Identifizierung dieser Plagen können wir des Weiteren voraussetzen, dass sie nach der Veröffentlichung der Offenbarung (also nach 95 n. Chr.) kommen sollten, denn die Stimme hatte in 4,1 zu JOHANNES gesagt: „Ich will dir zeigen, was danach geschehen muss.“ Andererseits können wir aber nicht allzu weit über das Jahr 95 hinausgehen, da es in 1,1 hieß, es solle offenbart werden, ,was bald geschehen muss.“ Zu suchen sind also zwei Katastrophen des jüdischen Volkes, von denen getaufte Juden verschont wurden, und die bald nach $95 \mathrm{n}$. Chr. über das Judentum hereinbrachen. Die fünf größten Katastrophen in der Geschichte des Judentums sind nun aber folgende:

1. 587/6 v. Chr.: Der babylonische König NEBUKADNEZAR zerstört Jerusalem samt dem Tempel und führte große Teile des Volkes nach Babylonien.

2. 70 n. Chr.: Der römische Feldherr Titus zerstörte Jerusalem samt dem neu erbauten Tempel, der seitdem nicht wieder aufgebaut worden ist. ${ }^{39}$

3. 115-117 n. Chr.: Die Juden in Ägypten, Cyrene, Zypern und Mesopotamien erhoben sich gegen die Römer. Wie DiO CASSIUS berichtet, ${ }^{40}$ riefen sie in Cyrene einen ANDREAS zu ihrem König aus und ermordeten unter seiner Führung 220.000 ihrer Mitbürger, während sie in Zypern unter der Führung eines gewissen ARTEMION 240.000 Menschen niedermachten. Auf beiden Seiten kam es zu einem grausamem Vernichtungskampf, und schließlich ließ Kaiser TRAJAN die Aufstände durch seine Feldherrn MARCIUS TURBO und LusiUs QuIETUS niederschlagen. Turbo rückte mit Fußsoldaten, Kriegsschiffen und Reiterei an und tötete in einem langwierigen Krieg Zehntausende von Juden in Cyrene und Ägypten, während Quietus mit barbarischer Grausamkeit den Befehl des Kaisers ausführte, die Juden aus der Provinz Mesopotamien „,wegzufegen““41 Am Ende wurden die Juden aus Zypern vertrieben, und in Ägypten und Cyrene war das Judentum ,bis zur Bedeutungslosigkeit dezimiert““42

4. 132-135 n. Chr.: Die Juden in Palästina, die während der Provinzaufstände der Jahre 115-117 relativ ruhig geblieben waren, unternahmen einen letzten Aufstand gegen die Römer unter der Führung von BAR KOCHBA, der sich als Messias ausgab. Dieser Aufstand wurde von Kaiser HADRIAN durch seinen Feldherrn JULIUS SEVERUS niedergeschlagen. DIO CASSIUS berichtet, dass dieser Krieg ganz Judäa nahezu in eine Wüste verwandelte, wobei 50 Festungen und 985 Dörfer zerstört wurden und 580.000 Juden im Kampfe fielen, nicht mitgerechnet diejenigen, die durch Hunger und Krankheit umkamen. ${ }^{43}$ Am Ende wurden die noch lebenden Juden scharenweise in die Sklaverei verkauft, ${ }^{44}$ Jerusalem wurde als rein heidnische Stadt mit dem Namen „Aelia Capitolina“ neu errichtet und den Juden wurde streng verboten, diese Stadt jemals wieder zu betreten. ${ }^{45}$ Man kann von der größten Katastrophe in der antiken jüdischen Geschichte sprechen.

5. 1939-45 n. Chr.: Tötung von 6 Millionen Juden durch die Nationalsozialisten unter HitLER. (sog. Holocaust)

Man sieht, dass die 3. und 4. Katastrophe (und nur diese beiden) die genannten Bedingungen erfüllen, wenn man noch bedenkt, dass die getauften Juden in beiden Fällen dem Unheil weitgehend entronnen sind, da sie sich nicht an den Kämpfen gegen die Römer beteiligt hatten. ${ }^{46}$ So kommen wir zu dem Ergebnis, dass die erste Posaune sich auf den jüdischen Aufstand von 115-117 und die zweite auf den BAR-KOCHBA-Aufstand von 132-135 bezieht.

Die Zahl 1/3, welche die Zerstörungen der 1. - 4. und der 6. Posaune beschreibt, steht für eine große Anzahl, die weder die Gesamtheit noch den größten Teil der Gesamtheit abdeckt. Man darf vielleicht von der ,Zahl des göttlichen Zorns“" sprechen: Da Gottes Barmherzigkeit größer ist als seine Strafgerechtigkeit, überlässt er wohl nie eine ganze Hälfte der Welt den Katastrophen. Deshalb dürfte das Drittel, der größte Bruch unterhalb der Hälfte, symbolisch das

39 Hierüber und über den vorhergehenden Jüdischen Krieg (66-70) berichtet ausführlich als Zeitzeuge der jüdische Geschichtsschreiber FLAVIUS JOSEPHUS in seinem Buch vom Jüdischen Krieg.

40 Dio CASsius, Römische Geschichte Buch 68 Kap. 32.

41 EusEBIUS, Kirchengeschichte 4,2.

42 Johann Maier, Das Judentum, Bindlach: Gondrom, 3. Auflage 1988, S. 248.

43 Dio CAssius, Römische Geschichte Buch 69 Kap. 14.

44 Hieronymus, In Hieremiam, zu Jer 31,15 (CCSL 74 S. 307); vgl. auch In Zachariam, Kommentar zu Sach 11,5 (CCSL 75 S. 851 ).

45 EusEBIUS, Kirchengeschichte 4,6.

46 Nach Paulus Orosius, Historiae adversus paganos Buch 7 Kap. 13,4 waren die Christen sogar von Bar Kochba ,gefoltert“ worden, da sie sich nicht mit den Aufständischen gegen die Römer zusammenschlossen. 
„größtmögliche Maß der göttlich zugelassenen Bestrafung“ bezeichnen.

Nach dem Blasen der ERsten Posaune (zu Beginn der Provinzaufstände im Jahre 115) sah Johannes Hagel und Feuer (ein Gewitter mit Hagel und Blitzen) niedergehen, und zwar BLutvermischt, d. h. Menschen tötend. Das erinnert an die 7. Plage Ägyptens (Ex 9,13-35). Der Hagel verheerte ALLES GRÜNE GRAS, nicht weil jeder Grashalm verbrannte (sonst wäre unverständlich, dass nur 1/3 DER BÄUME verbrannte), sondern weil alle Arten von Gräsern betroffen waren - im Gegensatz zur 7. Plage Ägyptens, die nur Flachs und Gerste traf, nicht Weizen und Spelt.

Diese Bilder kann man, wie wir sahen, auf die Strafexpedition der Römer gegen die aufständischen Juden zur Zeit Trajans (115-117) beziehen. Im dem TÖTENDEN FEuERHAGEL könnte man einen Beschuss mit brennenden Pfeilen sehen. Der Krieg vernichtete einen großen, aber nicht den größten Teil (= 1/3) der Nation (= ERDE) und ihrer Familien (= BÄUME), und er verbrannte ,alles grüne Gras“. GRAS steht für das Volk (Jes 40,7), GRÜNES GRAS also für das gerade „ausgesähte“, noch blühende Volk (vgl. Ps 90,5-6): für die Jugend, die „Hoffnung der Nation“. Diese Jugend war es, die kämpfte, und sie aufgerieben, so dass zunächst alle Hoffnung auf einen Sieg gegen die Römer zugrunde ging.

Nach dem Blasen der ZWEITEn Posaune (zu Beginn des Bar-Kochba-Aufstandes im Jahre 132) sah Johannes einen FEUERBERG ins Meer fallen, d. h. entweder eine glühende Erdmasse oder einen Feuerregen (so dass er keinen festen Berg, sondern „Berge von Feuer“ gesehen hätte). Der Feuerberg machte 1/3 des Meeres zu Blut, d. h. das Meerwasser wurde mit dem Blut getöteter Seeleute vermischt.

Hier ist die Niederschlagung des Bar-Kochba-Aufstandes (132-135) gemeint. Weil diese Plage größer war als die erste, wird sie als FEUERBERg geschaut, während die erste nur im FEUERHAGEL bestand. Der BERG steht für das römische Reich: Berge bezeichnen auch anderswo Weltreiche (in Dan 11,34 das messianische Reich, in Jer 51,25 das babylonische Reich, vgl. auch Sach 4,7). Das MEER ist Symbol für eine Volksmenge (vgl. 17,15), hier für die Masse des jüdischen Volkes. Warum ist aber das jüdische Volk hier das MEER, während es bei der 1. Posaune die „Erde“ war? Beim Bar-Kochba-Krieg waren die Verluste auf beiden Seiten so groß, dass sich die Kämpfenden gewissermaßen gegenseitig neutralisieren, so wie Feuer und Wasser: So ist es passend, dass für die Römer das Symbol des FeuERberges, für die Juden aber jenes der WASSERmasse gewählt ist. Von den ungeheuren Verlusten der Juden war schon die Rede, und die Römer mussten ihrerseits einen so großen Blutzoll zahlen, dass der Kaiser es nicht mehr wagte, in seinem Schreiben an den Senat die übliche Eingangsformel, dass „er und das Heer sich wohl befinde“, zu gebrauchen. ${ }^{47}$ Auf jüdischer Seite wurde ein großer Teil (EIN DRITTEL DER BESEELTEN GESCHÖPFE IM MEER) vernichtet. Die untergehenden SCHIFFE könnten für jüdische Heere oder jüdische Kultur stehen; aber sie könnten auch lediglich Untermalung der Meereskatastrophe sein, denn nicht alle Einzelheiten müssen unbedingt eine besondere Bedeutung haben.

Anmerkung zur Seelenlehre: Vers 9 spricht von Geschöpfen, die „Seelen HABEN“ (nicht: Seelen SIND, wie es anderswo heißt), so dass die Seele hier als Teil des Wesens und nicht als mit diesem identisch gesehen wird (vgl. auch 18,13).

\subsubsection{Apk 8,10-11: Dritte Posaune (Bar Kochba 135)}

Text

8,10 Und der dritte Engel blies in die Posaune.

Und es fiel ein großer Stern vom Himmel, brennend wie eine Fackel.

Und er fiel auf den dritten Teil der Flüsse und auf die Wasserquellen.

8,11 Und der Name des Sterns heißt „Der Wehrmut“.

Und es wurde der dritte Teil der Gewässer zu Wehrmut.

Und viele Menschen starben durch die Gewässer, weil sie bitter geworden waren.

Auslegung

Emil SCHÜRER, Geschichte des Jüdischen Volkes im Zeitalter Jesu Christi, Leipzig 1901 (Nachdruck Hildesheim: Olms, 1970), Band 1 S. 698; Dio CAssius, Römische Geschichte Buch 69 Kap. 14. 
JOHANNES sieht einen großen Kometen oder Meteoriten glühend auf die Erde fallen, der während seines Falls in viele Teile zerfällt, von denen einige in Quellen und Flüsse fallen und so das Wasser vergiften.

An der Spitze des bei der zweiten Posaune genannten jüdischen Aufstandes stand SIMON BAR KosEBA, der vom einflussreichen Rabbi AQIBA als Messias anerkannt wurde; Aqiba änderte seinen Name in KoCHBA bzw. BAR-KOCHBA, d. h. Stern bzw. Sternensohn um, und bezog die messianische Bileam-Prophezeiung Num 24,17 (,ein Stern wird aufgehen aus Jakob“) auf ihn. Damit verband sich unter den Juden die Hoffnung, er sei gleichsam ein „Stern“, der im göttlichen Auftrag vom Himmel herabgestiegen war, um dem bedrängten jüdischen Volk das Heil zu bringen. An diesen Pseudomessias glaubten sehr viele Juden und ließen sich von ihm zum fanatischen Kampf gegen die Römer anstacheln. Die getauften Juden folgten ihm aber nicht und wurden daher von seinen Anhängern blutig verfolgt.

Der vom Himmel gefallene Stern scheint also Bar Kochba zu sein, der mit einer gewissen Ironie hier als vom Himmel „fallender“ (und nicht herabsteigender) Stern bezeichnet wird. Während die zweite Posaune im Jahre 132 bläst und die Niederschlagung des jüdischen Aufstandes durch die Römer einleitet, markiert die dritte Posaune das Ende dieses Aufstandes (135), als BAR KochBA ums Leben kam: der Tod war die Vollendung seines Himmelsturzes, der ihn als falschen Messias entlarvte. Nach dem Desaster änderten die Rabbinen seinen Namen abermals und nannten ihn fortan Ben KozIBA, Sohn der Lüge. Der Stern fiel in die Flüsse und QuELlen, d. h. in die verschiedenen Teile des jüdische Volkes (zur Gleichung Gewässer = Volksmassen siehe 17,15), wobei DIE QUELLEN für die Bewohner des Stamm- und Mutterlandes stehen. Der Stern machte die Gewässer BITTER, d. h. er brachte über die Juden die Bitterkeit der Enttäuschung über den Pseudomessias, die Bitterkeit der Vertreibung aus Jerusalem, die Bitterkeit der Totenklage um so viele Gefallene und die Bitterkeit der Sklaverei, in welche sie verkauft wurden. Von den FLÜSSEN machte der Stern nur EIN DRITTEL bitter, aber er brachte Bitterkeit über ALLE QUELLEN OHNE EINSCHRÄNKUNG, d. h. über alle Juden, die in der Hauptstadt wohnten, weil ihnen nach dem Siege Hadrians das Betreten Jerusalems verboten wurde: „Noch im vierten Jahrhundert war ihnen nur einmal im Jahre, am Tage der Zerstörung Jerusalems ..., das Betreten der Stadt erlaubt, um an der Stelle des Tempels ihre Klagegebete verrichten zu können.“48

\subsubsection{Apk 8,12: Vierte Posaune (Verdunkelung Christi nach 135)}

\section{Text}

8,12 Und der vierte Engel blies in die Posaune.

Und es wurde geschlagen der dritte Teil der Sonne

und der dritte Teil des Mondes und der dritte Teil der Sterne,

so dass der dritte Teil von ihnen verfinstert wurde

und der Tag nicht mehr den dritten Teil seines Lichtes gab, und die Nacht desgleichen.

\section{Auslegung}

Die Sonne steht wieder für CHRISTus, der MOND für die Kirche und die STERnE für die Kirchenlehrer. Hier wird jedoch nicht (wie in 6,12-13) gesagt, dass der Mond blutrot wurde und die Sterne vom Himmel fielen: Die Gestirne wurden lediglich dunkler. Somit ist nicht von einer blutigen Kirchenverfolgung die Rede, sondern von einer Verdunkelung der wahren Bedeutung Christi, der Kirche und der Apostel. Sehen wir diese Posaune im Zusammenhang mit den vorhergehenden, dann drängt sich folgende Deutung auf: Nach 135 verloren die Juden immer stärker den Kontakt zum christlichen Glauben, der für sie noch unverständlicher wurde, als er es bereits im 1. Jh. der Fall gewesen war (vgl. 2 Kor 3,15 und Röm 11,24-25). Das hatte mehrere Gründe: Da sie nach 135 Jerusalem nicht mehr betreten durften, war fortan die Jerusalemer Ortskirche rein heidenchristlich und auch die Bischöfe von Jerusalem waren keine Juden mehr. Zweitens kamen Bibelübersetzungen in Umlauf, welche die christliche Interpretation bestimmter Stellen nicht

48 Emil ScHÜRER, Geschichte des Jïdischen Volkes im Zeitalter Jesu Christi, Leipzig 1901 (Nachdruck Hildesheim: Olms, 1970), Band 1 S. 703. 
mehr zuließen, ${ }^{49}$ und drittens besann sich das Judentum stärker auf und außerbiblische Traditionen und rabbinischen Auslegungen, die seit 135 in der Mischna zusammengestellt wurden und später in den Talmud eingingen. ${ }^{50}$

Die geistige Entfremdung der nichtchristlichen Juden vom Christentum ist die unheimlichste aller sie betreffenden göttlichen Zulassungen. Von ihr hat schon PAULus gesagt, dass sie erst in am Ende der Weltgeschichte aufgehoben werden wird (Röm 11,25-26): „Brüder, ihr solltet dieses Geheimnis wissen: Verstockung liegt auf einem Teil Israels, bis die Heiden in voller Zahl das Heil erlangt haben: (Erst) dann wird ganz Israel gerettet werden.“ Tatsächlich hat die christliche Mission unter den Juden seit den Zeiten BAR KocHBAS keinen nennenswerten Erfolg gehabt.

\subsubsection{Apk 8,13: Zwischenruf als Einleitung zu den letzten drei Posaunen}

Text

8,13 Und ich sah, und ich hörte, wie ein Adler in der Mitte des Himmelsraumes flog

und mit lauter Stimme sagte: Wehe, wehe, wehe den Bewohnern der Erde

wegen der übrigen Posaunenstimmen der drei Engel, die noch blasen sollen!

\section{Auslegung}

Der bis zur Mitte des HimmelsRaumes Aufsteigende Adler ist Symbol für eine die Gesamtheit des Erdkreises betreffende Botschaft. Die letzten 3 Posaunen werden also Plagen bringen, welche die ganze dem JOHANNES bekannte Erde, d. h. das ganze römische Reich, betreffen. Der Ausdruck BEWOHNER DER ERDE bezeichnet irdisch gesinnte, antichristlich eingestellte Menschen: Denn die Christen sind von den Plagen ausgenommen (vgl. 9,4 und Kommentar zu 11,9).

49 IRENÄUs wirft in Adversus Haereses 3,21,1 den jüdischen Übersetzern AQUILASchriftübersetzer und THEODOTION vor, den Jesaja-Text „siehe die Jungfrau wird empfangen“ mit „siehe die junge Frau wird empfangen“ wiedergegeben zu haben. AQUILA schrieb zur Zeit von Rabbi AQIBA unter Kaiser Hadrian (vgl. Emil SCHÜRER, Geschichte des Jüdischen Volkes im Zeitalter Jesu Christi, Leipzig 1901 (Nachdruck: Hildesheim: Olms, 1970), Band 3 S. 436), Theodotion soll nach der von EPIPHANIUS überlieferten Tradition unter Kaiser Commodus (180192) gewirkt haben; nach SCHÜRER soll er seine Übersetzung allerdings schon vor AQUILA angefertigt haben (ebd. S. 439-442).

50 Nach Hermann Strack und Günter Stemberger, Einleitung in Talmud und Midrasch, München: Beck, 7. Auflage 1982, S. 79 haben die Schüler von Rabbi AQIBA ,,dessen Traditionen ... nach dem Bar-Kochba-Aufstand“ zum „Grundstock“ der Mischna gemacht (vgl. ebd. S. 127-142). 


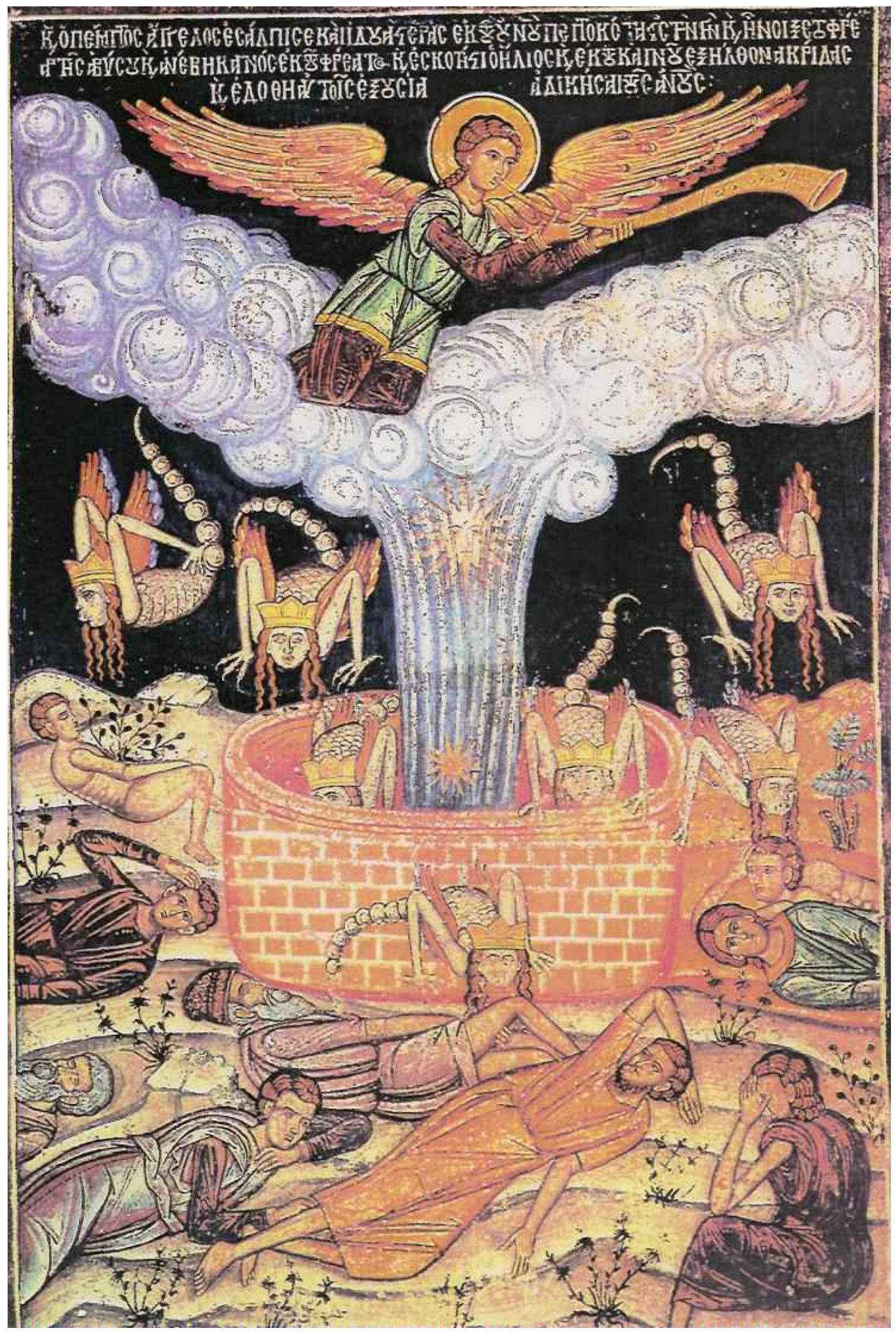

Die von der fünften Posaune ausgelöste Heuschreckenplage 


\subsubsection{Apk 9,1-12: Fünfte Posaune (die Sekte Theodots 190 bis 268)}

\section{Text}

9,1 Und der fünfte Engel blies in die Posaune.

Und ich sah einen Stern, der vom Himmel auf die Erde gefallen war.

Und ihm wurde der Schlüssel zum Schacht des Abgrunds gegeben.

9,2 Und er öffnete den Schacht des Abgrunds.

Und es stieg Rauch aus dem Schacht wie Rauch eines großen Ofens.

Und die Sonne und die Luft wurden verfinstert vom Rauch des Schachtes.

9,3 Und aus dem Rauch kamen Heuschrecken auf die Erde.

Und gegeben wurde ihnen Macht, wie sie die Skorpione der Erde haben.

9,4 Und es wurde ihnen gesagt,

dass sie nicht das Gras der Erde schädigen sollten noch jeden Baum,

sondern die Menschen, welche das Siegel Gottes nicht auf den Stirnen haben.

9,5 Und es wurde ihnen befohlen, sie nicht zu töten,

sondern sie zu quälen, fünf Monate lang.

9,6 Und in jenen Tagen werden die Menschen den Tod suchen,

und sie werden ihn nicht finden.

Und sie werden begehren zu sterben,

und der Tod flieht vor ihnen.

9,7 Und die Gestalten der Heuschrecken sind gleich Pferden,

die bereit gemacht sind für den Krieg.

Und auf ihren Köpfen war etwas, was goldschimmernden Kronen glich.

Und ihre Gesichter waren wie Gesichter von Menschen.

9,8 Und sie hatten Haare wie die Haare von Frauen, und ihre Zähne waren wie Zähne von Löwen.

9,9 Und sie hatten Panzer wie eiserne Panzer.

Und das Getöse ihrer Flügel war wie Getöse von vielen Wagen mit Pferden, die in den Krieg laufen.

9,10 Und sie haben Schwänze gleich denen der Skorpione und Stacheln.

Und in ihren Schwänzen ist ihre Macht zu schädigen die Menschen fünf Monate.

9,11 Und sie haben als König über sich den Engel des Abgrundes:

Sein Name lautet in hebräischer Sprache Abaddon,

in griechischer Sprache hat er den Namen Apollyon.

9,12 Das erste „Weh“ ist vorüber: Siehe es kommen noch zwei „Weh“ danach.

Auslegung

9,1 Und der fünfte Engel blies in die Posaune.

Und ich sah einen Stern, der vom Himmel auf die Erde gefallen war.

Und ihm wurde der Schlüssel zum Schacht des Abgrunds gegeben. 
Und er öffnete den Schacht des Abgrunds.

Und es stieg Rauch aus dem Schacht wie Rauch eines großen Ofens.

Und die Sonne und die Luft wurden verfinstert vom Rauch des Schachtes.

Unter dem ABGRUND versteht die Schrift zunächst die „Hölle“ im Sinne eines Strafortes, wie aus Lk 8,31 hervorgeht, wo gewisse Dämonen Jesus baten, „,dass er ihnen nicht befehle, in den Abgrund zu fahren.“ Der Abgrund ist aber zugleich, wie unser Abschnitt lehrt, die „Hölle“ im Sinne einer Brutstätte antichristlicher Einflüsse. Denn der „Rauch“, der aus dem Abgrund kommt, VERDUNKELT DiE Sonne, d. h. Christus (vgl. Kommentar zu 6,12). Der Rauch besteht also aus antichristlichen Gedanken. Diese VERDUnKELN, d. h. verschmutzten auch die LUFT. Damit ist in unübertreffbarer Weise ausgedrückt, dass jener antichristliche Rauch eine das Innere der Menschen (ihr Herz, ihre Gedanken) verschmutzende Wirkung hat, ebenso wie verschmutzte Luft durch die Atmung körperlich ins Innere der Menschen eindringt.

Wer ist nun der vom Himmel gefallene STERN, der den Abgrund aufschließt (Vers 1-2)? Es muss sich um eine Person (Mensch oder Engel) handeln, denn ein wirklicher Stern kann keinen Schlüssel betätigen. Johannes muss also mitten im Stern eine Person mit einem Schlüssel gesehen haben. Diese Sternenperson schloss den „Abgrund“ auf, woraufhin jener „Rauch“ christusverdunklender Inspiration herauskam. Das zeigt, dass es sich um eine böse, christusfeindliche Person handelt, und zwar um eine „Schlüsselperson“ im Reich des Bösen. Es gibt zwei hauptsächliche Auslegungen: Entweder der Stern ist ein Irrlehrer oder es ist Satan selber, der Anführer der bösen Engel (vgl. 12,7-8). Mir scheint jedoch die ersten Auslegung die wahrscheinlichere zu sein.

Die erste Auslegung ist naheliegend, weil auch bei der 3. Posaune mit dem gefallenen Stern ein Irrlehrer gemeint war. Auch der Judasbrief (Vers 13) nennt Irrlehrer ,,irrende Sterne“. Der hier gemeinte Irrlehrer lässt sich durch folgende Aussagen identifizieren:

Er ist erstens als „Schlüsselträger“ (Vers 1) Begründer einer Irrlehre.

Da die Sonne verfinstert wurde (Vers 2), kann man zweitens festhalten, dass er Christi Gottheit bestreitet, so wie es nach 8,12 auch die jüdische Irrlehre tat.

Drittens verfinstert er aber nicht Mond und Sterne (wie die jüdischen Irrlehren), d. h. er greift nicht direkt die Autorität der Apostel (Sterne) und der Kirche (Mond) an. So dürfte es sich um einen christlichen Irrlehrer handeln, der sich auf die Autorität der Apostel, der Bibel und der (früheren) Kirche beruft, so wie es christliche Sekten stets tun.

Viertens entfesselt er Heuschrecken, welche den Menschen schaden, die das Siegel Gottes nicht auf ihrer Stirn haben (Verse 3-4), d. h. die nicht durch die gläubig angenommene Taufe beschützt werden. Also überzeugen die Heuschrecken (d. h. die Prediger der Irrlehre) also vor allem Ungetaufte. Daher muss es sich um eine für wahre Christen leicht durchschaubare Irrlehre handeln.

Ein fünftes Merkmal ist, dass die Heuschreckenplage fünf Monate (Verse 5+10) dauert. Fünf Monate ist die Lebensdauer langlebiger Heuschrecken. Da diese Heuschrecken für Menschen stehen, entsprechen die fünf Monate vielleicht der Zeit eines langen Menschenlebens. In Psalm 90,10 werden 70-80 Jahre als die Höchstdauer eines Menschenlebens angegeben. So könnte es sich also um eine Irrlehre handeln, die etwa 70-80 Jahre Bestand hatte (zu anderen Geheimnissen der „fünf Monate“ siehe Kommentar zu Vers 5).

Sechstens muss der Irrlehrer wohl im 2. Jahrhundert oder bald danach gewirkt haben, da er einerseits erst nach den ersten vier Posaunen in Erscheinung tritt, die alle dem 2. Jahrhundert angehören, und da er andererseits nicht allzu lange nach der 4. Posaune kommen darf: Denn die Apokalypse beschreibt, „was bald geschehen muss" $(1,1)$. 
Alle diese Merkmale passen auf niemand anderen besser als auf den radikalsten rationalistischchristlichen Irrlehrer der ersten Jahrhunderte: THEODOT aus Byzanz. ${ }^{51}$ THEODOT war ein reicher, gebildeter Lederhändler (Schuster, Gerber) und zugleich ein angesehener christlicher Lehrer, der wegen seines Bekenntnisses in seiner Heimatstadt Byzanz ins Gefängnis kam (zwischen 161 und 180). Somit konnte THEODOT als ein „Stern“ bezeichnet werden, nicht nur um seiner Weisheit und Lehrtätigkeit willen, sondern auch, weil er zu den Bekennern gehörte, die um ihres Glaubens willen Leiden auf sich nahmen.

Aber als THEODOT sah, dass seine Mitgefangenen hingerichtet wurden, verleugnete er seinen Glauben und entkam so dem Tod. Weil er daraufhin von seinen Glaubensbrüdern geschmäht wurde, zog er nach Rom (um 190). Als er aber auch dort von einem Glaubensbruder erkannt und wegen seiner Nachgiebigkeit zur Rede gestellt wurde, rechtfertigte er sich, indem er sagte: „Nicht Gott habe ich verleugnet, sondern einen Menschen““52 Auf diese Weise kam er zu seiner Irrlehre, CHRISTUS sei nichts weiter als ein ,bloßer Mensch“ gewesen.

Um diese Behauptung zu stützen, bediente er sich einer Reihe geschickt ausgesuchter Schriftargumente, z. B. jener Stelle, wo CHRISTUS zu den Juden sagt: Nun wollt ihr mich töten, einen Menschen, der euch die Wahrheit sagt (Joh 8,40). „Du siehst also“, so soll THEODOT gesagt haben, „,dass er ein Mensch ist" ${ }^{53}$ Auch fügte er zur Rechtfertigung seiner Tat noch das Wort Christi hinzu: Wer etwas gegen den Menschensohn sagt, dem wird vergeben werden. Wer aber gegen den Heiligen Geist lästert, dem wird nicht vergeben werden. (Mt 12,32). So hatte THEODOT den Glauben an Christi Gottheit in Tat und Lehre verleugnet.

Er wurde vom römischen Bischof, Papst VICTOR, aus der Kirche ausgeschlossen, hatte jedoch zahlreiche Anhänger. In Rom stellten diese sogar einen Bischof auf, der mit ZEPHYRINUS, dem Nachfolger VICTORs, konkurrierte: das war jener NATALIS, der als erster „Gegenpapst“ in die Kirchengeschichte eingegangen ist. Die Anhänger THEODOTs beriefen sich auf die Apostel und verstiegen sich zu der Behauptung, dass die gesamte Kirche bis zur Zeit VICTORs die Lehre ThEODOTs vertreten habe. ${ }^{54}$ Sie fertigten eigene, auf ihre Lehre zugeschnittene Bibelabschriften an, die jedoch auch untereinander nicht übereinstimmten, ${ }^{55}$ und sie bedienten sich komplizierter Kunstgriffe bei der Schriftauslegung: „Hält ihnen jemand ein Wort der göttlichen Schrift vor“, so berichtete ein Zeitgenosse (Hippolyt von Rom), ,dann forschen sie darüber, ob dasselbe gestatte, den konjunktiven oder den disjunktiven Schluss anzuwenden“. 56

THEODOT hat die Würde Christi so radikal angegriffen, wie es nur wenige nach ihm gewagt haben. Daher war seine Irrlehre für wahre Christen besonders leicht zu durchschauen. Selbst ARIUS, jener gewaltige Gegner der katholischen Kirche im 4. Jahrhundert, der ebenfalls Christi Gottheit bestritt, hat nicht gewagt, CHRISTUS zum bloßen Menschen zu erklären, sondern hat ihn immerhin als den höchsten Engel bezeichnet.

THEODOT wurde zum Ausgangspunkt vieler Irrlehren der Folgezeit, vor allem des sogenannten Monarchianismus, deren Anhänger CHRISTUS nicht als dem Vater wesensgleiche göttliche Person anerkannten (vgl. Kommentar zu 1,4b), sondern ihn entweder als bloßen Menschen oder als Engel oder als personal identisch mit dem Vater ansahen.

Zum Folgenden vgl. vor allem EPIPHANIUS, Adversus Haereses, Häresie 34(54), PG 41 Sp. 961-972.

Zitat aus EPIPHANIUS, Adversus Haereses, Häresie 34(54), PG 41 Sp. 963-964.

Ebd.

EUSEBIUS, Kirchengeschichte 5,28,3-6.

EUSEBIUS, Kirchengeschichte 5,28,15-19.

EusEBIUS, Kirchengeschichte 5,28,13 (Zitat aus dem Werk eines Zeitgenossen, des Hippolyt). 
Die eigentliche Lehre Theodots jedoch wurde weitergeführt von den Melchisedekianern (unter Führung eines anderen, ebenfalls geschäftstüchtigen THEODOT mit dem Beinamen „,der Bankier“ oder „der Geldwechsler“") ${ }^{57}$ sowie von ASKLEPIODOT, APOLLONIADES, HERMOPHILUS und ARTEMON bis hin zu PAUl VON SAMOSATA, dem berüchtigten Bischof der syrischen Hauptstadt Antiochien, mit dessen Absetzung diese Irrlehre auf zwei Kirchenversammlungen in Antiochien (264 und 268 n. Chr.) wirkmächtig verurteilt wurde. So wurde die Irrlehre THEODOTs in ihrer ursprünglichen Form endgültig überwunden, in der sie ziemlich genau 80 Jahre lang bestanden hatte.

Allerdings trat ein wenig später eine ähnliche Lehre hervor, als aus den Reihen ehemaliger Anhänger des verurteilten Bischofs PAUL im 4. Jahrhundert der berühmte ARIUS hervorging, der die wahre Gottheit Christi ebenfalls bestritt, obgleich er Christus nicht als bloßen Menschen, sondern als den ersterschaffenen Engel betrachtete. Die Lehre des ARIUS konkurrierte noch bis ins 7. Jahrhundert mit der katholischen Lehre, und hat in moderner Zeit wieder ihre Vertreter in der Religionsgemeinschaft der ZEUGEN JEHOVAS gefunden, die sich interessanterweise selber mit den Heuschrecken identifizieren, die der vom Himmel gefallene Stern (der nach ihrer Auslegung JESUS CHRISTUS ist) entfesselt hat.

Die zweite Auslegung sieht im gefallenen STERN Satan. Dazu passt, dass Satan in Jes 14,12-15 als vom Himmel gefallenes Gestirn beschrieben wird, eine Stelle, die sich zunächst auf den verstorbenen „König von Babel“ (Jes 14,4) bezieht, aber auf einer tieferen Sinnebene den Teufel meinen kann: „Ach, du bist vom Himmel gefallen, du Morgenstern [lateinisch: Lucifer], Sohn der Morgenröte ... Du aber hattest in deinem Herzen gedacht: Ich ersteige den Himmel, dort oben stelle ich meinen Thron auf, über den Sternen Gottes ... Ich steige weit über die Wolken hinauf, um dem Höchsten zu gleichen. Doch in die Unterwelt wirst du hinabgeworfen, in die äußerste Tiefe." In der Tat gibt es einen mehrfachen „Himmelsturz“ Satans:

1. Sogleich nachdem der Teufel wie alle Geschöpfe Gottes als gutes Wesen erschaffen worden war, wurde er durch eigenen Willen böse: er ,sündigt von Anfang an“ (1 Joh 3,8) und ,war ein Mörder von Anfang an“ (Joh 8,44). Somit muss er bereits am Anfang der Schöpfung aus dem Himmel gestürzt worden sein (vgl. auch 2 Petr 2,4 und Jud 6-7), ${ }^{58}$ insofern mit „Himmel“ die Teilhabe an Gottes Liebe und Herrschaft gemeint ist.

2. Durch Christi Kommen wurde Satan in anderer Weise nochmals ,aus dem Himmel“ geworfen, („Himmel“ hier als Zustand scheinbarer Gottesähnlichkeit gedeutet), insofern Jesus kam, um „die Werke des Teufels zu zerstören“ (1 Joh 3,8) und die Macht des Teufels tatsächlich durch die Dämonenaustreibungen Jesu und seiner Jünger eingeschränkt wurde. Vgl. Jesu Wort Lk 10,18: „Ich sah den Satan wie einen Blitz vom Himmel fallen."

3. Besonders durch den Kreuzestod Christi erlitt Satan einen weiteren Himmelsturz, d. h. eine weitere Entmachtung. So sagte Jesus unmittelbar vor seinem Leiden: „Jetzt wird der Herrscher dieser Welt hinausgeworfen [Lesart: hinabgeworfen] werden“ (Joh 12,31), und nach Hebr 2,14 hat CHRISTUS den Teufel ,durch seinen Tod“ entmachtet.

Ein Argument dafür, dass an einen von diesen drei früheren Himmelstürzen Satans gedacht ist, glaubt man darin sehen zu können, dass JOHANNES hier nicht sagt: „Ich sah einen Stern fallen“, sondern: „Ich sah einen Stern, der [bereits in der Vergangenheit] vom Himmel gefallen war“. Doch dass Johannes den Stern als bereits früher Gefallenen daherkommen und den Abgrund aufschließen sah, passt ebenso gut zu einem Irrlehrer. Denn Irrlehrer brauchen meist viel Zeit, um sich nach ihrem Glaubensabfall ein neues Glaubenssystem zurechtzulegen. So war es auch bei THEODOT, dessen „Himmelsturz“ in die Jahre 161-180 fällt, während er seine Sekte erst um 190 gründete.

57 Die Melchisedekianer verehrten die geheimnisvolle Gestalt des Melchisedek (vgl. Gen 14,18-20; Ps 110,4; Hebr 5,6 und 5,10) als übermenschlichen Heilsvermittler, der eine ähnliches Werk unter den Engeln verrichtete wie Jesus unter den Menschen, und der ihrer Meinung nach größer ist als Jesus (der, wie sie glaubten, bloß ein Mensch war).

58 Auch Jes 14,12-15 hat man eine symbolische Anspielung an den anfänglichen Himmelsturz Satans gesehen. Doch dort ist die Rede davon, dass der Gestürzte vor seinem Fall ,alle Völker versklavte“ (Jes 14,12), weshalb hier wohl nicht an den anfänglichen Himmelsturz, sondern an eine spätere Entmachtung Satans zu denken ist, sei es an eine innergeschichtliche Entmachtung (Fall des babylonischen Reiches) oder an seine endgültige Entmachtung am Ende der Weltgeschichte. 
Ein anderes Argument für die Deutung des gefallenen Sterns auf Satan ist, dass in 9,11 der König der Heuschrecken DER ENGEL DES ABGRUNDS genannt wird, was für einen ENGEL spricht, ja für DEN bösen Engel schlechthin: Satan, den Höllenengel. Tatsächlich dürfte der 9,11 genannte „Engel des Abgrundes“ Satan sein. Aber: Es gibt keinen zwingenden Grund, den „gefallenen Stern“ aus 9,1 mit dem „Engel des Abgrundes“ aus 9,11 gleichzusetzen.

9,3 Und aus dem Rauch kamen Heuschrecken auf die Erde.

Und gegeben wurde ihnen Macht, wie sie die Skorpione der Erde haben.

Bei den HeusCHRECKEN handelt es sich eindeutig um christliche Verführer und Irrlehrer. Das zeigen folgende Details:

1. Sie SCHAdEN NiCht Pflanzen, sondern Menschen (Vers 4), sind also keine wirklichen Heuschrecken.

2. Ihre QUAL IST UNERTRÄGLICH, ABER TÖTET NICHT (Vers 5), ist also eine geistige Qual.

3. Sie scheinen zunächst harmlos zu sein, denn sie haben MENSCHENGESICHTER und FRAUENHAARE (Verse 7-8), wobei die Frauenhaare allerdings auch Verführung symbolisieren könnten; sind aber dennoch KRIEGSPFERDE (Vers 7) und somit auf heimtückisch-hinterhältige Weise gefährlich. Irrlehrer führen ihre Kriege nicht mit offener Gewalt, sondern sie versuchen, die Menschen anzulocken und durch Überredung und eher sanfte Verführung für sich zu gewinnen. Ihre Waffen sind versteckt, so wie auch diese Heuschrecken ihre Waffen hinter ihrem Rücken, nämlich in ihren SCHWÄNZEN tragen (Vers 10). Eine andere Waffe sind ihre LÖWENZÄHNE (Vers 8), die ebenfalls verborgen bleiben, solange sie den Mund geschlossen halten. Auch dass ihre Macht der Macht von SKORPIONEN gleicht (Verse 3 und 5), betont ihre Heimtücke.

4. Sie scheinen durch ihre Kronen $(9,7)$ zu den christlichen Siegern zu gehören, denn Kronen begegnen uns sonst nur bei den vierundzwanzig Ältesten und bei CHRISTUS selber (4,4, 4,10, 6,2, $14,14)$ sowie als Verheißung für alle Nachfolger CHRISTI $(2,10,3,11)$ und als Schmuck der verklärten „Frau“, welche die Kirche symbolisiert $(12,1)$. Durch die Kronen haben also die Heuschrecken ein christliches Gepräge. Aber die Kronen sind nur Scheinkronen (,etwas, was goldschimmernden Kronen glich"): Es sind Scheinchristen.

5. Ihre FlÜGEL RAUSCHEN WIE DAS DRÖHNEN VON SCHLACHTWAGEN (Vers 9). Sie gebrauchen die Flügel nicht zum Fliegen: nicht, um sich wirklich zu Gott zu erheben. Sie gebrauchen sie nur zum DRÖHNEN, d. h. zu leerem Gerede, zu streithaftem Disputieren über Gott.

6. Ihre EISENPANZERBRUST (Vers 9) versinnnbildet die Verhärtung ihres Herzens, dessen Undurchdringlichkeit und Verschlossenheit für das lebensrettende Wort Gottes.

7. Ihren wahren Charakter entlarvt der letzte Satz (Vers 11): Ihr König ist „,der Engel des Abgrundes“, also der Teufel.

9,4 Und es wurde ihnen gesagt, dass sie nicht das Gras der Erde schädigen sollten noch jeden Baum, sondern die Menschen, welche das Siegel Gottes nicht auf den Stirnen haben.

Die Prediger THEODOTs fallen nur die Nichtgesiegelten an. Zwar machen sie auch Gläubige der Kirche abtrünnig - aber im tiefsten Sinne gesiegelt sind eben nur die, die sich nicht durch eine so antichristliche Irrlehre wie die des THEODOT verführen lassen (vgl. 1 Joh 2,19), d. h. deren Taufgnade mit der Gnade der Beharrlichkeit verbunden ist.

Die in Kap. 7 beschriebene Siegelung betraf nur Israeliten, weil diese Siegelung eine Schutzmaßname vor einem Strafgericht gegen die Israel war. Daraus kann man nicht schließen, dass die Gesiegelten, die hier vor den Heuschrecken bewahrt werden, ebenfalls nur Israeliten sind; hier sind es offenbar getaufte und im Glauben gefestigte (gefirmte) Christen. 
9,5a Und es wurde ihnen befohlen, sie (die Menschen, die das Siegel nicht auf den Stirnen hatten) nicht zu töten, sondern sie zu quälen, fünf Monate lang.

Die FÜNF MONATE werden verschieden ausgelegt, vor allem sind drei Auslegungen zu besprechen, von denen die besseren Gründe m. E. für die erste sprechen.

1. Auslegung: Es ist die Dauer eines Menschenlebens. Denn Heuschrecken leben höchstens 4-5 Monate, und da die Heuschrecken Menschen sind, werden sie so lange auftreten, wie ein Menschenleben währt (d. h. 70-80 Jahre nach Psalm 90,10). Tatsächlich entspricht diese Zeit dem Auftreten der Anhänger des THEODOT (nämlich das Zeitintervall zwischen 190-268 n. Chr.) Passenderweise gilt die Zahl fünf auch als Zahl des Menschen oder Menschenlebens (wenngleich auch die Zahl sechs als Zahl des Menschen interpretiert werden kann, siehe den Exkurs zur Zahl 666 im Kommentar zu 13,18), denn das mit einer Spitze nach oben gestellte Petragramm (gleichmäßiges Fünfeck) ist ein altes Symbol für den Menschen, bei dem die obere Spitze den Kopf und die übrigen Spitzen Arme und Beine symbolisieren; außerdem hat der Mensch fünf Sinne (und Christus fünf Wundmale), und das menschliche Leben ist nach antiker Anschauung in fünf Perioden eingeteilt:

$\begin{array}{ll}\text { infantia } & =\text { Zeit des Kleinkindes (1-7 Jahre) } \\ \text { pueritia } & =\text { Kindheit }(7-14 \text { Jahre }) \\ \text { adolescentia } & =\text { Zeit des Heranwachsenden (14-21 Jahre) } \\ \text { iuventus } & =\text { Blütezeit des Erwachsenenalters } \\ \text { senectus } & =\text { Greisenalter }\end{array}$

Die 2. Auslegung besagt, dass die fünf Monate eine vergleichsweise kurze Epoche der Geschichte bezeichnen. Denn die Zahl fünf ist als Zahl der Finger einer Hand auch Zahl der geringen Menge: ein Symbol für das, was man „,an fünf Fingern einer Hand abzählen kann“. Vergleiche den Ausspruch Jesu: „Verkauft man nicht fünf Spatzen für ein paar Pfennig?“ (Lk 12,6). Ferner sind fünf Monate weniger als die Hälfte des Jahres. Da das ganze Jahr Symbol für „Vollendung“ sein kann, könnten fünf Monate für das noch gänzlich Unvollendete stehen: Es könnte stehen für „,nicht einmal halb so viel“", wie zur Vollendung notwendig ist. ${ }^{59}$

Nach dieser Deutung würden die Heuschrecken nur in einer relativ kurzen Geschichtsepoche auftreten, was nicht im Widerspruch zur ersten Auslegung stünde. Die erste Auslegung verdient aber m. E. den Vorzug, weil sie den fünf Monaten eine konkretere Bedeutung gibt.

Die 3. Auslegung besagt, dass fünf Monate die Zeit vom Auftreten der ersten Irrlehren bis zum Ende der Zeiten meint. Zur Begründung weist ALLO in seinem Kommentar darauf hin, dass Heuschrecken nach antiken hellenistischen Kalendern in den Monaten der TierkreisbilderKrebs (Juni/Juli) und Skorpion (Oktober/November) auftreten. Dass nun unsere Heuschrecken in den beiden Versen, wo von den fünf Monaten die Rede ist, mit Skorpionen verglichen werden (Verse 3,5b,10), soll darauf hinweisen, dass es sich um die Heuschrecken des Skorpion-Monats (Oktober/November) handelt. Vom Skorpion-Monat bis zum Jahreswechsel (der damals mit dem Frühlingsanfang März/April gleichgesetzt wurde) vergehen aber genau fünf Monate. Somit können die fünf Monate bedeuten: Die Irrlehre wird bleiben bis Ende des großen Weltenjahres (als welches man die gesamte Geschichte ansehen kann), d. h. bis zum Endgericht.

$59 \quad$ Allerdings kann die Fünf in manchem Kontext auch für eine Vollendung des Menschen stehen (wie wir in der 1. Auslegung sahen); und darüber hinaus auch für einen „Übervollendung oder Synthese oder Quintessenz der Natur“ (weil für die Natur die Zahl vier steht, wie wir in Exkurs 4 auf S. 48 sahen); so kann man zu den Gegenden der vier Himmelsrichtungen als fünfte Gegend etwa den Ort der Mitte hinzufüngen; Aristoteles fügte zusätzlich zu den vier irdischen Elementen ein fünftes, den Äther, für die Himmelskörper hinzu, während die Chinesen generell fünf irdische Elemente annahmen (Wasser, Feuer, Erde, Holz und Metall) und auch von fünf Jahreszeiten sprachen. Beachtlich ist in jedem Fall auch, dass es fünf platonische Körper gibt (siehe S. 49). 
Diese Deutung hat etwas für sich: Es könnte hier andeutet sein, dass es entweder die Irrlehren im Allgemeinen, oder auch im Besonderen die rationalistische Lehre des THEODOT, dass Christus nur ein bloßer Mensch war, in irgendeiner Form bis zum Ende der Weltgeschichte geben wird (in der Tat ist diese THEODOT'sche Überzeugung, obwohl sie der kirchlichen Lehre widerspricht, auch heute noch die mehr oder weniger offen vertretene Privatmeinung vieler Christen und sogar Theologen). Dass jedoch diese Deutung die hauptsächlich gemeinte ist, halte ich für unmöglich. Dem widerspricht Vers 12, wo von einem Ende der Heuschreckenplage die Rede ist, nach welchem noch zwei weitere Plagen kommen müssen. Ich bleibe also, wenigstens was den Literalsinn betrifft, bei der ersten Deutung.

9,5b Und ihre Qual ist wie die Qual eines Skorpions, wenn er einen Menschen sticht.

9,6 Und in jenen Tagen werden die Menschen den Tod suchen,

und sie werden ihn nicht finden,

und sie werden begehren zu sterben,

und der Tod flieht vor ihnen.

Dieser Satz beschreibt die größten Qualen bis zum Lebensüberdruss. Die Menschen wünschen die Erlösung durch den Tod, den ihnen aber diese Qualen nicht schenken, denn es sind geistige Qualen. Aber welche?

1. Auslegung. Die von den Irrlehrern Verführten, d. h. ihre Anhänger, werden bis zum Überdruss gequält: durch ihren unruhig gewordenen Geist, ihre Gewissensqualen, ihren Kräfteverbrauch bei der Gewinnung neuer Anhänger, die nur durch tausend Arten von künstlichen Argumenten geschehen kann, und schließlich dadurch, dass die von der Irrlehre infizierten den Geschmack am allein heilbringenden wahren Glauben verlieren und geistig dahinsiechen: Im Grunde ihres Herzens begehren sie den Tod, den die bloß geistigen Qualen aber nicht herbeiführen und den sie sich nach ihrer (in diesem Punkt mit dem wahren Glauben übereinstimmenden) Überzeugung auch nicht selbst geben dürfen.

2. Auslegung. Werden die Qualen unabhängig vom im Vorvers erwähnten Angriff der Heuschrecken gesehen, so betreffen diese Qualen allgemein „,die Menschen“ (nicht nur die Nichtgesiegelten). Denn die wahren Christen leiden ebenfalls an den Heuschrecken (wenn auch weniger stark als die von ihnen Verführten), weil sie die Schmähung der Wahrheit ertragen, nichtsnutzige Diskussionen über sich ergehen lassen müssen, Freunde und Verwandte ihnen durch die Irrlehre entfremdet werden usw. Sie wünschen sich dann ,zu sterben und bei CHRISTUS zu sein“, müssen aber um des Heiles ihrer Mitmenschen willen am Leben bleiben (vgl. Phil 1,21-25).

3. Auslegung. Man könnte die in diesem Vers beschriebenen Leiden sogar völlig unabhängig von den Heuschrecken sehen, d. h. so, dass ,in jenen Tagen“ die Menschen gequält werden, nicht nur von den Heuschrecken, sondern von den Zuständen der Welt in jener Zeit. Dies könnte man ebenfalls in der Zeit des Wirkens der Anhänger Theodots erfüllt sehen, die für das Römische Reich eine schwere Krisenzeit war.

Aber am wahrscheinlichsten ist die erste Deutung, denn die Zulassung der Heuschreckenplage ist dem Zusammenhang nach Teil des göttlichen Gerichts gegen die Nichtgesiegelten.

9,7 Und die Gestalten der Heuschrecken sind gleich Pferden,

die bereit gemacht sind für den Krieg.

Und auf ihren Köpfen war etwas, was goldschimmernden Kronen glich.

Und ihre Gesichter waren wie Gesichter von Menschen.

9,8 Und sie hatten Haare wie die Haare von Frauen, und ihre Zähne waren wie Zähne von Löwen.

9,9 Und sie hatten Panzer wie eiserne Panzer.

Und das Getöse ihrer Flügel war wie Getöse von vielen Wagen mit Pferden, die in den Krieg laufen. 
9,10 Und sie haben Schwänze gleich denen der Skorpione und Stacheln.

Und in ihren Schwänzen ist ihre Macht zu schädigen die Menschen fünf Monate.

9,11 Und sie haben als König über sich den Engel des Abgrundes:

Sein Name lautet in hebräischer Sprache Abaddon,

in griechischer Sprache hat er den Namen Apollyon.

Zur Gestalt der Heuschrecken und den FÜNF MONATE siehe Kommentar zu 9,3 bzw. zu 9,5a.

Der ENGEL DES ABGRUNDES ist Satan, denn der Artikel zeigt, dass es sich um „den“ bösen Engel schlechthin handelt. Satan wird hier also auch „Abaddon“ und „Apollyon“ genannt.

ABADDON (hebr.) bedeutet „Verderben“ und kommt im Alten Testament stets im Zusammenhang mit dem Tod vor. Vgl. Job 28,22 (,Abaddon und der Tod sprechen“) und Ps 88,11: „Wirst du an den Toten Wunder tun? Werden Totengeister aufstehen, dich zu preisen? Erzählt man im Grab von deiner Gnade? Von deiner Treue im Abaddon?"

Abaddon ist also „Engel des Todes“, was nur der Teufel sein kann: „Durch den Neid des Teufels kam der Tod in die Welt“ (Weish 2,24). „Er war ein Mörder von Anfang an“. (Joh 8,44). CHRISTUs kam, „um den zu entmachten, die die Gewalt über den Tod hat, nämlich den Teufel“ (Hebr 2,14).

APOLLYON (griech.) bedeutet „Zerstörer“, ist also in etwa eine Übersetzung von „Abaddon“. Der Name könnte eine Anspielung auf den Gott APOLLO sein, einen der damals meistverehrtesten Götter, angeblich der „Gott des Lichtes“, der sich zuweilen aber auch als Gott der Zerstörung betätigte.

9,12 Das erste „Weh“ ist vorüber: Siehe es kommen noch zwei „Weh“ danach.

Die drei WEH sind die Plagen der drei letzten Posaunen (siehe 8,13). Das erste Weh ist nun VORÜBER: Es umfasst also eine klar abgegrenzte Geschichtsperiode.

\subsubsection{Apk 9,13-21: Sechste Posaune, Teil 1 (Barbareneinfall ins Reich ab 250)}

9,13 Und der sechste Engel blies in die Posaune.

Und ich hörte eine Stimme von den vier Hörnern des goldenen Altars, der vor Gott steht,

9,14 zu dem sechsten Engel, der die Posaune hatte, sagen:

Binde die vier Engel los, die gebunden sind am großen Fluss Euphrat!

9,15 Und die vier Engel wurden losgebunden,

die bereit waren für die Stunde und den Tag und den Monat und das Jahr,

dass sie ein Drittel der Menschen töteten.

9,16 Und die Zahl der Truppen des Reiterheers war zwei Myriaden von Myriaden: Ich hörte ihre Zahl.

9,17 Und so sah ich die Pferde in der Erscheinung:

Die, die auf ihnen saßen,

hatten feuerrote und hyazinthfarbene (rauchblaue) und schwefelgelbe Panzer.

Und die Köpfe der Pferde waren wie die Köpfe von Löwen.

Und aus ihren Mäulern kamen Feuer und Rauch und Schwefel.

9,18 Von diesen drei Plagen wurde ein Drittel der Menschen getötet: vom Feuer und vom Rauch und vom Schwefel, der aus ihren Mäulern herauskam.

9,19 Denn die Macht der Pferde ist in ihrem Maul und in ihren Schwänzen: Denn ihre Schwänze sind wie Schlangen, die Köpfe haben, und mit ihnen schädigen sie. 
9,20 Und die übrigen der Menschen, die nicht durch diese Plagen getötet worden waren,

kehrten sich nicht ab von den Werken ihrer Hände,

um nicht mehr anzubeten die Dämonen und die Götzenbilder,

die goldenen und die silbernen und die kupfernen und die steinernen und die hölzernen,

die weder sehen können noch hören noch umhergehen.

9,21 Und sie kehrten sich nicht ab von ihren Mordtaten

noch von ihren Giftmischereien noch von ihrer Unzucht noch von ihren Diebstählen.

Auslegung

9,13 Und der sechste Engel blies in die Posaune.

Und ich hörte eine Stimme von den vier Hörnern des goldenen Altars, der vor Gott steht,

9,14 zu dem sechsten Engel, der die Posaune hatte, sagen:

Binde die vier Engel los, die gebunden sind am großen Fluss Euphrat!

Der GOldene AltaR, der Rauchopferaltar im himmlischen Tempel, der das Urbild des jüdischen Tempels ist, war schon in 8,3 erwähnt worden. Als VIER HÖRNER des Altars werden seine Ecken bezeichnet (Ex 30,2-3). Der Altar selber scheint hier den Befehl zum Losbinden der vier Engel zu geben, d. h. die an diesem Altar dargebrachten Gebete der Heiligen $(8,3)$ geben diesen Befehl.

Die VIER ENGEL, die nun LOSGEBUNDEN werden, sind böse Engel (Dämonen). Denn sie waren zuvor gebunden, d. h. in ihrer Betätigungsfreiheit eingeschränkt, was nur Dämonen zukommt (vgl. Tob 8,3, Mt 12,22-30, 2 Petr 2,4, Apk 20,1-3). Diese Engel werden am EuPHRAT losgebunden, d. h. sie bringen vom Euphrat her neues Unheil über die „Bewohner der Erde“.

Tatsächlich begann zwischen 253 und 260, als die Zeit der fünften Plage sich ihrem Ende näherte, eine neuartige Plage. Persische Truppen marschierten über den EUPHRAT, die Ostgrenze des Römischen Reiches. Die vier Dämonen betätigten sich also zugleich als Schutzgeister der Perser und als Schadensdämonen der Römer, indem sie dem persischen Heer den Weg über den Euphrat bahnten. Ohne es zu wollen, dienten sie jedoch dem Plan Gottes, weshalb sie vom 6. Engel und vom Gebet der Heiligen am himmlischen Altar, also von guten Mächten, „losgebunden“ wurden.

9,15 Und die vier Engel wurden losgebunden,

die bereit waren für die Stunde und den Tag und den Monat und das Jahr,

dass sie ein Drittel der Menschen töteten.

Bisher waren die Perser durch den Euphrat vom römischen Reich abgeschlossen gewesen. Kleinere Überfälle hatten die römischen Soldaten immer schnell und erfolgreich abgewehrt.

Das änderte sich unter der Regierung des Kaisers VALERIAN (253-260), als die Perser erstmals durch ausgedehntere Feldzüge römisches Gebiet verheerten, indem sie nach Syrien, Kilikien und Kappadozien einmarschierten. Valerian zog ihnen entgegen, aber dabei geschah das unerhörte: Der römische Kaiser 259 wurde selbst gefangengenommen.

Damit endete die vorletzte der großen römischen Christenverfolgungen, die Valerian in Gang gesetzt hatte. Die Gefangennahme dieses Christenverfolgers wurde von den Christen als befreiender Eingriff Gottes gefeiert und versetzte zugleich den Römern einen schweren Schock. Valerian wurde von den Persern an den Hof ihres Königs SAPOR (SCHAPUR I.) gebracht und dort außerordentlich brutal behandelt. Der Geschichtsschreiber OROSIUS berichtet:

„Vom persischen König Sapor gefangen genommen alterte der Kaiser des römischen Volkes in würdelosester Knechtschaft bei den Persern. Er wurde lebenslang zu einem infamen Dienst verdammt: Er musste sich auf den Boden bücken und dem König beim Besteigen des Pferdes statt der Hand den Rücken hinhalten."60

60 Paulus Orosius, Historiae adversus paganos Buch 7 Kap. 22,3-4. 
Nach dem Bericht des LAKTANZ ließ SAPOR schließlich den VALERIAN töten, indem er befahl, ihm die Haut abzuziehen. Die abgezogene Haut wurde rot gefärbt und in einem Tempel ausgestellt zum Andenken an den Triumph über einen einst so großen römischen Fürsten. ${ }^{61}$

Von diesem Schock sollte sich Rom nicht mehr erholen. Von nun an kam es immer häufiger zu Raubüberfällen der Perser und anderer Barbaren, die Rom immer mehr schwächten und schließlich zu Fall brachten. Durch die Barbaren ließen also die vier Dämonen-Engel EIN DRITTEL (d. h. einen großen, aber nicht den größten Teil) der Menschen, vor allem der Römer, töten.

9,16 Und die Zahl der Truppen des Reiterheers war zwei Myriaden von Myriaden: Ich hörte ihre Zahl.

Die MYRIADE bezeichnete die Zahl 10.000. Demnach sah Johannes ein Heer von 200.000.000 (zweihundert Millionen) Reitern. Das ist die größte in der Bibel genannte Zahl! Der Ausdruck ZWEI MYRIADEN VON MYRIADEN kann jedoch auch (wie das deutsche „Vieltausendmal Tausend“) einfach eine riesige Zahl meinen (vgl. 5,11).

Die Armeen der Perser waren für ihre große Stärke und ihre hervorragenden Reiter berühmt. So hatte einst der persische König Xerxes im 5. Jahrhundert v. Chr. laut Herodot ein Heer von etwa einer Million Menschen gegen die Griechen aufgeboten: das größte Heer der Antike. Freilich war dieses Heer immer noch 200 mal kleiner gewesen als das hier beschriebene. So ist die übertragene Bedeutung „Vieltausend mal Tausend“ einer wörtlichen Auffassung vorzuziehen.

Andererseits kommt man der wörtlich genommenen Zahl näher, wenn JOHANNES hier zugleich alle Barbarenheere erblickte, die zu verschiedenen Zeiten über die Ostgrenze des Reiches (Euphrat, Donau und Rhein) in dasselbe eindrangen. Er würde dann die gesamten Barbareneinfälle der Völkerwanderung, an der Rom zugrunde ging, unter dem Bild der über den Euphrat einfallenden persischen Reiter gesehen haben, weil diese Reiter seit alters die am meisten gefürchteten Symbole des Schreckens waren.

Ein interessantes Faktum ist außerdem, dass die Anzahl von 200 Millionen Menschen der geschätzten Weltbevölkerung in den ersten Jahrhunderten entspricht. Daher könnte JOHANNES vielleicht die gesamte damalige Weltbevölkerung in Form eines gegen Rom gerichteten Reiterheeres geschaut haben: denn ein großer Teil der Bewohner der Erde waren damals irgendwie an der Völkerwanderung beteiligt, in der Rom zugrundeging.

9,17a Und so sah ich die Pferde in der Erscheinung:

IN DER ERSCHEINUNG, d. h. nicht in Wirklichkeit, hatten die Pferde folgende Eigenschaften.

9,17b Die, die auf ihnen saßen,

hatten feuerrote und hyazinthfarbene (rauchblaue) und schwefelgelbe Panzer.

Die Perser waren berühmt für ihre hier beschriebenen Panzerreitern, die sog. Kataphrakten. RAUCHBLAU, die Farbe polierten Metalls, war die eigentliche Farbe der Metallrüstung der Reiter. Diese funkelt aber je nach Sonneneinstrahlung auch RÖTLICH (feuerfarben) oder GELBLICH wie Schwefel.

9,17c Und die Köpfe der Pferde waren wie die Köpfe von Löwen.

Dies schien so, weil sich Pferde und Reiter in ihrer Kampfesleidenschaft wie Löwen gebärdeten, so dass ihre Gegner Löwenungeheuer vor sich zu haben glaubten.

61 LaKTAnZ, Von den Todesarten der Verfolger Kap. 5. Zum Abziehen der Haut durch SAPOR vgl. auch AGATHIAS,Historiae 4,23 (PG 88, Sp. 1518-1519). 
9,17d Und aus ihren Mäulern kamen Feuer und Rauch und Schwefel.

Der Atem der schnaufenden Rosse spiegelte sich in den Metallrüstungen und leuchtete in deren Farben (Vers 17b).

9,18 Von diesen drei Plagen wurde ein Drittel der Menschen getötet: vom Feuer und vom Rauch und vom Schwefel, der aus ihren Mäulern herauskam.

Die Menschen wurden durch die Angriffslust und Wildheit der Reiter getötet, welche die Rosse so zum Schnaufen brachte, dass Feuer, Rauch und Schwefel aus ihren Nasen und Mäulern hervorzukommen schien.

9,19a Denn die Macht der Pferde ist in ihrem Maul und in ihren Schwänzen.

Die Perser pflegten sowohl nach vorn als auch (wenn sie flüchteten) nach hinten vergiftete Wurfspieße abzuschießen, die daher aus den Mäulern und Schwänzen der Pferde hervorzukommen schienen.

9,19b Denn ihre Schwänze sind wie Schlangen, die Köpfe haben, und mit ihnen schädigen sie.

Die Schlangenköpfe entstanden dadurch, dass die Perser die Schwanzhaare ihrer Pferde an ihrem Ende zusammenbanden.

9,20 Und die übrigen der Menschen, die nicht durch diese Plagen getötet worden waren, kehrten sich nicht ab von den Werken ihrer Hände, um nicht mehr anzubeten die Dämonen und die Götzenbilder, die goldenen und die silbernen und die kupfernen und die steinernen und die hölzernen, die weder sehen können noch hören noch umhergehen.

Hier wird deutlich, dass die Reiter gegen eine götzendienende Gesellschaft vorgerückt waren: Das Strafgericht richtet sich nicht mehr gegen die Juden, sondern gegen das heidnische Rom. Wir sehen auch, dass diese Plage noch nicht zur endgültigen Besiegung des römischen Götzendienstes führte.

9,21 Und sie kehrten sich nicht ab von ihren Mordtaten

noch von ihren Giftmischereien noch von ihrer Unzucht noch von ihren Diebstählen.

In diesem kurzen Lasterkatalog (vgl. 21,8 und 22,15) werden MoRD (5. Gebot), Giftmischerei, UNZuCht (6. Gebot) und Diebstahl (7. Gebot) aufgezählt. Auffällig ist die zwischen dem 5. und 6. Gebot eingeschobene GIFTMISCHEREI. Im Griechischen steht hier „Pharmakeia“, was im guten Sinn „Herstellung von Medikamenten“, im schlechten Sinn aber „Herstellung von Giften“ bedeutet. Zu den von den „Giftmischern“ hergestellten Giften (Pharmaka) gehörten:

- Drogen,

- Aphrodisiaka (potenzsteigernde Liebeszaubermittel),

- sowie abtreibende und sterilisierende Tränke.

Die Verurteilung dieser Gifte scheint ein besonderes Anliegen der Apokalypse zu sein, da die Giftmischerei hier gleich viermal erwähnt wird (9,21, 18,23, 21,8, 22,15, außerhalb der Apokalypse aber nur Gal 5,20). Dabei lässt die Platzierung des Wortes zwischen Mord und Unzucht besonders an Gifte zur Abtreibung und (künstlichen) Verhütung denken (für beides wurden dieselben Tränke verwendet). Man kann dies also als eine biblische Verurteilung von Abtreibung und künstlicher Empfängniverherhütung mittels „Giften“ verstehen. 


\subsubsection{Apk 10,1-11: Sechste Posaune, Teil 2 (Vorbereitung auf weitere Weissagungen)}

Text

10,1 Und ich sah einen anderen starken Engel aus dem Himmel herabkommen, bekleidet mit einer Wolke.

Und der Regenbogen stand über seinem Haupt.

Und sein Angesicht war wie die Sonne.

Und seine Füße (waren) wie Feuersäulen.

10,2 Und er hatte in seiner Hand ein geöffnetes Büchlein.

Und er setzte seinen rechten Fuß auf das Meer, den linken aber auf das Land.

10,3 Und er rief mit lauter Stimme, wie ein Löwe brüllt.

Und als er gebrüllt hatte, redeten die sieben Donner und (erhoben) ihre Stimme.

10,4 Und als die sieben Donner geredet hatten, wollte ich aufschreiben.

Und ich hörte eine Stimme aus dem Himmel sagen:

Versiegle, was die sieben Donner geredet haben, und schreibe es nicht auf!

10,5 Und der Engel, den ich auf dem Meer und auf dem Land stehen sah, erhob seine rechte Hand zum Himmel.

10,6 Und er schwor bei dem, der in Ewigkeit lebt, der den Himmel geschaffen hat und das, was in ihm ist, und die Erde und das, was in ihr ist, und das Meer und das, was in ihm ist:

Es wird keine Zeit mehr sein,

10,7 sondern in den Tagen der Stimme des siebten Engels, wenn er in die Posaune blasen wird, dann ist vollendet das Geheimnis Gottes, wie er es verkündet hat seinen Knechten, den Propheten.

10,8 Und die Stimme, die ich vom Himmel her gehört hatte, hörte ich wieder mit mir reden und sagen: Geh hin, nimm das geöffnete Buch,

das in der Hand des Engels ist, der auf dem Meer und auf dem Land steht!

10,9 Und ich ging hin zu dem Engel und sagte ihm, dass er mir das Büchlein geben solle.

Und er sagte zu mir: Nimm und verschling es,

und es wird deinen Bauch bitter machen, aber in deinem Mund wird es süß sein wie Honig.

10,10 Und ich nahm das Büchlein aus der Hand des Engels und verschlang es.

Und es war in meinem Mund wie süßer Honig.

Und als ich es gegessen hatte, wurde es bitter in meinem Bauch.

10,11 Und sie sagten zu mir:

Du musst wieder weissagen über Völker und Nationen und Sprachen und Könige.

\section{Auslegung}

10,1 Und ich sah einen anderen starken Engel aus dem Himmel herabkommen, bekleidet mit einer Wolke.

Und der Regenbogen stand über seinem Haupt.

Und sein Angesicht war wie die Sonne.

Und seine Füße (waren) wie Feuersäulen.

10,2 Und er hatte in seiner Hand ein geöffnetes Büchlein.

Und er setzte seinen rechten Fuß auf das Meer, den linken aber auf das Land.

10,3a Und er rief mit lauter Stimme, wie ein Löwe brüllt.

JOHANNES ist nun anscheinend wieder vom Himmel auf die Insel Patmos zurückversetzt worden. Ein ANDERER STARKER ENGEL leitet hier eine neue Phase der Gerichtsverkündigung ein, so wie vom ersten ,starken Engel“ $(5,2)$ die erste Phase eingeleitet worden war. 
Der Engel ist IN WOLKEN GEHÜLLT. Wolken werden sonst mit Christus (1,7, 14,14-15) und seinen Zeugen $(11,12)$ in Verbindung gebracht; sie dürften die Zugehörigkeit zu Gott, dem himmlischen Vater symbolisieren, und somit den Engel als guten Engel ausweisen. Der REGENBogEN auf seinem Haupt erinnert an den Regenbogen über Gottes Thron (4,3): Der Engel ist also trotz aller bedrohlichen Züge vom Gott des Friedens gesandt. Ein GESICHT, STRAHLEND WIE DIE SONNE sah Johannes auch in der einleitenden Christusvision $(1,6)$, so dass einige diesen Engel mit CHRISTUS gleichsetzen. Aber es ist wohl wie in 5,2 ein echter Engel gemeint. Wegen seiner Angriffsstellung ist es vielleicht MICHAEL, der Fürst der himmlischen Heerscharen (siehe 12,7). Das strahlende Gesicht zeigt seine Verklärung durch das göttliche Gnadenlicht an. Die FÜSSE, die WIE FEUERSÄULEN waren, zeigen seine Macht an, die Feinde Christi zu zertreten und im Feuer zu verbrennen.

Der Engel hat den RECHTEN Fuss AUf DEM MEER und DEN LINKEN AUF DEM LAND, d. h. er ist im Begriff, das antichristliche Römische Reich zu zertreten, welches sowohl das Land wie auch das gesamte Mittelmeer beherrscht. Die Stellung des RECHTEN Fußes auf dem Meer deutet auch an, dass er in Richtung Rom aufbrechen will, da das offene Meer auf der Westseite von Patmos liegt, wo auch Rom gelegen ist. Er zeigt sich also in einer Angriffsstellung gegenüber Rom, und dazu passt, dass er WIE EIN LÖWE BRÜLLT.

Das BÜCHLEIN in der Hand des Engels ist wohl das Buch, das in 5,7 sieben Siegel hatte: es ist nun GEÖFFNET, weil das Lamm die Siegel entfernt hat, und es ist jetzt ein KLEINES Buch (,Büchlein“), weil ein Großteil schon verlesen wurde.

10,3b Und als er gebrüllt hatte, redeten die sieben Donner und (erhoben) ihre Stimme.

Zum Siebenfachen Donner siehe Psalm 29, in dem sieben Mal von der „Stimme des Herrn“ die Rede ist, die sich in einem Gewitter offenbart (vgl. auch Joh 12,27-33 und Ex 19,19). Der DonNER ist also „Gottes Stimme“, und offenbart hier die Fülle des göttlichen Zorns gegen Rom (SIEBEN ist Zahl der Fülle, vgl. den Kommentar zu 13,18).

10,4 Und als die sieben Donner geredet hatten, wollte ich aufschreiben.

Und ich hörte eine Stimme aus dem Himmel sagen:

Versiegle, was die sieben Donner geredet haben, und schreibe es nicht auf!

JOHANNES soll die Botschaft der Donnerstimme VERSIEGELn, d. h. in seinem Herzen verschließen. Hier zeigt sich, dass es Offenbarungen gibt, die nicht für die Allgemeinheit bestimmt sind: sogenannte „Privatoffenbarungen“. Der Grund für die Geheimhaltung könnte sein, dass die Donnerstimme so schlimme Verhängnisse offenbarte, dass das Wissen um sie den Christen erspart werden sollte, die nicht die gleiche Reife hatten wie JOHANNES. JOHANNES aber sollte darum wissen, um mit größerem Eifer den Glauben seiner Mitknechte zu stärken.

10,5 Und der Engel, den ich auf dem Meer und auf dem Land stehen sah, erhob seine rechte Hand zum Himmel.

10,6a Und er schwor bei dem, der in Ewigkeit lebt, der den Himmel geschaffen hat und das, was in ihm ist, und die Erde und das, was in ihr ist, und das Meer und das, was in ihm ist:

SCHWÖREN ist also erlaubt (siehe auch Mt 26,63-64, Röm 1,9, 2 Kor 1,23, Phil 1,8, Hebr 6,13-17, 7,20-21). Jesu Wort in Mt 5,35-37 (,schwört überhaupt nicht, ... euer Ja sei ein Ja und euer Nein ein Nein“; vgl. auch Jak 5,12), das manche Nichtkatholiken, vor allem aus dem radikal-protestantischen und evangelikalen Bereich, als ein allgemeines Schwurverbot auslegen, bezieht sich also nicht auf jegliches Schwören, sondern nur auf das Schwören im Alltag. Jesu Anliegen kann es demnach nicht gewesen sein, das Schwören zur feierlichen Bekräftigung (etwa vor Gericht oder in einer religiösen Zeremonie, wie sie hier der Engel vollzieht) zu verbieten, sondern den damals anscheinend verbreiteten Irrtum abzustellen, dass man meinte, im Alltag bei Aussagen, die man nicht mit einem Schwur bekräftigt hat, lügen zu dürfen (zum Verbot der Lüge siehe auch 14,5; 21,8, 21,27 und 22,15) 
10,6b Es wird keine Zeit mehr sein,

10,7 sondern in den Tagen der Stimme des siebten Engels, wenn er in die Posaune blasen wird, dann ist vollendet das Geheimnis Gottes, wie er es verkündet hat seinen Knechten, den Propheten.

Das Geheimnis GotTes ist die Kirche als ,,alle Völker sowie Himmel und Erde umfassende Gemeinschaft in Christus“, und besonders die Einbeziehung der „Heiden“ (Nichtjuden) in diese Kirche. So war den Ephesern, denen JoHANNES die Apokalypse zuschickte, das „Geheimnis Gottes“ bereits von PAULUS erklärt worden:

„Gott hat uns das Geheimnis seines Willens kundgetan ... Er hat beschlossen, ... in Christus alles zu vereinen, was im Himmel und auf Erden ist.“ (Eph 1,9-10). „Durch eine Offenbarung wurde mir das Geheimnis kundgetan ...: dass nämlich die Heiden Miterben sind, zu demselben Leib gehören (wie die Juden) und an derselben Verheißung in Christus teilhaben“ (Eph 3,3-6). Auch an Timotheus, den Bischof von Ephesus (1 Tim 1,3), schrieb PAULus: „Das Geheimnis des Glaubens ist groß: Christus wurde offenbart im Fleisch, gerechtfertigt im Geist, verkündet unter den Heiden, geglaubt in der Welt, aufgenommen in die Herrlichkeit“ (1 Tim 3,16). Und an die Kolosser: „Jenes Geheimnis, das seit ewigen Zeiten und Generationen verborgen war, wurde jetzt seinen Heiligen offenbart. Gott wollte ihnen zeigen, wie herrlich dieses Geheimnis unter den Völkern ist: Christus unter euch, die Hoffnung auf Herrlichkeit“" (Kol 1,26-27).

Die VolLENDUNG dieses Geheimnisses ist also ein weltgeschichtliches Ereignis, durch welches den Völkern der Weg zur Kirche geöffnet wurde. Das aber war das Ende der Verfolgungen und die Anerkennung des Christentums als erlaubte Religion durch KONSTANTIN, welche die Grundlagen dafür schuf, dass sich das Christentum zur größten und bedeutendsten Religion der Welt entwickeln konnte.

Diese Vollendung WURDE VON DEN PROPHETEN VORHERGESAGT: Diese sprachen nämlich von der Ablösung des Alten Bundes durch den Neuen (Jer 31,31), von der Einbeziehung der Heiden in das Heil (z. B. Jes 49,6) und von einem Sieg des Reiches Gottes über die heidnischen Reiche (Dan 2,44), was im Siege Konstantins seine bedeutendste politisch-innergeschichtliche Erfüllung fand.

Zwar haben diese Verheißungen (und hat darum auch das GEHEIMNIS GOTTES) auch eine nachgeschichtliche Vollendung, aber diese ist hier nicht gemeint (zumindest nicht im Literalsinn), denn von der nachgeschichtlichen Vollendung ist erst am Ende des Buches die Rede (ab Kap. 21). Dass nach dem Blasen der 7. Posaune KEINE ZEIT MEHR SEIN WIRD (Vers 6b), bedeutet also hier nicht, dass dann die Zeit aufhört und die Ewigkeit beginnt, sondern einfach, dass die 7. Posaune unmittelbar die Vollendung des Geheimnisses Gottes einleitet.

10,8a Und die Stimme, die ich vom Himmel her gehört hatte (vgl. Vers 4),

$10,8 \mathrm{~b}$ hörte ich wieder mit mir reden und sagen: Geh hin, nimm das geöffnete Buch, das in der Hand des Engels ist, der auf dem Meer und auf dem Land steht!

10,9 Und ich ging hin zu dem Engel und sagte ihm, dass er mir das Büchlein geben solle. Und er sagte zu mir: Nimm und verschling es, und es wird deinen Bauch bitter machen, aber in deinem Mund wird es süß sein wie Honig. 
10,10 Und ich nahm das Büchlein aus der Hand des Engels und verschlang es.

Und es war in meinem Mund wie süßer Honig.

Und als ich es gegessen hatte, wurde es bitter in meinem Bauch.

JOHANNES VERSCHLANG das Buch (vgl. Ez 3,1-3): eine Zeichenhandlung, welche die Verinnerlichung des Inhalts anzeigt. Das Buch war SEINEM MUND SÜSS WIE HonIG, d. h. die erste Kenntnis des Inhalts bereitete ihm Freude, wegen der Neuheit einer so gewaltigen und trotz vieler furchtbarer Einzelheiten trostreichen Botschaft. Aber der Inhalt wurde IN SEINEM BAUCH BITTER, da JOHANNES, nachdem er alles ,,verdaut“ hatte, die Last spürte, die mit der Aufgabe verbunden war, eine solchen Botschaft zu verkünden, die ja nicht überall Begeisterung auslösen konnte. Der Grund, warum JOHANNES erst jetzt das Buch verschlingen musste, ist der, dass der verbleibende Inhalt (d. h. der verbleibende Rest der Apokalypse) der wichtigste Teil ist, den JOHANNES besonders intensiv verinnerlichen sollte.

10,11 Und sie sagten zu mir:

Du musst wieder weissagen über Völker und Nationen und Sprachen und Könige.

Der „,starke Engel“ und die „Stimme vom Himmel“ (Verse 4 und 8) weisen JoHANNES darauf hin, dass er den Inhalt des verschlungenen Buches den Menschen predigen muss. Er tat dies auch schriftlich, durch Niederschrift von Apk, Kap. 11-22. Es wird nun die durch Kap. 10 unterbrochene Prophetie fortgesetzt. Sie war unterbrochen worden, weil JOHANNES nun die leidvolle Bedrängnis der Kirche schauen sollte, worauf er durch eine besondere Stärkung vorbereitet werden musste. 


\subsubsection{Apk 11,1-14: Sechste Posaune, Teil 3 (Plagen durch verfolgte Christen, 303-312)}

Text

11,1 Und mir wurde ein Rohr gleich einem Stab gegeben, wobei (mir) gesagt wurde: Steh auf und miss den Tempel Gottes und den Altar und die, die in ihm anbeten.

11,2 Und den Außenhof des Tempels lass aus und miss ihn nicht, denn er ist den Heiden gegeben. Und sie (die Heiden) werden die heilige Stadt zertreten zweiundvierzig Monate lang.

11,3 Und ich werde meine zwei Zeugen aufbieten. Und sie werden mit Säcken bekleidet zwölfhundertsechzig Tage lang prophetisch auftreten.

11,4 Diese sind die zwei Ölbäume und die zwei Leuchter, die vor dem Herrn der Erde stehen.

11,5 Und wenn jemand ihnen (den zwei Zeugen) Schaden zufügen will, kommt Feuer aus ihrem Mund heraus und verzehrt ihre Feinde. Und wenn jemand ihnen Schaden zufügen will, muss er sterben.

11,6 Sie haben die Macht, den Himmel zu verschließen, so dass während der Tage ihres prophetischen Auftretens kein Regen fällt. Und (sie haben) Macht über die Gewässer, sie in Blut zu verwandeln und die Erde mit jeder Plage zu schlagen, sooft sie wollen.

11,7 Und wenn sie ihr Zeugnis vollendet haben, wird das Tier, das aus dem Abgrund heraufkommt, mit ihnen Krieg führen und sie besiegen und töten.

11,8 Und ihr Leichnam wird auf den Plätzen der großen Stadt liegen, welche geistlich genannt wird Sodom und Ägypten, wo auch ihr Herr gekreuzigt wurde.

11,9 Und es sehen Menschen aus allen Völkern und Stämmen und Sprachen und Nationen ihren Leichnam drei Tage und einen halben (Tag), und sie lassen nicht zu, dass sie in ein Grab gelegt werden.

11,10 Und die Bewohner der Erde freuen sich über sie (die toten „Zeugen“) und frohlocken. Und sie werden einander Geschenke schicken, weil diese zwei Propheten die Bewohner der Erde gepeinigt hatten.

11,11 Und nach den dreieinhalb Tagen kam der Geist des Lebens von Gott her in sie hinein. Und sie stellten sich auf ihre Füße, und große Furcht fiel auf die, die sie sahen.

11,12 Und sie hörten eine laute Stimme aus dem Himmel zu ihnen sagen:

Kommt hier herauf!

Und sie steigen in der Wolke zum Himmel hinauf, und ihre Feinde sahen sie.

11,13 Und in jener Stunde geschah ein großes Erdbeben.

Und der zehnte Teil der Stadt fiel zusammen.

Und es wurden bei dem Erdbeben 7000 Menschen getötet.

Und die übrigen gerieten in Furcht und gaben dem Gott des Himmels die Ehre.

11,14 Das zweite „Wehe“ ist vergangen: Siehe das dritte „Wehe“ kommt bald.

\section{Auslegung}

11,1a Und mir wurde ein Rohr gleich einem Stab gegeben, wobei (mir) gesagt wurde:

Der RoHRSTAB, der JOHANNES gegeben wurde, ist, wie die Fortsetzung zeigt, kein Schreibrohr, sondern eine Messlatte. Wer es ist, der hier mit JOHANNES redet, wird nicht gesagt - es ist aber wegen des Ausdrucks ,meine Zeugen“ in Vers 3 vermutlich CHRISTUS.

11,1b Steh auf und miss den Tempel Gottes und den Altar und die, die in ihm anbeten. 


\section{1,2a Und den Außenhof des Tempels lass aus und miss ihn nicht, denn er ist den Heiden gegeben.}

JOHANNES dürfte hier eine Miniaturmodell des Tempels vor sich gehabt haben, um den herum sich der Tempelhof sowie ein Modell der Stadt Jerusalem befand. Der Jerusalemer Tempel hatte einen Innenhof, in dem der Brandopferaltar stand, und einen Außenhof, welcher die Grenze war, bis zu der heidnische Besucher vordringen durften. JOHANNES sieht diese beiden Höfe, und außerdem Figuren, welchen die Anbeter symbolisieren. Er wird nun aufgefordert, den TEMPEL und den ALTAR zu messen, wobei „Tempel“ hier für den Innenraum und „Altar“ für den Innenhof zu stehen scheint, in dem der Brandopferaltar stand. JOHANNES soll diese Bereiche ausmessen und die Anbeter in ihnen zählen. Den AusSENHOF aber soll er auslassen.

Der vor JohAnNes stehende TEMPEL symbolisiert die Kirche Christi, da der Jerusalemer Tempel bereits im Jahre 70 zerstört worden war. Die Übertragung des Ausdrucks „Tempel“ auf die Kirche begegnete uns schon in 3,12 und ist auch sonst im Neuen Testament bezeugt. So schrieb Paulus an die Korinther: „Gottes Tempel seid ihr“ (1 Kor 6,16, vgl. 2 Kor 6,16, Eph 2,21, Joh 2,19, Petr 2,5).

MESSEN und ZÄHLEN steht für die Fürsorge Gottes, von dem JESUS sagt, dass er bei den Erwählten sogar „die Haare auf dem Kopf gezählt“ hat (Mt 10,30). Eine solche Fürsorge kam auch bereits in Kap. 7,1-8 zum Ausdruck in der Zählung und Versiegelung der 144.000 Israeliten. Wie dort scheint auch hier von einer Bewahrung der Gläubigen die Rede zu sein, diesmal allerdings nicht eine Bewahrung vor dem körperlichen Tod (siehe 11,7), sondern eine Bewahrung in der Gnade des wahren Glaubens.

Der TEMPEL bis einschließlich des Innenhofes versinnbildet also die „Seele“ der Kirche, d. h. die Gesamtheit der Seelen der wahrhaft Gläubigen. Der AUSSENHOF und erst recht der Stadtbezirk außerhalb des Außenhofes ist dagegen der Bereich, der den HeIDEN (d. h. hier: den Feinden des Christentums) ZUM ZERTRETEN ÜBERLASSEN IST. Gemeint ist hier alles, was nur äußerlich zur Kirche gehört: die äußeren Kirchenbauten, die Leiber der Gläubigen und die Seelen derer, die nur dem Namen nach Christen sind. All dieses wird ZERTRETEN: Das deutet auf eine furchtbare Christenverfolgung hin, in der nur die engsten Anbeter Gottes standhaft bleiben.

Von welcher Christenverfolgung ist hier die Rede? Die zuletzt in der Prophetie beschriebenen Ereignisse fanden zur Zeit des VALERIAN um 253-260 n. Chr. statt, dessen Gefangennahme von den Persern die vorletzte römische Christenverfolgung beendete. Das lässt vermuten, dass nun die letzte Christenverfolgung im Mittelpunkt des Interesses steht: die sogenannte diokletianische Verfolgung.

Diese wurde etwa 10 Jahre lang (hauptsächlich in der Zeit von 303 bis 312) ${ }^{62}$ von mehreren nebenund nacheinander herrschenden Kaisern durchgeführt, an deren Spitze anfangs Kaiser DIOKLETIAN stand. Dies wird sich in den folgenden Versen bestätigen (siehe den Kommentar zu Vers 7 und 13b).

62 Klar ist, dass die Verfolgung am 23. Februar 303 mit ersten Maßnahmen begann und nach dem Verfolgungsedikt vom Frühjahr 304 (allgemeiner Opferbefehl für alle Christen) in voller Schärfe von Diokletian im Osten ebenso wie von seinem Mitkaiser Maximianus im Westen betrieben wurde. Über das Ende der Verfolgung aber kann man streiten. Manche lassen sie im Westen schon am 1. Mai 305 mit dem gemeinsamen Rücktritt von Diokletian und Maximianus enden. Aber die Anordnungen zur Christenverfolgung blieben auch im Westen weiterhin in Kraft, auch wenn sie von den Herrschern des Westens (Chlorus, Konstantin, Licinius, (Flavius) Severus, Maxentius) nicht so grausam in die Tat umgesetzt wurden wie von jenen des Ostens (Galerius, Maximinus Daja). Aufgehoben wurden die Verfolgungsgesetze erst durch das Toleranzedikt des Galerius, das dieser auf dem Totenbett am 30. April 311 erließ. Aber Galerius starb wenige Tage nach der Publikation (wohl am 2. Mai 311). Der bedeutendste Mann im Osten war fortan Maximinus Daja, der zuvor als Unterkaiser das Toleranzedikt widerwillig unterschrieben hatte, nun aber zu den früheren Verfolgungsmethoden zurückkehrte, während das Edikt für den Usurpator Maxentius in Rom ohnehin keine Bedeutung hatte. Nachrichten über konkrete Maßnahmen des Maxentius gegen Christen sind zwar fast keine erhalten (abgesehen davon, dass er Papst Marcellus I. ebenso wie dessen Nachfolger Eusebius 309 in die Verbannung schickte, angeblich um den Bußstreitigkeiten in der römischen Ortskirche ein Ende zu bereiten), aber er gehört als fanatischer Heide, Sohn des Verfolgers Maximinian (der ja mit Diokletian sogar Initiator der Verfolgungen gewesen war) und Verbündeter des Verfolgers Maximinus Daja auf die Seite der Verfolger. Die entscheidende Wende brachte daher der Sieg Konstantins über Maxentius am 28. Oktober 312, den Konstantin selbst auf die Hilfe des Christengottes zurückführte. Er befahl nach der Machtübernahme noch 312 auch dem Maximinus Daja, die Verfolgung einzustellen, was dieser aber nicht tat. Mit seinem Mitkaiser Licinius erweiterte Konstantin im Februar 313 das Toleranzedikt des Galerius durch die Mailänder Konvention. Diese konnte aber erst im ganzen Reich durchgesetzt werden, nachdem Licinius den Maximinus Daja am 30. April 313 im Kampf besiegte. Licinius, der nun im Osten herrschte, begann um 320 erneut mit einer Christenverfolgung, bis er am 18. September 324 von Konstantin in der Schlacht von Chrysopolis entmachtet wurde. Der entscheidende geschichtliche Einschnitt, der den Übergang von der Verfolgung zur Freiheit am deutlichsten markiert, bleibt aber der Sieg Konstantins am 28. Oktober 312. 
Die Kirche hatte seit der Besiegung Kaiser VALERIANs durch die Perser (260) eine vierzigjährige Friedenspause gehabt. ${ }^{63}$ Auch Kaiser DioKletian hatte seit seiner Ausrufung zum Kaiser (284) die Christen zunächst in Ruhe gelassen. Er verhielt sich ihnen gegenüber sogar freundlich und duldete, dass christliche Gotteshäuser gebaut wurden, so dass gegenüber seinem Palast in Nikomedien eine prächtige Kirche entstand. Die Zahl der Christen im Reich konnte während dieser Zeit stark ansteigen, bis auf mehrere Millionen Mitglieder. ${ }^{64}$

Völlig unerwartet begann DiOKLETIAN dann am 23. Februar 303 mit der letzten, längsten und blutigsten aller römischen Christenverfolgungen, indem er zuerst die Zerstörung aller christlichen Gotteshäuser befahl, angefangen mit der Kirche vor seinem Palast. Nicht unpassend beginnt also die Prophetie des JOHANNES über die diokletianische Verfolgung mit einer Zählung der inzwischen gewaltigen Schar der Gläubigen und mit der Aussage, dass nur das innere Heiligtum der Kirche bewahrt werden würde, während alles Äußerliche, angefangen mit den Gotteshäusern, dazu bestimmt war, der Verfolgung zum Opfer zu fallen.

11,2b Und sie (die Heiden) werden die heilige Stadt zertreten zweiundvierzig Monate lang.

Die diokletianische Verfolgung dauerte ca. zehn Jahre, genauer 122 Monate. Wieso ist dann hier von 42 Monaten „Zertretung“ die Rede? 42 MONATE entsprechen 31/2 JAHREN und 1260 TAGEN (wenn man, wie bei den Juden üblich, den ,,vollkommenen“ Monat mit 30 Tagen gleichsetzt).

Die Zeitangaben „42 Monate“, „1260 Tage“ und ,3 1/2 Jahre“ (zuweilen auch: „,3 1/2 Zeiten“) sind ein symbolisches Zeitmaß, das in der Prophetie die Dauer einer Verfolgung des Volkes Gottes angibt: so auch beim Propheten DANIEL (7,25), wo die 3 1/2 Jahre in der abstrakt-geheimnisvollen Formulierung „eine Zeit und zwei Zeiten und eine halbe Zeit“" auftauchen.

Die Zahl 3 1/2 ist Symbolzeit einer jeden Kirchenverfolgung, und zwar aus folgenden Gründen:

- Die Zahl 3 1/2 ist die Hälfte der Siebenzahl und wird darum auch als ,gebrochene Siebenzahl“ bezeichnet. Sieben aber ist (wie im Kommentar zu 13,18 gezeigt wird) die Zahl der Vollkommenheit. Daher bezeichnet die Dreieinhalb als Hälfte der Siebenzahl das Abgebrochene und ist insofern das Zeitmaß für jede Kirchenverfolgung, weil diese nie ihr Ziel erreicht, sondern immer mitten in ihrem Verlauf durch Gottes Eingreifen vorzeitig beendet wird (vgl. Mt 24,22).

- Die Zeit der 3 1/2 Jahre ist auch deshalb das symbolische Zeitmaß der Verfolgung, weil die erste umfassende religiöse Verfolgung des Volkes Gottes, die Verfolgung der Juden durch ANTIOCHUS EPIPHANES, bzw. genauer deren Höhepunkt, genau 3 1/2 Jahre dauerte (die genaue Chronologie ist umstritten, nach einem recht plausiblen Ansatz fiel der Höhepunkt der Verfolgung aber in den Zeitraum vom Sommer 169 bis Winter 166/165 v. Chr.). Diese Verfolgung war von DANIEL vorhergesagt worden, und zwar vermischt mit endzeitlichen Prophetien. Daher wurde sie in der jüdisch-christlichen Tradition das Urbild aller späteren Verfolgungen.

- 3 1/2 Jahre ist auch die Zeit, in welcher der Prophet EliAS zur Zeit einer Verfolgung der wahren Anbeter Gottes den Regen zurückhielt (Lk 4,25; Jak 5,17; darauf wird in Apk 11,6 angespielt).

- Auch JESUS hat ungefähr 3 1/2 Jahre öffentlich gepredigt und wurde in dieser Zeit verfolgt.

63 Diese Friedenszeit wurde „nur kurz durch die unbedeutende Verfolgung ... Aurelians ... unterbrochen“ (BIHLMEYER, Kirchengeschichte § 16.3, Band 1 S. 91). Das 275 erlassene Verfolgungsedikt Kaiser AURELIANs kam nämlich kaum zur Durchführung, da AURELIAN kurze Zeit später umgebracht wurde, und seine Nachfolger bis Diokletian dem Edikt keine Beachtung schenkten.

64 BIHLMEYER nennt vermutungsweise die Zahl von 7-10 Millionen Christen bei einer Gesamtbewohnerzahl des römischen Reiches von ca. 50 Millionen (Kirchengeschichte §16.3, Band 1 S. 93). 
Die Zahl 1260 hat ebenfalls eine Bedeutung, die sie zu einer ,antichristlichen“ Zahl macht: 1260 ist $36 \cdot 36-36$ oder $(6 \cdot 6) \cdot(6 \cdot 6)-(6 \cdot 6)$, d. h. lässt sich als mathematischer Ausdruck schreiben, in dem die Ziffer 6 genau 6 mal zur Anwendung kommt. Die Zahl 6 aber ist die Zahl des Antichristen: Denn da die Zahl 7 die Zahl der Vollkommenheit ist, ist 6 als „knapp verfehlte Siebenzahl“ (7 - 1) die Zahl der Scheinvollkommenheit (siehe zur Zahl sechs weiteres im Kommentar zu 13,18).

Man kann das Scheinvollkommene der Zahl 1260 auch wie folgt anschaulich machen. Sie entspricht dem Flächeninhalt einer aus 35 Quadraten der Seitenlänge 6 zusammengesetzten beinah-quadratischen Fläche, der zur vollen Quadratform genau ein Quadrat fehlt:

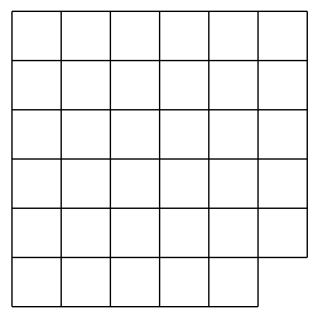

Schließlich zur Zahl 42, die ebenfalls eine entsprechende Symbolbedeutung hat (auch unabhängig von ihrer Eigenschaft, die Zahl der Monate von 3 1/2 Jahren zu sein):

- Denn 42 ist das Ergebnis der Multiplikation der Zahl der Vollkommenheit (=7) mit der Zahl der Scheinvollkommenheit (=6), was wiederum eine Scheinvollkommenheit ergibt. Auch die 42 ist also geeignet, eine Zeit des scheinbaren Triumphes der Teufels zu bezeichnen. Aus diesem Grund dürfte die Zahl 42 im Alten Testament als eine Art „Totenzahl“ gebraucht werden. Es ist jedenfalls auffällig, dass von den fünf biblischen Stellen, in denen die Zahl 42 vorkommt (Num 35,6, Ri 12,6, 2 Kön 2,24, 2 Kön 10,14, Neh 7,28), vier vom Tode handeln. Auch außerhalb der Schrift ist die 42 als negative Zahl bekannt: Im ägyptischen Totenbuch gibt es 42 Sünden und 42 Höllenrichter.

- Zugleich ist 42 die Zahl der „Zeit des Wartens auf den Messias“. Denn 42 ist die Zahl des Königs David, als dessen triumphaler Nachfolger ja der Messiaskönig erwartet und ersehnt wurde. Der Name „David“ kann nämlich im Hebräischen (in der Kurzform) durch eine Folge von drei Buchstaben geschrieben werden (Dalet-Waw-Dalet), und jeder dieser drei Buchstaben dient auch als Zahlzeichen (Dalet $=4$, und Waw $=6$ ), so dass die Zahlenwerte der Buchstaben von „David“ zusammenaddiert $(4+6+4)$ die Zahl vierzehn ergeben.

14 ist also eine „Davidszahl“, und wenn man diese mit 3 multipliziert (Multiplikation mit 3 bedeutet eindringliche Wiederholung), so ergibt sich 42. So ist auch 42 eine „Davidszahl“ und daher eine „Zahl des Wartens auf den Messias“. Dies wird dadurch bestätigt, dass der Evangelist Matthäus in seiner Liste der Vorfahren Christi genau 3 14 Generationen aufzählt, wobei er auf diese Einteilung extra hinweist (Mt 1,17), ihr also große Bedeutung beimisst. Eine weitere Bestätigung ist das dreimalige Opfer von 14 Opfertieren durch Bileam und Balak in 4 Mose 23,4, 23,14 und 23,29-30, jeweils verbunden mit einer messianischen Prophetie.

So ist die Zahl 42 (als 6*7) die ,Zahl des antichristlichen Scheintriumphs“ und zugleich (als 3*14) die „Zahl des Wartens auf den Messias Christus“. Beides passt zur Christenverfolgung. Denn in Verfolgungszeiten triumphieren scheinbar die antichristlichen Mächte, während zugleich die Christen verstärkt auf die Befreiung durch CHRISTUS hoffen, also das Kommen seines Triumphes erwarten.

11,3 Und ich werde meine zwei Zeugen aufbieten.

Und sie werden mit Säcken bekleidet zwölfhundertsechzig Tage lang prophetisch auftreten. 
11,4 Diese sind die zwei Ölbäume und die zwei Leuchter, die vor dem Herrn der Erde stehen.

Der SACK ist die traditionelle Bekleidung der Büßer, die sich vor Gott demütigen, um Vergebung ihrer Sünden sowie das Ende seines Zorns zu erlangen (vgl. Mt 11,21; Lk 10,13; Jona 3,6-8). Das PROPHETISCHE AUFTRETEN oder „prophezeien“ meint nicht unbedingt „die Zukunft voraussagen“, sondern ist allgemeiner ein Ausdruck für ein von Gott inspiriertes, den Glauben stärkendes Predigen: „Wer prophetisch redet ... baut auf, ermutigt, spendet Trost“ (1 Kor 14,4).

Wer sind aber nun diese ZWEI ZEUGEN Jesu, die als prophetische Bußprediger auftreten?

Nach der m. E. richtigen, kollektiven Auslegung bezeichnet der Ausdruck „zwei Zeugen“ die Gesamtheit aller hervorragenden Christen, die ihre Mitchristen während der Verfolgung gestärkt haben. Es gibt verschiedene Gründe, warum man hier gerade von ,zwei“ Zeugen sprechen könnte:

(a) Es können die zwei Stände der Christenheit gemeint sein: die Geistlichen und die Laien.

(b) Oder es sind „Zeugen“ (griech.: Märtyrer) im doppelten Sinn: Wortzeugen und Blutzeugen. Oder sie geben Zeugnis durch Wort und Beispiel. Oder predigen die Gottes- und Nächstenliebe.

(c) Oder es ist die aus zwei der Vereinigung von zwei Völkern (Juden und Heiden) hervorgegangene, mit dem Licht zweier Testamente (des alten und des neuen Testaments) erleuchtete Kirche. ${ }^{65}$

(d) Oder es sind ,zwei“ Zeugen genannt, um die rechtliche Gültigkeit ihrer Aussagen zu unterstreichen, da nach Dt 19,15 jede Gerichtssache durch zwei Zeugen bestätigt werden musste.

Von allen diesen Möglichkeiten scheint mir nur die erste vom Text her bestätigt zu werden. Denn es heißt Vers 4 über die zwei Zeugen: DIESE SIND DIE ZWEI ÖLBÄUME UND DIE ZWEI LEUCHTER, DIE VOR DEM HERRN DER ERDE STEHEN. Das ist der entscheidende Hinweis, der zur Identifizierung der zwei Zeugen führt. Denn es handelt sich hier um ein Zitat aus dem Propheten SACHARJA, der in einer Vision zwei Ölbäume links und rechts eines Leuchters gesehen hatte. „Was bedeuten die zwei Ölbäume auf der rechten und auf der linken Seite des Leuchters?“ so hatte SACHARIA den Engel Gottes gefragt (Sach 4,11). Darauf erhielt er die Antwort: „Das sind die beiden Gesalbten, die vor dem Herrn der ganzen Erde stehen“ (Sach 4,14). Mit den beiden „Gesalbten“ (es wurden geistliche und weltliche Oberhäupter zur Amtseinführung mit Öl gesalbt, daher das Bild der Ölbäume) aber sind im Sacharjabuch aber das geistliche und weltliche Oberhaupt des damaligen Judentums gemeint, nämlich der Hohepriester Jeschua (Sach 3,8) und der Fürst Serubbabel (Sach 4,9).

JESCHUA und SERUBBABEL waren besondere Werkzeuge Gottes, weil unter ihrer Führung das Volk aus der babylonischen Gefangenschaft zurückkehrte und im Jahre 520 v. Chr. der Wiederaufbau des zerstörten Tempels beginnen konnte. Die „zwei Zeugen“ in der Apokalypse entsprechen also dem Paar Jeschua/Serubbabel. Der eine „Zeuge“ ist demnach eine dem Hohepriester JeschuA entsprechende Gruppe: die treu zu ihrer Aufgabe stehenden Geistlichen. Der andere „Zeuge“ aber muss dann SERUBBABEL entsprechen: und das wäre die Gruppe der treuen Christen aus dem Laienstand. Wie JeschuA und SERUBbABEL das alte Volk Israel aus dem buchstäblichen Babylon geführt und den steinernen Tempel aus den Trümmern wieder erstehen ließen, so führen die „zwei Zeugen“ das Volk Gottes geistig aus dem Einflussbereich des neuen Babylon, nämlich des heidnischen Rom (vgl. Kommentar zu Kap. 17) heraus, und bauen den Tempel Christi wieder auf bzw. halten ihn instand, indem sie die Kirchengemeinden in der Verfolgung stärken.

Die individuelle Auslegung sieht demgegenüber in den zwei Zeugen genau zwei Männer. So denkt z. B. der Jesuit MarianA (17. Jh.) an die Apostel Petrus und PAUlus, die unter Nero in Rom den Märtyrertod starben. Aber dies kommt kaum in Betracht, da die neronische Verfolgung (64-68 n. Chr.) zur Zeit des Niederschrift der Apokalypse schon vergangen war.

65 So Beda Venerabilis, Explanatio Apocalysis, Kommentar 11,2, PL 93 Sp. 162. 
Die meisten Vertreter der individuellen Auslegung glauben, dass die zwei Zeugen erst kurz vor dem Weltende auftreten werden (eschatologisch-individuelle Deutung). In dem einen der beiden Zeugen sehen sie meist den wiedererstandenen Propheten ELIAS. Dieser ist nach 2 Kön 2,11 am Ende seines Lebens in den Himmel aufgefahren, und nach jüdischer Erwartung, die sich in Mal 4,5-6 sowie Sir 48,10 und Mt 17,11 niederschlägt, wird er vor dem Weltende als Bußprediger wiederkommen, um die Juden zu bekehren.

Aber es ist nicht sicher, ob ELIAS persönlich wiederkommen wird. JESUS sprach davon, dass im übertragenen Sinn „Elias schon gekommen“ sei (Mt 17,10-13), nämlich in JOHANNES DEM TÄUFER, der, wie das Lukasevangelium bezeugt, „,mit dem Geist und in der Kraft des Elias“ auftrat (Lk 1,17). Vielleicht kommt also ELIAS auch am Weltende nur im übertragenen Sinn. ELIAS ließ Feuer vom Himmel fallen und bewirkte, dass es drei Jahre nicht regnete (2 Kön 1,10.12; 1 Kön 17,1). Ähnliches tun auch die ,Zwei Zeugen“: Nach Vers 5 lassen sie Feuer vom Himmel fallen, und nach Vers 6 haben sie die Macht, Regen zurückzuhalten. Nach Vers 12 fahren sie schließlich wie EliAs in den Himmel auf. Es ist also zweifellos auf ELIAS angespielt. Aber diese Anspielungen müssen nicht so verstanden werden, dass einer der Zeugen ELIAS persönlich ist. Ebenso gut kann gemeint sein, dass die Zeugen „,im Geist und in der Kraft“ des ELIAS auftreten, wie dies auch JOHANNES DER TÄUFER tat.

Wer ist in der eschatologisch-individuellen Deutung der zweite Zeuge? Darüber herrscht große Uneinigkeit: Er wird z. B. mit HENOCH, MOSES oder JEREMIA gleichgesetzt.

HENOCH ist außer EliAS der einzige, von dem die Schrift sagt, dass er am Ende seines irdischen Daseins ohne zu sterben in den Himmel entrückt wurde (Gen 5,24; Hebr 11,5). Vergleiche dazu die Himmelfahrt beider „Zeugen“ in Vers 11. HENOCH hat das Endgericht Gottes vorausgesagt (Judasbrief, Verse 14-15) und wird in Sir 44,16 (in der griechischen Version und besonders in der Vulgataübersetzung) als ein (wiederkehrender, noch zu erwartender?) Bußprediger bezeichnet. Auch dies verbindet ihn mit EliAS. Da aber die Identität des ersten Zeugen mit ElIAS persönlich keinesfalls gesichert ist, ist erst Recht die Identität des zweiten Zeugen mit HENOCH fragwürdig.

Moses verwandelte einst in Ägypten Wasser in Blut (Ex 7,20, erste Plage Ägyptens). Dass dies nach Vers 6 auch die beiden Zeugen tun, ist für einige Ausleger eine Andeutung, dass MosES als Begleiter des EliAS auftreten wird. Sie können außerdem darauf hinweisen, dass das Paar „Moses und Elias“ auch bei der Verklärung JESU erscheint (Mt 17,3), kurz bevor JESUS von der Wiederkehr des ELIAS spricht (Mt 17,9-13). Aber man könnte die Anspielung an MosES auch einfach dahingehend verstehen, dass die zwei Zeugen im Geist des MOSES wirken werden.

JEREMIA wurde in Jer 1,5 als „Prophet für die Völker“ bezeichnet, obgleich er zu Lebzeiten nur in Israel (und am Ende seines Lebens auch in Ägypten) wirkte. Daraus hat man geschlossen, dass er am Ende der Zeiten mit ELIAS wiederkommen und allen Völkern predigen müsse. Mit einer Wiederkehr des JEREMIA rechneten schon die Juden (Mt 16,14). Jedoch kann man „Prophet für die Völker“ auch so verstehen, dass er von Israel aus die Geschicke der Völker prophezeien sollte, was auch den Tatsachen entspricht. Die Worte des Propheten JEREMIA werden Jer 5,14 als „Feuersglut“ bezeichnet; darauf könnte in Vers 5 angespielt sein, wo „Feuer aus dem Mund“ der zwei Zeugen kommt. Aber diese Anspielung zeigt eher, dass die zwei Zeugen im Geist des JEREMIA auftreten als dass JEREMIA selber einer von ihnen ist.

Gerade die Tatsache, dass die ,zwei Zeugen“ mit Zügen versehen sind, die sie sowohl mit ELIAS als auch mit Henoch, Mose, Jeremia, Serubbabel und Jeschua verbinden, zeigt m. E. sehr klar, dass hier nicht an eine persönliche Wiederkehr von genau zwei dieser Personen gedacht ist, sondern an eine große Gruppe von Zeugen Christi, die im Geist aller dieser Männer aus der Geschichte Israels auftreten. Somit bestätigt der Überblick über die Möglichkeiten der individuellen Auslegungen letztlich wieder die kollektive Auslegung.

Wann waren nun die symbolischen 1260 TAGE des Auftretens der zwei Zeugen? Ist diese Verfolgungsperiode identisch mit den „,42 Monaten“ der „Zertretung der Stadt durch die Heiden“, d. h. mit der diokletianischen Kirchenverfolgung, von der in Vers $2 b$ die Rede war? 
Die 42 Monate der ,Zertretung“ sind eine Art „Krieg“ gegen die Christen, in der die Heiden die heilige Stadt besetzen (d. h. die Kirche angreifen). Aber von einem „Krieg“ gegen die „zwei Zeugen“ ist erst in Vers 7 die Rede, und es heißt dort, dass dieser Krieg beginnt, ,wenn sie (die zwei Zeugen) ihr Zeugnis vollendet haben“, d. h. nach denn 1260 Tagen ihres Zeugnisses. Somit beginnen die 42 Monate nach den 1260 Tagen. Die 1260 Tage aber müssen folglich als eine Verfolgungs- und Zeugnisphase vor der diokletianischen Verfolgung verstanden werden.

Da aber direkt vor der diokletianischen Verfolgung keine besondere Verfolgungswelle zu verzeichnen ist, sagt man am besten: Die 1260 Tage bezeichnen in allgemeinen Zügen die römischen Verfolgungen bis zum Beginn der diokletianischen Verfolgung. Da es nun in Vers 3 heißt: „ICH WERDE meine Zeugen aufbieten“, scheint der Beginn ihrer Zeugnisperiode zum Zeitpunkt der Abfassung der Apokalypse (95 n. Chr.) noch in der Zukunft zu liegen. Darum beginnt ihr Zeugnis nicht mit der Verfolgung des Nero (64-68), die ebenso wie jene des Domitian (ca. 94-96) noch nicht systematisch ablief und nur auf Teile des Reiches beschränkt blieb. Es beginnt wohl erst mit dem Verfolgungsedikt des Trajan, auf dessen Basis seit 112 n. Chr. das Christsein im ganzen Reich als zu bestrafendes Verbrechen angesehen wurde. Das trajansche Edikt blieb auch fast ununterbrochen bis zur diokletianischen Verfolgung in Geltung: Es ist der eigentliche Beginn der römischen Verfolgungen und somit des Zeugnisses der ,zwei Zeugen“. Die 1260 Tage reichen somit von 112 bis 303, und dann folgen die 42 Monate, von 303 bist 312.

Die Prophetie beginnt also mit einer Ansage der diokletianischen Verfolgung (Verse 1-2), schildert dann die Zeugnisperiode vor dieser Verfolgung (Verse 3-6) und beschreibt ab Vers 7 die diokletianische Verfolgung im Einzelnen.

11,5 Und wenn jemand ihnen (den zwei Zeugen) Schaden zufügen will, kommt Feuer aus ihrem Mund heraus und verzehrt ihre Feinde. Und wenn jemand ihnen Schaden zufügen will, muss er sterben.

Hier wird angespielt auf Elias und Jeremia: die Zeugen Christi werden im Geist und in der Kraft dieser Propheten auftreten (siehe Kommentar zu Vers 3-4). Das FEUER aus ihrem Munde ist allerdings symbolisch zu verstehen. Gegen ein wörtliches Verständnis spricht nämlich, dass CHRISTUS seinen Jüngern verboten hat, gegen Feinde des Evangeliums „,Feuer vom Himmel“ herabzurufen (Lk 9,5155). Auch, dass das „Feuer“ aus dem Mund der Zeugen kommt, weist darauf hin, dass hier nicht wirkliches Feuer, sondern die feurige Predigt der Zeugen Christi gemeint ist. Dieses sinnbildliche Feuer finden wir auch bei Elias und Jeremia. So sprach Gott zu Jeremia (Jer 5,14): „Ich mache meine Worte in deinem Mund zu Feuersglut und dieses Volk da zum Brennholz, das von ihr verzehrt wird."

Und über Elias sagt Jesus Sirach (Sir 48,1): „Da stand ein Prophet auf wie Feuer, seine Worte waren wie ein brennender Ofen.“ Vergleiche noch das „Schwert“, das JOHANNES aus dem Munde Jesu kommen sah $(1,16 ; 2,12 ; 19,15)$, und das ebenfalls das wirkmächtige Wort meint.

Das „Feuer aus dem Mund“ der Zeugen Christi TÖTET ihre Feinde insofern, als diese, wenn sie das Wort der Zeugen verachten, der göttlichen Strafe verfallen, d. h. ins (wiederum sinnbildliche) „Feuer“ der ewigen Gewissensqualen in der Hölle fallen - welche der ,zweite Tod“ ist (siehe 20,14-15). Dabei beabsichtigen die Zeugen Christi nicht, diese „Tötung“ zu bewirken: denn sie „,segnen“ ihre Verfolger und ersehnen ihre Bekehrung, so wie es Paulus im Römerbrief $(12,14)$ gefordert hat: „Segnet eure Verfolger, segnet sie, verflucht sie nicht!“ Aber Paulus fügt hinzu, dass gerade diese wohlwollende Feindesliebe, der christliche Racheverzicht, den Bösen, wenn sie nicht zur Besinnung kommen, zum Verhängnis werden kann: „Rächt euch nicht selbst, Geliebte, sondern lasst Raum für den (göttlichen) Zorn. Denn es steht geschrieben: 'Mein ist die Rache, ich werde vergelten' spricht der Herr. Sondern wenn dein Feind Hunger hat, gib ihm zu essen, wenn er Durst hat, gib ihm zu trinken: denn dadurch sammelst du glühende Kohlen auf sein Haupt“" (Röm 12,19). 
Das Wort und Wirken der Zeugen Christi baut somit zugleich die Guten auf und bringt die Bösen zu Fall. Hierin gleicht es dem Wort und Wirken Jesu, welches ebenfalls ,zum Fall und zur Auferstehung vieler" führte (Lk 2,34). Die zugleich niederreißende und aufbauende Wirkung Jesu hat auch der Prophet Jesaja vorausgesagt (Jes 11,4): „Er richtet die Hilflosen gerecht und entscheidet für die Armen des Landes, wie es recht ist. Er schlägt den Gewalttätigen mit dem Stock seines Wortes und tötet den Schuldigen mit dem Hauch seines Mundes.“

11,6a Sie haben die Macht, den Himmel zu verschließen, so dass während der Tage ihres prophetischen Auftretens kein Regen fällt.

Dasselbe wird von EliAs gesagt (siehe Kommentar zu Vers 3-4). Wieder werden also die Zeugen mit dem gewaltigen Propheten in Verbindung gebracht. REGEN ist Symbol für das fruchtbare Wort Gottes (Dt 32,2; Jes 55,10-11). Die Zeugen haben Macht, den Himmel, d. h. die ewige Seligkeit zu verschließen: Wenn sie den „Regen“ des Wortes Gottes zurückhalten, d. h. wenn sie aufhören, ihren Verfolgern unter Einsatz des Lebens zu predigen, bleibt diesen der Himmel verschlossen.

11,6b Und (sie haben) Macht über die Gewässer, sie in Blut zu verwandeln und die Erde mit jeder Plage zu schlagen, sooft sie wollen.

Diese Macht verbindet die Zeugen mit MosES, der die zehn Plagen über Ägypten brachte, und unter anderem das Wasser des Nil in Blut verwandelte (siehe Kommentar zu Vers 3-4). Das Blut ist ein Symbol für den Krieg und die Gewässer stehen für Volksmassen (17,15). Die Zeugen haben also die Macht, Krieg und andere Plagen über das Volk zu bringen. Sie tun dies aber nicht, indem sie Gott direkt um diese Plagen bitten. Vielmehr beten sie für ihre Befreiung und die Bekehrung ihrer Feinde, woraufhin Gott manchmal solche Plagen zulässt, um der Verfolgung ein Ende zu bereiten und die Verfolger zur Besinnung zu bringen.

Tatsächlich brachen während der Christenverfolgungen entsprechende Plagen (Krieg, Hunger, Pest usw.) immer wieder über das römische Reich herein, so etwa zur Zeit des MARK AUREL (161-180), besonders aber während der drei letzten größeren Verfolgungswellen, unter DECIUS, VALERIAN und Diokletian. Während der Verfolgung des Decius (250-251) fielen die Goten in das Reich ein. DECIUS selbst trat ihnen entgegen und fiel 251 im Kampf, wodurch die Verfolgung zum Stillstand kam. Danach brach eine große Seuche aus, die das ganze Reich verheerte. Zur dieser Zeit kam es zu den schon bei der 6. Posaune erwähnten Einfällen der Perser, denen Valerian, der nächste große Christenverfolger, 260 zum Opfer fiel. Während der diokletianischen Verfolgung wüteten wiederum Bürgerkrieg, Hunger und Pest, was der Zeitzeuge EusEBIUS mit ergreifenden Worten schilderte:

„Während der vollen zehn Jahre der Verfolgung hörten die Nachstellungen und gegenseitigen Kämpfe nicht auf. Die Meere konnten nicht befahren werden. Und wenn jemand von irgendwoher zu Schiffe kam, so wurde er zerfleischt und unter verschiedenen Misshandlungen ausgefragt, ob er nicht etwa aus feindlichem Gebiete käme. Das Ende war Kreuzigung und Feuertod. Überdies wurden überall Schilde und Panzer angefertigt, Geschosse, Speere und sonstiger Kriegsbedarf und ihre Bestückung bereitgehalten. Jedermann musste täglich mit einem feindlichen Einfall rechnen. Das verschlimmerten sodann noch Hunger und Pest ... "66

66 Eusebius, Kirchengeschichte 8,15. 
11,7 Und wenn sie ihr Zeugnis vollendet haben, wird das Tier, das aus dem Abgrund heraufkommt, mit ihnen Krieg führen und sie besiegen und töten.

Als die zwei Zeugen IHR ZEUGNIS VOLLENDET HATTEN, d. h. am Ende ihrer von 112-303 reichenden Zeugnisperiode, taucht nun DAS TIER AUS DEM ABGRUND auf. Dieses Tier wird erst in Kap. 13,1-2 genauer beschrieben, und zwar als siebenköpfiges Ungeheuer. Im Kommentar zu 13,1-2 und 17,9-11 wird sich zeigen, dass es das römische Reich zur Zeit der diokletianischen Verfolgung darstellt, wie vor allem seine sieben Köpfe beweisen, welche die sieben an dieser Verfolgung beteiligten Herrscher darstellen: Hier haben wir die wichtigste Bestätigung dafür, dass ab jetzt von der diokletianischen Verfolgung die Rede ist.

Der Staat bot unter Diokletian all seine Kraft auf, um die Christen zu vernichten, so dass demgegenüber alle früheren Verfolgungen als reine Friedenszeiten erscheinen mussten. Darum beginnt jetzt der eigentliche, entscheidende KRIEG. Der zeitgenössische Kirchengeschichtsschreiber EUSEBIUS spricht von gebietsweise 10-100 Hinrichtungen am Tag, und das über Jahre hinweg. ${ }^{67}$

Die Verfolgung wurde am 23. Februar 303 von DiokLETIAN und seinen Mitkaisern MAXiMinus Herculius und Galerius begonnen. Der vierte Mitkaiser, Constantius Chlorus, der Vater KonSTANTINs, beteiligte sich kaum an den Maßnahmen. ${ }^{68} 305$ traten DiOKLETIAN und MAXIMIANUS HERCUliUS zurück. GALERIUS, der nun oberster Kaiser wurde, setzte die Verfolgung fort, unterstützt von Severus und Maximinus Daja, die er als Mitkaiser einsetzte. SEVERUS wurde aber bald darauf ermordet, so dass GALERIUS und MAXIMINUS DAJA als Verfolger übrigblieben. Aber im Frühjahr 311 wurde GALERIUS sterbenskrank und erklärte auf dem Totenbett, dass der Versuch, die Christen zu vernichten, gescheitert sei: Er befahl, die Verfolgung einzustellen und bat die Christen, für sein Heil zu beten (sogenanntes Toleranzedikt des Galerius). Bald darauf starb er. Jetzt hatten die Christen ein halbes Jahr lang Frieden.

Dann aber, im Herbst 311, begann MAXIMINUS DAJA, der jetzt im Osten des Reiches alleiniger Herrscher war, wieder mit der Verfolgung. In Rom hatte unterdessen der Tyrann MAXENTIUS, ein fanatischer Heide, die Regierung über den Westteil des Reiches an sich gerissen, und errichtete dort eine Schreckensherrschaft. Die beiden Verfolger hießen also jetzt MAXENTIUS und MAXIMINUS DAJA. Jetzt begann die furchtbarste Phase der Verfolgung. MAXIMINUs brachte seine Beamten in den Städten dazu, „Bittgesuche“ an ihn zu richten, die ihn baten, ihre Stadt zu einer Art ,christenfreien Zone“ zu machen. Diese Bittgesuche wurden auf eisernen Säulen in den Städten angebracht und hatten zur Folge, dass die Christen nirgendwo mehr ein Daseinsrecht hatten. Auf diesen Säulen wurde auch ein Schreiben des MAXIMINUS für die Bewohner der Städte angebracht, auf denen er sie lobte, dass sie zu den alten Göttern zurückgekehrt seien, und darauf hinwies, dass dafür nun Pest, Hunger, Krieg und alle Leiden aufgehört hätten: Plagen, für welche die Christen, also die ,zwei Zeugen“ verantwortlich gewesen seien. Sowohl das Zeugnis als auch die „Plagen“ der „zwei Zeugen“ schienen aufgehört zu haben: DIE ZEUGEN WAREN TOT. Die Christen schienen vernichtet zu sein.

Die TÖTUNG der Zeugen, d. h. die scheinbare Vernichtung des Christentums, war also ein Merkmal der diokletianischen Verfolgung, und sie war ein Merkmal nur dieser Verfolgung.

Diese Niederlage war freilich nur von kurzer Dauer (siehe die ,3 1/2 Tage“ im nächsten Vers). Bereits im Winter 311/312 brachen durch ungenügende Regenfälle Hunger und Pest wieder aus, und zudem wurde MAXIMINUS noch in einen Krieg gegen Armenien verwickelt: die „Plagen“ der „Zeugen“ begannen also von neuem. Jetzt begannen die ,Zeugen“ wieder aus ihrem „Tode“ aufzuerstehen, und ihre Auferstehung war am 28. Oktober 312 vollendet.

67 Vgl. Kirchengeschichte 8,9,3, wo EUSEBIUS nur von den Märtyrern der Thebais spricht.

68 Nach EusEBIUS, Kirchengeschichte 8,13,13 „,beteiligte er sich in keiner Weise am Krieg gegen uns [Christen]“. 
Am 28. Oktober 312 besiegte Konstantin den Tyrannen MAXENTIUS und zog siegreich in Rom ein. Konstantin hatte im Kampfe den Gott der Christen zu Hilfe gerufen. Zum Dank für den Sieg schenkte er den Christen die Freiheit. Nun gab es nur noch einen Christenverfolger: MAXIMINUS DAJA, der im Osten die Verfolgung immer noch fortsetzte. Er wurde jedoch am 30. April 313 von LiCINIUS, dem Schwager KonSTANTINs, besiegt. Jetzt regierten KONSTANTIN und LiciniUs und gaben den Christen im ganzen Reich die volle Freiheit. Gegen Ende seines Lebens wurde aber LICINIUS vom Wahnsinn befallen und begann die Christen im Osten des Reiches erneut zu verfolgen (320-324). Diese Verfolgung war aber unbedeutend und endete damit, dass LiCINIUS am 18. September 324 in einer Schlacht von Chrysopolis von KonstAnTIN besiegt wurde, der von da an der alleinige Herrscher über das ganze römische Reich war.

11,8 Und ihr Leichnam wird auf den Plätzen der großen Stadt liegen, welche geistlich genannt wird Sodom und Ägypten, wo auch ihr Herr gekreuzigt wurde.

11,9 Und es sehen Menschen aus allen Völkern und Stämmen und Sprachen und Nationen ihren Leichnam drei Tage und einen halben (Tag), und sie lassen nicht zu, dass sie in ein Grab gelegt werden.

Die LEICHEN getöteter Christen lagen oft offen herum, denn sie konnten nur unter großen Gefahren beerdigt werden. Die GROSSE STADT ist Rom und das Römische Reich:

- Rom kann SoDOM genannt werden wegen der dort verbreiteten so genannten sodomitischen Unzucht (vgl. zu dieser Kommentar zu 22,15).

- Rom kann ÄGYPTEN genannt werden, weil die Römer das Volk Gottes verfolgten wie einst die Ägypter.

- Das römische Reich kann auch die „Stadt“ genannt werden, in der IHR HERR, d. h. Jesus, GEKREUZIGT WURDE. Jesus starb zwar in der Stadt Jerusalem, aber im Gebiet des Römischen Reiches und auf Anordnung Römischer Machthaber.

- Die ,große Stadt“ wird in Kap. 17 wieder auftauchen, und dort wird ganz klar werden, dass hiermit nur Rom gemeint sein kann (siehe den einleitenden Kommentar zu Kap. 17).

Die „3 1/2 TAGE“ des Totseins stehen für die Zeit der größten Niederlage des Christentums auf dem Höhepunkt der diokletianischen Verfolgung unter MAXIMINUS DAJA, von Oktober 311 bis Oktober 312. Zur Symbolik der Zahl 3 1/2 siehe Kommentar zu 11,2b. Die Zeitangabe hängt mit den 1260 Tagen (= 3 1/2 Jahren) von Vers 3 zusammen: Die Zeit der absoluten Ohnmacht der Zeugen dauert nur so viele Tage, wie die Zeit ihres triumphalen Zeugnisgebens an Jahren dauert. Dieses Verhältnis bedeutet nichts weiter als dass die Zeitspanne des scheinbaren Sieges über das Christentum nur einen kleinen Bruchteil der Zeit seines Triumphes ausmacht.

Die 1260 Tage, 42 Monate und 3 1/2 Tage haben also insgesamt folgende Verwirklichung gefunden (siehe auch Exkurs 6):

1260 Tage Zeit des machtvollen Zeugnisses (Verse 3-6): römische Verfolgungen vor Diokletian (112-303),

42 Monate Zertretung der Stadt (Verse 1-2 und 7-11): diokletianische Verfolgung (303-312),

3 1/2 Tage Scheintod der Christenheit (Verse 8-11): Höhepunkt dieser Verfolgung (Okt 311 - Okt 312). 
Dass 42 Monate in der Realzeit mit 1260 Tagen identisch wären, während die 42 Monate und die 1260 Tage in unserer Deutung verschieden lange Perioden ausmachen, braucht uns nicht zu stören, da die Zeitangaben Symbole sind. Bemerkenswert ist indessen, dass für größere Zeitabschnitte hier stets größere Zahlen verwendet werden: 3 1/2 für eine Periode von einem Jahr, 42 für eine Periode von nahezu zehn Jahren, und 1260 für eine Periode von ca. hundertneunzig Jahren.

11,10 Und die Bewohner der Erde freuen sich über sie (die toten „Zeugen“) und frohlocken.

Und sie werden einander Geschenke schicken,

weil diese zwei Propheten die Bewohner der Erde gepeinigt hatten.

Die BEWOHNER DER ERDE sind hier klar von den zwei Zeugen, welche die treuen Christen darstellen, getrennt. Es handelt sich also um ,irdische“, antichristlich gesinnte Menschen.

Diese FROHLOCKEN, d. h. sie freuen sich, weil sie von den Zeugen GEPEINIGT worden waren, nämlich durch Plagen wie Pest, Hunger und Krieg, als deren Ursache sie selbst die Christen angesehen hatten. Sie SCHICKEN nun EINANDER GESCHENKE, d. h. verbrüdern sich.

Dies trifft besonders auf die damaligen Hauptakteure der Verfolgung zu, Maxentius in Rom und Maximinus im Osten: „Der Tyrann des Ostens, Maximinus, schloss mit dem zu Rom, gleichsam mit seinem Bruder in der Schlechtigkeit, heimlich ein Bündnis“ (EUSEBIUS, Kirchengeschichte 8,14,7)

11,11 Und nach den dreieinhalb Tagen kam der Geist des Lebens von Gott her in sie hinein. Und sie stellten sich auf ihre Füße, und große Furcht fiel auf die, die sie sahen.

Hier ist die Rede von einer sinnbildlichen AufERstenung der getöteten Zeugen Christi: Die Wiederbelebung des Christentums durch den Sieg Konstantins am 28. Oktober 312, welcher der Kirche - zunächst im Westen - den Frieden brachte. In einem ähnlichen Sinn hatte der Prophet EzECHIEL die Rückkehr der Israeliten aus der babylonische Gefangenschaft in einer Vision als eine „Auferstehung von den Toten“"geschaut (Ez 37,11-12).

GROSSE FURCHT überkam nun die heidnischen Römer, als sie die Wiederherstellung des totgeglaubten Christentums sahen, vor allem deshalb, weil nun KONSTANTIN das Christentum begünstigte und das Heidentum zurückgedrängte.

11,12 Und sie hörten eine laute Stimme aus dem Himmel zu ihnen sagen:

Kommt hier herauf!

Und sie steigen in der Wolke zum Himmel hinauf, und ihre Feinde sahen sie.

Diese HIMMELFAHRT ist die Verherrlichung der Kirche unter Konstantin. Zugleich kann man daran denken, dass den verstorbenen Märtyrern nun öffentliche Ehren zuteil wurden.

11,13a Und in jener Stunde geschah ein großes Erdbeben.

Und der zehnte Teil der Stadt fiel zusammen.

Und es wurden bei dem Erdbeben 7000 Menschen getötet.

Jene Stunde war die Zeit des großen Sieges Konstantins gegen MaXentius an der Milvischen Brücke nördlich von Rom (28. Oktober 312), bei dem MAXENTIUS in den Fluten des Tiber ertrank. Das GROSSE ERDBEBEN bezeichnet die verschiedenen Machtkämpfe, die zu jener Zeit das Reich erschütterten, und die schließlich zum vollkommenen Sieg von KONSTANTIN und LiCINIUS über MAXENTIUS und MAXIMINUS führten.

Bei diesem Sieg fiel DER ZEHNTE TEIL der Stadt zusammen. Diese Zahl bezeichnet hier symbolisch einen großen, spürbaren Verlust, der aber verhältnismäßig klein bleibt, etwa vergleichbar mit dem Verlust, den die Amputation eines Fingers für das Arbeiten mit den zwei Händen bedeutet.

7000 Menschen starben (7, Zahl der Vollkommenheit, multipliziert mit 1000, Zahl der großen Menge): Dies bezeichnet den vollkommenen Sieg Konstantins über seine Feinde. 
11,13b Und die übrigen gerieten in Furcht und gaben dem Gott des Himmels die Ehre.

Nach dem Siege Konstantins gingen die Menschen aus Furcht vor dem Kreuzzeichen, das der neue Herrscher in Rom aufgestellt hatte, in Scharen zum Christenglaubens über.

11,14 Das zweite „Wehe“ ist vergangen: Siehe das dritte „Wehe“ kommt bald.

Die drei „Wehe“ waren 8,13 angekündigt worden als Plagen, die unter der fünften, sechsten und siebten Posaune über die ,irdischen“ Menschen hereinbrechen würden. Das erste Wehe bestand in den „Heuschrecken“"Theodots, welche die Menschen ins geistige Verderben eines antichristlichen Irrglaubens und die damit verbundenen Qualen führten.

Das zweite Wehe, das nun vergangen ist, war eine körperliche Züchtigung der Menschen, einerseits durch die barbarischen „Panzerreiter“, die Krieg gegen das heidnische Rom unter Valerian führten (9,13-20), und andererseits durch die „Plagen“, welche die „,Zwei Zeugen“ über die Christenverfolger brachten, bis hin zu ihrer völligen Besiegung.

Durch diese beiden „Wehe“ führt uns die Apokalypse also schlimme geistige und körperliche Plagen vor Augen, welche in gewisser Weise sowohl die Christen wie auch ihre Feinde trafen, die jedoch für die Christen den Charakter der Läuterung hatten und daher nur für ihre Feinde als Bestrafung interpretiert werden.

Das dritte Wehe, dessen Startsignal der im nächsten Vers erfolgende 7. Posaunenstoß sein wird, hat einen anderen Charakter: Es ist der Untergang des heidnischen Rom. Dieses „Wehe“ reicht eigentlich vom nächsten Vers an bis Kap. 19, wo sein Abschluss markiert ist.

\subsubsection{Apk 11,15-19: Siebte Posaune (Signal für den Sieg über Rom, 312)}

Text

11,15 Und der siebte Engel blies in die Posaune.

Und es erhoben sich laute Stimmen im Himmel, die sagten:

Geworden ist die Weltherrschaft unseres Herrn und seinem Gesalbten!

Und er wird herrschen in alle Ewigkeit.

11,16 Und die vierundzwanzig Ältesten, die vor Gott auf ihren Thronen sitzen, fielen auf ihre Gesichter nieder und beteten Gott an,

11,17 und sagten: Wir danken dir, Herr, Gott und Allmächtiger, der du bist und der du warst, dass du deine große Macht und Herrschaft angetreten hast.

11,18 Und die Heiden sind zornig geworden, und gekommen ist dein Zorn.

Und (gekommen ist) die Zeit (für die) Toten, gerichtet zu werden, und (die Zeit), zu belohnen deine Knechte, die Propheten und die Heiligen, und die deinen Namen fürchten, die kleinen und die großen. Und (gekommen ist die Zeit), alle zu verderben, die die Erde verderben.

11,19 Und der Tempel Gottes im Himmel wurde geöffnet.

Und die Lade seines Bundes wurde in seinem Tempel sichtbar.

Und es geschahen Blitze und Stimmen und Donner und ein Erdbeben und großer Hagel.

Auslegung 
11,15 Und der siebte Engel blies in die Posaune.

Und es erhoben sich laute Stimmen im Himmel, die sagten:

Geworden ist die Weltherrschaft unseres Herrn und seinem Gesalbten!

Und er wird herrschen in alle Ewigkeit.

Der siebte Engel bläst beim Siege Konstantins am 28. Oktober 312, denn damit ist das „Geheimnis Gottes“, der weltgeschichtliche Durchbruch für die „Kirche Christi aus allen Nationen“ vollendet (siehe Kommentar zu 10,7). Tatsächlich gehört nun die HERRSCHAFT ÜBER DIE WELT Gott dem Herrn, und Jesus Christus: Der universellen Bekehrung der Völker steht nichts mehr im Wege. Gott WIRD IN EWIGKEIT HERRSCHEN, denn Gottes Herrschaft ist im Himmel ohne Ende, und diese ewige Herrschaft beginnt nun auch auf Erden sichtbar zu werden.

11,16 Und die vierundzwanzig Ältesten, die vor Gott auf ihren Thronen sitzen, fielen auf ihre Gesichter nieder und beteten Gott an,

11,17 und sagten: Wir danken dir, Herr, Gott und Allmächtiger, der du bist und der du warst, dass du deine große Macht und Herrschaft angetreten hast.

Gott wird hier als DER DU BIST UND DER DU WARST, aber nicht mehr als DER DU KOMMST bezeichnet (wie in 1,4), weil er durch die Befreiung seiner Kirche bereits in gewisser Weise „gekommen“ ist. Damit ist nicht geleugnet, dass es ein weiteres, nachgeschichtliches Kommen zum Weltgericht gibt, von aber erst in Kap. 20,11-15 die Rede sein wird.

11,18a Und die Heiden sind zornig geworden, und gekommen ist dein Zorn.

Die Heiden wurden ZORNIG, als sie die Wiederherstellung der Kirche sahen und mit ansehen mussten, dass beginnend mit Konstantin sogar die Kaiser das Christentum annahmen. Aber auch Gottes ZORN (vgl. Kommentar zu 14,10) ist jetzt gekommen, d. h. jetzt ist die Zeit angebrochen, die auf den vollkommenen Sieg über das heidnische Rom unter ALARICH zusteuert, welcher der in Kap. 14 und 17-19 beschriebene innergeschichtliche Höhepunkt der Apokalypse und der Abschluss des von der siebten Posaune angeblasenen dritten Wehe ist.

11,18b Und (gekommen ist) die Zeit (für die) Toten, gerichtet zu werden, und (die Zeit), zu belohnen deine Knechte, die Propheten und die Heiligen, und die deinen Namen fürchten, die kleinen und die großen.

Diese Worte beziehen sich im eigentlichen Sinne auf das Endgericht über diese Welt (siehe Kap. 20,1115). Es ist in der Prophetie üblich, innergeschichtliche Aussagen unlösbar mit endgeschichtlichen zu verbinden. Dabei taucht oft das Phänomen der sog. ,,prophetischen Perspektive“ auf: Der Prophet sieht (und redet über) zwei künftige Ereignisse, von denen eines sich bald erfüllen wird und das andere noch weit in der Ferne liegt, als würden sie zeitlich unmittelbar aufeinander folgen: ähnlich wie in der Perspektive eines Beobachters, der in die Ferne sieht, am Horizont zwei Objekte nahe beieinander zu sein scheinen, von denen in Wirklichkeit nur das eine in der Nähe ist, das andere aber sehr weit entfernt sein kann. So erklärt es sich auch, dass JESUS mit seiner Voraussage der Zerstörung des Jerusalemer Tempels (in Mt 24) Aussagen über das Weltende verbinden konnte. Ebenso sagte DANIEL (Dan 7 und 11) die Verfolgung des Judentums unter dem syrischen König Antiochus voraus und verband damit Aussagen über den Antichristen am Ende der Geschichte. Ebenso sieht hier JoHAnNes das Ende der römischen Verfolgung und erblickt dahinter zugleich das Ende der Welt. Ein ähnlicher „Sprung“ zur endgeschichtlichen Prophetie liegt in 19,7 vor. 
11,18c Und (gekommen ist die Zeit), alle zu verderben, die die Erde verderben.

Auch hier befinden wir uns noch in der endgeschichtlichen Prophetie (siehe Kommentar zu 18b). Denn in der Antike hatten man überhaupt keine Mittel, um DIE ERDE im eigentlichen Sinne ZU VERDERBEN. Das Verderben der Erde ist demgegenüber heute nicht nur möglich, sondern bereits in vollem Gang (Kernkraftwerke, Ozonloch, globale Umweltvergiftung usw.).

11,19a Und der Tempel Gottes im Himmel wurde geöffnet. Und die Lade seines Bundes wurde in seinem Tempel sichtbar.

Dies kann wieder gut auf die Zeit Konstantins gedeutet werden. Dadurch, dass damals die Kirche öffentlich zugänglich wurde, tat sich für alle Völker ein neuer, freier Zugang zum Himmel, zu Gott und zu seinem himmlischen Tempel auf.

Die Bundeslade, das größte Heiligtum der Juden, war im Tempel hinter Vorhängen versteckt. Die Lade steht also für die verborgenen Geheimnisse Gottes, die in der Kirche gelehrt und gefeiert werden. Diese Mysterien wurden nun öffentlich zugänglich: DIE LADE DES BUNDES wurde SICHTBAR.

11,19b Und es geschahen Blitze und Stimmen und Donner und ein Erdbeben und großer Hagel.

Blitze, Stimmen und Donner sind Zeichen der furchgebietenden Gegenwart Gottes (siehe Kommentar zu 4,5). ERDBEBEN und HAGEL bezeichnen die von Gott her kommende Vernichtung Roms. Denn Erdbeben und Hagel, mit der hier das Anblasen der 7. Posaune schließt, werden bei Schluss der 7. Zornesschale wieder auftauchen (16,18-21), und zwar in eindeutigem Zusammenhang mit Rom. Hier haben wir also eine Vorandeutung des Unheils, das die 7. Posaune noch bringen wird. 


\subsection{Apk 12,1-8: Der Drache und die Frau}

Vorbemerkung über den weiteren Inhalt des Buches. JoHANNES hat soeben die siebte Posaune gehört und die Ankündigung des letzten Gerichts am heidnischen Rom vernommen (11,15-19). Es handelt sich um das Gericht an den überzeugten Anhängern der heidnisch-römischen Religion, die nach dem Ende der blutigen Christenverfolgungen keineswegs ausgestorben waren, sondern neue Pläne zur Vernichtung des Christentums schmiedeten. Diese heidnische Bewegung gewann im 4. Jahrhundert immer mehr an Bedeutung, vor allem durch die sie unterstuitzende neuplatonische Philosophie, und sie feierte ihre größten Triumphe, als im Jahre 361 ein letztes Mal ein überzeugter Heide an die Macht kam: Kaiser JUliAn mit dem Beinamen DER ApOSTAT (DER ABTRÜNNIGE), der im ganzen Reich das Heidentum wiederherstellte und die diokletianische Verfolgung wieder aufleben lassen wollte. Er hatte zwar keinen dauerhaften Erfolg, da er schon 363 im Krieg mit den Persern fiel, aber die heidnische Bewegung, aus der er hervorgegangen war, blieb weiter lebendig und suchte nach immer neuen Gelegenheiten, um Einfluss zu gewinnen: Erst durch den Fall Roms 410 war ihr Schicksal besiegelt. Johannes bekommt nun nicht sofort das Gericht über diese letzte römisch-heidnische Bewegung zu sehen, sondern sieht in den folgenden zwei Kapiteln (12-13), offenbar wieder von der Erde aus (12,1), zunächst die Geschichte ihres Ursprungs, anfangen bei ihren tiefsten Wurzeln. Das vorliegende Kapitel zeigt Satan als den Urheber der genannten Bewegung, wie er seit seinem Himmelsturz am Anfang der Zeiten Anhänger ,zeugt“, wie er dann CHRISTUS ,,verschlingen“ will und schließlich die Kirche bis zu den Zeiten Konstantins verfolgt. In Kap. 13 folgt dann die Erneuerung des Heidentums unter Kaiser Julian JULIAN und den Neuplatonikern des 4. Jahrhunderts. Nachdem Johannes diesen geschichtlichen Hergang geschaut hat, sieht er in Kap. 14 (nach einer tröstenden Vision der treuen Christen) die Vorankündigung des Gerichts und Kap. 15 (wiederum nach einer tröstenden Vision der treuen Christen) Vorbereitungen für dessen Vollstreckung. Kap 16 zeigt endlich die Vollstreckung des Gerichts, in Form einer Ausgießung von sieben Plagen über das Reich. In Kap. 17 erfolgt die Deutung des Geschauten durch einen Engel, und Kap. 18-19 zeigt die Freude des Himmels über das Geschehene. Kap. 20 schließlich zeigt, was nach dem innergeschichtlichen Gericht am römischen Reich geschehen wird: eine lange Zeit („1000 Jahre“) wird vergehen, und dann kommt das Endgericht, nach welchem die Welt in ihren gottgewollten, ewigen Endzustand versetzt wird (Kap. 21-22).

12,1 Und ein großes Zeichen erschien am Himmel:

Eine Frau, bekleidet mit der Sonne, und der Mond war unter ihren Füßen, und ein Kranz von zwölf Sternen war auf ihrem Haupt.

12,2 Und sie ist schwanger, und schreit vor Schmerz in ihren Geburtswehen.

12,3 Und ein anderes Zeichen erschien am Himmel, und siehe: ein großer, feuerroter Drache. Er hatte sieben Köpfe und zehn Hörner und auf seinen Köpfen sieben Kronen.

12,4 Und sein Schwanz fegte den dritten Teil der Sterne vom Himmel und warf sie auf die Erde. Und der Drache stellte sich vor der Frau, die gebären sollte. Er wollte ihr Kind verschlingen, sobald sie geboren hat.

12,5 Und sie gebar einen männlichen Sohn, der alle Völker mit eisernem Stab weiden soll. Und ihr Kind wurde zu Gott und zu seinem Thron entrückt.

12,6 Und die Frau floh in die Wüste, wo Gott ihr einen Ort bereitet hat, damit man sie dort ernährt 1260 Tage.

12,7 Und es entstand ein Krieg im Himmel. Michael und seine Engel kämpften mit dem Drachen. Und der Drache und seine Engel kämpften.

12,8 Und er konnte sich nicht halten, und er verlor seinen Platz im Himmel.

12,9 Und geworfen wurde der große Drache, die alte Schlange, der „,Teufel“ und „Satan“ genannt wird, und die ganze Erde verführter wurde geworfen auf die Erde, und seine Engel wurden mit ihm (herunter)geworfen. 
12,10 Und ich hörte eine laute Stimme im Himmel sagen: Jetzt ist gekommen die Rettung und die Macht und die Herrschaft unseres Gottes und die Vollmacht seines Christus, weil der Ankläger unserer Brüder (herunter)geworfen wurde, der sie vor unserem Gott tags und nachts anklagt(e).

12,11 Und sie haben ihn besiegt kraft des Blutes des Lammes und kraft des Wortes und ihres Zeugnisses, und sie hielten ihr Leben nicht fest bis hinein in den Tod.

12,12 Daher freut euch, ihr Himmel und ihr, die ihr darin wohnt! Aber wehe der Erde und dem Meer, denn der Teufel ist zu euch herabgestiegen und hat großen Zorn, wissend, dass er (nur noch) wenig Zeit hat.

12,13 Und als der Drache sah, dass er auf die Erde geworfen war, verfolgte er die Frau, die den Knaben geboren hatte.

12,14 Und der Frau wurden die zwei Flügel des großen Adlers gegeben, damit sie in die Wüste an ihren Ort fliege: dort wird sie eine Zeit und zwei Zeiten und eine halbe Zeit ernährt.

12,15 Und es stieß die Schlange aus ihrem Rachen Wasser wie einen Fluss aus, in Richtung auf die Frau, damit sie vom Fluss fortgerissen würde.

12,16 Und die Erde half der Frau:

Und die Erde öffnete ihren Mund und verschluckte den Fluss, den der Drache aus seinem Mund ausgestoßen hatte.

12,17 Und der Drache wurde zornig über die Frau und ging weg, um Krieg zu führen mit den übrigen ihres Samens, (mit) denen, welche die Gebote Gottes und das Zeugnis Jesu festhalten.

12,18 Und er stelle sich an den Strand des Meeres.

\section{Auslegung}

Johannes sieht AM HIMMEL ein Zeichen: Er hat also anscheinend nach dem Blasen der letzten Posaune seinen visionären Ort im Himmel (4,1) verlassen und befindet sich wieder auf der Erde, offenbar am Strand von Patmos $(12,18)$. Er beobachtet, wie ein DRACHE gegen eine Frau kämpft. Der Drache ist, wie in Vers 9 ausdrücklich gesagt wird, ,die alte Schlange, die Satan oder Teufel heißt“. Wer aber ist die Frau? Der Ausdruck ,die alte Schlage“ erinnert an die Erzählung vom Paradies, in welcher der Teufel in Gestalt einer Schlange „die Frau“, nämlich Eva, verführte. Gott sprach damals zur Schlange (Gen 3,15): „Feindschaft setze ich zwischen dich und die Frau, zwischen deinem Samen (Nachwuchs) und ihrem Samen (Nachwuchs). Er wird dir den Kopf zermalmen und du wirst ihm die Ferse zermalmen." Das 12. Kapitel der Apokalypse scheint also auf diesen Gottesspruch anzuspielen, den die Theologen DAS PROTOEVANGELIUM nennen: Denn erstens handelt sowohl das Protoevangelium als auch Apk 12 von einem Kampf zwischen einer Schlange und einer „Frau“. Zweitens wird in Apk 12 wird die Schlange die ,alte“ genannt, was offenbar auf jenes uralte Geschehen im Paradies zurückverweist. Drittens ist sowohl im Protoevangelium als auch in Apk 12 vom „Samen“ bzw. von der Nachkommenschaft der Frau die Rede. Man darf also Apk 12 im Licht des Protoevangeliums auslegen. Was bedeutet aber das Protoevangelium? Es berichtet von einer Feindschaft zwischen einer Frau und ihrem Samen einerseits und einer Schlange und ihrem Samen andererseits. Sicher ist, dass die Schlange der Teufel ist (wie gerade Apk 12,9 beweist; siehe außerdem Weish 2,24 und Apk 20,2). Die Frau wäre nach dem unmittelbaren Zusammenhang EvA, die „Mutter der Lebendigen“ (Gen 3,20). Dann muss der Same der Frau die gesamte, von Ȩva abstammende Menschheit sein, und der Same der Schlange die Gesamtheit der bösen Mächte, deren geistiger „Vater“ der Teufel ist. Ganz falsch ist diese Sicht nicht, aber sie ist doch unzulänglich. Denn es ist nicht im eigentlichen Sinne das ganze Menschengeschlecht, das dem Satan den Kopf zertritt. Vielmehr gehören viele Menschen auf die Seite Satans, sie haben ihn zum geistigen „Vater“ erwählt (Joh 8,44; vgl. 1 Joh 3,8-10) und werden von JOHANNES DEM TÄUFER als „Schlangenbrut“ (Mt 3,7; Lk 3,7) bezeichnet. Der siegreiche Same der Frau ist also in einem engeren Sinne nicht die gesamte Menschheit, sondern die Kirche im Sinne der in Christus zusammengefassten Menschheit. Auf dieser Sinnebene kann nun aber die Frau nicht mehr EvA sein, sondern sie muss eine Frau sein, die den Namen „Mutter der Kirche“ verdient, die also in ähnlicher Weise am Ursprung der Kirche steht wie EvA am Ursprung der gesamten 
Menschheit. Diese Frau ist aber Maria, die Mutter Christi. Die Frau und ihr Same ist demnach Maria und die Kirche, und die Schlange und ihr Same umfasst SATAN und die ihm dienenden Engel und Menschen.

Doch kann man noch weiter überlegen: Letztlich ist es CHRISTUS, der SATAN besiegt, während die Kirche nur in und durch CHRISTUS ihren Fuß über die Schlange setzt. Man kann also sagen: der Same ist CHRISTUS - nur darf man dann CHRISTUS nicht als isolierte Einzelperson betrachten. Das verbietet sich deshalb, weil man sonst konsequenterweise auch im „Samen“ der Schlange eine einzelne, vom Satan verschiedenen Person sehen müsste, was jeder Grundlage entbehrt. Ist der Same der Schlange das ganze Heer SATANs, so muss der Same der Frau ebenfalls in gewissem Sinne eine Gesamtheit umfassen. Am besten sagt man also entweder, dass der Same der Frau Christus als Haupt seiner Kirche ist, oder aber (was dasselbe ist) die Kirche als in Christus ihrem Haupt repräsentierte und zusammengefasste Einheit. Auch bezüglich der Frau gibt es nun eine weiterführende Überlegung. Manche wollen in der Frau nicht eine Einzelperson wie MARIA sehen, sondern die gesamte Kirche. Doch muss man bedenken, dass in der Gegenüberstellung von „Schlange und Same“ auf der einen Seite und „Frau und Same“ auf der anderen Seite zweifellos die Schlange mit der Frau und der Same der Schlange mit dem Samen der Frau in einer Parallele stehen. Die Schlange aber ist SATAN, eine Einzelperson. Ebenso muss dann auch die Frau eine Einzelperson sein. Dennoch haben jene, die in der Frau die Kirche sehen wollen, nicht ganz Unrecht. Denn wie SATAN als „Urbild“ und Symbol aller zu seinem „Samen“ gehörenden bösen Mächte fungieren kann, so könnte man im gleichen Sinn auch MARIA als „Urbild“ der Kirche gelten lassen, als umfassendes Symbol also auch für ihren „Samen“. So kann man abschließend feststellen: Die Frau ist Maria in ihrer Rolle als Urbild der Kirche, und ihr Same ist Christus in seiner Rolle als Haupt der Kirche.

Die Deutung der „Frau“ des Protoevangeliums als MARIA wird sowohl durch Apk 12 als auch durch das Johannesevangelium (vgl. Joh 2,4 und Joh 19,26-27) bestätigt. In Apk 12,1-5 heißt es nämlich, dass die „Frau“ einen Sohn gebar, der nach der Geburt vom Drachen verschlungen werden sollte, aber zu Gott und seinem Thron entrückt wurde. Das ist offenbar CHRISTUS, so dass nahe liegt, in der Frau MARIA zu sehen. Was diese Deutung zunächst scheinbar wieder in Frage stellt, ist jedoch die Tatsache, dass die Frau bei der Geburt vor Schmerzen schrie (Apk 12,2). Das trifft auf die leibliche Geburt JESU nicht zu, bei der MARIA keine Schmerzen haben konnte, zumindest wenn man den Glauben der katholischen Kirche voraussetzt, dass MARIA durch eine außerordentliche göttliche Begnadung (Lk 1,28) von den Folgen der Erbsünde befreit worden war, zu der nach Gen 3,16 die Geburtswehen gehören. Diese Überlegung zeigt aber nicht, dass die Frau nicht MARIA ist, sondern nur, dass hier nicht (oder nicht nur) von der leiblichen Geburt CHRISTI in Bethlehem die Rede sein kann. Es gibt nämlich noch eine zweite „Geburt“ Christi, deren schmerzhafter Geburtsvorgang in der Kreuzigung bestand. Denn CHRISTUS erwarb sich durch sein am Kreuz vergossenes Blut die Kirche (Apg 20,28), mit der er so sehr verbunden ist, dass sie in geheimnisvoller (mystischer) Weise sein „Leib“ genannt wird (Eph 1,24, Joh 2,21): Die Kirche ist also ein Leib, dessen „Haupt“ CHRISTUS ist (Kol 1,18). Somit bildet ChRISTUS mit seiner Kirche gewissermaßen eine einzige Person: den mystischen oder „,vollständigen“ CHRISTUS ,mit Haupt und Leib“. Die Geburt dieses Christus wurde also am Kreuz vollendet, indem dort unter Schmerzen die Kirche geboren wurde. Bei dieser Geburt wirkte MARIA anscheinend mit, und zwar durch ihr Mitleiden mit dem Gekreuzigten, als sie seine Kreuzigung aus nächster Nähe miterleben musste. Ein aufopferungsvolles Leiden im Dienste CHRISTI als ein Gebären von Christen zu betrachten, liegt nahe, wenn man beachtet, dass auch PAULUS sagt, er leide „Geburtswehen“ für die Christen in Galatien, die er seine „Kinder“ nennt (Gal 4,19).

Tatsächlich deutet nun JOHANNES auch in seinem Evangelium an, dass „Christi Mutter“ am Kreuz auch „Mutter der Christen“ geworden ist. Es heißt nämlich in Joh 19,26-27, dass Jesus am Kreuz mit Bezug auf seinen Lieblingsjünger (nämlich Johannes) zu seiner Mutter sagte: „Frau, siehe da, dein Sohn“, und zu dem Lieblingsjünger: „Siehe da, deine Mutter" (Joh 19,26-27). Zunächst ist dies sicher eine persönliche Angelegenheit: Der sterbende Jesus übergibt seine Mutter seinem liebsten Jünger zur Obhut. Dafür, dass es hier jedoch nicht nur um eine Privatangelegenheit geht, spricht allein schon die Erwähnung dieser Worte an einer solch hervorragenden Stelle des Evangeliums, am Gipfelpunkt des Lebens Jesu, wo man von vornherein nicht theologisch unbedeutende Worte vermuten sollte. Sodann aber brauchte Jesus seine Mutter gar nicht anzureden, wenn er sie lediglich dem Jünger anvertrauen wollte: Mit den Worten „Frau, siehe da, dein Sohn“ scheint Jesus also auch umgekehrt den Jünger in die Obhut Marias zu übergeben. Was aber das wichtigste ist: Hier taucht die seltsame Anrede „Frau“ für Maria auf (wie schon Joh 2,4; dort ebenfalls an einer hervorragend wichtigen Stelle des Evangeliums). Hätte nicht eine allein aus der Sorge des Sohnes für seine Mutter kommende Anrede wenigstens hier „Mutter“ heißen müssen? Die Anrede „Frau“ aber gerade in dieser Situation, wo CHRISTUS durch seinen Tod der ,,alten Schlange“ den entscheidenden Schlag versetzte (vgl. Hebr 2,14) weist deutlich wiederum auf die Frau des Protoevangeliums und die Frau der Apokalypse hin. Dies bestätigt nochmals die Richtigkeit der Identifizierung dieser „Frau“ mit Maria. Maria wurde also am Kreuz in eine symbolische Mutterschaft bezüglich der aus Gnade geborenen Glieder der Kirche („Lieblingsjünger“) eingesetzt. Die GEBURT, von der in Apk 12,1-5 die Rede ist, ist demnach die Geburt des ganzen mystischen CHRISTUS, die mit der schmerzfreien Geburt des Erlösers in 
Bethlehem begann (= Geburt des Hauptes), aber erst am Kreuz mit der schmerzhaften Geburt der Kirche (= Geburt des Leibes) vollendet wurde. Dies wird dadurch bestätigt, dass gleich nach der hier geschilderten „Geburt“ die Himmelfahrt Christi erfolgt (Vers 5).

Die Frau in Apk 12 ist also MARIA, aber es sprechen viele Indizien dafür, dass mit der Frau in irgendeiner Weise auch die Kirche (mit)gemeint ist. Erstens ist es der 12-Sterne-Kranz der Frau (Vers 1), der ein Sinnbild der 12 Stammväter Israels oder (besser) der 12 Apostel, der Stammväter des neuen Bundesvolkes, ist. Sodann ist die Verfolgung der Frau und ihre Flucht in der Wüste zu nennen (Verse 6 und 10), was zwar an die Flucht MARIAs nach Ägypten erinnert, aber im eigentlichen Sinn eine Kirchenverfolgung sein muss. Denn zum einen ist von zwei solchen Wüstenaufenthalten die Rede, und zum anderen beginnen diese Wüstenzeiten erst nach Christi Himmelfahrt CHRISTI (Vers 5), im Gegensatz zu MARIAs Flucht nach Ägypten. Schließlich ist die „Frau“ wohl identisch mit der Kap. 21-22 erwähnten „Braut“ bzw. „Frau des Lammes“ (vgl. 21,2; 21,9 und 22,17), welche „die heilige Stadt Jerusalem“ $(21,10)$ ist: die vollendete Kirche. Die „Frau“ von Apk 12 ist also in stärkerem Maße als die „Frau“ des Protoevangeliums außer ein Symbol für Maria auch ein Symbol für die Kirche. Wenn man in der Frau die Kirche sieht, ist allerdings nicht die gesamte Kirche gemeint, sondern genauer das aktive Element in der Kirche: Denn nur diejenigen Christen können ja zur „Frau“ gehören, die durch ihren aktiven Einsatz CHRISTUS in den Seelen der Menschen ,gebären“.

Abschließend ist festzustellen: die FrAU der Apokalypse ist MARIA und zugleich die Kirche, wobei diese beiden Bedeutungen zu einer Einheit verschmelzen. Zum einen kann man also mit M. J. SCHEEBEN sagen: die Frau ist MARIA ,als ein mit der Kirche organisch verbundenes, wurzelhaft dieselbe in sich befassendes und repräsentierendes, sowie in derselben und durch dieselbe wirkendes Urbild“. Zum anderen ist die Frau der aktive Teil der KIRCHE: die „marianisch“ geprägte Gemeinschaft der Heiligen, die durch ihr Wort, Gebet und Opfer neue Christen gewinnen und Christus in den Herzen der Menschen neu „gebären“, wobei sie zur „Mutter Christi“ werden, gemäß dem Wort Jesu: „Wer den Willen meines Vaters im Himmel tut, ist für mich Bruder und Schwester und Mutter“. Die Frau der Apokalypse zeigt in ihrer Doppelbedeutung, dass Maria und Kirche eng zusammengehören: Maria ist das erste und reinste Glied der Kirche, in Maria ist die „heilige Kirche“ ohne Abstriche verwirklicht. Darum muss die Kirche Maria nachahmen, besonders in ihrer Eigenschaft als Christusgebärerin und Wegbereiterin Christi: Nur so verwirklicht die Kirche ihr ureigenes Wesen.

12,1 Und ein großes Zeichen erschien am Himmel:

Eine Frau, bekleidet mit der Sonne, und der Mond war unter ihren Füßen, und ein Kranz von zwölf Sternen war auf ihrem Haupt.

Die FRAU ist, wie soeben ausführlich erklärt wurde, MARIA und zugleich der „,marianisch“ geprägte Teil der Kirche. Dass die Frau AM HIMMEL erscheint, bedeutet jedoch nicht, dass vom schon im Himmel befindlichen Teil der Kirche oder von der in den Himmel aufgenommenen Gottesmutter MARIA die Rede ist. Das wäre unvereinbar mit den anschließend erwähnten Geburtsschmerzen (Vers 2) und mit der Wüstenflucht der Frau (Verse 6 und 13-16). Die Frau erscheint nur deshalb am Himmel, weil sie in enger Verbindung mit dem Himmel, d. h. mit Gott steht. Der Drache wird in Vers 3 ebenfalls am Himmel erscheinen, weil er in den Augen seiner Anhänger Gott gleich ist und sich an Stelle Gottes verehren lässt.

Die Sonne ist offenbar CHristus und sein Gnadenlicht. Dass Maria und die Kirche mit der Sonne umkleidet sind, zeigt, dass sowohl Maria als auch die Kirche ganz von CHRISTUS durchdrungen sind. Vergleiche Gal 3,21: „Ihr alle, die ihr auf Christus getauft seid, habt Christus angezogen“.

Der MOND unter den Füßen der Frau bezeichnet hier wahrscheinlich nicht die Kirche (denn diese ist schon durch die Frau selbst gekennzeichnet), sondern die wechselhafte, zeitliche, unbeständige Natur. Der Mond wechselt nämlich seine Gestalt, und er bewirkt die Gezeiten: das unbeständige Hinund Herfluten des Meeres. Vergleiche zu dieser Symbolik des Mondes Sir 27,11: „Der Unverständige ändert sich wie der Mond“. Die von der Sonne umkleidete Kirche dagegen ist beständig in Glaube, Lehre, Sitten und Verfolgungen. Vergleiche Sir 27,12 (Vulgata-Version): „Der heilige Mensch bleibt in der Weisheit wie die Sonne, der Dumme aber verändert sich wie der Mond“.

Daher zeigt das STEHEN MARIAs bzw. der Kirche ÜBER DEM MOND ihren Sieg über die Unbeständigkeit, die zeitlichen Übel und über SATAN als denn „Gott dieser Zeit“ (2 Kor 4,4). Der Mond unter den Füßen der Frau erinnert hier an das „Zertreten“ der Schlange aus dem Protoevangelium. 
Der KRAnZ VON ZWÖLF Sternen zeigt, dass Maria die „Königin der Apostel“ ist. Aufgabe der Apostel und daher auch der Kirche ist es ja, Christi Botschaft allen Menschen zu verkünden (Mk 16,15; Mt 28,19-20), d. h. Christus in den Herzen der Menschen zu ,gebären“ (vgl. Gal 4,19), und somit das von Maria begonnene Werk des Gebärens Christi fortzusetzen. Darum steht Maria als „Königin der Apostel“ am Anfang des apostolischen Wirkens (vgl. Apg 1,13-14). Der Kranz von zwölf Sternen zeigt auch, dass das wertvollste Werk der Kirche, mit dem sie „gekrönt“ wird, die Fortsetzung des Werkes der Apostel, also die Christianisierung der Welt sein muss.

12,2 Und sie ist schwanger, und schreit vor Schmerz in ihren Geburtswehen.

MARIA hat Christus, das Haupt der Kirche, in Bethlehem ohne Schmerzen geboren. Aber die SCHWANGERSCHAFT MARIAs ging in gewissem Sinne weiter, und kam in eine schmerzhafte Phase. Unter vielen SCHMERZEN, mit denen sie ihr Leben mit dem Opfer Christi vereinte (vgl. das Wort vom Schwert, das durch MARIAs Seele ging in Lk 2,34-35, die Flucht nach Ägypten Mt 1,13-15, und vor allem das Stehen am Kreuz Joh 19,26-27) gebar MARIA schließlich auch die Glieder der Kirche und somit den vollständigen Leib Christi: Gott ließ sie auf geheimnisvolle Weise mitwirken an der grundlegenden Geburt aller Christen, wie aus Vers 17 klar hervorgeht.

Ähnlich wie Jesus durch sein Leiden der „,neue Adam“ geworden ist (vgl. 1 Kor 15,45), so ist also MARIA durch ihr Mit-Leiden eine Art ,neue Eva“ geworden, die Mutter aller an CHRISTUs Glaubenden. Denn am Kreuz ist gewissermaßen bereits die ganze Kirche einschließlich aller ihrer zukünftigen Glieder geboren, und zwar dadurch, dass CHRISTUS für alle diese Glieder aufgrund seines Sühneleidens im voraus die Erlösung verdient hat, wobei er MARIA zur Mutter all dieser Glieder machte, indem er zu dem „Jünger, der ihn liebte“ (stellvertretend für alle von ihm Geliebten) sagte: „Siehe da, deine Mutter" (Joh 19,26-27).

Danach beginnt jedoch eine neue Reihe von Schwangerschaften der Frau, die bis zum Ende der Zeiten fortgesetzt wird, insofern die Frau (nun als Kirche gedeutet) stets unter mehr oder weniger großen Schwierigkeiten das Evangelium verkünden und dadurch zur tatsächlichen Geburt Christi in den aufeinander folgenden Generationen und Zeitphasen der Menschheitsgeschichte beitragen muss. In ganz besonderer Weise war die Kirche jedoch in den ersten drei Jahrhunderten ,schwanger“. Denn diese Zeit, die Zeit der blutigen Christenverfolgungen im römischen Reich, war entscheidend dafür, dass das Christentum nicht geschichtlich ausstarb, sondern sich endgültig durchsetzte. Nach dem entscheidenden Sieg des Jahres 312 hatte die „Frau“ CHRIstus neu in Form eines das „Licht der Welt" erblickenden, aus den Katakomben befreiten Christentums geboren.

In welcher Schwangerschaft befindet sich die Frau nun im vorliegenden Vers: in jener, die bis zur Kreuzigung Christi reicht, oder in jener, die mit dem Ende der diokletianischen Verfolgung endet oder in einer noch späteren? Die in Vers 5 berichtete Himmelfahrt Jesu zeigt, dass ersteres der Fall ist: Der für alle Zeiten grundlegende mystische CHRISTUS wird hier am Kreuz geboren. Auf die weiteren Schwangerschaften der Frau ist erst am Ende des Kapitels angespielt (Vers 17), wo nach dem Ende der Beschreibung der diokletianischen Verfolgung (Verse 7-16) von den ,übrigen“ Nachkommen der Frau die Rede ist.

12,3 Und ein anderes Zeichen erschien am Himmel, und siehe: ein großer, feuerroter Drache. Er hatte sieben Köpfe und zehn Hörner und auf seinen Köpfen sieben Kronen.

Der Drache ist SATAn, der Teufel (Vers 9). Die ROte FARbe (Farbe des Feuers, des Blutes und der Wut) kennzeichnet ihn als Engel des Todes und der Zerstörung. 
Was bedeuten die SIEBEN KÖPFE und die ZEHN HÖRnER? Die einzige Deutung, die einen Anhaltspunkt im Text hat, ist meines Erachtens die folgende. In Kap. 13,1 zaubert der Drache ein „Tier“ hervor, das ebenfalls sieben Köpfe und zehn Hörner hat. Dieses Tier ist, wie sich zeigen wird, das Römische Reich, seine Köpfe sind die sieben an der diokletianischen Verfolgung beteiligten Kaiser (siehe Kommentar zu 11,7), und seine Hörner sind die Barbaren, die das römische Reich zu Fall brachten. Somit können die sieben Köpfe und zehn Hörner S ATANs als Hinweis darauf gedeutet werden, dass die erwähnten Kaiser und Barbarenkönige auf Betreiben des Teufels hin die Macht ergreifen werden.

Die KRONEN auf den sieben Köpfen kennzeichnen also die sieben „diokletianischen“ Kaiser als Herrscher, die der Teufel auf den Thron zu bringen plant (im Gegensatz zu 13,1, wo sich die Kronen nicht mehr auf den sieben Köpfen, sondern auf den zehn Hörnern befinden, weil in 13,1 die Herrschaftszeit der sieben diokletianischen Kaiser bereits abgelaufen ist und die Zeit der zehn Barbarenkönige naht). ${ }^{69}$

12,4a Und sein Schwanz fegte den dritten Teil der Sterne vom Himmel und warf sie auf die Erde.

SATAN warf den DRITTEN Teil, d. h. einen großen, aber nicht den größten Teil der STERNE vom Himmel. Wenn die Sterne Engel sind, wäre hier vom sogenannten „Engelsturz“ am Anfang der Zeiten die Rede, bei dem SATAN mit einer Schar von Engeln gegen Gott rebellierte und diese Engel zu Dämonen machte (vgl. Kommentar zu 9,1). Es könnten auch vorbildliche Lehrer des wahren Glauben gemeint sein, die SATAN zu Fall brachte (siehe Kommentar zu 1,20 und 9,1). Dass diese vom Himmel auf die Erde geworfen wurden, würde bedeuten, dass ihr Sinn vom Himmel abgezogen und auf niedrige, irdische Ziele hin ausgerichtet wurde. Gemeint ist wahrscheinlich beides: SATAN gliedert STERNE, d. $h$. sowohl Engel als auch hervorragende Menschen, in sein Heer ein.

Dieser mit dem ScHWANZ des Teufels (Anspielung an das männliche Genital) durchgeführte Vorgang ist das Gegenstück zum „Gebären“ der Frau: der Teufel „zeugt“ den „Samen der Schlange“, während die Frau dem guten Samen, angefangen mit CHRISTUS, das Leben gibt. JOHANNES sieht hier, wie sich die im Protoevangelium (Gen 3,15) genannte Kampfesfront zwischen der DrachenSchlange und ihrem „Samen“ einerseits und der Frau und ihrem „Samen“ andererseits ausbildet.

12,4b Und der Drache stelle sich vor der Frau, die gebären sollte.

Er wollte ihr Kind verschlingen, sobald sie geboren hat.

12,5 Und sie gebar einen männlichen Sohn, der alle Völker mit eisernem Stab weiden soll. Und ihr Kind wurde zu Gott und zu seinem Thron entrückt.

Der Sohn ist Christus, der bereits in 2,27 von seiner Aufgabe, DIE VölKER MIT EISERNEM StAB ZU WEIDEN, gesprochen hat. Dort war auch von einer „Teilhabe“ der treuen Christen bei diesem WEIDEN (d. h. Regieren) die Rede. Der Sohn ist also CHRISTUS „,mit Haupt und Leib“, d. h. der mystische CHRISTUS, dessen Geburt bei der Kreuzigung vollendet wurde. Daher kann auch sofort nach der „Geburt“ des Sohnes von seiner Entrückung zum Thron Gottes, d. h. von seiner Himmelfahrt gesprochen werden.

Der Versuch Des DRACHEN, DAS Kind ZU Verschlingen, ist der Versuch des Teufels, den mystischen CHRISTUS dadurch zu töten, dass er die Menschen zuerst dazu brachte, CHRISTUS leiblich zu töten (vgl. Joh 13,2), um danach den Leib Jesu bis zur Verwesung im Grab festzuhalten und so seine Jünger zur Hoffnungslosigkeit (vgl. Lk 24,17-21) und zum Abfall vom Glauben zu bringen.

69 Andere mögliche Deutungen (die vielleicht mitgemeint sind), sind folgende:

Die SIEBEN KÖPFE könnten sein: 7 Dämonen, die SATAN entsprechend den „sieben Geistern am Thron Gottes“ $(1,4)$ einsetzt, die 7 Hauptsünden, das Gegenteil der sieben Geistesgaben (siehe Kommentar zu 1,4c) oder ein Symbol für die vollkommene Schläue SATANs (Kopf = Schlauheit, sieben $=$ Vollkommenheit $)$.

Die ZEHN HÖRNER könnten sein: die 10 Christenverfolgungen im Römischen Reich oder ein Symbol für die gewaltige Macht Satans (Hörner $=$ Macht, $10=$ Vollkommenheit .

Die KRONEN könnten schließlich Requisiten SATANs als dem „Fürsten dieser Welt“ (Joh 12,31) sein. 
Aber gerade die Kreuzigung Jesu war die endgültige Geburt des Kindes, so dass der Teufel wider Willen in gewisser Weise Geburtshilfe bei der Geburt seines Überwinders leistete. Das lehrt auch das Protoevangelium (Gen 3,15): „Er (der Same der Frau) wird dir (der Schlange) den Kopf zermalmen und du (die Schlange) wirst ihm (dem Samen) die Ferse zermalmen“.

Die Schlange tut also ihrem Besieger dasselbe an, was dieser ihr antut: Sie zermalmen sich gegenseitig. Dabei erleidet die Schlange eine Totalkatastrophe (sie wird am Kopf zermalmt), während der siegreiche Same, d. h. CHRISTUS, nur an der Ferse getroffen wird. Genauer: Indem die Schlange einen Teil ihres Besiegers (nämlich seine Ferse) zermalmt, wird sie selber vollständig zermalmt, und zwar durch genau den Teil ihres Besiegers, den sie zermalmt. Was das Protoevangelium auf so geheimnisvolle Weise beschreibt, ist das Mysterium, dass CHRISTUS ,durch seinen Tod den Gewalthaber über den Tod, nämlich den Teufel, entmachtet hat" (Hebr 2,14), der fälschlich geglaubt hat, seinerseits CHRISTUS am Kreuz entmachtet zu haben. Freilich war die Entmachtung SATANs am Kreuz vorerst nur eine Art Richterspruch, dessen faktische Vollstreckung erst nach und nach in der Geschichte (und in letzter Vollendung erst am Ende der Geschichte) erfolgen wird: die unheilbare „Kopfwunde“ der Schlange braucht also noch Zeit, um ihre vernichtende Wirkung auszuüben. Das geplante VERSCHLINGEN misslang jedenfalls: Jesus erstand von den Toten und wurde ZU GOTTES THRON ENTRÜCKT.

12,6 Und die Frau floh in die Wüste, wo Gott ihr einen Ort bereitet hat, damit man sie dort ernährt 1260 Tage.

Die FLIEHENDE FRAU ist hier die marianische, vom Staat verfolgte Kirche. Die WÜSTE bezeichnet den Untergrund, in dem sich Christen während der Verfolgung verbergen müssen, denn während der ersten großen religiösen Verfolgung Israels durch Antiochus Epiphanes (168-164 v. Chr.) musste das Volk tatsächlich in die Wüste fliehen (1 Makk 2,31). Zu der symbolischen Zeitangabe der 1260 TAGE siehe Kommentar zu 11,2b. Die ERNÄHRUNG DER FRAU IN DER WÜSTE bedeutet ihre Versorgung im Untergrund mit geistlichen Gütern, d. h. mit den Sakramenten und dem Wort Gottes.

Manche sehen in dieser Verfolgungsphase ganz allgemein die gesamte Zeit der Kirche, von der Zeit Christi bis zum Ende der Geschichte. Aber damit ist unvereinbar, dass nach der Verfolgung der 1260 Tage, die mit einem großartigen „Sieg“ Gottes endet (Verse 10-12a), eine weitere Verfolgung mit einer erneuten Wüstenflucht von 3 1/2 Zeiten folgt (Verse 12b-14), und dass, nachdem auch diese Verfolgung beendet wurde (Verse 15-16), noch eine dritte, zeitlich nicht befristete Verfolgung einsetzt (Vers 17).

Die erste Verfolgungswelle, gegen welche die Kirche zu kämpfen hatte, waren die römischen Verfolgungen der ersten Jahrhunderte. Die 1260 Tage scheinen daher identisch zu sein mit den 1260 Tagen der Zeugnisperiode der ,zwei Zeugen“ in 11,3. Es ist die Zeit von 112 (Trajansches Edikt) bis 303 (Anfang der diokletianischen Verfolgung).

Anmerkung: Die Zeit von Christi Himmelfahrt bis zum Trajanschen Edikt kann man dann als der Prozess des „Fliehens“ der Kirche in die Wüste ansehen: Denn die Kirche musste sich seit 64 (Beginn der neronischen Verfolgung), immer mehr zurückziehen, bis sie seit 112 überall im Reich verfolgt wurde, so dass sie nun ihre „Wüste“ erreicht hatte und die 1260 Tage ihres Wüstenaufenthaltes begannen.

12,7 Und es entstand ein Krieg im Himmel.

Michael und seine Engel kämpften mit dem Drachen.

Und der Drache und seine Engel kämpften.

12,8 Und er konnte sich nicht halten, und er verlor seinen Platz im Himmel. 
12,9 Und geworfen wurde der große Drache, die alte Schlange,

der „Teufel“ und „Satan“ genannt wird, und die ganze Erde verführt-

er wurde geworfen auf die Erde, und seine Engel wurden mit ihm (herunter)geworfen.

Mit diesem KRIEG beginnt folgerichtig die Phase der diokletianischen Kirchenverfolgung. Jedoch ist hier nicht (wie in 11,7) vom irdischen Ablauf dieses Krieges die Rede, sondern vom Kampf der guten und bösen Engel, der diesen Krieg hintergründig begleitete (KRIEG IM HIMMEL). Der HIMMEL bezeichnet dabei nicht die Verbundenheit mit Gott, sondern allgemeiner den Bereich wahrer oder scheinbarer himmlischer (gottähnlicher) Machtstellung, in dem sich auch die bösen Engel vor ihrer Entlarvung als böse Geister befanden.

Die guten Engel werden von MICHAEL angeführt: Dieser Engel wird auch beim Propheten DANIEL $(12,1 ; 10,13.21)$ als ,Fürst“ (Schutzgeist) des Volkes Gottes bezeichnet. Er ist der oberste der „,sieben Engel“" im Dienste Christi (siehe Kommentar zu 1,4).

Michael kämpft gegen den TEufEL UND SEINE ENGEL, die Dämonen, und wirft sie auf die Erde herab. Der Name TEUFEL (griech. „Diabolos“) bedeutet „Verleumder“. Ähnliches bedeutet der hebräische Name SATAN: „Widersacher“, „Gegner“, „Ankläger“. Der Teufel ist auch DIE ALTE SCHLANGE, weil er einst im Paradies die Stammeltern in Gestalt einer Schlange zum Bösen verführt hatte (Gen, Kap. 3).

Der HimmelstuRz der bösen Engel hat mehrere Dimensionen, wie bereits im Kommentar zu 9,1 gezeigt wurde. SATAN wurde auf jeweils anderer Ebene aus dem „Himmel“ gestürzt

- am Anfang der Zeiten,

- beim Kommen Christi,

- und bei Christi Kreuzigung.

Ein weiterer Himmelsturz geschieht bei jeder weiteren Entlarvung SATANs, und wird in letzter Konsequenz nochmals beim letzten Gericht geschehen, wenn SATAN in den „Feuersee“ hineingeworfen werden wird $(20,10)$.

Dem Zusammenhang nach bedeutet der Himmelsturz, von dem hier die Rede ist, wohl die Erniedrigung Satans durch das „Toleranzedikt des Galerius“ vom April 311 (siehe Kommentar zu 11,7), welches die diokletianische Verfolgung zwar noch nicht ganz beendete - vorerst wurde sie nur unterbrochen - aber doch bereits die entscheidende Wende einleitete, die nun bald zum Sieg des Christentums führen sollte. Die Dämonen wurden hier aus den Himmelshöhen ihrer bisher als unanfechtbar erschienenen Machtposition herabgestürzt.

Ihr Sturz AUF DIE ERDE bedeutet, dass sie nun ihren irdischen Untertanen nicht mehr wie unangefochtene, „himmelhoch“ thronende Herrscher in aller Ruhe vorstehen, sondern wie gestürzte Tyrannen, die um ihr Leben bangen müssen, in den „Untergrund“ gehen. Sie begeben sich zu ihren Untertanen hinab, um durch rastlose Tätigkeit jeden einzelnen für den Kampf zur Wiedergewinnung ihrer Herrschaft zu mobilisieren. Siehe genauer Verse 12-13.

12,10 Und ich hörte eine laute Stimme im Himmel sagen: Jetzt ist gekommen die Rettung und die Macht und die Herrschaft unseres Gottes und die Vollmacht seines CHRISTUS, weil der Ankläger unserer Brüder (herunter)geworfen wurde, der sie vor unserem Gott tags und nachts anklagt(e). 
12,11 Und sie haben ihn besiegt kraft des Blutes des Lammes

und kraft des Wortes und ihres Zeugnisses,

und sie hielten ihr Leben nicht fest bis hinein in den Tod.

Die Stimme stammt von Menschen: das zeigt der Ausdruck „Ankläger unserer Brüder“ (Vers 10). Denn diese „Brüder“ sind Menschen, die durch das „Blut“ des Lammes erlöst sind und das Martyrium erlitten (Vers 11). Somit spielt sich dieser Lobpreis ab zu einer Zeit, da bestimmte Menschen im Himmel sind, welche das christliche Martyrium anderer Menschen rühmen können. Es ist also unmöglich, diesen Jubelruf, wie es einige Ausleger tun, in den Zeitpunkt des Todes Jesu zu verlegen, denn dort gab es weder Menschen im Himmel (vergleiche Kommentar zu 14,13), noch gab es bereits christliche Märtyrer. Ebenso wenig geht es an, diesen Jubel auf den ,jüngsten Tag“, also an das Ende der Menschheitsgeschichte zu verlegen. Denn bereits im nächsten Vers beginnt Satan eine neue Kirchenverfolgung, was beweist, dass die Geschichte noch nicht abgelaufen ist. Also muss dieser Jubel ein ,Zwischensieg“ sein zwischen dem Siege Christi am Kreuz und dem endgültigen Sieg Christi am Ende der Geschichte. Es gibt dafür keinen passenderen Zeitpunkt als den Thriumph des Christentums am Ende der römischen Christenverfolgungen. Nach unserer Auslegung von Vers 9 fällt dieser Jubel in die Zeit des Toleranzediktes des Galerius vom 30. April 311.

Inwiefern wurde aber damals SATAN ALS ANKLÄGER der Menschen gestürzt? SATAN ist „Ankläger“, wie schon sein Name sagt (siehe Kommentar zu 12,7-9), und wir sehen ihn im Alten Testament die Menschen vor Gott wegen ihrer Schuld anklagen, weil er ihnen aus Neid dieselbe Verurteilung wünscht, die ihn selbst getroffen hat (Job 1,6-11; 2,1-5; Sach 3,1). Durch Jesu Tod aber wurde, wie Paulus in Kol 2,14 sagt, ,der Schuldschein, der gegen uns sprach, durchgestrichen und seine Forderungen, die uns anklagten, aufgehoben. (Christus) hat ihn getilgt, indem er ihn an das Kreuz geheftet hat."

Somit endete die Karriere SATANs als „Ankläger“ in gewisser Weise mit dem Tode Christi. Freilich ist dies nur ein relativer „Hinauswurf“ des Anklägers aus dem Himmel, da sich die Schuldscheintilgung nur auf die vor der Taufe bestehende Schuld bezieht (Kol 2,12-13), so dass ein gewisser Spielraum für weitere Anklagen bleibt. Dieser durch das Kreuz Christi erfolgte Sturz Satans als Ankläger wird bei jedem Sieg der Kirche über die sie verfolgenden gottfeindlichen Mächte vertieft, weil es dadurch zur Bekehrung der Menschen, zum Sieg über die Sünde und somit zum Verlust an „Anklagematerial“ kommt, das Satan gegen die Menschen vorbringen kann. In diesem Sinne kann bei jedem Sieg der Kirche von einem weiteren Sturz Satans aus der Position des Anklägers geredet werden.

In der Tat kam es nach dem Toleranzedikt des Galerius 311 zu Massenbekehrungen. Der Zeitgenosse EUSEBIUS berichtet in (Kirchengeschichte 9,1), es habe ,in allen Städten gefüllte Kirchen, zahlreich besuchte Zusammenkünfte und die hierbei üblichen Gottesdienste“ gegeben, so dass „die ungläubigen Heiden ... über diesen unerwarteten und gewaltigen Umschwung staunten und riefen: ,Groß und allein wahr ist der Gott der Christen; “"

Auch die in der Verfolgung schwach gewordenen Christen, so fährt EUSEBIUS fort, „mühten sich eifrig um ihre Gesundung und richteten an die Starken inständige Bitten, dass sie ihnen die Hand zur Rettung reichten, und flehten zu Gott, dass er ihnen gnädig sei“. Und als die Christen aus den schlimmen Leiden in den Bergwerken, wohin man viele verbannt hatte, zurückkehrten, da ,wanderten Scharen um Scharen dahin, mitten auf Heerstraßen und Marktplätzen in Liedern und Psalmen Gott preisend. ... So kam es, dass selbst jene, die früher Mord wider uns sannen, angesichts des ganz unerwarteten Wunders sich an dem Geschehenen mitfreuten.“

\section{Daher freut euch, ihr Himmel und ihr, die ihr darin wohnt!}

Die hier gemeinten BewOHNER DES HIMMELs sind die Christen, und zwar neben den schon im Himmel weilenden wohl auch die noch auf Erden lebenden. Diese befinden sich in einem geistigen Sinn bereits im Himmel, insofern sie, von den Sünden befreit, mit dem im Himmel befindlichen Herrn JESUS CHRISTUS verbunden sind: „Gott ... hat uns, als wir infolge unserer Sünden tot waren ... mit CHRISTUS auferweckt und uns zusammen mit ihm einen Platz im Himmel gegeben“. (Eph 2,4-6) „Ihr seit ... Mitbürger der Heiligen und Hausgenossen Gottes“. (Eph 2,19) 
12,12b Aber wehe der Erde und dem Meer, denn der Teufel ist zu euch herabgestiegen und hat großen Zorn, wissend, dass er (nur noch) wenig Zeit hat.

Während sich der Teufel im „Himmel“ befand, d. h. in einer scheinbar gottgleichen Herrscherstellung, begnügte er sich damit, die Christenverfolgung ,,aus der Ferne“ zu leiten. Jetzt aber ist er symbolisch in die irdischen Bereiche (Erde und Meer) heruntergekommen. Dies bedeutet, dass er nun unmittelbar in das irdische Geschehen eingreift, nicht mehr wie ein himmelhoch-unnahbarer Herrscher, der sich um nichts zu kümmern braucht, weil ihm sowieso alles tief zu Füßen liegt, sondern wie ein gestürzter Regent, der in einem Verzweiflungsakt selbst zur Waffe greift und an den Operationen seiner Soldaten aktiv teilnimmt. (vgl. auch Vers 9).

Daher WeHE DER ERDE UND DEM MEeR! D. h. wehe den noch auf Erden lebenden Untertanen SATANs, wo der SATAN jetzt eigenhändig für eine KURZE ZEIT wüten wird (wie wir sehen werden, vom Herbst 311 - Oktober 312), um seine sich schon abzeichnende endgültige Niederlage unter KONSTANTIN aufzuhalten.

Das Wehe gilt denen, die SATAN jetzt zu einer neuen Verfolgungswelle aufstachelt und in ihr seelisches Verderben führt. Es gilt nicht den Christen, die nicht als „Bewohner der Erde“, sondern als Bewohner des Himmels bezeichnet worden sind (siehe Kommentar zu 12a), und die darum auch, wie Vers 14 zeigen wird, von Gott in Sicherheit gebracht werden. Es handelt sich hier um eine Vorandeutung des „3. Wehe“, mit dem die 7. Posaune abschließt, und das in Kap. 18 erklingen wird.

12,13 Und als der Drache sah, dass er auf die Erde geworfen war, verfolgte er die Frau, die den Knaben geboren hatte.

Der Friede nach dem Toleranzedikt des GaleriUs (April 311) hielt nicht lange an. Schon im Herbst 311 begann MAXIMINUS DAJA, der nach dem Tod des GaleRIUS der neue Oberherrscher geworden war, erneut die Christen zu verfolgen, und zwar in einer viel brutaleren Weise, als es DiOKLETIAN und GALERIUS getan hatten. ${ }^{70}$

12,14 Und der Frau wurden die zwei Flügel des großen Adlers gegeben,

damit sie in die Wüste an ihren Ort fliege:

dort wird sie eine Zeit und zwei Zeiten und eine halbe Zeit ernährt.

Hier erfolgt die ZWEITE WÜstenflucht der Frau, d. h. ein erneuter Rückzug der Kirche in den Untergrund (siehe Kommentar zu 12,6). Der Rückzug war diesmal vollständiger als beim ersten Mal, als immerhin noch die „Zwei Zeugen“ ihr machtvolles Wirken entfalten konnten (vgl. 11,3-6), während die neue Wüstenflucht der Phase des scheinbaren „Totseins“ der Zeugen entspricht (vgl. 11,8-11). MaXiminus sah die Christen nämlich als eine Pest an, so dass er nach den Worten des damals lebenden Christen Eusebius (Kirchengeschichte 9,10,12), ,uns in keiner Stadt, ja nicht einmal auf dem Land und in der Wüste zu wohnen gestattete".

Der GROSSE ADLER bezeichnet Gott als den Retter in der Not. Vergleiche Ex 19,4, wo Gott spricht: „Ihr habt gesehen, was ich den (euch verfolgenden) Ägyptern angetan habe, wie ich euch auf Adlerflügeln hierher zu mir (zum Berg in der Wüste Sinai) gebracht habe“. Vergleiche auch Jes 40,31: „Die dem Herrn vertrauen, ... bekommen Flügel wie Adler. Sie laufen und werden nicht müde.“

Als Dauer der vorliegenden Wüstenflucht werden hier als 3 1/2 ZEITEN, in 11,8-11 dagegen 3 1/2 TAGE angegeben. Der Grund, warum einmal von „Tagen“ und einmal von „Zeiten“ die Rede ist, dürfte der sein, dass dem Leser klar werden soll, dass es sich um ein symbolisches Zeitmaß handelt.

70 Vgl. EuseBius, Kirchengeschichte 9,11. 
Die 3 1/2 Zeiten sind nicht mit den 1260 Tagen von Vers 6 identisch, wie manche Ausleger glauben, welche die Gleichung 3 1/2 Zeiten“ (= 3 1/2 Jahre) = 1260 Tage aufstellen, und wegen der so „,bewiesenen“ gleichen Zeitdauer nur von einer einzigen Wüstenflucht sprechen.

Die 3 1/2 Zeiten müssen nämlich kürzer sein als die 1260 Tage: Denn andernfalls wäre es unverständlich, dass Satan diese Verfolgung in Hast begeht, weil er nur noch ,wenig Zeit“" hat (Vers 12b). Außerdem fand die Wüstenflucht in Vers 6 vor dem Sturz Satans aus dem Himmel statt (Vers 7-8), während die jetzige eindeutig eine Folge dieses Sturzes ist.

12,15 Und es stieß die Schlange aus ihrem Rachen Wasser wie einen Fluss aus, in Richtung auf die Frau, damit sie vom Fluss fortgerissen würde.

Der FLuSs steht für eine Menschenmenge (vgl. 17,15). Der aus dem Mund der ScHLANGE kommende Fluss, der die FRAU ertränken sollte, ist die letzte Phase der Verfolgung, gesehen unter dem Bild eines den Christen hinterherjagenden Heeres.

12,16 Und die Erde half der Frau:

Und die Erde öffnete ihren Mund und verschluckte den Fluss, den der Drache aus seinem Mund ausgestoßen hatte.

Der FRAU wurde tatsächlich durch die ERDE, d. h. durch weltliche Mächte geholfen, welche den FLUSS der Christenverfolger VERSCHLUCKTEN: Unter Konstantin und LiCINIUS griff der Staat zum ersten Mal zugunsten der Kirche ein, vernichtete die Tyrannen MAXENTIUS und MAXIMINUS und ihre Helfershelfer und brachte die Verfolgung dadurch 312/313 zu ihrem Ende. 


\section{Exkurs 6: Überblick über die Ereignisse in Kap. 11-12}

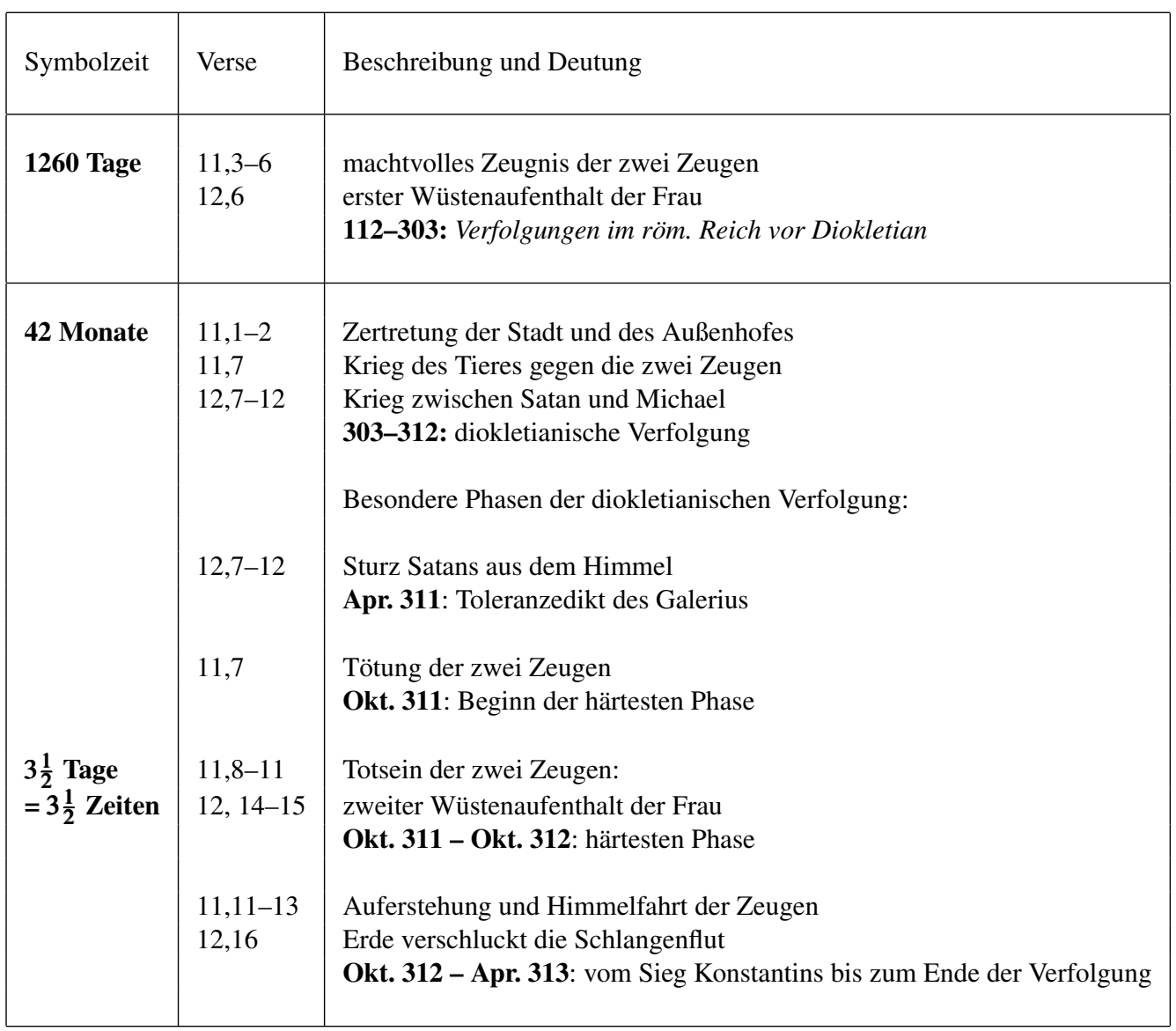

12,17 Und der Drache wurde zornig über die Frau und ging weg,

um Krieg zu führen mit den übrigen ihres Samens,

(mit) denen, welche die Gebote Gottes und das Zeugnis Jesu festhalten.

Dieser KRIEG geht gegen die ÜBRIGEN Nachkommen der FRAU: die Christen aller kommenden Generationen, welche die Frau bis zum Ende der Zeiten „gebären“ wird. Ihnen gegenüber stehen die Christen der Märtyrerkirche der ersten Jahrhunderte, welche die Frau nun erfolgreich durchgebracht hat. Dieser neue Krieg ist nicht mehr durch eine Wüstenflucht der Frau gekennzeichnet, d. h. die Kirche muss nicht mehr als ganze in den Untergrund gehen. Satan konnte seit Konstantin nur noch örtlich beschränkte Verfolgungen ausbrechen lassen, die jeweils nur einen relativ kleinen Teil der Christenheit erfassten, also nur einzelne Nachkommen der Frau bedrohten, aber nicht die Frau als ganzes. 


\section{Exkurs 7: Anmerkungen zur Mariologie}

Im Licht von Apk 12 können mehrere Lehren der katholischen Christenheit über Maria verständlich gemacht werden, für welche auch Luther noch aufgeschlossen war, die aber im heutigen Protestantismus zumeist auf Ablehnung stoßen, weil sie als unbiblisch gelten: Leicht verständlich wird in Apk 12 vor allem die Lehre, dass Maria die größte aller Heiligen ist. Denn sie muss als Urbild und Repräsentantin der Kirche dieselbe Heiligkeit haben wie die marianische Kirche insgesamt.

Ebenfalls lässt sich aus Apk 12 die Lehre von der Unbefleckten Empfängnis Marias (= die Lehre von der absoluten Sündenfreiheit Marias seit ihrer Empfängnis) begründen. Denn diese Lehre folgt logisch aus der Annahme einer vollkommenen Bewahrung vor dem Einfluss Satans. Die Verse 6,14,15, und 16 zeigen, dass die „Frau“ in allen Anstürmen Satans göttlich beschützt wurde, und in Vers 17 erfahren wir schließlich, dass Satan gänzlich von der Verfolgung der Frau absah. Somit ist die Frau endgültig gerettet, und zwar ohne irgendeinen Schaden erlitten zu haben. All dies muss, wenn es für die „marianisch geprägte Kirche“ gilt, erst recht und in vollkommenster Weise für Maria als Einzelperson zutreffen. Eine zweite Überlegung hierzu ist folgende: Wie im Protoevangelium, wo ein und dieselbe „Feindschaft“" CHRISTUS und Maria von der Schlange trennt (,Feindschaft stifte ich zwischen dir und der Schlange, zwischen deinem Samen und ihrem Samen“), so stehen sich auch in Apk 12 Maria und Satan als zwei entgegengesetzte „Zeichen“ gegenüber. Genauso, wie Satan ganz auf der Seite des Bösen steht, steht demnach Maria ganz auf der Seite des Guten, ganz auf der Seite Christi. Damit wäre unvereinbar, wenn Maria irgendwie mit der Sünde in Berührung gekommen wäre: Folglich war sie seit ihrer Empfängnis, d. h. vom ersten Augenblick ihres Daseins an frei von aller Sünde.

Schließlich wird auch die Lehre von der Aufnahme Marias mit Leib und Seele in den Himmel („Mariä Himmelfahrt“) verständlich. Diese Lehre folgt ebenfalls aus der völligen Bewahrung vor dem Teufel, denn der leibliche Verwesungstod ist eine Folge der Knechtschaft unter Satan als den „Machthaber über den Tod“ (Hebr 2,14). Folglich durfte Marias Leib nicht verwesen. Wenn sie im Kampf gegen die Schlange ganz auf die Seite Jesu gehört, muss sie auch am Sieg Jesu über die Schlange in vollem Maße teilnehmen, durfte also ebenso wenig wie ihr Sohn im Grab verbleiben.

12,18 Und er stellte sich an den Strand des Meeres.

Der DRACHE (Teufel) stellt sich an den Strand des Meeres, um von hier aus den Krieg gegen die „übrigen Nachkommen“ der Frau zu führen. Nach einer anderen Lesart heißt es „Und ich stelle mich an den Strand des Meeres“. Diese Lesart scheint nicht die ursprüngliche zu sein, aber sie drückt sachlich richtig aus, dass Johannes nun am Strand von Patmos steht und dort die jetzt folgende Visionen hat.

Das MEER steht für Menschenmassen und für die unruhig wogende, von Stürmen gepeitschte Menschheitsgeschichte. Es ist wegen seiner unabsehbaren Tiefe auch Symbol für den „Abgrund“ des Bösen. Zugleich ist MEER eine alttestamentliche Bezeichnung für den Westen, weil das Mittelmeer Israels Westgrenze war. Der Westen ist aber wegen der dort untergehenden Sonne symbolisch die Himmelsrichtung des Antichristen und des Weltuntergangs.

Sehr passend also stellt sich der Drache an das Meer: d. h. er schaut nach „Westen“ und in den „Abgrund“ und über die unsteten Menschenmassen der Weltgeschichte, um aus diesem MEER immer neues Unheil heraufzubeschwören. 


\subsection{Apk 13,1-18: Die zwei Tiere}

\section{Text}

13,1 Und ich sah aus dem Meer ein Tier heraufkommen: Es hatte zehn Hörner und sieben Köpfe, und auf seinen Hörnern zehn Kronen und auf seinen Köpfen gotteslästerliche Namen.

13,2 Und das Tier, das ich sah, glich einem Panther, und seine Füße waren wie die eines Bären, und sein Maul war wie das Maul eines Löwen. Und der Drache gab ihm seine Kraft und seinen Thron und seine große Macht.

13,3 Und einer seiner Köpfe war wie geschlachtet zum Tode. Aber seine Todeswunde wurde geheilt. Und die ganze Erde sah dem Tier staunend nach.

13,4 Und (die Menschen) beteten dem Drachen an, weil er die Macht dem Tier gegeben hatte.

Und sie beteten das Tier an und sagten:

Wer ist dem Tier gleich und wer kann mit ihm Krieg führen?

13,5 Und das Tier wurde ermächtigt,

mit seinem Maul anmaßende Worte und Lästerungen auszusprechen.

Und es wurde ihm Macht gegeben, (dies) 42 Monate lang zu tun.

13,6 Und das Tier öffnete sein Maul gegen Gott, um seinen Namen zu lästern, und seine Wohnung, und alle die im Himmel wohnen.

13,7 Und es wurde ihm (Macht) gegeben, gegen die Heiligen Krieg zu führen und sie zu besiegen. Und es wurde ihm Macht gegeben über alle Stämme, Völker, Sprachen und Nationen.

13,8 Und anbeten werden ihn alle Bewohner der Erde, (jeder,) dessen Name nicht eingetragen ist ins Lebensbuch des Lammes, das geschlachtet wurde, seit Anbeginn der Welt.

13,9 Wer Ohren hat, der höre:

13,10 Wer in die Gefangenschaft (geht oder gehen lässt?), der geht in die Gefangenschaft. Wer mit dem Schwert (getötet wird oder tötet?), der wird mit dem Schwert getötet. Hier ist die Geduld und der Glaube der Heiligen.

13,11 Und ich sah: Ein anderes Tier stieg aus der Erde herauf. Es hatte zwei Hörner wie ein Lamm, aber es redete wie ein Drache.

13,12 Und die ganze Macht des ersten Tieres übte es vor ihm aus. Und es (das zweite Tier) veranlasst die Erde und ihre Bewohner, dass sie das erste Tier anbeten, dessen tödliche Wunde geheilt worden war.

13,13 Es tat große Zeichen, so dass es sogar Feuer vom Himmel auf die Erde fallen ließ vor den Augen der Menschen.

13,14 Und es verführt die Bewohner der Erde durch die Zeichen, die zu tun ihm gewährt wurden vor dem Tier.

Und es sagt den Bewohnern der Erde, dass sie ein Bild machen sollten vom Tier, das mit dem Schwert erschlagen war und wieder lebendig geworden ist.

13,15 Und es wurde ihm die Macht gegeben, dem Bild des Tieres Lebensgeist zu verleihen, damit das Bild des Tieres spreche und (damit es) bewirke, dass alle getötet würden, die das Bild des Tieres nicht anbeten würden.

13,16 Und es (das zweite Tier) veranlasst die Kleinen und die Großen und die Reichen und die Armen und die Freien und die Sklaven, ein Kennzeichen auf ihrer rechten Hand und auf ihrer Stirn anzubringen.

13,17 Und (das zweite Tier veranlasst,) dass niemand kaufen oder verkaufen könne, der nicht das Kennzeichen, den Namen des (ersten) Tieres oder die Zahl seines Namens hat. 
13,18 Hier ist Weisheit. Wer Verstand hat, berechne die Zahl des Tieres.

Es ist nämlich die Zahl eines Menschen,

und seine Zahl ist 666 (nach einigen Handschriften statt dessen: 616).

\section{Auslegung}

13,1 Und ich sah aus dem Meer ein Tier heraufkommen: Es hatte zehn Hörner und sieben Köpfe, und auf seinen Hörnern zehn Kronen und auf seinen Köpfen gotteslästerliche Namen.

13,2 Und das Tier, das ich sah, glich einem Panther, und seine Füße waren wie die eines Bären, und sein Maul war wie das Maul eines Löwen.

Und der Drache gab ihm seine Kraft und seinen Thron und seine große Macht.

Dieses TIER, was offenbar vom Teufel selber, d. h. von dem am Strand des Meeres befindlichen Drachen $(12,18)$ hervorgezaubert wurde, kann nicht, wie oft behauptet wird, der endzeitliche Antichrist sein, denn damit wäre unvereinbar, dass diejenigen, ,die das Tier nicht angebetet haben“ nach dessen Untergang $(19,20)$ noch 1000 Jahre herrschen müssen $(20,4-6)$.

Das Tier gleicht dem vierten Tier der Daniel-Prophetie (Dan 7,7), hat aber Merkmale aller vier Tiere, und seine sieben Köpfe ergeben sich aus der Summe der Köpfe aller vier Tiere der Daniel-Prophetie $(1+1+4+1)$. Die Tiere DANIELs bezeichnen vier nacheinander kommende Weltreiche (Dan 7,23), und daher scheint auch das Tier der Apokalypse ein Weltreich zu sein, das die Macht aller vorherigen Reiche in sich vereinigt. Wie sich im Schlüsselkapitel 17 zeigen wird, ist mit dem Tier hier (ebenso wie mit dem vierten Tier bei Daniel) das heidnisch-römische Reich gemeint.

Die SIEBEN KÖPFE sind nach 17,9 „sieben Könige“. Die Anzahl dieser sieben Könige muss wegen der präzisen Angaben über einzelne dieser Könige in 17,10 wörtlich genommen werden. Es handelt sich um die sieben Kaiser, die an der diokletianischen Verfolgung beteiligt waren (zum Nachweis dieser Behauptung siehe Genaueres im Kommentar zu 17,10):

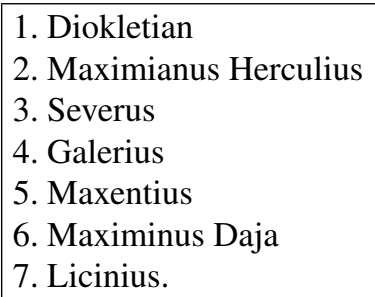

Die ZEHN HÖRNER sind die Barbarenfürsten und -völker, die als Verbündete in den römischen Heeresdienst eintraten, und später das Römische Reich vernichteten (siehe Kommentar zu 17,3 und 17,12-17).

Die GOTTESLÄSTERLICHEN NAMEN auf den Köpfen sind gotteslästerliche Titel, die sich diese sieben Kaiser gaben: So nannte sich z. B. Diokletian JUPITER, Maximianus HERCULES, Galerius MARS und Maximinus Daja ebenfalls JUPITER. 
Das Tier, d. h. sein Leib, Glich EINem PAnther. Dies könnte auf MaXimianus Herculius hinweisen, den Kaiser des Westreiches. Denn der Panther ist wegen seines gefleckten Fells Symbol der Unbeständigkeit, des Flatterhaften, des Hin- und Herschwenkens. Maximianus Herculius war ein wechselhafter Mann: Er dankte als Kaiser 305 ab, wurde 306 wieder Kaiser, wurde 308 wieder abgesetzt, erklärte sich im selben Jahre abermals zum Kaiser und wurde schließlich endgültig abgesetzt. Er unterstützte zunächst seinen Sohn, dem Usurpator Maxentius, versuchte ihn dann aber zu stürzen. Er war zuerst Freund des Galerius, dann sein Feind. Er verbündete sich mit Konstantius Chlorus, plante dann aber seinen Sturz und beging nach Aufdeckung dieses Plans Selbstmord (310). Der „Panther“ Maximianus wird zuerst genannt und mit dem Leib des Tieres identifiziert, vielleicht weil Maximianus als erster, bereits vor dem 303 erlassenen allgemeinen Edikt Diokletians, Christen verfolgte, wohl schon seit 286, und bis 310 weitermachte, also länger als jeder andere Kaiser als Verfolger tätig war.

Die FÜSSE DES TIERES waren WIE DIE FÜSSE EINES BÄREN. Diese Bärenfüße könnten GALERIUS charakterisieren, den Kaiser des Ostreiches. Wie Laktanz berichtet, hatte Galerius die Gewohnheit, Bären aufzuziehen, die ihm an Größe und Wildheit glichen. ${ }^{71}$ Galerius kann man mit den FüsSEN des Bären vergleichen, denn er war es, der Diokletian überredete, mit der Verfolgung der Christen zu beginnen: Galerius war also der eigentliche „Schrittmacher“ der Verfolgung.

Das Tier hatte ein Löwenmaul. Das Löwenmaul scheint DiOKLETIAN selbst zu charakterisieren, der den Befehl zur allgemeinen Christenverfolgung im ganzen Reich gab: einen Befehl, der wie eine brüllende Löwenstimme den Hunger der römischen Bestie nach Christenblut zum Ausdruck brachte.

Johannes sieht hier also das heidnisch-römische Reich im Zustand der diokletianischen Verfolgung aus dem Meer hervorkommen. Dennoch bedeutet das Aufsteigen des Tieres aus dem Meer hier nicht die Entstehung der diokletianischen Kirchenverfolgung:

- Die Geschichte der diokletianischen Verfolgung wurde bereits in Kap. 11 und 12 beschrieben, und der an den Strand des Meeres getretene Satan $(12,18)$ zauberte dieses Tier erst nach ihrem Abschluss aus dem Meer hervor.

- Ein Anzeichen dafür, dass die Herrscher der diokletianischen Verfolgung, also die „Köpfe“ des Tieres, nicht mehr an der Macht sind, ist darin zu sehen, dass das Tier seltsamerweise seine KRONEN nicht auf seinen sieben Köpfen hat (wie man es erwartet, und wie es auch beim Drachen in 12,1 der Fall war), sondern auf den zehn Hörnern: Das bedeutet wohl, dass die Köpfe schon entthront sind und das Reich auf seinen endgültigen Untergang durch die zehn Barbarenkönige zusteuert (siehe Kap. 17).

- In Vers 3 wird deutlich, dass Johannes das Tier als getötetes aus dem Meer heraufsteigen sieht, das nun wieder lebendig wird. Man beachte: Er sieht nicht, dass es getötet wird, sondern dass es bereits eine Todeswunde hat, die wieder geheilt wird. Die Todeswunde ist aber die Besiegung des Tieres unter Konstantin (siehe Kommentar zu Vers 3).

Was JOHANNES hier sieht, ist also eine Erneuerung des antichristlichen römischen Reiches nach seiner Besiegung durch Konstantin, bei der das Reich wieder die Züge annimmt, die es unter Diokletian hatte. Diese Erneuerung geschah, wie wir sehen werden, unter Kaiser JULIAN dem Abtrünnigen.

71 LAKTANZ, Von den Todesarten der Verfolger Kap. 21 
13,3a Und einer seiner Köpfe war wie geschlachtet zum Tode.

Der Sieg Konstantins über Maxentius am 28. Oktober 312 schien dem Tier den Todesstoß gegeben zu haben. Denn fünf seiner „Köpfe“ waren jetzt tot oder abgesetzt (siehe Kommentar zu 17,10 11). Nur der sechste Kopf, der Ostkaiser MAXIMINUS DAJA, verfolgte immer noch die Christen, aber seine Macht war seit dem 28. Oktober 312 derart angeschlagen, dass man von einer Todeswunde sprechen kann, die auch ihn getroffen hatte (siehe Kommentar zu 17,8a), und die ihn bald darauf zu Fall brachte. Der siebte Kopf aber, nämlich LiciniUs, war in jener Zeit noch nicht zum „Kopf“ des Tieres geworden, sondern begünstige zusammen mit KONSTANTIN die Christen und sollte sich erst 320 zum verspäteten Christenverfolger entwickeln.

13,3b Aber seine Todeswunde wurde geheilt.

Diese Heilung besagt nun offenbar eine Wiederherstellung des „diokletianischen“ römischen Reiches. Damit ist aber wohl nicht die Verfolgung durch LICINIUS (ca. 320-324) gemeint, die nach SULPICIUS SEVERUS ,eine zu leichte Sache war, als dass sie zu den Wunden der Kirche gerechnet werden könnte“ ${ }^{72}$ Besser versteht man darunter den Wiederaufbau des heidnischen Reiches durch Julian (361363). Denn auf die Regierung Julians trifft Vers 3c zu, wonach ,die ganze Erde dem Tier staunend nachsah“, und Kaiser JULIAN hatte auch, wie Vers 7 sagt, „Macht über alle Völker“. Dagegen war die Herrschaft des LICINIUS nur auf den Osten beschränkt.

13,3c Und die ganze Erde sah dem Tier staunend nach.

JULIAN erregte auf der ganzen dem JOHANNES bekannten Erde, die vom römischen Weltreich beherrscht wurde, Bewunderung: Überall staunte man über das TIER, d.h. über das wiedererstandene römische Heidentum, als es 50 Jahre nach KonstanTINs Sieg plötzlich wieder lebendig war.

13,4 Und (die Menschen) beteten den Drachen an, weil er die Macht dem Tier gegeben hatte.

Und sie beteten das Tier an und sagten:

Wer ist dem Tier gleich und wer kann mit ihm Krieg führen?

JUlian, der Sohn eines Stiefbruders des Kaisers Konstantin, war christlich getauft und erzogen worden, trat aber als junger Mann im Winter 352/353 heimlich zum Heidentum über, ohne dass der Kaiser davon erfuhr. Im Sommer 355 ließ er sich in Athen in die eleusinischen Mysterien einweihen. Als er sich 360 als Soldat und Feldherr ausgezeichnet hatte, riefen ihn seine Truppen zum Kaiser aus. Im nächsten Jahr drohte die blutige Auseinandersetzung mit dem rechtmäßigen Kaiser CONSTANTIUS, aber dieser starb unerwartet am 3. November 361, und so wurde JULIAN Alleinherrscher.

Nun tat er alles, um das Christentum durch das Heidentum zu ersetzen. Zwar gab es keine systematische blutige Verfolgung, abgesehen davon, dass Kaiser hier und dort die Hinrichtung von Christen durch seine Statthalter duldete. Aber er entfernte die Christen aus allen Ämtern und besetzte ihre Stellen mit Heiden. Er verbot den klassischen Unterricht an christlichen Schulen, um so die Jugend wieder auf die von ihm begünstigten heidnischen Schulen zu drängen. Außerdem begünstige er die christlichen Sekten gegenüber der Kirche, ließ die heidnischen Tempel wieder aufbauen und brachte jeden Tag persönlich das heidnische Opfer als Pontifex Maximus dar.

So kam es, dass man überall im Reich, zumindest an allen offiziellen Stellen, DAS TIER ANBETETE und DEN DRACHEN (Teufel) durch die heidnischen Mysterien wissend oder unwissend VEREHRTE.

13,5a Und das Tier wurde ermächtigt, mit seinem Maul anmaßende Worte und Lästerungen auszusprechen.

72 Sulpicius Severus, Chronik Buch 2 Kap. 33 (CSEL Band 1 S. 87). 
13,6 Und das Tier öffnete sein Maul gegen Gott, um seinen Namen zu lästern, und seine Wohnung, und alle die im Himmel wohnen.

Die Kirchenverfolgung JULIANs kann man nicht treffender kennzeichnen, als es hier geschieht: Sie war eine Periode der LÄSTERUNGEN. Der Kaiser plante zwar, die blutigen Verfolgungen in aller Schärfe zu erneuern, ${ }^{73}$ aber in kluger Abwägung entschied er, sich zunächst etwas Zeit zu lassen, um die Menschen systematisch zum Hass gegen das Christentum zu erziehen. Dieselbe Taktik hat auch HITLER gegen die Kirche angewendet: zuerst keine offene Verfolgung, sondern geschickte Propaganda. Kurz vor dem geplanten Beginn der blutigen Verfolgung überraschte JULIAN jedoch der Tod.

Die LÄSTERUNGEN des JULIAN sind berühmt: er hasste das Christentum mehr als alle seine Vorgänger, so dass er sogar persönlich predigend gegen das Christentum auftrat. Seine Briefe, Predigten und satirischen Schriften gegen das Christentum sind zum Teil noch erhalten. Seine Satire Die Caesaren gipfelt beispielsweise in einer Verhöhnung Jesu, sowie der christlichen Taufe und Busse ${ }^{74}$ und sein Buch Gegen die Galiläer (so nannte er die Christen), an dem er 362/363 in Antiochien arbeitete, sollte alles Negative, was er über die ihm verhasste christliche Religion zu sagen hatte, zusammenfassen.

Julian lästerte nicht nur Gott selber, d. h. seinen NAMEN (besonders in der Person Jesu Christi), sondern auch seine WoHnung (d. h. den Himmel) bzw. ALLE, DIE IM HiMMEL WOHNEN. Er bezeichnete nämlich die christlichen Märtyrer als ,gesetzmäßig bestrafte Verbrecher, die von Wahnsinnigen angebetet werden“. Gotteslästerlich war auch sein Selbstruhm. Am Schluss seiner Satire Die Caesaren schrieb er, Merkur, der Gott der Redekunst und Beschützer der Genies, habe zu ihm gesagt: „Dich aber lasse ich wissen, dass dein Vater Mithras [der Sonnengott] ist.“

13,5a Und es wurde ihm Macht gegeben, (dies) 42 Monate lang zu tun.

Die JUlian gegebene MACHT umfasste prophetisch 42 Monate. Wie im Kommentar zu 11,9 (vgl. Exkurs 6) gezeigt wurde, bezeichnete in den vorhergehenden Kapiteln die Zahl 1260 symbolisch eine sehr lange, mehr als 100 Jahre umfassende Verfolgungszeit, die Zahl 3 1/2 dagegen eine nur kurze, kaum ein Jahr dauernde Verfolgung, und die Zahl 42 eine Verfolgung mittlerer Länge. Hierzu passend wird für die Herrschaft Julians die Zahl 42 verwendet, die überdies wohl tatsächlich etwa 42 Monate umfasste: JULIAN wurde nämlich von seinen Truppen erstmals zwischen Januar und März 360 zum Augustus ausgerufen und gekrönt, ${ }^{75}$ auch wenn er die tatsächliche Macht über das Reich erst nach dem Tod seines Vorgängers CONSTANTIUS am 3. November 361 übernehmen konnte, und er starb am 26. Juni 363. Die Zeit seiner Herrschaft umfasste (nach jüdischer einschließender Zählweise) demnach 40-42 Monate, von denen er allerdings nur 20 Monate als von allen anerkannter Alleinherrscher regierte.

Man beachte, dass dieses Mal nicht von einer Wüstenflucht der Kirche die Rede ist: Während der ganzen Regierungsdauer Julians durften die Kirchen offiziell geöffnet bleiben.

13,7a Und es wurde ihm (Macht) gegeben, gegen die Heiligen Krieg zu führen und sie zu besiegen.

JULIAN führte gegen die Christen KRIEG durch Benachteiligung und Verführung, und er BESIEGTE zahllose Gläubige, indem er sie zum Abfall vom Christentum brachte.

73 Vgl. Paulus Orosius, Historiae adversus paganos Buch 7 Kap. 30,4-5.

74 JESUS habe den Leuten zugerufen: „Wer ein Sittenverderber, wer ein Meuchelmörder, wer ein Verfluchter, wer ein Schandkerl ist, der komme zu mir ohne Scheu; denn ich werden ihn, indem ich ihn mit diesem Wasser hier reinige, sofort entsühnen; und wenn einer erneut mit derselben Schuld sich belädt, werde ich ihn, sofern er sich klagend an die Brust schlägt und sich das Haupt rauft, erneute Reinigung schenken“ (Die Caesaren Kap. 38).

75 Den genauen Tag seiner Ausrufung zum Augustus durch seine in Paris versammelten Soldaten (die sog. Pariser Militärrevolte) kennt man nicht. Nach den Quellen kommt hierfür der Zeitraum von Januar bis März 360 in Frage (vgl. Rosen, Julian S. 482 Fußnote 10); genauere Festlegungen gelingen nur durch mehr oder weniger spekulative Überlegungen. Man darf aber wohl in jedem Fall sagen, dass der Prozess, der zur Ausrufung des Kaisers durch seine Truppen in Gallien führte, schon zur Jahreswende 359/60 damit begann, dass die damals in Gallien überwinternden Soldaten Julians mit der Regierung des Kaisers Constantius unzufrieden waren. 
13,7b Und es wurde ihm Macht gegeben über alle Stämme, Völker, Sprachen und Nationen.

JULIAN herrschte über fast alle damals bekannten Völker.

13,8 Und anbeten werden ihn alle Bewohner der Erde, (jeder,) dessen Name nicht eingetragen ist ins Lebensbuch des Lammes, das geschlachtet wurde, seit Anbeginn der Welt.

Alle BEWOHNER DER ERDE, d. h. alle irdisch gesinnten Untertanen des weltumspannenden römischen Reiches, beteten das Reich und seinen Kaiser an, d. h. bewunderten Reich und Kaiser abgöttisch. Interessant ist hier, dass es hier plötzlich heißt: sie beteten IHN an (nicht ES, wie es grammatisch korrekt heißen müsste)! Der Wechsel vom sächlichen zum männlichen Pronomen dürfte anzeigen, dass sich das „Tier“ des römischen Reiches nun in einer einzigen Person konzentriert: in der eines über das ganze Reich herrschenden, engagierten Kaisers, wie es auf Julian tatsächlich zutraf.

Nur diejenigen beten das Tier nicht an, deren Name SEIT ANBEGINN DER WeLT in das Lebensbuch eingetragen war (vgl. auch 17,8). Im Gegensatz zu diesen stehen die ,erst später in dieses Buch Eingetragenen“, die irgendwann wieder gestrichen werden (zum LEBENSBUCH und seinen Einträgen siehe Kommentar zu 3,5).

Man könnte den Vers auch so verstehen, dass das Lamm seit Anbeginn der Welt geschlachtet war (aus der Perspektive Gottes), was dann die Überzeitlichkeit Gottes bezeugen würde.

13,9 Wer Ohren hat, der höre:

13,10 Wer in die Gefangenschaft (geht oder gehen lässt?), der geht in die Gefangenschaft. Wer mit dem Schwert (getötet wird oder tötet?), der wird mit dem Schwert getötet.

Hier ist die Geduld und der Glaube der Heiligen.

Der Leser wird hier zu GLAUBE und GEDUlD aufgerufen. Es gibt zwei mögliche Übersetzungen dieser Textstelle. Eine erste Übersetzung des Textes ist folgende:

„Wer in die Gefangenschaft geht, der geht in die Gefangenschaft, und wer mit dem Schwert getötet wird, der wird mit dem Schwert getötet. “

Ist diese Übersetzung richtig, dann ist hier gesagt, dass sich die Christen geduldig dem Schicksal der Gefangenschaft oder des Todes überlassen sollen, weil dieses Unheil eine Zulassung Gottes ist, gegen das nichts getan werden kann.

Die meine Erachtens sinnvollere, zweite Übersetzung lautet:

„Wer in die Gefangenschaft gehen lässt, geht selber in die Gefangenschaft. Und wer mit dem Schwert tötet, wird selber durch das Schwert getötet“.

Dies ergibt einen besseren Sinn. Die Geduld der Christen wird dadurch gestärkt, dass den Christenverfolgern die gerechte Vergeltung angesagt wird: Sie werden zur Strafe selber das erleiden, was sie den Christen antun. Dies hat tatsächlich oftmals bewahrheitet, namentlich an den Initiatoren der letzten großen Christenverfolgungen. Z. B. fiel Kaiser DECIUS kurz nach dem Erlass seines Verfolgungsediktes im Kampf gegen die Goten, und Kaiser VALERIAN, der so viele Christen in die Gefangenschaft und in den Tod geschickt hatte, kam am Ende selber in die Gefangenschaft und kam dort grausam zu Tode (vgl. Kommentar zu 9,15). Nicht besser ging es den Kaisern der diokletianischen Verfolgung, die alle einen unfriedlichen Tod hatten (vgl. Kommentar zu 17,10). Und Kaiser Julian? Er kam auf seinem Feldzug gegen Persien ums Leben, nach dessen Ende er eine blutige Christenverfolgung im Stil des Diokletian hatte beginnen wollen: Er hatte nämlich gelobt, seinen Göttern das Blut der Christen als Opfer darzubringen, sobald er von seinem Feldzug gegen Persien heimkäme. ${ }^{76}$ Aber in der Nähe von Bagdad wurde er vom Pfeil eines persischen Soldaten getroffen.

76 Vgl. Paulus Orosius, Historiae adversus paganos Buch 7 Kap. 30,4. 
Um den Tod Julians ranken sich verschiedene Legenden. Nach THEODORET soll er mit folgendem verzweifelten Aufschrei an JESUS CHRISTUS gestorben sein: „Du hast gesiegt, Galiläer“ ${ }^{77}$ Nach einem anderen Bericht soll er sich fluchend an seinen „Beschützer“, den Sonnengott HeLios gewandt haben: Er habe sein Blut in die Luft geworfen und dem Helios zugerufen: „Sättige dich!“‘78

\section{Exkurs 8: Gibt es im Neuen Testament ein absolutes Tötungsverbot?}

Manche Christen haben aus Apk 13,10 ein absolutes Tötungsverbot ableiten wollen. Aber der Vers bezieht sich dem Zusammenhang nach nur auf die Christenverfolger. Wäre hier ein absolutes Tötungsverbot gemeint, dann müsste man konsequenterweise auch ein absolutes Verbot der „Abführung in die Gefangenschaft“ aufstellen, weil hier ja beides im selben Sinn durch göttliche Strafen bedroht wird. So weit aber will keiner gehen, und so zeigt sich, das diese Auslegung völlig absurd ist.

Hier sollte man noch einen Blick auf eine ähnliche Schriftstelle werfen: Als PETRUS nach der Gefangennahme JESU einem Diener des Hohenpriesters mit dem Schwert ein Ohr abgeschlagen hatte (Mt 26,52; Joh 18,10), wies JESUS ihn mit folgenden Worten zurück: „Steck dein Schwert in die Scheide. Denn alle, die zum Schwert greifen, werden durch das Schwert umkommen." (Mt 26,52). Auch hier ist nicht jeglicher Schwertgebrauch bzw. jegliches Töten verurteilt. JESUS verurteilt nur den unrechtmäßigen, nicht von Gott autorisierten Gebrauch des „Schwertes“. Das kommt darin zum Ausdruck, dass es heißt: ,jeder, der zum Schwert greift“", d. h. der sich den Schwertgebrauch eigenmächtig anmaßt, wird durch das Schwert umkommen. Es gibt aber auch einen rechtmäßigen Gebrauch des Schwertes, bei dem man das Schwert sich nicht „greift“, sondern es ausgehändigt bekommt, nämlich von Gott. Davon ist klar in Röm 13,1-4 die Rede, wo PAUlus sagt, dass der Staat das „,Schwert“ als Diener Gottes führt, um die Guten zu schützen und die Bösen zu bestrafen, d.h. Unrecht zu vergelten. Diese „Schwertvollmacht“ haben jedoch keine Privatpersonen (Röm 12,19: „rächt euch nicht selbst“), sondern nur die hierzu beauftragten Polizisten und Soldaten, welche die zur Verteidigung des Rechts erforderliche Gewalt auf das nötige Mindestmaß zu beschränken haben (Lk 3,19).

Auch für Privatpersonen gibt es allerdings einen erlaubten Schwertgebrauch, der aber nur deshalb erlaubt ist, weil die „Tötung“ nicht willentlich angestrebtes Ziel ist: Erlaubt ist die Tötung in Notwehr, d. h. die Abwehr eines ungerechten Angriffs auf das Leben, und zwar im selben Augenblick, in dem das Leben unmittelbar bedroht ist. Dann kann nämlich der Tod des Angreifers eine (eigentlich nicht gewollte, sondern notgedrungen in Kauf genommene) Nebenwirkung eines erlaubten Lebensrettungsaktes sein: Der Wille kann in letzter Ausweglosigkeit ausschließlich auf die Lebensrettung gerichtet sein, ohne den damit unlösbar verbundenen Tod des Angreifers gutzuheißen. Biblische Begründung für diesen Schwertgebrauch ist die Lehre, dass der Mensch nur durch willentlich angestrebte, ,,aus dem Herzen kommende“ Taten schuldig wird: „Aus dem Herzen kommen böse Gedanken, Mord usw.“ (Mt 15,19).

PETRUS wurde also getadelt, nicht weil jegliches Töten verboten wäre, sondern weil sein Schwertgebrauch ein angemaßtes „Greifen“ nach dem Schwert war. Denn er handelte weder in legitimer Notwehr noch als legitimer Staatsdiener. Der Schwertschlag des Petrus war keine legitime Notwehr, bei der eine Tötung in Kauf genommen werden durfte, denn die Festnahme Jesu war kein Angriff auf das Leben Jesu. Nur wenn der Diener des Hohenpriesters es in jenem Moment unmittelbar auf das Leben Jesu abgesehen hätte, hätte man Petri Schwertschlag in Richtung des Kopfes dieses Dieners als legitimen Notwehrakt entschuldigen können. Petrus konnte auch nicht als legitimer Staatsdiener handeln, denn er war nicht Diener des römischen Staates, sondern Diener des Messiaskönigs Jesus, der keinen neuen irdischen Staat gegründet hat, sondern sich dem bestehenden unterordnete (Mt 22,21) - vergleiche Joh 18,36: „Mein Königreich ist nicht von dieser Welt. Wenn es von dieser Welt wäre, würden meine Leute kämpfen, damit ich den Juden nicht ausgeliefert würde. Aber mein Königreich ist nicht von hier.“

\footnotetext{
77 TheOdoret, Kirchengeschichte 3,25 (GCS neue Folge Band 5, 3. Auflage 1998, S. 205).

78 Philostorgius, Kirchengeschichte 7,15 (GCS 21 S. 102-103).
} 
13,11 Und ich sah: Ein anderes Tier stieg aus der Erde herauf.

Es hatte zwei Hörner wie ein Lamm, aber es redete wie ein Drache.

Dieses ANDERE, zweite TIER wird in 16,13 sowie 19,20 und 20,10 als FALSCHER PROPHET bezeichnet. Unter „Prophet“ versteht die Schrift nicht bloß Wahrsager, sondern alle Glaubensverkündiger (siehe Kommentar zu 11,3).

Weil das erste Tier ein Reich ist (vgl. Kommentar zu 13,1), so dürfte auch dieses zweite Tier nicht eine Einzelperson, sondern ein Kollektiv sein. Es handelt sich um eine geistige Macht, die für den Teufel intellektuelle Arbeit leistet. Dieser ,falsche Prophet“" sieht aus WIE EIN LAMM, d. h. er gleicht äußerlich Christus. Er REDET ABER WIE EIN DRACHE, d. h. wie der Teufel. Ähnlich hat JESUS die falschen Propheten beschrieben (Mt 7,15): „Hütet euch vor den falschen Propheten: Sie kommen zu euch wie Schafe, in Wirklichkeit aber sind sie reißende Wölfe“. Während also das erste Tier die Herrschaft des Teufels mit Gewalt durchsetzen wollte, versucht das zweite Tier dasselbe auf sanfte Weise, durch List und Überredung.

Das zweite Tier versucht die Menschen zur Anbetung des ersten Tieres zu veranlassen (siehe Vers 12b). Es muss also eine Macht sein, welche die Wiederherstellung des heidnisch-römischen Reiches unter Kaiser JULIAN unterstützte. Das aber war, wie man in allen Geschichtsbüchern nachlesen kann, der Neuplatonismus, auf dessen Grundlage Kaiser JULIAN das Heidentum zu erneuern suchte.

Dieses Tier sah Johannes AUS DER ERDE hervorkommen, weil es aus der ,irdischen, ... dämonischen Weisheit" (Jak 3,15) hervorgegangen war. Der Neuplatonismus war im 3. Jahrhundert durch AMmONiOS SAKKAS $(† 242)$ und PlOTIN $(† 269)$ gegründet worden, dessen berühmtester Schüler PORPHYRIOS $(\dagger 303)$ war. Der Neuplatonismus erlebte aber erst zur Zeit Julians seine größte Blüte: Darum sieht Johannes ihn jetzt hervorkommen.

Dieses Tier hatte ZWEI HÖRNER. Denn die bezaubernde Kraft des Neuplatonismus bestand darin, dass sich in ihm Philosophie und Religion zu einer Einheit verbanden. Historiker sprechen von einer „philosophischen Religion“ oder einer „,religiösen Philosophie“ (LORTZ). ${ }^{79}$ Die Neuplatoniker waren zugleich Philosophen und heidnische Priester bzw. mystische Wundertäter (,Theurgen“). Die beiden „Hörner“ des Neuplatonismus könnten also bedeuten:

- falsche philosophische Argumente und

- „Wunder“ und „Tugenden“ der magisch-heidnischen Religion.

Das Tier SAH AUS WIE EIN LAMM. Der Neuplatonismus war die beste und raffinierteste Philosophie, die das Heidentum je hervorgebracht hatte: Diese Philosophie übte selbst auf hervorragende Christen wie Augustinus große Anziehungskraft aus, weil sie CHRIstus in listiger Weise nachzuahmen wusste. Wie das Christentum bot der Neuplatonismus eine Einheit von Philosophie und Religion, d. h. er verband intellektuelle Überzeugungskraft mit sittlicher, das Herz ergreifender Praxis.

Die intellektuellen Leistungen des Neuplatonismus verdienen zum Teil dauerhafte Anerkennung, so etwa die berühmten Erläuterungen des PORPHYRIUS zu den Kategorien des ARISTOTELES und auch die teilweise faszinierenden philosophischen Einsichten des PLOTIN. Es sollte uns daher fernliegen, den Neuplatonismus pauschal zu verteufeln, zumal es heute viel gefährlichere Philosophien gibt. Damalige Christen, allen voran Augustinus, haben es bald nach dem Tode Julians verstanden, diese Philosophie zu ,taufen“, d.h. sie von ihren heidnischen Wurzeln zu lösen und in Form eines christlichen Platonismus für christliche Denker und Theologen dienst- und fruchtbar zu machen.

Auch die religiösen Lehren des Neuplatonismus waren keineswegs primitives Heidentum, sondern eine Umdeutung und Vertiefung des alten heidnischen Volksglaubens, wobei der Polytheismus durch eine mystische All-Einheits-Lehre geläutert und dadurch geschickt gerechtfertigt wurde. So war der Neuplatonismus eine gehaltvolle Religion, die höhere religiöse Bedürfnisse zu befriedigen wusste: „die letzte große Leistung des (alt)griechischen Geistes“ (LORTZ). ${ }^{80}$

79 LORTZ, Geschichte der Kirche Band 1 S. 113-114.

80 LORTZ, Geschichte der Kirche Band 1 S. 114. 
Gerade deshalb aber war der Neuplatonismus für das Christentum so gefährlich. Die religiöse Praxis der Neuplatoniker bestand vor allem in asketischen Übungen, Abstinenz, Meditationen, Mystischen Extasen und im Opferkult. Unter Kaiser Julian versuchten die Neuplatoniker auch die Heiligkeit und Liebeswerke des Christentums nachzuahmen, indem sie christliche Einrichtungen ins Heidentum übernahmen: z. B. übernahm man den hierarchischen Aufbau sowie gottesdienstliche Einrichtungen der Kirche, richtete Hospitäler ein und organisierte ein System der Armenpflege und Almosenvergabe. Die Neuplatoniker hatten auch ihren „Christus“, den sie abgöttisch verehrten: APOLLONIUS VON TYANA, einen Philosophen und Magier der Pythagoräersekte (aus welcher die Neuplatoniker hervorgegangen waren), der ca. 3-97 n. Chr. lebte. Die Schriften über ApOLlONIUS vON TyANA waren mit dem direkten Ziel verfasst worden, den Glauben an CHRISTUS zu verdrängen und dafür einen Ersatz zu schaffen. Darin sollte gezeigt werden, dass APOLLONIUS viel heiliger war und viel größere Wunder vollbracht hatte als CHRISTUS. Sehr treffend ist also gesagt, dass dieses antichristliche Tier aussah WIE EIN LAMM und hierin CHRISTUS selbst glich.

ABER DAS TIER REDETE WIE EIN DRACHE. Tatsächlich machten sich die Neuplatoniker zu Wortführern des Drachen bzw. Teufels. Sie waren nämlich die eigentlichen, unsichtbaren Drahtzieher der diokletianischen Christenverfolgung gewesen.

Zur Zeit DiOKLETIANs wirkten die neuplatonischen Philosophen PORPHYRIUS ( $† 303$ ) und HIEROKLES daraufhin, das Heidentum gegen das Christentum zu mobilisieren. Beide verfassten Schriften, in denen sie die Welt gegen die Christen aufwiegelten, besonders Porphyrius in seinen 15 Büchern Gegen die Christen und in seiner Schrift Philosophie aus Orakelsprüchen, und HIEROKLES gab schließlich den Rat zur Christenverfolgung. Er war also ihr ,geistiger Vater“. Die Neuplatoniker waren auch die Ratgeber JULIANs, deren Führung er sich vollständig überließ und deren Orakeln er blind vertraute: Neuplatonische Wahrsager hatten ihn ermutigt, sich des Reiches zu bemächtigen, indem sie ihm einen glücklichen Ausgang seiner Unternehmungen prophezeiten.

Die religiöse Lehre dieser Philosophen, welche in ihren Schriften Philosophie und Magie vermischten, hatte auch betont antichristliche Elemente: Sie besagte, dass es eine Reihe von guten und bösen Geistern gebe, von denen man die einen ehren, und die anderen durch Opfer besänftigen müsse, so dass die Neuplatoniker bewusst auch den bösen Geistern opferten. Weiterhin lehrten sie, dass man durch bestimmte Reinigungen und Zeremonien mit den Geistern in Kontakt treten und in die Zukunft eindringen könne. Letzteres zeigt, dass sie FALSCHE PROPHETEN nicht nur im allgemeinen Sinne, sondern auch im Sinne von „Wahrsagern“ waren. Des weiteren verehrten sie außer allen heidnischen Göttern auch Menschen, vor allem ihre beiden Gründerväter PLOTIN und seinen antichristlichen Schüler PORPHYRIUS, denen man sogar Altäre baute.

13,12a Und die ganze Macht des ersten Tieres übte es vor ihm aus.

Tatsächlich war es im Prinzip das zweite Tier, das die GANZE MACHT des ersten ausübte. Die ganze Politik des ersten Tieres, d. h. des Reiches Julians des Abtrünnigen, wurde nämlich ganz von der neuplatonischen Bewegung gestützt und gesteuert.

Schon vor seiner Machtübernahme war Kaiser JULIAN ein blind-gehorsamer Schüler neuplatonischheidnischer Götzenpriester geworden. „Der Kaiser verfiel der Blasphemie des Porphyrius“ schreibt der Kirchengeschichtsschreiber Sokrates, ${ }^{81}$ und alle maßgebenden Ratgeber seiner Politik waren Neuplatoniker.

Den Neuplatoniker JAMBLICH (†330) verehrte er als einen Gott, und vor allem hatte MAXIMUS VON EPHESUS, ein anderer Parteigänger dieser Sekte, einen absoluten Einfluss auf das Denken des Kaisers. Ein dritter Neuplatoniker, LiBAnIUS, war Julians Lobredner. Der Kaiser ließ sich in seinem ganzen Denken und Handeln von neuplatonischen Philosophen und Wahrsagern bestimmen, wie übereinstimmend christliche und heidnische Zeitzeugen berichten.

SOKRATES, Kirchengeschichte Buch 3 Kap. 23 (PG Band 67 Spalten 445-446). SOKRATES hat seine Kirchengeschichte im Jahre 439 abgeschlossen. 
13,12b Und es (das zweite Tier) veranlasst die Erde und ihre Bewohner,

dass sie das erste Tier anbeten, dessen tödliche Wunde geheilt worden war.

Das zweite Tier, also der Neuplatonismus, bekämpfte im Auftrage Julians das Christentum und förderte den heidnisch-römischen Götzendienst, bei dem nicht nur zahlreiche falsche Götter, sondern auch die römischen Kaiser angebetet wurden. Somit VERANLASSTE DAS ZWEITE TIER DIE ANBETUNG DES ERSTEN TIERES, d. h. des römischen Reiches.

13,13a Es tat große Zeichen,

Die Schriften der Neuplatoniker waren voll von Wunderberichten, wodurch die Menschen verführt wurden, allen voran Kaiser JULIAN, der eine Schwäche für derlei Geschichten hatte. Neuplatonische Magier sollen auch eine Fülle von Scheinwundern vollbracht haben, bis hin zu Totenauferweckungen.

13,13b so dass es sogar Feuer vom Himmel auf die Erde fallen ließ vor den Augen der Menschen.

Dieses Wunder verdient es, extra erwähnt zu werden, weil dadurch JULIAN zum Anhänger seines großen Verführers Maximus wurde. Als JuliAn in Asien die heidnische Philosophie und Religion erlernen wollte und nach Meistern suchte, die ihn darin einweihen konnten, traf er einen gewissen Gelehrten namens EusebiUs, Schüler des Neuplatonikers AIDESIUS, der auf den neuplatonischen Philosophen und Magier MAXIMUS VON EPHESUS eifersüchtig war, weil dessen Ruhm den seinen weit übertraf. Dieser wollte JULIAN vor MAXIMUS warnen, den er als Scharlatan betrachtete; und so erzählte er dem JULIAN folgende Geschichte über MAXIMUS: ${ }^{82}$

MAXIMUS habe vor kurzen durch Weihrauch und Zaubersprüche eine Statue der Göttin HEKATE zum Lachen gebracht; außerdem hätten sich in seiner Gegenwart die ausgelöschten Fackeln von selbst entzündet, welche die Göttin in der Hand hatte.

Als JULIAN den EUSEBIUS so reden hörte, schickte er ihn fort und glaubte nun endlich den gefunden zu haben, den er suchte: Er ließ MAXIMUS zu sich kommen, wurde sein Schüler und folgte ihm von da an kritiklos.

FEUER VOM HIMMEL ist in der Schrift (Job 1,16) auch eine Bezeichnung für den Blitz. Die damaligen neuplatonischen Wahrsager betrieben sehr intensiv die Deutung von Blitzen, die sie als Ratgeber bezeichneten (,consiliarum fulmen“). Es schien, als würden die Blitze auf ihren Befehl hin erscheinen, um ihnen den Rat der Götter kundzutun. Man glaubte, dass sie nicht nur die Blitze deuteten, sondern dass sie sie vom Himmel kommen ließen. Genau diese Macht schrieb sich auch MAXIMUS, jener große Betrüger des Kaisers, zu.

13,14a Und es verführt die Bewohner der Erde durch die Zeichen, die zu tun ihm gewährt wurden vor dem Tier.

Das zweite Tier tat (besonders in der Person des MAXIMus) Zeichen vor dem ersten Tier (besonders in der Person des Julian), so wie es im Kommentar zu 13,13 beschrieben wurde. Dadurch gewann es einen so großen Einfluss, dass es die BEWOHNER DER ERDE, d. h. alle irdisch gesinnten Bewohner des römischen Reiches, verführen konnte.

Eunapius, Leben der Philosophen, Ausgabe Wright S. 432-435. EunAPIUS (ca. 346-414) war ein Verehrer Kaiser Julians und des Neuplatonismus. 
13,14b Und es sagt den Bewohnern der Erde, dass sie ein Bild machen sollten vom Tier, das mit dem Schwert erschlagen war und wieder lebendig geworden ist.

Das BILD DES TIERES muss eine Abbildung des heidnischen Rom sein, also eine Bild der das heidnische Rom „regierenden“ Götter oder ein Bild des Kaisers. Beides wurde nicht klar getrennt, denn man gab Göttern die Züge der Kaiser und umgekehrt, so wie man es auf den Medaillen JuLIANs sieht, der mit den Zügen des Gottes SERAPIS dargestellt wurde. Unter allen derartigen Darstellungen des „Tieres" ragen zur Zeit des JULIAN die überall aufgestellten Exemplare jenes Bildes hervor, auf dem der Kaiser zusammen mit heidnischen Göttern dargestellt war. ${ }^{83}$ Auf diesem Bild war zu sehen, wie der Kaiser von JUPITER gekrönt wurde, von MARS die Tapferkeit und von MERKUR die Beredsamkeit erhielt. Hätte JULIAN sich allein darstellen lassen, wäre es den Christen unter Umständen möglich gewesen, ein solches Bild in Ehren zu halten, da sie dann den Kaiser als Menschen hätten ehren können (vgl. 1 Petr 2,17: ,ehrt den Kaiser“ und Jesu Haltung zum Kaiserbild in Mt 22,20-21). Da Julian sich aber unter die heidnischen Götter einreihte, konnte die Verehrung dieses Bildes kaum anders gedeutet werden als eine Anbetung des wiedererstandenen Tieres bzw. des heidnischen Reiches.

83 Sozomenus, Kirchengeschichte Buch 5 Kap. 17 (PG 67 Spalten 1265-1266). 


\section{Exkurs 9: Berechtigung und Grenzen christlicher Bilderverehrung}

Die eben besprochene Stelle Apk 13,14 ist keine Verurteilung des Bilderkultes überhaupt: Im Christentum gibt es vielmehr eine berechtigte Bilderverehrung. Zwar gab es im Alten Testament ein allgemeines Bilderverbot, das sogar Bestandteil der zehn Gebote war: „Du sollst dir kein Götterbild machen, auch keine Abbildung dessen, was oben im Himmel oder was unten auf der Erde oder was in den Gewässern unter der Erde ist“ (Ex 20,4). Dieses Bilderverbot ist aber für Christen (wenigstens in seiner strengen Form) eine nicht mehr gültige alttestamentlich-jüdische Zeremonialvorschrift. CHRISTUS hat uns vorgelebt, dass wir die Gesetze des Alten Testaments nicht einfach blind und dem Buchstaben nach befolgen sollen (vgl. 2 Kor 3,6), denn mit CHRISTUS hat eine neue Epoche begonnen, die in vielen Fällen ein verändertes Verhalten gegenüber den alttestamentlichen Gesetzen und Geboten erforderlich macht:

- Manche haben eine Verschärfung erhalten: Hierzu gehört der Grundgehalt der 10 Gebote (vergleiche die Bergpredigt im Matthäusevangelium, Kap. 5-7).

- Andere haben ihre bindende Kraft gänzlich verloren: Dazu gehören Zeremonialvorschriften wie z. B. die Beschneidung, Reinheits-, Speise- und Festvorschriften (Mk 7,19; Gal 5,2; Apg Kap. 15; Hebr 9,10; Kol 2,16-17).

- Und wieder andere haben ihre buchstäbliche, strenge Verbindlichkeit verloren: siehe Jesu freieren Umgang mit dem Sabbatgebot (Mt 12,1-8 und 9-14), ein Gebot, das ebenso wie das Bildverbot zu den 10 Geboten gehört. Im Einklang mit Kol 2,16-17 und mit Jesu Wort in Mk 2,27-28 hat sich die Kirche berechtigt gefühlt, den wöchentlichen Ruhe- und Festtag vom Samstag auf den Sonntag als den Auferstehungstag Christi zu verlegen (siehe auch 1,10)!

Wenn man nun prüfen will, ob und in welcher Weise das Bilderverbot noch gilt, muss man fragen, aus welchen Gründen es eingesetzt war (vgl. 1 Thess 5,21). Es gab zwei wesentliche Gründe, einen für das Verbot von Gottesbildern und einen für das Verbot von Bildern der Geschöpfe (d. h. von Heiligenbildern).

Der Grund für das Verbot von Gottesbildern war, dass Gott den Menschen seine Erhabenheit über alles Sichtbare nahebringen wollte und sich daher nicht in einer sichtbaren Gestalt offenbart hatte (5 Mose 4,15-18). Dieser Grund ist aber durch Christi Kommen weggefallen, denn Gott ist uns in CHRISTUS ,erschienen“ (Tit 3,4). Christus ist das „Bild des unsichtbaren Gottes“ (Kol 1,15), in dessen Angesicht die „Herrlichkeit Gottes“ erstrahlt (2 Kor 4,6), und ,wer Christus sieht, sieht den Vater“ (vgl. Joh 14,9). Siehe außerdem 2 Kor 4,4, Röm 8,29 und Hebr 1,3. In dieser neuen Atmosphäre der Offenheit Gottes gegenüber dem Menschen ist christliche Kunst möglich, welche die symbolische Abbildung Gottes und Christi nicht mehr zu scheuen braucht. Darstellungen Christi sind jetzt nicht nur erlaubt, sie haben sogar den Charakter eines Bekenntnisses zu seiner Menschwerdung. Übrigens entstehen durch Visionsbeschreibungen wie Apk 4,2-3 automatisch Bilder Gottes in der Phantasie: Warum sollte man diese nicht wenigstens zur Illustration des Bibeltextes aufmalen dürfen?

Um nun zu den Bildern der Geschöpfe zu kommen: Der Grund für das Verbot von Heiligenbildern war offenbar der, dass in der noch nicht erlösten Welt des Alten Bundes eine tiefe Kluft zwischen Gott und der sündhaften Schöpfung bestand, so dass man Gott keine Geschöpfe an die Seite stellen durfte. Aber auch dies hat sich durch CHRISTUS geändert. CHRISTUS hat Himmel und Erde am Kreuz versöhnt und vereint (Eph 1,10; Kol 1,20). Der Erniedrigung Gottes in die Welt hinein entspricht nun eine Erhöhung des Menschen zu Gott hin (2 Kor 8,9), so dass der Mensch nach diesem Leben sogar in gewisser Weise „Anteil an der göttlichen Natur“ erhalten kann (2 Petr 1,4). Wie also die Menschwerdung Gottes seine Abbildung in den Christus-Ikonen rechtfertigt, so rechtfertigt die Erhöhung der Menschen zu Gott ihre Mit-Abbildung mit CHRISTUS in den Heiligen-Ikonen. Und wie Gottesbilder ein Bekenntnis zur Menschwerdung Gottes sind, so sind Heiligenbilder ein Bekenntnis zur siegreichen göttlichen Gnade, zur gnadenhaften Erhöhung des Menschen zu Gott: Sie feiern die Berufung des Menschen zu einer engen Gottesgemeinschaft, wie sie in Eph 2,6, Hebr 12,22-23 und zahlreichen Szenen der Apokalypse zum Ausdruck kommt (4,2-11, 7,9-17, 14,1-5, 15,1-4, 21-22).

Sowohl Gottes- als auch Heiligenbilder dürfen also im christlichen Gottesdienst verwendet werden: Sie stehen stellvertretend für die dargestellten Personen, weshalb auch Huldigungsgesten (z. B. das Knien) vor den Bildern erlaubt sind, die den dargestellten Personen (nicht aber dem Bildmaterial) gelten. Zur Huldigung der Heiligen siehe auch Exkurs 12. Es gibt aber auch einen weiterhin gültigen Kern des Bilderverbotes. Er betrifft die abgöttische Verehrung von Bildern, wie sie die Neuplatoniker lehrten, die davon ausgingen, dass die Bilder und Skulpturen von den Göttern beseelt seien, und die daher die Kunstwerksmaterie als Körper der Gottheit verehrten. 
13,15a Und es wurde ihm die Macht gegeben, dem Bild des Tieres Lebensgeist zu verleihen, damit das Bild des Tieres spreche.

Der Neuplatonismus verlieh den Statuen LEBENSGEIST durch seine Lehre, dass die Statuen von den Seelen der Götter bewohnt seien. Dadurch und durch das Vorweisen entsprechender „Wunder“ förderte er den Glauben an sprechende Statuen. JULIANs Oberpriester MAXIMUS ließ tatsächlich Statuen sprechen, wovon schon die Rede war (Kommentar zu Vers 13b). Die Beratungen JuLIANs fanden ständig vor den Statuen der Götter (besonders des APOLLON) statt, und es ist bekannt, dass die Orakelsprüche der Götter zuweilen durch sprechende Statuen verkündigt wurden. Auf diese Weise wird wohl auch das Pseudo-Orakel ergangen sein, dass JULIAN für seinen letzten Feldzug gegen die Perser fälschlich den Sieg verhieß. Bei Ammianus MARCEllinus liest man ferner von einem Traum des JULIAN in Vienna, in dem er ein leuchtendes Bild sah, das ihm in vier griechischen Versen den nahen Tod von Kaisers Konstans voraussagte. ${ }^{84}$ Sprechende Bilder spielten also in jener vom Neuplatonismus geprägten Zeit eine große Rolle.

13,15b und (damit es) bewirke, dass alle getötet würden, die das Bild des Tieres nicht anbeten würden.

Es heißt hier nicht, dass tatsächlich alle getötet wurden, die das Bild nicht anbeteten, sondern nur, dass dem zweiten Tier die Macht gegeben war, das Bild des Tieres auf das Ziel hinzuordnen, dass alle Nichtanbeter getötet würden.

Die neuplatonischen Berater JULIANs hatten das „Bild des Tieres“ tatsächlich auf dieses Ziel hingeordnet: Denn sie hatten ihn dazu gebracht, dass er die Christenverfolgung des DiOKLETIAN wieder aufnehmen wollte, und wenn es dazu gekommen wäre, dann hätte zweifellos das Opfern oder Nichtopfern vor dem Kaiserbild über Leben und Tod entschieden, so wie es während der römischen Verfolgungen üblich gewesen war. JULIAN hatte auch tatsächlich bereits die Nichtanbetung des „Bildes des Tieres“ mit Strafen belegt. Der Geschichtsschreiber SozomENUs berichtet, dass der Kaiser durch das Bild, auf dem er selbst mit den Göttern dargestellt war (siehe Kommentar zu 14b), erreichen wollte, dass die christlichen Untertanen unmerklich an die Verehrung der heidnischen Götter gewöhnt werden sollten, indem sie, wenn sie nach gewohnter Sitte dem Kaiserbild Ehren darbrachten, auch die heidnischen Götter mitverehren sollten. Diejenigen aber, die dabei ertappt wurden, dass sie sich der Verehrung des Bildes widersetzten, sollten nach dem Willen des Kaisers ,gnadenlos bestraft werden als Neuerer, die sich über die Sitten der Römer hinwegsetzen, und als Sünder gegen den Staat und den Kaiser“. 85 Über den Erfolg dieses Vorhabens des Kaisers berichtet SozOMENUS: „Nur wenige, die sich dann auch die Strafe einhandelten, erkannten die Schliche, und wagten es nicht, anzubeten, wie es üblich war. Die Menge aber glaubte wie üblich aus Unwissenheit oder Einfalt, dass der alten Gewohnheit zu folgen sei, und schritt unbedenklich zu den Bildern. “ 86

Es hielten sich also nur wenige bewusst und auffällig von der Anbetung des „Bildes“ fern, und diese erlitten Strafen, wohl auch die Todesstrafe. Aber es wurden noch nicht alle Nichtanbeter des Bildes getötet, denn anscheinend konnten sich die meisten Christen durch unauffällige Nichtbeachtung der Bilder retten. JULIAN hatte nämlich noch keinen Befehl gegeben, dass jeder Bürger den Bildern opfern musste. Aber das Bild war auf einen solchen Befehl hingeordnet, und er wäre gekommen, wäre JULIAN nicht in Persien gefallen.

13,16 Und es (das zweite Tier) veranlasst die Kleinen und die Großen und die Reichen und die Armen und die Freien und die Sklaven, ein Kennzeichen auf ihrer rechten Hand und auf ihrer Stirn anzubringen.

Ammianus Marcellinus, Res gestae Buch 21 Kap. 2,2. Der Geschichtsschreiber Ammianus war ein heidnischer Zeitgenosse Julians. Sozomenus, Kirchengeschichte Buch 5 Kap. 17 (PG 63 Spalten 1265-1266).

Sozomenus, Kirchengeschichte Buch 5 Kap. 17 (PG 63 Spalten 1265-1267). 
Manche Verehrer heidnischer Gottes brannten sich mit einem heißen Eisen eine Narbe an der Hand oder an der Stirn ein. Andere brachten an diesen Körperstellen den Namen eines Gottes oder die ersten Buchstaben dieses Namens oder auch die Zahl dieses Namens an (d. h. die Summe der Zahlenwerte der einzelnen Buchstaben des Namens).

Jedoch dürfte hier nicht an ein körperliches Kennzeichen gedacht sein, denn auch bei dem entsprechenden Kennzeichen der Erwählten (vgl. 7,3 und 14,1) war eine geistige Wirklichkeit gemeint: die innere Taufgnade. Mit dem Kennzeichen dürfte also die innere Hingabe an das Tier gemeint sein. Dabei steht die RECHTE HAND für das Tun, und die STIRN für das Denken. Dass also jemand das Kennzeichen auf Stirn und rechter Hand anbringt, bedeutet, dass er sich mit seinem Tun und Denken bzw. „mit Leib und Seele“ dem heidnischen Rom „verschreibt“. Der Neuplatonismus veranlasste in der Tat die Leute zu einer solchen Ganzhingabe an das heidnische Rom.

13,17 Und (das zweite Tier veranlasst,) dass niemand kaufen oder verkaufen könne,

der nicht das Kennzeichen, den Namen des (ersten) Tieres oder die Zahl seines Namens hat.

Nur wer den NAMEN oder die ZAHL DES NAMENS des Tieres als KenNZEICHEN an Hand oder Stirn angebracht hatte, d. h. wer sich mit Leib und Seele dem heidnischen Rom verschrieben hatte (vgl. Kommentar zu Vers 16), konnte KAUfEN ODER VERKAUfEn. Dies war nun in der Tat eine Besonderheit der Kirchenverfolgung des DIOKLETIAN und jener des JULIAN:

Dem Kirchengeschichtsschreiber BEDA zufolge war es den Christen in der diokletianischen Verfolgungszeit ,weder erlaubt, etwas zu kaufen, noch zu verkaufen, und noch nicht einmal Wasser zu schöpfen, ohne dass sie vorher den Götterbildern geopfert hätten, die überall herumstanden““ 87

JULIAN unternahm in dieser Beziehung etwas ähnliches wie DIOKLETIAN: Er ließ Götzenopferfleisch in die Quellen werfen, und ließ Wasser, das den Dämonen geweiht war, auf alles, was auf dem Markt verkauft wurde, sprengen, damit er die Christen so, wie er glaubte, zwang, am Götzendienst teilzunehmen. Dadurch wurden die Christen - wenigstens in der Vorstellung JULIANs - dem Heidentum geweiht, ${ }^{88}$ nahmen also das „Kennzeichen“ an.

13,18 Hier ist Weisheit. Wer Verstand hat, berechne die Zahl des Tieres.

Es ist nämlich die Zahl eines Menschen,

und seine Zahl ist 666 (nach einigen Handschriften statt dessen: 616).

Diese Zahl dürfte eine Verschlüsselung für den Namen Kaiser DiOKLETIANs sein. Diese Deutung und zahlreiche andere Deutungen werden im folgenden Exkurs vorgestellt und diskutiert.

\section{Exkurs 10: Die Zahl 666}

\section{Die eigentliche Deutung}

Das TIER, dessen Zahl 666 ist, ist dem Zusammenhang nach das erste Tier, also das siebenköpfige Tier, welches das Römische Reich in seinem diokletianischen Triumph darstellt. Zugleich ist die 666 ZAHL EINES MENSCHEN. Demnach sollte die Zahl 666 Zahl eines Menschennamens sein, welcher das „diokletianische“ Reich darstellt. Dazu würde es am Besten passen, wenn dieser Name ein Name des Herrschers DiOKLETIAN selbst wäre. DiOKLETIAN war ja auch der Erfinder jener im Vorvers erwähnten Schikane, dass es zum „Kaufen und Verkaufen“ erforderlich war, sich auf den „Namen“ des Tieres oder die „Zahl seines Namens“ zu verpflichten. Wenn sich also tatsächlich die Zahl 666 im Namen Diokletians nachweisen lässt, wäre dies eine Bestätigung für die Richtigkeit unserer Deutung.

\footnotetext{
87 BEDA in seinem einleitenden Hymnus zur Passio von Justin, einem Märtyrer der diokletianischen Verfolgung, PL 94 Sp. $595-596$.

88 THEODORET, Kirchengeschichte Kap. 15.
} 
In welchem Alphabet ist der Name Diokletians zu untersuchen? Nur die im Umkreis des Neuen Testaments verbreiteten Sprachen dürften in Frage kommen: Griechisch, Hebräisch und Lateinisch (Joh 19,20). In allen drei Sprachen stellte man die Zahlen durch Buchstaben dar:

Die Zahlenwerte der hebräischen Buchstaben sind:

\begin{tabular}{|c|c|c|c|c|c|c|c|c|c|c|c|}
\hline Aleph & $(\boldsymbol{\aleph})$ & $=$ & 1 & Jod & (') & $=$ & 10 & Qoph & $(p)$ & $=$ & 100 \\
\hline Beth & (ב) & $=$ & 2 & Kaph & $(\supset, ך)$ & $=$ & 20 & Resch & (ר) & $=$ & 200 \\
\hline Gimel & (d) & $=$ & 3 & Lamed & (ל) & $=$ & 30 & Sin/Schin & (ש) & $=$ & 300 \\
\hline Dalet & (7) & $=$ & 4 & Mem & $(\boldsymbol{a}, \mathbf{a})$ & $=$ & 40 & Tau & (ת) & $=$ & 400 \\
\hline $\mathrm{He}$ & (ה) & $=$ & 5 & Nun & $(נ, ;)$ & $=$ & 50 & & & & \\
\hline Waw & (१) & $=$ & 6 & Samech & (0) & $=$ & 60 & & & & \\
\hline Sajin & (i) & $=$ & 7 & Ajin & (ע) & $=$ & 70 & & & & \\
\hline Chet & $(\Pi)$ & $=$ & 8 & $\mathrm{Pe}$ & $(פ, 7)$ & $=$ & 80 & & & & \\
\hline Tet & (ט) & $=$ & 9 & Zade & $(\Im, \gamma)$ & $=$ & 90 & & & & \\
\hline
\end{tabular}

Hebräisch wird von rechts nach links geschrieben; kommt Kaph, Mem, Nun, Pe oder Zade am Wortende (also ganz rechts) vor, nehmen diese Buchstaben eine Sonderform, nämlich ך, घ \}, ๆ bzw. Y an. Gewöhnlich werden nur Konsonanten notiert. Für Vokale kann man (aber muss man nicht) folgende Buchstaben setzen:

Aleph («) für alle langen Vokale,

He (ה) für alle langen Vokale außer i und u,

Waw (1) für langes u und o,

Jod (י) für langes i, e und ä.

Die Zahlenwerte der griechischen Buchstaben sind:

\begin{tabular}{|c|c|c|c|c|c|c|c|c|c|c|c|}
\hline Alpha & $(A, \alpha)$ & $=$ & 1 & Iota & $(\mathrm{I}, \iota)$ & $=$ & 10 & Rho & $(\mathrm{P}, \rho)$ & $=$ & 100 \\
\hline Beta & $(B, \beta)$ & $=$ & 2 & Карра & $(K, x)$ & $=$ & 20 & Sigma & $(\Sigma, \sigma, \varsigma)$ & $=$ & 200 \\
\hline Gamma & $(\Gamma, \gamma)$ & $=$ & 3 & Lambda & $(\Lambda, \lambda)$ & $=$ & 30 & Tau & $(\mathrm{T}, \tau)$ & $=$ & 300 \\
\hline Delta & $(\Delta, \delta)$ & $=$ & 4 & My & $(\mathrm{M}, \mu)$ & $=$ & 40 & Ypsilon & $(\Upsilon, \cup)$ & $=$ & 400 \\
\hline Epsilon & $(\mathrm{E}, \varepsilon)$ & $=$ & 5 & $\mathrm{Ny}$ & $(\mathrm{N}, \nu)$ & $=$ & 50 & Phi & $(\Phi, \varphi)$ & $=$ & 500 \\
\hline Stigma & $(\varsigma)$ & $=$ & 6 & $\mathrm{Xi}$ & $(\Xi, \xi)$ & $=$ & 60 & Chi & $(\mathrm{X}, \chi)$ & $=$ & 00 \\
\hline Zeta & $(Z, \zeta)$ & $=$ & 7 & Omikron & $(\mathrm{O}, \mathrm{o})$ & $=$ & 70 & Psi & $(\Psi, \psi)$ & $=$ & 70 \\
\hline Eta & $(H, \eta)$ & $=$ & 8 & $\mathrm{Pi}$ & $(\Pi, \pi)$ & $=$ & 80 & Omega & $(\Omega, \omega)$ & $=$ & 80 \\
\hline Theta & $(\Theta, \vartheta)$ & $=$ & 9 & Qoppa & (8) & $=$ & 90 & Sampi & $(\lambda)$ & $=$ & 90 \\
\hline
\end{tabular}

Die veralteten Buchstaben Stigma (ৎ), Qoppa (९) und Sampi ( $\lambda$ ) dienten in neutestamentlicher Zeit nur noch als Zahlzeichen. O؟ bzw. ov ergibt den Laut $u$. Ein kleines Sigma am Ende eines Wortes (,Schlusssigma“) hat dieselbe Form wie Stigma, nämlich $\varsigma$.

Die Zahlenwerte der lateinischen Buchstaben sind:

$\mathrm{I}=1, \quad \mathrm{~V}($ später auch $\mathrm{U})=5, \quad \mathrm{X}=10, \quad \mathrm{~L}=50, \quad \mathrm{C}=100, \quad \mathrm{D}=500, \quad \mathrm{M}=1000$.

Da DiOKLETIAN römischer Kaiser war, ist es am vernünftigsten, das römische (lateinische) Alphabet zu benutzen. DiOKLETIAN hieß vor seiner Kaiserernennung DiOCles. ${ }^{89}$ Das war sein eigentlicher Name, den er erst nach seiner

89 Vgl. LaKtanZ, Von den Todesarten der Verfolger Kap. 9. 
Kaiserernennung zu dem voller klingenden „Diocletianus“ erweiterte. ${ }^{90}$ Es gab ferner zwei Kaisertitel: Augustus und Caesar. Der Titel „Augustus“ bezeichnete zur Zeit des Diokletian den Oberkaiser, „Caesar“ dagegen einen untergeordneten Kaiser. Diokletian kam als dem höchsten Kaiser die Amtsbezeichnung „Augustus“ zu. Da nun in jener Zeit die Buchstaben „,u“ und „, form seines Kaisertitels: „AVGVSTVS“. Eine eindeutige Kennzeichnung der Person des Diokletian war also der Name DIOCLES AVGVSTVS. Dieser Name enthält die Zahlzeichen DICLVVV, deren Addition 666 ergibt:

$\begin{array}{llr}\mathrm{D} & = & 500 \\ \mathrm{I} & = & 1 \\ \mathrm{C} & = & 100 \\ \mathrm{~L} & = & 50 \\ \mathrm{~V} & = & 5 \\ \mathrm{~V} & = & 5 \\ \mathrm{~V} & = & 5\end{array}$

Keine andere Deutung ist, wie sich im folgenden zeigen wird, so überzeugend wie diese, wie in der Nachfolge von Bossuet auch Wouters, CALMET und andere erkannt haben. Warum ist der Name aber nicht im Klartext offenbart worden? Die Verschlüsselung entspricht hier einer theologischen Notwendigkeit: Würde Gott nämlich die Zugehörigkeit einer Person zur Schar seiner Widersacher in eindeutiger Weise voraussagen, so hätte diese Person nach Kenntnisnahme der Prophezeiung nicht mehr die Freiheit, sich für oder gegen Gott zu entscheiden. Denn wie könnte sich jemand, der erfährt, dass über ihn eindeutig vorausgesagt ist, er werde Gottes Feind sein, noch bemühen, diesem Gott zu dienen? Eine solche Voraussage widerspricht also der Gerechtigkeit und Güte Gottes, der jedem Menschen die Chance gibt, sich in Freiheit auf den Weg des Heils zu begeben (vgl. 1 Tim 2,4).

\section{2a. Die rein symbolische Deutung: Symbolik der Zahlen 6,7,8 und 666}

Die Zahl sechs und erst recht 666 (dreimalige, also nachdrückliche Wiederholung der 6) hat eine Symbolkraft, die sie als antichristliche Zahl geeignet macht wie keine andere. Um diese Symbolkraft voll zu erfassen, ist es von Nutzen, zuerst die Symbolik der Zahlen sieben und acht zu betrachten.

Die Zahl sieben ist die Zahl der Fülle, Vollständigkeit und Vollkommenheit. Dafür gibt es eine Reihe unterschiedlichster natürlicher Ursachen:

- Die ungeraden Zahlen eins, drei, fünf und sieben stehen jeweils für die Anzahl der ausgezeichneten Punkte eines menschlichen Beobachters, der sich inmitten einer 0-, 1-, 2- und 3-dimensionalen Welt befindet. Denn eine nulldimensionale Welt ist eine nicht-ausgedehnte Welt, die nur aus einem einzigen Punkt besteht, der dann natürlich zugleich die Mitte dieser Welt ist. Eine eindimensionale Welt ist eine Linie, und auf jedem beidseitig begrenzten Abschnitt von ihr gibt es drei ausgezeichnete Punkte: zwei Randpunkte und einen Mittelpunkt. Eine zweidimensionale Welt ist eine Fläche, und wenn sich ein Beobachter inmitten eines allseitig begrenzten Teilstücks einer Fläche befindet, gibt es für ihn fünf ausgezeichnete Punkte: den Punkt, in dem er sich aufhält, und die vier Randpunkte des Flächenstücks, die er erreichen kann, wenn er geradeaus oder rückwärts oder nach rechts oder nach links bis zum Rand läuft. Eine dreidimensionale Welt ist ein Raum, und wenn sich ein Beobachter inmitten eines Teilstücks eines Raums befindet, gibt es für ihn sieben ausgezeichnete Punkte: den Punkt, an dem er sich aufhält, und die sechs Randpunkte des Raumteils, die er erreichen kann, wenn er sich geradeaus oder rückwärts oder nach rechts oder nach links oder nach oben oder nach unten hin zum Rand bewegt. Da unsere diesseitige Lebenswelt dreidimensional ist, gibt es also für jeden Beobachter in einem beliebigen ringsum abgeschlossenen Teil dieser Welt stets insgesamt immer genau sieben ausgezeichnete Punkte: den Mittelpunkt

90 Wie wir sehen werden, ergibt sich die Zahl 666 als Zahl des Namens „Diocles Augustus“, nicht als Zahl des Namens „Diocletianus Augustus“. Die Erweiterung des Namens „Diocles“ zum volleren „Diocletianus“-Namen könnte man daher vielleicht als eine Namens-Verschönerung ansehen, welche Gott nicht anerkennt, im Gegensatz zu der ehrenhalber dem „Abram“ (= mein Vater ist erhaben) verliehenen Namenserweiterung zu ,Abraham“ (vgl. Gen 17,5, siehe auch Apk 2,17). 
(d.h. seinen Aufenthaltsort) und den vorderen, hinteren, rechten, linke, oberen und unteren Randpunkt des Raumteils. Da unsere Welt dreidimensional ist, ist die Siebenzahl die vollständige Anzahl aller hauptsächlich ausgezeichneten Punkte, die jeden Beobachter in dieser Welt umgeben: die in den sechs Haupt-Bewegungsrichtungen erreichbaren Randpunkte seiner näheren Umgebung, und seine einige Position als „Mittelpunkt“ dieser Punkte.

- Die Woche hat sieben Tage, wobei die Sieben-Tage-Woche auf natürliche Weise entstand: Ein Monat ist nämlich ursprünglich die Zeit eines synodischen Mondumlaufs (d.h. die Zeit zwischen aufeinander folgenden gleichen Mondphasen, etwa von Neumond zu Neumond), das sind ca. 29,5 Tage, und diese Zeit ist natürlicherweise in vier Teile von je sieben Tagen eingeteilt, die sich um die vier Mondphasen (Neumond, zunehmender Halbmond, Vollmond und abnehmender Halbmond) gruppieren.

- Es gibt sieben deutlich sichtbare Wandelsterne, die am Himmel ihre Position relativ zu den Fixsternen verändern: Sonne, Mond, Merkur, Venus, Mars, Jupiter und Saturn.

- Sieben ist auch die Anzahl jener Sterne, die sich am Himmelsnordpol, d. h. an jenem Punkt des nördlichen Sternenhimmels, um den sich scheinbar alle Sterne drehen, auf engem Raum zusammendrängen und dort die Umrisse des Sternbilds des „Kleinen Wagens“ (oder kleinen Bären) bilden. In unmittelbarer Nähe des kleinen Wagens befindet sich das prächtige Sternbild des ,großen Wagens“ (des Hauptteils des sog. großen Bären) mit ebenfalls sieben Sternen. Des weiteren besteht auch die Sterngruppe der Plejaden, welche die auffälligste Sternhäufung am Himmel darstellt, aus sieben eng aneinander gedrängten Sternen, weshalb man die Plejaden auch das Siebengestirn nennt. Aus jeweils sieben Sternen bestehen zudem zwei auffällige Sterngruppen, die man als die nördlichen Krone (corona borealis) und die südliche Krone (corona australis) bezeichnet. Sieben helle Sterne bilden auch den Hauptteil des Orion, des einprägsamsten Sternbildes. Und sieben helle Sterne markieren die Ecken und den Mittelpunkt des „Winter-Sechsecks“, der einprägsamsten Sternbilderreihe.

- Der Regenbogen hat sieben natürliche Farben: rot, orange, gelb, grün, blau, indigo und violett.

- Die Tonleiter hat sieben Töne, denn der achte schwingt wieder im Einklang mit dem ersten.

- In der Antike kannte man sieben Metalle: Gold, Silber, Kupfer, Zinn, Eisen, Blei und Quecksilber. Wir kennen heute weit mehr Metalle, aber aus heutiger Sicht haben die chemischen Elemente ebenfalls einen Bezug zur Siebenzahl: Es gibt im „Periodensystem der Elemente“ genau sieben Perioden, auf welche sich sämtliche natürlicherweise vorkommenden Elemente verteilen.

- Es gibt sieben Kristallsysteme: triklin, monoklin, orthorhombisch, tetragonal, trigonal, hexagonal und kubisch.

- Es gibt im Gesicht sieben Körperöffnungen (Ohren, Augenhöhlen, Nasenlöcher, Mund).

- Es gibt sieben Zähne je Gebisshälfte oben und unten (wenn man die „überflüssigen“ Weisheitszähne mitzählt, sind es acht), also insgesamt 7 × $4=28$ (wenn man die Weisheitszähne mitzählt, allerdings 8 × 4 = 32) Zähne.

- Sieben ist die Summe der vollkommenen Zahlen 3 und 4 (zu diesen siehe Exkurs 4).

- Außerdem ist die Summe der ersten sieben Zahlen $(1+2+3+4+5+6+7)$ gleich 28, was die Zahl des sog. Mondzyklus ist (der Zeitraum von 28 Tagen alias 4 Wochen liegt etwa in der Mitte zwischen der siderischen Umlaufzahl des Mondes mit ca. 27,3 Tagen, und seiner synodischen Umlaufzeit von ca. 29,5 Tagen.) Hierauf legte man in der Antike besonderen Wert.

- An mathematischen Besonderheiten der Zahl sieben ist ihre „Kompliziertheit“ auffällig, die sie von den vorhergehenden Zahlen stark abhebt. So ist das regelmäßige Siebeneck nicht mit Zirkel und Lineal konstruierbar, im Gegensatz zum regelmäßigen Sechs-, Fünf-, Vier- und Dreieck. Außerdem ist 1/7 unter den Stammbrüchen 1/2, $1 / 3,1 / 4,1 / 5,1 / 6,1 / 7,1 / 8,1 / 9$ dadurch ausgezeichnet, dass 1/7 die komplizierteste Dezimalbruch-Darstellung hat $(1 / 7=0, \overline{142857})$. Besonders die Babylonier, in deren Zahlensystem und Zeitrechnung (die wir von ihnen übernommen haben) die Zahl Sechzig eine zentrale Rolle spielte, fanden es bemerkenswert, dass ein Siebtel der einzige der oben genannten Stammbrüche ist, der nicht als endlicher Sexagesimalbruch darstellbar ist; und dass ein Siebtel zugleich der erste dieser Stammbrüche ist, der nicht durch eine ganzzahlige Anzahl von Sechzigsteln darstellbar ist (es ist ja 1/2 dreißig Sechzigstel, 1/3 zwanzig Sechzigstel, 1/4 fünfzehn Sechzigstel, 1/5 zwölf Sechzigstel, 1/6 zehn Sechzigstel, aber 1/7 ist 8, $\overline{571428}$ Sechzigstel). 
- Sieben Jahre bilden offenbar einen natürlichen Rhythmus im Leben des Menschen: Die ersten sieben Jahre bilden die frühe Kindheit bis zur Ausbildung des vollen Vernunftgebrauchs, die nächsten sieben Jahre die späte Kindheit bis zur Pubertät, und die nächsten sieben Jahre das Jugendalter bis zur vollen Reife (siehe auch Kommentar zu 9,5b). Alle sieben Jahre soll sich nach antiker Anschauung daher auch die gesamte Materie des menschlichen Körpers durch den Stoffwechsel erneuern (nach heutigen Erkenntnissen geht das allerdings viel schneller, nämlich in weniger als einem Jahr). Auch das Nilhochwasser soll nach neueren Erkenntnissen einen siebenjährigen Zyklus aufweisen (vgl. die sieben fetten und sieben dürren Jahre Ägyptens in Gen 41).

- Das Interessanteste dürfte aber vielleicht die bekannte Erfahrung sein, dass der erwachsene Mensch, dem kurz eine Menge von Gegenstände gezeigt werden, sich an alle diese Gegenstände bei guter Konzentration dann und nur dann zuverlässig erinnern kann, wenn die Menge die Zahl sieben nicht übersteigt. Diese Tatsache beschreibt bereits der Philosoph John Locke (†1704), und sie wurde durch Untersuchungen des Kurzzeitgedächtnisses von dem Psychologen George A. Miller bestätigt und 1954 ausführlich beschrieben (weshalb die Zahl Sieben auch die „Millersche Zahl“ heißt). Man spricht daher auch von „sieben Sachen“, die man sinnvollerweise auf Reisen mitnehmen kann, um auf sie Acht zu haben. Wenn man sich daher eine möglichst große noch in allen Details zugleich überschaubare Vielheit vorstellt, stellt man sich eine Vielheit von sieben Dingen vor. So ist die Sieben mit Recht die Zahl der maximalen Vollkommenheit und Vollständigkeit. Dies deckt sich auch damit, dass die Sieben nach psychologischen Untersuchungen und Umfragen die Lieblingszahl der meisten Menschen ist (sog. Blue-Seven-Phänomen).

Weil also die sieben eine vollständige Fülle bezeichnet, spricht die Bibel symbolisch von sieben Schöpfungstagen, und definiert den siebten Tag als Tag der Ruhe nach vollbrachtem Werk. Passend dazu war der siebte Wochentag (der Samstag) der Tag der Grabesruhe Christi nach seinem Tod (am Freitag) und vor seiner Auferstehung (am Sonntag). Die Verwendung der Zahl sieben als Zahl der Fülle offenbart sich deutlich im Spruch Jesu bei Mt 18,21-22, wonach ein Jünger Jesu verpflichtet ist, täglich nicht nur siebenmal, sondern siebenundsiebzigmal seinem Bruder zu verzeihen. Vergleiche auch die sieben Paare von allen reinen Tieren in der Arche Noahs (Gen 7,2), die sieben fetten und die sieben mageren Jahre (Gen 41,29-30), die siebenfache Umschreitung der Mauern Jerichos (Jos 6,14-15, Hebr 11,30), die sieben von Gott vertriebenen Völker (Dt 7,1, Apg 13,19), die sieben bösen Geister im Gleichnis Jesu (Mt 12,45), die sieben Dämonen der Maria Magdalena (Lk 8,2), die sieben Brote, die Jesus in eine Vielzahl verwandelte (Mt 15,34), die sieben Brüder, die nacheinander dieselbe Frau heirateten (Mt 22,25) und die sieben ersten Diakone (Apg 6,3-5). Die Siebenzahl spielte außerdem eine wichtige Rolle im jüdischen Kalender: Jeder siebte Tag war heilig (Lev 23,3), ebenso jedes siebte Jahr (Lev 25,3-4) und das nach jeweils $7 \cdot 7$ Jahren eintretende „Jobeljahr“ (Lev 25,8).

Die Zahl sieben wird auch in der Apokalypse ständig verwendet: sieben Geister (1,4), sieben Ortsgemeinden, Leuchter, Sterne und Engel (1,11.12.20), sieben Fackeln (4,5), sieben Siegel $(5,1)$, sieben Hörner und Augen des Lammes $(5,6)$, siebenfacher Donner (10,3-4), sieben Köpfe des Drachen und des Tieres (12,3, 13,1), sieben Engel mit sieben Posaunen $(8,2)$, sieben Engel mit sieben Zornesschalen (16,1), sieben Seligpreisungen (1,3, 14,13, 16,15, 19,9, 20,6, 22,7, $22,14)$ und siebenmalige Erwähnung des Sturzes der „Hure Babylon“ (14,8, 16,19, 17,16, 18,2, 18,8, 18,10, 18,21). Der Evangelist Johannes verwendet die Siebenzahl darüber hinaus auch ständig in seinem Evangelium, in welches er genau sieben von Jesus bewirkten Wunderzeichen (vor seiner Auferstehung) aufgenommen hat, sieben gewichtige „Ich bin“-Sätze Jesu erwähnt, von den ersten sieben Tagen am Anfang des öffentlichen Lebens Jesu berichtet, ebenso wie von den letzten sieben Tagen vor seinem Tod, und wo er sieben der zwölf Apostel namentlich bezeichnet und am Ende von einer Erscheinung Jesu vor sieben Aposteln berichtet.

Die Zahl acht ist als „,überschrittene Siebenzahl“ (7+1) die Zahl der Überfülle und der Übervollkommenheit. Passend zu dieser Symbolik ist der achte Zahn je oberer und unterer Gebisshälfte der ,überflüssige“ Weisheitszahn. Die acht ist auch die Zahl des Neubeginns, denn mit dem achten Ton, der Oktave, beginnt eine neue Tonleiter, mit dem achten Tag beginnt eine neue Woche und mit dem achten Jahr ein neuer Lebensabschnitt im menschlichen Leben. Diese Eigenschaften machen die Zahl acht geeignet, die Zahl Christi zu sein, des übervollkommenen Gottmenschen, mit dem Gott eine Neuschöpfung der Welt vollzog (2 Kor 5,17; Gal 6,15; Jak 1,18). So ist es wohl auch kein Zufall, dass die beiden großen Feste des Judentums, das Paschafest (mit dem Fest der ungesäuerten Brote) und das Laubhüttenfest je acht Tage lang gefeiert wurden (Lev 23, Verse 4-8, 33-36 und 39) und dass Kinder am achten Tag beschnitten werden mussten (Lk 2,21): Zeremonien, die alle auf CHRISTUS hinwiesen. Vor allem ist es wohl kein Zufall, dass CHRISTUS an einem Sonntag, also am ersten Tag der Woche, der zugleich der achte Tag der vergangenen Woche ist, von den Toten auferstanden ist, wodurch der Neubeginn in CHRISTUS sichtbar wurde. Damit wurde die Zahl acht zugleich zur Zahl der Auferstehung. Die Verbindung zwischen der Zahl acht und der Auferstehung Christi ist wohl auch der Hintergrund 
für die Stelle 1 Petr 3,20-21 (vgl. 2 Petr 2,5), wo Petrus die Rettung von acht Personen in der Arche als Sinnbild der christlichen Taufe deutet, die er wiederum als ,eine Bitte an Gott um ein reines Gewissen aufgrund der Auferstehung Christi“" erklärt. Die verblüffendste Eigenschaft der Zahl acht aber, die sie mit JESUS ChRISTUS verbindet, ist, dass 888 die Zahl des Namens „Jesus “ ist. Jesus wird nämlich im Urtext des Neuen Testaments so geschrieben: $\mathrm{IH} \Sigma \mathrm{O} \Upsilon \Sigma$, und die Addition der Buchstaben dieses Namens ergibt 888. Die dreifache Wiederholung der acht im Namen Jesu passt zu der Tatsache, dass Jesus ,,am dritten Tag“ auferstanden ist, welcher der achte Tag der Woche war. Zugleich ist auch bemerkenswert, dass die Addition der Buchstaben des für Jesus charakteristischen Titels „Herr“ (1 Kor 8,6; griech.

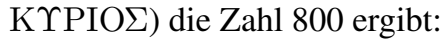

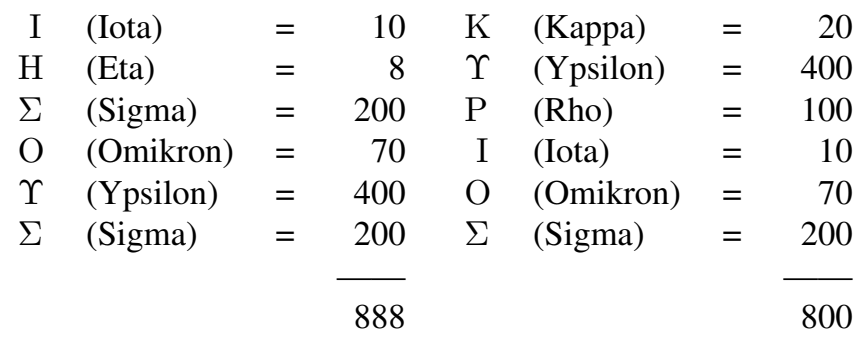

Schließlich zur Zahl sechs: Diese ist nun gewissermaßen das Gegenteil der Zahl acht, nämlich die ,verminderte Siebenzahl“ (7-1) und bezeichnet somit eine nur geringfügig unterschrittene Vollkommenheit. Es wird daher die Zahl sechs (ebenso wie auch die Zahl fünf; siehe Kommentar zu 9,5a) interpretiert als Zahl des Menschen, denn der Mensch ist nach Ps 8,5 von Gott ,nur wenig geringer, gemacht worden als Gott; dazu passend hat der Mensch sechs Körperteile (zwei Arme, zwei Beine, Rumpf und Kopf) und wurde nach Gen 1,26-31 am sechsten Tag erschaffen.

Als Zeichen einer knapp unterschrittenen Vollkommenheit ist die sechs aber auch die Zahl der Scheinfülle und der Scheinvollkommenheit und hat insofern of eine negative Bedeutung. Dazu kommt, dass die Zahl sechs die halbierte Vollkommenheitszahl zwölf ist, daher (wie die 3 1/2 als halbierte Siebenzahl) eine negative Bedeutung hat. Wegen der sechs Richtungen, in die sich ein Körper bewegen kann (nach rechts, links, vorn, hinten, oben, unten) ist die sechs die Zahl der räumlichen Bewegung und daher im weiteren Sinne Zahl der Veränderung. Daher ist es sehr angemessen, dass die Schrift die ruhelose „Arbeitsphase“ der Erschaffung der Welt als eine Periode von sechs symbolischen Tagen beschreibt, denen der siebente Tag als Ruhetag gegenübersteht. Als Zahl der Veränderung ist die sechs auch Zahl der Zeit, und dazu passt es, dass die beiden auffälligsten natürlichen Zeiteinheiten, nämlich der Tag und das Jahr, über die Zahl sechs miteinander verbunden sind: das Jahr besteht aus 365 1/4 Tagen, was einschließlich des angebrochenen Tages genau 6 $60+6$ Tage sind. Dass die sechs sich auf diese Weise als Zahl der Zeit auszeichnet, ist wohl auch der Grund, weshalb man den Tag in 24(=4.6) Stunden eingeteilt hat, indem man um die vier natürlichen Angelpunkte des Tages (Morgen, Mittag, Abend und Mitternacht) jeweils sechs Stunden gruppiert hat. So lag es auch nahe, die Stunde in sechzig Minuten und der Minute in sechzig Sekunden einzuteilen.

Die genannten Eigenschaften machen nun offenbar die Zahl sechs und besonders ihre dreifache Wiederholung 666 geeignet, die Zahl des Teufels und des Antichristen genannt zu werden: Der Teufel verspricht wie CHRISTUS seinen Anhängern das vollkommene Glück, aber dies entpuppt sich am Ende immer als Blendwerk und Scheinvollkommenheit. Satan ist auch der revoltierende Unruhestifter und der „Gott dieser Zeit“ (2 Kor 4,4), im Gegensatz zu CHRISTUS, dem Herrscher der Ewigkeit. Schließlich ist Satan der „Fürst dieser Welt“(Joh 12,31), die in sechs symbolischen Tagen geschaffen wurde.

Die Zahl sechs ist ferner eng mit der Kreuzigung Christi verbunden, die der größte antichristliche Scheintriumph war. Zunächst wurde CHRISTUS am sechsten Tag der Woche, am Freitag, gekreuzigt. Morgens ,um die sechste Stunde“ setzte sich Pilatus auf den Richterstuhl und gab den Befehl zur Kreuzigung (Joh 19,13-16): das war morgens um 6 Uhr (Johannes benutzt in Gegensatz zu den anderen Evangelisten die damalige römische Stundenzählung, die mit unserer heutigen übereinstimmt). Als Jesus dann gekreuzigt wurde, war es nach Auskunft des Markus, der die jüdische Zählung benutzt (wonach die erste Stunde mit Sonnenaufgang, also morgens um 6 Uhr beginnt), ,zur dritten Stunde“ (Mk 15,25), d. h. um 9 Uhr. Nachdem Jesus drei Stunden am Kreuz hing, begann sich zur „sechsten Stunde“ nach jüdischer Zählung, d. h. um 12 Uhr, die Sonne zu verfinstern, die bis zur jüdischen „,neunten Stunde“, d. h. bis 15 Uhr dauerte, als Jesus starb (Mk 15,33-37; Mt 27,45; Lk 23,44-46). Demnach hing Jesus am sechsten Wochentag sechs Stunden lang am Kreuz, wobei genau in der Mitte dieser sechs Stunden die jüdische sechste Stunde (12 Uhr) lag.

Zur sechs als Zahl der Scheinvollkommenheit und Bosheit passt es auch, dass das sechste Gebot das Verbot des Ehebruchs ist, welches die meistbegehrteste scheinglückverheißende Sünde anspricht. Auch zahlreiche andere Bibelstellen 
deuten den Charakter der sechs als Zahl der Schlechtigkeit an. Irenäus weist in diesem Zusammenhang darauf hin, dass Noah sechshundert Jahre alt war, als die zur Vernichtung des Bösen hereinbrechende Sintflut über die Erde kam (Gen 6,7), und dass das goldene Standbild, das der babylonische König Nebukadnezar errichtet hatte und dessen Anbetung unter Androhung des Feuertodes allen Reichsbewohnern befohlen wurde, sechzig Fuß hoch und sechs Ellen breit war (Dan 3,1). Man könnte hinzufügen, dass der Riese Goliath sechs Ellen und eine Spanne groß war (1 Sam 17,4), dass der Riese, den Jonathan erschlug, an jeder Hand sechs Finger und an jedem Fuß sechs Zehen hatte (2 Sam 21,20), und dass vor der Erzählung von Salomons Sündenfall (1 Kön 11) vom Reichtum des Königs die Rede ist, der Einkünfte in Höhe von 666 Goldtalenten hatte (1 Kön 10,14) sowie einen goldenen Thron, zu dem 6 Stufen hinaufführten (1 Kön 10,19). Alles vorstehende bekräftigt die antichristliche Symbolik der Zahl sechs. Vor allem aber macht die Tatsache, dass 888 die Zahl des Namens Jesu ist (siehe oben), die 666 zur Zahl des Antichristen.

Es sei aber angemerkt, dass die sechs an sich auch positiv gedeutet werden kann. Wir wird als Zahl der Schöpfung betrachtet, da man sich in der geschaffenen dreidimensionalen Welt in sechs Hauptrichtungen fortbewegen kann (vorwärts, rückwärts, nach rechts, nach links, nach oben und nach unten); dazu passt, dass die biblische Erzählung von der Erschaffung der Welt dieses Schöpfungswerk auf sechs „Werktage“ einer Woche verteilt, weshalb die sechs auch angesehen wird als Zahl der Arbeit, der Entwicklung, des Fortschritts und schließlich als Zahl des Menschen (weil dieser das „Lebewesen des Fortschritts“ ist, das sich selbst und Gottes Schöpfung durch seine Arbeit weiterentwickelt, und daher passenderweise am sechsten Tag als Krönung des Schöpfungswerkes geschaffen wurde). Dass das göttliche Schöpfungswerk auf sechs Tage verteilt wird, hat dem hl. Augustinus zufolge seinen Grund auch darin, dass sechs die kleinste der sog. ,,perfekten Zahlen“ ist (eine Zahl heißt perfekt, wenn sie die Summe ihrer echten Teiler ist; so ist 6 durch 1,2,3 ohne Rest teilbar, und es gilt $6=1+2+3) .{ }^{91}$ Dazu passt, dass der Name Jesus, welcher der menschliche Name des Sohnes Gottes war, ihm also als „Menschensohn“ und „,neuem Adam“ zusteht, in der biblischen Originalform (Inбous) sechs Buchstaben hat. Negativ wird die sechs nur, wenn man in ihr stehenbleibt, wenn man sie also nicht als Durchgangsstadium zur sieben hin betrachtet, sondern in ihr selber das Ziel sieht.

Dieser negative Sinngehalt kommt besonders in der Zahl 666 zum Ausdruck, denn die dreimalige Wiederholung der 6 symbolisiert offenbar das trotzige Beharren und Stehenbleiben auf der 6: In diesem Sinne ist die sechs und die 666 die „Vollkommenheit des Geschöpfes, aber ohne das Siegel des göttlichen Segens und der Sabbatruhe, ... der Humanismus, die Anbetung des Menschen durch den Menschen“. 92

Die Zahl 666 hat einen weiteren antichristlichen Symbolgehalt in der originalen griechischen Form ihrer Darstellung. Sie wird nämlich im Griechischen dargestellt durch die Buchstabenfolge $\chi \xi \varsigma$ (Chi-Xi-Stigma). Die Folge Chi-Stigma $(\chi \varsigma)$ sieht genauso aus wie die Folge Chi-Schlusssigma, welche den ersten und letzten Buchstaben des Namens „Chri-

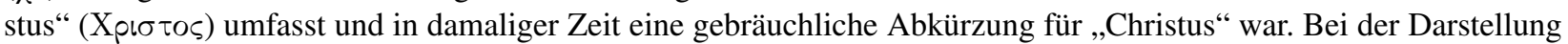
der Zahl 666 steht also zwischen den beiden Buchstaben dieser Abkürzung für „Christus“ noch das Zeichen Xi. Das

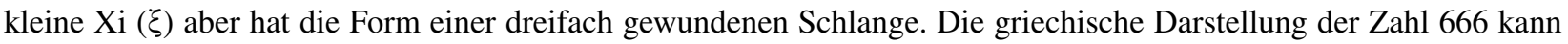
somit gedeutet werden als ein durch Satan, die ,alte Schlange“ (Apk 12,6) durchkreuztes und dadurch zerrissenes Christussymbol: das Symbol des Antichristen.

Ferner ist 666 zwei Drittel der „stabilen Ganzheitszahl“ 1000 (die Zahl 1000 entspricht dem Rauminhalt eines Würfels mit der Kantenlänge 10, wobei der Würfel Zeichen der Stabilität und die 10 Zeichen der Ganzheit ist; siehe auch Kommentar zu 20,2b). Manche sehen in dieser Eigenschaft der 666 eine Anspielung auf die vorerwähnte Zerstörung von jeweils einem Drittel der verschiedenen Weltbereiche $(8,7 ; 8,8 ; 8,10-11 ; 8,12 ; 9,15 ; 12,4)$ : Wenn ein Drittel der stabilen Weltganzheit (also der 1000) zerstört wird, bleiben zwei Drittel (=666) von dieser Ganzheit übrig. Die 666 ist darum Symbol für die antichristliche Welt, insofern diese als eine durch den Finger des göttlichen Gerichts berühre Welt angesehen werden muss (so Austin FARRER).

Es gibt also zahlreiche symbolische Verbindungen zwischen der sechs bzw. 666 und der christusfeindlichen Welt. Diese

\footnotetext{
91 Perfekte Zahlen sind relativ selten; die zweitgrößte perfekte Zahl ist 28: 28 ist ohne Rest durch 1,2,3,7 und 14 teilbar, und es ist $28=1+$ $2+4+7+14$. Die drittgrößte perfekte Zahl ist 496. Man kennt bis heute (Stand Dezember 2018) einundfünfzig perfekte Zahlen; ob es unendliche viele oder nur endlich viele perfekte Zahlen gibt, ist bis heute unbekannt. Auch ist unbekannt, ob es ungerade perfekte Zahlen gibt (alle bisher bekannten sind gerade). - Zur Zahl sechs als Zahl der Schöpfungstage passt auch, wie Augustinus bemerkt, eine durchaus sinnvolle schematische Aufteilung der Schöpfungstage in 1, 2 und 3 Tage. Am ersten Tag wird die gesamte, aus Himmel und Erde bestehende Rahmen der Welt geschaffen und ausgeleuchtet, in den zwei folgenden Tagen 2 und 3 wird der Himmel droben und Erde und Meer unten hergerichtet; und in den drei folgenden Tagen 4,5,6 werden die geschaffenen Lebensräume mit sich bewegenden Geschöpfen bevölkert (Sternen, Fischen und Vögeln, Tieren und Menschen).
}

92 A. LECERF, Artikel „Le nom de la bête“, Christianisme 3.9.1942. 
Symbolhaftigkeit der Zahl 666 kann nun jedoch nicht der einzige Grund für ihre Verwendung in Apk 13,18 sein. Denn Johannes fordert die Verständigen unter seinen Lesern dazu auf, die Zahl des Tieres, welche die Zahl eines Menschen ist, zu „berechnen“. Die symbolische Deutung dieser Zahl allein kann also nicht hinreichend sein, weil es dann eben nichts weiter zu berechnen gäbe.

\section{2b. Berechnung der Zahl des Tieres durch das Gefüge der Dreieckszahlen}

Die sechs ist mathematisch gesehen eine bemerkenswerte, eine sogenannte „magische“ Zahl. Es ist nämlich $1+2+3=$ 6 und $1 \bullet 2 \bullet 3=6$. Eine im höchsten Grade magische Zahl aber ist zweifellos die 666, die seit alters immer wieder die Aufmerksamkeit der Zahlenmagier auf sich zog. Ihre Symmetrien sind in der Tat erstaunlich, z. B. ist

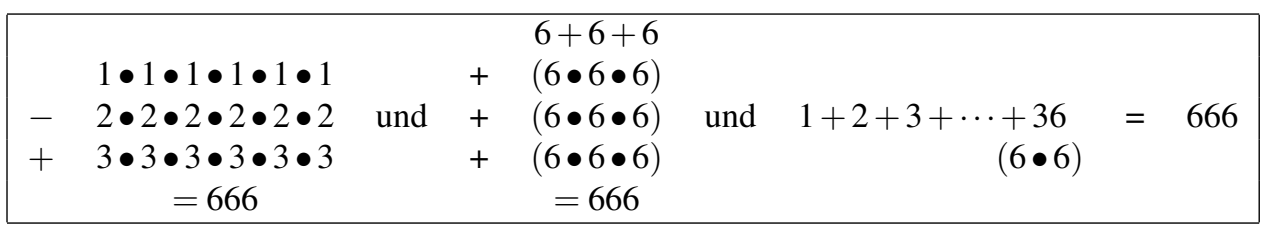

Besondere Aufmerksamkeit verdient die Tatsache, dass

$$
1+2+3+\ldots+36=666
$$

ist. Zahlen, welche die Summe aller Zahlen von 1 bis zu einer bestimmten Zahl bilden, nannte man schon im Altertum „Dreieckszahlen“. So ist 3 die „Dreieckszahl zu 2“ (weil $3=1+2$ ist), 6 ist die „Dreieckszahl zu 3“ (weil $6=1+2+3$ ist), 10 ist die „Dreieckszahl zu 4“ (weil $10=1+2+3+4$ ist) usw. Allgemein ist die Dreieckszahl zu einer Zahl x die Anzahl der Quadrate, die man braucht, um ein gleichseitiges ,Stufendreieck“ mit x Stufen zusammenzustellen:

die Dreieckszahl zu 2 ist 3:

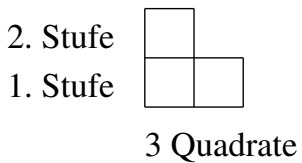

die Dreieckszahl zu 3 ist 6:

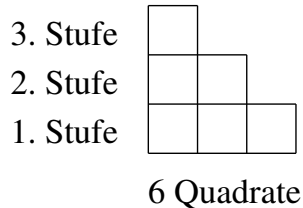

die Dreieckszahl zu 4 ist 10:

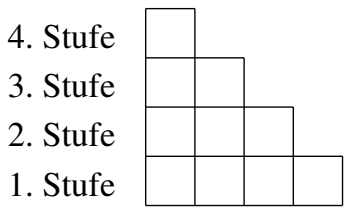

10 Quadrate

Der Dreieckszahl gab man im Altertum dieselbe symbolische Bedeutung wie der Grundzahl, zu der sie Dreieckszahl ist. So sah man eine Verbindung zwischen den 153 Fischen, welche die Apostel auf das Geheiß Jesu hin fingen (Joh 21,11) und der Zahl der 17 Völkerschaften, die sich durch die Pfingstpredigt der Apostel begeistern ließen (Apg 1,9-11): Denn 153 ist die Dreieckszahl zu 17.

Der jüdische Autor Philon (1. Jahrhundert) brachte auf dieselbe Weise die 55 Säulen des Wüstenheiligtums (vgl. Ex 26,18.20.22.32.37, gerechnet ohne die zwei Ecksäulen Vers 23) mit der vollkommenen Zahl 10 in Zusammenhang (55 ist Dreieckszahl zu 10), und die 10 führte er an anderer Stelle auf die noch vollkommenere Zahl 4 zurück (10 ist Dreieckszahl zu 4). Durch einen solchen Abstieg zu immer kleineren, ,vollkommeneren“ Zahlen meinte man, zum Wesen einer Zahl vordringen zu können.

Nun ist die 666 Dreieckszahl zu 36, und 36 ist wiederum Dreieckszahl zu 8. So konnte man von der 666 zur 36 und von dort zur 8 absteigen. Genau dieser Abstieg von der 666 über die 36 zur 8 ist nun nach Berg VON EYSINGEN und Ernst LOHMEYER die Berechnung, zu der Johannes seine Leser auffordert. Dies wird damit begründet, dass in Kap. 17,11 über das Tier gesagt wird, dass es als „,ein achter“ König auftreten wird. Die dämonische „Zahl des Tieres“, die bei der Berechnung herauskommen soll, wäre demnach die 8, die aufgrund der Dreieckszahlen-Spekulation dieselbe Bedeutung hätte wie die 666, welche „Zahl eines Menschen“ im allgemeinen genannt werden kann (siehe oben, Deutung 2a). Im Sinne dieser Argumentation kann man noch anführen, dass sich sowohl in Apk 13,18 bei der Erwähnung der Zahl 666 als auch in Apk 17,9-11, wo das Tier als der unheimliche ,achte König“ bezeichnet wird, der Hinweis findet, es sei hier zum Verständnis „Weisheit“ nötig (Apk 13,18 und 17,9).

Dieser Gedankengang hat etwas Beeindruckendes an sich. Aber es ist mehreres kritisch anzumerken. Zunächst wird in Apk 17,11 nicht gesagt, dass die Zahl acht „Zahl des Tieres“ ist, sondern nur, dass das Tier als achter König auftritt. Ein schwerwiegenderer Einwand ist, dass die Achtzahl nur in antichristlich-gnostischen Kreisen als dämonische Zahl galt, 
während sie in christlichen Kreisen gerade umgekehrt eine positive Bedeutung hatte und geradezu als die Zahl Christi angesehen wurde (siehe oben, Deutung 2a). Man kann also höchstens sagen, dass die acht als „Zahl der Überfülle“ die übermenschliche Kraft des Tieres versinnbilden könnte, oder dass das Tier die Vollkommenheit Christi dadurch nachzuäffen versucht, dass es als ,,achter“ König auftritt. In diesem Sinne mag man dann vielleicht zwischen der 666 in Apk 13,18 und der acht in Apk 17,11 eine geheimnisvolle Verbindung zugeben, wenn man nicht einfach mit Heinrich KRAFT sagen will, dass der Zusammenhang zwischen beiden Stellen bzw. Zahlen ,,auf einem vom Verfasser nicht vorgesehenen Zufall“" beruht. ${ }^{93}$

Jedenfalls - und das ist der entscheidende Einwand - wird durch die Berechnung, die uns von der Zahl 666 auf die Zahl 8 führt, keinerlei neue Information über das Tier gewonnen: Es ist, wie wenn man in einer mathematischen Gleichung ein , $x$ für ein $u^{\prime \prime}$ setzt. Daher kann man wohl erwarten, dass die Berechnung, zu der Johannes auffordert, uns nicht wieder zu einer anderen Zahl, sondern zu einem konkreten Menschennamen führt. Es bleibt also hier die Aufgabe der Bibelauslegung, einen entsprechenden konkreten Namen herauszubekommen: Dieser aber ist sehr wahrscheinlich schon gefunden und lautet, wie wir bereits gesehen haben, DiOcLES AUGUSTUS.

Im Folgenden seien aber noch einige andere, zum Teil recht bedenkenswerte, wenn auch weniger überzeugende Versuche zur Identifizierung des Namens vorgestellt.

\section{Die Deutung auf andere römische Kaiser}

\section{3a. Deutung auf Kaiser Caligula}

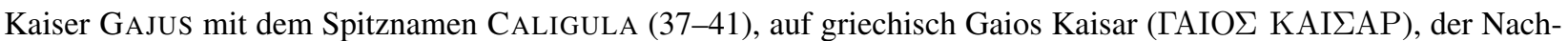
folger des TIBERIUS, war der erste Kaiser, der nach Christi Tod zu regieren begann. Dieser Kaiser war auch der erste und vielleicht extremste in der Reihe der krankhaft-überspannten römischen Kaiser, hierin ein Vorläufer NEROs und Domitians. So hielt sich CALIGULA beispielsweise für die Inkarnation mehrerer olympischer Götter und verlangte göttliche Ehren für sich auch in Rom. Schließlich gab er den Befehl, sein Standbild im Tempel zu Jerusalem aufstellen zu lassen, und allein sein Tod verhinderte, dass dies tatsächlich geschah. Aufgrund dieses Befehls kann man CALIGULA als den ersten römischen Kaiser bezeichnen, der Gott und sein Volk zum Zorn reizte, und dadurch erklärt sich die namentlich bei den Juden verbreitete Auffassung, dass Caligula der Antichrist sei oder ein Typus für den Antichristen

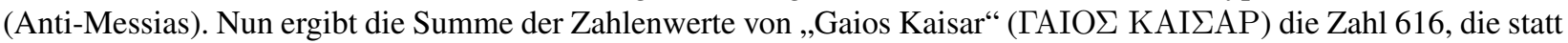
der 666 in einigen Bibelhandschriften steht. Wenn die Zahl 616 die ursprüngliche ist, wäre die Deutung auf Caligula in der Tat sehr überzeugend (so SPITTA, HoltZMAnN, ZAHN u. a.).

Doch ist sehr wahrscheinlich 666 die ursprüngliche Zahl, weil sie in den meisten älteren Handschriften zu finden ist. Die Zahl 616 kann durch einen Abschreibfehler entstanden sein, denn 666 wird im griechischen Original durch die Buchstabenfolge Chi-Xi-Stigma $(\chi \xi \varsigma)$ dargestellt und 616 durch Chi-Iota-Stigma $(\chi\llcorner\varsigma)$, wobei das schlangenähnliche

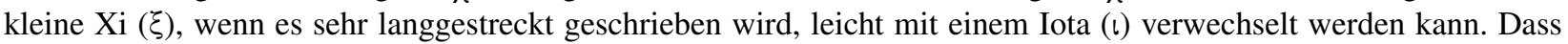
dieser Schreibfehler sich dann so hartnäckig fortgepflanzt hat, könnte unter anderem der Tatsache zu verdanken, dass TAIO $\Sigma$ KAI $\Sigma$ AP die Zahl 616 ergibt. DEISSMANN hat darauf aufmerksam gemacht, dass auch der antichristliche Ausdruck „Kaisar Theos“ (KAI 2 AP $\Theta E O \Sigma)$, deutsch = „Caesar Gott“, „Gottkaiser“) zur Zahl 616 führt, was wohl ein weiterer Grund für die Verbreitung der 616 in den Bibelhandschriften ist. Zur Zahl 616 siehe noch die folgenden Deutung sowie die Fußnoten zu den Deutungen 3e, 4, und 5p.

\section{3b. Die Deutung auf Kaiser Nero}

NERO (54-68) war der erste eindeutige römischen Christenverfolger und so gewissermaßen der Vater des „Tieres“. Nicht unpassend wäre es also, wenn man in seinem Namen die Zahl 666 finden würde. Entsprechende Versuche führten tatsächlich zum Erfolg, wobei man aber das hebräische Alphabet benutzen muss. Es gibt im Hebräischen allerdings mehrere Möglichkeiten, den Ausdruck „Kaiser Nero“ zu buchstabieren. Denn für „Kaiser“ (hebräisch: „Qesar“) kann man oder pיסר schreiben, und noch mehr Möglichkeiten hat man, um Nero zu bezeichnen: Man kann am Schluss ein „," anhängen oder dieses auch weglassen, außerdem kann man die beiden Vokale „e“ und „, “ entweder durch

$93 \quad$ KRAFT, Offenbarung S. 184. 
Vokalbuchstaben wiedergeben oder dies bei einem oder auch bei beiden Vokalen unterlassen. Eine der vielen möglichen Schreibweisen führt nun auf 666 und eine andere auf 616:

- Qesar Neron = Qoph-Samech-Resch Nun-Resch-Waw-(Schluss-)Nun (קסר נרון) =666.

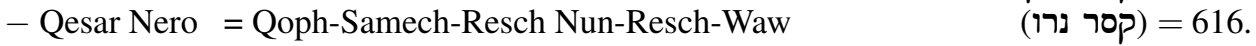

Diese Deutung wurde zischen 1830 und 1840 fast gleichzeitig von FRITZSCHE, BENARY, HITZIG und REUSS vorgeschlagen und ist heute die beliebteste, wohl deshalb, weil man meist voraussetzt, dass mit der 666 ein Name verschlüsselt ist, der zur Zeit des Johannes bereits bekannt und in aller Munde war. Unter dieser Voraussetzung gibt es allerdings keine bessere Deutung der 666 als „Kaiser Nero“. Falls die Deutung auf Nero in der frühen Christenheit verbreitet war, so würde dies auch zur Erklärung der Tatsache beitragen, dass in einem Teil der alten Bibelhandschriften statt der Zahl 666 die Zahl 616 steht, und zwar meist nur in solchen Handschriften, die im Westteil des Reiches geschrieben wurden. 616 ergibt sich nämlich als Zahl des Namens „Kaiser Nero“, wenn man für Nero die im Westteil des Reiches übliche Form des Namens „Nero“ (ohne das „n“ am Schluss) voraussetzt, während 666 herauskommt, wenn man die im Ostteil des Reiches übliche Aussprache „Neron“ wählt. Diese Beobachtung lässt also vermuten, dass westliche Bibelabschreiber, die von einer möglichen Deutung auf Nero gehört hatten, die Zahl 666 in 616 umänderten, weil sie (vielleicht aus Unkenntnis der östlichen Aussprache) die 666 für einen Abschreibfehler hielten (siehe zur Zahl 616 aber auch Deutung 3a).

Die Deutung auf Kaiser Nero hat aber den entscheidenden Nachteil, dass mit hebräischen Buchstaben gearbeitet werden muss, was zu einem römischen Kaiser weniger gut passen will. Ein solcher Kunstgriff ist bei der Deutung auf Diokletian nicht notwendig. Diokletian trägt also die Zahl 666 viel offensichtlicher als Nero: Er und nicht Nero dürfte darum im eigentlichen Sinne gemeint sein.

\section{3c. Deutung auf die Reihe aller römischen Kaiser von Caesar bis Otho oder bis Vespasian}

Stanislas GIET (L'Apokalypse et l'histoire, Étude historique sur l'Apocalypse johannique) hat herausgefunden, dass die Summe der griechischen Anfangsbuchstaben der acht ersten römischen Kaiser die Zahl 666 ergibt:

$\begin{array}{lll}\text { 1. } & \text { Caesar } & (45-44 \text { v. Chr. }), \\ \text { 2. Augustus } & (44 \text { v. Chr. }-14 \text { n. Chr. }), \\ \text { 3. Tiberius } & (14-37), \\ \text { 4. Gajus-Caligula } & (37-41), \\ \text { 5. Claudius } & (41-54), \\ \text { 6. Nero } & (54-68), \\ \text { 7. Galba } & (68-69), \\ \text { 8. Otho } & (69),\end{array}$

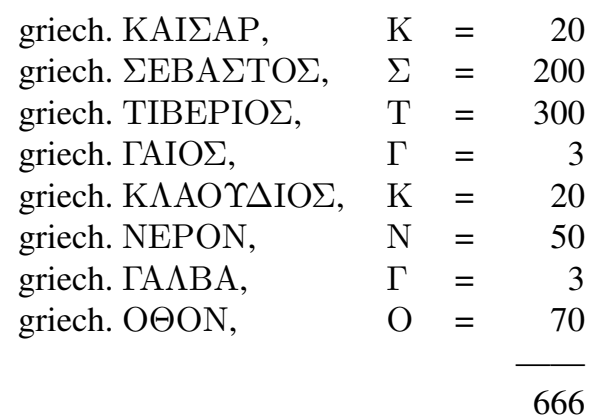

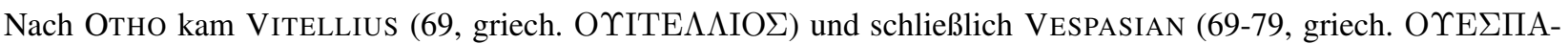
$\Sigma$ IANO $\Sigma$ ). Man kann auf drei Weisen durch Abwandlung des vorstehenden Rechenschemas bis zu Kaiser Vespasian gelangen. Am einfachsten erreicht man dies, indem man in oben stehender Rechnung das „O“ zugleich für die drei Kaiser Otho, Vitellius und Vespasian stehen lässt, da die Namen dieser drei hintereinander kommenden Herrscher im

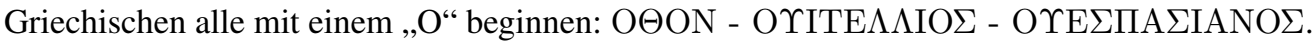

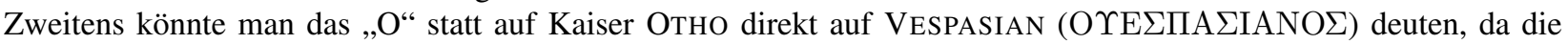
drei Kaiser Galba, Отно und Vitellius, die sich 68-69 in den Thronwirren nach Neros Tod rasch ablösten (sog. „Zwischenkaiser“) nicht überall als Kaiser anerkannt wurden.

Drittens aber könnte man aus demselben Grund die Zahl 3, die in oben stehender Rechnung für den griechischen Anfangsbuchstaben $\Gamma$ von GALBA steht, als Zahl rechnen, die nicht vom Anfangsbuchstaben eines Kaisers herrührt, sondern für Anzahl der drei umstrittenen Kaiser GALBA, Отно und VITELLIUS steht. Dann würde folgerichtig das „O“ für Vespasian stehen. Kritisch ist aber anzumerken, dass 666 die Zahl eines Menschen sein soll und nicht die Zahl einer ganzen Reihe von Menschennamen. 


\section{3d. Deutung auf Kaiser Titus (bzw. auf Vespasian, Titus und Domitian zugleich)}

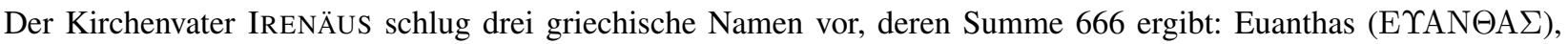
Lateinos $(\Lambda$ ATEINO $\Sigma$ ) und Teitan (TEITAN). Zu Lateinos siehe auch die 4. Deutung, zu Euanthas und Teitan siehe auch Deutung 5r. Der Namen TEITAN bedeutet „Titan“: so hießen die furchterregenden vorolympischen Götter der griechischen Mythologie. Noch kein Kaiser habe es gewagt, so sagt Irenäus, sich diesen Namen zuzulegen, aber der Antichrist werde es vielleicht tun.

Möglich ist jedoch, dass Irenäus den Lösungsvorschlag TEITAN aus einer Tradition entnommen hat, die dieses Wort ursprünglich als Anspielung auf den Kaiser TITUS verstanden hat (Titus = Titanus?) Kaiser TITUS (79-81) hat zwar nichts besonderes gegen die Christen unternommen. Aber er war der Feldherr, der im Jahre 70 (noch unter Kaiser Vespasian) Jerusalem und den dortigen jüdischen Tempel zerstört hat. Darum gilt Titus bei den Juden als Typus des Antichristen. „Titus“ war auch der Familienname der Kaiser VESPASIAN (69-79) und DOMITIAN (81-96). Es ist daher möglich, dass man die Kaiser Vespasian, Titus und Domitian „die Titanen“ nannte.

Jedoch ist diese Deutung der Zahl 666 auf TITUS (oder auf VESPASIAN, TITUS und DoMITIAN zugleich) äußerst vage ist und daher als Hauptlösung nicht in Frage kommt.

\section{3e. Deutung auf Kaiser Domitian}

Kaiser Domitian (81-96), der zweite in der Reihe der großen Christenverfolger, war der Kaiser, unter dem die Apokalypse geschrieben wurde. Man hat daher versucht, diesen Kaiser mit der Zahl 666 in Verbindung zu bringen. Als Erstes fällt auf, dass DOMITIAN den Nebennamen „Nero“ hatte: Er hieß nämlich mit vollem Namen „Titus Domitianus Flavius Nero“. Als ein zweiter „Kaiser Nero“ wäre er also ebenso wie der erste ein Träger der Zahl 666.

Es wurden aber noch zwei andere Beziehungen zwischen Domitian und der Zahl 666 entdeckt. Lyder BRUNS (Zeitschrift für Neutestamentliche Wissenschaft 1926) geht davon aus, dass man sich die Zahl 666 auf einer Münze aufgedruckt vorstellen muss, da sich auf diese Weise leicht erklären ließe, warum diese Zahl beim KAUFEN UND VERKAUFEN unerlässlich sei. 666 wird in römischen Ziffern DCLXVI geschrieben. Nimmt man nun an, es habe eine Münze mit dem Kaiserbild und der Aufschrift DCLXVI gegeben, so könnte diese Münze wie folgt gelesen werden: „DC“ wäre eine Abkürzung für „Domitianus Caesar“ (= Kaiser Domitian), und der Rest „LXVI“ würde das Regierungsjahr des DOMITIAN enthalten, in dem die Münze geprägt wurde. Dabei ist „L“ die gebräuchliche Abkürzung für „Lykabantos“ (= des Jahres) und „XVI“ bezeichnet die Zahl 16. Die Münze würde also aus dem 16. Regierungsjahr des DomitiAN stammen: Das wäre sein letztes Regierungsjahr (96 n. Chr.), in dem die domitianischen Verfolgung noch tobte, bevor sie durch die Ermordung des Kaisers abgebrochen wurde. ${ }^{94}$

Man könnte freilich gegen diese Überlegungen anführen, dass es sich bei der Zahl 666 keineswegs zwingend um eine Münze handeln muss: Johannes sagt ja nicht, dass die Zahl auf einem Geldstück, sondern auf der Stirn und der rechten Hand der Anbeter des Tieres aufgeprägt ist. Außerdem scheint der Text zu besagen, dass die ganze Zahl (und nicht nur ihre ersten beiden Ziffern) einen Menschennamen ergibt. Darum fällt diese Lösung, so bestechend sie auf den ersten Blick auch wirken mag, als eigentliche Lösung aus.

Eine dritte Art der Berechnung, die auf Domitian führt, stammt von E. STAUFFER (Coniecta Neotestamentica XI, ab S. 237). Eine volle Titulation Domitians lautete „Imperator Caesar Domitianus Augustus Germanicus“. Auf Griechisch

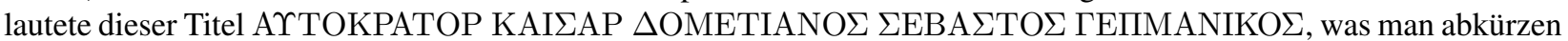
konnte zu A. KAI. $\triangle$ OMET. 5 EB. ГE., und die Zahlensumme dieser Buchstaben liefert 666. Jede der in diesem Titel vorkommenden fünf Abkürzungen ist tatsächlich auf Münzfunden bezeugt, aber leider gibt es keine Münze, die alle fünf Abkürzungen zugleich enthält. Darüber hinaus spricht die Kompliziertheit dieser Namensaufschlüsselung dagegen, dass dies die eigentlich gemeinte Lösung ist, wenngleich hier ein mystischer Nebensinn vorliegen mag.

\section{3f. Deutung auf Kaiser Nerva}

Kaiser M. NERVA (96-98), der Nachfolger des DomitiAn, wird auf Griechisch M. NEPO؟A geschrieben, was 666 ergibt. Diese Lösung wird von Heinrich KRAFT vertreten, ${ }^{95}$ für den feststeht, dass die Apokalypse nicht unter DoMI-

\footnotetext{
94 Ohne Bedeutungsänderung könnte man das L für „Jahr“ auch weglassen: Dann ergäbe sich eine Münze mit der Aufschrift DCXVI, welche der Zahl 616 entspricht. Sowohl die Zahl 666 als auch die Zahl 616 könnte also als Münzaufschrift „Domitianus Caesar im 16. Regierungsjahr“ bedeuten: So könnte man die Textvariante 616 erklären, worauf TouILLEUX hingewiesen hat. Siehe zu 616 aber auch Deutung $3 a$.

95 Vgl. KRAFT, Offenbarung S. 222
} 
TIAN, sondern unter Kaiser Marcus Cocceius NERVA geschrieben wurde. Jedoch ergibt dies keinen rechten Sinn, denn NERVA hat die Christen nicht verfolgt. Auch ist der Hauptgrund, warum die Apokalypse unter NERVA geschrieben sein soll, und den Heinrich KRAFT dann durch die auf NERVA passende Zahl 666 bestätigt sieht, nicht stichhaltig. KRAFT glaubt nämlich, der Verfasser der Apokalypse müsse zu der Zeit geschrieben haben, da NERVA bereits den TRAJAN zum Mitregenten gemacht habe, denn nur so habe der Verfasser in 17,11 das Kommen eines weiteren römischen Herrschers nach dem schon bestehenden voraussehen können, weil er nämlich diesen (TRAJAN) schon gekannt habe. Der in 17,11 vorausgesagte kommende Herrscher kann jedoch in Wirklichkeit nicht TRAJAN sein, weil TRAJAN sehr lange regierte, während JOHANNES über jenen Herrscher sagt, dass er ,nur kurze Zeit“ bleiben wird. Obgleich also die Zahl des Namens „M. Nerva“ 666 ist, ist diese Deutung unpassend.

\section{3g. Deutung auf Kaiser Trajan}

Der dritte Christenverfolger, Kaiser TRAJAN (98-117), mit dem die allgemeine Christenverfolgungszeit im römischen Reich begann, hatte den Familiennamen UlPIUS. Wie GroTIUS erkannte, ergibt dieser Name in griechischen Buchstaben $(\mathrm{O} \cup \lambda \pi เ \circ$ ) die Zahl 666:

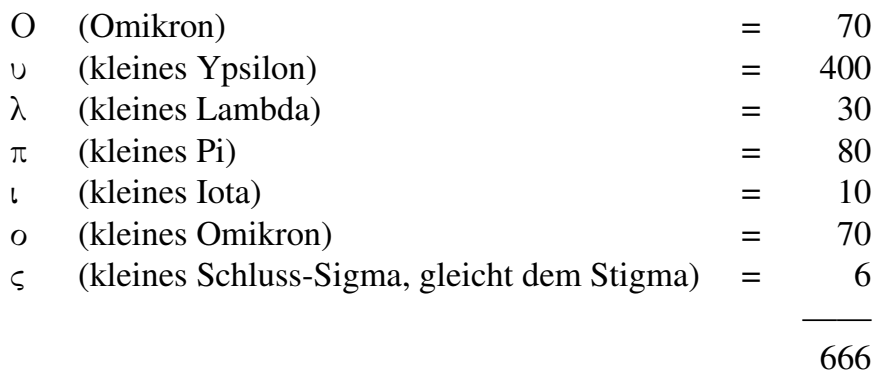

Wenn man aber das Schluss-Sigma als regelrechtes Sigma (=200) rechnet, ergibt sich 860. Auch, dass hier ein anderer als der Hauptname TRAJANs herangezogen wird, ist ein Nachteil dieser Deutung.

\section{3f. Deutung auf Kaiser Julian}

Kaiser JUliAN (361-363) ging mit dem Beinamen „der Abtrünnige“ bzw. „der Apostat“ in die Geschichte ein. Auf Griechisch, der Sprache der meisten damaligen Geschichtsschreiber, schreibt man diesen Beinamen AПO $\Sigma T A T H \Sigma$. Für das ST $(\Sigma T)$ in diesem Namen konnte man auch das alte Zeichen Stigma ( $\varsigma)$ verwenden. Mit Stigma ergibt sich:

$\begin{array}{lllr}\mathrm{A} & \text { (Alpha) } & = & 1 \\ \Pi \text { (Pi) } & = & 80 \\ \mathrm{O} \text { (Omikron) } & = & 70 \\ \mathrm{~S} & \text { (Stigma) } & = & 6 \\ \mathrm{~A} & \text { (Alpha) } & = & 1 \\ \mathrm{~T} & \text { (Tau) } & = & 300 \\ \mathrm{H} & \text { (Eta) } & = & 8 \\ \Sigma & \text { (Sigma) } & = & 200 \\ & & & \end{array}$

Diese Deutung hat jedoch gegenüber jener auf DiOKLETIAN den Nachteil, dass sie keinen Personennamen ergibt, sondern nur einen Beinamen, und noch dazu einen, der dem Kaiser erst durch die Nachwelt verliehen wurde.

Wir bleiben also bei der Entschlüsselung „Diocles Augustus“. Vielleicht ist es jedoch kein Zufall, dass die vier Kaiser, die an den „Eckpunkten“ der römischen Christenverfolgung stehen, alle mit der Zahl 666 mehr oder weniger deutlich in Verbindung gebracht werden können:

- NERO, der erste eindeutige römische Christenverfolger,

- TRAJAN, der die Verfolgungen auf das ganze Reich ausgedehnte,

- Diokletian, der die letzte blutige Verfolgungswelle einleitete, und 
- JULIAN, der die blutigen Verfolgungen erneuern wollte.

\section{Die Deutung auf allgemeine Bezeichnungen für das Römische Reich und seine Kaiser}

Die Zahl 666 ergibt sich als Zahlenwert der Ausdrücke

- He Latine Basileia (griech. H $\Lambda$ ATINH BA $\Sigma$ I $\Lambda$ EIA), deutsch: „das lateinische Königreich“,

- Lateinos (griech. $\Lambda$ ATEINO $\Sigma$ ), zu deutsch: „Lateiner“,

- Qesar Romim (hebr. קיסר רומים), zu deutsch: ,Kaiser der Römer“.

In gewisser Weise ebenfalls passend, kennzeichnen diese Begriffe das römische Reich und seine Kaiser. Doch ist einzuwenden, dass 666 die Zahl eines Menschen sein soll, nicht eines Reiches. Und zwar dürfte ein konkreter Mensch gemeint sein, nicht eine so abstrakte Bezeichnung wie „Lateiner“ oder „Kaiser der Römer“. Zum „Lateiner“ ist außerdem anzumerken, dass die normale Schreibweise nicht $\Lambda$ ATEINO $\Sigma$, sondern $\Lambda$ ATINO $\Sigma$ war, was nur 661 ergäbe. ${ }^{96}$

\section{Weitere Deutungen}

5a. BRUSTON fand als Lösung NiMROD, den Sohn des Kusch, der nach Gen 10,8-12 der erste Machthaber auf Erden und der Gründer Babylons war. „Nimrod, Sohn des Kusch“, auf hebräisch Nimrod ben Kusch (נמרד בן כש) ergibt 666, wenn man buchstabiert: Nun-Mem-Resch-Daleth-Beth-Nun-Kaph-Schin. Als Gründer Babylons weist NIMROD auf Rom hin, die Stadt, die in der Apokalypse „Babylon“ genannt wird (siehe Kommentar zu Kapitel 17). Den Namen „Nimrod“ kann man auf die hebräische Wortwurzel „marad“ zurückführen, was „,rebellieren“ bedeutet. NIMROD ist auch in der rabbinischen Tradition eine negative Gestalt: Man erzählt, er habe Abraham in einen Feuerofen geworfen, weil dieser sich weigerte, Götzen zu verehren.

5b. Die Nikolaiten (Nikolaos = Sieg des Volkes), jene in den sieben Briefen der Apokalypse erwähnten Sektierer, wurden in Apk 2,14-15 als Bileamiten (Bileam = Verderben des Volkes) entlarvt. Im griechischen Urtext von Apk 2,14 steht für Bileam „Balaam“. Der Ausdruck „Ho Nikolaos, Ho Balaam“ (O NIKO $\Lambda$ AO $\Sigma$, O BA $\Lambda$ AAM), zu deutsch „der Nikolaos (ist) der Bileam“, ergibt die Zahl 666.

5c. Auch den französischen Kaiser NAPOLEON (1804-1814) brachte man mit der Zahl 666 in Verbindung (siehe ToLSTOIs Krieg und Frieden, Band 2, Teil 1, Kap. 19). Napoleon war der letzte Kaiser, der die Weltherrschaft anstrebte, keine Macht über sich duldete und die Kirche verfolgte, wobei er sich mit ihr zeitweise zum Schein arrangierte. Die Zahl 666 ergibt sich im hebräischen Ausdruck für „Kaiser Napoleon“ (Qesar Napoleon, נפליסר), wenn man buchstabiert: Qoph-Jod-Samech-Resch-Nun-Pe-Lamed-Ajin-Waw-Nun.

5d. Aleister CROWley (1875-1947), der Begründer des modernen Satanismus, der heute immer mehr um sich greift, sah sich selber als den Antichristen, bezeichnete sich als „,das große Tier“ der Apokalypse (griech. To Mega Therion, TО МЕГА $\Theta H P I O N)$, und deutete die Zahl 666 auf sich selbst. To Mega Therion ergibt in der Tat die Zahl 666. Auch ergibt auch der Ausdruck „A. Crowley“, wenn er Buchstabe für Buchstabe ins Griechische transkribiert wird (A. KPOM $\Lambda$ E ), die Zahl 666. Für den mittleren Buchstaben von „Crowley“, das W, gibt es im Griechischen allerdings keine lautgleiche Entsprechung, so dass in der genannten Transkription für das W die formgleiche Entsprechung M gesetzt wird, wobei man $\mathrm{M}$ als ein auf den Kopf gestelltes $\mathrm{W}$ betrachten muss (das auf den Kopf stellen bzw. rückwärts lesen von Worten war charakteristisch für den Satanismus Crowleys).

96 Wenn man statt „,das lateinische Königreich“ den Ausdruck „,das italische Königreich“ (He Itale Basileia, H ITA $\Lambda H$ BA $\Sigma$ I $\Lambda$ EIA) wählt, ergibt sich 616. Diese Zahl ergibt sich auch, wenn man statt „Kaiser der Römer“ (Qesar Romim) den von EwALD vorgeschlagenen Ausdruck ,Kaiser von Rom“ (Qesar Rom, קיסר רום) nimmt. Das könnten abermals Gründe dafür sein, warum in einigen Handschriften die Zahl 616 statt 666 zu lesen ist (siehe auch Deutung 3a): ein Bibelabschreiber könnte von der Deutung „Lateinisches Königreich“ oder „Kaiser der Römer“ gehört und diese Deutung in der Form ,,italisches Königreich“ bzw. „Kaiser von Rom“ im Kopf behalten haben. Das könnte ihn dazu veranlasst haben, die 666 in seiner Vorlage für einen Abschreibfehler zu halten und entsprechend zu ,korrigieren“. 
5e. Statt die in der Antike übliche Zahlenbedeutung der griechischen, hebräischen und lateinischen zu verwenden, könnte man den Buchstaben auch auf andere Weise eine Zahlenbedeutung verleihen. Das einfachste Verfahren bestünde darin, dem $x$. Buchstaben eines Alphabets stets die Zahl $x$ zuzuordnen. Aber auf diese Weise kann der Zahlenwert eines gewöhnlich langen Namens niemals 666 ergeben. Für Wörter mit 6 Buchstaben wird dagegen die 666 optimal erreichbar, wenn man dem 1. Buchstaben die 100 (oder die 101) zuordnet, dem 2. Buchstaben 101 (bzw. 102) usw. Diese Verschlüsselung kann man Hundert-Verschlüsselung bzw. Hunderteins-Verschlüsselung nennen. Die HundertVerschlüsselung im deutschen und die Hunderteins-Verschlüsselung im griechischen Alphabet sehen wie folgt aus:

Die Hundert-Verschlüsselung im deutschen (alias modernen lateinischen) Alphabet:

$\begin{array}{ccccccccccccccc}\mathrm{A} & \mathrm{B} & \mathrm{C} & \ldots & \mathrm{H} & \mathrm{I} & \mathrm{J} & \mathrm{K} & \mathrm{L} & \ldots & \mathrm{R} & \mathrm{S} & \mathrm{T} & \ldots & \mathrm{Z} \\ 100 & 101 & 102 & \ldots & 107 & 108 & 109 & 110 & 111 & \ldots & 117 & 118 & 119 & \ldots & 125\end{array}$

Die Hunderteins-Verschlüsselung im griechischen Alphabet:

$\begin{array}{ccccccccccccccc}\mathrm{A} & \mathrm{B} & \Gamma & \Delta & \mathrm{E} & \mathrm{Z} & \mathrm{H} & \Theta & \mathrm{I} & \ldots & \mathrm{O} & \ldots & \mathrm{T} & \ldots & \Omega \\ 101 & 102 & 103 & 104 & 105 & 106 & 107 & 108 & 109 & \ldots & 115 & \ldots & 119 & \ldots & 124\end{array}$

Hier legt man passenderweise das normale griechische Alphabet zugrunde, d. h. ohne die Sonderzeichen Stigma, Koppa und Sampi.

THEODOT, der Irrlehrer, auf den wir Apk 9,1-13 bezogen haben, heißt im Griechischen „Theodotos“ ( $\Theta E O \Delta O T O \Sigma)$. Lässt man die Endung -os $(\mathrm{O} \Sigma)$ weg, so bleibt THEODOT ( $\Theta E O \Delta O T)$ übrig, was im Griechischen ein Ausdruck mit genau sechs Buchstaben ist. Diese Buchstaben ergeben in der Hunderteins-Verschlüsselung 666.

5f. Da die sechs so etwas wie eine antichristliche Grundzahl ist, bietet es sich zur Verschlüsselung eines antichristlichen Namens an, dem 1. Buchstaben die Zahl 6, dem 2. Buchstaben die 12 usw. zuzuordnen, was man als SechserVerschlüsselung bezeichnen kann:

Die Sechser-Verschlüsselung im deutschen (alias modernen lateinischen) Alphabet:

$$
\begin{array}{cccccccccccccccccc}
\mathrm{A} & \mathrm{B} & \mathrm{C} & \ldots & \mathrm{J} & \mathrm{K} & \mathrm{L} & \mathrm{M} & \mathrm{N} & \mathrm{O} & \mathrm{P} & \mathrm{Q} & \mathrm{R} & \mathrm{S} & \mathrm{T} & \mathrm{U} & \ldots & \mathrm{Z} \\
6 & 12 & 18 & \ldots & 60 & 66 & 72 & 78 & 84 & 90 & 96 & 102 & 108 & 114 & 120 & 126 & & 156
\end{array}
$$

Die Sechser-Verschlüsselung im hebräischen Alphabet:

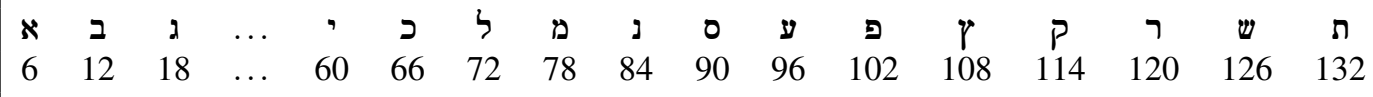

Die Sechser-Verschlüsselung im russischen Alphabet:

$\begin{array}{cccccccccccccccc}\text { А } & \text { Б } & \text { В } & \text { Г } & \text { Д } & \text { Е } & \text { Ж } & 3 & \text { И } & \text { Й } & \text { К } & \text { Л } & \text { М } & \text { Н } & \ldots & \text { Я } \\ 6 & 12 & 18 & 24 & 30 & 36 & 42 & 48 & 54 & 60 & 66 & 72 & 78 & 84 & \ldots & 192\end{array}$

Hier wurde der Buchstabe $\ddot{E}$, der oft zwischen E und $K$ angeführt wird, ausgelassen, weil er sich in der normalen Druck- und Schreibschrift nicht von E unterscheidet. 
Die Sechser-Verschlüsselung im arabischen Alphabet:

$\begin{array}{cccccccccccccccc}\text { Alif } & \ldots & \text { Cha } & \ldots & \text { Dal } & \ldots & \text { Ra } & \text { Saj } & \text { Sin } & \ldots & \text { Lam } & \text { Mim } & \ldots & \text { Waw } & \text { Ja } \\ 6 & \ldots & 36 & \ldots & 48 & \ldots & 60 & 66 & 72 & \ldots & 138 & 144 & \ldots & 162 & 168\end{array}$

Der zweitletzte Buchstabe Waw wird zuweilen auch als drittletzter gebraucht, dann wäre sein Zahlenwert 156 (statt 162).

Der falsche Messias BAR KochBA (Sternensohn), von dem in 8,10-11 die Rede war, hieß eigentlich Schimon. Berechnet man im System der Sechserverschlüsselung den Namen Schimon Bar Kochba (hebr. שמען בר ככבא, also Schin-Mem-Ajin-Nun-Beth-Resch-Kaph-Kaph-Beth-Aleph), so erhält man 666.

5g. Die von dem Araber Mонамmмed gegründete Religion des Islam versuchte jahrhundertelang das christliche Abendland zu erobern. Mohammed nannte sich „der Gesandte“. „Mohammed, der Gesandte“ heißt auf Arabisch „Muchammad 'al-rasul“ (gesprochen: 'ar-rasul), und da kurze Vokale im Arabischen nicht geschrieben werden, kommen darin die folgenden Buchstaben vor: Mim, Cha, Dal, Alif (für den Knacklaut vor dem ,al“), Lam, Ra, Sin, und Waw (für langes u). Zählt man die Werte dieser Buchstaben zusammen, die sich nach dem System der Sechserverschlüsselung ergeben (mehrfach vorkommende Buchstaben nur einmal gerechnet), so erhält man 666.

5h. MARX und LENIN sind die Väter des „Marxismus-Leninismus“, jener Politphilosophie, auf deren Grundlage viele Christen brutal verfolgt worden sind. Der Ausdruck „Marx Lenin“ ergibt die Zahl 666, wenn man den deutschen Namen Marx im deutschen Alphabet und den russischen Namen Lenin im russischen Alphabet schreibt („MARX Ленин“) und dann die Zahlenwerte der Buchstaben addiert, die sich nach der Sechserverschlüsselung ergeben.

5i. Dass Hitler, der Führer des nationalsozialistischen Deutschland, eine antichristliche Gestalt war, braucht nicht betont zu werden. Der aus sechs Buchstaben bestehende Name „Hitler“ setzt sich nach der Hundert-Verschlüsselung zur Zahl 666 zusammen.

5j. Gegen die vorstehenden Deutungen kann man mit Recht einwenden, dass die kriegerischen Auseinandersetzungen des Christentums mit dem Islam, die Geschichte Napoleons, Hitlers, des Marxismus-Leninismus und des modernen Satanismus außerhalb dessen liegt, wovon die Apokalypse konkret redet. Anders ist es mit dem eigentlichen Antichristen, dem letzten Gewaltherrscher der Geschichte. Dieser wird in Apk 20,8 als GoG bezeichnet, ein geheimnisvoller Name, die schon bei Ezechiel (38,2) auftaucht, und zwar in der Verbindung: „Gog im Land Magog, ein Fürst, Haupt von Meschech und Tubal“. Die ersten Worte dieses Ausdrucks lauten im hebräischen Originaltext Gog Äräz Hamagog Nesi (Gog im Land Magog, ein Fürst): גוג ארץ המגוג נשיא. Dies ergibt in der Sechserverschlüsselung 666, wenn man mehrfach vorkommende Buchstaben nur einmal zählt.

Doch ist zu beachten, dass 666 die „Zahl des Tieres“ ist, das zur Zeit des Gog längst endgültig besiegt sein wird: Zwischen dem Ende des Tieres (19,20) und dem Auftreten Gogs (20,8) liegen nämlich sogar „tausend Jahre“ (20,7). Es wäre zwar durchaus passend, wenn Gog in irgendeiner Weise Träger der antichristlichen Zahl ist, aber dies ist nur Spekulation und keineswegs geoffenbart.

5k. Der COMPuTER, ein zweifellos nützliches Hilfsmittel, könnte zu einer totalen Datenüberwachung eingesetzt und so zu einem antichristlichen Hilfsmittel missbraucht werden. Das Wort „Computer“ ergibt im System der Sechserverschlüsselung im lateinischen Alphabet die Zahl 666. Adressen im InTERnET (dem World Wide Web) beginnen mit „Www“, und das hebräische „W“, d. h. der Buchstabe „Waw“ (१) hat den Zahlenwert 6. Wenn zunehmend alle Käufe und Verkäufe über das Internet getätigt werden, spielt so gesehen die Ziffernfolge 6-6-6 beim Kaufen und Verkaufen eine Schlüsselrolle. Außerdem kann man die Ziffernfolge 6-6-6 auch mit dem 1973 von George Joseph LAURER im Auftrag von IBM entwickelten computerlesbaren STRICH-CODE (dem sog. Universal Product Code UPC) in Verbindung bringen, der heute auf nahezu allen Produkten angebracht ist und an den Kassen abgelesen wird. Die Zahl 6 ist in der rechten Hälfte des Strichcodes (wo das Produkt kodiert wird, vgl. dazu die Aussage, dass das Kennzeichen auf der rechten Hand angebracht wird) stets durch die Folge 1010000 kodiert, die für das menschliche Auge durch eine 
Folge von zwei parallelen schwarzen Strichen gleicher Dicke erkennbar ist. ${ }^{97}$ Eine solche Strichfolge erscheint aber auf jedem Produkt am Anfang, in der Mitte und am Ende jedes Code-Streifens als Markierung für den Lesekopf, was also 6-6-6 ergibt. Daher hat es den Anschein, als könne man heute kein Produkt mehr „kaufen oder verkaufen“, auf dem die 6-6-6 nicht angebracht ist. George Joseph Laurer hat auf seiner Homepage zu dem Vorwurf Stellung genommen, der Strichcode enthalte die Zahl des Tieres aus der Apokalypse. Laurer schreibt, es sei nur dem Zufall zu verdanken, dass der Strichcode so aussehe, ebenso wie es Zufall sei, dass seine drei Namen „George Joseph Laurer“ jeweils aus 6 Buchstaben bestehen. ${ }^{98}$ In der Tat ist gegen die obigen Deutungen daran zu erinnern, dass die Zahl 666 nach dem Text der Apokalypse nicht auf Handelswaren angebracht ist und kein technisches Produkt bezeichnet.

51. Die Zahl bezeichnet auch keine Stadt, so dass NEW YORK, die Welthandelsmetropole und Börsenstadt, die im System der Sechserverschlüsselung Trägerin der Zahl 666 ist, nicht die eigentliche Lösung des Zahlenrätsels sein kann.

5m. Die Adventisten glauben, dass der PAPst der Antichrist sei. Sie weisen darauf hin, dass der Titel ,Stellvertreter des Sohnes Gottes“ auf lateinisch VICARIUS FILII DEI heißt. Die darin enthaltenen Zahlzeichen (VICarIVs fILII DeI) ergeben 666. Doch steht trotz gegenteiliger Behauptungen der genannte Titel nicht auf der Tiara, der dreifachen Krone des Papstes, und außerdem ist dieser Titel auch nie offizielle Amtsbezeichnung des Papstes gewesen, die statt dessen höchstens „Vicarius Christi“ (Stellvertreter Christi) lautet. Dabei bedeutet „Stellvertreter“ nicht, dass der Papst CHRISTUS ersetzen will, sondern dass er in besonderer Weise in seinem Dienst steht. Der Titel „Stellvertreter des Sohnes Gottes“ ist auch theologisch falsch: Denn der Papst repräsentiert CHRISTUS als Haupt der Kirche, nicht aber den „Sohn Gottes“ als zweite göttliche Person. Die Adventisten haben noch einen zweiten „Beweis“. Der Titel „Lateinischer Priesterkönig“, auf lateinisch „Latinus Rex Sacerdos“ enthält die Zahlzeichen LatInVs reX saCerDos, was ebenfalls 666 ergibt. Aber auch dieser Titel steht weder auf der päpstlichen Tiara, noch ist er offizieller Papsttitel, noch ist er theologisch richtig: Der Papst versteht sich nicht als König. Auch ist gegen beide Titel einzuwenden, dass sie nicht Eigenname eines Menschen sind, und dass die Apokalypse vom heidnischen Rom spricht: nicht von einem christlichen oder scheinchristlichen Rom.

Zur Beziehung zwischen dem Papsttum und dem Antichristen sei noch angemerkt: Ein Papst kann, solange er rechtmäBig im Amt ist, nicht der Antichrist sein, weil er als Nachfolger des Petrus dessen Rolle als Felsenfundament der Kirche Christi (vgl. Mt 16,18-19) innehat. Doch könnte der Antichrist einst als ein „Vicarius Filii Dei“ auftreten, vielleicht in Konkurrenz zum wahren Papst und zugleich in jenem gotteslästerlichen Sinn, dass er CHRISTUS verdrängen und an seine Stelle treten will (1 Thess 2,4).

5n. Gegner der Adventistenprophetin Ellen Gould WhITE (1827-1915), die den Papst auf die eben beschriebene Weise als Antichristen bloßstellen wollte, haben entdeckt, dass die unheimliche Zahl sich just auch im Namen dieser ,Prophetin“ befindet: Ihr Name enthält die römischen Zeichen eLLen goVLD VVIte $=666$. (Das W des Nachnamens wird hier als doppeltes $\mathrm{V}$ gelesen, was historisch korrekt ist).

5o. Der Franziskanermönch UBERTINO von CASALE ( $\dagger$ um 1330) hat in den beiden Tieren Papst BonIFAZ VIII (1294-1303) und dessen Nachfolger BENEDIKT XI (1303-1304) gesehen (als Katholik konnte er dies nur, indem er die Wahl der beiden Päpste für unrechtmäßig erachtete). Er wies darauf hin, dass der Name BENEDIKT auf griechisch

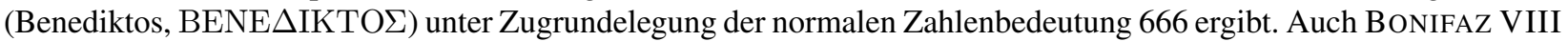
trug den Namen Benedikt: er hieß eigentlich Benedikt Gaetani. Man hat bei BoNIFAZ VIII antichristliche Züge sehen wollen, da er die päpstliche Macht auf weltliches Gebiet ausdehnen wollte. Der Dichter DANTE versetzt ihn wegen Geldgier und Begünstigung von Verwandten in die Hölle, und auch der Kirchenhistoriker BIHLMEYER schildert ihn als ,schroffen und hochfahrenden Wesens, rücksichtslos und gewalttätig“. 99 Bekannt war er für „,derbe, unvorsichtige Äußerungen“, die von einigen seiner Gegner ,diaboliae“ genannt wurden; nach BIHLMEYER darf man „,vielleicht an einen krankhaften Geisteszustand bei ihm denken“. ${ }^{100}$ Dagegen war BENEDIKT XI ein friedliebender Mann, der viele Verfügungen seines Vorgängers rückgängig machte, sich aber dennoch zu ihm bekannte, weshalb UBERTINO ihn für

\footnotetext{
97 Ein schwarzer Strich erscheint für 1, ein weißer Zwischenraum für 0. In der linken Hälfte (in welcher der Hersteller kodiert ist) lautet der Code für die Zahl 6 dagegen 0101111, und man erkennt diese 6 durch einen dünnen und einen parallelen viermal so dicken schwarzen Strich.

98 "It is simply a coincidence like the fact that my first, middle, and last name all have 6 letters".

99 BIHLMEYER, Kirchengeschichte $\$ 137.1$, Band 2 S. 376).

100 BIHLMEYER, Kirchengeschichte $§ 137.4$, Band 2 S. 372).
} 
das zweite Tier hält, das aussieht ,wie ein Lamm“ (13,11).

Die Deutung Ubertinos, die von vielen nichtkatholischen Papstgegnern übernommen wurde, ist abzulehnen, nicht nur deshalb, weil die Apokalypse vom heidnischen und nicht vom christlichen Rom spricht, sondern auch, weil die Rechtmäßigkeit der beiden Päpste heute feststeht, und ein rechtmäßiger Papst nie direkt auf der Seite des Antichristen stehen kann. Es dürfte auch so gut wie sicher sein, dass der Antichrist, falls er denn tatsächlich einst als falscher Papst auftreten sollte, in leicht durchschaubarer Weise unrechtmäßig amtieren wird, weil andernfalls eine mit der kirchenstützenden Funktion des Papsttums kaum vereinbare Verwirrung eintreten müsste.

5p. Papst FranZiSKuS (mit weltlichem Namen Jorge Mario Bergoglio), der seit dem 13. März 2013 als 266. Papst amtiert, wird von manchen aufgrund seines von vielen als ,radikal neuartig“ gewerteten (und kritisierten) Auftretens und Lehrens mit Argwohn betrachtet. So konnte es nicht ausbleiben, dass man auch in seinem Namen nach der Zahl 666 gesucht hat, zumal der Name GOG für den Antichristen bei Ezechiel just mitten im Namen BerGOGlio enthalten ist. Man setzt dabei den 1963 eingeführten ASCII-Code (American Standard Code for Information Interchange, Amerikanischer Standardcode für Informationsaustausch) voraus, der eine international gültige Standard-7-Bit-Codierung für 128 Zeichen geworden ist (33 nicht druckbare Steuerzeichen und 95 druckbare Zeichen). Hierbei werden den lateinischen Großbuchstaben von $A$ bis $Z$ die Zahlen 65 bis 90 zugeordnet. Unter der Annahme, dass das Zahlenrätsel sich auf eine Codierung beziehen könnte, die in der Zeit des Antichristen am Ende der Tage weltweit bekannt sein wird, wäre in der Tat die ASCII-Kodierung eine vielleicht naheliegende Wahl:

Die ASCII-Kodierung der lateinischen Großbuchstaben:

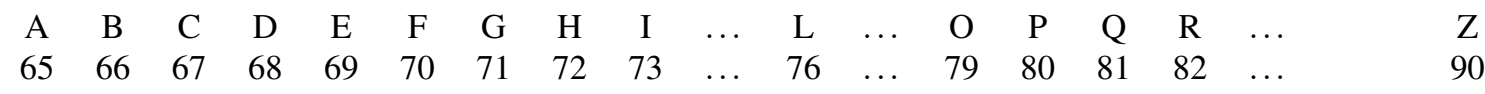

Wertet man nach dieser Codierung den Namen „Bergoglio“ aus, ergibt sich $66+69+82+71+79+71+76+73+79=$ 666. Doch die schon besprochenen berechtigten Einwände, die gegen andere Päpste als Träger der Zahl erhoben werden können (siehe $5 \mathrm{~m}$ und 5o), gelten natürlich auch hier.

5q. Eine originelle Lösung des Zahlenrätsels stammt von OBERWEIS (Zeitschrift für neutestamentliche Wissenschaft 1986). OBERWEIS vermerkt, dass das griechische Wort für „berechnen“ (psefizo) auch die Bedeutung „in Ziffern / Buchstaben aufschreiben“ haben kann. Für ihn bedeutet deshalb die Aufforderung, die Zahl des Tieres zu „,berechnen“ nicht, irgendein Wort zu suchen, dessen Buchstabensumme die Zahl 666 ergibt, sondern einfach, die Zahl 666 „,aufzuschreiben“ und zu sehen, was sich dann für ein Wort ergibt. Die 666 wird durch die griechische Zeichenfolge Chi-Xi-Stigma $(\chi \xi \varsigma)$ dargestellt. Wie schon auf S. 147 erwähnt, ist Chi-Stigma $(\chi \varsigma)$ die übliche Abkürzung des Namens „Christus“; der dazwischenliegende Buchstabe $\xi$ symbolisiert eine Schlange, und so könnte das ganze ein Symbol dafür sein, dass der Antichrist versucht, Christus oder die Christenheit zu zerreißen. Doch ist $\chi \xi \varsigma$ kein sinnvolles griechisches Wort, und die Aufforderung, die Zahl ,aufzuschreiben“, dürfte sich nicht auf die griechische Darstellung beziehen, die ja der Leser bereits im Text der Apokalypse vor Augen hatte. Er könnte also auf die Idee kommen, die Zahl in einer anderen Schrift und Sprache aufschreiben. Im Hebräischen wird nun die Zahl 666 durch die Zeichenfolge Tau-ReschSamäch-Waw (תרסו) dargestellt. Diese Zeichenfolge ergibt aber nun tatsächlich ein hebräisches Wort, nämlich taróssu, was bedeutet „sie zerstören“ oder ,ihr sollt zerstören“. Oberweis deutet „tarossu“ als Aufforderung (,,ihr sollt zerstören“): Die Anbeter des Tiers haben somit auf ihrer Stirn ein Wort, mit dem sie ihre Bestrafung durch Gott geradezu herausfordern. ${ }^{101}$ So bemerkenswert aber diese Ausführungen auch sind: Mir scheint dennoch die Hauptbedeutung von Apk 13,18 hier nicht getroffen zu sein. Johannes meint mit dem „Berechnen“ des Tieres kaum das bloße „Aufschreiben“ einer Zahl. Er sagt nämlich: „Hier ist Weisheit. Wer Verstand hat, berechne die Zahl des Tieres ... “ Zum bloßen Aufschreiben der Zahl aber wäre keine besondere „Weisheit“ nötig.

101 OBERWEIS bietet mit seiner Methode auch einen interessanten Hinweis, wie sich die Variante 616 (statt 666) in die Handschriften eingeschlichen haben könnte (siehe auch Deutung 3a). Auf Hebräisch wird nämlich die Zahl 616 durch die Buchstabenfolge „Tau-Resch-Jod-Waw“ (תריו) dargestellt. Das ergibt zwar kein hebräisches Wort, ist aber die hebräische Umschrift des griechischen Wortes „Theriu“ ( $\Theta E P I O \Upsilon)$, was zu deutsch ,des Tieres“ bedeutet. Hier hat, so meint OBERWEIS, ein Bibelabschreiber die Anweisung des Johannes in naivster Weise wörtlich genommen: WER VERSTAND HAT, so las er, BERECHNE (= schreibe auf) DIE ZAHL DES TIERES. So habe er einfach die Wortverbindung „,des Tieres“ als Zahl aufgefasst, und kam bei Zugrundelegung hebräischer Zahlzeichen auf 616. Die 666 in der Vorlage habe er dann als Schreibfehler angesehen und „korrigiert“. Die Wortverbindung „,es Tieres“ konnte er passend zum Text als Besitzanzeige deuten: „(ich bin) des Tieres" $=$ ich gehöre dem Tier. 
5r. APRingius (6. Jahrhundert) vermutete als erster hinter der Zahl 666 den Ausdruck DiC LuX (zu deutsch: ,sprich: Licht“). Diese Worte sollen aussagen, dass der Antichrist sich als Lichtbringer feiern lassen wird. Bemerkenswert an DIC LUX ist, dass dieser Ausdruck exakt aus jenen Buchstaben besteht, mit welchen in römischen Ziffern die Zahl 666 gebildet wird: $666=$ DCLXVI (man beachte, dass V und U nicht unterschieden wurden). Der Ausdruck DIC LUX ergibt sich also (ähnlich wie in der vorhergehenden Deutung das Hebräische „tarossu“) durch einfaches „Aufschreiben“ der Zahl 666, verbunden mit einer kleinen Umstellung der Zeichen. „DICLUX“ klingt im übrigen ähnlich wie „DIOCLES AUGUSTUS“: Es ist so etwas wie das Skelett dieses Kaisernamens, so dass Diokletian als ein mit Leben gefülltes „DIC LUX“ erscheinen will.

5s. Es gibt eine Unzahl anderer zum Tier und zum Antichristen mehr oder weniger passender Namen und Titel, welche (unter Zuhilfenahme der normalen Zahlenwerte der hebräischen und griechischen Buchstaben) die Zahl 666 ergeben. Beispielsweise:

- Das hebräische „Neron Scheni“ (נרון שני), deutsch: ,Zweiter Nero“.

- Das griechische Wort für „Tier“ (Therion, Inpıov) in hebräischen Buchstaben: Tet-Resch-Jod-Waw-Nun (טריון).

- Der griechische Ausdruck „To Mega Therion“ (TO MEГA ӨHPION), zu deutsch: „das große Tier“.

- Der hebräische Ausdruck „Tehom Qadmonijja“ in der Schreibweise Tau-He-Waw-Mem-Qoph-Daleth-MemWaw-Nun-Jod-He (תהום קדמוניה), deutsch: „Chaos der Urzeit“ oder „alte Wasserflut“ oder ,altes Meeresungeheuer“ oder ,,altes Chaos-Monster“. Vergleiche hierzu den Ausdruck ,die alte Schlange“ in Apk 12,9 als Titel Satans.

- Der griechische Ausdruck „Palai Baskanos“ (ПA $\Lambda$ AI BA $\Sigma K A N O \Sigma$ ), zu deutsch: „Von alters her Boshafter/Verleumder/Neidischer".

- Der griechische Ausdruck „Kakos Odegos“ (KAKO $\Sigma$ O $\Delta$ HГО $\Sigma$ ), zu deutsch: „,böser Führer“.

- Der griechische Ausdruck „Alethes Blaberos“ (A $\Lambda \mathrm{H} \Theta H \Sigma$ B $\Lambda$ ABHPO $\Sigma$ ), zu deutsch: „,wahrhaft Verderbender".

- Der griechische Ausdruck „Amnos Adikos“ (AMNO $\Sigma$ A $\triangle \mathrm{IKO} \Sigma$ ), zu deutsch: ,ungerechtes Lamm“, in Umkehrung der Bezeichnung „Lamm Gottes“ für CHRISTUS in Joh 1,29 und in Anlehnung an das zweite Tier der Apokalypse, das aussah ,wie ein Lamm“ (13,11).

- Der griechische Name „Euanthas“ (EイAN $\Theta A \Sigma)$, zu deutsch: „Wohlblühender“, „,kräftig Sprossender“. So ähnlich (EイAN $\mathrm{EH} \Sigma$ ) hieß auch ein Sohn des BACCHUS, des Gottes des Weins.

- Der griechische Name „Ho Niketes“ (O NIKHTH $\Sigma$ ), zu deutsch: „Der Sieger“, ein Titel, den sich der Antichrist selber geben könnte.

- Der lateinische Name BENEDIKT in seiner griechischen Form BENE $\triangle \mathrm{IKTO} \Sigma$, zu deutsch: „der Gepriesene“: Der Antichrist wird von aller Welt gepriesen werden.

- Der griechische Name „Lampetis“ ( $\Lambda$ AMПETI $\Sigma)$, zu deutsch: „Strahlender“: Der Antichrist wird als Lichtbringer auftreten, so wie der Teufel sich als Lucifer, „Engel des Lichts“, tarnt (2 Kor 11,14).

- IRENÄUS († 202) schlug die griechische Bezeichnung „Teitan“ (TEITAN) vor (siehe auch Deutung 3c). ,Titanen“ hießen die vorolympischen Götter. „Titan“ war aber auch Titel des Sonnengottes und des Lichtgottes Apollon, an den in Apk 9,11 wahrscheinlich als „Apollyon“ angespielt ist. Jedoch ist „TEITAN“ nicht die richtige Schreibweise: Eigentlich müsste es TITAN heißen, was nur 661 ergäbe. Irenäus hat also das I in der ersten Silbe zu EI erweitert, wodurch der Name nebst vollerem Klang 6 Buchstaben erhält und die Zahl 666 wiedergibt.

- HiPPOLYT († nach 235) schlug das griechische „arnume“ (APNOYME), zu deutsch: „ich verneine“ vor: Der Antichrist wird den Glauben verneinen. - Doch ist die richtige Schreibweise nicht ARNOYME, sondern ARNOYMAI, was 672 ergäbe. Hippolyt konnte E für AI setzen, weil „AI“ in schneller Aussprache wie „E“ klingt, so dass im Neugriechischen „AI“ immer wie „E“ gesprochen wird. 
- PRIMASIUS (um 540) schlug den rätselhaften Namen „Antemos“ (ANTEMO $\Sigma$ ) vor, der im Mittelalter oft wiederholt wurde. Diese soll ,der Unehrenhafte“ heißen, aber dies müsste man eigentlich mit ANTIMO $\Sigma$ oder ANTITIMO $\Sigma$ wiedergeben, was 671 bzw. 981 ergäbe.

Die Liste der Deutungen, welche das Zahlenrätsel im Lauf der Geschichte erfahren hat, ist hier keineswegs erschöpfend behandelt: Man könnte noch nennen Geiserich, Attila, Martin Luther, Johannes Calvin, John Knox, Ignatius von Loyola, Ludwig XIV, Winston Churchill, Kissinger, Ronald ReAgAn, BiLl Gates usw. usw. Da wundert es einen nicht mehr, dass man sogar JESUS CHRISTUS mit 666 zusammenbringen kann, und schon Berengaudus (9. Jh.) fürchtete nicht zu Unrecht, dass am Ende ein jeder womöglich auch seinen eigenen Namen finden könnte. ${ }^{102}$ Eine Mahnung zur Vorsicht ist also mehr als angebracht. Gegen die viele Rechnerei wandte sich im 17. Jahrhundert auch der Dichter ANGELUS SilESIUS mit den trefflichen Worten:

\author{
„Der Antichrist. \\ Was gaffst du viel, mein Mensch? \\ Der Antichrist unds Tier \\ (Im Fall du nicht in Gott) \\ sind alle zwei in dir". 103
}

\footnotetext{
102 Berengaudus, Apocalypsis, De visione quarta (PG 17 Spalte 972): „De hoc numero multi multa dixerunt, pluraque nomina repererunt .. sed de re tam incerta nihil audeo definiere. Quis enim scit, si nomen quod ei a parentibus imponetur, hunc numerum contineat?“. 


\subsection{Apk 14,1-5: Das Lamm und die 144.000}

Nachdem JohannES das Tier und die „Bewohner der Erde“ als seine Anbeter gesehen hat $(13,12-17)$, darf er nun zum Trost und Ausgleich auch sehen, dass es in jener Zeit auch treue Christen geben wird (14,1-5). Erst danach schaut er die Vorankündigung des Gerichtes (14,6-20), mit dessen Ausführung (Kap. 15-19) die siebente Posaune bzw. das dritte Wehe seinen Abschluss finden wird.

\section{Text}

14,1 Und ich sah, und siehe, das Lamm stand auf dem Berg Zion. Und bei ihm waren 144.000, auf deren Stirn sein Name und der Name seines Vaters geschrieben stand.

14,2 Und ich hörte eine Stimme aus dem Himmel wie eine Stimme von vielen Wassern und wie eine Stimme eines großen Donners.

Und die Stimme die ich hörte, war die Stimme von Harfensängern,

die auf ihren Harfen spielten.

14,3 Und sie singen etwas wie ein neues Lied vor dem Thron und vor den vier Wesen und den Ältesten.

Und niemand konnte das Lied erlernen außer den 144.000, die von der Erde erkauft sind.

14,4 Sie sind es, die sich mit Frauen nicht befleckt haben, denn sie sind Jungfrauen.

Sie sind es, die dem Lamm folgen, wohin es auch geht.

Sie wurden erkauft aus den Menschen als Erstlingsfrucht für Gott und das Lamm.

14,5 Und in ihrem Mund fand sich keine Lüge: Untadelig sind sie.

\section{Auslegung}

14,1 Und ich sah, und siehe, das Lamm stand auf dem Berg Zion.

Und bei ihm waren 144.000, auf deren Stirn sein Name

und der Name seines Vaters geschrieben stand.

JOHANNES stand noch immer am Strand von Patmos, wo er zuerst das eine Tier aus dem Meer, dann das andere aus der Erde hatte aufsteigen sehen. Er drehte sich nun wahrscheinlich nach Südosten um, in Richtung Jerusalem, wo in einer neuen Vision der Jerusalemer Tempelberg ZION mit dem Lamm und 144.000 Erwählten auftauchte. Ein grandioser Kontrast: das LAMM und die Seinen kommen nicht aus den Untiefen der Erde oder des Meeresabgrundes hervor, sondern „stehen“ auf einem „Berg“ als die wahren „Könige“ über Himmel und Erde.

Die hier genannten 144.000 können aus zwei Gründen nicht mit den 144.000 aus Kap. 7 identisch sein:

- Jene waren Christen, die vor dem Strafgericht des Jahres 135 lebten. Die jetzt auftretenden 144.000 aber lebten in die Zeit Julians, also ca. 200 Jahre später.

- Jene waren alle jüdischer Abstammung. Die hier auftretenden 144.000 aber sind in sittlicher Hinsicht hervorragende Christen (Verse 4-5): in diesem Sinn (nicht im zeitlichen Sinn) sind sie eine „Erstlingsgabe“ für Gott (Vers 5).

144.000 ist eine Symbolzahl (siehe den Kommentar zu 7,4). Hier soll sie wahrscheinlich die riesige Vervielfältigung des Christentums anzeigen: Während die ersten Christen nur die Apostel waren, zwölf an der Zahl, so sind es jetzt $12 \bullet 12 \bullet 1000$. 
Da es sich also bei diesen 144.000 nicht nur um Juden handelt, ist der Jerusalemer ZIONSBERG hier ebenso wie das Neue Jerusalem in 21,2 und der Jerusalemer Tempel in 11,2 ein Symbol für das Christentum, das neue Volk Gottes.

Sind die 144.000 auf Erden oder im Himmel? Im Hebr 12,22 heißt es: „Ihr seid hinzugetreten zum Berg Zion, zur Stadt des lebendigen Gottes, zum himmlischen Jerusalem“. Der Zion symbolisiert also in Hebr 12,22 zwar das himmlische Jerusalem, aber dennoch ist es die irdische Kirche, die zu diesem himmlischen Berg „,hinzugetreten“ (= mit ihm verbunden) ist. Ebenso sind wohl auch die von Johannes erblickten 144.000 Christen zum himmlischen Zionsberg „hinzugetretene“, aber doch noch auf Erden lebende Glieder der Kirche. Denn:

- In Versen 2-3 bringen Harfenspieler vom Himmel her den auf dem Zionsberg stehenden 144.000 ein Lied bei. Also können die 144.000 nicht ebenfalls im Himmel sein.

- In Vers 4b heißt es, dass die 144.000 dem Lamm „folgen, wohin es auch geht“, was wohl auf ein noch irdisches Leben in der „Nachfolge Christi“ hinweist. Wenn die 144.000 noch auf Erden leben, kommt auch der Kontrast zwischen ihnen und den Anhängern des Scheinlammes aus Kap. 13 besser zum Tragen.

Als hervorragende Christen auf Erden verkörpern die 144.000 eine ähnliche Idee wie die „Frau“ in Kap. 12 und die ,zwei Zeugen“ in Kap. 11. Auf ihrer Stirn sah Johannes den Namen Christi und seines Vaters geschrieben, dort wo die Diener des Tieres das Kennzeichen des Tieres trugen $(13,16)$. Der hier geschaute NAME DES LAMMES wird „Jesus“ (Inбovs) gewesen sein, der Name, dessen Zahl 888 ist - ein Gegensatz zu den Anbetern des Tieres, welche die Zahl 666 auf ihrer Stirn hatten. Als NAmE DES VATERS wird Johannes den Namen JAHWE (der Seiende), den meistgebrauchten Gottesnamen des Alten Testaments, auf den Stirnen geschaut haben (oder dessen Erweiterung zu „der ist und der war und der kommt"). Dieser Name kommt zwar auch CHRISTUS und dem Geist zu, aber weil hier von CHRIstus als Mensch die Rede ist („Lamm“), kann der Vater ihm gegenüber mit dem Namen der ganzen Dreifaltigkeit bezeichnet werden (siehe Kommentar zu 4,1c). Die Namen auf der Stirn sind Symbole für die Hingabe der Christen an Gott und Christus, die in der Taufe besiegelt wird. Darum ist hier auch angespielt auf die christliche Taufe, die ,,auf den Namen des Vaters und des Sohnes und des Heiligen Geistes“ erfolgt (Mt 28,19).

14,2 Und ich hörte eine Stimme aus dem Himmel wie eine Stimme von vielen Wassern und wie eine Stimme eines großen Donners.

Und die Stimme die ich hörte, war die Stimme von Harfensängern, die auf ihren Harfen spielten.

Diese Stimme kommt nicht von den 144.000: Denn Johannes hört sie vom Himmel her, während er die 144.000 auf dem Berg Zion, also auf Erden vor sich sieht.

14,3a Und sie singen etwas wie ein neues Lied vor dem Thron und vor den vier Wesen und den Ältesten.

Die himmlischen „Harfenspieler“ singen das NEUE LIED des Lobpreises Christi, das in 5,9 von den vier Wesen und den Ältesten selber gesungen worden war. Die jetzt singenden „Harfenspieler“ sind, wie in 15,2-4 klar werden wird, die im Himmel ankommenden römischen Märtyrer und Bekenner Christi

14,3b Und niemand konnte das Lied erlernen außer den 144.000, die von der Erde erkauft sind.

Niemand auf Erden konnte das von den himmlischen Harfenspielern gesungene Lied erlernen außer den 144.000 von der Erde ,erkauften“, d. h. erwählten Christen. Das „Lied““ist offenbar von den vier Wesen und den 24 Ältesten, die es zuerst sangen $(5,9)$ den im Himmel angekommenen „Harfenspielern" beigebracht worden, und diese singen es nun vom Himmel herab, wodurch es die 144.000 noch auf Erden streitenden Erwählten erlernen. Alle andere aber sind dafür taub. 
14,4 Sie sind es, die sich mit Frauen nicht befleckt haben, denn sie sind Jungfrauen.

Der Begriff „Hure“ steht in der Apokalypse für das götzendienende Rom, siehe Kap. 17. Daher bedeutet der Gegenbegriff ,Jungfrau“ das treue christliche Volk, das sich mit CHRISTUS einst ,vermählen“ wird $(21,9)$. JUNGFRAU hier also eine geistige Bedeutung: Gemeint sind alle Christen, ob verheiratet oder unverheiratet, die in treuer Hingabe auf ihre einstige „,Vermählung mit Gott“ hinleben, ohne durch Seitenblicke oder Kompromisse „Unzucht“ mit den heidnischen Göttern zu begehen.

Diesen Sinn hat der Begriff ,Jungfrau“ auch im Gleichnis von den klugen und den törichten Jungfrauen Mt 25,1-12. Vgl. auch 2 Kor 11,2, wo Paulus, der ganzen Kirche von Korinth (und nicht nur den Unverheirateten) schreibt: „Ich habe euch einem einzigen Mann verlobt, um euch als reine Jungfrau zu Christus zu führen“.

14,4b Sie sind es, die dem Lamm folgen, wohin es auch geht. Sie wurden erkauft aus den Menschen als Erstlingsfrucht für Gott und das Lamm.

14,5 Und in ihrem Mund fand sich keine Lüge: Untadelig sind sie.

Die 144.000 werden hier wie auch in den Vorversen eindeutig als die erwählten Heiligen, als die ersten und die besten geschildert (,Erstlingsfrucht“ im Sinne der Qualität, nicht im zeitlichen Sinne). Es sind untadelige, CHRISTUS in allem folgende, absolut wahrhaftige Christen.

Nebenbei zeigt sich hier (vgl. auch 21,8, 21,27, 22,15 und Kommentar zu 10,6a), dass die Lüge Tadel verdient: Das Christentum hat in der Nachfolge Jesu das achte Gebot, nicht falsch Zeugnis zu geben (Ex 20,16, was manche Ausleger auf die Situation des Gerichts und des Eides beschränkten konnten), zu einem Verbot des Lügens allgemein (auch im Alltag) verschärft (vgl. Mt 5,33-37).

Nach dieser trostreichen Vision, die zeigte, dass es in den Verfolgungen absolut treue Christen in so großer Zahl geben wird, kann nun die Ankündigung des Gerichts über das heidnische Rom erfolgen.

\subsection{Apk 14,6-20: Vorankündigung des Gerichts}

\section{Text}

14,6 Und ich sah einen anderen Engel in der Mitte des Himmelsraumes fliegen.

Der hatte ein ewiges Evangelium zu verkünden für die, die auf der Erde sitzen, und für alle Nationen, Stämme, Sprachen und Völker.

14,7 Und er sagte mit lauter Stimme: Fürchtet Gott und gebt ihm die Ehre, denn gekommen ist die Stunde seines Gerichts! Und betet den an, der den Himmel und die Erde und Meer und Wasserquellen gemacht hat.

14,8 Und ein anderer Engel, ein zweiter, folgte und sagte:

Gefallen, gefallen ist Babylon die Große, die von dem Zorneswein ihrer Unzucht alle Völker hat trinken lassen.

14,9 Und ein anderer Engel, ein dritter, folgte ihnen und sagte mit lauter Stimme: Wenn jemand das Tier und sein Bild anbetet, und (das) Kennzeichen auf seine Stirn oder seine Hand empfängt,

14,10 so wird er trinken von dem Zorneswein Gottes, der unvermischt eingeschenkt wird in den Becher seines Zornes, und er wird gepeinigt werden in Feuer und Schwefel vor den heiligen Engeln und vor dem Lamm. 
14,11 Und der Rauch ihrer Qual steigt auf in alle Ewigkeit.

Und sie haben keine Ruhe tags und nachts:

(alle,) die das Tier und sein Bild anbeten,

und wenn jemand annimmt das Kennzeichen seines Namens.

14,12 Hier ist die Geduld der Heiligen,

welche an den Geboten Gottes und am Glauben an Jesus festhalten.

14,13 Und ich hörte eine Stimme aus dem Himmel sagen:

Schreibe: Selig sind die Toten, die im Herrn sterben, von jetzt an.

Ja, spricht der Geist,

sie werden ausruhen von ihren Mühen, denn ihre Werke folgen ihnen nach.

14,14 Und ich sah, und siehe, eine weiße Wolke.

Und auf der Wolke saß einer, der einem Menschensohn glich.

Er hatte auf seinem Haupt eine goldene Krone und in seiner Hand eine scharfe Sichel.

14,15 Und ein anderer Engel kam heraus aus dem Tempel,

und rief mit lauter Stimme dem zu, der auf der Wolke saß:

Schicke deine Sichel aus und ernte, denn die Stunde zur Ernte ist gekommen,

denn die Ernte der Erde ist trocken (d. h. das Korn ist reif).

14,16 Und der auf der Wolke saß, warf seine Sichel über die Erde, und die Erde wurde abgeerntet.

14,17 Und ein anderer Engel kam aus dem Tempel des Himmels heraus.

Auch er hatte eine scharfe Sichel.

14,18 Und ein anderer Engel kam heraus aus dem Altar,

(Es war derjenige,) der Macht über das Feuer hat.

Und er rief mit lauter Stimme dem zu, der die scharfe Sichel hatte.

Und er sagte: Schicke deine scharfe Sichel aus,

und schneide die Beeren des Weinstocks der Erde ab, weil seine Beeren reif geworden sind!

14,19 Und der Engel warf seine Sichel über die Erde, und er erntete den Weinstock der Erde ab.

Und er warf (die Trauben) in die große Kelter des Zornes Gottes.

14,20 Und die Kelter wurde außerhalb der Stadt getreten.

Und es kam Blut aus der Kelter heraus bis an die Zügel der Pferde,

(über eine Strecke) von 1600 Stadien.

Auslegung

14,6a Und ich sah einen anderen Engel in der Mitte des Himmelsraumes fliegen.

Er flog IN DER MitTE Des HimmelsRAumes, weil er offenbar eine ähnlich wichtige Mitteilung hatte wie jener Adler, der in 8,13 die letzten drei „Wehe“ angekündigt hatte. Er verkündigte nämlich, wie das Folgende zeigt, das Kommen des Gerichts am heidnischen Rom.

14,6b Der hatte ein ewiges Evangelium zu verkünden für die, die auf der Erde sitzen, und für alle Nationen, Stämme, Sprachen und Völker.

14,7 Und er sagte mit lauter Stimme: Fürchtet Gott und gebt ihm

die Ehre, denn gekommen ist die Stunde seines Gerichts!

Und betet den an, der den Himmel und die Erde und Meer und Wasserquellen gemacht hat.

Evangelium heißt Frohbotschaft. Man beachte, was der Engel hier eine EWIGE FrohbotschafT nennt: das GERICHT! Das göttliche Gericht ist tatsächlich eine „Frohbotschaft“ für diejenigen, die dadurch aus großer Bedrängnis und Gefahr befreit werden, und es ist sogar eine „ewige“ Frohbotschaft, wenn die Befreiung eine endgültige ist. So ist Israel beim Auszug aus Ägypten endgültig aus der ägyptischen Sklaverei befreit worden und kann Gott ewig dafür preisen, wenngleich es in seiner Geschichte noch andere und ähnliche Schicksale erleben wird. 
Ebenso war das Gericht Gottes am heidnischen Rom, auf welches dem Zusammenhang nach der Ruf des Engels zu beziehen ist, ein endgültiges, wofür die Christen in Ewigkeit Dank sagen können, auch wenn am Ende der Zeiten ähnliche Drangsale wiederkehren werden. Der Engel verkündet diese Frohbotschaft denen, DIE AUF DER ERDE SITZEN: dieser Ausdruck meint alle noch auf Erden Lebenden - im Gegensatz zum Ausdruck „Bewohner der Erde“, der in der Apokalypse immer die Feinde Gottes meint.

14,8 Und ein anderer Engel, ein zweiter, folgte und sagte:

Gefallen, gefallen ist Babylon die Große,

die von dem Zorneswein ihrer Unzucht alle Völker hat trinken lassen.

Der ZWEITE ENGEL konkretisiert das vom ersten Engel angekündigte Strafgericht: Es handelt sich um das Gericht an BABYLON: in Kapitel 17 wird sich klar zeigen, dass mit „Babylon“ Rom gemeint ist. Der Engel kündigt das Strafgericht an, als wäre es bereits geschehen (GEFALLEN IST BABYLON), um zu zeigen, dass Roms kommender Untergang unabänderlich feststeht. In Kapitel 17 wird Rom „Hure“ genannt, und ihr Götzendienst als „Unzucht“ bezeichnet. So heißt es auch hier, dass die Stadt alle Völker VOM ZORNESWEIN IHRER UNZUCHT trinken ließ. Die Unzucht, d. h. der ausschweifende Götzendienst, wird WEIN genannt wegen seines berauschenden Taumels und Überschwangs. Es ist aber ein ZoRNESwein, weil er Gottes Zorn über Rom bringt. Siehe Vers 10.

14,9 Und ein anderer Engel, ein dritter, folgte ihnen und sagte mit lauter Stimme:

Wenn jemand das Tier und sein Bild anbetet,

und (das) Kennzeichen auf seine Stirn oder seine Hand empfängt,

14,10 so wird er trinken von dem Zorneswein Gottes,

der unvermischt eingeschenkt wird in den Becher seines Zornes,

und er wird gepeinigt werden in Feuer und Schwefel

vor den heiligen Engeln und vor dem Lamm.

14,11 Und der Rauch ihrer Qual steigt auf in alle Ewigkeit.

Und sie haben keine Ruhe tags und nachts:

(alle,) die das Tier und sein Bild anbeten,

und wenn jemand annimmt das Kennzeichen seines Namens.

Während der vorhergehende Engel das kollektive Gericht an der Stadt Rom verkündigt hat, so verkündigt dieser DRITTE ENGEL das individuelle Gericht für die Teilnehmer am römischen Götzendienst. Zu KennZEICHEN und BILD des Tieres vgl. Kap. 13.

Der ZORNESWEIN Gottes ist das Gegenstück zum „Wein der Unzucht“ Roms (Vers 8), d. h. die verdiente Strafe für jene götzendienerische „Unzucht“. Gottes „Zorn“ ist aber kein unbeherrschtes Gefühl wie der menschliche Zorn: Gott wird nur deshalb gegenüber den Bösen ,zornig“ genannt, weil er der Gründer und Erhalter einer gerechten Weltordnung ist, in welcher sich diese Menschen, wenn sie ihr böses Tun nicht bereuen, unausweichlich eine Strafe zuziehen: eine Strafe, der man ebenso wenig entgehen kann, wie der Züchtigung durch einen König, den man zum Zorn gereizt hat.

In den Versen 10 und 11 haben wir eine biblische Beschreibung der Höllenstrafe. Dass die Qual VOR DEN HEILIGEN ENGELN UND VOR DEM LAMM stattfindet, wird beschämend sein, weil die Verdammten erkennen, dass sie sich in ihrer Bosheit unwiderruflich von denen entfernt haben, die sie hatten zum Heil führen wollen. Man beachte, dass es nicht heißt, dass das Lamm oder die Engel das Höllenfeuer entfachen oder dass sie den Verdammten absichtlich Qual bereiten. Vielmehr ist anzunehmen, dass FEUER UND SCHWEFEL Symbole für die Qualen sind, die sich die Verdammten selber bereiten, und zwar durch ihren Gottes- und Selbsthass, den sie durch ihre bösen Werke mit sich führen, ebenso wie die Geretteten (in Vers 13) durch die ihnen nachfolgenden guten Werke selig sind. 
Das Wesen der Höllenstrafe besteht jedoch nicht in diesem symbolischen Feuer des Hasses, sondern im Ausgeschlossensein (= Verdammtsein) von der Gemeinschaft mit Gott und mit den Seligen, in einer Existenz „ewigen Verderbens fern vom Angesicht des Herrn und von der Herrlichkeit seiner Majestät“, wie Paulus sagt (2 Thess 1,9). Diese Isolation lässt sich als eine automatisch eintretende Strafe für diejenigen begreifen, die es nicht gelernt haben, Gott und den Nächsten zu lieben, und die in ihrem endgültig verhärteten Egoismus nicht mehr fähig sind, in glücklicher Gemeinschaft mit anderen zu leben. Dass die Verdammten VOR DEM ANGESICHT DES LAMMES UND VOR DEN HEILIGEN ENGELN stehen, scheint also nur ein Zwischenzustand bis zum Endgericht zu sein, nach welchem die Verdammten von Gott und den Seligen völlig getrennt werden (vgl. 2 Thess 1,9 und Apk 22,15).

Vers 11 spricht von einer Qual, die IN ALLE EWIGKEIT währt. Da das Wort „Ewigkeit“ in der Schrift manchmal tatsächliche Ewigkeit ohne Ende meint, manchmal aber nur eine unabsehbar lange, aber doch irgendwann endende Zeitperiode, fragt sich, was hier mit EWIGKEIT gemeint ist. Zweifellos meint Johannes eine Ewigkeit ohne Ende. Andernfalls hätte er in den letzten beiden Kapiteln seines Buches (Kap. 21-22), in denen er den endgültigen Endzustand der Welt schildert, die Wiedereingliederung der Verdammten in die Gemeinschaft der Seligen erwähnen müssen. Statt dessen betont er dort aber das „Draußensein“ der Verdammten (22,15). Auf die endlose Ewigkeit der Höllenstrafe hat auch CHRISTUS mehrfach unmissverständlich hingewiesen, z. B. als er vom Feuer sprach, „das nicht erlischt“" (Mk 9,42-48). ${ }^{104}$

\section{Exkurs 11: Reflexionen über die Höllenstrafe}

Die Höllenstrafe gehört seit jeher zu den schwer verdaulichen Teilen der Apokalypse (vgl. Apk 10,10). So sollte man genauer überlegen, wie sich das Gesagte vernünftig verstehen und in das christliche Glaubensgebäude integrieren lässt, dessen Mitte der gütige und barmherzige Gott ist. Die Hölle ist die ewige Existenzweise derjenigen, die sich aus freiem Willen endgültig von Gott abgewendet haben, eine Existenz, die aus zwei Gründen qualvoll ist: (a) hauptsächlich wegen der selbstgewollten Gottesferne, und (b) zusätzlich wegen des symbolischen Feuers des Hasses, der Gewissensqualen und der Unzufriedenheit mit dieser Situation. Zunächst sollte man festhalten, dass diese Strafe in der Schrift nur zeitlich, nicht aber der momentanen Stärke nach als unendlich geschildert wird. In der Hölle kann es daher also wohl „,dem einen erträglicher gehen als dem anderen“ (so AUGUSTINUS, Enchiridion ad Laurentium Kap. 29 Nr. 111), was auch aus Schriftstellen wie Mt 11,22 und Lk 20,47 folgt. Die verschiedene Intensität dürfte sich von selbst dadurch einstellen, dass das durch den Hass des Verdammten entfachte „Höllenfeuer“ je nach der Größe dieses Hasses verschieden intensiv ist. Der größte Stein des Anstoßes ist aber indessen die zeitliche Unbegrenztheit der Strafe. Diese dürfte wohl nur dann mit der Güte Gottes vereinbar sein, wenn auch sie nicht als eine willkürliche Festsetzung Gottes, sondern eine unabwendbar eintretende, natürliche Folge der Sünde ist, die auch von Gott nicht fortgenommen werden kann. ${ }^{105}$

In der Tat folgt die Ewigkeit der Höllenstrafe logisch aus zwei Prämissen: Aus der endgültige Entscheidung gegen Gott einerseits und aus der „Unsterblichkeit der Seele“ (vgl. hierzu Weish 2,23 und 3,4 sowie Mt 10,28), welche im Wesentlichen die Unvernichtbarkeit des seiner selbst bewussten Ich bedeutet. Für den Sünder, der mit Gott und seiner Schöpfung nie wieder etwas zu tun haben will, wäre ja die einzige Alternative zur qualvollen Existenz in der Hölle (= Gottesferne) seine Vernichtung durch die Auslöschung seines Selbstbewusstseins, aber das scheint durch die Unsterblichkeit seiner Seele ausgeschlossen zu sein: Die Natur des Selbstbewusstseins scheint keine vollkommene Auslöschung zuzulassen, wie man sich auch philosophisch klarmachen kann. ${ }^{106}$ Das einzige, was dann vielleicht noch zur Linderung des Loses eines Verdammten führen könnte, wäre, dass die subjektiv empfundene Intensität seiner Strafe im Verlauf der Zeit immer mehr abnimmt, ohne den Nullpunkt je zu erreichen, ähnlich wie sich die Intensität radioaktiver Strahlung ihrer „Halbwertszeit“ immer wieder halbiert, ohne je ganz abzuklingen. Es wäre dann (wie sich

105 Dass Gott etwas nicht kann, steht nur scheinbar im Widerspruch zu seiner Allmacht: Denn Allmacht kann vernünftigerweise nur bedeuten, dass Gott alles logisch Mögliche durchführen kann, nicht aber auch das logisch Unmögliche. Zum Beispiel kann Gott kein rundes Quadrat erschaffen und er kann sich selbst nicht umbringen (da dies der Unzerstörbarkeit seines Wesens widerspricht). So kann Gott auch nicht erzwingen, dass alle seine Wesen sich ihm freiwillig in Liebe zuwenden (weil Liebe und Zwang sich logisch ausschließen), und ebenso müsste man sagen, dass Gott die menschliche Seele nicht vernichten kann, wenn er sie wirklich als absolut unvernichtbar erschaffen hat. 
durch mathematische Integration nachweisen lässt) nicht nur die momentan empfundene, sondern auch die durch alle Ewigkeit hindurch summierte Intensität der Strafe nur eine endliche, und man kann sich gut vorstellen, dass eine solche Abnahme durch ein fortschreitendes Abstumpfen und immer stärkeres Wegtreten des Bewusstseins auf natürliche Weise tatsächlich eintritt. Die Worte vom „ewig aufsteigenden Rauch“ der Qual der Verdammten (Apk 14,11; vgl. auch 19,3 und 20,10) würden dadurch nicht außer Kraft gesetzt, sie würden aber etwas von ihrer Anstößigkeit verlieren: man müsste dann sinnbildlich sagen, dass dieser Rauch, auch wenn er nicht aufhört, nach einer gewissen Zeit so dünn wird, dass er kaum noch wahrgenommen und auch das Gesamtbild der verklärten zukünftigen Welt nicht mehr merklich trüben kann.

Darüber hinaus dürfen wir hoffen, dass viele und vielleicht sogar die allermeisten Geschöpfe der Höllenstrafe entgehen. Die dem scheinbar entgegenstehenden Bibelstellen sind nämlich nicht beweiskräftig. Jesus antwortet auf die Frage Lk 13,24, ob nur wenige gerettet werden, nämlich nicht einfach mit ja oder nein, sondern fordert zur Bemühung auf, durch das (zum ewigen Heil führende) enge Tor zu schreiten. Wenn er sodann ausführt, dass viele auf dem breiten Weg dahingehen, der zum Verderben führt (Mt 7,13), dass sie das Tor zum Leben gar nicht erst finden (Mt 7,14) oder es zwar zu durchschreiten versuchen, es aber es nicht vermögen (Lk 13,24) und dass ,viele berufen, aber nur wenige auserwählt sind“ (Mt 22,14), so kann man dies so verstehen, dass das eigene Bemühen der meisten in die falsche Richtung geht oder keinen Erfolg haben wird; dies schließt aber nicht aus, dass viele derer, deren eigenes Lebenswerk gescheitert ist, durch ein besonderes Entgegenkommen Gottes am Ende nicht doch die rettende Hand Gottes ergreifen und erlöst werden könnten. Dieser Gedanke ist nämlich in 1 Kor 3,15 ausgedrückt, und in diesem Sinn muss man auch Jesu tröstende Antwort auf die Frage der mutlosen Jünger „,wer kann dann noch gerettet werden?“ verstehen: „Bei den Menschen ist das unmöglich, aber bei Gott ist alles möglich“ (Mt 19,25-26). Auch Stellen wie Apk 14,9-14 und Apk 22,15, in denen die Verdammnis beschrieben wird, sagen nichts über eine konkrete Zahl der Verdammten aus: Es könnte sich um die bildhafte Darstellung einer realen Möglichkeit handeln, was auch sinnvoll wäre, wenn diese Möglichkeit für menschliche Personen gar nicht oder nur in wenigen Fällen verwirklicht werden sollte. Ebenso könnten die Aussagen in Apk 19,20 und 20,10 sowie im Judasbrief (Vers 7) über das ewige Bestrafung der beiden „Tiere“ (d. h. des heidnisch-römischen Reiches und der als „falscher Prophet“ bezeichneten heidnischen Philosophie) und der Städte Sodom und Gomorrha als kollektive Verdammung (ewige Ächtung) der mit diesen Begriffen verbundenen Untaten gedeutet werden, welche die konkreten Einzeltäter aber nur dann tatsächlich betrifft, falls diese sich nicht noch vor ihrem Tode bekehrt haben. In diesem Zusammenhang muss man nun vor allem bedenken, dass Gott ,will, dass alle Menschen gerettet werden“ (1 Tim 2,4) und „,keiner verlorengeht“ (2 Petr 3,9). Daher hat Christus nach seiner Erhöhung am Kreuz alle an sich gezogen (vgl. Joh 12,32), ,sein Leben als Lösegeld für alle hingegeben“ (1 Tim 2,6; vgl. Hebr 9,28 und 1 Joh 2,2) und wurde demzufolge „Retter aller Menschen“ (1 Tim 4,10; vgl. Tit 2,11, Eph 1,10, Joh 17,2 und das 5. Kapitel des Römerbriefes). Außerdem ist eine zukünftige allumfassende Gottesherrschaft verheißen, die mit der Verdammnis eines großen Teils der Geschöpfe nicht leicht vereinbart werden kann: vgl. 1 Kor 15,24-27, Apg 3,21 und nicht zuletzt die Vision, in der Johannes eine in den Himmel kommende gewaltige Schar erblickte, ,die niemand zählen konnte“ (Apk 7,9), wozu auch die nahezu unvorstellbare Größe des „himmlischen Jerusalem“ in Apk 21,16 passt (siehe Kommentar S. 223).

Schließlich ist es bemerkenswert, dass die Bibel (und auch die Kirche) über keinen einzigen Menschen mit Bestimmtheit sagt, dass er ewig verloren ist. ${ }^{107}$ Selbst über das ewige Schicksal des „Verräters“ JuDAS, über den Jesus kurz vor seiner Festnahme sage: ,wehe jenem Menschen, durch den der Menschensohn verraten wird, für ihn wäre es besser, wenn er nicht geboren wäre“ (Mt 26,24), hat sich die Kirche nicht eindeutig ausgesprochen: Papst JOHANNES PAUL II. erklärte zu dieser Schriftstelle, sie könne ,nicht mit Sicherheit im Sinne der ewigen Verdammnis aufgefasst

$107 \quad$ Anders scheint es allerdings im Fall des Teufels und der ihm folgenden abgefallenen Engel zu sein, deren Verdammnis in Mt 25,41 und Jud 6 (vgl. auch Apk 20,10) klar ausgesagt ist; auch die kirchliche Lehrtradition geht von der schon jetzt feststehenden Verdammnis der abgefallenen Engel aus (vgl. Katechismus der Katholischen Kirche $§ 393$ und DH 411 und 801). Theologen, welche die Möglichkeit einer ganz leeren Hölle verteidigen, beziehen diese Aussagen nur auf das Böse: Gott flucht die bösen Taten und Resultate der Geschichte für immer von sich weg, nicht aber die Täter (so VorgRIMMLER, Hoffnung auf Vollendung. Aufriss der Eschatologie, Düsseldorf: Patmos, 1985, 3. Auflage 1993, S. 162). Die Worte „Teufel“ und „Engel“ müssten dann zumindest an den Stellen, wo die Verdammnis dieser Wesen ausgesagt ist, nur als Symbole für das Böse gedeutet werden. Problematisch an dieser modernen Interpretation der Bibelstellen (und auch der entsprechenden kirchlichen Lehrdokumente) und ist aber, dass sie dem ursprünglichen und natürlichen Sinn dieser Texte ebenso wenig zu entsprechen scheint, wie ihrem traditionellen Verständnis. Man kann gegen falsches Mitleid mit einem personalen Teufel und personalen Dämonen anführen, dass die Personalität und Wesenskonstitution dieser Geschöpfe von allem uns Bekannten stark abweichen dürfte, so dass Schmerz und Leid, wie wir Menschen es kennen, ihnen möglicherweise völlig fern liegt. Daher dürfte menschliches Mitleid hier unangebracht sein. 
werden“. ${ }^{108}$ Dieses erschütternde Jesuswort über Judas könnte nämlich vielleicht so verstanden werden, dass es sich nur auf die Stunden unmittelbar nach dem Verrat bezieht: Jesus wollte möglicherweise nur voraussagen, dass es Judas dann so schlimm ergehen wird, dass er sich wünscht, nie geboren zu sein. Diese Situation ist ja auch eingetroffen, weshalb Judas den Freitod wählte (Mt 27,5). Sollte er dann aber diese letzte Verzweiflungstat im letzten Moment vor dem Eintreten seines Todes noch bereut haben - worüber wir allerdings nichts wissen - könnte er noch gerettet worden sein und die Höllenstrafe durch eine lang andauernde, aber doch endliche und schließlich zum Heil führende Fegfeuerstrafe eingetauscht haben. Als Jesus den Judas als verlorengegangenen „Sohn des Verderbens“ bezeichnete (Joh 17,12), würde er dann nur den vorläufigen, nicht den endgültigen Verlust des Judas im Blick gehabt haben. Diese Möglichkeit ist nicht von der Hand zu weisen, da auch Petrus in seiner Rede Apg 1,25 anscheinend sein Unwissen über das Schicksal des toten Judas zum Ausdruck brachte, indem er sagte: ,er ist an seinen Ort gegangen“, nicht aber: „,in die Hölle“.

14,12 Hier ist die Geduld der Heiligen,

welche an den Geboten Gottes und am Glauben an Jesus festhalten.

14,13 Und ich hörte eine Stimme aus dem Himmel sagen:

Schreibe: Selig sind die Toten, die im Herrn sterben, von jetzt an.

Ja, spricht der Geist,

sie werden ausruhen von ihren Mühen, denn ihre Werke folgen ihnen nach.

Nach der Ankündigung der Höllenqualen für die Anbeter des Tieres folgt hier als tröstender Ausgleich eine Schilderung des Loses derer, die IM HERRN (d. h. in Verbundenheit mit CHRISTUS) sterben. Während das Gericht an den Bösen von einem Engel verkündigt wurde, kommt die trostreiche Botschaft für die Erwählten von Gott selber: Johannes vernimmt eine himmlische STIMME (Vers 13a), die sich als Stimme des HL. GeISTES zu erkennen gibt (Vers 13b).

Welches ist der Inhalt dieser Trostbotschaft? Die Gerechten werden nach ihrem Tode AUSRUHEN von ihren Mühen, im Gegensatz zu den Vers 11 erwähnten Verdammten, die „keine Ruhe haben Tag und Nacht“". Vom Ausruhen der Seelen der gerechten Märtyrer war schon 6,11 die Rede. Hier ist nun nicht nur von den Märtyrern die Rede, sondern von der Seligkeit aller TOTEN, DIE IM HERRN STERBEN.

Die Seligkeit beginnt vON JETZT AN. Welches JETZT ist gemeint? Die Stimme befiehlt dem Johannes, den Satz „SELIG DIE TOTEN, DIE IM HERRN STERBEN, vON JETZT AN“ aufzuschreiben, was keinen Sinn hätte, wenn Johannes diesen Satz ebenso aufschreiben sollte wie alles andere auch. Die Aufforderung hat nur Sinn, wenn er diesen Satz gesondert vom Buche der Apokalypse aufschreiben sollte. Der vorliegende Satz muss daher eine Bedeutung haben, die getrennt vom Zusammenhang, in dem er steht, verständlich sein muss: Also bezieht sich das VON JETZT AN nicht auf die Zeit Julians, die Johannes in der prophetischen Vision gerade noch vor sich hatte, sondern auf die Zeit des Johannes.

Heißt dies aber, dass erst von jenem Augenblick an, da Johannes die Stimme hörte, die „im Herrn Sterbenden“ selig wurden? Das kann nicht sein, denn Johannes traf die „24 Ältesten“ bereits im Himmel an, bevor er diese Stimme hörte, und lange vorher hatten bereits Paulus und Stephanus die Hoffnung ausgesprochen, sofort nach dem Tod zu CHRISTUS in den Himmel zu gelangen (Phil 1,21-23, 2 Kor 5,8, Apg 7,59). Außerdem lehrt die Schrift sehr klar, welches der Zeitpunkt war, von dem an die „im Herrn Sterbenden" in die Seligkeit eingingen: Es war der Zeitpunkt des Todes Christi (siehe Exkurs 3). Wieso konnte Johannes dann im Jahre $95 \mathrm{n}$. Chr. vernehmen: vON JETZT AN? Das „,von jetzt an“ bedeutet hier nicht „erst von jetzt an“, sondern ,schon von jetzt an“. Schon von jetzt an, so belehrt der Geist den Johannes, können die im Herrn Sterbenden die Seligkeit erlangen: Sie brauchen nicht erst bis zum Weltende und bis zu der dann erfolgenden leiblichen Totenauferstehung (zu dieser siehe Kommentar zu Apk 20,13-14) zu warten. Diese Belehrung ist offenbar mit der Seelenschlaf- und Seelentodtheorie unvereinbar.

108 Zitat aus VitToRio Messori [Hg]. Die Schwelle der Hoffnung überschreiten. Aus dem Italienischen von Irene Esters. Hamburg: Hoffmann und Campe, 1994, S. 211. 
Der Satzteil DENN IHRE WERKE FOLGEN IHNEN NACH lässt sich als eine Andeutung dahingehend verstehen, dass die guten Werke ursächlich mit der Seligkeit zu tun haben (vgl. auch 2,5, 2,23, 20,1213, 22,12). Die Seligkeit ist demnach kein ohne Rücksicht auf gute Werke gewährtes Gnadengeschenk, wie LUTHER glaubte. Zwar wird der Mensch allein durch die Gnade und ohne seine Verdienste ,gerechtfertigt“ (Röm 3,24), d. h. er empfängt am Anfang seiner Heilsberufung unverdientermaßen die Vergebung seiner Sünden. Aber dies reicht zur Erreichung des Heils noch nicht aus, sondern schafft die Voraussetzung dafür, dass der Mensch anschließend zu seinem Heile durch gute Werke mit der Gnade mitwirken kann (1 Kor 15,10, Phil 2,12-13). Das Bemühen seitens des Menschen ist erforderlich, denn die Gnade ist nicht unverlierbar. Man kann sie vergeblich empfangen haben (2 Kor 6,1), kann aus der Gnade herausfallen (Gal 5,4) und den Geist der Gnade verhöhnen (Hebr 10,29). Petrus fordert uns auf, empfangene Gnade klug zu verwalten (1 Petr 4,10), und Paulus mahnt uns, der Gnade treu zu bleiben (Apg 13,43). So muss der Mensch durch sein eigenes Bemühen zur Erlangung der ewigen Seligkeit beitragen.

14,14 Und ich sah, und siehe, eine weiße Wolke.

Und auf der Wolke saß einer, der einem Menschensohn glich.

Er hatte auf seinem Haupt eine goldene Krone und in seiner Hand eine scharfe Sichel.

14,15 Und ein anderer Engel kam heraus aus dem Tempel, und rief mit lauter Stimme dem zu, der auf der Wolke saß:

Schicke deine Sichel aus und ernte, denn die Stunde zur Ernte ist gekommen, denn die Ernte der Erde ist trocken (d. h. das Korn ist reif).

14,16 Und der auf der Wolke saß, warf seine Sichel über die Erde, und die Erde wurde abgeerntet.

Johannes sieht nun nach der Vorankündigung des Gerichts in einer Art „Vorschau“ die Ausführung.

Der auf der Wolke Sitzende ist ChRISTUs. Denn die WOLKE in Verbindung mit der Bezeichnung MENSCHENSOHN ist eine Anspielung an die Antwort, die Jesus seinerzeit dem Hohenpriester gegeben hatte, als dieser ihm die entscheidende Frage stellte: „Bist du der Christus, der Sohn des Hochgelobten?"“ Darauf hatte Jesus geantwortet: „Ich bin es. Und ihr werdet den Menschensohn zur Rechten der Kraft sitzen und auf den Wolken des Himmels kommen sehen" (Mk 14,61-62).

Der ANDERE Engel, das ist der VIERTE ENGEl dieses Kapitels, kündigt nun eine ERnTE an. Dabei handelt es sich um eine GeTreIDEernte, Denn der Satz „die Ernte der Erde ist TROCKEN“ weist auf das reife Getreidekorn hin. Die Ernte ist in der Bibel Symbol für Gottes Gericht: teils für das Strafgericht an den Bösen (Jer 51,33, Jes 18,5, Joel 4,12-13, und wohl auch Hos 6,11), teils für die Auslese der Guten (Lk 10,2; Mt 13,30) und teils für beides (Mt 13,39). Manche sehen nun in dieser Ernte die Auslese der Erwählten. Sieht man sich jedoch alle Schriftstellen an, wo von einer Ernte die Rede ist, so erkennt man, dass es zur vorliegenden Stelle keine auffälligere Parallele gibt als Jer 51,33: „So spricht der Herr der Heere, der Gott Israels: Die Tochter Babel gleicht einer Tenne, wenn sie festgestampft wird. Noch eine kurze Frist, dann ist für sie die Erntezeit da." JEREMIA drohte also der Stadt Babel (= Babylon) das Strafgericht unter dem Namen „Erntezeit“ und unter dem Bild einer Getreideernte an (Tenne), ebenso wie hier der Stadt Rom (unter dem Decknamen Babylon!) in Vers 8 das Gericht angedroht wurde, und dann die Ernte folgt. Im Warnruf von Vers 8 hatte es geheißen: „Babylon die Große ist gefallen!“, und ganz ähnlich hatte auch Jeremia vor der Erwähnung der Ernte den Untergang des historischen Babylon vorhergesagt: „Erobert ist Babel“ (Jer 50,1). Die Parallele zwischen der Ernte bei Jeremia und der hier vorliegenden Ernte lässt meines Erachtens nur einen Schluss zu: Dass die „Ernte“ hier ein Strafgericht ist, und zwar das entscheidende Strafgericht an Rom, dem neuen „Babel“. Es ist also in diesen Versen bereits das große Strafgericht an Rom durch ALARICH (am 24. August $410 \mathrm{n}$. Chr.) vorweggenommen, dass in Kap. 17 noch ausführlicher beschrieben wird. 
ALARICH selber hat übrigens seinen Schlag gegen Rom im Spott als Getreideernte beschrieben. Als er die Stadt belagerte, sandten die Römer Boten zu ihm, die ihn von einem Angriff abhalten sollten, mit dem Argument, es stünden zahlreiche Krieger zur Verteidigung Roms bereit. Doch ALARICH gab ihnen zur Antwort: „Dichteres Gras lässt sich leichter mähen als dünneres!“109

Eine noch ausführlichere Begründung, warum es sich hier um ein Strafgericht und nicht um eine Auslese der Erwählten handelt, erfolgt im Kommentar zu den folgenden drei Versen.

14,17 Und ein anderer Engel kam aus dem Tempel des Himmels heraus. Auch er hatte eine scharfe Sichel.

14,18 Und ein anderer Engel kam heraus aus dem Altar, (Es war derjenige,) der Macht über das Feuer hat. Und er rief mit lauter Stimme dem zu, der die scharfe Sichel hatte. Und er sagte: Schicke deine scharfe Sichel aus, und schneide die Beeren des Weinstocks der Erde ab, weil seine Beeren reif geworden sind!

14,19 Und der Engel warf seine Sichel über die Erde, und er erntete den Weinstock der Erde ab. Und er warf (die Trauben) in die große Kelter des Zornes Gottes.

14,20 Und die Kelter wurde außerhalb der Stadt getreten. Und es kam Blut aus der Kelter heraus bis an die Zügel der Pferde, (über eine Strecke) von 1600 Stadien.

Zwei ANDERE Engel treten hier auf: der FÜNFTE und der SECHSTE in diesem Kapitel. Zusammen mit MichaEL in Kap. 12,7 ist damit wieder die Zahl von sieben Engeln erreicht (nach den sieben Posaunenengeln in Kap. 8-11 und vor den sieben Schalenengeln, von denen im Folgenden die Rede sein wird).

Wie bei der ersten Ernte ein Engel Jesus zugerufen hatte, seine Sichel über die Erde zu schicken, so ruft hier ein Engel dem anderen zu, seine Sichel auszuschicken. Der rufende Engel kommt AUS DEM AltAR, d. h. aus dem Brandopferaltar, so dass er wohl durch das Gebet der dort weilenden Märtyrer (6,9-11) hinausgeschickt wird, um die Vollendung der in 6,10 ausgesprochenen Bitte der Märtyrer um ihr Blut einzuleiten. Dieser Engel ist der ENGEL DES FEUERS, was uns lehrt, dass Engel über einzelne Elemente der Welt gesetzt sind. In der apokryphen jüdisch-christlichen Tradition heißt der Feuer-Engel URIEL. Zur Aufgabe dieses Engels wird passenderweise auch das Wachen über das Kriegsgeschehen gehören, weshalb es gut passt, dass gerade dieser Engel den Befehl zu jener blutigen „Ernte“ gab.

Dieses Mal ist es keine Getreideernte, sondern eine TRAUBEnERnTE. Diese Ernte ist deutlicher als die erste als Strafgericht gekennzeichnet: Denn aus der Kelter kommt Blut. Daher sind viele der Auffassung, die vorangehende Getreideernte der Verse 14-15 müsse im Gegensatz zur der vorliegenden blutigen Ernte die Auslese der Erwählten sein. Dagegen sprechen aber die folgenden Argumente:

- Die schon im Kommentar zu 14-16 besprochene Parallele zwischen der Getreideernte in Versen 1416 und der Ernte bei Jeremia, wo das Strafgericht an Babylon als Getreideernte (nicht als Weinlese) geschildert wird.

- Das entscheidende Argument dafür, dass die Getreideernte in Vers 14-16 ein Strafgericht sein muss, ist aber, dass man nach der Gerichtsankündigung des Engels in Vers 8: „Babylon die Große ist gefallen!“ den Vollzug des Strafgerichts an der Stadt „Babylon“ (= Rom) erwarten muss. Das Strafgericht an Rom muss also entweder in der Getreideernte ausgesagt sein, oder in der Traubenernte. Nun kann es aber nicht in der Traubenernte ausgesagt sein, denn bei dieser heißt es, dass das Blut außerhalb der Stadt vergossen wurde (Vers 20). Daher bleibt nur noch übrig, dass das Gericht an der Stadt in der Getreideernte ausgesagt ist.

109 Zosimus, Neue Geschichte Buch 5 Kap. 40,3, Ausgabe Rebenich S. 247. 
- Dass die Bilder einer Getreideernte und einer Traubenernte zusammengestellt werden, und beide für ein Strafgericht stehen, ist nichts Befremdliches, denn hierfür gibt es eine Parallele beim Propheten Joel (4,12-13): „Die Heiden sollen sich aufmachen und heraufkommen zum Tal Joschafat, denn dort will ich sitzen und richten alle Heiden ringsum. Sendet die Sichel aus, denn die (Getreide)Ernte ist reif! Kommt und tretet, denn die Kelter ist voll, die Kufen laufen über, denn ihre Bosheit ist groß! ‘

Wenn also die Getreideernte der Verse 14-16 bereits das entscheidende, von ALARICH vollstreckte Gericht Gottes an der Stadt Rom im Jahre 410 beschreibt, was beschreibt dann noch die blutige Weinlese, von der jetzt die Rede ist? ALARICH hatte Rom verwüstet und dem weströmischen Reich den entscheidenden Todesstoß versetzt. Aber das weströmische Reich bestand nach 410 noch weiter und wurde erst im Jahre 476 formal aufgelöst. In der Zeit zwischen 410 und 476 wurde es durch weitere Raubzüge verschiedener Barbaren immer mehr geschwächt. Vor allem waren es die Hunnen, die unter ihrem König ATTILA in den Jahren 451 und 452 Italien und viele andere Provinzen des Reiches verheerten. Attila, den der Historiker GREGOROVIUS als „,den furchtbarsten Mann“ seiner Zeit bezeichnet hat ${ }^{110}$ und den man die „Geißel Gottes“ nannte, hatte ein Heer hatte 700.000 Soldaten, und der Kampf war derart furchtbar und blutig, wie es bis dahin in kaum einem anderen Krieg der Fall gewesen war. Der Höhepunkt war die „Völkerschlacht“ zwischen Attila und dem römischen Feldherrn Aetius auf den Katalaunischen Feldern in Gallien (451), bei der sich verschiedene Germanenvölker auf beiden Seiten beteiligen. In dieser unentschiedenen Schlacht betrug die Zahl der Gefallenen 162.000! Attila und seine Hunnen zogen nach dieser Schlacht nach Italien und marschierten 452 auch gegen Rom, aber Papst LEO DER GROSSE stellte sich ihnen bei Mantua entgegen und bewog Attila zur Umkehr: Rom blieb verschont. Somit sagt die Apokalypse sehr passend, dass DIE KELTER AUSSERHALB DER Stadt Getreten wurde, und dass dabei eine riesige Menge von Blut aus der Kelter floss. Das große Blutvergießen unter Attila ist auch der Grund, warum diese Ernte als Traubenernte dargestellt werden musste, während die Ernte Alarichs eine Ernte ,trockenen“ Getreides war: Alarich hat weitaus weniger Blut vergossen als Attila.

Kurz nach dem Abzug der Hunnen kam im Jahre 455 der nächste Barbarenzug nach Italien: die Vandalen unter GEISERICH. Auch mit diesem Barbaren verhandelte Papst Leo und erreichte, dass sie sich mit einer vierzehntägigen Plünderung der Stadt begnügten, aber auf Mord und Brandschatzung verzichteten. Auch mit Bezug auf Geiserich kann also gesagt werden, dass die KelTER AUSSERHALB DER STADT GETRETEN WURDE.

Die „Mengenangabe“ des Blutes in Vers 20 ist nicht wörtlich zu nehmen: Die Länge von 1600 STADIEN (zu dieser Längeneinheit siehe Kommentar zu 21,16) entspräche wörtlich genommen (falls das olympische Stadion mit ca. $192 \mathrm{~m}$ gemeint ist) ca. 307 Kilometer. Die Zahl 1600 ist vielmehr als 4.4 1000 das Ergebnis der Multiplikation der Zahl der Natur (4) mit sich selbst und mit der Zahl der unabsehbar großen Menge (1000) und symbolisiert daher die unvorstellbar große Menge der Getöteten aus allen vier Himmelsrichtungen.

Die Angabe BIS ZU DEN ZÜGELN DER PFERDE zeigt, dass das Gericht durch Reiter vollstreckt wird: Das passt gut zu Attila und seinen Hunnen, die ein Reitervolk waren.

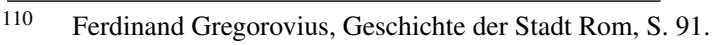




\subsection{Apk 15,1 - 16,21: Die Ausgießung der sieben Schalen}

Nach der Vorankündigung des Gerichts über Rom (14,6-20) erfolgt nun seine Vollstreckung, die von sieben Engeln durch die Ausgießung von sieben Schalen über die Erde ausgelöst wird.

Der Befehl zur Schalenausgießung ergeht zugleich an alle sieben Engel (16,1). Während die Posaunen nacheinander geblasen worden waren $(9,1,9,12-13,11,14-15)$ ist es nicht ganz klar, ob auch die Schalen nacheinander oder gleichzeitig ausgegossen werden. Die Ausgießung löst aber nach der sich nun nahelegenden Interpretation Ereignisse und Entwicklungen aus, die sich teilweise zeitlich überschneiden und alle nahezu gleichzeitig im Zeitraum zwischen dem Ende der Regierung Julians (363) und dem Schlag Alarichs gegen Rom (410) begannen.

\author{
1. Geschwür \\ 2. das Meer wird zu Blut \\ 3. Flüsse und Quellen werden zu Blut \\ 4. Sonnenhitze \\ 5. Finsternis \\ 6. Vorbereitung zur Schlacht \\ 7. Erdbeben

\section{Die Auswirkungen der sieben Schalen im Überblick:} \\ - der Dienst für das Tier wird schmerzhaft (363) \\ - Krieg an den Grenzen des Reiches \\ - Krieg im Inneren des Reiches \\ - die „Sonne“ des Christentums brennt \\ - Verfall der Macht Roms \\ - Barbaren dringen ins Reich ein \\ - der Entscheidende Schlag gegen Rom (410)
}

In der abstrakt-kirchengeschichtlichen Auslegung könnte man die Schalen wie folgt deuten: Moralische Verderbnis (1. Schale: Geschwür) führt die Menschen dazu, durch Krieg und Gewalt (2. und 3. Schale: es fließt Blut) einen antichristlichen Staat zu errichten. Es folgt eine Glanzperiode dieses Staates, in welcher der „Sonnenglanz“ seiner pseudo-göttlichen Macht unerträglich wird (4. Schale). Daraufhin kommt zu inneren Machtkämpfen und die Sonne des Reiches geht unter (5. Schale). Das führt zur Invasion fremder Mächte (6. Schale) und zum Untergang des Reiches (7. Schale). Aber die Menschen ,verfluchen Gott“ (16,28) und bilden das nächste antichristliche Reich, so dass sich der Kreislauf wiederholt. Doch kann ein solcher Kreislauf nicht der Literalsinn sein, da die Schalen nach 15,1 die „letzte“ Vollendung des Zornes Gottes sind.

\subsubsection{Apk 15,1 - 16,1: Vorbereitung der Schalenausgießung}

15,1 Und ich sah ein anderes Zeichen am Himmel, groß und wunderbar: Sieben Engel hatten sieben Plagen. Es sind die letzten, weil in ihnen der Zorn Gottes vollendet ward.

15,2 Und ich sah etwas wie ein gläsernes Meer, vermischt mit Feuer. Und die Sieger über das Tier und über sein Bild und über die Zahl seines Namens standen auf dem gläsernen Meer, und hatten Harfen Gottes.

15,3 Und sie singen das Lied des Mose, des Knechtes Gottes, und das Lied des Lammes und sagten: Groß und wunderbar sind deine Werke, Herr, Gott, du Allmächtiger. Gerecht und wahrhaftig sind deine Wege, du König der Völker.

15,4 Wer wird dich nicht fürchten, Herr, und deinen Namen nicht preisen? Denn du allein bist heilig: alle Völker werden kommen und werden dich anbeten, weil deine gerechten Taten offenbar geworden sind.

15,5 Und danach sah ich: Und der Tempel des Zeltes des Zeugnisses wurde geöffnet.

15,6 Und die sieben Engel, welche die sieben Plagen haben, kamen aus dem Tempel heraus, bekleidet mit reinem, glänzendem Leinen, und um die Brüste mit goldenen Gürteln gegürtet. 
15,7 Und eines von den vier Wesen gab den sieben Engeln sieben goldene Schalen, gefüllt mit dem Zorn des in alle Ewigkeit lebenden Gottes.

15,8 Und erfüllt wurde der Tempel mit Rauch von den Herrlichkeit Gottes und von seiner Macht. Und niemand konnte hineingehen in den Tempel, bis die sieben Plagen der Engel vollendet waren.

16,1 Und ich hörte eine laute Stimme aus dem Tempel zu den sieben Engeln sagen: Geht hin und gießt aus die sieben Schalen des Zornes Gottes auf die Erde!

Auslegung

15,1 Und ich sah ein anderes Zeichen am Himmel, groß und wunderbar: Sieben Engel hatten sieben Plagen.

Es sind die letzten, weil in ihnen der Zorn Gottes vollendet ward.

Diese SIEBEN ENGEL sind wahrscheinlich nicht identisch mit den sieben Posaunen-Engeln (8,2), denn andern falls hätte Johannes wohl gesagt: „Ich sah ... die sieben Engel“. Aber er lässt den Artikel weg. Es handelt sich wohl um sieben Engel, die dem siebten Posaunen-Engel untergeordnet sind, da sie das von ihm angekündigte Gericht ausführten.

Die Engel sollen die LETZTEN Plagen bringen, durch welche sich DER ZORN GOTTES VOLLENDET. Zum „Zorn“ Gottes siehe Kommentar zu 14,10. Es handelt sich hier um den Zorn Gottes über das heidnische Rom: Die Plagen sind also die letzten für Rom bestimmten Plagen (nicht die letzten überhaupt).

15,2 Und ich sah etwas wie ein gläsernes Meer, vermischt mit Feuer.

Und die Sieger über das Tier und über sein Bild und über die Zahl seines Namens

standen auf dem gläsernen Meer, und hatten Harfen Gottes.

15,3 Und sie singen das Lied des Mose, des Knechtes Gottes, und das Lied des Lammes und sagten:

Groß und wunderbar sind deine Werke, Herr, Gott, du Allmächtiger.

Gerecht und wahrhaftig sind deine Wege, du König der Völker.

15,4 Wer wird dich nicht fürchten, Herr, und deinen Namen nicht preisen?

Denn du allein bist heilig: alle Völker werden kommen und werden dich anbeten,

weil deine gerechten Taten offenbar geworden sind.

Nach dem Erscheinen der sieben Engel sieht Johannes ETwAS WIE EIN GLÄSERNES MEER - dieses glasmeerähnliche ,etwas“ hatte er bereits in seiner Himmelsvision 4,6 vor dem Thron Gottes geschaut. Dieses Mal ist das Meer aber Mit Feuer vermischt, d. h. rötlich gefärbt. So erinnert es an das „Rote Meer“, durch welches einst das Volk Israel auf der Flucht vor den Ägyptern hindurchgeschritten war. Wie damals die verfolgten Israeliten durch das rote Meer gingen und ihren Verfolgern entkamen, so steigen hier die verfolgten Christen über das feuerrote gläserne Meer und gelangen so als SIEGER ÜBER DAS TIER zum Thron Gottes. Die geretteten Israeliten brachen einst nach dem Durchzug durch das rote Meer in Jubelgesänge aus: „Damals sang Mose mit den Israeliten dieses Lied .... Ich singe dem Herrn ein Lied, denn er ist hoch und erhaben: Rosse und Wagen warf er ins Meer." (Ex 15,1)

Dieses LIED DES Mose singen nun auch die „Sieger über das Tier“, aber als Christen verbinden sie es mit dem LIED DES LAMMES, also mit einem Lobpreis Christi.

Die SIEGER ÜBER DAS TIER, die hier als Sänger und HARFENSPIELER auftreten, sind offenbar die schon 14,2-3 genannten Sänger und Harfenspieler, die den noch auf Erden lebenden 144.000 vom Himmel aus den Lobpreis Christi beibrachten: das „,neue Lied“ (14,3), das LIED DES LAMMES. Hier werden sie nun als SIEGER ÜBER DAS TIER UND SEIN BILD UND DIE ZAHL SEINES NAMENS genannt, und so zeigt sich, dass es sich um Christen handelt, welche die diokletianische Verfolgung und die Verführungskünste Julians des Abtrünnigen (361-363) heil überstanden haben, und nun im Himmel angekommen sind. 
DU ALLEIN BIST HEILIG singen sie Gott zu. Dennoch werden auch Menschen ,heilig“ genannt (Mk 6,20, Mt 27,52, 1 Thess 3,13, 2,10, Tit 1,8, Apk 14,10). Das Wort „heilig“ bedeutet also in seiner Anwendung auf Gott etwas anderes als in seiner Anwendung auf Menschen: Gott allein ist von sich aus heilig, die Geschöpfe dagegen durch Gottes Gnade.

15,5 Und danach sah ich: Und der Tempel des Zeltes des Zeugnisses wurde geöffnet.

15,6 Und die sieben Engel, welche die sieben Plagen haben, kamen aus dem Tempel heraus, bekleidet mit reinem, glänzendem Leinen, und um die Brüste mit goldenen Gürteln gegürtet.

Der Tempel Des Zeltes Des Zeugnisses ist der vordere Tempelraum, in dem die „Bundeslade“ stand, in welcher das ,Zeugnis“ (die Tafeln mit den 10 Geboten) aufbewahrt wurde. Die Öffnung des Tempels dient nicht (wie in 11,19) dazu, den Menschen einen neuen Zugang zum Himmel aufzutun (ganz im Gegenteil, siehe Vers 8), sondern hat nur den Sinn, die Engel herauszulassen, welche das Strafgericht ausführen. Zum priesterlichen Zeichen der BRUSTGÜRTUNG vgl. Kommentar zu 1,13.

15,7 Und eines von den vier Wesen gab den sieben Engeln sieben goldene Schalen, gefüllt mit dem Zorn des in alle Ewigkeit lebenden Gottes.

Zu den vier Wesen vgl. 4,6-8. Der Zorn Gottes (vgl. Kommentar 14,10) ist hier eine Flüssigkeit in GOLDENEN SCHALEN.

15,8 Und erfüllt wurde der Tempel mit Rauch von den Herrlichkeit Gottes und von seiner Macht. Und niemand konnte hineingehen in den Tempel, bis die sieben Plagen der Engel vollendet waren.

Diese Vision vom Rauch, der Gott verhüllt (ihn also für Bittsteller unsichtbar macht) und das Betreten Tempels verunmöglicht, zeigt eindringlich die Unumkehrbarkeit des Beschlusses zur Vernichtung Roms: Niemand darf sich zu Gott in den Tempel hineinbegeben, um ihn ,umzustimmen“.

16,1 Und ich hörte eine laute Stimme aus dem Tempel zu den sieben Engeln sagen: Geht hin und gießt aus die sieben Schalen des Zornes Gottes auf die Erde!

Die Stimme Aus Dem Tempel ist Gottes Stimme, da niemand den Tempel betreten durfte (Vers 8).

\subsubsection{Apk 16,2: Erste Schale (Geschwür)}

\section{Text}

16,2 Und der erste (Engel) ging hin und goss seine Schale auf die Erde. Und es entstand ein böses und schlimmes Geschwür an den Menschen, die das Kennzeichen des Tieres haben und sein Bild anbeten.

\section{Auslegung}

Alle sieben Engel werfen nach 16,1 ihre Schale auf die ERDE, d. h. auf die auf Erden wohnenden Menschen. In einem anderen Sinn aber muss der erste Engel seine Schale auf die Erde werfen, während die zweite auf das Meer, die dritte auf die Flüsse usw. geworfen wird. AUF DIE ERDE hat hier also einen besonderen Sinn und meint wohl: direkt auf die Menge der irdisch gesinnten Gottlosen. Die Nachfolger JULIANs bekannten sich wieder zum Christentum, auch wenn sie zunächst die arianische Irrlehre begünstigten. Das Heidentum aber erfreute sich nicht mehr des kaiserlichen Wohlwollens: Es wurde nun wieder zurückgedrängt und teilweise sogar verfolgt. So begann sich das „Kennzeichen“ des Tieres auf den Stirnen seiner Verehrer gleichsam in ein schmerzhaftes GESCHWÜR zu verwandeln. 


\subsubsection{Apk 16,3: Zweite Schale (das Meer wird zu Blut)}

Text

16,3 Und der zweite (ENGEL) goss seine Schale in das Meer.

Und es wurde zu Blut wie (das Blut) eines Toten.

Und jedes Lebewesen (wörtlich: Seele des Lebens) starb: (alles,) was im Meer war.

Auslegung

Hier ist die Rede von Kriegen, die die ganze Volksmasse (= das MEER, vgl. 17,15) des Imperiums erschütterten. Tatsächlich wurde nach dem Tod JULIANs (363) das römische Reich von verschiedendsten Kriegen nur so überschwemmt, als die Perser in der Osthälfte, die Goten und andere Barbaren in der Westhälfte des Reiches für Unruhe sorgten. 364 rebellierte PROCOPIUS gegen Kaiser VALENS. 365 überquerten die Germanen den Rhein. 366 verheerten die Isaurier die Provinz Asien, während die Asturier die Provinz Africa entvölkern. 367 wurde Britannien durch Pikten und Skoten verwüstet. 375 fielen schließlich die Hunnen, jenes gefürchtete asiatische Reitervolk, in Europa ein und lösten die Völkerwanderung aus, prophetisch als „Schlacht von Harmagedon“ bezeichnet (sieht 16,16), an der das antike Rom zugrunde ging. Vergleiche hierzu HIERONYMUS, einen Zeitzeugen:

„Goten, Sarmaten, Quaden, Alanen, Hunnen, Vandalen,Markomannen haben Skythien, Thrazien, Mazedonien, Thessalien, Dardanien, Dacien, Epirus, Dalmatien und ganz Pannonien verwüstet, an sich gerissen und ausgeraubt. ... Überall ist Klage, überall Seufzen und weit verbreitet ist das Bild des Todes ... Und als ob uns dies an Übeln nicht ausreicht, verderben die Bürgerkriege fast noch mehr Menschen als das feindliche Schwert."111

Das MeER wurde jetzt zu Blut WiE DAS Blut EINES Toten, d. h. das Reich glich nun einem toten, seelenlosen Körper, dem die Seele (die funktionierende Autorität) fehlt. Wörtlich heißt es: JEDE SEELE DES LEBENS STARB, ALLES WAS IM MEER WAR. Hier ist also vom „Sterben“ von Seelen die Rede (wie in Ez 18,4: Die Seele, die sündigt soll sterben; aber im Gegensatz zu Mt 10,28, wo das Töten des Leibes nicht zum Töten der Seele führt). Wie kann das sein? Mit den „Seelen“ sind hier offensichtlich nicht für die unvergänglichen Wesenskerne der Menschen gemeint, sondern die sterblichen Lebewesen, von welchen einige Besitzer solcher Seelen sind (vgl. 8,9), ähnlich wie mit „er ist ein kluger Kopf“ kein Kopf, sondern der Besitzer eines Kopfes gemeint ist. Außerdem dürfte mit dem „Sterben“ ein geistiges Sterben gemeint sein: ein Versinken im Elend. Das ganze ist ein Bild dafür, dass das Römische Reich den letzten Lebensnerv verlor.

Doch warum wird das Römische Reich erst jetzt gestraft, wo es bereits unter christlichen Kaisern stand? Die Mächte, die Kaiser Julian hervorgebracht hatten, waren immer noch stark und hofften auf eine heidnische Wiederbelebung. Erst der Fall Roms im Jahre 410 bereitete diesen Mächten ein Ende (siehe Kommentar zu 18,6).

\subsubsection{Apk 16,4-7: Dritte Schale (Flüsse und Quellen werden zu Blut)}

\section{Text}

16,4 Und der dritte (Engel) goss seine Schale in die Flüsse und in die Wasserquellen. Da wurde (das Wasser) zu Blut.

16,5 Und ich hörte den Engel der Gewässer sagen: Gerecht bis du, der du bist und der du warst, du Heiliger, dass du so gerichtet hast.

16,6 Sie haben das Blut der Heiligen und Propheten vergossen, und du gabst ihnen Blut zu trinken, denn sie sind es wert.

16,7 Und ich hörte den Altar sagen: Ja, Herr, Gott, du Allmächtiger, wahrhaftig sind deine Gerichte.

111 Hieronymus, Epistola 70 Kap. 16-17 (CSEL Band 54 S. 570-572). 


\section{Auslegung}

Hier ist von einer Ausweitung der schon bei der 2. Schale genannten Kriege bis in die innersten Teile des Reiches hinein die Rede (FLÜSSE und QUELLEN). Der ENGEL DER GEWÄSSER (vgl. den „Engel des Feuers“ in 14,18 und die vier ,Engel der Winde“ in 7,1) verwaltet das Wasser, das wichtigste Lebenselement, und wacht darum wohl auch über das durch das Wasser ermöglichte und geförderte Leben. So ist es besonders beeindruckend, dass gerade dieser Engel bekennt, dass jene todbringenden Kriege eine gerechte Strafe waren. Er redet Gott an als DER DU BIST UND DER DU WARST, nicht mehr als DER DU KOMMST, weil jetzt Gottes Gericht gekommen ist: Seit dem Blasen der 7. Posaune wird „der du kommst“ weggelassen (11,17). Auch DER ALTAR preist die Gerechtigkeit des göttlichen Strafgerichts. Mit dem „Altar“ ist hier wohl die Gemeinschaft der Märtyrer gemeint, deren Seelen Johannes unter dem Altar geschaut hatte (6,9-11). Diese preisen Gott, weil ihre in 6,10 ausgesprochene Bitte um Vergeltung ihres Blutes sich nun erfüllt.

\subsubsection{Apk 16,8-9: Vierte Schale (Sonnenhitze)}

Text

16,8 Und der vierte (Engel) goss seine Schale aus über die Sonne. Und ihr wurde Macht gegeben, die Menschen mit Feuer zu versengen.

16,9 Und versengt wurden die Menschen mit großer Hitze.

Und sie lästerten den Namen Gottes, der die Macht über diese Plagen hat. Und sie bereuten nicht, und gaben Gott nicht die Ehre.

\section{Auslegung}

Die Sonne steht für Christus und Christi Gottheit (siehe Kommentar zu 6,12). Der Glaube an die Gottheit Christi setzte sich in der Kirche endgültig unter THEODOsıUs dem Großen (379-395) durch. Theodosius war der erste Kaiser, der sich klar und entschieden vom arianischen Christentum abwandte und das rechtgläubige Bekenntnis vorbehaltlos akzeptierte. Er ging sogar soweit, dass er das Christentum zur Staatsreligion erklärte. Damit begann die „Sonne“ des rechtgläubigen Christentums für die Heiden gleichsam eine unerträgliche Hitze zu erzeugen, welche das zum Geschwür gewordene „Kennzeichen“ auf ihrer Stirn $(16,2)$ noch schmerzhafter machte. Doch sie gaben GOTT NICHT DIE EHRE (d. h. glaubten nicht an Christi Gottheit) und lästerten weiterhin den Namen Gottes.

\subsubsection{Apk 16,10-11: Fünfte Schale (Finsternis)}

\section{Text}

16,10 Und der fünfte (Engel) goss aus seine Schale auf den Thron des Tieres. Da wurde sein Reich verfinstert. Und sie zerbissen sich die Zungen vor der Qual.

16,11 Und sie lästerten den Gott des Himmels wegen ihrer Qualen und wegen ihrer Geschwüre. Und sie bereuten nicht und wendeten sich nicht ab von ihren Werken.

\section{Auslegung}

Der THRON DES TIERES ist Rom. Denn Rom war der Regierungssitz der Christenverfolger gewesen. Rom war außerdem die Vorreiterin des Götzendienstes gewesen, und blieb es auch dann noch, als die Kaiser schon christlich waren (siehe Kommentar zu 18,6).

Nach dem Tode Theodosius' des Großen wurde das Reich endgültig in zwei Reiche gespalten, als zwei Söhne des Theodosius je eine Hälfte des Reiches übernahmen: ARKADIUS erhielt den Osten, HONORIUS den Westen. Durch diese Reichsteilung wurde in Verbindung mit den nun massiv einsetzenden Eroberungsstürmen der Barbaren das Reich 
in seinem Ansehen Verfinstert. Der Höhepunkt dieser Verfinsterung war die Zeit der Belagerung Roms durch Alarich (408-410).

In dieser Zeit wurde Gott GELÄSTERT, denn die Heiden gaben den Christen die Schuld an der schlimmen Lage. „Rom wurde belagert und erobert“, so stellte SALVIANUS VON MARSEILLE ( $\dagger$ um 480) fest, und fragt ironisch: ,,aber hörten die Römer [etwa deshalb] auf, zu lästern und zu wüten?“‘.112

\subsubsection{Apk 16,12-16: Sechste Schale (Vorbereitung zur Schlacht)}

\section{Text}

16,12 Und der sechste (Engel) goss seine Schale auf den großen Fluss, den Euphrat. Und es vertrocknete sein Wasser, so dass den Königen vom Aufgang der Sonne der Weg bereitet wurde.

16,13 Und ich sah aus dem Mund des Drachens und aus dem Mund des Tieres und aus dem Mund des falschen Propheten drei unreine Geister herauskommen wie Frösche.

16,14 Sie sind nämlich Geister von Dämonen, die Zeichen tun. Sie gehen aus zu den Königen der ganzen bewohnten Erde, um sie zu versammeln zum Krieg am großen Tage Gottes des Allmächtigen.

16,15 Siehe ich komme wie ein Dieb.

Selig ist, der wacht und seine Kleider bewahrt, damit er nicht nackt einhergeht und man nicht seine Schande sieht.

16,16 Und sie (die Geister) versammelten sie (die Könige) an dem Ort, der auf hebräisch Harmagedon genannt wird.

\section{Auslegung}

Der EuphRAT war der Grenzfluss, hinter dem der seit alters am meisten gefürchtete Erzfeind lauerte: Persien. Hier dürfte „Euphrat“ für die gesamten Ostgrenze des Reiches stehen, die durch die drei Flüsse Euphrat, Donau und Rhein gebildet wurde.

Das TROCKENWERden DES EUPHRAT bedeutet das Wegfallen der Grenzsicherheit im Osten, so dass den KÖNIGEN vom AUfGANG DER SONNE (= Osten) her der Einmarsch ins Reich offen stand Dies ereignete sich nach dem Sturz Julians, dessen Besiegung durch die Perser eine entscheidende Schwächung des Ansehens Roms und seiner Grenzen einleitete, ähnlich wie seinerzeit die Gefangennahme Valerians. Dass der „Euphrat“ bzw. die Ostgrenze tatsächlich keine Hürde mehr war, zeigten die schon genannten Kriege.

Johannes sieht nun wieder den DrACHEN, d. h. den Teufel, der wohl immer noch am Strand von Patmos steht $(12,18)$. Daneben steht jetzt anscheinend das TIER, das aus dem Meer hervorgekommen war $(13,1)$ und das wir als das heidnisch-römische Reich interpretiert haben. Dem Tier gesellt sich schließlich noch eine dritte Gestalt hinzu, DER FALSCHE PROPHET, ebenso wie in Kap. 13 dem Tier ein zweites Tier beigesellt wurde. Der ,falsche Prophet“ scheint also dieses zweite Tier zu sein, das wir mit dem Neuplatonismus identifiziert haben, eine Bewegung, die in der Tat ein „falscher Prophet“ genannt werden kann. (vgl. auch 19,20 mit 13,14). Nun sieht Johannes aus dem Mund dieser drei teuflisch-dämonischen Gestalten Frösche hervorgehen. Diese Frösche sind DÄMONEN, böse Geister, welche die „Könige der Erde“ zum Krieg reizen, und zwar durch ZEICHEN, d. h. durch falsche Orakel, die den Sieg verheißen. Dazu passt die Gestalt des Frosches, dessen Quaken leeres Gerede bezeichnet und dessen Schlüpfrigkeit Symbol für verführendes Schmeicheln ist. Der eine Frosch kam aus dem MUND DES DRACHEN, d. h. er wurde auf direkten Befehl Satans hin tätig. Die beiden anderen kamen aus dem MUND DES TIERES und aus dem MUND DES FALSCHEN Propheten, d. h. aus dem prahlenden Mund Julians und aus dem Mund seiner neuplatonischen Lobredner. Als das julianisch-neuplatonische Rom sich seiner „Unbesiegbarkeit“ rühmte, sprangen diese Dämonen wahrscheinlich zu den

SAlvianus, De gubernatione Dei Kap. $6 \S 67$ (CSEL Band 8 S. 144): „obsessa est urbs Roma et expugnata: ergo desierunt blasphemi ac furiosi esse Romani?“ 
Barbarenkönigen hinüber, um sie zum Widerspruch zu reizen und so Krieg heraufzubeschwören. Eine erste Frucht dieser Taktik scheint der Krieg mit Persien gewesen zu sein, dem Julian zum Opfer fiel.

Die Könige versammeln sich für den großen TAG des Kampfes: den „Tag“ des Untergangs Roms in der Völkerwanderung (ca. 375-600). Diese KÖNIGE waren die Perser, Hunnen, Goten und alle anderen an der Völkerwanderung, dem gewaltigsten Spektakel der Geschichte, teilnehmenden Völker. Mit Recht spricht also der Text von einer Versammlung DER KÖNIGE DER GANZEN BEWOHNTEN ERDE. Da diese alle von Osten her ins Römische Reich eindringen mussten (der ganze Westen war ja in römischer Hand), kann Vers 12 den Kampf als ein Einrücken von KÖNIGEN DES OSTENS über den Euphrat beschreiben. Der ORT des Kampfes ist HARMAGEdon. Dieses hebräische Wort bedeutet „Berg Megiddo“. Megiddo war eine Stadt im Norden Israels, wo wiederholt furchtbare Schlachten stattgefunden haben. Hier starben einst SISERA und die Könige von Kanaan (Richterbuch, Kap. 4 und 5, bes. 5,17), aber auch die jüdischen Könige Ahasja und JoschiJa (2 Kön 9,27 und 23,29). Der Prophet SACHARJA 12,11 vergleicht die Klage in Megiddo mit der Klage beim End(?)gericht: „An jenem Tag wird die Totenklage in Jerusalem so laut sein wie die Klage um HadadRimmon in der Ebene von Megiddo." HARMAGEDON (= Berg Megiddo) muss ein rein symbolischer Ort sein, da das wirkliche Megiddo in einer Ebene lag: „Berg“ bedeutet vielleicht, dass Gott die Hauptrolle spielt (weil der „Berg“ als Ort göttlicher Offenbarung gilt). „Megiddo“ aber bedeutet wohl, dass die Schlacht große Klage auslöst, sowohl bei den Heiden (da in Megiddo einst die heidnischen Könige von Kanaan starben), als auch bei den Gottesfürchtigen (da in Megiddo auch der gottesfürchtige Joschija starb). Tatsächlich haben nicht nur die Heiden, sondern auch die Christen den Fall Roms beklagt, da sie vom Kulturrückfall ins Barbarentum genauso betroffen waren wie die Heiden (siehe den Kommentar zu 19,1-3). Die Schlacht von Harmagedon war ein Kampf auf allen Ebenen: ein Kampf der Barbaren gegen Rom, aber auch der Barbaren gegeneinander, und weiterhin ein Kampf der Barbaren, die entweder Heiden oder arianische Christen waren, gegen das rechtgläubige Christentum, worin sie von den heidnischen Römern unterstützt wurden. Das Ende dieses universalen Kampfes aber war der endgültige Untergang des heidnisch-römischen Reiches und der geschichtliche Sieg des rechtgläubigen Christentums: Die heidnische Antike ging unter, damit sich auf ihren Trümmern eine neue, christlich geprägte Kultur erheben konnte. Darum ist dieser Kampf der GROSSE TAG GOTTES Des Allmächtigen. Darum ist er auch ein Tag Des Kommens Christi. Der Einschub Vers 15 (SIEHE ICH KOMME WIE EIN DIEB) stammt wahrscheinlich von CHRISTUS, der sein Kommen auch in 3,3 (vgl. Mt 24,43-44, 1 Thess 5,2-4) mit dem Einbruch eines Diebes vergleicht (wegen der unvermuteten und unangenehmen Überraschung, die dieses Kommen vielen bereiten wird). Christi „Kommen“ geschieht also nicht nur beim Tod (3,3 und 3,20), sondern es ereignet sich auch bei gewissen geschichtlichen Ereignissen, welche wiederum Vorankündigungen seines letzten Kommens am Ende der Geschichte sind.

\subsubsection{Apk 16,17-21: Siebte Schale (Erdbeben)}

Text

16,17 Und der siebte (Engel) goss aus seine Schale in die Luft.

Da kam eine laute Stimme aus dem Tempel, vom Thron her, die sagte: Es ist geschehen.

16,18 Und es folgten Blitze und Stimmen und Donner.

Und es folgte ein Erdbeben, so gro $\beta$ wie es nicht geschehen ist seit ein Mensch auf Erden war:

So groß war das Erdbeben (und) so stark.

16,19 Und die große Stadt zerfiel in drei Teile und die Städte der Völker fielen ein.

Und Babylon die Große wurde in Erinnerung gerufen vor Gott,

dass ihr gegeben wurde der Becher des Weines der Wut seines Zornes.

16,20 Und jede Insel floh, und Berge wurden nicht mehr gefunden.

16,21 Und großer Hagel, zentnerschwer, kommt aus dem Himmel herab auf die Menschen.

Und doch lästerten die Menschen Gott wegen der Plage des Hagels.

Denn die Plage des Hagels war sehr groß.

Auslegung

Die letzte Plage wird in die LuFT geworfen, weil sie Rom zu Fall bringt: Ein Ereignis, dessen Verkündigung laut durch 
die Luft über den ganzen Erdkreis schallen soll. Die STimme Aus DEM TemPel ist Gottes Stimme (vgl. 16,1). Es IST GESCHEHEN, so verkündigt sie, d. h. jetzt ist der „große Tag Gottes des Allmächtigen“ gekommen. STIMMEN, BLITZE und DonNer sind Symbole der furchterregenden göttlichen Gegenwart (siehe Kommentar zu 8,5).

Das ERDBEBEN Vers 18 bedeutet einen weltgeschichtlichen Umsturz (siehe Kommentar zu 6,12). Da das vorliegende Erbeben als das bis dahin größte Erdbeben der Menschheitsgeschichte bezeichnet wird, muss es sich um die bis dahin größten Veränderungen der Geschichte handeln. Das trifft nun eindeutig auf den Untergang Roms und der gesamten Antike in der Völkerwanderung zu. Die Völkerwanderung bewirkte eine einzigartige politische Veränderung der Machtverhältnisse und der Landkarte, auf der fast nichts gleich blieb. Zugleich bewirkte sie eine kulturelle Veränderung: den Sturz von der antiken Hochkultur auf die Kulturstufe der Barbaren. Dazu erfolgte noch eine tiefgreifende religiöse Veränderung: die Ablösung des Heidentums durch das Christentum.

DIE STÄDTE DER VÖLKER STÜRZTEN EIN, denn die Goten verheerten zahlreiche Orte, Völker und Landstriche des römischen Reiches. ALLE INSELN UND BERGE VERSCHWANDEN, d. h. alles bis dahin Feststehende brach zusammen (siehe Kommentar zu 6,12-14). So meinte der Zeitzeuge HiERONYmus, dass mit der Stadt Rom ,der ganze Erdkreis untergegangen ist“. ${ }^{113}$ BABYLON, d. h. Rom (siehe Kap. 17), wurde in DREI TEILE geteilt. Dies kann symbolisch als definitiver Zerfall der Macht Roms gedeutet werden (drei, = nachdrückliche Betonung). Man könnte die Zahl aber auch wörtlich nehmen, denn das Westreich wurde zur Zeit der Erstürmung Roms durch ALARICH tatsächlich in drei Teile geteilt: Der rechtmäßige Kaiser HONORIUS regierte in Ravenna, in Rom wurde ATTALUS eingesetzt und CONSTANTIUS wurde um dieselbe Zeit von revoltierenden britischen Soldaten zum König erklärt. ${ }^{114}$

Der ZENTNERSCHWERE HAGEL ${ }^{115}$ ist ein Bild für die erdrückende Schwere Untergangs der Stadt Rom. Darum LäSTERTEN die immer noch ungläubigen Menschen Gott: Denn die Heiden machten die Vernachlässigung des Götterkultes durch die Christen für diesen Untergang verantwortlich. Um diesen Vorwurf zu entkräften, schrieb damals Augustinus sein Buch mit dem Titel Über den Gottesstaat. Mochten die Heiden auch weiter lästern: Ihre Stunde war nun endgültig vorbei. Die einzig tragende Kulturkraft war fortan Christi Kirche.

113 HiERONYMUS, Ezechielkommentar, Vorwort Einleitung zum Ezechielkommentar (CCSL Band 75 S. 3): ,in una urbe totus orbis interiit“. (um 500 - 562) war der bedeutendste Geschichtsschreiber der Spätantike.

115 Wörtlich wird der Hagel in 16,21 beschrieben als „talent-schwer“, wobei das Gewicht von einem Talent ursprünglich die maximale Traglast eines (gewöhnlichen) Mannes war, ca. $30 \mathrm{~kg}$; von der Größenordnung her entspricht dies in etwa einem Zentner (= $50 \mathrm{~kg})$. 


\subsection{Apk 17,1 - 19,10: Das Gericht über die Stadt}

Die folgenden drei Kapitel sind die SCHLÜSSELKAPITEL der Apokalypse, die unsere Deutung des „Tieres“ (= römisches Weltreich) und der „Stadt Babylon“ (= heidnisches Rom) bestätigen.

Text

17,1 Und es kam einer von den sieben Engeln, welche die sieben Schalen haben.

Und er redete mit mir und sagte: Komm hierher!

Ich will dir das Gericht über die große Hure zeigen, die an vielen Gewässern sitzt.

17,2 Mit ihr haben Unzucht getrieben die Könige der Erde.

Und die Bewohner der Erde sind betrunken geworden vom Wein ihrer Unzucht.

17,3 Und er (der Engel) führte mich im Geist in die Wüste.

Und ich sah eine Frau auf einem scharlachroten Tier sitzen.

Das Tier war über und über mit gotteslästerlichen Namen beschrieben.

Es hatte sieben Köpfe und zehn Hörner.

17,4 Und die Frau war bekleidet mit Purpurgewand und Scharlachgewand und mit Gold, wertvollem Stein und Perlen geschmückt.

Sie hatte einen goldenen Becher in ihrer Hand,

der gefüllt war mit Abscheulichkeiten und mit den Unreinheiten ihrer Unzucht.

17,5 Und an ihrer Stirn war ein Name geschrieben, ein Geheimnis:

„Babylon die Große, die Mutter der Huren und der Abscheulichkeiten der Erde“.

17,6 Und ich sah, dass die Frau betrunken war

vom Blut der Heiligen und vom Blut der Zeugen Jesu.

Und ich geriet in Verwunderung, als ich sie sah, in große Verwunderung.

17,7 Und der Engel sagte zu mir: Weswegen gerietest du in Verwunderung?

Ich will dir das Geheimnis der Frau enthüllen

und das Geheimnis des Tieres

mit den sieben Köpfen und den zehn Hörnern, auf dem sie sitzt.

17,8 Das Tier, das du gesehen hast, war und ist nicht, und wird heraufsteigen aus dem Abgrund, und es geht ins Verderben. Und verwundern werden sich die Bewohner der Erde, deren Name nicht geschrieben ist im Buch des Lebens seit Grundlegung der Welt, wenn sie das Tier sehen: dass es war und nicht ist und (wieder) da sein wird.

17,9 Hier ist Verstand (nötig), der Weisheit hat.

Die sieben Köpfe sind sieben Berge, auf denen die Frau sitzt. Und sieben Könige sind sie.

17,10 Die fünf (von den sieben Königen) sind gefallen, der sechste ist da, der andere (siebte) ist noch nicht gekommen, und wenn er kommt, darf er nur kurze Zeit bleiben.

17,11 Und das Tier, das war und nicht ist, ist sowohl ein achter als auch (einer) von den sieben, und es geht ins Verderben.

17,12 Und die zehn Hörner, die du gesehen hast, sind zehn Könige, welche die Herrschaft noch nicht erlangt haben, aber sie erhalten Macht wie Könige eine Stunde lang mit dem Tier.

17,13 Diese haben eine Meinung und geben ihre Macht und Gewalt dem Tier.

17,14 Diese werden mit dem Lamm Krieg führen.

Und das Lamm wird sie besiegen, weil es Herr der Herren ist und König der Könige.

Und die Seinen sind Berufene und Auserwählte und Treue.

17,15 Und er sagt zu mir: Die Gewässer, die du gesehen hast, an denen die Hure sitzt,

sind Völker und Scharen und Nationen und Zungen. 
17,16 Und die zehn Hörner, die du gesehen hast, und das Tier: Diese werden die Hure hassen.

Sie werden sie zu einer Verwüsteten und Nackten machen.

Und ihr Fleisch werden sie essen, und sie werden sie verbrennen im Feuer.

17,17 Denn Gott hat in ihre Herzen gegeben, seinen Willen auszuführen und einer Meinung zu sein und ihre Herrschaft dem Tier zu geben, bis die Worte Gottes erfüllt sein werden.

17,18 Und die Frau, die du gesehen hast, ist die große Stadt, welche die Herrschaft hat über die Könige der Erde.

18,1 Und danach sah ich einen anderen Engel aus dem Himmel herabkommen, der große Macht hatte, und die Erde wurde von seinem Glanz erhellt.

18,2 Und er rief mit lauter Stimme: Gefallen, gefallen ist Babylon die Große! Und sie ist geworden eine Behausung von Dämonen und ein Verbannungsort für jeglichen unreinen Vogel und ein Verbannungsort für jegliches unreine und verhasste Tier.

18,3 Denn vom Wein des Zornes ihrer Unzucht haben alle Völker getrunken und die Könige der Erde haben mit ihr Unzucht getrieben und die Kaufleute der Erde sind von der Macht ihrer Üppigkeit reich geworden.

18,4 Und ich hörte eine andere Stimme aus dem Himmel sagen: Verlass die Stadt mein Volk, damit du nicht mitschuldig wirst an ihren Sünden, und von ihren Plagen nicht mitgetroffen wirst.

18,5 Denn angehäuft haben sich ihre Sünden bis zum Himmel, und Gott gedachte ihrer Schandtaten.

18,6 Zahlt ihr mit gleicher Münze heim, gebt ihr doppelt zurück, was sie getan hat.

18,7 In dem Maße, wie sie sich Glanz verschafft und ein üppiges Leben geführt hat, im gleichen Maße gebt ihr Peinigung und Trauer.

Denn in ihrem Herzen sagte sie: Ich throne als Königin, eine Witwe bin ich nicht, und Trauer werde ich niemals sehen.

18,8 Deshalb kommen an einem einzigen Tag ihre Plagen: Tod, Trauer und Hunger, und mit Feuer wird sie verbrannt werden.

Denn stark ist der Herr, Gott, der sie gerichtet hat.

18,9 Und es werden weinen und sich an die Brust schlagen wegen ihr die Könige der Erde und diejenigen, die mit ihr Unzucht getrieben und üppig gelebt haben, wenn sie den Rauch ihres Brandes sehen.

18,10 Und sie werden in der Ferne aus Angst vor ihrer Qual stehen bleiben und sagen: Wehe, wehe, du große Stadt, Babylon, du starke Stadt: In einer Stunde ist dein Gericht gekommen!

18,11 Und die Kaufleute der Erde weinen und trauern um sie, weil ihre Ladung niemand mehr kauft.

18,12 Ihre Ladung an Gold und Silber und wertvollem Stein und Perlen und Byssus und Purpur und Seide und Scharlachstoff und allerlei vom Citrusbaum stammendes Holz und allerlei elfenbeinernes Gerät und allerlei Gerät aus wertvollstem Holz und Erz und Eisen und Marmor,

18,13 und Zimt und Haarsalbe und Räucherwerk und Myrrhe und Weihrauch und Wein und Öl und Feinmehl und Weizen und Rinder und Schafe und Pferde und Wagen und Leiber und Seelen von Menschen.

18,14 Und das Obst, nach dem die Begierde deiner Seele stand, ist dir abhanden gekommen.

Und alles Kostbare und Glänzende ist verloren gegangen,

(ist) weg(genommen) von dir und man wird es nie mehr finden.

18,15 Die Kaufleute, (die mit) diesen Dingen (Handel trieben), sind an ihr (an der Stadt) reich geworden.

In der Ferne werden sie stehenbleiben wegen der Furcht vor ihrer Peinigung. Sie werden weinen und trauern

18,16 und sagen: Wehe, wehe, du große Stadt, bekleidet mit Byssus und Purpur und Scharlach und vergoldet mit Gold und wertvollem Stein und Perlenschmuck. 
18,17 In einer einzigen Stunde wurde der große Reichtum verwüstet.

Und jeder Steuermann und jeder, der an dem Ort vorbeisegelt, und Seeleute, und alle die das Meer befahren, standen von ferne

18,18 und riefen, als sie den Rauch ihres Brandes sahen: Welche Stadt war der großen Stadt gleich?

18,19 Und sie warfen Staub auf ihrer Häupter und riefen weinend und trauernd: Wehe, wehe, du große Stadt, in der alle reich geworden sind, die Schiffe auf den Meeren haben, durch die Fülle an Kostbarkeiten. In einer einzige Stunde wurde sie verwüstet.

18,20 Freue dich über sie, du Himmel, und ihr Heiligen und ihr Apostel und ihr Propheten. Denn Gott hat für euch das Strafgericht an ihr vollzogen!

18,21 Und ein starker Engel hob einen Stein auf, der wie ein Mühlstein war und warf ihn ins Meer, und sagte: Mit solcher Wucht wird Babylon die große Stadt niedergeschleudert werden, und sie wird nicht mehr gefunden werden.

18,22 Und einen Ton von Harfensängern und Musikern und Flötenspielern und Posaunenbläsern hört man nicht mehr in dir.

Und Handwerker jeglicher Art werden nicht mehr in dir gefunden werden. Und das Geräusch der Mühle wird nicht mehr in dir gehört werden.

18,23 Und das Licht der Lampe wird nicht mehr in dir scheinen.

Und die Stimme des Bräutigams und der Braut wird nicht mehr in dir gehört werden.

Denn deine Kaufleute waren die Großen der Erde,

denn durch deine Giftmischerei wurden alle Völker verführt.

18,24 Und in ihr wurde das Blut der Propheten und der Heiligen gefunden und aller Hingeschlachteten auf der Erde.

19,1 Danach hörte ich etwas wie eine laute Stimme einer großen Schar im Himmel sagen: Halleluja! Das Heil und die Herrlichkeit und die Macht sind bei unserem Gott.

19,2 Denn wahrhaftig und gerecht sind seine Gerichte, denn er hat die große Hure gerichtet, welche die Erde verdorben hat mit ihrer Hurerei, und er hat das Blut seiner Knechte an ihr gerächt.

19,3 Und zum zweiten Mal sagte sie: Halleluja! Und ihr Rauch steigt auf in alle Ewigkeit.

19,4 Und die vierundzwanzig Ältesten und die vier Wesen fielen nieder und beteten Gott an, der auf dem Thron sitzt, und sagten: Amen, Halleluja.

19,5 Und eine Stimme ging vom Thron aus und sagte:

Lobt unseren Gott, all seine Knechte, und die ihn fürchten, die Kleinen und die Großen!

19,6 Und ich hörte etwas wie eine Stimme vieler Gewässer und etwas wie eine Stimme starker Donner sagen:

Halleluja! Denn zur Herrschaft gelangt ist der Herr, unser Gott, der Allmächtige.

19,7 Lasst uns froh sein und jubeln und ihm die Ehre erweisen.

Denn gekommen ist die Hochzeit des Lammes und seine Frau hat sich bereit gemacht.

19,8 Und gegeben wurde ihr, dass sie sich kleidet mit reinem, weisglänzendem Byssus. Denn der Byssus sind die gerechten Taten der Heiligen.

19,9 Und er (ein Engel) sagt mir: Schreibe!

Selig sind, die zum Hochzeitsmal des Lammes geladen sind.

Und er sagt mir: Dies sind die wahrhaftigen Worte Gottes.

19,10 Und ich fiel ihm zu Füßen, um ihm zu huldigen.

Er aber sagte zu mir: sieh dich vor, tu dies nicht!

Ich bin dein Mitknecht und Mitknecht deiner Brüder, die das Zeugnis Jesu festhalten.

Gott bete an! Denn der Geist der Weissagung ist das Zeugnis Jesu.

Auslegung

Die HuRE BABYLON ist weder der Antichrist noch das historische Babylon, noch das päpstliche Rom, sondern das HEIDNISCHE ROM. Denn: 
1. Sie ist nicht der am Ende der Zeiten auftretende Antichrist, da sie von den ,zehn Hörnern“ vernichtet wird $(17,16)$, der Antichrist aber von CHRISTUS selbst (2 Thess 2,8). Außerdem liegen zwischen der Vernichtung der Hure und dem Antichristen noch die tausend Jahre aus Kapitel 20.

2. Die Hure ist nach 17,18 eine „große Stadt“. Aber sie kann nicht die Stadt Babylon in Mesopotamien sein. Denn der Rauch der verbrennenden Stadt war vom Meer aus sichtbar (18,17-19), was nicht auf das historische Babylon zutrifft, wohl aber auf Rom.

3. Schon in 16,12-19 kann man sehen, dass mit BABYLON nicht das historische Babylon gemeint ist. Denn die Könige, die „Babylon“ vernichten, kommen aus dem Osten und überquerten den Euphrat. „Babylon“ liegt also westwärts vom Euphrat, während das historische Babylon gerade umgekehrt auf dessen Ostseite lag.

4. Außerdem wird in 17,5 der Name „Babylon“ als „Geheimnis“ bezeichnet. Daher kann „Babylon“ nicht einfach mit dem historischen Babylon gleichgesetzt werden, sondern muss ein Deckname für eine dem Christentum feindliche Stadt sein, ähnlich wie das alte Babylon für Israel eine feindliche Stadt gewesen war: Das spricht für Rom. ${ }^{116}$

5. Die Hure ist nicht das christliche Rom oder das mit diesem verbundene Papsttum, wie einige protestantische Ausleger glauben. Denn abgesehen davon, dass man das Papsttum als Fortsetzung des universalkirchlichen Amtes PETRI begreifen kann (Mt 16,18-19; Joh 20,15-19; Lk 22,31-32), muss man sagen: Selbst wenn wir einmal annehmen, dass das christliche Rom vom wahren Glauben abgefallen ist, so wäre das Wort „Hure“ keine geeignete Bezeichnung für dieses Rom. Die symbolische Beschreibung für den Glaubensabfall ist nämlich der „Ehebruch“ (Jer 3,8-9, Jes 50,1), weil das Volk Gottes symbolisch als mit Gott vermählte „Ehefrau“ betrachtet wird (Hos 1-3, Ez 16,20, 16,23, Jer 2,2, Jes 54,6-7, 60,4-5, Mt 22,1-4, 25,1-13, 9,15, Joh 3,29, 1 Kor 6,15-17, 2 Kor 11,2, Eph 5,25-33, Apk 21,2). Wenn also ein vom wahren Glauben abgefallenes Rom gemeint wäre, wäre dieses wohl kaum als „Hure“, sondern als „Ehebrecherin“ bezeichnet worden, denn „Hurerei“ ist, wenn nicht vorher von einer Ehe die Rede war, Symbol für eine rein heidnische Religion (Jes 23,17, Nah 3,4).

6. Der Engel erklärt ausdrücklich, dass die Hure die große Stadt ist, welche die Herrschaft hat $(17,18)$ : Zur Zeit des Johannes war das Rom.

7. Die Hure war „trunken vom Blut der Heiligen“ (17,6 und 18,24). Tatsächlich verfolgte Rom wie keine andere Stadt die Christen.

8. Die Hure sitzt auf den „,sieben Bergen“ $(17,9)$. Rom ist bekannt als die „Stadt mit den sieben Hügeln“.

9. Der erste Petrusbrief wurde nach 1 Petr 5,13 in „Babylon“ geschrieben. Da aber der Apostel Petrus nach dem verlässlichen Zeugnis der Tradition in Rom gewirkt hat, erweist sich „Babylon“ auch hier als Deckname für Rom.

17,1 Und es kam einer von den sieben Engeln, welche die sieben Schalen haben.

Und er redete mit mir und sagte: Komm hierher!

Ich will dir das Gericht über die große Hure zeigen, die an vielen Gewässern sitzt.

Es werden nun die Ereignisse der letzten Schale erläutert. Deshalb spricht hier einer der Schalen-Engel. Rom SITZT AN VIELEN GEWÄSSERN, d. h. herrscht über viele Völker $(17,15)$.

17,2 Mit ihr haben Unzucht getrieben die Könige der Erde.

Und die Bewohner der Erde sind betrunken geworden vom Wein ihrer Unzucht.

Die KöNIGE und Bewohner der Erde sind die irdisch gesinnten Gottlosen. Sie haben mit der Hure UnZuChT getrieben, d. h. das Reich, seine Götter und seine Kaiser verehrt. Der WeIN steht für den ausschweifenden Charakter des Götzendienstes.

116 Auch in anderen frühchristlichen Schriften taucht der Name „Babylon“ als Deckname für Rom auf. Das bekannteste Beispiel ist 1 Petr 5,13, wo der Apostel Petrus, dessen Romaufenthalt bestens bezeugt ist, schreibt: „Es grüßt euch die in Babylon mitauserwählte [Kirche]“. Hierzu kommentiert Eusebius um 324 in seiner Kirchengeschichte (2,15,2), Petrus sage hier, er habe seinen ersten Brief in Rom verfasst, ,was er

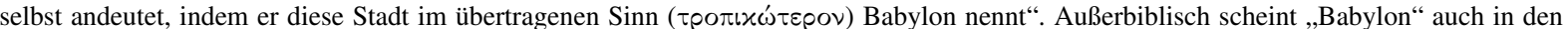
(aus verschiedenen zwischen 180 und 300 verfassten Quellen zusammengestellten) frühchristlichen Sibyllinischen Orakeln 5,158-160 (bzw. 205-206 bzw. 210-216) für Rom zu stehen: „Es wird vom Himmel ein großer Stern kommen ... und er wird tiefes Meer verbrennen, und Babylon, das italische Land." Dasselbe gilt für 4 Esr 3,1 (wie eine eingehende Textanalyse des apokryphen 4. Esrabuches wahrscheinlich machen kann). 
17,3 Und er (der Engel) führte mich im Geist in die Wüste.

Und ich sah eine Frau auf einem scharlachroten Tier sitzen.

Das Tier war über und über mit gotteslästerlichen Namen beschrieben.

Es hatte sieben Köpfe und zehn Hörner.

Johannes, bisher am Strand von Patmos stehend, sieht sich plötzlich in eine Wüste versetzt. Dort sieht er eine FRAU (nämlich die „Hure“) auf dem TIER MIT DEN SIEBEN KÖPFEN UND DEN ZEHN HÖRNERN (nämlich auf dem Tier aus Kap. 13, welches das Römische Reich versinnbildet).

Die SCHARLACHROTE Farbe ist das Rot der Könige, kennzeichnet also das Tier als Herrschaftssystem. Schauplatz der Vision ist die WÜSTE: War es in Kap. 12 die das Christentum symbolisierende Frau, die vor den römischen Verfolgern in die Wüste floh, so ist es nun umgekehrt das Tier und die antichristliche Frau, die auf der Flucht vor dem göttlichen Strafgericht in die Wüste fliehen.

17,4 Und die Frau war bekleidet mit Purpurgewand und Scharlachgewand und mit Gold, wertvollem Stein und Perlen geschmückt.

Sie hatte einen goldenen Becher in ihrer Hand,

der gefüllt war mit Abscheulichkeiten und mit den Unreinheiten ihrer Unzucht.

17,5 Und an ihrer Stirn war ein Name geschrieben, ein Geheimnis:

„Babylon die Große, die Mutter der Huren und der Abscheulichkeiten der Erde“.

17,6 Und ich sah, dass die Frau betrunken war vom Blut der Heiligen und vom Blut der Zeugen Jesu.

Und ich geriet in Verwunderung, als ich sie sah, in große Verwunderung.

17,7 Und der Engel sagte zu mir: Weswegen gerietest du in Verwunderung?

Ich will dir das Geheimnis der Frau enthüllen

und das Geheimnis des Tieres

mit den sieben Köpfen und den zehn Hörnern, auf dem sie sitzt.

Purpurgewand und Scharlachgewand sind Zeichen königlicher Macht. Der Becher ist mit ABSCHEULICHKEITEN gefüllt, d. h. hinter dem äußeren Glanz Roms sind Sünden verborgen, die den gesunden Menschen abschrecken. Besonders wird an das hier vergossene BLUT der Heiligen erinnert. 
17,8a Das Tier, das du gesehen hast, war und ist nicht, und wird heraufsteigen aus dem Abgrund, und es geht ins Verderben.

Das Tier IST NICHT. Dies bezieht sich nicht auf die Zeit, in der Johannes schreibt (95 n. Chr.), denn damals war das Tier keineswegs abwesend, sondern verfolgte die Christen unter Kaiser DoMITIAN. Vielmehr bezieht sich der Satz auf die Zeit, in die Johannes hier prophetisch versetzt wurde, und dürfte hier das Jahr 312 sein. Denn erstens wollte der Engel Johannes nach 17,1 das Gericht über die Hure zeigen, und musste ihn demgemäß genau in die Zeit versetzen, wo dieses begann: das war aber 312, zum Zeitpunkt, da die siebte Posaune blies. Zweitens traf Johannes das „Tier“ des römischen Reiches in der Wüste (= auf der Flucht) an: Das aber kann nicht vor dem Siege Konstantins sein. Drittens ist die Parallelstelle 13,3a heranzuziehen, wo Johannes dieses Tier schon einmal als ,geschlachtet zum Tode“ erblickt hatte; im dortigen Kontext aber hatten wir gesehen, dass diese Situation in der Zeit unmittelbar nach dem Siege Konstantins gegeben war. - Dass das Tier NICHT IST, ist demnach eine Anspielung auf den Todesstoß, den das Tier erhalten hatte, als KonSTANTIN im Jahr 312 den römischen Tyrannen MAXENTIUS besiegt hatte, die Kirchen wieder geöffnet wurden, und in Rom die Massenbekehrungen einsetzten (11,11-19). In verblüffender Übereinstimmung mit den Tatsachen sagt nun Vers 10, dass zu diesem Zeitpunkt nur noch ein Kopf des Tieres vorhanden ist, und zwar der sechste. Nach dem Siege KONSTANTINs verfolgte nämlich nur noch MAXIMINUS DAJA die Christen, nachdem seine fünf Vorgänger Diocletian, Maximianus Herculius, Severus, Galerius, und Maxentius schon gestorben waren oder abgedankt hatten. Trotz der noch anhaltenden Verfolgung konnte man sagen, dass das Tier NICHT IST, denn der 28. Oktober 312 war auch für MAXIMINUS bereits der Todesstoß: der Anfang vom Ende. Von jetzt an nahm seine Macht ständig ab, und kurz vor seiner endgültigen Besiegung (30. April 313) gab auch er (wie kurz zuvor GALERIUS) ein Toleranzedikt heraus: einen Erlass, in dem er den Christen seinerseits die Freiheit gewährte. Der ,prophetische Standort“ des Johannes liegt also hier zwischen dem 28. Oktober 312 und dem 30. April 313.

17,8b Und verwundern werden sich die Bewohner der Erde, deren Name nicht geschrieben ist im Buch des Lebens seit Grundlegung der Welt, wenn sie das Tier sehen: dass es war und nicht ist und (wieder) da sein wird.

Hier wird erinnert an das Verwundern der Menschen über die Heilung der Todeswunde unter Kaiser Julian (vgl. 13,3-4).

17,9 Hier ist Verstand (nötig), der Weisheit hat.

Die sieben Köpfe sind sieben Berge, auf denen die Frau sitzt. Und sieben Könige sind sie.

Der Engel gibt den SIEBEN KÖPFEN zwei Bedeutungen (was die Berechtigung einer mehrdimensionalen Auslegung der Apokalypse beweist). Die Köpfe sind die SIEBEN BERGE, auf denen die Frau sitzt, d. h. die sieben Hügel, auf denen Rom erbaut ist (Capitol, Palatin, Caelius, Esquilin, Viminal, Quirinal und Aventin). Die Köpfe sind aber zugleich SIEBEN KöNIGE, zu deren Identifizierung die beiden folgenden Verse dienen.

17,10 Die fünf (von den sieben Königen) sind gefallen, der sechste ist da, der andere (siebte) ist noch nicht gekommen, und wenn er kommt, darf er nur kurze Zeit bleiben.

17,11 Und das Tier, das war und nicht ist, ist sowohl ein achter als auch (einer) von den sieben, und es geht ins Verderben.

Erste, m. E. wahre Auslegung: Die SIEBEN KÖNIGE sind die an der diokletianischen Verfolgung beteiligten Kaiser. In jener Zeit regierten neun Kaiser (vgl. Kommentar zu 11,7): 
1. Diokletian (284-305)

2. Maximianus Herculius (285-305 und wieder 306-308)

3. Constantius Chlorus (293-306)

4. Galerius (293-311)

5. Severus (305-307)

6. Maxentius (306-312)

7. Maximinus Daja (305-313)

8. Licinius (307-324)

9. Konstantin (306-337)

Von diesen waren jedoch Konstantin und sein Vater Constantius ChloRus keine Verfolger, deren milde Haltung gegen die Christen und überhaupt gegen ihre Untertaten bekannt ist. Die übrigen sieben waren hingegen alle mehr oder weniger an der Verfolgung beteiligt:

- auch MaXentius, der als Tyrann gleichermaßen gegen Christen und Nichtchristen wütete, aber als fanatischer Heide besonders die Christen hasste (siehe auch Fußnote 62 auf S. 102),

- und auch SEvERUs, der wegen der Kürze seiner Regierung nicht recht zum Zuge kam, bei dem aber keine Anzeichen für eine von der christenfeindlichen Linie seines Vorgesetzten GALERIUS abweichende Einstellung vorhanden sind.

Die ERSTEN FÜNF, BEREITS GEFALlEnEn Könige wären also DioKLetian, MAXimianus, GaleRIUS, SEVERUS und MAXENTIUS. Sie alle konnten seit Oktober 312 als GEFALLEN gelten:

MAXENTIUS war in der Schlacht gegen Konstantin am 28. Oktober 312 im Tiber ertrunken. GALERIUS war 311 an einem Geschwür im Genitalbereich gestorben.

MAXIMIANUS HERCULIUS beging im Jahre 310 Selbstmord.

SEVERUS war 307 durch Maxentius hingerichtet worden.

DIOKLETIAN lebte nach seiner Abdankung (305) gänzlich zurückgezogen und soll zwischen 311 und 316 unter großen Qualen (Geisteskrankheit?) gestorben sein

Dass diese Könige GEFALLEN sind, bedeutet also mindestens, dass sie zu dem Zeitpunkt, den Johannes jetzt einnimmt (siehe Kommentar zu Vers 8a) von ihrer Machtposition abgefallen sind, sei es durch Abdankung oder Tod. Falls DiOKLETIAN schon 311 gestorben sein sollte, könnte man das Wort „gefallen“ auch als Andeutung des unfriedlichen Todes aller fünf Herrscher verstehen.

Der SEChSTE, GEgEnwÄrTIGE König, UNTER DEM DAS TIER NICHT IST, ist MAXIMINUS DAJA (trotz seines Daseins ist das Tier nicht mehr da, denn es hatte durch KonsTANTIN den entscheidenden Todesschlag erhalten: siehe Kommentar zu Vers 8a). MAXIMINUS starb 313 durch Gift, das er entweder selber genommen oder das ihm durch feindliche Agenten gereicht worden war. Der SIEBTE, DER NOCH KOMMT UND NUR KURZ BLEIBT ist LICINIUS, der damals noch kein Verfolger war, sondern zu Konstantin hielt. Erst lange Zeit später (ca. 320-324) wurde er zum Verfolger (wie Eusebius meint, verfiel er dem Wahnsinn). Nach seiner Besiegung durch KonstANTIN im Jahre 324 wurde er gefangengenommen und ein Jahr später hingerichtet. Die Zeit der Verfolgung des LiCINIUS war, verglichen mit den 10 Jahren der eigentlichen diokletianischen Verfolgung, eine KURZE Zeit. Außerdem war LICINIUS nach seinem verspäteten „Kommen“ als Christenverfolger nur noch ein KURZES BLEIBEN beschieden, verglichen mit der Gesamtzeit seiner Regierung.

Wer ist der ACHTE, der IDENTISCH MIT DEM TIER ist und zugleich EINER VON DEN SIEBEN? Diese geheimnisvolle Beschreibung findet ihre Erklärung nach BOSSUET durch die Gestalt des MAXIMIANus Herculius. Dieser sei „ein achter und einer von den sieben“, weil er ein zweites Mal die Herrschaft an sich nahm. Zugleich sei er „das Tier“, weil in der Vision von 13,2 der Leib des Tieres, der aussah „wie ein Panther“, den Maximianus versinnbildet (siehe Kommentar zu 13,2). Unpassend hierzu ist aber, dass dann der achte König vor dem siebten auftritt. 
Besser scheint daher die Erklärung von CALMET zu sein: Der achte König ist Kaiser JULIAN. Dieser ist „einer von den sieben“, weil er ein „,neuer Diokletian“ ist, sowohl hinsichtlich seiner Machtentfaltung als auch hinsichtlich seines Planes, die blutige Verfolgung zu erneuern, als auch hinsichtlich des Gesetzes, dass „Kaufen und Verkaufen“ nur derjenige konnte, der das „Kennzeichen“ auf seiner Stirn anbrachte (siehe Kommentar zu 13,16-17). DiOKLETIAN (und folglich auch JULIAN) ist auch identisch mit dem „Tier“, weil er der für die Verfolgung hauptverantwortliche „Kopf“ des Tieres war, und vor allem, weil die „Zahl des Tieres“ die Zahl seines Namens ist (vgl. Kommentar zu 13,18).

Zweite Auslegung: Manche deuten die sieben Könige als sieben „Weltreiche“, die Gottes Volk nacheinander bedrohten, unterdrückten, oder beherrschten. Als die gefallenen ERSTEN FÜNF gelten dann:
1. Ägypten
(1570-1070 v.Chr.: Neues Ägyptisches Reich dominiert im Nahen Osten),
2. Assyrien (911-609 v.Chr.: Neuassyrische Vorherrschaft im Nahen Osten)
3. Babylonien
4. Persien (609-539 v.Chr.: Neubabylonische Vorherrschaft im Nahen Osten)
5. Griechenland (539-330 v. Chr.: Persische Vorherrschaft im Nahen Osten)
(330-30 v. Chr.: Alexander und seine Nachfolger herrschen in Nahen Osten)

Der SECHSTE, gegenwärtige, unter dem das Tier NICHT IST, ist nach dieser Auslegung das römische Reich, der SIEBTE, DER NOCH KOMMT UND NUR KURZ BLEIBT, ist das heutige Staatensystem und der ACHTE, der DAS TIER und zugleich EINER VON DEN SIEBEN ist, ist schließlich das noch zu erwartende Reich des Antichristen. Dieses Reich ist „,das Tier“, weil die ganze Macht des Tieres in ihm verwirklicht sein wird, und es ist zugleich „,einer von den sieben“, weil es die schlimmsten Merkmale aller sieben in sich vereint. Problematisch an dieser Auslegung ist aber unter anderem, dass dann ausgerechnet zu der Zeit, da das christenverfolgende römische Weltreich herrscht, das Tier „nicht ist“!

Dritte Auslegung: Es handelt sich um sieben bzw. acht römische Kaiser aus der Anfangszeit des Reiches, von denen fünf bereits vor der Abfassung der Apokalypse regiert haben und der sechste zur Zeit der Abfassung gerade an der Macht ist. Von welchen Kaisern dann genau die Rede ist, ist aber bei den Anhängern dieser Auslegung sehr umstritten. Die Liste der ersten vierzehn römischen Kaiser ist:

1. Caesar, erster faktischer Kaiser

2. Augustus, erster legaler Kaiser

3. Tiberius

4. Caligula

5. Claudius

6. Nero

7. Galba

8. Otho

9. Vitellius

10. Vespasian

11. Titus

12. Domitian

13. Nerva

14. Trajan (ermordet 44 v. Chr.),

(friedlicher Tod $14 \mathrm{n}$. Chr.). (ermordet 37 n. Chr.), (ermordet $41 \mathrm{n}$. Chr.), (ermordet 54 n. Chr.), (Selbstmord 68 n. Chr.), (ermordet 69 n. Chr.), (ermordet 69 n. Chr.), (ermordet 44 n. Chr.), (ermordet 79 n. Chr.), (ermordet? 81 n. Chr.), (ermordet 96 n. Chr.), (friedlicher Tod 98 n. Chr.), (friedlicher Tod 117 n. Chr.).

(a) Manche zählen die Kaiser von der Grundlegung des römischen Kaiserreiches an. Nun könnte man entweder mit Caesar beginnen (erster faktische Kaiser) oder mit Augustus (erster legaler, allgemein anerkannter Kaiser). Aber wenn man mit Caesar beginnt, wäre der sechste König der Christenverfolger Nero, und es kann unmöglich gesagt werden, dass das Tier ausgerechnet unter Nero „nicht ist“. Man muss also mit Augustus beginnen. 
Die ERSTEN FÜNF, SCHON GEFALLENEN Kaiser wären daher: Augustus, Tiberius, Caligula, Claudius, Nero. Wer dann der SECHSTE ist, ist jedoch unklar. Denn nach Neros Tod begann das sogenannte „Vierkaiserjahr“ (68/69), in dem drei Kaiser kurz nacheinander herrschten, die teilweise nicht als vollwertige Kaiser akzeptiert wurden: Galba, Otho, und Vitellius. Erst der vierte Kaiser war wieder allgemein anerkannt: nämlich Vespasian. Meist wird dieser daher als der Sechste gezählt. Daraus würde aber folgen, dass Johannes die Apokalypse (zumindest die vorliegenden Verse) nicht unter Domitian, sondern schon unter Vespasian geschrieben hat. Der SIEBTE, DER NOCH KOMMT UND NICHT LANGE BLEIBT, wäre dann Titus (79-81), der tatsächlich nur kurz regierte. Der ACHTE, IDENTISCH MIT DEM TIER UND EINER VON DEN SIEBEN wäre schließlich Domitian, der zweite große Christenverfolger. Dieser wäre ,einer von den sieben“, weil er als „,neuer Nero“ interpretiert werden konnte, ${ }^{117}$ und er wäre das Tier, weil sich in seiner Gestalt sich (wie in Nero) das christenverfolgende Tier besonders deutlich zeigte.

Gegen diese Auslegung spricht jedoch, dass Johannes nach verlässlichen Zeugnissen die Apokalypse um 95 n. Chr. unter Domitian verfasst hat und nicht unter Vespasian. Auch scheint es nicht gut möglich zu sein, dass die vorliegenden Verse schon unter Vespasian geschrieben und später unter Domitian in das Buch der Apokalypse eingearbeitet worden sind. Denn dann wäre bei der Einarbeitung die Aussage, dass der sechste König (Vespasian) ,,jetzt ist“, doch wohl korrigiert worden.

(b) Eine andere Auslegungsrichtung hält es für ausgemacht, dass der SECHSTE, GEGENWÄRTIGE KÖNIG, UNTER DEM DAS TIER NICHT IST, sein muss, weil dieser Kaiser zur Zeit des Johannes der ,gegenwärtige" Herrscher war.

Die FÜNF ERSTEN, DIE SCHON GEFALLEN SIND, werden dann also von Domitian aus zurückgerechnet. Zählt man genau fünf Kaiser zurück und rechnet die drei Zwischenkaiser zwischen Nero und Vespasian mit, dann wäre der erste Kaiser Galba, der Nachfolger Neros (so zählt VICTORIN). Die Liste lautet dann: Galba, Otho, Vitellius, Vespasian, Titus. Jedoch ist nicht einzusehen, warum die Köpfe des Tieres mit dem unbedeutenden Kaiser Galba beginnen sollten, so dass sein Vorgänger, der Christenverfolger Nero, nicht dazugehörte.

Besser scheint daher der Vorschlag zu sein, mit Nero zu beginnen, mit der Begründung, dass dies der erste Christenverfolger war (so ALLO). Aber dann darf man nur zwei der drei umstrittenen Zwischenkaiser dazurechnen. So zählt Allo: 1. Nero, 2. Galba oder Otho, 3. Otho oder Vitellius, 4. Vespasian, 5. Titus. Doch die Kürzung der drei Zwischenkaiser auf zwei erscheint recht willkürlich.

Einige (z. B. FÉRET) rechnen darum die drei Zwischenkaiser nur als einen und kommen so auf Claudius als den ersten Kaiser: Man zählt dann Claudius, Nero, Galba-Otho-Vitellius (als Einheit), Vespasian, Titus. Die Wahl des Claudius als ersten Kaiser ließe sich damit begründen, dass dieser Kaiser in gewisser Weise schon vor Nero die Christen verfolgt hat: Claudius hat nämlich, wie SUETON berichtet, die Juden aus Rom vertrieben wegen der Unruhen, die durch einen gewissen CHRESTUS (= CHRISTUS?) entstanden waren. Dabei könnte es sich um Streitigkeiten zwischen Juden und Christen gehandelt haben. Während also Nero der erste war, der die Christen als Christen verfolgte, verwechselte sie Claudius noch mit den Juden, ,was ihn natürlich in den Augen der Christen nicht weniger zum Verfolger machte“ (Féret). Dann wäre Claudius also der erste indirekte Christenverfolger. Sonderbar ist hier aber, dass die drei Zwischenkaiser als „ein“ König gesehen werden.

117 Nach LakTAnZ, Todesarten der Verfolger Kap. 2 entstand nach Neros Tod, weil er spurlos verschwunden war und niemand sein Grab kannte, der Aberglaube, ,dass Nero von der Erde hinweggenommen wurde und lebend aufbewahrt wurde, um wie der erste, so auch der letzte Christenverfolger zu sein und dem Reiche des Antichrist voranzugehen“; er werde also „einst wiederkommen“ als ,Vorläufer und Vorbote des Teufels, wenn dieser zur Verwüstung der Erde und zur Ausrottung des menschlichen Geschlechts erscheinen wird". Nun wurde Domitian sowohl von Christen als auch von Heiden mit Nero verglichen (,kahlköpfiger Nero“, JUVENAL, Satiren 4,37-38; „Nero sehr ähnlich“, PLINIUS DER JÜNGERE, Panegyricus 53; ,,eine Portion Nero an Grausamkeit“, TERTUlLIAN, Apologeticum 5). Domitian hatte auch den Namen Neros, sein voller Name war (,Titus Domitianus Flavius Nero“). 
Am besten lässt man also diese unbedeutenden Zwischenkaiser ganz weg und gelangt dann zur Lösung von August STROBEL, wonach man von Caligula an zählen muss: Caligula, Claudius, Nero, Vespasian, Titus. Aber warum gerade Caligula als ersten zählen? Darauf antwortet Strobel, dass mit Christi Tod eine neue Geschichtsperiode begonnen habe und Caligula der erste Kaiser war, der nach Christi Tod zu regieren begann. Außerdem war Caligula durch seinen Plan, sein Bild im Tempel von Jerusalem aufstellen zu lassen (dessen Ausführung durch seinen Tod vereitelt wurde), der erste sich antichristlich gebärdende Kaiser. Strobel weist noch darauf hin, dass alle Kaiser von Caligula an auch als ,gefallen“ im engeren Sinne gelten konnten, weil sie alle gewaltsam ums Leben gekommen waren.

Zu nennen ist noch die Zählung von G. M. CAMPS, der als die fünf vor Domitian „,gefallenen“ Kaiser die offiziell zu Göttern erklärten Kaiser zählt, nämlich Caesar, Augustus, Claudius, Vespasian, Titus.

Der SIEBTE, DER NOCH KOMMT UND NICHT LANGE BLEIBT, wäre nun bei all diesen Auslegungen der Nachfolger Domitians, Nerva (96-98), der tatsächlich nur kurz regierte.

Der aChte,Trajan, KAiser (98-117)!- Derachte@ - Der ACHTE König? Der Mit Dem Tier IDENTISCH UND DOCH EINER VON DEN SIEBEN IST, wäre folglich der Nachfolger Nervas, Kaiser Trajan,Trajan, Kaiser (98-117)!- Dritter Christenverfolger der dritte große Christenverfolger, der die Verfolgung erstmals auf das ganze Reich ausweitete. Dieser wäre darum als ein „neuer Nero“ einer von den sieben.

Für ALLO ist der ,achte“ allerdings nicht Trajan allein, sondern die Gruppe aller kommenden römischen Christenverfolger von Trajan an. Dazu passt die Zahl acht, welche die Zahl der Wiederholung und Erneuerung ist (siehe Kommentar zu 13,18). Dieser achte Kollektiv-König ist „einer von den sieben“, nämlich Nero, insofern alle folgenden Christenverfolger als „Neuauflage“ von Nero verstanden werden können.

Gegen alle diese Auslegungen, die Domitian als sechsten König zählen, kann man aber einwenden, dass kaum verständlich zu machen ist, warum das Tier ausgerechnet unter Domitian, dem zweiten großen Christenverfolger, ,nicht ist“", zumal diese Aussage ja gemäß diesen Auslegungen nicht von den ersten, relativ ruhigen Jahren Domitians gilt, sondern von den letzten, in denen Johannes als verbannter, also verfolgter Christ die Apokalypse schrieb.

(c) Warum die Auslegung von H. KRAFT abzulehnen ist, wonach NERVA der sechste König wäre, unter dem Johannes schrieb, wurde bereits im Kommentar zu 13,18, Auslegung 3f gesagt.

(d) Als letztes sei noch die sonderbare Auslegung von G. EDMUNDSON und J. A. T. RoBINSON genannt. Diese Gelehrten halten daran fest, dass die Apokalypse unter Domitian geschrieben wurde, aber sie setzten dafür nicht die Kaiserzeit des Domitian an (81-96), sondern ein früheres Datum, nämlich das Jahr 70, in dem Domitian kurzzeitig der faktische Regent in Rom gewesen war. Nach der Ermordung des VITELLIUS im Dezember 69 wurde nämlich VESPASIAN zum Kaiser ausgerufen, aber bis Mitte 70 hielt sich dieser in Alexandrien auf, während sein Sohn DomitiAn für ihn in Rom die Amtsgeschäfte führte.

Die ERSTEN FÜNF GEFALLENEN KAISER sind für EDMUNDSON Claudius, Nero und die Zwischenkaiser Galba, Otho, Vitellius, während RoBINSON ohne die Zwischenkaiser Augustus, Tiberius, Caligula, Claudius, und Nero zählt.

Der SECHSTE, GEGENWÄRTIGE, UNTER DEM DAS TIER NICHT IST soll sodann Domitian als Vertreter seines Vaters Vespasian im Jahre 69/70 sein. Der SIEBTE, DER NOCH KOMMT UND NICHT LANGE BLEIBT ist dann Vespasian, dessen Kommen nach Rom der im Jahre 70 schreibende Johannes schon absehen konnte.

Der ACHTE, DER IDENTISCH MIT DEM TIER UND EINER VON DEN SIEBEN IST aber wäre der wiederkehrende Nero, der nach einem damals verbreiteten Gerücht nicht wirklich tot war, sondern bald aus dem Osten, wohin er geflüchtet sei, wiederkommen und sich abermals auf den Thron setzten würde. ${ }^{118}$

$118 \quad$ Siehe Fußnote 117 
Doch ist diese Auslegung aus zwei Gründen kaum annehmbar. Zum einen hätte sich Johannes darin geirrt, dass er Vespasian nur eine kurze Regierungsdauer zugeschrieben und den persönlich wiederkehrenden Nero als dessen Nachfolger prophezeit hätte. Zum anderen aber wurde die Apokalypse, wir wir einleitend gesehen haben, nach dem verlässlichen Zeugnis des IRENÄUS ,gegen Ende der Herrschaft des Domitian“ geschrieben, womit nicht die Zeit einer anfänglichen Regierung im Jahre 70, sondern nur das Ende der Kaiserzeit Domitians gemeint sein kann.

17,12 Und die zehn Hörner, die du gesehen hast, sind zehn Könige, welche die Herrschaft noch nicht erlangt haben, aber sie erhalten Macht wie Könige eine Stunde lang mit dem Tier.

Die ZEHN HÖRNER sind nach Vers 16 die KöNIGE, die Rom vernichten werden. Manche denken hier an die Parther (Perser). Aber das Volk der Parther war nicht in 10, sondern in 14 Stämme eingeteilt und besaß ebenso viele Fürsten (Satrapen). Außerdem waren die Parther niemals mit Rom verbündet, können also kaum als Hörner zum siebenköpfigen römisch-heidnischen „Tier“ dazugehören. Andere sehen in den zehn Hörnern asiatische Vasallen-Fürsten der Römer oder die zehn römischen Prokunsuln. Aber diese haben Rom nicht zu Fall gebracht. Am vernünftigsten ist es daher, in den zehn Königen die Barbarenstämme bzw. -fürsten der Völkerwanderung (ca. 375-600) zu sehen, denn diese dienten zuerst in römischen Heeren, waren also tatsächlich mit dem Tier als dessen HÖRNER (= Streitmacht) verbunden, und vernichteten schließlich Rom. Es waren neben den Hunnen und Alanen vor allem die zur germanischen Stammesfamilie gehörenden Westgoten, Ostgoten, Vandalen, Sueben, Burgunder, Heruler, Skiren, Franken, Alamannen, Sachsen, Langobarden und andere.

Die Zahl ZEHN muss nicht wörtlich genommen werden: Als Grundlage des Zahlensystems (Zahl der Finger) kann sie einfach eine vollständige Menge bedeuten. Dennoch meinte BERENGAUdus (9. Jahrhundert), folgende zehn Barbarenstämme als die wichtigsten aufzählen zu können: ${ }^{119}$

die Perser (1) und Sarazenen (2) eroberten die Provinz Asien,

die Vandalen (3) Nordafrika,

die Goten (4) Spanien,

die Langobarden (5) Italien,

die Burgunder (6) Gallien,

die Franken (7) Germanien,

die Hunnen (8) Pannonien, d. h. Ungarn, und

die Alanen (9) und Sueben (10) viele andere Provinzen.

Interessant ist auch, dass die wichtigsten „Könige“, d. h. Anführer der Rom zerstörenden Barbaren, die am direktesten mit dem Fall Roms zu tun hatten, tatsächlich etwa zehn waren:

119 Berengaudus, Apocalypsis, De visione quinta (PG 17 Spalte 1000). 
Unter der Führung des heidnischen Ostgotenkönig RADAGAIS stieß erstmalig in den letzten Monaten des Jahres 405 ein für damalige Verhältnisse ungeheuer großer Heerhaufe (200.000-400.000 Mann) von der Donau her bis nach Italien vor, mit dem Ziel, Rom zu erobern: Dieses Barbarenheer wurde zwar besiegt, aber dazu musste der römische Feldherr Stilicho die römischen Truppen von der Rheingrenze und aus Britannien abziehen. Dadurch ging Britannien verloren, und vor allem konnte nun ein anderer „,internationaler“ Barbarenzug von Vandalen, Alanen, Sueben und Burgundern am letzten Tag des Jahres 406 bei Mainz über den wahrscheinlich zugefrorenen Rhein ins römische Reich einbrechen. Nach dieser sogenannten ,großen Invasion“ stand den Barbaren das Gebiet Frankreichs fast wehrlos offen, und es wurde bis 409 der ganze europäische Teil des weströmischen Reiches mit Barbaren überschwemmt, die zunächst ganz Frankreich und dann Spanien verwüsteten. Bei der entscheidenden Rheinüberquerung wurden die silingischen Vandalen durch König GUNTHARICH, die asdingischen Vandalen wahrscheinlich durch König FRIDIBALD, die Alanen durch König RESPENDIAL, die Sueben wahrscheinlich durch König HERMERICH und die Burgunder durch König GIBIKA angeführt. Nun musste nur noch Italien und Rom selbst erobert werden. Diesen entscheidenden Schlag führte der Westgotenkönig AlARICH im Jahre 410 durch. Aber die Westgoten blieben nicht in Rom und Italien; sie zogen weiter und ließen sich in Südfrankreich und Spanien nieder, wo sie den ersten germanischen Staat auf römischen Reichsboden gründeten. Weitere Meilensteine zur Vernichtung des weströmischen Reiches waren das vom Hunnenkönig ATTILA angerichtete Blutbad (451-452; siehe das „Keltertreten“ Apk 14,20) und der Raubzug des Vandalenkönigs GEISERICH, bei dem Rom 455 geplündert wurde. Schließlich übernahm der Herulerkönig ODOAKER, ein Skire, 476 die Herrschaft über Italien und brachte das weströmische Kaisertum zum Erlöschen.

Den bis hierher genannten zehn Königen könnte man noch weitere hinzufügen, besonders solche, die nach 467 am weiteren Verfall Roms einen besonderen Anteil hatten: z. B. die Ostgotenkönige TheOdorich, Witigis und TOTILA, den Frankenkönig THEUDEBERT I. und den Langobardenkönig Alboin(zu diesen Königen siehe Kommentar zu 81,21). Nachstehend seien die Regierungsdaten der genannten Könige angeführt:

1. Radagais, König der Ostgoten (um 405)

2. Guntharich, König der (asdingischen) Vandalen (406-428)

3. Fridibald, König der (silingischen) Vandalen (um 411)

4. Respendial, König der Alanen (um 406; † vor 415?)

5. Hermerich, König der Sueben (um 411)

6. Gibika, König der Burgunder (um 406, † vor 411)

7. Alarich, König der Westgoten (382-410)

8. Attila, König der Hunnen (um 434-453)

9. Geiserich, König der Vandalen (428-477)

10. Odoaker, König der Heruler (476-489/90 Regent Italiens)

- Theodorich, König der Ostgoten (471-526)

- Witigis, König der Ostgoten (536-540)

- Theudebert I., König der Franken (533-548)

- Totila, König der Ostgoten (541-552)

- Alboin, König der Langobarden (565-573)

Es ist offenbar schwierig, alle Aussagen der Apokalypse über die ZEHN KÖNIGE ausschließlich auf genau zehn konkrete Fürsten anzuwenden. So ist es vorzuziehen, die Zehnzahl nicht wörtlich zu nehmen und die Aussagen auf alle Barbarenfürsten der Völkerwanderung bzw. auf alle daran beteiligten Barbarenstämme im allgemeinen anzuwenden.

Die zehn Könige hatten NOCH NICHT DIE HERRSCHAFT AN SICH GENOMMEN, was sowohl auf die Zeit des Johannes (95 n. Chr.) als auch auf die Zeit, in welche Johannes prophetisch versetzt war (312/313 n. Chr.), zutrifft. 
Sie werden aber EINE STUNDE LANG, so sagt der Engel, mit dem Tier zusammen zur Herrschaft kommen. Dies begann im Jahre 376, als der römische Kaiser Valens den Westgoten gestattete, über die Donau ins Reich einzuwandern und sich dort als Foederaten (Verbündete) anzusiedeln. Die STUNDE symbolisiert eine kurze geschichtliche Übergangsperiode. Bei dieser STUNDE kann man denken an die Zeit von 376 bis zur Erstürmung Roms durch ALARICH (410) oder bis zum politischen Ende Westroms (476). Die ,zehn Könige“ kamen ZUSAMMEN MIT ROM ZUR HERRSCHAFT. Vergleiche den Geschichtsschreiber PROCOPIUS vON CAESAREA: „Die Größe der römischen Fürsten war so geschwächt worden, dass sie, nachdem sie viel von den Barbaren gelitten hatten, kein besseres Mittel fanden, ihre Schande zu verdecken, als ihre Feinde zu ihren Verbündeten zu machen und ihnen das Land bis nach Italien hin zu überlassen, unter dem trügerischen Titel des Bündnisses und der Allianz"“.

Derselbe Autor schreibt, dass Rom sich seit der Zeit Alarichs mit den Sciren, Alanen und Goten verbündet hatte. ${ }^{120}$ Der Heruler-König ODOAKER, der den letzten römischen Kaiser ablöste, war zuvor Söldnerführer in römischen Diensten gewesen. Unter Kaiser Theodosius nahmen die Franken einen beträchtlichen Rang im römischen Heer unter ihrem Heerführer ARBOGAST ein. Die Alanen und Hunnen kämpften in der Armee des Kaisers Honorius unter der Führung des Halb-Vandalen STILICHO. ULDIS, der König der Hunnen, war Verbündeter der Römer. Selbst ATTILAs Politik mit Westrom war zunächst meist freundschaftlich. Die Vandalen waren durch Kaiser Konstantin in die Provinz Pannonien eingelassen worden und dienten dort den Kaisern. Franken, Goten, Sachsen, Burgunder kämpften unter AEtiUs in römischen Diensten gegen ATtiLA. Schon 370 hatten 30.000 Burgunder mit Kaiser Valentinian I gegen die Alamannen gekämpft. Die Goten, die Hauptzerstörer Roms, sehen wir zuvor in den Armeen Konstantins, Julians des Abtrünnigen, Theodosius' und Arkadius' kämpfen, und selbst in der Armee des Honorius, in dessen Regierungszeit Rom durch ALARICH erobert wurde. ALARICH selber war General unter Honorius und hatte schon unter Theodosius in römischen Diensten gekämpft. So wurde Rom wurde besiegt durch Alarich, der selbst einer seiner Fürsten war.

17,13 Diese (die zehn Könige) haben eine Meinung und geben ihre Macht und Gewalt dem Tier.

Die Könige waren trotz ihrer Kämpfe gegeneinander EINER MEINUnG, insofern sie das gemeinsame Ziel hatten, sich ein neues Siedlungs- und Herrschaftsgebiet innerhalb der Grenzen des römischen Reiches zu erobern. Sie hatten auch dieselbe Taktik, um ihr Ziel zu erreichen: Sie GABEN IHRE MACHT UND GEWALT DEM TIER, d. h. sie boten sich bei verschiedenen Gelegenheiten den Römern als Verbündete an.

17,14 Diese werden mit dem Lamm Krieg führen.

Und das Lamm wird sie besiegen, weil es Herr der Herren ist und König der Könige.

Und die Seinen sind Berufene und Auserwählte und Treue.

Die Barbaren FÜHRTEN MIT DEM LAMM KRIEG: Sie verfolgten das rechtgläubige Christentum, denn sie waren teils Heiden und teils arianische Christen (siehe Kommentar zu 19,19). ABER DAS LAMM WIRD SIE BESIEGEN. Einige der auf römischen Boden gegründeten Barbarenreiche gingen bald nach der Zerstörung Roms selbst unter (so die Ostgoten und Vandalen im sechsten Jahrhundert). Die übrigen aber nahmen alle nach und nach das rechtgläubige Christentum an: Die Franken unter CHLODWIG (496), die Burgunder vielleicht schon Anfang des 5. Jahrhunderts, spätestens aber unter SIGISMUND (516), die Sueben nach ersten Ansätzen Mitte des 5. Jahrhunderts endgültig unter CHARARICH (550), die Westgoten unter REKKARED (586), und die Langobarden und Angelsachsen bald nach 600. So war Christi Sieg ein vollständiger: CHRISTUS erwies sich als KÖNIG DER KÖNIGE UND HERR DER HERREN, indem er alle Barbaren seiner Herrschaft unterwarf.

$\overline{120}$ Procopius, Kriegsgeschichte Buch 5 (Gothenkrieg) Kap. 1 § 3 (Ausgabe Wright Band 3 S. 3). 
17,15 Und er sagt zu mir: Die Gewässer, die du gesehen hast, an denen die Hure sitzt, sind Völker und Scharen und Nationen und Zungen.

Das Wasser erscheint als Symbol für eine Menschenmenge bereits bei Jesaja $(8,7)$ und $(47,2-3)$.

17,16 Und die zehn Hörner, die du gesehen hast, und das Tier: Diese werden die Hure hassen.

Sie werden sie zu einer Verwüsteten und Nackten machen.

Und ihr Fleisch werden sie essen, und sie werden sie verbrennen im Feuer.

Hier ist der Sieg der HöRnER, d. h. der Barbaren über Rom ausgedrückt, besonders der Sieg ALARICHs über Rom am 24. August 410, durch den das Ende der Macht Roms vor aller Welt offenbar wurde. Denn nachdem ALARICH Rom genommen hatte, VERBRANNTEN die Barbaren einen großen Teil dieser Stadt, teilten sich die Reichtümer und verurteilten einen großen Teil der Senatoren zum Tode durch verschiedene Todesarten.

Auch das TIER, also das heidnisch-römische Reich, hatte begonnen, die HURE Rom zu hassen, denn die Kaiser hatten sich von Rom gelöst und die Stadt sträflich vernachlässigt. Der von Konstantin besiegte Tyrann Maxentius war der letzte in Rom residierende römische Kaiser gewesen. Konstantin hatten seine Residenz nach Byzanz (,Konstantinopel“) verlegt, und auch die weströmischen Kaiser residierten lieber in Mailand oder Ravenna, aber nicht mehr in Rom. Diese Vernachlässigung Roms wurde auch durch Kaiser Julian, den letzten kaiserlichen Vertreter des „Tieres“, nicht wieder aufgehoben: Julian residierte ebenfalls in Konstantinopel. Und so war auch das Tier selbst Mitursache an der Zerstörung Roms.

17,17 Denn Gott hat in ihre Herzen gegeben, seinen Willen auszuführen und einer Meinung zu sein und ihre Herrschaft dem Tier zu geben, bis die Worte Gottes erfüllt sein werden.

Diejenigen, die Gott als Werkzeuge seiner Strafgerechtigkeit benutzte, haben oft eine entsprechende Ahnung gehabt. So soll TiTus, der Jerusalem im Jahre 70 n. Chr. zerstört hatte, als man ihn wegen seiner Siege über die Juden rühmte, gesagt haben: „Ich habe nichts anderes getan, als Gott meine Hand zu leihen, der gegen dieses Volk erzürnt war.“

Ein ähnliches Gefühl hatten auch die Barbarenkönige, die das Römische Reich zerstörten. So nannte sich ATTILA selber „die Geisel Gottes, das Beil für das Menschengeschlecht“ und GEISERICH sagte, als er Spanien per Schiff verließ, zum Steuermann, ,er solle ihn zu den Völkern führen, die Gott durch ihn strafen wolle“. Vor allem aber ALARICH hatte ein unheimliches Sendungsbewusstsein. Als ein italienischer Mönch ihn bat, Rom zu verschonen, „da antwortete er, er handle nicht von sich aus, sondern irgend jemand [offenbar eine höhere Macht] setze ihm beständig zu, dränge ihn und befehle ihm, Rom einzunehmen“. ${ }^{121}$ Kurz nach der Einnahme Roms starb Alarich, und so will es scheinen, als sei er einzig deshalb auf der Welt gewesen, um dieses Werk zu vollenden.

17,18 Und die Frau, die du gesehen hast,

ist die große Stadt, welche die Herrschaft hat über die Könige der Erde.

Mit dieser Erklärung, welche die Gleichsetzung der Hure mit Rom nochmals bestätigt, endet die Ausführung des Engels.

18,1 Und danach sah ich einen anderen Engel aus dem Himmel herabkommen, der große Macht hatte, und die Erde wurde von seinem Glanz erhellt.

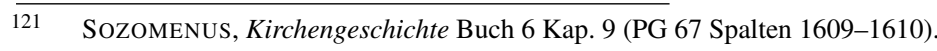


18,2 Und er rief mit lauter Stimme: Gefallen, gefallen ist Babylon die Große!

Und sie ist geworden eine Behausung von Dämonen

und ein Verbannungsort für jeglichen unreinen Vogel

und ein Verbannungsort für jegliches unreine und verhasste Tier.

Ein anderer Engel beschreibt nun die totale Verwüstung „Babylons“. Man beachte, dass damit nur das heidnische Rom gemeint ist. Die Barbaren zerstörten dieses Rom und ließen nur die christlichen Kirchen übrig. Das heidnische Rom ist für immer verwüstet: seine Ruinen dienen nur noch den Tieren als Behausung. Vgl. 6,8, 18,22-23 und Jer 51,34-64.

18,3 Denn vom Wein des Zornes ihrer Unzucht haben alle Völker getrunken und die Könige der Erde haben mit ihr Unzucht getrieben und die Kaufleute der Erde sind von der Macht ihrer Üppigkeit reich geworden.

18,4 Und ich hörte eine andere Stimme aus dem Himmel sagen: Verlass die Stadt mein Volk, damit du nicht mitschuldig wirst an ihren Sünden, und von ihren Plagen nicht mitgetroffen wirst.

Die Stimme ist nicht die Stimme Gottes (des Vaters), denn Vers 5 spricht von Gott in der dritten Person. Es ist wohl Christi Stimme, wie der Ausdruck „mein Volk“ zeigt.

VERLASS DIE STADT, MEIN VOLK: Tatsächlich verließen Christen vor 410 auf verschiedene Weise die Stadt. Manche wurden rechtzeitig durch den Tod von Gott abberufen: so Papst ANASTASIUS, ( $\dagger$ 401), von dem der damals lebende Kirchenlehrer HiERONYMUS sagt: „Rom verdiente es nicht, ihn lange zu besitzen: damit die Hauptstadt der Welt nicht unter einem so großen Bischof zerschlagen würde“, sei er aus dieser Welt „herausgerissen“ und in die andere „hinübergeführt“ worden. ${ }^{122}$

Andere hatten die Stadt durch eine göttliche Fügung verlassen, unter ihnen der damalige Papst INNOZENZ I, der gerade in Ravenna war, als Rom das Schicksal ereilte. „Wie der gerechte Lot, der geheimnisvoll aus Sodom entfernt wurde“, so meint OROSIUS, sei auch „der selige Innozenz“ durch die „,verborgene Vorsehung Gottes“ nach Ravenna geführt worden, um den „Untergang des sündigen Volkes“ nicht mit ansehen zu müssen. ${ }^{123}$ Auch die heilige PAULA war schon etliche Zeit vorher zusammen mit vielen vornehmen Römern nach Bethlehem ausgewandert. ${ }^{124}$ Bei OrosIUS heißt es schließlich ganz allgemein, dass sehr viele Christen in jener Zeit der Wirren die Weisung Christi befolgten: „Wenn man euch in einer Stadt verfolgt, flieht in eine andere“ (Mt 10,23), was demgegenüber diejenigen, die nicht an das Evangelium glaubten, in keiner Weise taten, so dass sie ,gerechterweise von einer Rache, die sie überraschte, erfasst und vernichtet" wurden. ${ }^{125}$

Viele Christen flüchteten - drittens - in die christlichen Kirchen, besonders in die außerhalb der Stadt gelegene Petruskirche, und wurden dort von ALARICH geschont. Denn dieser bekannte sich bereits zu Christus, er war Arianer. Darum ordnete er an, dass seine Soldaten die christlichen Kirchen und vor allem die Peterskirche schonen sollten. ,Aus Ehrfurcht gegenüber dem Apostel Petrus befahl er, dass die große und geräumige Basilika um dessen Grabmal unversehrt bleibe. Dadurch wurde verhindert, dass die Stadt Rom vollkommen unterging. Denn jene, die dort [in der Kirche] gerettet wurden - es war eine große Menge - haben die Stadt wieder aufgebaut."126

122 Epistula 127 Kap. $10 \$ 2$ (CSEL 56/1 S. 153): ... Anastasius, quem diu Roma habere non meruit, ne orbis caput sub tali episcopo truncaretur; immo idcirco raptus atque translatus est ...".

123 PAUlus Orosius, Historiae adversus paganos Buch 7 Kap. 39,2.

124 Vgl. Hieronymus, Epistula 108 (CSEL Band 55, S. 306-351).

125 Paulus Orosius, Historiae adversus paganos Buch 7 Kap. 41,4-6.

126 Sozomenus, Kirchengeschichte Buch 9 Kap. 9 (PG 67 Spalten 1215-1216). 
Augustinus fasste dies in seiner Rede von der Zerstörung der Stadt wie folgt zusammen: „Es wanderten aus, die flüchteten, [ebenso jene] die aus dem Körper auswanderten, [und] viele von den Anwesenden verbargen sich, viele bewahrten an heiligen Orten ihr Leben, und blieben unversehrt. “127

18,5 Denn angehäuft haben sich ihre Sünden bis zum Himmel, und Gott gedachte ihrer Schandtaten.

Rom stand zur Zeit ALARICHs schon seit fast 100 Jahren unter mehr oder weniger christlichen Kaisern, aber das Volk war immer noch dem Heidentum zugetan. Das Heidentum blieb nämlich auch nach dem Tod Julians (363) und sogar nach der Erhebung des Christentums zur Staatsreligion unter Theodosius (394) in Rom weiterhin stark. ${ }^{128}$

Beispielsweise verlangte der Stadtpräfekt Symmachus im Namen des Senats von den Kaisern Valentinian, Theodosius und Arkadius, die gestrichenen Geldzahlungen an die heidnischen Vestalinnen wieder aufzunehmen und den Altar der Victoria wieder aufzurichten. Solche Forderungen sind bemerkenswert, auch wenn sie nicht beim Kaiser durchkamen.

Was aber wichtiger ist: Im römischen Senat waren immer noch die Heiden in der Mehrzahl, so dass dieses Organ immer noch „,das Tier“ verkörperte. Bei den das Heidentum fördernden Beschlüssen des Senats konnten die christlichen Senatoren nichts weiter tun, als den Sitzungen fernzubleiben. Der Senat sah das Christentum als Privatreligion der Kaiser an, betrachtete aber trotz gegenteiliger Erklärungen der Kaiser den Götzendienst weiterhin als die Reichsreligion.

Trotz des kaiserlichen Verbots wurde daher auch der heidnische Kult in Rom fortgesetzt: ,alles war in Rom durch den Rauch unreiner Opfer infiziert“ schreibt Bischof AMBROsIUs, ,und man sah an allen Ecken die Götzenbilder, die Gott zur Eifersucht reizten“. Als nun vor Alarich ein anderer Gote, der Heide RADAGAIS, der seinen Götzen das Blut der Römer versprochen hatte, mit einer 200.000 400.000 Mann starken Armee von Goten, Alanen, Vandalen und Alamannen die Donau und die Alpen überquerte und gegen Rom anrückte, hatten große Teile des römischen Volkes mehr Angst vor den heidnischen Opfern des Radagais als vor seinem Heer: Man glaubte, die Götter würden Rom strafen, weil Rom ihnen nicht mehr so eifrig opferte wie früher. Daraufhin erwog man, wie OROSIUS berichtet, die offizielle Wiedereinführung der heidnischen Opfer, und die ganze Stadt „war von heftigen Gotteslästerungen erfüllt“, es „wurde vor aller Welt der Name Christi wie irgendeine Pest durch beschimpfende Vorwürfe ... belastet“. ${ }^{129}$ Doch das Heer des Radagais wurde besiegt (405).

Dann aber rückte ALARICH an und belagerte Rom. Den heidnischen Senatoren „schien es nun notwendig, dass sowohl auf dem Kapitol als auch in den übrigen Tempeln geopfert würde“. ${ }^{130}$ Man rief auch die toskanischen Wahrsager zu Hilfe. Während der christliche Kaiser HonORIUS, der Sohn des Theodosius, seinen Sitz nach Ravenna verlegt hatte, wurde in Rom ATTALUS zum Kaiser gemacht, der seiner Neigung nach Heide war, und der große Hoffnungen auf eine volle Wiederbelebung des Heidentums weckte. Am Anfang des Jahres 410, in dessen Verlauf Rom fallen sollte, machte ATTALUS den TERTULLUS zum Konsul, einen leidenschaftlichen Verehrer der heidnischen Götter, der sein Konsulat mit einer heidnischen Vogelschau begann und das Heidentum mit allen Kräften förderte.

\footnotetext{
127 Augustinus, De urbis excidio sermo Kap. 7 (PL 40 Spalte 723): „Migrarunt qui fugerunt qui de corpere exierunt: multi praesentes utcunque latuerunt, multi in locis sanctis vivi salvique servati sunt.“

128 So sagt der Historiker Ferdinand Gregorovius: „Soviel ist übrigens gewiss, dass in den Tagen desselben Theodosius, welcher das Christentum gewaltsam zur Staatsreligion erhob, trotz allen Edikten und trotz dem Verschließen der Tempel der öffentliche Charakter Roms noch immer ein heidnischer war" (Geschichte der Stadt Rom, S. 33).

129 PAulus Orosius, Historiae adversus paganos Buch 7 Kap. 37,7. Als unmittelbaren Grund der Verwüstung Roms durch Alarich nennt Orosius die „starke Zunahme der Gotteslästerungen“ und das „Ausbleiben der Reue“ (ebd. Kap. 38,7).

130 Sozomenus, Kirchengeschichte Buch 9 Kap. 6 (PG 63 Spalten 1609-1610).
} 
So schien das belagerte Rom eindeutig zu seinen heidnischen Göttern zurückkehren zu wollen: Gott hatte zugelassen, dass das Heidentum ein letztes Mal in Rom die dominierende Religion wurde, damit kein Zweifel bleiben konnte, gegen wen das Strafgericht gerichtet war. Dies geht auch hervor aus der Person des Zerstörers: Nicht dem Heiden RADAGAIS überließ Gott die Durchführung des Strafgerichts, sondern dem Halbchristen ALARICH, der die Christen und ihre Kirchen schonte, so dass Rom alles, was von ihm noch übrigblieb, einzig den Christen verdankte. Die damaligen Christen erkannten auch tatsächlich Gottes Fügung in diesem Strafgericht, und besonders AUGUSTINUS wies immer wieder in seinen Schriften darauf hin.

18,6 Zahlt ihr mit gleicher Münze heim, gebt ihr doppelt zurück, was sie getan hat.

18,7a In dem Maße, wie sie sich Glanz verschafft und ein üppiges Leben geführt hat, im gleichen Maße gebt ihr Peinigung und Trauer.

Kaiser Claudius II. (268-270) hatte einst 320.000 Goten töten lassen. Auch nach der Niederlage des Radagais (405) gab es eine Unzahl gotischer Sklaven: „Für einzelne Goldstücke“, sagt OROSIUS, wurden „Herden von Menschen zum Verkauf angeboten“. ${ }^{131}$ Die Goten zahlten also Rom das Unrecht heim, das an ihnen begangen worden war. Zu einer solchen Vergeltung scheint der Text sie aufzurufen. Man kann den Vers aber auch so verstehen, dass sie Rom all das heimzahlen sollten, was es an anderen Nationen verbrochen hatte.

18,7b Denn in ihrem Herzen sagte sie: Ich throne als Königin, eine Witwe bin ich nicht, und Trauer werde ich niemals sehen.

18,8 Deshalb kommen an einem einzigen Tag ihre Plagen: Tod, Trauer und Hunger, und mit Feuer wird sie verbrannt werden.

Denn stark ist der Herr, Gott, der sie gerichtet hat.

Als weitere Ursache der Vernichtung Roms durch das Feuer wird hier das freche Rühmen dieser Stadt genannt. Rom nannte sich stolz ,die ewige Stadt“ und noch im Jahre 403 hatten die Römer an den Stadtmauern die Inschrift DIE EwIGE anbringen lassen. (vgl. auch die Münzen des Kaisers Attalus mit der Aufschrift „Invicta Roma aeterna“: unbesiegbares, ewiges Rom).

Diese Behauptung wurde durch ALARICH Lügen gestraft: AN EINEM EINZIGEN TAG kam das Unheil über Rom. Dieser „eine Tag“ ist hier offenbar bedeutungsgleich mit der EINEN STUNDE in 17,12; 18,10; 18,17 und 18,19. Tag und Stunde sind Metaphern für die erschreckend kurze Zeit, innerhalb derer Rom zugrunde gerichtet wurde. Will man im wörtlichen Sinn ,einen Tag“ angeben, an dem Rom vor aller Welt ,unterging“, d. h. erniedrigt wurde und seinen einstigen Glanz für immer verlor, so war es der 24. August 410, an dem Alarich mit seinen Goten Rom erstürmte und große Teile der Stadt in Brand setzte.

Als konkrete PlaGE wird das FEUER genannt. Tatsächlich setzte ALARICH das heidnische Rom in Flammen.

Weiterhin ist vom HUNGER die Rede. Hieronymus bestätigt uns, dass Rom, schon bevor es durch das Schwert erobert wurde, durch den Hunger aufgerieben wurde, ,,so dass nur ein kleiner Teil seiner Bewohner verblieb, der erobert werden konnte". ${ }^{132}$

Auch die PEST stellte sich ein, wie der Christ SOZOMEnUs und der Heide Zosimus übereinstimmend berichten. ${ }^{133}$ Hier haben wir also die apokalyptischen Reiter von Kap. 6 in Aktion: Krieg, Hunger, Pest und Tod.

131 Paulus Orosius, Historiae adversus paganos Buch 7 Kap. 37,16.

131 Hieronymus, Epistula 128 Kap. $12 \S 15$ (CSEL Band 54/1 S. 154): ,capitur urbs, quae totum cepit orbem, immo fame perit ante quam gladio et vix pauci, qui caperentur, inventi sunt“. Nach Zosimus (Neue Geschichte Buch 5 Kap. 39,1-2, Ausgabe Rebenich S. 246-247) wurden bei der ersten Belagerung Roms durch Alarich (408) in der Stadt die Lebensmittelrationen zuerst halbiert, dann gedrittelt.

132 Sozomenus, Kirchengeschichte Buch 9 Kap. 6 (PG 63 Spalten 1609-1610); Zosimos, Neue Geschichte Buch 5 Kap. 39 , Ausgabe Rebenich S. 247. Zosimus führt aus, dass infolge der bei der ersten Belagerung durch Alarich (408) ausgebrochenen Pest die Stadt Rom ein ,Grab von Toten“ bildete, da man die Toten nicht außerhalb der belagerten Stadt bestatten konnte. Es sei so schlimm gewesen, dass ,,der von den Leichen ausgehende Geruch genügte, um Menschen zu töten“. 
18,9 Und es werden weinen und sich an die Brust schlagen wegen ihr die Könige der Erde und diejenigen, die mit ihr Unzucht getrieben und üppig gelebt haben, wenn sie den Rauch ihres Brandes sehen.

Die Klage um das gefallene Rom war in der Tat groß, nicht nur bei den Heiden, sondern auch bei den damaligen Christen. Aber die Christen erkannten das Strafgericht Gottes im Untergang Roms und fanden sich damit ab. Dagegen hatte die Klage der Heiden, die den Christen die Schuld am Untergang Roms gaben, einen verzweifelten Unterton.

18,10a Und sie werden in der Ferne aus Angst vor ihrer Qual stehen bleiben und sagen:

18,10b Wehe, wehe! .. 18,16 Wehe, wehe! .. 18,19 Wehe, wehe!

Hier ist es nun endlich, das dritte und letzte Wehe, auf das wir seit 9,12 und 11,14 warten mussten: das Wehe der siebten Posaune, dass hier deutlich ausgerufen wird.

Das dritte Wehe gipfelt also im 410 deutlich gewordenen Untergang des heidnischen Rom, und so haben wir rückblickend die Bestätigung dafür, dass die ersten zwei Wehe als Ereignisse vor 410 angesetzt werden müssen. Ein Überblick über die drei Wehe ist also nun der folgende:

1. Wehe: Von Theodot (um 190) bis Kaiser VALERIAN (260): die „Heuschrecken“, eine Irrlehre, die diejenigen Christen ergriff, die im Grunde Heiden waren.

Von Kaiser Valerian (260) bis Konstantin (312): die persischen „Reiterheere“, welche gegen 2. Wehe: den christenverfolgenden Staat wüten, und der Sieg der „Zwei Zeugen“ Christi über die Verfolger, gipfelnd im Siege Konstantins.

3. Weh: Vom Ende Julians (363) bis Alarich (410) Plagen gegen das heidnische Rom, bis die „Hörner“ des Tieres, die Barbaren, Rom stürzen.

Man beachte, dass diese drei „Wehe“ nicht nur eine zeitliche, sondern auch in eine logische Reihenfolge bilden: Mit dem ersten „Wehe“ werden Heiden bestraft, die noch so sehr mit dem Christentum verbunden sind, dass sie eine scheinchristliche Lehre anzunehmen bereit sind. Mit dem zweiten „Wehe" werden die aus politischen Gründen gegen das Christentum vorgehenden Heiden bestraft. Das dritte „Wehe“ trifft die am weitesten vom Christentum entfernten, die antichristlichen Heiden vom Schlage Julians, die nach dem politischen Verfall Roms weiterhin Gott ,zum Zorne“ reizten.

18,10b Wehe, wehe, du große Stadt, Babylon, du starke Stadt: In einer Stunde ist dein Gericht gekommen!

18,11 Und die Kaufleute der Erde weinen und trauern um sie, weil ihre Ladung niemand mehr kauft.

18,12 Ihre Ladung an Gold und Silber und wertvollem Stein und Perlen und Byssus und Purpur und Seide und Scharlachstoff und allerlei vom Citrusbaum stammendes Holz und allerlei elfenbeinernes Gerät und allerlei Gerät aus wertvollstem Holz und Erz und Eisen und Marmor, 
18,13 und Zimt und Haarsalbe und Räucherwerk und Myrrhe und Weihrauch und Wein und Öl und Feinmehl und Weizen und Rinder und Schafe und Pferde und Wagen und Leiber und Seelen von Menschen.

Bemerkenswert ist in 18,13 die nochmalige Erwähnung der (nach 6,6 auch in Zeiten der Hungersnot nach dem Kriege „nicht beschädigten“) Waren WEIN UND ÖL. Außerdem ist hier die Zweiteilung des Menschen in LEIB und SEELE deutlich angesprochen (siehe auch 8,9).

18,14 Und das Obst, nach dem die Begierde deiner Seele stand, ist dir abhanden gekommen. Und alles Kostbare und Glänzende ist verloren gegangen,

(ist) weg(genommen) von dir und man wird es nie mehr finden.

18,15 Die Kaufleute, (die mit) diesen Dingen (Handel trieben), sind an ihr (an der Stadt) reich geworden.

In der Ferne werden sie stehenbleiben wegen der Furcht vor ihrer Peinigung.

Sie werden weinen und trauern

18,16 und sagen: Wehe, wehe, du große Stadt, bekleidet mit Byssus und Purpur und Scharlach und vergoldet mit Gold und wertvollem Stein und Perlenschmuck.

18,17 a In einer einzigen Stunde wurde der große Reichtum verwüstet.

Hier ist angespielt auf die Plünderung Roms durch die Goten unter ALARICH (410), und im weiteren Sinn vielleicht auch auf die späteren Plünderungen durch die Vandalen unter GEISERICH (455) und durch die Ostgoten unter TOTILA (546 und 550).

18,17b Und jeder Steuermann und jeder, der an dem Ort vorbeisegelt, und Seeleute, und alle die das Meer befahren, standen von ferne

18,18 und riefen, als sie den Rauch ihres Brandes sahen: Welche Stadt war der großen Stadt gleich?

18,19 Und sie warfen Staub auf ihrer Häupter und riefen weinend und trauernd: Wehe, wehe, du große Stadt, in der alle reich geworden sind, die Schiffe auf den Meeren haben, durch die Fülle an Kostbarkeiten. In einer einzige Stunde wurde sie verwüstet.

Der Rauch ist vom Meer aus zu sehen, was zu Rom passt.

18,20 Freue dich über sie, du Himmel, und ihr Heiligen und ihr Apostel und ihr Propheten. Denn Gott hat für euch das Strafgericht an ihr vollzogen!

Freuen sollen sich die Heiligen, Apostel und Propheten des Himmels - ein Zeugnis dafür, dass diese bereits jetzt bewusst im Himmel sind und an den Geschicken der Welt teilhaben (gegen die Seelenschlaftheorie).

Die Heiligen aber, die zur Zeit des Unterganges Roms noch auf der Erde weilten (Augustinus, Hieronymus usw.) konnten sich nicht so sehr wie der Himmel über den Untergang Roms freuen. Sie nahmen an der allgemeinen Trauer der römischen Bürger teil, weil die antike Hochkultur, von der alle profitiert hatten, nun heillos erschüttert war und nach dem Sieg der Barbaren überall das Chaos um sich griff. Dennoch war die Trauer der noch auf Erden weilenden Christen nicht so hoffnungslos und verzweifelt wie jene der Heiden.

18,21 Und ein starker Engel hob einen Stein auf, der wie ein Mühlstein war und warf ihn ins Meer, und sagte: Mit solcher Wucht wird Babylon die große Stadt niedergeschleudert werden, und sie wird nicht mehr gefunden werden.

Mit AlARICHs Eroberung tauchte das alte Rom gleichsam wie ein weggeworfener Stein ins Meer der Vernichtung ein, und sank durch immer weitere Katastrophen immer tiefer hinab. 
452 kamen die Hunnen (Attila) und verwüsteten Italien: nur knapp entging Rom ihrem Schwert. 455 wurde Rom durch die Vandalen (Geiserich) geplündert. 476 wurde der letzte weströmische Kaiser abgesetzt und Italien kam unter die Herrschaft Odoakers. Dieser wurde 489/90 vom Ostgoten Theodorich verdrängt, und die Ostgoten wurden ihrerseits nach einem zwanzigjährigen Krieg durch den oströmischen Kaiser Justinian besiegt, ein Krieg, der die Stadtkultur Italiens endgültig in Trümmer legte. Dieser Krieg war für Italien ähnlich verheerend wie der hundertjährige Krieg für Frankreich und der dreißigjährige Krieg für Deutschland.

Zunächst wurde Rom 536 von Belisar, dem Feldherrn Justinians, erobert, dann aber in den Jahren 537 38 vom Ostgotenkönig Witigis mit 150.000 Mann belagert, wobei die Stadt unsäglich leiden musste. Witigis zog zwar ab, aber der Frankenkönig Theudebert, zunächst ein Verbündeter Justinians, sandte ihm 10.000 Burgunder, mit deren Hilfe er 539 Mailand, die zweitgrößte Stadt Italiens eroberte, wobei die unglaubliche Anzahl von 300.000 Menschen getötet worden sein sollen. 546 wurde Rom von Totila, dem Nachfolger des Witigis erobert, der die schon begonnene Plünderung und Massakrierung der Bevölkerung auf Vermittlung des Diakons und späteren Papstes Pelagius wieder einstellte.

Justinians Feldherr Belisar konnte Rom 547 zurückerobern, aber schon 550 fiel die Stadt nach drei Belagerungen wieder an Totila, dem sie 552 wiederum von Narses, einem anderen Feldherrn Justinians, entrissen wurde. Aber 568 fielen die Langobarden unter ihrem König Alboin in Italien ein, durch welche auch die letzten Reste der oströmischen Herrschaft über Rom beseitigt wurden.

So war um 600 mit dem Ende der Völkerwanderungswirren der „Stein“ des alten Rom auf dem Tiefpunkt des Meeresgrundes angelangt. Von nun an erhebt sich Rom langsam wieder, aber es ist nicht mehr das alte, das für immer auf dem Meeresgrund begraben bleibt, sondern ein neues, christliches Rom entsteht auf den Trümmern des alten. Ein Anzeichen dafür ist, dass 609 das Pantheon in Rom als erster heidnischer Tempel in eine christliche Kirche verwandelt wird. Auch findet die Bekehrung der im ehemaligen römischen Reichsgebiet herrschenden Barbaren zum katholischen Christentum bald nach 600 ihren Abschluss.

18,22 Und einen Ton von Harfensängern und Musikern und Flötenspielern und Posaunenbläsern hört man nicht mehr in dir.

Und Handwerker jeglicher Art werden nicht mehr in dir gefunden werden.

Und das Geräusch der Mühle wird nicht mehr in dir gehört werden.

18,23 Und das Licht der Lampe wird nicht mehr in dir scheinen.

Und die Stimme des Bräutigams und der Braut wird nicht mehr in dir gehört werden.

Denn deine Kaufleute waren die Großen der Erde, denn durch deine Giftmischerei wurden alle Völker verführt.

Alle Drohungen gelten für das heidnische Rom. Damit ist nicht unvereinbar, dass in dem nun gewandelten, christlichen Rom sehr wohl Musiker, Handwerker usw. vorhanden sind.

18,24 Und in ihr wurde das Blut der Propheten und der Heiligen gefunden und aller Hingeschlachteten auf der Erde.

Rom hat tatsächlich Blut vergossen wie keine andere Stadt. Wieso wird der Stadt nun aber sogar das Blut der Propheten Israels und aller jemals hingeschlachteten Gerechten zugeschrieben? Wer immer die Absicht hat, alle gerechten Diener Gottes, deren er habhaft werden, zu töten und somit das Volk der Heiligen vollständig auszurotten, dem wird die Schuld am vergossenen Blut aller jemals getöteten Gerechten angerechnet, angefangen vom Blut Abels (vgl. Mt 23,35).

19,1 Danach hörte ich etwas wie eine laute Stimme einer großen Schar im Himmel sagen: Halleluja! Das Heil und die Herrlichkeit und die Macht sind bei unserem Gott.

19,2 Denn wahrhaftig und gerecht sind seine Gerichte, denn er hat die große Hure gerichtet, welche die Erde verdorben hat mit ihrer Hurerei, und er hat das Blut seiner Knechte an ihr gerächt. 
19,3 Und zum zweiten Mal sagte sie: Halleluja! Und ihr Rauch steigt auf in alle Ewigkeit.

19,4 Und die vierundzwanzig Ältesten und die vier Wesen fielen nieder und beteten Gott an, der auf dem Thron sitzt, und sagten: Amen, Halleluja.

19,5 Und eine Stimme ging vom Thron aus und sagte: Lobt unseren Gott, all seine Knechte, und die ihn fürchten, die Kleinen und die Großen!

19,6 Und ich hörte etwas wie eine Stimme vieler Gewässer und etwas wie eine Stimme starker Donner sagen: Halleluja! Denn zur Herrschaft gelangt ist der Herr, unser Gott, der Allmächtige.

Viermal erklingt das Halleluja: „lobet Jahwe“. Die Kosmos-Zahl vier (vgl. Kommentar zu 4,6b-8) weist hin auf die vier Elemente, vier Himmelsrichtungen, und vier „Stockwerke“ des Alls. Gott erhält also hier Lob aus allen Teilen des Universums. Vergleiche auch 5,13.

19,7 Lasst uns froh sein und jubeln und ihm die Ehre erweisen.

Denn gekommen ist die Hochzeit des Lammes und seine Frau hat sich bereit gemacht.

19,8 Und gegeben wurde ihr, dass sie sich kleidet mit reinem, weisglänzendem Byssus. Denn der Byssus sind die gerechten Taten der Heiligen.

Die FRAU DES LAMMES, von der hier die Rede ist, ist das Gegenstück zur Hure Babylon, meint also die „Stadt Gottes“, das „,neue Jerusalem“, von dem in Kap. 21 die Rede sein wird. Gemeint ist damit die Kirche, aber nicht im Zustand ihrer irdischen Qualen (siehe die Frau in Kap. 12), sondern in ihrer endzeitlichen Vollendung.

Die Prophetie springt also hier zur Endzeit über. Solche Sprünge sind in der Prophetie üblich: Es handelt sich um die ,,prophetische Perspektive“ (siehe Kommentar zu 11,18).

19,9a Und er (ein Engel) sagt mir: Schreibe!

Selig sind, die zum Hochzeitsmal des Lammes geladen sind.

Der Sprechende ist, wie sich im nächsten Vers zeigt, ein Engel, der Johannes zur Seite stand.

19,9b Und er sagt mir: Dies sind die wahrhaftigen Worte Gottes.

19,10 Und ich fiel ihm zu Füßen, um ihm zu huldigen.

Er aber sagte zu mir: sieh dich vor, tu dies nicht!

Ich bin dein Mitknecht und Mitknecht deiner Brüder, die das Zeugnis Jesu festhalten.

Gott bete an! Denn der Geist der Weissagung ist das Zeugnis Jesu.

Der Engel soll nicht angebetet werden, weil „der GEIST DER WEISSAGUNG DAS ZEUGNIS JESU ist“, d. h. weil der prophetische Geist von Jesus ausging. Diese Begründung zeigt, dass der Engel hätte angebetet werden dürfen, wenn der „Geist der Weissagung“ vom Engel ausgegangen wäre, denn dann wäre dieser Engel folgerichtig eine göttliche Person gewesen.

Genau dies scheint Johannes geglaubt zu haben: Dass nämlich der neben ihm stehende Engel eine Erscheinung Gottes und somit die Quelle jener gewaltige Weissagung war. Hatte doch der Engel gerade gesagt: DiES SIND DIE WAHRHAFTIGEN WORTE GOTTES, woraus Johannes anscheinend schloss, dass er eine der drei göttlichen Personen vor sich hatte.

Aber der Engel korrigiert ihn, in dem er sagt: Die Weissagung kommt nicht von mir, sondern von Jesus, und daher bete Gott an. Die selbstverständliche Voraussetzung für diese Argumentation ist, dass Jesus (im Gegensatz zum Engel) mit Gott dem Vater eines Wesens ist. Der Gegensatz zwischen Jesus und einem Engel tritt hier also scharf zutage: Jesus gehört ganz auf die Seite Gottes und darf angebetet werden, die Anbetung des Engels hingegen ist verboten. Damit ist trotzdem eine (nicht-anbetende, dennoch kniefällige) Verehrung von Engeln (und Heiligen) vereinbar, wie der folgende Exkurs zeigt. 


\section{Exkurs 12: Die Berechtigung der Heiligenproskynese}

Vorliegende Stelle verbietet die Anbetung von Engeln, aber sie lehrt keinesfalls, dass jegliche Huldigung (knie- und fußfällige Verehrung) von Engeln verboten ist!

Es gibt zwei Arten von Huldigung (griech. „Proskynese“), von den Theologen „Verehrungsproskynese“ und „Anbetungsproskynese“ genannt. Die Anbetungsproskynese darf nur Gott dargebracht werden, die Verehrungsproskynese aber auch Engeln, Heiligen, Bischöfen, Königen, Wohltätern und überhaupt allen, denen man Ehre erweisen will.

Der Unterschied ist nicht äußerlich sichtbar (beides ist knie- oder fußfällige Verehrung), sondern liegt in der inneren Absicht: Wer die Proskynese als Ausdruck einer grenzenlosen Bewunderung und Hingabe vollzieht, betet an (= Anbetungsproskynese). Wer aber lediglich seine Dankbarkeit, Anerkennung, Demut usw. bezeugen will, vollzieht bloß eine Verehrungsproskynese.

Eine Anbetungsproskynese liegt außer an vorliegender Stelle z. B. in Apk 22,8-9 vor, wo Johannes ebenfalls einem Engel göttliche Ehren erweisen will, sowie in Apg 10,25-26, wo der Hauptmann CoRNELIUS daran gehindert wird, dem Apostel Petrus Proskynese zu erweisen.

Die Beispiele für die auch zur Ehrung von Geschöpfen erlaubte Verehrungsproskynese sind besonders im Alten Testament zahlreich: Die Brüder JosEPHS vollziehen eine Proskynese vor JosEF (Gen 37,7; 37,9; 37,10; 42,6), MOSES vor seinem Schwiegervater JiTRo (Ex 18,7), die Prophetenjünger bzw. eine Frau vor EliAs (2 Kön 2,15 und 4,37), JosuA vor einem Engel (Jos 5,14-15) und in Jes 49,23 wird verheißen, dass der Berg Zion Objekt einer Proskynese sein wird. Vergleiche noch 1 Mose 23,22; 27,29; 1 Sam 24,9; 2 Sam 1,2; 1 Kön 1,53 usw. Im Neuen Testament gibt es nur zwei Stellen, in denen von einer erlaubten Proskynese die Rede ist, die sich nicht auf Gott oder CHRISTUS bezieht: In Mt 18,26 ist von einer Proskynese eines Dieners vor seinem Herrn, einem König, die Rede. Das andere Beispiel stammt aus dem Buch der Apokalypse: die Verheißung der Proskynese neubekehrter Christen vor dem Bischof (,Engel“) von Philadelphia $(3,9)$.

Wenn, wie manche Protestanten glauben, die vorliegende Stelle sowie Apk 22,9 und Apg 10,25-26 wirklich ein Beweis für die Unerlaubtheit jeglicher Proskynese vor Geschöpfen sein soll, dann müsste sich zeigen lassen, dass hier eine Proskynese zurückgewiesen wird, die nur eine Ehrbezeugung sein sollte. Aber in allen drei Fällen ist deutlich vom Versuch einer Anbetungsproskynese die Rede: denn CORNELIUS musste in Apg 10,25-26 darüber aufgeklärt werden, dass Petrus nur ein Mensch ist - er wollte also in Petrus mehr als nur einen Menschen und Apostel Jesu Christi ehren. Ähnlich war es mit JoHANNES und dem Engel: JOHANNES meinte irrtümlich, dass der neben ihm stehende Engel göttliche Eigenschaften hatte und wollte ihm darum göttliche Ehre (= Anbetung) erweisen. Darum musste ihn der Engel hier und 22,8 darüber aufklären, dass er lediglich sein „Mitknecht“ war. Also lehren diese Stellen nur die Verkehrtheit einer Anbetungsproskynese vor Geschöpfen: Sie ermahnen uns zur Wachsamkeit, die uns davor bewahrt, Gottes Geschöpfe mit Gott selber zu verwechseln.

Auch der Ausspruch JeSU „Dem Herrn, deinem Gott, sollst du Proskynese erweisen und ihm allein dienen“ (Mt 4,10; Lk 4,8) ist kein Beweis für ein Verbot jeglicher Proskynese vor Geschöpfen. Denn dieser Ausspruch kommt aus dem Alten Testament (Dt 6,13): JESUS hat nur das Wort „allein“ hinzugefügt. Aber nun setzte Jesus das Wort ,allein“ gerade nicht vor „Proskynese erweisen“, was er doch hätte tun müssen, wenn er die Neuerung hätte einführen wollen, dass von nun an Proskynese nur noch Gott darzubringen sei. Statt dessen setzte er das ,,allein“ vor das Wort „dienen“. Das hier gebrauchte griechische Wort ist „latreuo“ (davon abgeleitet: „Latrie“) und bezeichnet nicht gewöhnliches Dienen, sondern den Gottesdienst bzw. die Anbetung Gottes. Nicht die Proskynese also, sondern die Latrie (= Anbetung) bezeichnet Jesus als allein Gott gebührend.

Im Übrigen: Es wäre mit dem Geist des Evangeliums doch wohl kaum vereinbar, wollte man die Proskynese als solche verbieten, unabhängig davon, ob sie als Anbetung oder nur als Geste einer nicht-anbetenden Ehrerbietung oder Höflichkeit vollzogen wird. Oder sollte man glauben, dass JESUS, der den Menschen sonst immer nach seiner inneren Einstellung beurteilt (vgl. z.B. Mk 7,1-23), in diesem Fall einfach bestimmte Körperhaltungen und Gesten verurteilt, ganz ohne Rücksicht auf die innere Einstellung und Absicht, die damit verbunden ist? 


\subsection{Apk 19,11-21: Das Gericht über die beiden Tiere}

Nach dem Sieg über die „Hure“ müssen noch die beiden „Tiere“ besiegt werden. Das erste, das einst so stolze siebenköpfige Ungeheuer, bestand nach 410 fast nur noch aus einem „kopflosen Körper“ von Anhängern des alten heidnischen Reichsgedankens. Außerdem hatte es noch einige seiner „Hörner“, denn solange die Barbaren noch Heiden waren, setzten sie das heidnisch-römische Reich in gewisser Weise fort. Die Hoffnungslosigkeit dieses kläglichen Überrests wurde immer größer, bis um 600 der absoluten Tiefpunkt erreicht war (siehe Kommentar zu 18,21). Das zweite Tier, die neuplatonisch gefärbte heidnisch-römische Religion, ging ungefähr im gleichen Zeitraum zugrunde. Nach ihrem letzten Aufblühen während der Belagerung Roms trat sie immer mehr zurück, bis Kaiser Justinian (527-565) im Jahre 529 die letzte heidnische Hochschule in Athen schloss und die letzten Stützpunkte des Heidentums beseitigte. Um 600 war also die Zerschlagung der beiden Tiere vollendet und hatte ein furchtbares Trümmerfeld hinterlassen. Indessen war es aber dem rechtgläubigen Christentum gelungen, die nun herrschenden Barbarenstämme zu christianisieren bzw. vom arianischen Christentum zum katholischen zu bekehren (siehe Kommentar zu 17,14). Somit waren am Punkt Null die Grundlagen für einen Neuaufstieg Europas unter christlichem Vorzeichen gelegt, weshalb der Untergang Roms ein Sieg Christi war. Diese Geschichte ist der Hintergrund für den letzten Teil von Kap. 19. der Apokalypse.

Text

19,11 Und ich sah den Himmel geöffnet, und siehe, eine weißes Pferd.

Und der auf ihm sitzt, wird „Der Treue und Wahrhaftige“ genannt.

Und er richtet in Gerechtigkeit und führt Krieg.

19,12 Aber seine Augen waren wie eine Feuerflamme.

Und auf seinem Haupt waren viele Kronen.

Und (auf seinem Haupt) stand ein Name geschrieben, den niemand kennt, außer er selbst.

19,13 Und er war bekleidet mit einem Mantel, der in Blut getaucht war. Und sein Name ist „das Wort Gottes“.

19,14 Und die Heere im Himmel folgen ihm auf weißen Pferden, bekleidet mit weißer, reiner Leinwand.

19,15 Und aus seinem Mund geht ein scharfes Schwert heraus, damit er mit ihm die Völker schlage. Und er wird sie weiden mit eisernem Stab.

Und er tritt die Kelter des Weines der Zorneswut Gottes des Allmächtigen.

19,16 Und er hat am Mantel und an seinem Schenkel einen Namen geschrieben: König der Könige und Herr der Herren.

19,17 Und ich sah einen Engel in der Sonne stehen. Und er rief mit lauter Stimme und sagte zu allen Vögeln, die in der Mitte des Himmelsraumes fliegen:

Kommt her, versammelt euch zum großen Mahl Gottes,

19,18 damit ihr fresst Fleisch von Königen und Fleisch von Befehlshabern und Fleisch von Starken und Fleisch von Pferden und von denen, die auf ihnen sitzen und Fleisch aller Freien und Sklaven und Kleinen und Großen!

19,19 Und ich sah das Tier und die Könige der Erde und ihre Heere versammelt, Krieg zu führen mit dem, der auf dem Pferd sitzt und mit seinem Heer.

19,20 Und ergriffen wurde das Tier und mit ihm der falsche Prophet, der die Zeichen vor ihm getan hatte, mit denen er die verführt hat, die das Kennzeichen des Tieres angenommen und sein Bild angebetet haben. Die beiden wurden lebend in den Feuersee geworfen, der im Schwefel brennt.

19,21 Und die übrigen wurden getötet mit dem Schwert, das aus dem Mund dessen kommt, der auf dem Pferd sitzt. Und alle Vögel sättigten sich an ihrem Fleisch.

Auslegung 
19,11 Und ich sah den Himmel geöffnet, und siehe, eine weißes Pferd.

Und der auf ihm sitzt, wird „Der Treue und Wahrhaftige“ genannt.

Und er richtet in Gerechtigkeit und führt Krieg.

Johannes sieht jetzt aus dem Himmel den WEISSEN REITER herabkommen, den er schon in 6,1 als ersten der vier apokalyptischen Reiter geschaut hatte. Hier wird klar gesagt, dass es CHRISTUS ist. Das zeigt der Name DER TREUE UND WAHrhaftige, aber auch der Name „das Wort Gottes“ (Vers 13), was bei Johannes ein CHRISTUS-Titel ist (vgl. Joh 1,1-17). CHRISTUS kommt nun persönlich, um das Gericht an den Tieren zu vollstrecken (19,20). Der hier beschriebene KRIEG beginnt nach 410 (denn von der Hure ist nicht mehr die Rede), und endet mit dem Sieg über die „Tiere“ um 600.

19,12 Aber seine Augen waren wie eine Feuerflamme.

Und auf seinem Haupt waren viele Kronen.

Und (auf seinem Haupt) stand ein Name geschrieben, den niemand kennt, außer er selbst.

Der Geheimnisvolle Name auf dem Haupt Christi ist der Name „das Wort Gottes“ (Vers 13). Niemand KENNT diesen Namen außer CHRISTUS, d. h. kein Geschöpf kann seine volle Bedeutung ermessen. Die Theologen haben etwa folgende Bedeutung dieses Namens aus der Schrift herausgearbeitet: CHRISTUs heißt „,das Wort Gottes“, weil er als zweite Person in der Dreifaltigkeit das im Geist des Vaters innerlich gesprochene „Gedankenwort“ ist, in dem der Vater sich selbst aussagt. Aber so richtig diese Feststellung auch ist: Die volle Bedeutung dieses Geheimnisses kennt nur CHRISTUS.

19,13 Und er war bekleidet mit einem Mantel, der in Blut getaucht war. Und sein Name ist „das Wort Gottes“.

Christi MANTEL ist entweder getränkt vom Blut seiner Feinde, oder er ist seine menschliche Natur, die von seinem eigenen Blut getränkt ist, das er am Kreuz vergossen hat.

19,14 Und die Heere im Himmel folgen ihm auf weißen Pferden, bekleidet mit weißer, reiner Leinwand.

Die Kämpfe gegen das Tier wurden zwar durch irdische Könige und Heere ausgefochten, aber hinter der Kulisse dieser sichtbaren Ereignissen wirkte im Verborgenen auch CHRISTUS und sein himmlisches Heer der Engel und Heiligen. Dieses himmlische Heer hat in den verschiedenen Kämpfen, sei es durch direktes Eingreifen oder durch überlegenes Zulassen des Wütens irdischer oder auch höllischer Mächte alles letztlich zum Sieg des Guten geführt.

19,15 Und aus seinem Mund geht ein scharfes Schwert heraus, damit er mit ihm die Völker schlage.

Und er wird sie weiden mit eisernem Stab.

Und er tritt die Kelter des Weines der Zorneswut Gottes des Allmächtigen.

Das SCHWERT AUS SEINEM MUND ist das „Wort Gottes“ (vgl. Eph 4,17 und Hebr 4,12). Jesus braucht kein materielles Schwert, die Natur gehorcht seinem Wort, wie seine Wunder gezeigt haben. Das KELTERTRETEN wurde in 14,17-20 angekündigt als blutige Traubenernte, die einer Getreideernte $(14,14$ 16) nachfolgt. Bei der Traubenernte waren auch Pferde erwähnt worden. Wir dürfen hier also die Verwirklichung jener Ankündigung sehen. Während die Getreideernte das Gericht über die Stadt Rom ankündigte, deutete die Traubenernte, bei der das Blut ,,außerhalb der Stadt“ floss $(14,20)$, den nachfolgenden Totaluntergang der römischen Antike an. Davon ist also nun die Rede. Das zeigt sich auch darin, dass dieser Krieg Christi gegen DIE VÖLKER gerichtet ist, also nicht nur gegen Rom, sondern auch gegen die Barbaren. CHRISTUS lenkt die Schlachten der Völkerwanderung so, dass das Christentum daraus als Sieger hervorgeht: so dass er MIT EISERNEM STAB (durchdringender Kraft) die Völker erst SCHLÄGT (das Antichristliche in ihnen vernichtet) und sie dann WEIDET (fürsorglich regiert). 
19,16 Und er hat am Mantel und an seinem Schenkel einen aufgeschriebenen Namen: König der Könige und Herr der Herren.

Als KÖNIG DER KÖNIGE macht er sich alle Könige untertan.

19,17 Und ich sah einen Engel in der Sonne stehen. Und er rief mit lauter Stimme und sagte zu allen Vögeln, die in der Mitte des Himmelsraumes fliegen:

Kommt her, versammelt euch zum großen Mahl Gottes,

19,18 damit ihr fresst Fleisch von Königen und Fleisch von Befehlshabern und Fleisch von Starken und Fleisch von Pferden und von denen, die auf ihnen sitzen und Fleisch aller Freien und Sklaven und Kleinen und Großen!

Das schreckenerregende Bild vom Aufgefressenwerden der Leichen durch Tiere steht für die völlige Verwüstung von Städten und Reichen sowie für die äußerste Bestrafung gottloser Menschen (vgl. die Kommentare zu 6,8 und zu 18,2.

19,19 Und ich sah das Tier und die Könige der Erde und ihre Heere versammelt, Krieg zu führen mit dem, der auf dem Pferd sitzt und mit seinem Heer.

Hier ist vom Krieg der Barbarenkönige gegen Christus die Rede, sowohl von denen, die letzte Vertreter des „Tieres“ sind (die heidnischen Barbaren) als auch die anderen, die als arianische Barbaren ebenfalls (nicht-arianische, katholische) Christen verfolgen. Besonders harte Christenverfolger waren bei den Westgoten der Heide ATHANARICH (348 und 370-372) und der Arianer LEOVIGILD (568-586), bei den Vandalen die arianischen Könige GEISERICH (428-477), HUNERICH (477-484), Thrasamund (496-523) und Gelimer (530-534), und bei den Ostgoten der Arianer THEODORICH (471-526) in seinen letzten Jahren (524-526).

19,20 Und ergriffen wurde das Tier und mit ihm der falsche Prophet,

der die Zeichen vor ihm getan hatte, mit denen er die verführt hat,

die das Kennzeichen des Tieres angenommen und sein Bild angebetet haben.

Die beiden wurden lebend in den Feuersee geworfen, der im Schwefel brennt.

Das Tier und der Prophet (= das zweite Tier, vgl. Kommentar zu 16,13) wurden nach ihrer Vernichtung auch noch im Jenseits weiterbestraft: Sie wurden in die Hölle hinabgestürzt, indem sie (und alle ihre unbekehrbaren Anhänger) der ewigen Ächtung verfielen. Siehe Kommentar zu 14,9-11. Durch das Wort LEBEND soll wahrscheinlich unterstrichen werden, dass die Qualen der Hölle bewusst wahrgenommen werden: ein Argument gegen die Seelentod- und die Seelenschlaftheorie.

19,21 Und die übrigen wurden getötet mit dem Schwert,

das aus dem Mund dessen kommt, der auf dem Pferd sitzt.

Und alle Vögel sättigten sich an ihrem Fleisch.

Die ÜBRIGEN sind jene CHRISTUS verfolgende Könige, bzw. heidnischen Reiche, die nie in römischen Diensten standen, also keine Hörner des „Tieres“ waren (z.B. die heidnischen Skoten, Pikten, Angeln, Friesen, Dänen usw.). Auch diese heidnischen Reiche wurden schließlich GETÖTET, d. h. vernichtet, und durch christliche Reiche ersetzt. Zum Aufgefressenwerden vgl. den Kommentar zu Versen 17-18. 


\subsection{Apk 20,1-6: Das Tausendjährige Reich (Millenium)}

Nach Ansicht der Chiliasten oder (Prä-)Millenniaristen, ${ }^{133}$ zu denen heute vor allem die Zeugen Jehovas und Adventisten sowie große Teile der freikirchlich-evangelikalen Bewegung gehören, ist das in Apk 20,1-6 beschriebene Tausendjährige Reich ein noch bevorstehender paradiesähnlicher Zwischenzustand zwischen dem Ende des jetzigen Weltzustandes und dem Beginn des ewigen Reiches Gottes. Die meisten Millenniaristen glauben, dass das TausendjahrReich mit der Wiederkehr CHRISTI beginnen wird: Satan wird dann „gebunden“, so dass das Böse 1000 Jahre lang völlig oder weitgehend beseitigt ist und die Erde von Christus und seinen Heiligen beherrscht wird. Nach den 1000 Jahren aber wird Satan wieder für kurze Zeit losgebunden, eine letzte Prüfung kommt über die Erde, und dann erfolgt die endgültige Trennung der Guten und Bösen.

Unter den Millenniaristen gab es einige von großkirchlichen Theologen heftig kritisierte sog. „Schwärmer“, die oft in geschmackloser Weise von zügellosen ,fleischlich-irdischen“ Freuden dieser Zeit fabulierten. ${ }^{134}$ Eine millenniaristische Interpretation ist aber auch bei einigen hochangesehenen frühkatholischen Autoren der ersten Jahrhunderte zu finden. Die berühmtesten von diesen waren im 2. Jahrhundert Bischof PAPIAS von Hierapolis (um 120) und die beiden Kirchenväter JUSTIN ( $† 165)$ und IRENÄUS $(† 202),{ }^{135}$ wobei die letzten zwei zugleich wichtige Tradenten der Nachricht von der Abfassung der Apokalypse durch den Apostel Johannes waren. Auch der Kirchenvater AugusTiNUS $(† 430)$ neigte anfangs dem Millenniarismus zu, ${ }^{136}$ gelangte aber wohl aufgrund eines vertieften Bibelstudiums und Nachdenkens zu einer grundlegend anderen Auffassung, wonach das Tausendjahr-Reich eine innergeschichtliche Epoche in der Zeit zwischen der ersten und der zweiten Ankunft Christi ist, in der wir uns bereits jetzt befinden. ${ }^{137}$ Diese Sicht setzte sich in der katholischen Kirche ebenso wie in den anderen großen christlichen Kirchen weitgehend durch, obgleich bestimmte Formen eines ,gemäßigten“ Millenniarismus auch heute noch innerhalb der katholischen

133 Das Wort „Chiliasten“ ist abgeleitet von griech. chilias = die Tausendzahl, und „Millenniaristen“ von lat. millennium = Jahrtausend. Diese Bezeichnungen bringen zum Ausdruck, dass für die so bezeichneten Christen die Lehre vom Tausendjährigen Reich ein zentraler Punkt ihres Glaubens ist. Genauer ist hier der klassische Prä-Millenniarismus gemeint (von lat. prae = vor), dessen Anhänger glauben, dass die erwartete Wiederkehr Christi (siehe Kommentar zu 1,7) bereits unmittelbar vor dem Beginn des Tausendjahr-Reichs stattfinden wird.

134 Im 2. Jh. werden namentlich CERINTH und MONTANUS zu diesen Schwärmern gerechnet. CERINTH (ein um das Jahr 100 wirkender jüdischchristlicher Gnostiker und Zeitgenosse des Apostels Johannes) lehrte, dass die Seligkeit des künftigen Reiches Christi in irdischen Genüssen bestehen werde, ,d.h. in der Befriedigung des Magens und der noch tiefer gelegenen Organe, also in Speise und Trank und ehelichen Genüssen“ sowie ,in Festen, Opfern und Schlachtungen von Opfertieren“ (Zitat aus dem Buch Über die Verheißungen des Bischofs DiONYSIUS vON ALEXANDRIEN ( $†$ 264/65), von dem der entsprechende Auszug bei EusEBIUS, Kirchengeschichte 7,25,2-3 erhalten ist.). Um 170 erwartete sodann der berüchtigte „Prophet“ und Sektenführer MONTANUS ein irdisches Tausendjahr-Reich Christi, dessen Hauptstadt (das „Neue Jerusalem“) er mit der kleinasiatischen Stadt Pepuza, dem Hauptquartier der Sekte, gleichsetzte. Ein ähnliches „Neues Jerusalem“ errichtete in der Reformationszeit (1534/5) eine Gruppe von radikal politisierten charismatischen Täufern in Münster.

135 Justin belehrt in seinem Dialog mit Tryphon (Kap. 80) den Juden Tryphon darüber, dass er selbst (JustiN) und die Fraktion der seiner Meinung nach rechtgläubigen Christen überzeugt sind, ,dass es eine Auferstehung des Fleisches gibt, und dass tausend Jahre kommen werden in dem aufgebauten, geschmückten und vergrößerten Jerusalem“; zugleich weißt er drauf hin, „dass aber andererseits auch unter den Christen der reinen und frommen Richtung viele diese Anschauung nicht teilen“.

IRENÄUS folgt in dieser Sache dem PAPIAS, indem er aus dessen verlorengegangenen Werk (offenbar zustimmend) Folgendes zitiert: „Es werden Tage kommen, in denen Weinstöcke wachsen, einzelne zehntausend Äste haben, und an einem Ast zehntausend Zweige, und wirklich an einem Zweig zehntausend Ranken, und an jeder Ranke zehntausend Trauben und an jeder Traube zehntausend Beeren, und jede ausgepresste Beere wird fünfundzwanzig Maß Wein geben. Und wenn einer der Heiligen von ihnen eine Traube anrührt, wird eine andere Traube rufen: Ich bin besser; nimm mich; Preise durch mich den Herrn!“ Papias habe hinzugefügt: „Diese Dinge sind nur dem Gläubigen glaubhaft“, und: Als Judas fragte, wie eine solche Fruchtbarkeit zustande kommen soll, habe Jesus gesagt: „Das werden die sehen, die in jene [Zeiten] hineinkommen“ (Irenäus, Adversus Haereses 5,33,3-4). Es ist jedoch unklar, inwieweit IRENÄUS oder PAPIAS oder dessen apostolische Tradenten (die ihm dies überliefert haben sollen) diese Aussagen wörtlich oder symbolisch verstanden haben. Der Kirchengeschichtsschreiber EUSEBIUS aus dem 4. Jh., ein früher Kritiker des Millenniarismus, berichtet über PAPIAS das folgende (Kirchengeschichte 3,39,11-12): ,Er hat noch andere Dinge aufgezeichnet, die angeblich aus ungeschriebener Tradition zu ihm gelangt sind ... Zu diesen gehörte seine Behauptung, dass es nach der Auferstehung von den Toten tausend Jahre geben werde, in denen das Reich Christi in leibhaftiger Gestalt hier auf Erden bestehen werde“. EUSEBIUS nennt PAPIAS ,geistig beschränkt“ $(3,39,13)$ und kommentiert: "Ich meine, dass er diese Ansichten auf die apostolischen Erzählungen gründet, indem er die Aussagen, die sie auf geheimnisvolle Weise in Bildern gemacht hatten, nicht verstanden hat." $(3,30,12)$. EUSEBIUS glaubte also, dass PAPIAS symbolisch gemeinte Aussagen der Apostel fälschlich wörtlich nahm. Ob er damit Recht hatte, können wir nicht entscheiden. Es könnte auch umgekehrt sein: dass nämlich EUSEBIUS hier einem Irrtum unterlag, indem er (EUSEBIUS) die Aussagen des PAPIAS fälschlich wörtlich nahm, die dieser womöglich einfach nur weitergegeben hatte, ohne sie zu interpretieren.

136 Vgl. Augustinus, De Civitate Dei 22,7: „Auch ich habe das früher einmal so aufgefasst.“

137 Vgl. Augustinus, De Civitate Dei 22,7. 
Kirche existieren und durchaus scharfsinnige Verteidiger gefunden haben (etwa FÉRET und neuerdings IANNUZZI). ${ }^{138}$ Wie ALLo bin ich allerdings der Meinung, dass die übliche „großkirchliche“ Interpretation, wie AuGUSTINUS sie vorgedacht hat, sachlich angemessener ist, auch wenn frühchristliche Autoren wie PAPIAS, JUSTIN und IRENÄUS sie noch nicht kannten. Obgleich diese Autoren noch in einer engen Schülertradition zum Apostel JOHANNES standen, muss ihre Auslegung deshalb nicht richtiger sein als diejenige späterer Theologen. Selbst wenn ihre Auslegung irgendwie auf mündlich tradierte Erklärungen des Apostels JOHANNES zurückgehen sollte (wie es PAPIAS zu behaupten scheint), so könnten diese Erklärungen ursprünglich sinnbildlich gemeint und von den Schülern falsch verstanden und weitergegeben worden sein; außerdem wäre zu bedenken, dass JOHANNES wohl kaum zusätzlich zu den Visionen auch noch Hinweise zur „richtigen“ Interpretation des Geschauten von Gott empfangen haben dürfte (andernfalls hätte er diese Hinweise doch wohl mit aufgeschrieben), so dass es zu diesem Text keine mündlich tradierte „göttlich autorisierte“ Auslegung geben dürfte, die PAPIAS, JUSTIN und IRENÄUS empfangen haben könnten. - AUGUSTINUS scheint mir jedenfalls eine tiefere Einsicht gehabt zu haben und den verborgenen Sinn der durchaus nicht leicht verständlichen Aussagen des Johannes in Apk 20,1-6 besser erfasst zu haben als die Millenniaristen.

Ein starkes Argument hierfür ist vorab, dass die millenniaristische Auffassung nur schwer mit den Aussagen Christi über die Endzeit zusammenzupassen scheint. Denn:

- Christus scheint in seinen Gleichnissen (Mt 13,29, 13,47-50) vorauszusetzen, dass bis zum Ende der menschlichen Geschichte gute und böse Menschen zusammenleben werden.

- Christus erklärt, dass nach seiner Wiederkehr sofort die ewige Trennung der Guten und Bösen erfolgt (Mt 25,31-46).

Das Tausendjährige Reich sollte demnach nicht erst mit der bevorstehenden zweiten Ankunft Christi beginnen, sondern es sollte kurz vor dieser Ankunft bereits enden. Das Tausendjährige Reich beginnt meines Erachtens in gewisser Weise schon mit dem ersten Kommen Christi und in voller Weise mit dem Sturz Roms. Dabei handelt es sich um eine Zeit des relativen Gebundenseins Satans, in welcher die Heiligen des Himmels bereits mit CHRISTUS herrschen. Im Folgenden wird gezeigt, wie diese Konzeption zum Text passt und sich aus ihm ergibt.

Text

20,1 Und ich sah einen Engel aus dem Himmel herabkommen, der den Schlüssel zum Abgrund und eine große Kette in seiner Hand hielt.

20,2 Und er ergriff den Drachen, die alte Schlange, die Teufel und Satan heißt. Und er fesselte ihn für tausend Jahre.

20,3 Und er warf ihn in den Abgrund und verschloss und versiegelte über ihm, damit er nicht mehr die Völker verführe, bis die tausend Jahre vorüber sind. Dann muss er für kurze Zeit losgebunden werden.

20,4 Und ich sah Throne, und man nahm darauf Platz.

Und das Gericht wurde ihnen (denen, die auf den Thronen Platz genommen hatten) gegeben.

Und (ich sah) die Seelen derer, die mit dem Beil enthauptet worden waren wegen des Zeugnisses Jesu und wegen des Wortes Gottes.

Und (ich sah) alle (Seelen), die nicht angebetet hatten das Tier und sein Bild

und nicht angenommen hatten das Kennzeichen auf ihre Stirn und auf ihre Hand.

Und sie wurden lebendig und herrschten mit CHRISTUS tausend Jahre.

138 Die Katholische Kirche hat den Milleniarismus nicht in jeder Form definitiv verurteilt. Klar verurteilt wurden nur die „krasse, radikale, schwärmerische“ Form des Millenniarismus mancher Irrlehrer (wie etwa Montanus im 2. Jh.), welche von zügellosen ,fleischlichen Genüssen“ während der tausendjährigen Zeit schwärmten. Viel vorsichtiger aber lautete die Stellungnahme des Hl. Offiziums (DH 3839; vgl. auch Katechismus der Katholischen Kirche Nr. 676) unter Pius XII. vom 20. Juli 1944 zu der Anfrage, was vom ,gemäßigten Millenniarismus“ zu halten sei (beschrieben als die Lehre, dass Christus, vor dem Endgericht sichtbar auf dieser Erde regieren werde, sei es mit oder ohne einer vorhergehenden Auferstehung vieler Gerechter): „Das System des gemäßigten Millenniarismus kann nicht sicher gelehrt werden.“ Es darf demnach nicht als sichere Glaubenswahrheit ausgegeben, aber eben doch vertreten werden. Erst recht gilt dies für Vorstellungen vom Millenium, wie sie z.B. Iannuzzi vertritt, wonach Christus während des Millenniums nicht in menschlicher Gestalt auf Erden herrschen wird, sondern nur von Himmel aus über die Erde herrscht und auf ihr lediglich durch seine (dann allgemein anerkannte) Präsenz in Gestalt des eucharistischen Brotes anwesend sein wird. Iannuzzis Buch erschien mit kirchlicher Druckerlaubnis. 
20,5 Die übrigen der Toten wurden nicht lebendig, bis die tausend Jahre vorüber waren. Dies ist die erste Auferstehung.

20,6 Selig und heilig sind alle, die Anteil haben an der ersten Auferstehung. Über sie hat der zweite Tod keine Macht und sie werden Priester Gottes und Christi sein und mit ihm in den tausend Jahren herrschen.

\section{Auslegung}

20,1 Und ich sah einen Engel aus dem Himmel herabkommen, der den Schlüssel zum Abgrund und eine große Kette in seiner Hand hielt.

20,2a Und er ergriff den Drachen, die alte Schlange, die Teufel und Satan heißt. Und er fesselte ihn (...)

Der Engel könnte Christus sein, der als Engel (= Bote) Gottes kam, um Satan zu entmachten (Hebr 2,14). Oder es ist ein Engel im eigentlichen Sinn. Dann dürfte es Michael sein, der nach Apk 12,7 den Kampf gegen Satan leitet. Die FeSSELUNG SATANS bedeutet seine Entmachtung, womit aber nur eine relative Entmachtung gemeint sein kann (siehe Vers 5).

WANN ist (oder wird) diese Fesselung geschehen? Wir haben bereits in der Einleitung zu Apk 20 gesehen, dass der Beginn des Tausendjahr-Reichs (und folglich die Fesselung, die diesen Beginn kennzeichnet) nicht erst mit der der Wiederkehr Christi erfolgt, sondern vorher angesetzt werden sollte. Im Wesentlichen gibt es hierzu drei in der katholischen Bibelauslegung vertretene Ansichten: Entweder man sagt mit Augustinus, dass die Fesselung Satans bereits bei der ersten Ankunft Christi geschah. Oder man sagt mit AlCAZAR, dass sie mit dem Sturz des römischen Reiches erfolgte. Oder man sagt schließlich mit FÉRET, dass die Fesselung noch in der Zukunft liegt. Ich würde für eine Kombination der beiden ersten Ansichten plädieren, ohne die dritte ganz ausschließen zu können.

(1) Zunächst hat AUgustinUs recht, dass schon bei der ersten Ankunft Jesu eine „Fesselung“ Satans vollzogen wurde. Das zeigen z. B. Christi Worte in Mt 12,26-29: „Wenn ich durch den Geist Gottes die Dämonen austreibe, so ist das Reich Gottes schon zu euch gekommen. Oder wie kann jemand hineingehen in das Haus des Starken und dessen Gefäße rauben, wenn er nicht zuvor den Starken fesselt?"

Nur weil Jesus „den Starken“ (d. h. Satan) bereits gefesselt hatte, konnte er ihm also seine „Gefäße“ (d. h. die dämonisch Besessenen) entreißen. Die Fesselung des Satans leitet aber das Tausendjährige Reich ein, und im Einklang damit folgert Jesus: „so ist das Reich Gottes schon zu euch gekommen“. Die durch CHRISTUS bewirkte Fesselung Satans erfolgte somit anfanghaft schon bei seinen ersten Dämonenaustreibungen (Mt 12,29, Lk 11,21). Sie erreichte dann aber einen geheimnisvollen Höhepunkt bei seinem Tod. Denn kurz vor seinem Leiden sagte Jesus: „Nun wird der Herrscher dieser Welt (Satan) herausgeworfen" (Joh 12,31). Und im Hebräerbrief $(2,14)$ heißt es, dass CHRISTUs kam, um „,durch seinen Tod den Teufel zu entmachten“ Vgl. auch Kol 2,14-15. Diese Entmachtung zeigt sich vor allem darin, dass die wahre Gottesverehrung in nachchristlicher Zeit auf einem größeren Teil der Erde verbreitet ist vorher, wo sie auf das Volk Israel beschränkt war, und auch dort nur in sehr beschränktem Maße Wirklichkeit wurde.

(2) Satans Fesselung begann also beim ersten Kommen Christi, aber (und hierin hat ALCAZAR recht) sie wurde in ihrer geschichtlich sichtbaren Auswirkung erst nach den Ereignissen vollendet, von denen bis zum Ende von Kapitel 19 die Rede war, insbesondere nach dem Ende der Verfolgungen (312), dem Fall Roms (410) und dem Sturz der beiden Tiere (um 600).

(3) Wenn man das Mittelalter aber nicht als genügend christlich einschätzt, um von einer relativen Fesselung Satans sprechen zu können, müsste man mit FÉRET sagen, dass auch heute die Fesselung Satans noch nicht ihre volle Auswirkung gezeitigt hat, und dass möglicherweise die Krisen unserer Zeit (Hitler usw.) ein letzter Verzweiflungskampf der Höllenmächte vor ihrer kurz bevorstehenden Fesselung sind. Ich würde jedoch diese in Richtung eines gemäßigten Millenniarismus weisende Sicht Férets eher ablehnen und die Fesselung Satans um das Jahr 600 als abgeschlossen betrachten. 
Die Fesselung Satans dauert TAUSEND JAHRE, d. h. symbolisch: „eine unüberschaubar lange Zeit“. Nach unserer Auslegung reicht sie von der ersten Ankunft Christi bzw. von der Überwindung Roms bis zur erneuten Entfesselung Satans am Ende der Geschichte, von in den Versen 7-15 noch die Rede sein wird.

Die Zahl 10 bezeichnet eine (relativ kleine, übersichtliche) vollständige Menge (Zahl der Finger, Zahl der Gebote, Zahl der Plagen), die Zahlen $100(=10 \cdot 10=$ Flächeninhalt eines Quadrats mit Seitenlänge 10) und $1000(=10 \cdot 10 \cdot 10=$ Rauminhalt eines Würfels mit Seitenlänge 10) bezeichnen ebenfalls eine vollständige Menge, wobei 100 aber eine große Menge symbolisiert (siehe Mt 13,23, wo Jesus den eifrigsten Jüngern einen ,hundertfachen“ Lohn verheißt) und die Zahl 1000 eine unüberschaubar große Menge. 1000 kann sogar für die Unendlichkeit im strengen Sinn stehen: Gott ,gedenkt auf ewig seines Bundes, des Wortes, das er verheißen hat für tausend Generationen." (Ps 105,8), d. h. für immer. Siehe auch Ps 90,4 (= 2 Petr 3,9): ,tausend Jahre sind vor dir [Gott] wie ein Tag“, womit nicht gesagt werden soll, dass Gott einen ganzen Tag braucht, um 1000 Erdenjahre zu überschauen, sondern dass er als überzeitliches Wesen eine unübersehbar große (hier sogar: unendliche) Zeitspanne in einem einzigen Moment überblicken kann. Vergleiche noch Ex 20,6, Dt 5,10 und 7,9.

Obgleich die Zeitdauer der 1000 Jahre also nicht wörtlich genommen werden muss, so können die 1000 Jahre gleichwohl eine wörtliche Erfüllung erhalten. Denn die „Fesselung“ Satans scheint ein halbes Jahrtausend gedauert zu haben, von Christi Geburt bis zum Ende des heidnischen Altertums im 6. Jahrhundert. Danach begann das christliche Mittelalter, das durch die Vorherrschaft des Christentums geprägt war. Dieser Zustand dauerte ziemlich genau 1000 Jahre, nämlich bis ins 16. Jahrhundert. Dann begann die Neuzeit, in welcher das Christentum immer mehr geschwächt und zurückgedrängt wurde. Könnte die Neuzeit der (vielleicht ebenfalls mehrere Jahrhunderte dauernde) Prozess der „Entfesselung“ Satans sein, ganz entsprechend zu dem Prozess seiner „Fesselung“? Es scheint einiges dafür zu sprechen, aber wir können es nicht mit Sicherheit behaupten.

Dass der Teufel seit Anbruch der Neuzeit in besonderer Weise „los“ ist, wird man nicht leicht bestreiten können, wenn man den Ausbruch des Hexenverfolgungswahns beim Übergang vom Mittelalter zur Neuzeit, sodann die Konfessionskriege, den Nationalismus, Absolutismus, Atheismus und Kommunismus, die Weltkriege, Umweltzerstörungen, Drogen, den Abtreibungswahn, und schließlich den Kult des Bösen bis hin zum offen propagierten Satanismus unserer Tage in Betracht zieht. Aber es ist unklar, was dies bedeutet: Es könnten Zeichen der Entfesselung Satans nach den tausend Jahren sein, aber vielleicht auch Zeichen seiner bevorstehenden erstmaligen weltweiten Fesselung, welcher sich Satan verzweifelt entwinden möchte. FÉRET glaubt das Zweite.

Nach der 1942 von FÉRET veröffentlichten Auslegung lebt das „Tier“ nach der Besiegung Roms noch bis heute in seinen ,zehn Hörnern“ bzw. ,zehn Königen“ weiter, d. h. in den Staaten, die auf das Römische Reich gefolgt sind. Diese Staaten haben, so meint FÉRET, zwar bereits in der Vergangenheit christliche Werte verwirklicht, aber noch längst nicht so überzeugend, dass man von einer Überwindung des Tieres und einer Bindung Satans sprechen könne. Jetzt aber liege das Tier in den letzten Zügen, und bald könnte das tausendjährige Reich beginnen, in dem zwar das Böse nicht völlig ausgerottet sein wird, aber das Evangelium klar die Oberhand behält. Im Sinne von FÉRET schrieb 1942 auch ein anderer berühmter Katholik, er sei überzeugt, dass das „Zukunftsprogramm“ der Kirche „,bestimmt viel größer und gesicherter ist als ihre zweitausendjährige Vergangenheit“, und dass „,die Frohbotschaft erst in der Zeit ihres Beginnens steht“ (A. D. SERTILlangES).

Das Hauptargument von FÉRET ist, dass im Mittelalter die christlichen Ideale nur mäßig verwirklicht waren, wenn man von den Heiligen absieht. Aber ich würde einwenden: Die tausend Jahre werden in der Apokalypse keineswegs als glorreiche Zeit für die Kirche auf Erden beschrieben. Es ,,herrschen“ nämlich während der tausend Jahre mit CHRISTUS nur auserwählte Heilige vom Himmel aus, während die anderen „,nicht zum Leben kamen“ (siehe Vers 5). Diese ,anderen“, die den größten Teil der Menschheit ausmachen, verblieben also im Herrschaftsbereich des Teufels, ,der die Macht hat über den Tod" (Hebr 2,14). Somit ist das Tausendjahrreich ein Zwischenreich, in dem Tod und Leben, Licht und Schatten, Unkraut und Weizen nebeneinander stehen. Das passt meines Erachtens sehr gut zum christlichen Mittelalter. 
Aber ich wiederhole: Wir können hier nichts mit Sicherheit behaupten. Denn Jesus hat jegliche Äußerung über die Zeit des Weltendes als ungebührlich zurückgewiesen: „Es ist nicht eure Sache, Zeiten oder Fristen zu wissen, die der Vater in seiner Macht festgesetzt hat“" (Apg 1,7). Äußerst scharf betonte Jesus, dass niemand den Termin des Weltendes kennt, da noch nicht einmal er selber (als Offenbarungsmittler, d. h. Mensch) davon wusste: „Jenen Tag und jene Stunde kennt niemand, auch nicht die Engel im Himmel, auch nicht der Sohn, sondern nur der Vater allein" (Mt 24,36). Schließlich warnte Jesus ausdrücklich davor, auf falsche „Propheten“ zu hören, welche die Zeit des Weltendes kennen wollen: „Seht zu, dass ihr nicht verführt werdet! Denn viele werden in meinem Namen kommen und sagen ,Ich bin es ', und: ,Die Zeit ist gekommen'. Lauft ihnen nicht nach!“”(Lk 21,8).

\section{0,3a Und er warf ihn in den Abgrund und verschloss und versiegelte über ihm, ...}

Mit ABGRUND ist hier nicht die Hölle als Strafort gemeint (wie in Lukas 8,31), da der Teufel erst in Vers 20,10 in die Strafhölle geworfen wird. Gemeint ist die Hölle als Ursprung verderblicher Einflüsse („Höllenmächte“), gedacht als symbolischer Ort, wo alle bösen Geister und Gedanken wohnen, und von wo aus sie zuvor ihre Angriffe auf die Welt führen (vgl. 9,2-3, 11,7 und 17,8 wo die Heuschrecken und das „Tier“ aus diesem Abgrund hervorgekommen waren).

Das FeStBINDEn des Teufels in diesem Abgrund bedeutet also, dass der Teufel dort festgehalten wird, wo er „zu Hause“ ist. Damit kann er nur noch über die Menschen herrschen, die sich mit einem großen $\mathrm{Ma}$ von Freiwilligkeit zu ihm hin begeben. Der Teufel gleicht also einem angeketteten Hund, der zwar noch innerhalb eines begrenzten Wirkbereichs - im Abgrund und seinen Randbereichen - ,umhergeht wie ein brüllender Löwe und sucht, wen er verschlingen kann“ (1 Petr 5,8), aber eben nur denjenigen verschlingen kann, der sich aus freien Stücken nah genug an ihn heranwagt. Wer sich dagegen eng genug an CHRISTUS klammert, kann nicht mehr vom Teufel überwältigt werden. ${ }^{139}$

Das Verschliessen des Abgrundes über dem Teufel bedeutet somit, dass der Teufel nicht hinaus kann; nicht aber, dass die Menschen nicht zu ihm hineinkönnen.

Die zusätzliche Versiegelung des Abgrundes könnte folgende Bedeutung zu haben: Wenn der Durchgang zum Teufel durch ein Siegel verschlossen ist, so muss jeder, der sich in die Nähe des Teufels begibt, das Siegel brechen. Dadurch macht er sich aber einer besonderen Gotteslästerung schuldig. Wer also nach dieser Versiegelung sich dennoch zum Teufel begibt, läd größere Schuld auf sich als jemand, der in vorchristlicher Zeit auf seiner Seite stand.

Wichtig ist, dass das BINDEn, Verschliessen und Versiegeln keine totale Entmachtung Satans bedeutet. Ganz im Gegenteil kann Satan seine Wut im Abgrund austoben bei denen, die sich in seine Gewalt begeben, wie wir es in all den antichristlichen Aktivitäten und Ereignissen sehen, welche sich zwischen der ersten und der zweiten Ankunft Christi abspielen. Aber all diese Aktivitäten sind begrenzt, stoßen auf den Widerstand der Christen, und werden niedergehalten durch die Predigt des Evangeliums, die Arbeit der Kirche und das segensreiche Wirken der Heiligen im Lauf der Geschichte. Darin offenbart sich also die relative Begrenzung der Macht des Teufels und seine Gefangenschaft im „Abgrund“.

Möglich wäre auch eine etwas andere Deutung: Die Bindung des Teufels bedeutet sein persönliches Festgehaltenwerden an einem Strafort, so dass er die Menschen und Völker in eigener Person nicht mehr verführen kann, sondern nur noch indirekt und in abgeschwächter Weise durch die anderen Dämonen. Man müsste dann sagen, dass z. B. die Versuchung des Hl. ANTONIUS durch den Teufel in Wirklichkeit durch stellvertretend für diesen auftretende untere Dämonen erfolgte. Im Ergebnis kommt diese Auslegung aber mit unserer darin überein, dass die Bindung des Teufels nur zu einer relativen Abschwächung dämonischer Aktivität führt.

139 Vgl. die Klage Satans vor dem Mönchsvater AnTonıUs: „Ich habe keinen Platz mehr, keine Waffe, keine Stadt. Überall sind Christen, und jetzt ist auch noch die Wüste mit Mönchen erfüllt“ (Athanasıus, Vita Antonii Kap. 41). „Als der Herr auf die Erde kam, da stürzte der böse Feind nieder, und seine Kräfte wurden schwach“ (ebd. Kap. 28). Er ,wurde gebunden vom Herrn wie ein Sperling, damit er von uns verspottet werde“ (ebd. Kap. 24). Ebenso sagt der Dämon in der Vita des hl. Pachomius: „Seitdem die allgewaltige, heilbringende Menschwerdung Christi auf der Welt zur Tat geworden ist, sind wir machtlos“ (ANonymus, Vita Pachomii (griechische Ausgabe von Haltin: Vita Altera Kap. 83, vgl. auch Paraliponema Kap. 26; deutsche Ausgabe Stegmann Kap. 44). 
20,3b (und versiegelte über ihm,) damit er nicht mehr die Völker verführe, bis die tausend Jahre vorüber sind. Dann muss er für kurze Zeit losgebunden werden.

Vor dem Kommen Christi hatte der Satan DIE VÖLKER verführt, da alle Völker, bis auf jenes der Juden (des erwählten Volkes), den falschen Göttern gedient hatten. Unter „Völker“ hat man nach biblischem Sprachgebrauch vor allem die nichtjüdischen Völker, d. h. die „Heidenvölker“ zu verstehen, so dass man schlicht sagen kann: Die Völker waren alle in der Hand Satans.

Nach dem Fall Roms, das nochmals ,alle Völker“ verführt hatte (18,23), kam aber die Fesselung Satans zum Abschluss. Von da an verlor Satan immer mehr Völker an die Kirche, die bis zum Ende der Zeiten sogar ,allen Völkern“ das Evangelium verkündet haben wird (Mt 24,14). Zwar gelingt es Satan auch jetzt immer wieder einmal, einzelne Völker von CHRISTUS abfallen zu lassen, nicht mehr jedoch DIE Völker, d. h. ihre Gesamtheit.

Am Ende der Zeiten wird Satan FÜR KURZE ZEIT LOSGEBUnDEN werden, d. h. dann wird er wieder eine allgemeine Verfolgung entfachen und die Gesamtheit der Völker verführen.

20,4a Und ich sah Throne, und man nahm darauf Platz.

Und das Gericht wurde ihnen (denen, die auf den Thronen Platz genommen hatten) gegeben.

Und (ich sah) die Seelen derer, die mit dem Beil enthauptet worden waren

wegen des Zeugnisses Jesu und wegen des Wortes Gottes.

Johannes sieht die SEELEN der Märtyrer, die sich auf Throne setzten. Den verstorbenen Märtyrern wurde DAS GERICHT gegeben, d. h. sie dürfen als „Beisitzer“ teilnehmen an den Gerichtsentscheidungen Gottes. Die MÄRTYRER werden hier extra erwähnt, nicht weil sie die einzigen Heiligen sind, die am Gericht teilnehmen werden, sondern weil sie es in besonderer Weise verdienen, beim gerechten Gericht über diejenigen dabei zu sein, von denen sie einst ungerecht gerichtet worden sind. An sich werden aber auch Nicht-Märtyrer am Gericht teilnehmen, denn Jesus lehrt eine besondere Teilnahme der Apostel am Gericht (Mt 19,28, Lk 22,30), von denen nicht alle als Märtyrer gestorben sind, und Paulus sagt ganz allgemein: „Wisst ihr nicht, dass die Heiligen die Welt richten werden?“ (1 Kor 6,2)

Die Seelen der Märtyrer hatte Johannes bereits in 6,9-11 gesehen, jedoch nicht auf den Gerichtsthronen, sondern unter dem himmlischen Altar: Denn ihre Herrschaft hatte damals noch nicht im vollem Maß begonnen. Erst nach dem Fall Roms und der beiden Tiere, beginnend mit der Himmelfahrt der „Zwei Zeugen“ $(11,12)$, kam die Epoche ihrer eigentlichen, weltgeschichtlich sichtbaren Herrschaft.

20,4b Und (ich sah) alle (Seelen), die nicht angebetet hatten das Tier und sein Bild und nicht angenommen hatten das Kennzeichen auf ihre Stirn und auf ihre Hand. Und sie wurden lebendig und herrschten mit CHRISTUS tausend Jahre.

Nach den Seelen der Märtyrer sieht Johannes die Seelen aller, DIE DAS TIER NICHT ANGEBETET hatten. Diese kamen zusammen mit den Märtyrern zur Herrschaft: In unsichtbarer Weise gleich nach ihrem Tod, in weltgeschichtlich sichtbarer Weise nach dem Fall Roms und der beiden Tiere.

Was ist aber damit gemeint, dass sie Lebendig wurden? Da von SEELEN die Rede ist, ist keine leibliche Auferstehung gemeint. Tod und Leben wird von der Seele insofern ausgesagt, als sie sich entweder in der Gnade und Gottesgemeinschaft befindet (= Leben) oder in der Sünde und Gottesferne (= Tod). Vom Geistigen TOD der Seele war bereits in 3,1 die Rede, wo der Bischof von Sardes ermahnt wurde: „Du hast einen Namen, dass du lebst, und doch bis zu tot“. Vgl. auch 1 Tim 5,6 sowie Eph 2,5, wo Paulus sagt, dass ,wir tot waren durch die Sünden“. 
Diesem geistigen Seelentod, der schon vor dem körperlichen Tod beginnen kann und nach dem körperlichen Tod in der Hölle vollendet wird, entspricht ein geistiges zum-Leben-Kommen der Seele, das ebenfalls schon mitten im Leben vor dem körperlichen Tod beginnen kann und nach dem körperlichen Tod im Himmel vollendet wird. Von diesem GeIsTigen ZUM-LEBEN-Kommen spricht Jesus, wenn er im Johannesevangelium sagt: „Wer mein Wort hört und dem glaubt, der mich gesandt hat, ... ist schon aus dem Tod in das Leben hinübergegangen“ (Joh 5,24). Auch PAULUS spricht von einer schon erfolgten geistigen Auferstehung: „Gott ... hat uns, die wir infolge unserer Sünden tot waren, in seiner großen Liebe ... zusammen mit CHRISTUS lebendig gemacht. ... Er hat uns mit CHRISTUS auferweckt und uns mit ihm in den Himmel hineinversetzt" (Eph 2,4-6; vgl. Eph 5,14, Kol 1,3).

Das geistige Leben beginnt mit der Taufe, wie die Umschreibung der Taufe als „Bad der Wiedergeburt“ (Tit 3,5) zeigt. Meint also Johannes mit dem Zum-Leben-Kommen hier Glaube und Taufe? Wohl nicht in erster Linie. Denn es ist die Rede von Seelen der bereits hingerichteten Märtyrer im Himmel. Außerdem heißt es, dass der zweite Tod (= die Hölle, siehe Vers 14) diese Seelen nicht mehr berühren kann (Vers 6): sie sind also bereits endgültig zum Leben ,wiedergeboren“, was auf die noch auf Erden lebenden Getauften nicht zutrifft. Beim Zum-Leben-Kommen dieser Seelen muss man also an jene endgültige „Wiedergeburt“ denken, die sich beim körperlichen Tod der Heiligen ereignet: Denn der Todestag der Heiligen ist ihr „Geburtstag“ für den Himmel, an dem sie in die Seligkeit eingehen (vgl. 14,13). Von dieser Wiedergeburt spricht Jesus wohl auch in Mt 19,28, wo er sagt: „Ihr, die ihr mir nachgefolgt seit, werdet bei der Wiedergeburt, wenn der Menschensohn sich auf den Thron seiner Herrlichkeit setzt, auf zwölf Thronen sitzen und die zwölf Stämme Israels richten." (Mt 19,28)

Die Zeit der hier gemeinten „Wiedergeburt“ beginnt damit, dass Jesus sich auf den „Thron“ setzt; das aber geschah bei seiner Himmelfahrt (vgl. Hebr 12,2 und Apk 12,5), ist also zur Zeit des Johannes schon Vergangenheit. Dies wird durch Jesu Worte in Apk 3,21 bestätigt: „Wer siegt, dem werde ich gewähren, mit mir auf meinem Thron zu sitzen, wie auch ich (bereits) gesiegt habe und mich mit meinem Vater auf seinen Thron gesetzt habe“. Neben der Auferstehung durch Glaube und Taufe und der Vollendung dieser Auferstehung durch das Eingehen in den Himmel gibt es noch eine dritte Entfaltung des geistigen Zum-Leben-Kommens: die sichtbaren Auswirkungen des neuen Lebens durch positiven Beeinflussung der Weltgeschichte vom Himmel aus. Vgl. hierzu das Lebendigwerden der ,zwei Zeugen“ in 11,11-12: „Nach dreieinhalb Tagen kam wieder Lebensgeist in sie, und sie standen auf“".

Johannes meint also meines Erachtens mit dem Zum-Leben-Kommen dreierlei: Die Grundlegung des geistigen Lebens in Glaube und Taufe, den Einzug der Heiligen in den Himmel und das Offenbarwerden ihres Einflusses nach dem Fall Roms. In erster Linie dürfte er hier die letzten zwei Bedeutungen im Auge haben.

Wie das „Leben“ der Heiligen, beginnt auch ihre HERRSCHAFT anfanghaft schon in diesem Leben durch Taufe und Glaube, insofern sie andere im Glauben zum rechten Tun anleiten können. Im eigentlichen Sinn aber beginnt ihre Herrschaft erst nach dem Tode, insofern die Heiligen dann Anteil an der göttlichen Weltregierung erhalten. Und in einer für alle Welt sichtbaren Weise beginnt ihre Herrschaft sogar erst nach dem Fall Roms. Dass aber die Herrschaft der Heiligen nicht erst nach der Wiederkehr Christi beginnt, zeigen auch die Stellen 1,5, 1,6, 1,9, 2,26-28, 3,21 und 5,10.

\section{Die übrigen der Toten wurden nicht lebendig, bis die tausend Jahre vorüber waren.}

Der Ausdruck DIE ÜBRIGEN TOTEN zeigt noch einmal, dass im Vorvers von Verstorbenen die Rede war, die geistlich „lebendig“ wurden. Die übrigen Toten, die sich nicht von der Anbetung des Tieres ferngehalten haben, wurden NICHT LEBENDIG, weder körperlich noch geistig, zumindest nicht in dem Maße, wie es bei den Heiligen in Vers 4 der Fall ist.

Diejenigen, die sich vollkommen von Gott lossagen, kommen nämlich in die Hölle (siehe 14,9-10), d. h. in den endgültigen Zustand des geistigen Todes, wo sie in einer Weise weiterexistieren, die den Namen „Leben“ nicht mehr verdient. 
Diejenigen aber, die zwar prinzipiell auf der Seite Gottes standen, aber Kompromisse eingegangen sind, kommen ins Fegfeuer, einem Durchgangsstadium zum Himmel, in dem sie geläutert werden (siehe Exkurs 3). In diesem Zustand sind sie ebenfalls noch nicht zum vollen Leben gekommen. Wenn sie schon während der 1000 Jahre ihre Läuterung im Fegfeuer beendet haben, kommen sie zwar in den Himmel, haben aber dort nicht in derselben Weise Anteil an der Herrschaft Christi wie die Heiligen von Vers 4, denn sie erlangen keinen Ruhm und keine große, weltbewegende Fürbittmacht. NACH DEN TAUSEND JAHREN aber werden alle Menschen wenigstens körperlich lebendig werden.

Im vorliegenden Text werden nur zwei Klassen von Toten aufgeführt: diejenigen, die während der 1000 Jahre herrschen, und die ,übrigen“, die in dieser Zeit nicht zum Leben kommen. Wo bleiben aber die Heiligen, die inmitten der tausend Jahre sterben und dann ruhmreich sofort in den Himmel kommen? Diese übergeht Johannes wohl deshalb, weil er sich als Betrachter am Anfang der Tausend Jahre befindet und nur die bis zum Untergang Roms gestorbenen Heiligen im Blick hat. Das zeigt sich darin, dass sich das Los der hier genannten Toten an ihrer Einstellung zum „Tier“ entscheidet.

Unser Vers zeigt, dass die „Fesselung“ Satans seine Macht nicht ganz aufhebt: Denn dass DIE ÜBRIGEN TOTEN NICHT LEBENDIG WURDEN zeigt, dass der Teufel, welcher der „Gewalthaber über den Tod“ ist (Hebr 2,14), während der tausend Jahre doch noch relativ viel Macht auf der Erde behält.

20,5b Dies ist die erste Auferstehung.

Diese Feststellung bezieht sich natürlich auf Vers 4 zurück (nicht auf 5a).

20,6 Selig und heilig sind alle, die Anteil haben an der ersten Auferstehung.

Über sie hat der zweite Tod keine Macht und sie werden Priester Gottes und Christi sein und mit ihm in den tausend Jahren herrschen.

Die Begriffe ERste Auferstehung und ZWEITER TOD zeigen, dass es eine doppelte Auferstehung und einen doppelten Tod gibt:

Die ERSTE AUfERSTEHUNG ist das Zum-Leben-Kommen von Vers 4, also die geistige Auferstehung, die anfanghaft durch Glaube und Taufe geschieht und nach dem Tod durch das Eingehen in den Himmel vollendet wird. An ihr nehmen jetzt schon die Erwählten teil.

Die ZWEITE AUfERSTEHUnG ist die körperliche Auferstehung. Sie wird ,auch die Übrigen“ von Vers 5a betreffen, also alle Menschen, und findet erst nach den 1000 Jahren statt.

Über den ersten und zweiten Tod gibt Apk 20,14 Aufschluss: „Und der Tod ... wurde in den Feuersee geworfen. Dies ist der zweite Tod: der Feuersee".

Der ERSTE TOD ist somit der nach dem Endgericht in den Feuersee geworfene Tod: der körperliche Tod, der nach dem Endgericht aufhören wird.

Der ZWEITE TOD ist nach Apk 20,14 die Weiterexistenz im Feuersee, d. h. die Höllenstrafe. Diese umfasst zunächst nur die Seele und beginnt im Zeitpunkt des körperlichen Todes (vgl. Kommentar zu 14,11 und 20,10 sowie Lk 12,4-5 und 16,22-30). Daher beginnt der zweite Tod in gewisser Weise schon in der Jetztzeit, und zwar zeitgleich mit dem ersten Tod. Die Höllenstrafe muss aber nach 20,13-15 am Weltende irgendwie auch den wiedererstandenen Leib umfangen, wie immer man sich das auch vorstellen mag. Der zweite Tod hat also einen geistigen und einen körperlichen Aspekt. Die Existenz dieser zwei Aspekte wird durch Jesu Wort in Mt 10,28 bestätigt:

„Fürchtet euch nicht vor denen, die den Leib töten,

(erster Tod)

die Seele aber nicht töten können. (umfasst nur den Leib)

Fürchtet vielmehr den,

der in der Hölle

Leib und Seele verderben kann." $\quad$ (umfasst Seele und Leib)

Der zweite Tod beginnt also in seinem geistige Aspekt schon in der Jetztzeit, aber in voller Weise erst nach den 1000 Jahren beim Endgericht. 
Eine interessante Beobachtung ist, dass die Heiligen hier PRIESTER GOTTES UND CHRISTI genannt werden. Es gibt also im Himmel „Priester Christi“, was ein klarer Beweis für die Gottheit Christi ist, denn ,,jeder Hohepriester wird aus den Menschen auserwählt und für die Menschen eingesetzt zum Dienst vor Gott“ (Hebr 5,1). CHRISTUS wird in dem Ausdruck „Priester Gottes und Christi““ also nicht von Gott unterschieden, sondern mit ihm identifiziert: „Priester Gottes und (daher auch) Christi“. Der Ausdruck „Priester Christi“ ist auch ein Beweis für die Mittlerschaft der Heiligen im Himmel, denn ein Priester ist Heilsmittler zwischen Gott und den Menschen, wobei christliche Priester der einzigartigen Mittlerschaft Christi (1 Tim 2,5) untergeordnet sind. 


\subsection{Apk 20,7-15: Das Endgericht}

In diesem kurzen Abschnitt schaut Johannes, dass nach den „tausend Jahren“ wieder alle Christen verfolgt werden wie zu Zeiten des römischen Reiches. So endet die menschliche Geschichte in einer Katastrophe, und danach kommt das Endgericht. Da das Christentum heute auf der ganzen Welt verbreitet ist, muss diese Verfolgung eine wahrhaft weltweite sein. Voraussetzung dafür scheint eine einheitliche Weltregierung zu sein, die eine derart umfassende Christenverfolgung in Gang setzen kann. Tatsächlich spricht Johannes von einem Weltdiktator, den er „Gog“ nennt. Wir steuern heute auf eine politische Einigung der Welt hin. Eine solche Einigung hätte viele Vorteile. Sie würde die Kriege der Staaten untereinander beenden, die Menschen können sich freier bewegen, das Evangelium könnte leichter verbreitet werden usw. Die Welteinigung ist also an sich nichts Negatives, so dass Christen sie unterstützen können. Wie einst die Christen im römischen Reich, können auch wir an den Idealen einer geeinten Welt mitarbeiten, diese mitgestalten und zum Guten beeinflussen: auch wenn wir wissen, dass es das Schicksal des kommenden Weltreiches sein wird, einst aufgrund der Unfähigkeit und Bosheit des erbsündlich verdorbenen Menschen unterzugehen.

\section{Text}

20,7 Und wenn die tausend Jahre vorüber sind, wird der Satan aus seinem Gefängnis losgelassen werden.

20,8 Und er wird herausgehen, die Völker an den vier Ecken der Erde zu verführen, den Gog und Magog, um sie zu versammeln für den Krieg. Die Zahl (der Kämpfenden) ist wie der Sand des Meeres.

20,9 Und sie stiegen hinauf auf die Fläche der Erde. Und sie kreisten das Lager der Heiligen ein und die geliebte Stadt. Und es kam Feuer vom Himmel herab und verzehrte sie.

20,10 Und der Teufel, ihr Verführer, wurde in den Feuer- und Schwefelsee geworfen, wo auch das Tier und der falsche Prophet (sind).

Und sie werden gepeinigt werden tags und nachts in alle Ewigkeit.

20,11 Und ich sah einen großen weißen Thron.

Und vor dem Angesicht dessen, der auf ihm saß, floh die Erde und der Himmel.

Und es wurde für sie kein Platz mehr gefunden.

20,12 Und ich sah die Toten, die großen und die kleinen, wie sie vor dem Thron standen.

Und Bücher wurden geöffnet, und noch ein anderes Buch wurde geöffnet, das Buch des Lebens.

Und die Toten wurden gerichtet nach ihren Werken aufgrund dessen,

was in den Büchern geschrieben war.

20,13 Und das Meer gab die Toten heraus, die in ihm waren, und der Tod und der Hades gaben die Toten heraus, die in ihnen waren.

Und sie wurden gerichtet, jeder nach ihren Werken.

20,14 Der Tod und der Hades aber wurden in den Feuersee geworfen.

Dies ist der zweite Tod: der Feuersee.

20,15 Wer nicht im Buch des Lebens verzeichnet war, wurde in den Feuersee geworfen.

Auslegung 
20,7 Und wenn die tausend Jahre vorüber sind,

wird der Satan aus seinem Gefängnis losgelassen werden.

Satan erhält am Ende der Geschichte wieder Macht. Aber es ist nicht erforderlich, zu sagen, dass er in allem dieselbe Macht erhält wie er sie vor dem Kommen Christi hatte. Denn die Herrschaft der Heiligen wird nach Ablauf der Tausend Jahren wohl nicht gänzlich aufhören, sondern nur (in ihrem irdischen Auswirkungen) gehemmt sein. Ebenso, wie die Fesselung Satans während der tausend Jahre nur eine relative war, so wird auch seine Entfesselung nur eine relative Einschränkung der Herrschaft der Heiligen bringen. Diese Einschränkung wird, wie der nächste Vers zeigt, vor allem durch eine politische Verfolgung der Christen bedingt sein.

20,8a Und er wird herausgehen, die Völker an den vier Ecken der Erde zu verführen, den Gog und Magog, ...

Die rätselhaften Namen Gog und Magog tauchen auch im Buch des Propheten Ezechiel (Kap. 38-19) auf. Dort ist Gog der Fürst von Magog, eines unbekannten Landes (Ez 38,2). Ezechiel sieht Gog ,nach vielen Jahren“ das Volk Israel angreifen, womit wohl das christliche Gottesvolk, das ,neue Israel", am Ende der Zeiten gemeint ist. Denn nach der Besiegung Gogs tritt das Ende der Geschichte ein (was in Ez 39,22-29 sowie in der Fortsetzung Kap. 40-48 angedeutet ist, wo ein geheimnisvoller Tempel beschrieben wird, welcher mit dem himmlischen Jerusalem identisch sein dürfte). GoG ist also Symbolname des letzten Gewaltherrschers der Geschichte, der gegen das Gottesvolk kämpfen wird:

Er ist der eigentliche ANTICHRIST, von dem Johannes in seinen Briefen spricht (1 Joh 2,18; 2 Joh 7), und den Paulus im zweiten Brief an die Thessalonicher als „Mensch der Gesetzwidrigkeit“ und „Sohn des Verderbens“ bezeichnet (2 Thess 2,1-12). Es ist der „Widersacher, der sich über alles erhebt, was Gott oder Gottesverehrung heißt", so dass er ,sich in den Tempel setzt und sich selbst als Gott ausgibt" (2 Thess 2,3-4). Man beachte, dass der Antichrist alle Götter, den wahren Gott ebenso wie die falschen, verwerfen wird, um an ihre Stelle zu treten. Vergleiche dazu den Wahlspruch des modernen Satanismus: „Es gibt keinen Gott außer dem Menschen“.

Im Gegensatz zu MAGOG setzt Johannes vor Gog den Artikel, um anzudeuten, dass es sich bei Gog um eine Person, bei Magog aber um ein Volk handelt. MAGOG, das bei Ezechiel geheimnisvollunbekannte Land oder Volk, entpuppt sich nun hier als Ausdruck für DIE VÖLKER AN DEN VIER ECKEN DER ERDE, die unter Gogs Führung gegen Christus kämpfen. Magog ist also ein die ganze Welt umfassendes Reich: das Reich des Gog.

20,8b . . um sie zu versammeln für den Krieg.

Die Zahl (der Kämpfenden) ist wie der Sand des Meeres.

20,9a Und sie stiegen hinauf auf die Fläche der Erde.

Und sie kreisten das Lager der Heiligen ein und die geliebte Stadt.

Dass die Krieger Gogs auf die Fläche der Erde HINAUfSTEIGEN, klingt ganz so, als kämen sie aus dem „Abgrund“. Es handelt sich also um Personen, die sich schon während der tausend Jahre sich vom Satan beherrschen ließen, indem sie freiwillig bei ihm im „Abgrund“ weilten. Dass sie auf die FLÄCHE DER ERDE hinaufstiegen, weist darauf hin, dass die Christen zu jener Zeit die ganze Erde ausfüllen werden: Das Evangelium wird also zuvor überall verkündigt worden sein (vgl. Mt 24,14 und Mt 28,18-20). DIE GELIEBTE STADT ist demnach die bereits über die ganze Erde ausgebreitete Kirche, und das EINKREISEN der Stadt bedeutet eine weltweite Kirchenverfolgung. 
20,9b Und es kam Feuer vom Himmel herab und verzehrte sie.

Durch einen Eingriff Gottes wird die Geschichte menschlicher Auflehnung beendet. Das FEUER erwähnt auch PETRUS: „Es gab einst (mehrere) Himmel und eine Erde, die aus Wasser und durch Wasser (Bestand hatten) kraft des Wortes Gottes. Durch beides (Wasser und Gottes Wort) ging die damalige Welt zugrunde, als sie vom Wasser überflutet wurde. Die jetzigen Himmel aber und die jetzige Erde sind durch dasselbe Wort für das Feuer aufgespart: Sie werden bewahrt bis zum Tag des Gerichts und des Verderbens der gottlosen Menschen." (2 Petr 3,5-7). Eine Feuerflut ähnlich der einstigen Wasserflut macht also der Gottlosigkeit ein Ende, und zugleich wird durch das Feuer ,der Himmel prasselnd vergehen, die Elemente werden verbrannt und aufgelöst werden“" (2 Petr 3,10). Das Feuer dieses Weltenbrandes verursacht also nicht nur das Ende der Menschheitsgeschichte, sondern auch das Ende des Kosmos in seinem bisherigen Zustand: Es erfolgt der „Weltuntergang“, bei dem jedoch keine gänzliche Vernichtung, sondern eine grundlegende Umgestaltung der Welt erfolgt (vgl. 20,11).

20,10 Und der Teufel, ihr Verführer, wurde in den Feuer- und Schwefelsee geworfen, wo auch das Tier und der falsche Prophet (sind).

Und sie werden gepeinigt werden tags und nachts in alle Ewigkeit.

Das Tier und der falsche Prophet, d. h. die politischen und philosophisch-religiösen Mächte des heidnischen Rom, waren bereits seit langem in der Hölle, in welche sie schon zu Beginn der 1000 Jahre hineingeworfen worden waren (vgl. Kommentar zu 19,20). Keineswegs beginnt also die Höllenstrafe erst am jüngsten Tag (vgl. Kommentar zu 14,11).

20,11 Und ich sah einen großen weißen Thron.

Und vor dem Angesicht dessen, der auf ihm saß, floh die Erde und der Himmel.

Und es wurde für sie kein Platz mehr gefunden.

Vor Gott FliEhEN ERdE UND HIMMEL, d.h. sie lösen sich auf, nicht um vernichtet, sondern um erneuert zu werden. Denn nicht die Substanz von Erde und Himmel, sondern nur ihre jetzige „Gestalt“ wird durch den Weltenbrand (siehe 20,9 und 2 Petr 3,10) vergehen (Kor 7,31), so dass ,,auch die Schöpfung selber befreit werden wird von der Knechtschaft der Vergänglichkeit“ (Röm 8,21). das Weltall wird völlig neue Eigenschaften bekommen, so dass man von einem Neuen Himmel und einer Neuen Erde sprechen kann (21,1): Alles wird in einen unvergänglichen Endzustand erreichen.

Der GROSSE WEISSE THRON ist der Richterthron für das Endgericht; er ist weiß, hat also die Farbe Christi $(6,1)$, der hier offenbar wie in Joh 5,26-30 als der Weltenrichter gedacht ist, der als Richter wiederkommt $(22,12)$ und im Auftrag und in der Vollmacht des Vaters richtet.

20,12 Und ich sah die Toten, die großen und die kleinen, wie sie vor dem Thron standen.

Und Bücher wurden geöffnet, und noch ein anderes Buch wurde geöffnet, das Buch des Lebens.

Und die Toten wurden gerichtet nach ihren Werken aufgrund dessen,

was in den Büchern geschrieben war.

Die BÜCHER enthalten die Werke der Menschen, und das ANDERE BUCH, DAS BUCH DES LEBENS, enthält die Namen der Erwählten. Siehe dazu Kommentar zu 3,5. Gerichtet wird nach den WERKEN im Sinne einer gerechten Vergeltung, siehe 2,23; 22,12 und 14,13 mit Kommentar.

Das GERICHT ist hier das allgemeine Weltgericht am Ende der Geschichte, mit der die eigentliche Endzeit abschließt, im Gegensatz zu dem individuellen Gericht beim Tode jedes Einzelnen (zu diesem siehe den Kommentar zu 6,11, vgl. auch 14,13). Während beim individuellen Gericht bereits das ewige Schicksal eines jeden entschieden wird, werden beim allgemeinen Weltgericht die Taten jedes einzelnen nun vor dem Forum der Gesamtmenschheit „veröffentlicht“ (vgl. Mt 10,26 und Mt 10,26). 
Diesem Gericht wird die leiblichen Totenauferstehung vorausgehen: So lehrt Paulus in 1 Thess 4,1416, dass ,zuerst die Toten in CHRISTUS auferstehen“, und dass diese dann zusammen mit den in jener Zeit noch Lebenden CHRISTUS begegnen werden (vgl. auch 1 Kor 15,22-24). Hier ist auch gesagt, dass es einige Menschen geben wird, die dem wiederkommenden CHRISTUS lebend begegnen werden und die daher nicht zu sterben brauchen. So wird das Endgericht ein Gericht über „Tote und Lebende“ sein (vgl. Apg 10,41; 1 Petr 4,5; 2 Tim 4,1). In 1 Kor 15,51 lehrt Paulus über diese zur Zeit der zweiten Ankunft Christi noch Lebenden, dass ihre Körper durch Verwandlung sogleich in die unvergängliche Existenzweise übergehen, die auch die Körper der Toten nach ihrer Auferstehung haben werden: „Wir werden nicht alle entschlafen (d. h. sterben), alle aber werden wir verwandelt werden".

Welche TOTEN sind nun in vorliegendem Vers gemeint?

- Nach der ersten, meines Erachtens richtigen Auslegung sind es die wiederauferstandenen, zuvor körperlich Toten aller Zeiten, und zwar sowohl die Guten wie auch die Bösen. Da die Toten erst nach ihrer körperlichen Auferstehung gerichtet werden, muss der Begriff TOTE in dieser Deutung die wiedererstandenen Toten meinen, obgleich Johannes ihre Auferstehung erst im nächsten Vers erwähnt. Der nächste Vers ist daher nicht als Fortsetzung, sondern als erläuternde Wiederholung des hier Gesagten aufzufassen: Tatsächlich wird dort wiederholt, dass die (auferstandenen) Toten nach ihren Werken gerichtet wurden.

Eine Schwierigkeit dieser Auslegung scheint zu sein, dass hier die am Ende der Weltgeschichte noch Lebenden, die ebenfalls gerichtet werden müssen, unerwähnt bleiben. Aber diese werden wahrscheinlich im nächsten Vers erwähnt.

- Eine zweite Auslegung wäre, dass hier von allen geistig Toten (= Sündern) die Rede ist, also von einer Gruppe, die sowohl die zur Zeit der Wiederkehr Christi noch lebenden Sünder als auch wiederauferstandene, zuvor körperlich Tote umfasst. Das Gericht wäre dann ein reines Strafgericht. Aber man kann einwenden, dass nach Mt 10,25 und 25,31-46 beim Endgericht alle Menschen anwesend sind und die Taten aller offenbart werden. In diesem Sinn werden also auch alle gerichtet: sogar auch die Heiligen des Tausendjahrreiches, welche selber „Beisitzer“ des Gerichts sind. Im negativen Sinn werden allerdings nur die Bösen gerichtet (= bestraft) werden (vgl. Joh 3,18), aber das hier beschriebene Gericht wird nicht als reines Strafgericht beschrieben. Das Vorhandensein der „Bücher“ spricht vielmehr für ein gute und böse Taten abwägendes Gericht. Daher plädiere ich für die erste Auslegung.

20,13 Und das Meer gab die Toten heraus, die in ihm waren, und der Tod und der Hades gaben die Toten heraus, die in ihnen waren.

Und sie wurden gerichtet, jeder nach ihren Werken.

Von drei Arten von „Toten“ ist hier die Rede: die TOTEN DES MEERES, die Toten DES Todes und die Toten DEs Hades.

Dass die „Toten des Todes“ extra erwähnt werden, lässt vermuten, dass die beiden anderen Gruppen keine „Toten“ im eigentlichen Sinne sind. Diese Vermutung bestätigt sich jedoch nicht für die ,Toten des Hades“, denn der Hades ist ja Aufenthaltsort von Seelen der Verstorbenen (Lk 16,23; Apg 2,27; Apk 1,18). Dass die „Toten des Hades“ zu den „Toten des Todes“ gerechnet werden müssen, ist auch dadurch angedeutet, dass die „Toten des Todes“ und die „Toten des Hades“ hier zu einer Einheit zusammengefasst werden (,gaben die Toten heraus, die in ihnen waren“, d. h. im Tod und im Hades). Diese Toten werden aber von den zuerst erwähnten „Toten, die im Meer waren“ abgegrenzt.

Somit bleibt die Vermutung bestehen, dass wenigstens die „Toten des Meeres“ keine Toten im eigentlichen Sinne sind. Diese Vermutung wird erhärtet durch die Tatsache, dass es einige Verse später heißt, dass das „Meer nicht mehr ist“ (21,1). Mit MEER ist also etwas Negatives gemeint, was in der erneuerten Welt keinen Platz mehr hat. Das aber wäre vom physischen Meer nicht verständlich: Warum sollte es, wenn es ,eine neue Erde und einen neuen Himmel“" gibt $(21,1)$, nicht auch ein neues Meer geben? Also ist das hier gemeinte MEER wohl die wogende und sturmgepeitschte Geschichte der gegenwärtigen Weltzeit, denn die Gleichsetzung von Wasser mit „,bewegten Menschenmassen“ ist bereits in Apk 17,15 ausgesprochen worden: „Die Gewässer ... bedeuten Völker und Menschenmassen, Nationen und Sprachen“. 
„DAs Meer Gab DiE Toten Heraus“ dürfte also bedeuten: Die Weltgeschichte, die nun beendet ist, gibt die in ihr befangenen Menschen heraus, sie spült diejenigen zum Thron des Endgerichts hin, die zur Zeit der Wiederkehr Christi noch am Leben waren. Warum werden diese aber ToTE genannt? Wenn man sagt, dass es sich um geistig Tote (= Sünder) handelt, müsste man fragen, wieso das MEER nur diese herausgibt und nicht auch die noch lebenden Heiligen. Mir scheint daher, dass der Begriff TOTE hier alle noch körperlich Lebenden als körperlich Todverfallene beschreibt: Personen, die ohne den Eingriff Gottes hätten körperlich sterben müssen.

Die Toten, Die Der Tod Und Der Hades Herausgeben, sind dagegen die leiblich Toten, die körperlich auferstehen. Der Unterschied zwischen beiden scheint der zu sein, dass die TOTEN DES TODES alle Verstorbenen sind, die TOTEN DES HADES aber nur diejenigen, die sich in der Hölle oder im Fegfeuer befinden (vgl. Exkurs 3).

Die Auferstehung der TOTEN DES HADES wird extra genannt, um klar zu machen, dass wirklich alle eine körperliche Auferstehung zu erwarten haben, was für die Bösen nicht leicht einsehbar ist, und daher extra betont werden muss.

20,14 Der Tod und der Hades aber wurden in den Feuersee geworfen. Dies ist der zweite Tod: der Feuersee.

Der TOD (= der geistige und körperliche Tod), und der HADES (= die Hölle und das Fegfeuer, siehe Exkurs 3), werden in den FEUERSEE geworfen, sie gehen im ZWEITEN TOD, in der Höllenstrafe auf. Damit ist das Ende des körperlichen Todes und das Ende des Fegfeuers ausgesagt. Denn wenn der Tod, der bisher den „,ersten“ (körperlichen) und „,zweiten“ (geistigen) Tod umfasste, ,,in den Feuersee geworfen" wird, welcher der zweite (geistige) Tod ist, so muss dadurch der erste Tod wegfallen. Und wenn der Hades in seiner bisherigen Form, die Fegfeuer und Hölle umfasst, ,in den Feuersee geworfen" wird, welcher die Hölle ist, so muss das Fegfeuer wegfallen.

20,15 Wer nicht im Buch des Lebens verzeichnet war, wurde in den Feuersee geworfen.

Alle Nichterwählten verfallen nun auch leiblich der Höllenstrafe: Auf nicht vorstellbare Weise wird ihr Leib, der ebenfalls als unvergänglicher und vergeistigter Leib auferstanden sein muss, in die Höllenstrafe einbezogen werden. 


\subsection{Apk 21,1-22,21: Das neue Jerusalem}

Text

21,1 Und ich sah einen neuen Himmel und eine neue Erde.

Denn der erste Himmel und die erste Erde sind vergangen, und das Meer ist nicht mehr.

21,2 Und ich sah die heilige Stadt, das neue Jerusalem, aus dem Himmel herabkommen von Gott, bereitet wie eine Braut, die sich für ihren Mann geschmückt hat.

21,3 Und ich hörte eine laute Stimme vom Thron her sagen:

Siehe das Zelt Gottes bei den Menschen, und er wird bei ihnen zelten.

Und sie werden seine Völker sein und er selbst, „Gott mit ihnen“, wird ihr Gott sein.

21,4 Und er wird jede Träne aus ihren Augen wischen, und der Tod wird nicht mehr sein, noch Trauer noch Geschrei noch Schmerz wird sein, denn das erste ist vergangen.

21,5 Und der auf dem Thron sitzt, sprach: Siehe ich mache alles neu. Und er sagt: Schreibe! Diese Worte sind glaubwürdig und wahr.

21,6 Und er sagte zu mir: Sie sind in Erfüllung gegangen.

Ich bin das Alpha und das Omega, der Anfang und das Ende.

Ich werde dem Dürstenden umsonst aus der Quelle des Lebens zu trinken geben.

21,7 Der Sieger wird dies empfangen.

Und ich werde für ihn Gott sein, und er wird für mich Sohn sein.

21,8 Aber die Feigen und Ungläubigen und Greuelbefleckten und Mörder und Unzüchtigen und Giftmischer und Götzendiener und alle Lügner:

Ihr Anteil ist der See mit brennendem Feuer und Schwefel. Das ist der zweite Tod.

21,9 Und es kam einer von den sieben Engeln, welche die sieben Schalen voll der letzten Plagen haben, und sagte: Komm hierher, ich will dir die Braut zeigen, die Frau des Lammes.

21,10 Und er brachte mich weg im Geiste auf einen großen und hohen Berg, und zeigte mir die Stadt, das heilige Jerusalem, aus dem Himmel von Gott her herabkommen.

21,11 Sie hatte die Herrlichkeit Gottes, ihr Lichtglanz war wie (der Glanz) eines wertvollen Steines, wie (der Glanz) eines wie kristallglänzenden Jaspissteines.

21,12 Sie hatte eine große und hohe Mauer, die zwölf Tore hatte.

Und auf den Toren waren zwölf Engel.

Und es waren darauf Namen geschrieben: die Namen der zwölf Stämme der Söhne Israels.

21,13 Im Osten (waren) drei Tore und im Norden drei Tore und im Süden drei Tore und im Westen drei Tore.

21,14 Und die Mauer der Stadt hatte zwölf Fundamente. Und auf ihnen waren die Namen der zwölf Apostel des Lammes.

21,15 Und der (Engel, der) mit mir redete, hatte einen goldenen Messstab, damit er die Stadt und ihre Tore und ihre Mauer messen konnte.

21,16 Und die Stadt ist viereckig angelegt, und ihre Länge ist gleich der Breite.

Und er maß die Stadt mit dem Rohr auf 12.000 Stadien.

Ihre Länge und ihre Breite und ihre Höhe sind gleich.

21,17 Und er maß ihre Mauer auf 144 Ellen nach dem Maß des Menschen, welches ist (das Maß) des Engels.

21,18 Und der Baustoff ihrer Mauer war Jaspis, und die Stadt war reines Gold gleich reinem Glas.

21,19 Die Fundamente der Stadtmauer waren mit jedem wertvollem Stein geschmückt: das erste Fundament ein Jaspis,

das zweite ein Saphir,

das dritte ein Chalcedon

das vierte ein Smaragd, 
21,20 das fünfte ein Sardonyx,

das sechste ein Sarder (Karneol),

das siebte ein Chrysolith,

das achte ein Beryll,

das neunte ein Topas,

das zehnte ein Chrysopras,

das elfte ein Hyazinth,

das zwölfte ein Amethyst.

21,21 Und die zwölf Tore waren zwölf Perlen; jedes einzelne Tor war aus einer Perle.

Und die Straße der Stadt war reines Gold wie durchsichtiges Glas.

21,22 Und einen Tempel sah ich nicht in ihr.

Denn der Herr, Gott, der Allmächtige, ist ihr Tempel: (Er) und das Lamm.

21,23 Und die Stadt braucht nicht mehr die Sonne und den Mond, damit sie in ihr scheinen. Denn Gottes Herrlichkeit scheint in ihr, und ihre Leuchte ist das Lamm.

21,24 In ihrem Licht (dem Licht der Stadt) werden die Völker wandeln. Und die Könige der Erde bringen ihre Herrlichkeit in sie.

21,25 Und ihre Tore werden am Tage nicht geschlossen werden. Nacht wird es dort nicht mehr geben.

21,26 Und man wird die Herrlichkeit und den Ehre der Völker in sie bringen.

21,27 Und nichts Unreines wird hineinkommen, und keiner, der Greuel und Lüge tut, sondern nur, wer geschrieben steht im Lebensbuch des Lammes.

22,1 Und (der Engel) zeigte mir den Fluss des Wassers des Lebens, klar wie Kristall, der ausgeht vom Thron Gottes und des Lammes.

22,2 Und inmitten der Straße und aufden beiden Seiten des Flusses war das Holz (= die Bäume) des Lebens, das zwölf(mal) Früchte bringt: in jedem Monat bringt es seine Frucht.

Und die Blätter des Holzes (d. h. der Bäume) dienen zur Heilung der Völker.

22,3 Und es wird nichts Verfluchtes mehr sein.

Und der Thron Gottes und des Lammes wird in ihr (in der Stadt) sein.

Und seine Knechte werden ihm dienen.

22,4 Und sie werden sein Angesicht schauen.

Und sein Name wird auf ihrer Stirn geschrieben stehen.

22,5 Und Nacht wird nicht mehr sein.

Und sie brauchen weder das Licht einer Lampe noch das Licht der Sonne,

denn der Herr, Gott, wird über ihnen leuchten, und sie werden herrschen in alle Ewigkeit.

22,6 Und er (der Engel) sagte zu mir: Diese Worte sind zuverlässig und wahr.

Gott, der Herr der Geister der Propheten hat seinen Engel gesandt, um seinen Knechten zu zeigen, was bald geschehen muss.

22,7 Und siehe, ich komme bald. Selig ist, wer die Worte der Prophezeiung dieses Buches bewahrt.

22,8 Und ich, Johannes, bin es, der dies gehört und gesehen hat.

Und als ich gehört und gesehen hatte, fiel ich nieder,

um vor den Füßen des Engels anzubeten, der mir dieses alles gezeigt hatte.

22,9 Und er sagte zu mir: Sieh dich vor, tu es nicht!

Dein Mitknecht bin ich und (der Mitknecht) deiner Brüder,

der Propheten und aller, welche die Worte dieses Buches bewahren. Bete Gott an!

22,10 Und er sagte zu mir:

Versiegle die Worte der Prophetie dieses Buches nicht! Denn die Zeit ist nahe.

22,11 Wer Unrecht tut, tue weiter Unrecht, und der Schmutzige beschmutze sich weiter, und der Gerechte übe weiter Gerechtigkeit und der Heilige heilige sich weiter!

22,12 Siehe, ich komme bald und mein Lohn ist mit mir, um jedem zu vergelten wie sein Werk es verdient. 
22,13 Ich bin das Alpha und das Omega, der Erste und der Letzte, der Anfang und das Ende.

22,14 Selig sind die, die ihre Kleider waschen, damit sie Anrecht haben auf das Holz des Lebens und damit sie durch die Tore eingehen in die Stadt.

22,15 Draußen sind die Hunde und die Giftmischer und die Unzüchtigen und die Mörder und die Götzendiener und jeder, der die Lüge tut.

22,16 Ich, Jesus, habe meinen Engel gesandt, um euch dieses zu bezeugen um der (Orts-)Kirchen willen. Ich bin die Wurzel und das Geschlecht Davids, und der glänzende Morgenstern.

22,17 Und der Geist und die Braut sagen: Komm!

Und der, der es hört, soll sagen: Komm!

Und der Dürstende soll kommen,

und wer will, empfange das Wasser des Lebens als Geschenk.

22,18 Ich bezeuge jedem, der die Worte der Prophetie dieses Buches hört:

Wenn jemand zu ihnen etwas hinzufügt,

wird Gott ihm die Plagen auferlegen, die in diesem Buch aufgezeichnet sind.

22,19 Und wenn jemand von den Worten des Buches dieser Prophetie etwas wegnimmt,

wird Gott ihm seinen Anteil am Holz des Lebens und an der heiligen Stadt nehmen,

(Dinge,) die in diesem Buche aufgezeichnet sind.

22,20 Der dies bezeugt, sagt: Ja, ich komme bald.

Amen, komm, Herr Jesus!

22,21 Die Gnade des Herrn Jesus sei mit allen!

Auslegung

21,1 Und ich sah einen neuen Himmel und eine neue Erde.

Denn der erste Himmel und die erste Erde sind vergangen, und das Meer ist nicht mehr.

NeU ist nicht die Substanz von Himmel Und ERDE, sondern ihr Zustand, ihre „Gestalt“ (vgl. 1 Kor 7,31), indem das Vergängliche in einen Zustand der Unvergänglichkeit übergegangen ist (vgl. 1 Röm 8,21 und 1 Kor 15,53). DAS MEER IST NICHT MEHR. Das dürfte nicht vom buchstäblichen Meer gelten. MEER ist hier wahrscheinlich Symbol für das unruhigen Hin- und Herwogen der Menschheitsgeschichte vor dem Weltgericht (siehe Kommentar zu 20,13).

21,2 Und ich sah die heilige Stadt, das neue Jerusalem, aus dem Himmel herabkommen von Gott, bereitet wie eine Braut, die sich für ihren Mann geschmückt hat.

Die HEILIGE STADT ist die vollendete Kirche, ein Gegenbild der antichristlichen Stadt „Babylon“ aus Kap. 17. Die Kirche wird auch das NEUE JERUSALEM genannt, im Gegensatz zum alten Jerusalem, dem Sinnbild Israels.

Die Stadt kommt AUS DEM HIMMEL HERAB: bislang war die absolut reine Kirche nur bei den Heiligen im Himmel verwirklicht, während die Kirche auf Erden aus „Unkraut und Weizen“ (vgl. Mt 13,24-30), d. h. aus Sündern und Heiligen bestand. Jetzt aber, nach dem Endgericht, sind Sünder und Heilige getrennt, und es gibt nur noch eine „Abteilung“ der Kirche: die himmlische, die ihren Glanz nun auf die ganze Erde (d. h. auf das ganze körperliche Universum) hin ausbreitet und so die Erde vollständig ,in Besitz nimmt“.

Die Kirche wird hier BRAUT, und in Vers 9 (EHE)FRAU Jesu genannt (vgl. auch 21,9 und 22,17). Sie ist also Ehefrau und doch ewig Braut, weil sie ein ewiges Hochzeitsfest mit Jesus feiert (vgl. Mt 25,10). Die Ehefrau-Braut erinnert auch an die Frau aus Apk 12: Maria und die marianisch geprägte Kirche. 
21,3 Und ich hörte eine laute Stimme vom Thron her sagen:

Siehe das Zelt Gottes bei den Menschen, und er wird bei ihnen zelten.

Und sie werden seine Völker sein und er selbst, ,Gott mit ihnen“, wird ihr Gott sein.

21,4 Und er wird jede Träne aus ihren Augen wischen, und der Tod wird nicht mehr sein, noch Trauer noch Geschrei noch Schmerz wird sein, denn das erste ist vergangen.

Hier wird die vertraute Gemeinschaft der Heiligen mit Gott beschrieben, ihre Unsterblichkeit (,,der Tod wird nicht mehr sein") und das Fernsein jeglichen Leidens.

Gott wird „GOTT MIT IHNEN“ genannt, was an den Namen erinnert, der Jesus gemäß der JesajaProphezeiung gegeben werden soll: „Man wird ihm den Namen Immanuel geben, das heißt: ,Gott mit uns “" (Mt 1,23, Jes 7,14). JESUS ist es also, der hier als IHR GOTT bezeichnet wird: ein klares Zeugnis für seine Gottheit. Jesus ist bei seinem ersten Kommen nicht als „Immanuel“ bezeichnet worden, weil seine Gottheit noch nicht offensichtlich war. Jetzt aber, im „Neuen Jerusalem“, wird er von allen so benannt werden. Es ist sein „,neuer Name“, von dem schon in 3,12 die Rede war.

21,5 Und der auf dem Thron sitzt, sprach: Siehe ich mache alles neu. Und er sagt: Schreibe! Diese Worte sind glaubwürdig und wahr.

21,6 Und er sagte zu mir: Sie sind in Erfüllung gegangen. Ich bin das Alpha und das Omega, der Anfang und das Ende. Ich werde dem Dürstenden umsonst aus der Quelle des Lebens zu trinken geben.

21,7 Der Sieger wird dies empfangen.

Und ich werde für ihn Gott sein, und er wird für mich Sohn sein.

Gott ist AlPha und OMEgA (erster und letzter Buchstabe des griechischen Alphabets), d. h. Ursprung und Ziel der Geschichte, des Menschen und der Welt: Alles ist ,,aus ihm und durch ihn und auf ihn hin geschaffen“ (Röm 13,36).

Gott selbst (genauer der Hl. Geist) ist auch die QUELLE DES LEBENS (zu ihr siehe auch Kommentar zu 7,17 und 22,1), aus der die DüRSTENDEN, d. h. jene, die sich nach Gott sehnen, trinken werden. Gott wird ihnen schenken, dass sie ihn schauen dürfen von Angesicht zu Angesicht (siehe auch Kommentar zu 22,4). Das TRINKEN aus der Quelle ist die lebendigmachende und beseligende Gottesschau, welche Jesu Hauptverheißung für das ewige Leben ist (Joh 17,3). Diese Schau setzt eine enge Vertrautheit zu Gott voraus, wie sie nur Kindern Gottes zusteht. Daher erfolgt hier auch die Verheißung der Gottessohnschaft: Gott wird die Heiligen gleichsam als seine Kinder adoptieren.

21,8 Aber die Feigen und Ungläubigen und Greuelbefleckten und Mörder und Unzüchtigen und Giftmischer und Götzendiener und alle Lügner:

Ihr Anteil ist der See mit brennendem Feuer und Schwefel. Das ist der zweite Tod.

Nach der Schilderung der Seligkeit der Heiligen wendet sich nochmals der Blick der den Gottlosen in der Hölle zu (vgl. 14,11 und 20,14-15). Das fressende FEUER steht im Gegensatz zum WASSER der Seligen (Vers 6). Beides ist symbolisch.

Zu den GifTMischern vgl. den Kommentar zu 9,21.

Zur den LÜGE vgl. auch die Kommentare zu 10,6a, 14,5, 21,27 und 22,15.

Es ist besonders bemerkenswert, dass auch die im Alltag häufig als Kavalliersdelikt angesehene Lüge in diesem Lasterkatalog (vgl. 9,21 und 22,15) unter den verdammenswerten Lastern erscheint. Bei näherem Nachdenken erscheint dies jedoch als konsequent: Der Lügner (Betrüger) kann in der Gemeinschaft des wahrhaftigen Gottes keinen Bestand haben.

21,9 Und es kam einer von den sieben Engeln, welche die sieben Schalen voll der letzten Plagen haben, und sagte: Komm hierher, ich will dir die Braut zeigen, die Frau des Lammes. 
21,10 Und er brachte mich weg im Geiste auf einen großen und hohen Berg, und zeigte mir die Stadt, das heilige Jerusalem, aus dem Himmel von Gott her herabkommen.

Der EINE VON DEN SIEBEN SCHALEN-ENGELN ist wohl immer noch derselbe, der schon 17,1 erschienen war und JOHANNES in die Wüste entrückt hatte $(17,3)$; seitdem hatte JOHANNES keinen Ortswechsel vorgenommen. Es ist passend, dass dieser Engel, dem die Aufgabe zukam, JoHANNES die grauenhafte Stadt Babylon als HuRE zu zeigen, ihm nun auch die HEILIGE STADT JERUSALEM als BRAUT (vgl. 21,2; 22,17) vorstellen darf. Der Kontrast wird dadurch verschärft, dass JOHANNES von den irdischen Niederungen der „Wüste“, in der Babylon lag, auf einen HOHEN BERG gelangt: ein Sinnbild der Gottesnähe. Auf diesen schwebt das Neue Jerusalem aus dem Himmel kommend nieder.

21,11 Sie hatte die Herrlichkeit Gottes, ihr Lichtglanz war wie (der Glanz) eines wertvollen Steines, wie (der Glanz) eines wie kristallglänzenden Jaspissteines.

Der JASPIS ist ein grüner Edelstein, der teils undurchsichtig, teils durchsichtig wie KRISTALL ist. Die letztere Sorte ist hier gemeint. Grün ist Farbe des Lebens. Durchsichtiges Grün symbolisiert also vielleicht die durchsichtig-wahrhaftige Lebensgemeinschaft in der Stadt der Seligen.

Dieser durchsichtig-grüne Glanz der Stadt ist der Glanz der HeRRLICHKEIT GoTTES. In der Tat war das Aussehen Gottes in der Himmelsvision zu Anfang des Buches gleich einem (grünen) Jaspis und einem (roten) Karneol gewesen (4,3). Das rot stand für Gottes Strafgerechtigkeit, das grün aber für seine lebensspendende Güte (Kommentar zu 4,3). Da nach dem letzten Gericht kein Strafurteil mehr auszusprechen ist, ist Gott nun ganz in die Farbe des Lebens gehüllt.

21,12 Sie hatte eine große und hohe Mauer, die zwölf Tore hatte.

Und auf den Toren waren zwölf Engel.

Und es waren darauf Namen geschrieben: die Namen der zwölf Stämme der Söhne Israels.

21,13 Im Osten (waren) drei Tore und im Norden drei Tore

und im Süden drei Tore und im Westen drei Tore.

Die MAUER und die auf den Toren als Wachtposten aufgestellten ENGEL bezeichnen die Unerreichbarkeit der Stadt für die „draußen“ befindlichen Verdammten $(22,15)$ sowie die absolute Unangreifbarkeit und Geborgenheit der Stadtbewohner.

Die ZwÖLFZAHL der Tore mit den darauf geschriebenen NAMEN DER ZWÖLF STÄMME ISRAELS symbolisiert die Universalität des Heiles: Für jeden der 12 Stämme Israels gibt es ein „Tor“, d. h. einen Zugang zum Heil. Die 12 Stämme versinnbilden wiederum alle Stämme der Erde (12 als Zahl der Universalität der Heiligen, Exkurs 4), so dass der Sinn dieser Symbolik ist: Keinem Volk ist der Zugang zum Heil verschlossen. Dasselbe zeigt die Anordnung der Tore: In JEDER HIMMELSRICHTUNG gibt es DREI TORE. Den Menschen aus allen Himmelsrichtungen steht also der Weg zum Heil in derselben Weise offen.

21,14 Und die Mauer der Stadt hatte zwölf Fundamente.

Und auf ihnen waren die Namen der zwölf Apostel des Lammes.

Da Johannes diese Fundamente erkennen kann, liegen sie über der Erde: Es handelt sich entweder um die unteren Steine der Mauer oder um Stufen, die zur Mauer führen. Die Namen der APOSTEL stehen auf diesen Fundamenten verzeichnet, weil die Apostel geistige Fundamente der Kirche sind (Mt 16,18, Eph 2,12). Dieser Symbolik entsprechend muss man sagen, dass die ganze Stadt auf diesen Fundamenten erbaut war. Johannes konnte aber diese Fundamente nur als Fundamente der Mauer sehen, weil er als Betrachter außerhalb der Mauer stand.

21,15 Und der (Engel, der) mit mir redete, hatte einen goldenen Messstab, damit er die Stadt und ihre Tore und ihre Mauer messen konnte. 
21,16 Und die Stadt ist viereckig angelegt, und ihre Länge ist gleich der Breite.

Und er maß die Stadt mit dem Rohr auf 12.000 Stadien.

Ihre Länge und ihre Breite und ihre Höhe sind gleich.

21,17 Und er maß ihre Mauer auf 144 Ellen nach dem Maß des Menschen, welches ist (das Maß) des Engels.

Das Mass des Menschen ist das Mass Der Engel, d. h. Menschen und Engel sind in der Stadt Gottes gleichgestellt: Die Engel sind den Menschen nicht mehr grundsätzlich überlegen. So sagte auch Jesus über die Auferstandenen: „Sie können auch nicht mehr sterben, weil sie den Engeln gleich sind“" (Lk 20,36).

DAS MASS DER STADT war 12.000 Stadien. Die Zahl 12.000 symbolisiert die gewaltige Fülle des heiligen Gottesvolkes: Zwölf (die heilige Zahl des neuen Israel) multipliziert mit Tausend (Zahl der unabsehbar großen Menge). Da ein Stadion zumeist zwischen ca. 150 und 210 Meter messen konnte, ${ }^{140}$ entsprechen die 12.000 Stadien einer Länge von ungefähr 1.800 bis $2.520 \mathrm{~km}$. Von Berlin aus reichen also 12.000 Stadien in etwa bis Griechenland (bis Athen ca. 1.800 km, bis Zypern ca. 2490 $\mathrm{km})$.

Die Stadt war QUADRATISCH. Nun ist nicht ganz klar, ob der Gesamtumfang der Stadt oder nur die Länge einer ihrer Seiten 12.000 Stadien ausmachte. Sollte der Umfang gemeint sein (wofür der Ausdruck ,er maß die Stadt“ spricht), dann wäre die Länge einer ihrer Seiten genau 3000 Stadien, und zwischen zwei benachbarten Stadttoren würden (wenn die Tore in gleichmäßigen Abständen über den Umfang verteilt sind) genau 1000 Stadien liegen. Die Seitenlänge der Stadt würde dann in etwa 450 bis $630 \mathrm{~km}$ betragen, d. h. eine Seite würde von Hamburg aus in etwa bis Nürnberg bzw. bis nach Kempten reichen. So hatte die Stadt Maße, die eher einem ganzen Land als einer Stadt zukommen.

DAs MASs DER MAUER war 144 Ellen. Gemeint ist die Höhe, denn die Länge der Mauer muss der Länge der Stadt entsprechen, beträgt also 12.000 Stadien. Auch die Zahl 144 ist eine Symbolzahl: $12 \cdot 12$ (vgl. Exkurs 4). Da eine Elle 45,8 cm entspricht, war die von Johannes geschaute Mauer etwa 70 Meter hoch.

Die HÖHE DER STADT hatte dasselbe Maß wie Breite und Länge. Die Höhe betrug also je nachdem 3.000 oder 12.000 Stadien, d.h. zwischen 450 und 2.520 Kilometer. Häuser mit einer solchen Höhe wird nie ein Mensch bauen: Sie wären ca. 51-285 mal so hoch wie der 8848 Meter hohe Mt. Everest, der höchste Berg der Erde, und würden weit in den Weltraum hineinragen (der nach heutiger Definition 100 Kilometer über dem Erdboden beginnt)!

Wie hat man sich eine solche Stadt vorzustellen? Beginnen hinter der Stadtmauer Hochhäuser mit 12.000 bzw. 3000 Stadien Höhe, so dass die Stadt die Form eines Riesenwürfels hat? Mir scheint diese verbreitete Vorstellung unangemessen zu sein: Denn was hätte eine Stadtmauer von 70 Metern Höhe für eine Bedeutung, wenn dahinter Häuser beginnen, welche die unvorstellbare Höhe von 450 oder gar 2500 Kilometern haben? Und wie soll man sich in einer solchen Stadt einen Fluss, Straßen und Bäume vorstellen, von denen später die Rede sein wird? Liegen diese in unvorstellbar grauenhaften Schluchten zwischen gigantischen Hochhäusern? Offensichtlich führt hier ein wörtliches Verständnis zu absurden Vorstellungen.

Mit der „Höhe“ der Stadt kann also nicht die Höhe der Häuser gemeint sein. Entweder ist die Höhe des „großen und hohen Berges“ gemeint, auf dem Johannes die Stadt sah (Vers 10), oder - und das scheint mir der Fall zu sein - die Stadt ist selber ein Berg, dessen Höhe (an der Spitze) der Breite und Länge der Stadt entspricht. Die Stadt hat also nicht die Form eines Würfels, sondern eher die Form einer Pyramide (so wie die terassenartig aufgebauten Städte der Sumerer).

140 In der griechischen Welt benutzte man üblicherweise das attische Stadion, das einer Länge von 185 Metern (Stadion in Athen) oder 177,5 Metern (Stadion in Delphi) entsprach. Es gab aber auch zum Beispiel das phönizisch-ägyptische Stadion (209 m), das babylonisch-persische Stadion (196 m), das olympische Stadion (192 m) oder das mesopotamische Stadion (149 m). Anderen Quellen zufolge maß das ägyptische Stadion 157,5 Meter. 
Allo hat diese Pyramide sehr treffend wie folgt beschrieben. Sie befindet sich auf dem Gipfel bzw. ist der Gipfel eines ,,hohen Berges“, der die ganze Erde, oder vielmehr das ganze Universum ausmacht. Unten wird die Stadt von einer Mauer umrahmt. Auf der Spitze der Stadtpyramide befindet sich der „Thron Gottes und des Lammes“ (22,3). Dort entspringt der „Fluss“ mit dem „Wasser des Lebens“ $(22,2)$. Um sich diesen Fluss nicht als reißenden Wasserstrom vorstellen zu müssen, der von der Spitze des Stadtberges auf direktem Wege nach unten fällt, könnte man sich vorstellen, dass er sich spiralförmig von der Bergspitze aus nach unten windet. Entlang des Flusses sind die „Bäume“ und die „Straße“ anzusiedeln (22,1-3). Erleuchtet wird die ganze Stadt vom Thron her (22,5).

Was symbolisiert die LÄNGE, BREITE und HöHE der Stadt? Die LÄNGE könnte Symbol für die Fähigkeit der Heiligen sein, Gott zu erkennen, d. h. tief in die Betrachtung göttlicher Geheimnisse einzudringen, welche die natürliche menschliche Vorstellungskraft nur von ferne erahnen kann. Die BREITE könnte dagegen die Fähigkeit bezeichnen, Gott zu lieben, denn Liebesfähigkeit ist in poetischer Sprache eine „Weite“ oder „Breite“ des Herzens. Und die HöHE steht dann wahrscheinlich für die Erhabenheit der Heiligen, d. h. für das Maß ihrer Gottähnlichkeit. In der Aussage, dass Länge, Breite und Höhe DASSELBE MASS haben, wäre dann ausgesprochen, dass die Gotteserkenntnis und somit auch die Erhabenheit der Heiligen sich nach dem Maße ihrer Liebesfähigkeit richtet: d. h. je mehr ein Mensch in diesem Leben gelernt hat, zu lieben (Breite), umso mehr wird er im ewigen Leben mit der Erkenntnis Gottes belohnt (Länge), und umso größer ist das Maß seiner herausragenden Erhabenheit unter den Heiligen (Höhe).

Es ist in diesem Zusammenhang daran zu erinnern, dass alle Seligen in vollkommenem Maße selig sein werden, weil sie in dem ihnen größtmöglichen Maße Gott erkennen und lieben werden, dass aber dennoch das absolute Maß der Seligkeit bei den einzelnen Heiligen verschieden groß sein wird. Man kann die Gemeinschaft der Heiligen vergleichen mit einer Reihe verschieden großer Gläser, die aber alle randvoll gefüllt sind: Jeder Heilige ist in höchstem Maß, d. h. randvoll mit „Seligkeit“ erfüllt, aber dennoch ist die Seligkeit bei den einzelnen verschieden groß. Diese Verschiedenheit wird auch keinen Neid verursachen, weil die Einheit der Liebe herrschen wird, die bewirkt, dass sich jeder an den Freuden aller anderen mitfreut. Außerdem wird auch der kleinste Heilige zur Schönheit des Ganzen einen unersetzlichen Beitrag leisten, so wie in einem schönen Garten bzw. in einer schönen sternklaren Nacht auch die kleinen Blumen bzw. Sterne nicht fehlen dürfen (vgl. 1 Kor 15,41-42).

Dass die Seligkeit der Heiligen im ewigen Leben verschieden groß ist, deutete Jesus an, als er sagte: „Im Hause meines Vaters sind viele Wohnungen“ (Joh 14,1). Deutlicher lehrt Paulus, dass ,jeder seinen Lohn empfangen wird gemäß seiner Arbeit" (1 Kor 3,8, vgl. 2 Kor 9,6): Das Maß der Seligkeit richtet sich nach den „Werken“ (vgl. 14,13, 20,12, 22,12), womit tätige Liebe gemeint ist (Gal 5,6). Diese Liebe also bestimmt das Maß der ewigen Seligkeit, und da die Seligkeit vor allem im Erkennen Gottes besteht (Joh 17,3), muss die Liebe die Tiefe der Gotteserkenntnis festlegen. So bestätigt sich, dass das Maß der (auf Erden durch tätige Liebe gewonnen) Liebesfähigkeit das Maß der Gotteserkenntnis und damit auch das Maß der Erhabenheit im Himmel bestimmt.

Da Gottesliebe, Gotteserkenntnis und Erhabenheit bei jedem Heiligen verschieden ist, sind die Heiligen symbolisch verschieden große „Gebäude“ in der Stadt Gottes. Wegen der Liebe, die alle Heiligen vereint, scheint die Vorstellung angemessen zu sein, dass sich die kleineren Gebäude innerhalb der größeren befinden, so dass das größte aller dieser Gebäude alle anderen Gebäude als Innenräume in sich birgt. Daraus folgt, dass die Außenfassade der Stadt, d. h. die ganze Stadtpyramide, ein einziges, allumfassendes Gebäude ist: Und dieses Gebäude muss dann ein SYMBOL MARIAS sein, der größten aller Heiligen, die als solche in Apk 12 beschrieben wurde. Dass die Stadt in gewisser Weise Maria ist, wird dadurch bestätigt, dass die Stadt FRAU (Vers 9) genannt wird, wodurch die Stadt zweifellos mit der „Frau“ in Apk 12 in Verbindung gebracht werden soll. Die Frau in Apk 12 aber hatten wir als Maria und marianische Kirche zugleich interpretiert. Ähnliches scheint also auch für die vorliegende „Frau“ bzw. „Stadt“ zu gelten. Ein weiteres Indiz ist, dass die Stadt „Zelt Gottes unter den Menschen“ $(21,3)$ genannt wird, was in sehr konkreter Weise auch für Maria zutrifft, insofern CHRISTUS, das „Wort Gottes, das Gott war“ (vgl. Joh 1,1) bei seiner Menschwerdung im Schoß Marias ,unter den Menschen sein Zelt aufgeschlagen hat" (Joh 1,14). 
21,18 Und der Baustoff ihrer Mauer war Jaspis, und die Stadt war reines Gold gleich reinem Glas.

Die Mauer leuchtet grünlich (Jaspis) und die Stadt ist GOLDEN und zugleich DURCHSICHTIG. Nach 21,11 ist der Glanz der ganzen Stadt allerdings nicht der des Goldes, sondern ein grünlicher JaspisGlanz, wohl wegen der Mauer. Während dieser Jaspis-Glanz, wie schon zu 21,11 bemerkt, das Leben in der Stadt bezeichnet, bezeichnet das „Glasgold“ den hohen Wert, die Pracht und Vollkommenheit dieses Lebens. „Unserem Golde fehlt nichts“ sagt CoRnELIUS, ,,außer der Durchsichtigkeit, so wie auch dem Glas nichts fehlt außer der Festigkeit“. „Glasgold“ vereint also diese beide Vorzüge.

21,19 Die Fundamente der Stadtmauer waren mit jedem wertvollem Stein geschmückt:

das erste Fundament ein Jaspis,

das zweite ein Saphir,

das dritte ein Chalcedon

das vierte ein Smaragd,

21,20 das fünfte ein Sardonyx,

das sechste ein Sarder (Karneol),

das siebte ein Chrysolith,

das achte ein Beryll,

das neunte ein Topas,

das zehnte ein Chrysopras,

das elfte ein Hyazinth,

das zwölfte ein Amethyst.

Von einem mit verschiedenen Edelsteinen gebauten neuen Jerusalem hatte im Alten Testament bereits Tobit in Tob 13,16-17 (Vulg: 13,21-22) gesprochen. Wie schon im Kommentar zu Vers 14 festgestellt wurde, sind diese Fundamente als Edelsteinplatten zu verstehen, auf denen die ganze Stadt aufruht, die jedoch von außen, vom Standort des Johannes aus, nur als Fundamente der Mauer sichtbar sind (wahrscheinlich als 12 Stufen, die zur Mauer führen). Wie in Vers 14 zu erfahren war, stehen auf den Fundamenten die Namen der 12 Apostel verzeichnet. Jeder Edelstein ist also einem Apostel zuzuordnen und muss gewisse Eigenarten dieses Apostels zum Ausdruck bringen.

Die Edelstein-Namen sind noch heute in Gebrauch, sie wurden aber vielfach in der Antike für andere Edelsteine verwendet, als es heute der Fall ist. Aufgabe der Einzelauslegung ist es hier, die einzelnen Edelsteine genauer zu beschreiben und sie den Aposteln zuzuordnen. Da es eine in etwa feststehende Reihenfolge unter den Aposteln gibt, die in den vier Apostel-Listen (Mt 10,2-4; Mk 3,16-19; Lk 6,13-16; Apg 1,13) nur geringfügig variiert, ist dies ein erster Anhaltspunkt dafür, welcher Edelstein welchem Apostel entspricht; weitere Anhaltspunkte können die Überlieferungen über Leben und Eigenart der Apostel sein, die sich symbolisch in Eigenschaften der Edelsteine widerspiegeln könnten.

1. Der JASPIS der Alten war ein grünlicher, teils durchsichtiger und teils undurchsichtiger Stein, der heute als ,grüner Jaspis“ bezeichnet wird. Das Grün des besten Jaspis ist nicht gleichartig, sondern mit verschiedenen Flecken in verschiedenen Grünfarben durchzogen, teils hat er auch purpurfarbene, rote oder rosa Flecken. Nach Plinius dem Älteren ist der Jaspis ein sehr harter Edelstein, wenn auch nicht der härteste; und es ist der älteste Edelstein, denn er ist auf der Erdoberfläche zu finden. ${ }^{141}$

Der Jaspis muss als unterster Grundstein auf jeden Fall dem Apostel PETRUS zugeordnet werden, der in allen vier Apostellisten (Mt 10,2-4; MK 3,16-19; Lk 6,14-16; Apg 1,13) als erster erwähnt wird und von dem CHRISTUS sagt: „Du bist Petrus (was bedeutet: der Felsenmann), und auf diesen Felsen werde ich meine Kirche bauen" (Mt 16,18).

Abweichend von der obigen Beschreibung setzen manche den Jaspis auch mit dem Diamanten gleich. Heute versteht man unter einem normalen „Jaspis“ nicht den grünen Jaspis, sondern ein graues, bläuliches, gelbes, rotes oder braun gefärbtes, zum Teil gebändertes Mineral. 
Petrus bekam als einzelner von CHRISTUS den Auftrag, die „Schafe“ Christi, d. h. die ganze Kirche zu ,weiden“ (Joh 21,15-17) und die Mitapostel zu stärken (Lk 22,32). Ihm wurde auch als einzelnem die Verheißung gegeben, dass er die Vollmacht bekommen würde, bindende Entscheidungen für die Gesamtkirche zu treffen (Mt 16,19), noch bevor die Gruppe aller Apostel eine ähnliche Verheißung bekam (Mt 18,18). Hier haben wir die biblische Wurzel des päpstlichen Amtes.

Wieso ist aber als Edelstein PETRI ausgerechnet der Jaspis gewählt? Von allen grünlichen Edelsteinen ist der Jaspis am meisten geeignet, Farbe des Lebens zu sein. Denn die verschiedenen Flecken und Arten des Grün, die in seinem Grün vorkommen können, symbolisieren die Vielfalt des Lebens. Deshalb ist der Glanz der Stadt und der Mauer der des Jaspis $(21,11 ; 21,18)$ und Jaspisfarben ist daher auch Gott selber (4,3). Petrus hat aber als „unterstes Felsenfundament“ der Kirche die Aufgabe, die Kirche mit allen ihren verschiedenen Lebensäußerungen zusammenzuhalten, sie so zu verwalten, dass die verschiedenen Lebensäußerungen und Gaben der Christgläubigen nicht erstickt werden, und dass trotzdem nicht alles ausufert und wuchert, sondern in der Einheit des Glaubens zusammenbleibt. Der Jaspis ist auch deshalb für Petrus angemessen, weil er als ,ältester“ Edelstein galt, so wie Petrus als erster in das Apostelamt eingesetzt wurde und der erste ,amtliche“ Zeuge der Auferstehung war (1 Kor 15,5; Lk 24,34).

2. Der SAPHIR der Alten ist wahrscheinlich der heutige Lapislazuli (deutsch: „Blaustein“), womit ein undurchsichtig blauer, mit Silber- und Goldpünktchen besäter Lasurstein bezeichnet wird. Plinius beschreibt den Saphir als himmelsfarben. Das stimmt mit Ex 24,10 überein, wo bei einer Gotteserscheinung die Fläche unter den Füßen der Erscheinung ,wie ein Saphir ausgelegt war und glänzte wie der Himmel, wenn er klar ist“. Außerdem glänzen und funkeln im Saphir goldene Punkte wie Sterne (so Plinius und Isidor), was ebenfalls dazu passt, dass der Saphir ein Abbild des Himmels ist. ${ }^{142}$

Der Saphir entspricht wahrscheinlich dem Apostel ANDREAS, dem Bruder des PeTRUS. In den Apostel-Listen wird dieser als zweiter oder vierter erwähnt. ANDREAS ist der erste im Johannesevangelium namentlich genannte Apostel: einer der zwei Johannesjünger, die sehen wollten, wo Jesus wohnt (Joh 1,38); das aber ist im eigentlichen Sinne der Himmel. Der Saphir könnte außer ANDREAS auch den Apostel PAULus symbolisieren, der zwar nicht zu den Zwölf gehört, aber als außerordentlicher Apostel im seiner Bedeutung für das Christentum dem Petrus nicht nachsteht. Anknüpfungspunkt könnte sein, dass PAULUS schon zu Lebzeiten ,,in den dritten Himmel entrückt“ wurde („Himmelfahrt des Paulus“), was er selbst andeutet (2 Kor 12,4).

3. Der Chalcedon (abgeleitet von der Stadt Chalzedon am Bosporus) war nach Cornelius, der sich auf Plinius beruft, der feuerrote KARFUNKEL. Von Plinius wird dieser nämlich „Carchedonius“ genannt. Der Karfunkel leuchtet wie brennende Kohle. ${ }^{143}$

Der Chalzedon dürfte dem Apostel JАКоBUS, dem Sohn des Zebedäus entsprechen, der als dritter oder zweiter Apostel in den Apostellisten erwähnt ist. Dieser Apostel vergoss als erster sein Blut für CHRISTUS (Apg 12,2) und ist stets der erstgenannte (also wohl der älteste) von den beiden „Donnersöhnen“ (Mk 3,17: Jakobus und Johannes), die gegen JESU Feinde Feuer vom Himmel herabflehen wollten (Lk 9,54).

4. Der SMARAGD bezeichnet damals wie heute übertrifft das Grün der Blätter und taucht sowohl die Luft als auch andere Dinge in seiner Umgebung in grüne Farbe ein. Das Grün des Smaragdes gleicht der Farbe reinsten Öls, sagt Joachim von Fiore.

Der Smaragd könnte dem Apostel und Evangelisten JoHANNES entsprechen, der in den Apostellisten als zweiter, dritter oder vierter genannt wird. Denn der Apostel Johannes lebte von allen Aposteln am längsten (grün = Farbe des Lebens) und er überlieferte uns in seinem Evangelium ein Bild von Jesus, was lebendiger ist (mehr interessante und in die Tiefe gehende Einzelheiten hat) als die drei anderen Evangelien.

Was wir heute dagegen als „Saphir“ bezeichnen, ist ein wertvoller, durchsichtig-blauer Edelstein.

143 Abweichend meint allerdings Allo, der sich ebenfalls auf Plinius beruft, dass der Chalcedon ein grüner und schillernder Stein ist, ähnlich dem Schwanz eines Pfaus und der Kehle einer Taube. - Heute versteht man unter einem „Chalzedon“ ein bläuliches oder weißgraues Mineral. 
5. Der SARDONYX (abgeleitet von „Sardinien“ und „Onyx“, d. h. Fingernagel) ist, wie der Name sagt, ein aus Sardinien kommender „Fingernagelstein“. Der ONYX ist nämlich ein dem Fingernagel ähnliches, aus unterschiedlich gefärbten Lagen bestehendes Mineral, das eine Abart des Quarzes darstellt. Der Sardonyx der Alten war die beste Art des Onyx. Beim Sardonyx mischt sich die weiße Farbe mit dem Roten: Er sah innen wie das Fleisch aus, und außen wie der Nagel, der das Fleisch bedeckt. So glich er also tatsächlich einem Fingernagel. Plinius vergleicht ihn mit dem Fleisch hinter dem Fingernagel, das in einem schönen Rosa erstrahlt, wenn man es im Lichtschein betrachtet. An der Oberfläche ist der Sardonyx rot (gelblichrot wie Zinnober), in der Mitte hat er einen weißen Kreis und der tiefste Teil ist schwarz, sagen Plinius, Solinus, Isidor und Alcazar. Im weißen Kreis ist die Andeutung eines Regenbogens, sagt Plinius. ${ }^{144}$

Der Sardonyx symbolisiert wohl den Apostel PHILIPPUS. Dieser ist nämlich in allen Apostellisten als fünfter genannt. Was aber den Philippus mit dem Sardonyx verbindet, ist vielleicht die Tatsache, dass Philippus als eine Art „Zeigefinger“ beschrieben wird, insofern er den Nathanael sowie die Griechen zu Jesus führte (Joh 1,45-46; 12,21-22) und Jesus bat: „Herr, zeige uns den Vater“ (Joh 14,8-9).

6. Der SARDER (Name abgeleitet von der Stadt Sardes), den man auch KARNEOL nannte, war ein dunkelroter, halb-durchsichtiger, blut-und feuerfarbener Stein. Plinius nennt ihn fleischfarben. Damit stimmt überein der Name KARNEOL, der vom lateinischen carnis (Fleisch) oder cornu (Horn) abgeleitet ist. Im Hebräischen heißt er „Odäm“, was verwandt ist mit dem Wort „Adam“ (= Mensch). Der Sarder hat keinerlei Flecken wie andere Edelsteine. ${ }^{145}$

Der Sarder bzw. Karneol symbolisiert wohl den Apostel BARTHOLOMÄUs, der in den Apostellisten als sechster oder siebter Apostel genannt ist. Die Farbe des Sarders erinnert an den Märtyrertod des Bartholomäus, dem nach der Überlieferung die Haut abgezogen wurde.

7. Der ChrYSOLith (deutsch: „Goldstein“) war vermutlich ein goldfarbener Beryll (siehe den nächsten Stein). Er glänzt so stark in goldener Farbe, dass das Gold, das man daneben stellt, weiß zu werden scheint (so Plinius). Er ist durchsichtig, und vermischt mit dem Gold die blau-grüne Meeresfarbe des Berylls; seine Durchsichtigkeit ist also zu vergleichen mit der Durchsichtigkeit reinen Meerwassers, das den Blick auf den Meeresgrund freigibt. Das durchsichtige Gold des Chrysoliths gleicht in gewisser Weise dem „Glasgold“, aus dem nach Vers 21,18 die Stadt gebaut ist. ${ }^{146}$

Der Chrysolith entspricht wohl dem Apostel MATTHÄUs, der in den Apostellisten als siebenter oder achter genannt ist. Das Matthäusevangelium, das auf die Überlieferungen dieses Apostels zurückgeht, war in der alten Kirche das meistgebrauchte, mit dem sich die Irrlehren am leichtesten widerlegen ließen. Es ist also das Evangelium, auf welches sich die Kirche, jenes irdische Abbild der ,glasgoldenen“ Gottesstadt, am meisten stützte. MAтTHÄUS, der von Beruf Zöllner war (Mt 9,9) und daher einst ein reicher Mann gewesen sein muss, hatte außerdem eine besondere Beziehung zum Gold: Sein Evangelium ist das einzige, in dem das Wort „Gold“ vorkommt, und zwar gleich fünfmal: 2,11, 10,9, 23,16 und 23,17 (zweimal).

8. Der BERYLL (sein Name geht vermutlich auf die südindische Stadt Belur zurück) war bei den Alten ein grüner Stein, der vom Smaragd verschieden ist; sein grün ist nach Plinius das „Grün des Meeres“, also ein blaugrün. Der Beryll leuchtet nicht, außer er wird in sechseckiger Form poliert. Er sieht schöner aus, wenn er nicht vergoldet ist: Plinius überliefert, der Beryll sei ,der einzige Edelstein, der lieber des Goldes entbehren will“. ${ }^{147}$

\footnotetext{
Der heutige Sardonyx ist dagegen ein braun und weiß gestreifter Chalzedon.
}

145 Heute wird der Karneol als ein durch Eisenoxyde blutrot bis gelblich gefärbter Schmuckstein definiert.

146 Heute versteht man unter Chysolith = Peridot = Olivin ein glasig glänzendes, durchscheinendes, flaschengrünes bis gelbliches, in Kristallen vorkommendes Material.

147 Heute versteht man unter Beryll ein in reinem Zustand glasklares, farbloses, oft gelbliches Mineral, das je nach Gehalt an bestimmten Stoffen auch in Gestalt von Kristallen verschiedener Färbung vorkommen kann. 
Der Beryll dürfte dem Apostel ThOMAS zukommen, der in den Apostellisten als sechster, siebter oder achter Apostel erwähnt ist. Thomas ist der „Apostel Indiens“, wohin er übers Meer gefahren sein soll. Außerdem galt die meeresgrüne Farbe des Berylls als die schönste Augenfarbe, was daran erinnert, dass Thomas so begierig war, den Auferstandenen zu sehen: „Wenn ich nicht sehe ..., glaube ich nicht“ (Joh 20,25), was ihm Jesus gewährte mit den Worten: „Weil du mich gesehen hast, glaubst du. Selig sind, die nicht sehen, und doch glauben" (Joh 20,29).

9. Der TOPAS der Alten war durchsichtig und hatte als Farbe ein grünliches Gold. Sein Grün gleicht den Blättern der Lauchpflanze. Aber stärker als das Grün leuchtet sein Gold, das in wunderbarer Weise glänzt, wenn der Stein von der Sonne angestrahlt wird. Der Topas ist der größte Edelstein, sagt Plinius, denn man fand Topas-Steine in der Größe von 4 Ellen $(183,2 \mathrm{~cm}) .{ }^{148}$

Der Topas als neuntes Fundament dürfte dem Apostel JAKOBUS, DEM SoHN DES ALPHÄUS zuzuordnen sein: Dieser ist nämlich in allen Apostellisten als neunter Apostel aufgeführt. Er ist identisch mit JAKOBUS, DEM BRUDER DES HERRN, einem „Bruder“, d. h. nahem Verwandten (wahrscheinlich Vetter) Jesu, wie ich in meiner Ausarbeitung Die immerwährende Jungfräulichkeit Mariens und die Brüder Jesu gezeigt habe. Der besonders im Sonnenlicht golden zurückstrahlende Topas kann darauf hinweisen, dass Jakobus seinem „Bruder“ CHRISTUS, der „Sonne der Gerechtigkeit“ (Mal 3,20), so ähnlich war, dass er schon zu Lebzeiten wegen seiner Frömmigkeit von nichtchristlichen Juden ,Jakobus der Gerechte“ genannt wurde (Eusebius, Kirchengeschichte 2,23). Die lauchgrüne Farbe (Lauch als Symbol der Fastenspeise) kennzeichnet treffend den Jakobus als Asketen und Faster, der sein Leben lang ein absolutes Fleischfasten einhielt (Eusebius, Kirchengeschichte, Kap. 3,23).

10. Der Chrysopras (von Chrysos = Gold, und Prason = Lauch) hatte eine mit Gold durchsetzte, lauchgrüne Farbe, die dunkler war als das Grün des Berylls. Er gleicht also dem vorgenannten Topas, nur dass beim Topas das Gold stärker ist, und beim Chrysopras das Grün. Sein Gold ist in Form goldener Tropfen im Grün enthalten. Ein weiterer Unterschied zum Topas ist, das der Chrysopras im Gegensatz zu diesem nicht durchsichtig ist. ${ }^{149}$

Der Chrysopras kennzeichnet den Apostel JudAS THADDÄUS-LEBBÄUS, der in den Apostellisten als zehnter oder elfter erscheint. Dieser Apostel gleicht dem Lauch, insofern er in seinem Brief (dem neutestamentlichen Judasbrief) im scharfer Weise gegen Irrlehrer Stellung nimmt, wozu auch seine beiden Beinamen passen: Thaddäus = der Mutige, und Lebbäus = der Beherzte oder Herzige. Der letzte Beiname weist auch auf die Eigenschaft der Liebe hin, deren Symbol das Gold ist.

11. Der damalige HYAZINTH ist wahrscheinlich der heutige Saphir, ein durchsichtiger, tiefblauer Edelstein mit einem Stich ins Violette. Er gleicht der Blume gleichen Namens. ${ }^{150}$

Der Hyazinth entspricht dem Apostel Simon KANAAnäUS-ZELOTES, der als zehnter oder elfter in den Apostellisten erwähnt ist. Seine beiden Beinahmen bedeuten „der Eiferer“, was ihn vielleicht als ehemaligen Anhänger der militant-jüdischen Zelotenpartei kennzeichnet, aber eher noch als Eiferer für das Himmelreich, wozu passen würde, dass sein Edelstein mit der Farbe des Himmels versehen ist.

12. Der Name Amethyst bedeutet: „nicht betrunken“ (man nahm an, dass der Stein vor Trunkenheit schützt). Der Amethyst war ein durchsichtiger Stein, dessen Farbe als violett oder purpurfarben beschrieben werden kann. Er unterscheidet sich vom Hyazinth dadurch, dass der violette Glanz hier strahlend-kräftig ist, während er beim Hyazinth nur verwaschen-schwach ausgeprägt ist. ${ }^{151}$

Der Amethyst dürfte dem Apostel MATTHiAs entsprechen, welcher der letzte der zwölf Apostel ist, weil er erst nach dem Tod des Verräters Judas Iskariot als Ersatzmann für diesen aus- erwählt wurde (Apg 1,15-26). Das violett, die letzte Farbe des Regenbogens, passt zu diesem letzten Stein, das den letzten der Apostel bezeichnet.

\footnotetext{
148 Nach einer anderen Beschreibung ist er blau (statt grün) und braungelb statt gold. Nach Isidor ist der Stein teils blau, teils golden, und sogar in allen Farben glänzend. Der heutige „Topas“ ist ein farbloses bzw. in vielen hellen Farben vorkommendes, durchsichtiges, glänzendes Mineral. 149 Heute versteht man unter einem Chysopras einen grünen Halbedelstein.

150 Das Wort „Hyazinth“ bezeichnet dagegen heute ein durchsichtiges, gelbrotes Mineral, eine Abart des Zirkons. Es ist nicht ausgeschlossen, dass damit auch damals schon dieser Edelstein gemeint war. Dann könnte man auch die Brustpanzer in 9,7 als gelbrot ansehen.

151 Der heutige „Amethyst“ ist ein violetter Halbedelstein.
} 
Die zwölf Fundamente ergeben insgesamt eine Farbenpracht, die der des Regenbogens gleicht, wobei das grünliche, d. h. die Farbe des Lebens, überwiegt:

- Violett und Blau (Saphir, Hyazinth, Ametyst),

- Rot (Chalcedon, Sardonyx, Karneol),

- Grün und Gelb (Jaspis, Smaragd, Crysolith, Beryl, Topas, Chysopras).

Warum aber wird in den Fundamente der Stadt nicht der DIAMANT verwendet? Darauf ist wohl zu antworten: Der glasklar-durchsichtige Diamant, der härteste aller Edelsteine, wäre derartig aus der Reihe gefallen, dass er nicht mehr einen der Apostel, sondern nur noch CHRISTUS selber hätte darstellen können. CHRISTUS ist tatsächlich das tiefste Fundament der Kirche (vgl. 1 Kor 3,11), das noch unter den 12 von Johannes gesehenen Fundamenten liegen muss.

Die verwendeten zwölf Edelsteine entsprechen in etwa den zwölf Edelsteinen auf der Brusttasche des Gewandes für die alttestamentlichen Hohenpriester in Ex 28,17-20. Diese Steine waren zu je vier Reihen zusammengefasst:

1. Reihe: Odäm (= Sarder), Pitda (= Topas) und Baräkät (= Smaragd)

2. Reihe: Nofäch (= Karfunkel), Sappir (= Saphir) und Jahalom (= Jaspis)

3. Reihe: Läschäm (= Linkurer, d. h. rötlicher Hyazinth), Schebo (= Achat) und Achlama (= Amethyst)

4. Reihe: Tarschisch (= Chrysolith), Schoham (= Onyx) und Joschfä (= Beryll)

Manche behaupten, dass diese Liste vier Steine enthält, die in den Fundamenten der Stadt fehlen:

- der feuerrote KARFUNKEL,

- der LINKURER (wahrscheinlich ein rötlicher Hyazinth)

- der schwarze, mit weißen Kreisen durchzogene ACHAT

- und der fingernagelfarbene, mehr weiße als rote ONYX.

Aber den „Karfunkel“ nennt Johannes wahrscheinlich „Chalcedon“, für den Linkurer steht der Hyazinth, statt des Onyx hat die Stadt den wertvolleren Sardonyx, und für den Achat finden wir in den Stadtfundamenten den Chrysopras, der dem Korallachat gleicht, einem Achat mit goldenen Tropfen. Demnach sind alle Steine der hohenpriesterlichen Brusttasche in die Fundamente der Stadt eingegangen, bis auf drei, bei denen die Steine der Brusttasche durch ähnliche, aber wertvollere Steine ersetzt wurden.

Die Ähnlichkeit der Fundamente der Stadt mit den Steinen der hohepriesterlichen Bekleidung ist wohl beabsichtigt und erinnert daran, dass die Bewohner der Stadt einst - während der Tausendjahrherrschaft - als „Priester“ Gottes tätig waren $(20,6)$. Und dass die Steine nicht genau übereinstimmen, zeigt, dass die „Priester“ des Neuen Testaments zwar ihre Wurzeln im alttestamentlichen Priestertum haben, dieses aber an Herrlichkeit übertreffen.

21,21a Und die zwölf Tore waren zwölf Perlen; jedes einzelne Tor war aus einer Perle.

Wahrscheinlich handelt es sich um Edelsteinperlen, wobei wohl dieselben Edelsteine verwendet wurden, die auch die Fundamente der Mauer bildeten. Jedes Tor würde auf diese Weise einem der Apostel zugeordnet sein, ebenso wie die Fundamente. Das ergibt einen guten Sinn, da die Apostel ja diejenigen sind, denen der Auftrag gegeben wurde, alle Völker zu Jesu Jüngern zu machen (Mt 28,19-20), und ihnen so einen Zugang zur Stadt zu öffnen.

\section{1,21b Und die Straße der Stadt war reines Gold wie durchsichtiges Glas.}

Die Straße der Stadt (es gibt also nur eine) ist wahrscheinlich eine von der Spitze des Stadtberges ausgehende Straße, die in immer größeren Kreisen abwärts führt und somit alle Teile der Stadt miteinander verbindet (siehe Kommentar zu 21,15-17). Die Straße ist aus demselben Material wie der ganze Stadtberg: „Glasgold“ (21,18). Da diese Straße der Verbindungsweg zwischen den Teilen dieser Stadt ist, symbolisiert sie die Verbindung zwischen den Heiligen, d. h. ihre Kommunikation. Diese Kommunikation ist golden (von Liebe geprägt und glückbringend) sowie durchsichtig (wahrhaftig). 
21,22 Und einen Tempel sah ich nicht in ihr.

Denn der Herr, Gott, der Allmächtige, ist ihr Tempel: (Er) und das Lamm.

Anstelle eines Tempels steht auf der Spitze des Stadtberges der Thron Gottes und CHRISTUS, das Lamm. Ein Tempel bzw. ein Kirchengebäude ist ein vom weltlichen Treiben abgegrenzter Bereich, der es den Menschen ermöglicht, ungestört Gott und CHRISTUS anzubeten. Dabei sind die sichtbaren Symbole der Gegenwart Gottes und Christi hilfreich, die im Tempel bzw. in den Kirchengebäuden aufgestellt sind (z.B. Bundeslade, Kreuz). Alles dieses ist in der künftigen „Stadt“ Gottes nicht mehr nötig, da es in ihr keine weltliche Ablenkung mehr geben wird, und da Gott und CHRISTUS unmittelbar geschaut werden (vgl. 22.4), so dass Symbole wegfallen.

21,23 Und die Stadt braucht nicht mehr die Sonne und den Mond, damit sie in ihr scheinen. Denn Gottes Herrlichkeit scheint in ihr, und ihre Leuchte ist das Lamm.

Johannes sieht von der Spitze des Berges, wo der Thron Gottes und das Lamm stehen (siehe Kommentar zu 21,15-17), strahlendes Licht ausgehen. Keine materielle Sonne und kein materieller Mond ist mehr notwendig. Damit ist nicht gesagt, dass es Sonne und Mond nicht mehr geben wird, sondern nur, dass die in das Licht Gottes eingetauchten Seligen das materielle Licht nicht mehr brauchen und begehren, ähnlich wie auch schon in dieser Welt ein blinder Mensch, der in seinem Inneren das Licht des Glaubens hat, zufriedener sein kann als ein Sehender, dem jenes innere Licht fehlt.

Gott erleuchtet aber die Heiligen nun nicht mehr mit dem Licht eines in relativem Dunkel tastenden Glaubens, sondern mit der alle Zweifel ausschließenden, beseligende „Gottesschau“, wodurch sie Anteil an der nie ausschöpfbaren göttlichen Erkenntnis haben, und mit Gott in einer unaussprechlichen Gemeinschaft der Liebe verbunden werden, die sie Gott ähnlich macht. Vergleiche 1 Joh 3,2: „Geliebte, wenn (Gott) offenbar wird, werden wir ihm ähnlich sein, denn wir werden ihn sehen, wie er ist."

Das Lamm, d. h. der Mensch Jesus Christus, wird ebenfalls zur Erleuchtung des Verstandes der Seligen beitragen, wohl dadurch, dass Gott besondere Geheimnisse zuerst dem menschlichen Verstand Jesu mitteilt und dieser dann mit dieser Erkenntnis die übrigen erleuchtet.

Auf Gott und das Lamm (= den Menschen Jesus) als die beiden Leuchten des ewigen Lebens wird auch in Joh 17,3 hingewiesen: „Das aber ist das ewige Leben: dass sie dich erkennen, den einzigen wahren Gott und JESUS CHRISTUS, den du gesandt hast.“

21,24 In ihrem Licht (dem Licht der Stadt) werden die Völker wandeln. Und die Könige der Erde bringen ihre Herrlichkeit in sie.

21,25 Und ihre Tore werden am Tage nicht geschlossen werden. Nacht wird es dort nicht mehr geben.

21,26 Und man wird die Herrlichkeit und den Ehre der Völker in sie bringen.

DIE VÖLKER ohne Einschränkung, d. h. alle Völker werden gerettet werden: Es wird also kein Volk geben, aus dem nicht wenigstens einige Menschen gerettet werden. Und diese Menschen werden nicht etwa dadurch gerettet, dass sie ihr Volk verlassen, sondern sie bringen die Herrlichkeit und die EHRE, d. h. die ehrbaren Traditionen und Kulturleistungen der Völker, in sie hinein. Alles Gute, was Völker geleistet haben, erhält in der künftigen Stadt Gottes seine ewige Anerkennung. Es ist also falsch, was einige Sekten behaupten, die sagen, man müsse sich aus der Gesellschaft, aus der kulturellen und politischen Struktur eines Staates zurückziehen, um Christ sein zu können.

Interessant ist, dass nun sogar die KÖNIGE DER ERDE mit ihrer Herrlichkeit in die Stadt einziehen. Der Ausdruck „Könige der Erde“ bezeichnete bis hierher immer die Führer und Idole der „Bewohner der Erde“, d. h. der irdisch gesinnten Menschen. Nun aber hat der Ausdruck offenbar eine andere Bedeutung: Die Heiligen sind es nun, die das Amt von „Königen der Erde“ innehaben, insofern sie jetzt in vollster Weise auch über die Erde herrschen (wie in 5,10 verheißen war). 
Johannes sieht sie nun in die Stadt einziehen: Mit ihrem beim letzten Gericht auferstandenen, verklärtem Leib ziehen sie nun als wunderbar wiederhergestellte ,ganze Menschen“ in jene „Stadt“ der Gottesschau ein, in welcher sie bislang nur der Seele nach weilten.

Dass Die ToRe Nicht MeHR Geschlossen werden, ist Symbol für das Fehlen jeder Gefahr: für immer ist alle Gefahr eines Angriffs auf die Heiligen beseitigt.

Dass es KEINE NACHT MEHR geben wird, bedeutet, dass die lichtvolle Gottesschau und damit die Seligkeit der Heiligen weder Ende noch Unterbrechung haben wird.

21,27 Und nichts Unreines wird hineinkommen, und keiner, der Greuel und Lüge tut, sondern nur, wer geschrieben steht im Lebensbuch des Lammes.

Nichts UnReines Wird hineinkommen(vgl. Jes 35,8): Aus diesem Satz lässt sich eine Bestätigung für die Existenz des sogenannten „Fegfeuers“ gewinnen (vgl. dazu auch Exkurs 3). Denn da einerseits nur die wenigsten Menschen in völliger sittlicher Reinheit aus dem Leben scheiden, so dass sie sofort vor Gott treten könnten, und andererseits dennoch eine sehr große Zahl von Menschen gerettet werden wird (siehe die Größe der Stadt, Vers 16), bedarf es für viele eines Reinigungsprozesses nach dem Tode. Diesen Prozess nennt die katholische Theologie „Fegfeuer“.

KEINER, DER GREUEL UND LÜGE TUT, kommt in die Stadt (vgl. zur Lüge auch 21,8, 22,15, 14,5 und den Kommentar zu 10,6a). Ein „Greuel“ ist eine äußerlich auffallende Schandtat. Die „Lüge“ ist dagegen eine verborgene Sünde, von der zunächst nur der Lügner selbst weiß. Derartige Sünden gelten in der Schätzung vieler Menschen von jeher als Bagatellen. Das Buch der Apokalypse aber erteilt uns hier die wichtige Lektion, dass auch derartige geheimen Sünden den Menschen so verderben können, dass er nicht in die Stadt Gottes hineinkommen kann. Hier ist mit „Lüge“ allerdings nicht nur die Lüge im eigentlichen Sinne, die Lüge in Worten gemeint, sondern jegliche verborgene Sünde: Daher ist hier vom „Tun“ der Lüge die Rede. - Zum Lebensbuch Des Lammes siehe Kommentar zu 3,5.

22,1 Und (der Engel) zeigte mir den Fluss des Wassers des Lebens, klar wie Kristall, der ausgeht vom Thron Gottes und des Lammes.

Von der Spitze des Stadtberges aus, wo sich der „Thron Gottes und des Lammes“ befindet, sieht Johannes einen Fluss mit klarem Wasser ausgehen, der sich wahrscheinlich in Kreisen nach unten windet.

Zum Fluss mit dem WASSER Des Lebens vergleiche Gen 2,10; Psalm 46,5; Jer 2,13; Sach 14,8; Apk 7,19; Apk 21,6; Joh 4,19; und Joh 7,38-19. Die letztere Stelle zeigt wohl am deutlichsten, dass der lebensspendende Heilige Geist bzw. das vom Heiligen Geist ausgehende lebensspendende und beseligende zur Gottesschau befähigende Glorienlicht gemeint ist: „Jesus rief: Wer an mich glaubt, ... aus dessen Inneren werden Flüsse lebendigen Wassers fließen“ (Joh 7,38). Im nächsten Vers wird dies näher erläutert: „Dies aber sagte er vom Geist, den die empfangen sollten, die zum Glauben kommen würden". Es ist also mit dem Wasser des Lebens eine Gabe gemeint, die man in besonderer Weise dem Heiligen Geist zuschreiben muss.

Nach 21,23 geht vom Thron auf der Spitze des Stadtberges das Licht Gottes und des Lammes aus, und nach der vorliegenden Stelle geht von dort auch das Wasser aus. Licht und Wasser bezeichnen hier in etwa dasselbe: die beseligende Gottesschau (siehe Kommentare zu 21,23 und zu 21,6).

Aber es handelt sich um zwei verschiedene Aspekte der Gottesschau: Das Licht symbolisiert die Bewusstseinserweiterung der Gottesschau (ihren Wissensgehalt) und das Flusswasser, das nach 22,17 zum Trinken dient, symbolisiert die Leib und Seele der Heiligen mit göttlicher Liebe ausfüllende, labende und lebensstärkende Wirkung der Gottesschau (ihren Seligkeitsgehalt).

Letzteres ist eine Wirkung, die man dem Heiligen Geist zuschreiben kann, nicht weil er allein diese Wirkung hervorbringt, sondern weil sich in dieser Wirkung die Eigenart des Heiligen Geistes deutlich zeigt (der die „Liebe zwischen Vater und Sohn“ ist, siehe Exkurs 1). In gewisser Weise finden wir also auf der Spitze des Stadtberges Hinweise auf alle drei göttlichen Personen: 
- Der Thron weist uns auf den ganzen dreifaltigen Gott hin („Thron Gottes“), aber in besonderer Weise auf den Vater (3,21: ,Thron meines Vaters").

- Das Lamm ist ein Symbol des Menschen Christus und (wegen dessen Personenidentität mit dem göttlichen Sohn) auch ein Hinweis auf den Sohn als zweite göttlichen Person.

- Das Wasser des Lebens weist uns, wie gezeigt, in besonderer Weise auf den Heiligen Geist hin, die dritte göttliche Person.

- Dass das Wasser vom gemeinsamen „Thron Gottes und des Lammes“ ausgeht, deutet also an, dass Vater und Sohn den Geist senden, dass dieser also „vom Vater und vom Sohn“ ausgeht.

22,2 Und inmitten der Straße und auf den beiden Seiten des Flusses war das Holz (= die Bäume) des Lebens, das zwölf(mal) Früchte bringt: in jedem Monat bringt es seine Frucht.

Und die Blätter des Holzes (d. h. der Bäume) dienen zur Heilung der Völker.

InMitTen der Strasse Und auf beiden Seiten des Flusses sieht Johannes Bäume. Diese schwierige Ortsangabe kann man am besten so erklären, dass der Fluss in der Mitte der Straße fließt, diese also gewissermaßen in zwei Straßen teilt.

Das Holz DES Lebens bzw. die „Bäume des Lebens“, die an den Ufern des „Wassers des Lebens“ wachsen, sind eine zweite Wirkung des Wassers des Lebens. Denn das Wasser lässt die besagten Bäume wachsen. Das Wasser als Trank symbolisiert, wie schon festgestellt, die seligmachende Wirkung der Gottesschau. Die durch das Wasser hervorgebrachte Speise der Baumfrüchte aber symbolisiert wahrscheinlich die ewig am Leben erhaltende Wirkung dieser Gottesschau. Denn im Trank ist eher Erfrischung und Genuss, in der Speise mehr die kräftigende, lebenserhaltende Wirkung spürbar. Dass die FRÜCHTE der Lebensbäume die ewig lebenserhaltende Wirkung der göttlichen Gnade bezeichnen, geht auch aus der Paradieserzählung in Gen 3,22 hervor, wo erstmals vom „Baum des Lebens“ die Rede ist, von dem Adam nicht essen sollte, der aufgrund seiner Sünde zum Tode verurteilt war, „damit er nicht isst und ewig lebt“".

Dass die Bäume ZWÖLFMAL im Jahr Frucht bringen, also ununterbrochen davon gegessen werden kann, könnte so gedeutet werden, dass es im ewigen Leben keine „langweiligen“ Wartezeiten gibt, sondern eine ständige Auffrischung und Erneuerung des Lebens erfolgt, so dass jeder Augenblick wie neu erlebt werden wird.

Die BLÄTTER der Bäume dienen den Völkern ZUR HEILUNG: nicht zur Heilung von neu auftretenden Krankheiten, sondern Heilung von allen Übeln dieses Lebens und ewige Bewahrung der Seligen in diesem geheilten Zustand. Mit den Blättern sind offenbar alle Wirkungen der seligmachenden Gottesschau gemeint, die zu den beiden wesentlichen Aspekten, nämlich zu der Freude an Gott (= Wasser) und der ewigen Dauer (= Früchte der Bäume) noch hinzukommen. $\mathrm{Zu}$ nennen wäre vor allem die Befreiung des auferstandenen Körpers der Seligen von Tod, Leiden, Schwachheit und Hässlichkeit.

22,3a Und es wird nichts Verfluchtes mehr sein.

Der Ausdruck Verfluchtes meint das von Gott Verbannte, Weggestoßene, Ausgeschlossene. Gemeint ist damit (a) die Sünde und (b) das Leid als Folge der Sünde. Beides WIRD NICHT MEHR SEIN, d. h. in der Stadt Gottes, der Kirche, wird es nicht mehr sein. Außerhalb dieser Stadt aber werden die Verfluchten sehr wohl weiterexistieren, und eine ewige Strafe abbüßen. Siehe dazu Vers 22,15.

22,3b Und der Thron Gottes und des Lammes wird in ihr (in der Stadt) sein.

Und seine Knechte werden ihm dienen.

22,4 Und sie werden sein Angesicht schauen.

Und sein Name wird auf ihrer Stirn geschrieben stehen. 
22,5 Und Nacht wird nicht mehr sein.

Und sie brauchen weder das Licht einer Lampe noch das Licht der Sonne,

denn der Herr, Gott, wird über ihnen leuchten, und sie werden herrschen in alle Ewigkeit.

SEINE Knechte werden IHM dienen. Wessen Knechte, und wem werden sie dienen? Das Wort „seine“ und das Wort ,ihm“ muss sich auf das beziehen, was vorher genannt war: also das Lamm oder aber „Gott und das Lamm“ als Einheit betrachtet. Das Wort DIENEN, das hier verwendet wird (latreuo), ist in der Schrift ein Spezialwort für „Gottesdienst verrichten“. Es zeigt sich also hier, dass auch dem Lamm eine göttliche Verehrung zuteil wird, die sich in ungeteilter Weise auf CHRISTUS und Gott den Vater bezieht. Sehr deutlich zeigt sich also wieder die Wesenseinheit Christi mit dem Vater, d.h. Christi wahre Gottheit.

Ferner werden sie SEIN Angesicht schauen und SEIN Name wird auf ihrer Stirn geschrieben stehen wessen Angesicht und wessen Name? Wieder muss die Antwort lauten: das Angesicht und der Name des Lammes oder „Gottes und des Lammes“.

Man wird hier daran erinnert, dass Vater, Sohn und Geist nur „einen NAMEN“, d. h. ein Wesen haben, wie auch aus dem Taufbefehl Jesu klar hervorgeht: „Gehet hin ... und taufet sie auf den Namen (nicht: auf die Namen) des Vaters und des Sohnes und des Heiligen Geistes“ (Mt 28,19). Dieser gemeinsame Name der ganzen Dreifaltigkeit lautet JAHWE (= der Seiende), vgl. Exkurs 1. Der Name auf der Stirn ist Symbol dafür, dass die Seligen mit ihrem ganzen Denken Gott hingegeben sind.

Diese Verheißung, das Angesicht Gottes zu SCHAuen, ist die Hauptverheißung für die Seligen und macht ihre Seligkeit aus: „Das ist das ewige Leben: dich, den einzig wahren Gott zu schauen“ (Joh 17,3). „Wir werden Gott sehen, wie er ist“ (1 Joh 3,2). ,Jetzt schauen wir durch einen Spiegel in Rätseln, dann aber von Angesicht zu Angesicht". (1 Kor 13,12). Diese Gottesschau wird eine klare Gotteserkenntnis, eine klare Gewissheit seiner Gegenwart und ein nie satt machendes Schauen herrlicher Geheimnisse sein; vielleicht werden immer neue Herrlichkeiten geschaut und in einem nie endenden Abenteuer „erlebt“ werden, wie der Apostel Paulus andeutet: „Der Herr aber ist der Geist, und wo der Geist des Herrn ist, da ist Freiheit. Wir aber schauen mit unverhülltem Angesicht die Herrlichkeit des Herrn wie in einem Spiegel, und werden in dieselbe verwandelt, von Herrlichkeit zu Herrlichkeit.“ (2 Kor 3,17).

Nochmals betont die Apokalypse hier, dass die Gottesschau ohne Ende und Unterbrechung sein wird (,KEINE NACHT MEHR“), und das sie alles materielle Sehen übertreffen wird: „Sie brauchen weder das Licht einer Lampe noch das Licht der Sonne“. So auch schon in 21,23-24.

So endet dieser Ausblick auf das himmlische Jerusalem mit der Verheißung, dass seine Bewohner IN ALLE EWIGKEIT HERRSCHEN ${ }^{152}$ werden. Eine Herrschaft setzt Untertanen voraus. Über wen herrschen sie in Ewigkeit? Die Antwort kann nur sein: über die gesamte verklärte Materie des Universums, auf die in unvorstellbarer Weise die Seligkeit der Heiligen überfließen wird. Gäbe es überhaupt kein materielles Universum mehr, wäre eine ewige Herrschaft der Heiligen wohl ausgeschlossen. Somit zeigt der vorliegende Vers, dass die Materie auch im endgültigen Endzustand der Schöpfung als Betätigungsfeld für die Herrschaft der Heiligen eine Rolle spielen wird. Diese werden möglicherweise mit der Materie des Universums in immer neuer Weise Wunderbares gestalten und hervorbringen zur Verherrlichung und zur Ehre Gottes.

152 Wörtlich heißt es in 22,5 ,,in die Äonen der Äonen“. Während das Wort Äon ursprünglich die Bedeutung „Zeitalter“ hat (also einen langen, aber begrenzten Zeitraum bezeichnet), meint die Steigerung ,die Äonen der Äonen“ hier eine unendliche Dauer. Dass eine endlose Herrlichkeit gemeint ist, folgt auch bereits aus der vorhergehenden zweimaligen Bemerkung über das Fehlen der Nacht (hier und in 21,25): Denn wenn es heißt, dass es KEINE NACHT MEHR gibt, so ist damit auch gesagt, dass der von Gottes Herrlichkeit erleuchtete „Tag“ für die Bewohner des Neuen Jerusalem kein Ende mehr haben wird. 
22,6 Und er (der Engel) sagte zu mir: Diese Worte sind zuverlässig und wahr.

Gott, der Herr der Geister der Propheten hat seinen Engel gesandt,

um seinen Knechten zu zeigen, was bald geschehen muss.

Die Geister Der Propheten sind wohl die Gaben Gottes, durch die er die Propheten zu ihrem Prophetendienst befähigt. Gott ist HERR dieser Geister, d. h. von ihm geht alle wahre Prophetie aus.

WAS BALD GESCHEHEN MUSS: Dies kann sich wohl nicht auf den letzten Teil des Buches (ab Kap. 20) beziehen, der vom Ende der Welt handelt. Von diesem Weltende wusste Johannes, dass es noch weit in der Zukunft liegt, denn er hatte erfahren, dass bis dahin noch die „tausend Jahre“ vergehen mussten (20,1-4). Das, was BALD geschehen muss, ist also der große erste Teil der Prophezeiungen bis einschließlich Kap. 19.

22,7 Und siehe, ich komme bald. Selig ist, wer die Worte der Prophezeiung dieses Buches bewahrt.

Hier spricht nun JESUS CHRISTUS, welcher in geheimnisvoller Weise hinter allen genannten Gerichten Gottes steht als der „Reiter auf dem weißen Pferd“ (6,1-2). Sein BALDIGES KOMMEN bezieht sich wie im Vorvers auf die Gerichte Gottes in den ersten Jahrhunderten, von denen bis Kap. 19 die Rede ist.

Die Worte Christi werden ohne Überleitung an die Worte des Engels von Vers 6 angeschlossen, so dass JOHANNES anscheinend diese Worte aus dem Mund des Engels hörte. Engel übermitteln oft Befehle Gottes in einer Weise, dass man sie mit Gott selber verwechseln kann (vgl. Gen 22,11-12; Ex 3,2.5)

22,8 Und ich, Johannes, bin es, der dies gehört und gesehen hat.

Und als ich gehört und gesehen hatte, fiel ich nieder,

um vor den Füßen des Engels anzubeten, der mir dieses alles gezeigt hatte.

22,9 Und er sagte zu mir: Sieh dich vor, tu es nicht!

Dein Mitknecht bin ich und (der Mitknecht) deiner Brüder,

der Propheten und aller, welche die Worte dieses Buches bewahren. Bete Gott an!

Wie in 19,9-10, so irrt sich Johannes auch hier wieder und glaubt, dass der vor ihm stehende Engel als Gotteserscheinung zu werten ist, so dass er ihm mit der fußfälligen Verehrung göttliche Ehre (Anbetungsproskynese) erweisen will. Diese Stelle zeigt aber NICHT (ebensowenig wie 19,9-10), dass jegliche fußfällige Verehrung vor Engeln abzulehnen sei (siehe Kommentar zu 19,9-10 mit dem dortigen Exkurs). Da der Engel anscheinend im Vers vorher Jesu Worte übermittelt hat (,siehe ich komme bald“), ist der Irrtum des Johannes verständlich, der plötzlich glaubte, Jesus selber vor sich zu haben. Einem ähnlichen Irrtum war er in 19,9-10 erlegen: Auch dort hatte der Engel vorher gesagt: ,dies sind die wahrhaftigen Worte Gottes“, was Johannes wahrscheinlich so verstand, dass der sprechende Engel Gott selber sei. Beide Stellen zeigen uns, dass man bei einer Erscheinung, die sich als Gott auszugeben scheint, zuerst kritisch zu prüfen hat, ob es sich wirklich um Gott selber handelt, bevor man ihr göttliche Ehren erweist.

22,10 Und er sagte zu mir:

Versiegle die Worte der Prophetie dieses Buches nicht! Denn die Zeit ist nahe.

Johannes hört dies und die folgenden Worte bis Vers 16 (und wohl weiter bis 19) immer noch aus dem Mund des Engels, da keine neue Person eingeführt wird. Dem Inhalt nach sind diese Worte aber Worte Jesu, wie besonders deutlich wird in Vers 12 (,siehe, ich komme bald“), Vers 13 (,ich bin das Alpha und das Omega“) und mit aller wünschenswerten Klarheit in Vers 16 (,ich, Jesus“). Der Engel nimmt also jetzt eine Funktion als unmittelbares Sprachrohr Jesu ein (wie schon in 22,7). 
Dem Propheten DANIEL war einst befohlen worden, seine Prophezeiung zu VERSIEGELN, d. h. geheim zu halten: „Geh, Daniel! Diese Worte bleiben verschlossen und versiegelt bis zur Zeit des Endes“ (Dan 12,9). Vieles, was DANIEL über die Endzeit prophezeit hat, wurde erst in der Apokalypse des JOHANNES klarer verständlich: Bis hierhin also blieb es versiegelt. Jetzt wird nicht mehr versiegelt, weil die Zeit des Endes gekommen ist. Unter „Endzeit“ versteht die Bibel die gesamte Zeitperiode von Christi erster Ankunft bis zu seiner zweiten Ankunft am zum Ende der Weltgeschichte (siehe Kommentar zu 6,3-4, 1. Auslegung). Zu „DIE ZEIT IST NAHE“ siehe Kommentar zu 22,6.

22,11 Wer Unrecht tut, tue weiter Unrecht, und der Schmutzige beschmutze sich weiter, und der Gerechte übe weiter Gerechtigkeit und der Heilige heilige sich weiter!

Diese Verse zeigen, dass Gott die Freiheit des Menschen absolut achtet. Gott will, dass alle Sünder sich bekehren und gerettet werden (1 Tim 2,4), aber er lässt zu, dass die Sünder, wenn sie wollen, auch noch mehr sündigen. Der erste Teil dieses Verses ist also als Zulassung zu deuten, der zweite Teil aber gibt die eigentliche Absicht und den Willen Gottes kund, der auf eine Heiligung der Menschen zielt. Der ganze Vers will sagen, dass es die Aufgabe der Menschen ist, zum Guten oder zum Bösen heranzureifen, und wenn sie ihre endgültige Reife erreicht haben (die Einzelmenschen beim Zeitpunkt ihres Todes; die Gesellschaft zum Zeitpunkt des Endgerichts), werden die Guten und die Bösen den ihnen gebührenden Lohn erhalten.

22,12 Siehe, ich komme bald und mein Lohn ist mit mir, um jedem zu vergelten wie sein Werk es verdient.

Jesus kommt also bald als Richter. Zu denken ist bei dem BALD vor allem an die Christusbegegnung, die jeder Mensch bei seinem Tode erfahren wird. In zweiter Linie ist an die Gerichte Gottes innerhalb der Geschichte zu denken, die BALD nach der Abfassung der Apokalypse sich ereigneten, und die viele Menschen ums Leben und somit vor das Gericht Gottes brachten. In einem weiteren Sinn ist das BALD auch auf das Endgericht zu beziehen, da auch die Weltgeschichte insgesamt nur ein kurzer Augenblick ist im Vergleich mit der Ewigkeit (vgl. 1 Petr 3,8). Zur Vergeltung NACH DEN WERKEN vgl. 2,23, 14,13 und 20,12-13.

22,13 Ich bin das Alpha und das Omega, der Erste und der Letzte, der Anfang und das Ende.

Christus ist Alpha und OMega, ERster und Letzter, ANFAng und Ende: Ursprung und Ziel der Schöpfung. Er ist der alles entscheidende Punkt, von dem alles ausgeht und in den alles einmündet. Hier haben wir eines der schönsten und klarsten Bekenntnisse zur Gottheit Jesu Christi und zu seiner absoluten Wesensgleichheit mit Gott dem Vater, der ebenfalls Alpha und Omega genannt wird, vgl. 21,6 und Exkurs 1.

22,14 Selig sind die, die ihre Kleider waschen, damit sie Anrecht haben auf das Holz des Lebens und damit sie durch die Tore eingehen in die Stadt.

Die KLEIDER bezeichnen den moralischen Charakter der Seele (vgl. Kommentar zu 3,4). Das WASCHEN DER KLEIDER geschieht durch Reue, Gebet und Taten der Liebe. Wer auf diese Weise seine Sünden tilgt, hat Anrecht auf das HOLZ DES Lebens, d.h. auf die ewige Seligkeit, für welche die Früchte der „Bäume des Lebens“ Symbol sind (siehe Kommentar zu 22,2).

22,15 Draußen sind die Hunde und die Giftmischer und die Unzüchtigen und die Mörder und die Götzendiener und jeder, der die Lüge tut. 
DRAUSSEN: d. h. ausgeschlossen von der Stadtgemeinschaft, verbannt und verdammt. Einige von den Lastern, die den Menschen von der Seligkeit ausschließen, werden hier aufgeführt (vgl. auch die Lasterkataloge in 9,21 und 21,8). Dabei ist immer im Auge zu behalten, dass nicht allen Unzüchtigen, Mördern usw. der Ausschluss aus der Stadt droht, sondern nur denen, die ,,ihre Kleider nicht gewaschen haben“, also bis zuletzt reuelos in ihrer Sünde verharrten.

Als erstes sind hier HUNDE genannt. Was ist damit gemeint? Von PAULUS wurden gewisse jüdische Irrlehrer in ihrem Christushass als „Hunde“ bezeichnet (Phil 3,2). PETRUS verglich mit „Hunden“ vom christlichen Glauben abgefallene, sich schamlos gebärdende Personen (2 Petr 2,2). CHRISTUS verglich in Mt 7,6 mit „Hunden“ Menschen ohne Wertschätzung für die Heiligkeit, und in Mt 15,21-28 (Mk 7,24-30) Nicht-Israeliten. Aber die Nähe des Wortes „Hunde“ zu „Unzüchtigen“ und „Giftmischern“ (siehe Kommentar zu 9,21) lässt hier eher an eine sexuelle Sünde denken. Dann müssen mit „Hunden“ praktizierende Homosexuelle gemeint sein (vielleicht im Kontext der Tempelprostitution). Das Wort „Hund“ wurde nämlich für praktizierende Homosexuelle verwendet, wie Dt 23,18-19 beweist: „Unter den Töchtern Israels soll es keine Tempelhure sein und kein Tempelhurer unter den Söhnen Israels. Du sollst keinen Hurenlohn und kein Hundegeld in das Haus Jahwes, deines Gottes, bringen“"

In Dt 23,18-19 ist von homosexueller Hurerei bzw. Tempelprostitution die Rede. In der Bibel wird der homosexuelle Akt deutlich als Sünde verurteilt; abgesehen von Dt 23,18-19 befassen sich noch vier weitere Stellen im Alten Testament mit Homosexualität:

Erstens wurde die Stadt Sodom gemäß Gen 19 von Gott wegen der Sünden ihrer Einwohner vernichtet, wobei über die Art der Sünden zwar direkt nichts gesagt wird, wohl aber homosexuelle Praktiken angedeutet werden. Denn als die Männer von Sodom in der Nacht das Haus von Abrahams Neffen Lot umlagerten, riefen sie ihm zu: „Wo sind die Männer, die heute Abend zu dir gekommen sind? Bringe sie zu uns heraus, damit wir sie erkennen!“ (Vers 5), woraufhin Lot ihnen seine beiden Töchter anbot, die sie aber nicht haben wollen (Verse 6-9). Das Wort „erkennen“ wird hier offenbar als Umschreibung für den sexuellen Verkehr verwendet, was in der Bibel oft der Fall ist (vgl. z.B. Gen 4,1; Mt 1,25). Zweitens begegnet uns eine ähnliche Geschichte in Ri 19, wo in Vers 22 Männer, die als ,nutzlose“ Leute bezeichnet werden, ein Haus umringen und vom Hausherrn verlangen: „Bring den Mann heraus, der bei dir ist; wir wollen ihn erkennen“"

Drittens kommt praktizierte Homosexualität zwischen Männern auch in einem Katalog sexueller Fehltritte in Lev 18 vor. Dort heißt es gegen Ende (Vers 22): „Du darfst nicht mit einem Mann schlafen, wie man mit einer Frau schläft; es wäre ein Gräuel“ (Vers 22). An Ende der Liste (Vers 24-25) schärft Gott den Israeliten ein: „,.. denn durch all das haben sich die Völker verunreinigt, die ich vor euren Augen vertrieben habe. Das Land wurde unrein ... und hat seine Bewohner ausgespieen."

Viertens wird in der Liste alttestamentlicher Strafbestimmungen Lev 20 in Vers 13 für praktizierte Homosexualität die Todesstrafe ausgesprochen: „Wenn ein Mann mit einem anderen Mann wie mit einer Frau verkehrt, haben beide Schändliches begangen. Sie sollen mit dem Tod bestraft werden; es lastet Blutschuld auf ihnen“.

Auch im Neuen Testament werden homosexuelle Akte verurteilt, und zwar als vom Reich Gottes ausschließende, also schwere sittliche Verfehlungen. So mahnt Paulus in seinem Lasterkatalog 1 Kor 6,910: „Täuscht euch nicht! Weder Unzüchtige noch Götzendiener noch Ehebrecher noch Lüstlinge noch Männerbeschlafer ... werden das Reich Gottes erben.“ Mit dem Wort „Männerbeschlafer“ (so wörtlich), das oft weniger treffend mit „Knabenschänder“ übersetzt wird, sind offenbar alle praktizierenden Homosexuellen gemeint und nicht nur diejenigen, die „Knaben“ schänden. Die „Männerbeschlafer“ sind auch in dem Sündenkatalog 1 Tim 1,9-10 enthalten. In der Apokalypse ist eine Missbilligung der Homosexualität außer an vorliegender Stelle auch in 11,8 angedeutet, wo Rom im negativen Sinn „Sodom“ genannt wird. 
Vor allem aber werden gleichgeschlechtliche Sexualakte im Römerbrief als Verirrungen gekennzeichnet, die durch den „Zorn Gottes“ zugelassen wurden: „Sie vertauschten die Wahrheit Gottes mit der Lüge, sie beteten das Geschöpf an und verehrten es anstelle des Schöpfers ... Darum lieferte Gott sie entehrenden Leidenschaften aus: Ihre Frauen vertauschten den natürlichen Verkehr mit dem widernatürlichen. Ebenso gaben die Männer den natürlichen Verkehr mit der Frau auf und entbrannten in Begierde zueinander: Männer trieben mit Männern Unzucht und erhielten den ihnen gebührenden Lohn für ihre Verirrung." (Röm 1,25-27). Man beachte, dass hier die gelebte Homosexualität geradezu die Sünde ist, an welcher eine innere Abwendung von Gott offenbar wird. Diesem Stellenwert entspricht es, wenn im letzten Sündenkatalog der Apokalypse als erstes die „Hunde“ genannt werden.

Nach den Hunden folgen die GifTMISCHER, deren Hauptprodukte der Unzucht dienen (siehe Kommentar zu 9,21), und dann die UnZÜCHTIGEN selbst. Es folgen die MöRDER, bei denen (wegen der Nähe des Wortes zur Unzucht und Giftmischerei) auch besonders an diejenigen zu denken ist, die die Leibesfrucht abtreiben. Schließlich kommen die GöTZENDIENER, die Diener jener falschen Religionen, die alle vorgenannten Sünden rechtfertigen, und JEDER, DER DIE LÜGE TUT. Mit Lüge ist hier wohl ganz allgemein die Sünde gemeint, denn die feierlichen Worte ,jeder, der“ zeigen eine allgemeine Zusammenfassung des Sündenkatalogs an, und die Redewendung „Lüge tun“ zeigt, dass hier nicht bloß das unaufrichtige Reden (Lügen im spezifischen Sinne) gemeint ist, sondern jegliche Tat, die von der moralischen „Wahrheit“ der Gebote Gottes abweicht. Eine etwas andere Bedeutungsnuance hatte die Lüge in 21,27 (geheime Sünde); vgl. zur Lüge auch 21,8, 14,5 und den Kommentar zu 10,6a.

22,16 Ich, Jesus, habe meinen Engel gesandt, um euch dieses zu bezeugen um der (Orts-)Kirche willen. Ich bin die Wurzel und das Geschlecht Davids, und der glänzende Morgenstern.

„MEINEn Engel habe ich gesandt“ - dies bezeugt wieder, dass Jesus Herr über die Engel ist, also auf die Stufe Gottes gehört. Nach 22,6 hat „Gott der Herr“ diesen Engel gesandt, und hier ist es Jesus. Auch diese Tatsache erklärt sich am besten durch die Wesenseinheit Jesu mit dem Vater: ,ich und der Vater sind eins“(Joh 10,30). Siehe Kommentar zu 1,4.

Jesus ist die WuRZEL UND DAS GESCHLECHT DAVIDS, denn er stammt vom König David ab: Sowohl über seine leibliche Mutter Maria (sonst könnte er kaum Sohn Davids „,dem Fleisch nach“ genannt werden - Röm 1,3) als auch über seinen gesetzlichen Vater Joseph, der ausdrücklich „Sohn Davids“ genannt wird (Mt 1,20).

„Wurzel“ Davids meint also nicht den Vater oder die Ahnenreihe, aus der David geboren wurde, sondern umgekehrt die Ahnenreihe, die von David ausging, und aus der CHRISTUS hervorging. „Wurzel“ und „Geschlecht“ Davids meinen also hier dasselbe: Nachkomme und Sohn Davids.

Dass Jesus aber nicht sagt ,,ich bin ein Spross aus der Wurzel und dem Geschlecht Davids“, sondern: „,ich bin die Wurzel und das Geschlecht Davids“, könnte seinen Grund darin haben, dass Jesus sich nicht nur als einen Endpunkt der von David ausgehenden Geschlechterreihe versteht, sondern zugleich als „den“ wesentlichen Teil dieser Wurzel und dieses Geschlechts, aus dem weitere Nachkommen sprossen werden. Alle Christen sind nämlich geistige Nachkommen Christi und somit wie CHRISTUS selber Thronfolger Davids: Sie haben am messianischen Königtums Christi Anteil, so dass sie mit ihm „herrschen werden in alle Ewigkeit“ $(22,5)$.

Christus ist auch der GLÄnZEnde MORgenstern, d. h. er vergleicht sich mit dem in der Frühe hellsten Stern, der den nahen Tagesanbruch ankündigt. In der Tat leuchtet der auferstandene CHRISTUS mit seiner Lehre und mit seiner Gnade in der Nacht dieser noch vergänglichen und gefährdeten Welt, die aber bald den Tagesanbruch ihres ewigen herrlichen Endzustandes erleben wird. Das untrügliche Zeichen dafür ist CHRIstus, der Auferstandene: der Morgenstern.

22,17 Und der Geist und die Braut sagen: Komm!

Und der, der es hört, soll sagen: Komm!

Und der Dürstende soll kommen,

und wer will, empfange das Wasser des Lebens als Geschenk. 
Der Sprechende ist hier wohl immer noch CHRISTUS in seinem Engel (vgl. Kommentar zu 22,10). Christus weist darauf hin, dass der GEIST (die dritte Person in der Dreifaltigkeit) und die BRAUT (die Stadt Gottes, die Kirche der Heiligen, vgl. 21,1; 21,9), die Menschen einladen, das WASSER DES LEBEnS, d. h. die ewige Seligkeit, zu empfangen.

Nicht unpassend ist es gerade der GEIST, der hier einläd, denn wir haben im Kommentar zu 22,1 gesehen, dass das „Wasser des Lebens“ eine Wirkung des dreifaltigen Gottes ist, die in besonderer Weise dem Heiligen Geist zugeschrieben werden muss.

Auch die BRAUT-Stadt muss diese Einladung aussprechen, da ja das Wasser des Lebens nur in ihr zu finden ist. Und schließlich soll auch derjenige, der ,angesprochen“ ist vom Geist und von der Braut, diese Einladung weitergeben.

Der DÜRSTENDE, d. h. derjenige, der „,ürstet nach dem Reich Gottes und seiner Gerechtigkeit“ (vgl. Mt 5,6 und 7,33) soll das Wasser, d. h. die Seligkeit, ALS GESCHENK empfangen. Hier verbirgt sich eine wichtige Lehre: Die Seligkeit ist immer ein Gnadengeschenk Gottes. Obgleich sie in gewisser Weise auch Lohn für die Werke ist (22,12-13 und 14,13), so ist sie dennoch Geschenk, weil alle Kraft für die guten Werke ein Gadengeschenk Gottes ist (vgl. Joh 15,5-7; Phil 2,13).

22,18 Ich bezeuge jedem, der die Worte der Prophetie dieses Buches hört:

Wenn jemand zu ihnen etwas hinzufügt,

wird Gott ihm die Plagen auferlegen, die in diesem Buch aufgezeichnet sind.

22,19 Und wenn jemand von den Worten des Buches dieser Prophetie etwas wegnimmt, wird Gott ihm seinen Anteil am Holz des Lebens und an der heiligen Stadt nehmen, (Dinge,) die in diesem Buche aufgezeichnet sind.

Jesus ist wohl immer noch der Sprechende. Dagegen kann nicht die Erwähnung eines „Buches“ angeführt werden, denn Jesus selbst hatte in 1,9 dem Johannes befohlen: „Was du siehst, schreibe in ein Buch“. Unter Androhung der strengsten Strafen werden hier die Christen ermahnt, das Buch der Apokalypse in seinem ursprünglichen Zustand zu belassen und es weder durch Zufügung noch durch Abstriche zu verfälschen. Da die Apokalypse aufgrund ihres Charakters in einer systematisch geordneten Bibelausgabe den Abschluss bilden muss, könnte man in einem übertragenen, mystischen Sinn sagen, dass CHRISTUS mit diesen Worten auch verbieten wollte, dem ganzen Bibelkanon etwas wegzunehmen oder hinzuzufügen.

Diese Stelle beweist jedoch NICHT die Lehre Luthers, dass die Hl. Schrift das alleinige Glaubensfundament der Christen ist, so dass die mündliche Tradition sowie das kirchliche Lehramt als überflüssig betrachtet oder gar als eine widergöttliche „Hinzufügung“ zur Bibel verworfen werden müssen. Denn verboten werden hier nur Kürzungen oder Erweiterungen des Bibeltextes. ${ }^{153}$

153 Die andere von manchen Lutheranern angeführte Bibelstelle ist das Pauluswort ,nicht über das hinaus, was geschrieben steht“ (1 Kor 4,6). Doch meint Paulus mit „das was geschrieben steht“ sicher nicht unsere heutige Bibel; für ihn war ,die Schrift“ das Alte Testament, denn das Neue war ja noch nicht vollendet. Demnach könnte hier, wenn überhaupt eine grundsätzliche Aussage über die Stellung der Schrift vorliegt, höchstens gemeint sein: Man soll sich nicht über die Weisungen des Alten Testament hinwegsetzen, sie haben einen bleibenden Wert. Dem Kontext nach dürfte allerdings Paulus hier überhaupt kein Grundsatzurteil über die Hl. Schrift im Sinn gehabt haben (auch nicht über das Alte Testament), sondern über den Selbstruhm, den die Hl. Schrift verurteilt. Der Kontext ist nämlich, dass Paulus die Korinther, welche sich in Parteien verschiedener christlicher Prediger gespalten hatte, zur Demut ermahnen wollte, als er in 1 Kor 4,6 schrieb: „Nicht über das hinaus, was geschrieben steht: dass sich keiner zugunsten des einen aufblähe gegen den anderen. "Die Korinther sollten also nicht so sehr auf spezielle Prediger, sondern auf Gott und Christus bauen (vgl. 1 Kor 3,5-11). Mit ,dem, was geschrieben steht" dürfte daher eine gegen den Selbstruhm gerichtete Weisung gemeint sein, und zwar scheint Paulus konkret auf Gottes Wort in Jer 9,22-23 anzuspielen: „Nicht rühme sich der Weise seiner Weisheit und nicht rühme sich der Starke seiner Stärke und nicht rühme sich der Reiche seines Reichtums: statt dessen soll sich rühmen, wer sich rühmen will, dass er versteht und mich kennt, der ich Gnade, Recht und Gerechtigkeit walten lasse auf Erden." Paulus hatte nämlich seinen Lesern vor 1 Kor 4,6 genau drei (freie) Schriftzitate vorgehalten, die alle drei mit der Eitelkeit des Selbstruhms zu tun hatten (1 Kor 1,19 - vgl. Jes 29,14; 1 Kor 1,31 - vgl. Jer 9,22-23; 1 Kor 3,19-vgl. Hiob 5,13), und in 1 Kor 1,31) und von diesen drei Zitaten scheint zu der Belehrung 1 Kor 4,6 am besten das Zitat in 1 Kor 1,31 zu passen. Es heißt dort in Anlehnung an Jer 9,22-23: ,Wie geschrieben steht: Wer sich rühmen will, der rühme sich des Herrn.“ 
Dass dieser aber einer Ergänzung im Sinne einer vertiefenden Erklärung bedarf, wird damit nicht in Frage gestellt. Eine solche vertiefende Erklärung aber darf vernünftigerweise nicht im Widerspruch zu den Grundsätzen des von CHRISTUS eingesetzen kirchlichen Lehramtes erfolgen, und sie darf die Tradition (d.h. den Erfahrungsschatz einer zweitausendjährigen vom Geist Gottes geleiteten Geschichte des Christentums) nicht unbesehen außer Acht lassen.

22,20a Der dies bezeugt, sagt: Ja, ich komme bald. Amen, komm, Herr Jesus!

Jetzt spricht nicht mehr Jesus, sondern Johannes, der den Herrn Jesus um die Erfüllung der Prophezeiungen bittet: um sein KommEN, das Kommen des Reiches Gottes in der Geschichte und an deren Ende. Nochmals wird auf das BALDIGE KOMMEN hingewiesen und damit angekündigt, das die Kette der vorausgesagten Ereignisse bald beginnen wird, sich zu erfüllen.

Es ist hier der rechte Ort, um zusammenfassend festzuhalten, was sich tatsächlich erfüllt hat. Schon im ersten Teil der Apokalypse, in den Briefen an die sieben Ortskirchen, waren andeutungsweise drei Prophezeiungen enthalten:

1. der Märtyrertod des Polykarp (2,8-11), der im Jahre 156 erfolgte,

2. der schnelle Untergang der Nikolaitensekte $(2,16)$, der Anfang des 2. Jahrhunderts eintrat,

3. die ,weltweite“ Ausdehnung der Christenverfolgung (3,10), die unter Trajan im Jahre 112 Wirklichkeit wurde.

Der eigentlich prophetische Teil begann aber erst mit den sieben Posaunen.

4. Das in den ersten vier Posaunen angekündigte Strafgericht gegen die christenfeindlichen Juden (8,712) erfüllte sich im 2. Jahrhundert mit der katastrophalen Niederschlagung der beiden jüdischen Aufstände 115-117 und 130-135, der Entlarvung des falschen Messias Bar Kochba, des ,Sternensohnes“, der nachfolgenden „Bitterkeit“ des Ausschlusses der Juden aus Jerusalem (135) und der Verfinsterung des wahren Glaubens im jüdischen Umfeld des 2. Jahrhunderts. Damit endete das in der Vision beschriebene Gericht am Judentum.

Die Botschaft der 5.-7. Posaune (= 1.-3. Weh) war das Gericht am Heidentum:

5. Die Prophezeiung der 5. Posaune (=1. Weh, 9,1-12) erfüllte sich in der Zeit von ca. 190-260, als die „Heuschreckenplage“ der Theodotianer viele scheinchristlichen Heiden zu Fall brachte.

6. Die Prophezeiung der 6. Posaune $(=2$. Weh, 9,13-11,14) erfüllte sich teils 260 durch die persischen Reiterheere, die der valerianischen Christenverfolgung ein Ende bereiteten, und teils im Jahr 312 durch den Sieg Konstantins und der Zeugen Christi über die diokletianische Verfolgung.

7. In dem durch die 7. Posaune markierten Hauptteil (= 3. Weh, 11,15 - 19,21) sah Johannes richtig voraus, dass der Kampf zwischen Satan und der Frau, der mit der Kreuzigung Christi begonnen hatte, in der diokletianischen Verfolgung seinen vorläufigen Höhepunkt haben würde (Kap. 12).

Dabei erkannte er, dass diese Verfolgung zwei Teile hatte: Zuerst eine längere Phase, die bereits mit einem Sieg Christi endet, und dann eine kürzere, härtere Phase, mit der die Verfolgung endgültig abschloss. Auch sah er voraus, dass zu dieser Zeit das heidnisch-römische Reich, das „Tier“, sieben „Köpfe“ (d. h. christenverfolgende Kaiser) hatte und nach einer Scheintodphase unter Kaiser Julian wieder zum Leben erweckt wurde, wobei es von einem zweiten „Tier“, dem Neuplatonismus, eine philosophisch-religiöse Stütze erhielt (Kap. 13). In der verschlüsselten Form der Zahl 666 wurde an dieser Stelle auch der Name Diokletians gekennzeichnet, in dem sich historisch der Höhepunkt antichristlicher Macht verkörperte $(13,18)$.

In 14,14-20 sind zwei „Ernten“ vorausgesagt, in denen sich das Gericht über Rom vollzog: Die erste, die unter ALARICH 410 Wirklichkeit wurde, ist richtig als weniger blutig charakterisiert. Und von der zweiten, sehr blutigen, ist vorhergesagt, dass sie ,außerhalb der Stadt“ erfolgen würde (was sich besonders im Jahre 451 unter Attila erfüllte). 
In Kap. 16 (Ausgießung der sieben Schalen) sah Johannes den schrittweisen Niedergang des heidnischen Rom: die Verschlechterung der Position der Heiden (Geschwür) nach dem Tod Julians im Jahre 363, die vielen Kriege jener Zeit, das stärker werdende Christentum unter Theodosius, die Verfinsterung des Reiches nach dem Tode des Theodosius, den Ansturm der Völkerwanderung („Krieg von Harmagedon“) und schließlich den Sturz Roms im Jahre 410 unter ALARICH mit der dabei erfolgten Dreiteilung.

Die Schlüsselkapitel 17,1 - 19,10 offenbaren weitere Einzelheiten: Details über die Reihe der sieben bzw. acht diokletianischen Verfolger (17,10-11) und vor allem über die Rom stürzenden Barbaren (,die zehn Hörner“" 17,12-14): vor allem, dass diese zuerst in Roms Heeren dienten, dann aber Rom vernichteten, und dass sie zuerst ebenfalls gegen CHRISTUS kämpfen, dann aber von CHRISTUS überwunden werden.

Über den Fall Roms im Jahre 410 wird richtig gesagt, dass die Stadt dabei verbrannt würde (17,16; $18,8 ; 18,9 ; 18,18)$. Angedeutet wird auch die Flucht der Christen (18,4). In 19,11-21 schließlich sah Johannes den völligen Untergang der beiden ,Tiere“, was sich in der Zeit vom 410 bis zum Ende der Völkerwanderungszeit (um 600) erfüllt hat.

8. Die letzten beiden Kapitel prophezeien das Tausendjährige Reich, dann eine neue, weltweite Christenverfolgung unter einem Diktator (Gog), und das Endgericht.

Konkretere Aussagen über unsere Zeit oder die Endzeit im engeren Sinne fehlen fast ganz. Bemerkenswert ist allerdings die Andeutung in 11,18, dass Menschen einst „die Erde verderben“ werden, was im eigentlichen Sinn nicht auf die Antike, wohl aber auf die moderne Zeit der Umweltzerstörung und der Massenvernichtungswaffen gedeutet werden kann.

Wir leben meines Erachtens in der Zeit des Tausendjährigen Reiches, und zwar eher an dessen Ende.

\section{Die Gnade des Herrn Jesus sei mit allen!}

JOHANNES beendet das Buch, indem er für alle Menschen die Gnade JESU erfleht, die all jene, die sich nicht in der Sünde verschließen, vor der ewigen Strafe erretten und zum ewigen Leben führen wird. 


\section{Literaturverzeichnis}

[1] AlCAZAR, Luis de. Vestigatio sensus Apocalypsis. Antwerpen 1614 und 1619.

[2] Allo, Ernest-Bernard. St. Jean L'Apocalypse. Paris, 3. Auflage 1933.

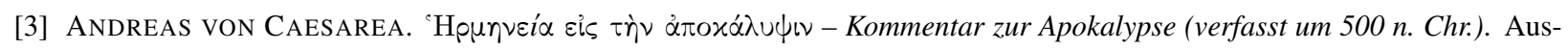
gabe: J. P. Migne, Patrologia Graeca Band 106, Spalten 199-786.

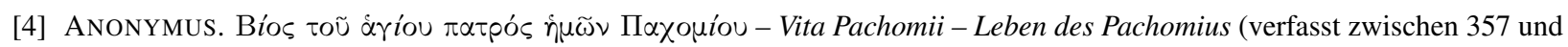
368 n. Chr.). Griechische Ausgabe: Halkin, Franciscus SJ, Sancti Pachomii Vitae Graecae, Brüssel: Société des Bollandistes, 1932. Deutsche Ausgabe: Hans Mertel [Übers], Leben des heiligen Pachomius, in: Anton Stegmann [Hg], Des heiligen Athanasius Schriften II. Band (BKV = Bibliothek der Kirchenväter, in der Reihenfolge des Erscheinens Band 31), München, 1917, S. 781-900.

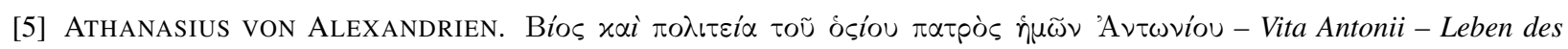
Antonius (verfasst 357 n. Chr.). Griechisch-Lateinische Ausgabe: J. P. Migne, Patrologia Graeca Band 26 Spalten 823-976. Deutsche Ausgabe: Hans Mertel [Übers], Des heiligen Athanasius Leben des heiligen Antonius, in: Anton Stegmann [Hg], Des heiligen Athanasius Schriften II. Band (Bibliothek der Kirchenväter, in der Reihenfolge des Erscheinens Band 31), München, 1917, S. 679-777.

[6] Aurelius Augustinus. De Civitate Dei (Vom Gottesstaat), verfasst 431-426. Ausgaben: (a) Lateinisch: B. Dombart /A. Kalb [Hgg.], CCSL (Corpus Christianorum Series Latina XLVII/XIV, 1 et 2, Turnhout 1955. (b) Deutsch: Des heiligen Kirchenvaters Aurelius Augustinus zweiundzwanzig Bücher über den Gottesstaat. Aus dem Lateinischen übers. von Alfred Schröder (BKV = Bibliothek der Kirchenväter, 1. Reihe, Bände 1, 16, und 28), München: Kösel Verlag, 1911-16.

[7] BARClay, William. Offenbarung des Johannes. Wuppertal, 1970, Band 2.

[8] Berengaudus. Expositio super septem visiones libri Apocalypsis (9. Jh.). hrsg. von J. P. Migne, PL Band 17, Spalten 841-1055.

[9] Binlmeyer, Karl. Kirchengeschichte. Neubesorgt von Hermann Tüchle. Paderborn: Schöningh, 18. Auflage $1982 / 83$ (3 Bände).

[10] Bossuet, Jacques-Bénigne. Französischer Kommentar zur Apokalypse aus dem Jahre 1689. hrsg. von J. P. Migne, Scripturae Sacrae Cursus Completus, Band 25, 1842, Spalten 1173-1446.

[11] BRÜTsCH, Charles. Die Offenbarung Jesu Christi. Johannes-Apokalypse. Zürich: Zwingli Verlag, 2. vollständig überarbeitete Auflage 1970 (3 Bände).

[12] CAIRD, G. B. A commentary on the Revelation of St. John the Divine. (Black's New Testament Commentaries), London 2. Auflage, 1984.

[13] Calmet, Augustin. Commentaire Littéral. Band 8, Paris, 1726.

[14] CoRnelius a LAPIDE (Cornelis Cornelissen van den Steen). Lateinischer Kommmentar aus dem Jahre 1625. Hrsg. von J. B. Pelagaud (Cornelii a Lapide Commentarii in Scripturam Sacram, Band 10), Paris und Lyon, 1854, S. 1015-1373.

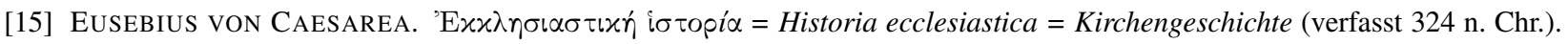
Ausgabe: Eduard Schwartz [Hg], Die Griechischen Christlichen Schriftsteller (GCS), Bd. 9, 1-3, Leipzig: Hinrichs 19031919; 2. Auflage 1914.

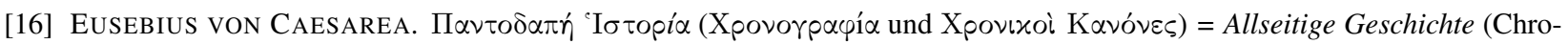
nographie und Chronologische Kanones), kurz Chronik (verfasst 325 n. Chr.), das griechische Original ist verloren, erhalten sind griechische Fragment und alte Übersetzungen ins Lateinische und Armenische. Ausgabe: Alfred Schoene [Hg.], Eusebii Chronicorum Libri duo, 2 Bände, Berlin, 1866-1875.

[17] FARrer, Austin. Revelation of St. John the Divine. Oxford, 1964.

[18] Feret, Henri-Marie. Die Geheime Offenbarung des Heiligen Johannes. Eine christliche Schau der Geschichte. Düsseldorf, 1955.

[19] Ford, J. Massyngberde. Revelation. (The Ancor Bible), New York, 1975.

[20] Gagnaeus (Gagnée oder Gagny), Johannes († 1549). lateinischer Kommentar. Abfassungszeit unbekannt, hrsg. von J.-P. Migne, Scripturae Sacrae Cursus Completus, Band 25, 1842, Spalten 1173-1438. 
[21] Gregorovius, Ferdinand. Geschichte der Stadt Rom im Mittelalter vom V. bis XVI. Jahrhundert. Darmstadt: Wissenschaftliche Buchgesellschaft, 1963 (unveränderter Nachdruck der Ausgabe Tübingen 1953).

[22] Hadorn, W. Die Offenbarung des Johannes. (Theologischer Handkommentar zum Neuen Testament Band 18), Leipzig, 1928.

[23] HÄring, P. Placidus. Die Botschaft der Offenbarung des Heiligen Johannes. München, 1953.

[24] IAnnuZzI, Joseph OSI. The Triumph of God's Kingdom in the Millennium and the End of Times. A proper belief from the Truth in Scripture and Church Teachings. Havertown, PA (USA): St. John the Evangelist Press, 1999.

[25] IRENÄUs von LyON. Adversus Haereses, fünf Bücher, verfasst um 180. Ausgabe: Norbert Brox [Hg.], FC (Fontes Christiani), Bände 8/1 bis 8/5, Freiburg: Herder 1993-2001.

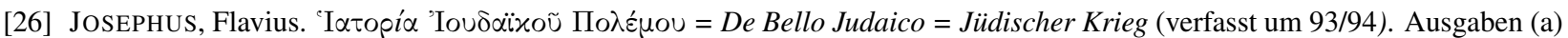
Griechisch: Benedictus Niese [Hg.] Flavii Josephi opera Band 1-4, Berlin: Weidmann 2. Auflage 1955. (b) Deutsch: Flavius Josephus, Jüdische Altertümer, übersetzt von Heinrich Clementz, Wiesbaden: Fourier Verlag 5. Auflage 1983 (2 Bände).

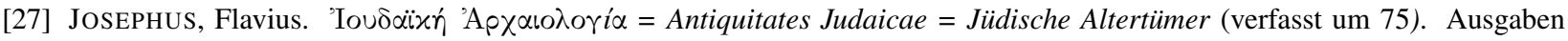
(a) Griechisch: Benedictus Niese [Hg.] Flavii Josephi opera Band 5, Berlin: Weidmann 2. Auflage 1955. (b) Deutsch: Flavius Josephus, Geschichte des Jüdischen Krieges, übersetzt von Heinrich Clementz, Wiesbaden: Fourier Verlag 1979.

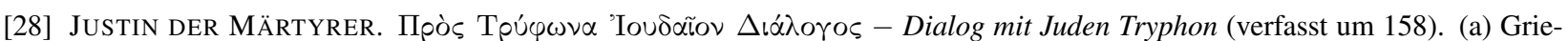
chisch: Miroslav Marcovich [Hg.], Iustini Martyris Dialogus cum Tryphone (PTS = Patristische Texte und Studien 47), Berlin/New York: de Gruyter, 1997.(b) Deutsch: Justinus, Dialog; Pseudo-Justinus, Mahnrede. Aus dem Griechischen übersetzt von Philipp Hauser (BKV = Bibliothek der Kirchenväter), 1. Reihe, Band 33) Kempten \& München 1917.

[29] KRAfT, Heinrich. Die Offenbarung des Johannes. (Handbuch zum Neuen Testament Band 16a), Tübingen, 1974.

[30] Lohmeyer, Ernst. Die Offenbarung des Johannes. (Handbuch zum Neuen Testament Band 16), Tübingen, 2. Auflage 1953.

[31] LORTZ, Joseph. Geschichte der Kirche in ideengeschichtlicher Betrachtung. Münster: Aschendorff, 1926/64 (2 Bände).

[32] OBERWEISS, Michael. Die Bedeutung der neutestamentlichen ,Rätselzahlen` 666 (Apk 13,18) und 153 (Joh 21,11). In: Zeitschrift für Neutestamentliche Wissenchaft 77(1986) S. 226-241.

[33] Pohl, Adolf. Die Offenbarung des Johannes. (Wuppertaler Studienbibel), Wuppertal und Zürich: Brockhaus Verlag 1989.

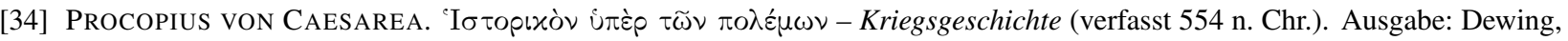
H. B. [Hg und Übers], Procopius (5 Bände), London: Heinemann, 1914-1928.

[35] Robinson, John Arthur Thomas. Redating the New Testament. London SCM-Press 1976, 4. Aufl. 1981. Deutsche Ausgabe: Wann entstand das Neue Testament? Übersetzt von Johannes Madey, Paderborn: Verlag Bonifatius-Druckerei, \& Wuppertal:Brockhaus, 1986. Hier wichtig Kap. VIII: Das Buch der Offenbarung. S. 232-264.

[36] RoHr, Ignaz. Deutscher Kommentar in: Die Heilige Schrift des Neuen Testaments. Bonn, 1916.

[37] Rosen, Klaus. Julian. Kaiser, Gott und Christenhasser. Stuttgart: Klett-Cotta, 2006.

[38] SeEcK, Otto. Geschichte des Untergangs der Antiken Welt. Band 4. Stuttgart: Poeschel, 1966 (unveränderter Nachdruck der 2. Auflage Stuttgart 1922).

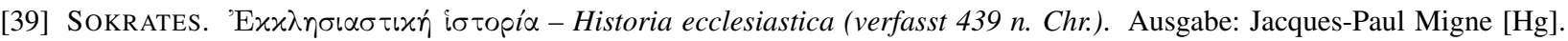
Patrologiae Graecae Tomus 25 Spalten 29-842.

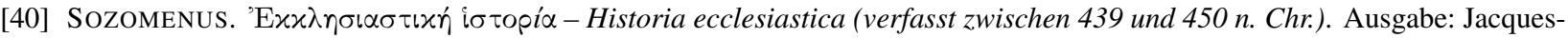
Paul Migne [Hg]. Patrologiae Graecae Tomus 25 Spalten 843-1630.

[41] Sulpicius Severus. Chronicorum libri duo (veröffentlicht nicht vor 403 n. Chr.). Ausgabe: Carolus Halm [Hg]. Sulpicii Severi libri qui supersunt (= Corpus Scriptorum Ecclesiasticorum Latinorum Band 1), Wien: Geroldi, 1866, S. 3-105.

[42] Victorin von Pettau. Scholia in Apocalypsin Beati Ioannis (um 270 n. Chr.). Ausgabe: Hausleitner, Johannes, Victorini Episcopi Petavionensis Opera (Corpus Scriptorum Ecclesiasticorum Latinorum 49), Wien 1916.

[43] Wouters, F. Martin (18. Jh.). Quaestionum Selectarum in Apocalypsim S. Joannis Apostolo Dilucidatio. Lateinischer Kommentar, hrsg. von J.-P. Migne, Scripturae Sacrae Cursus Completus, Band 25, Spalten 1039-1174.

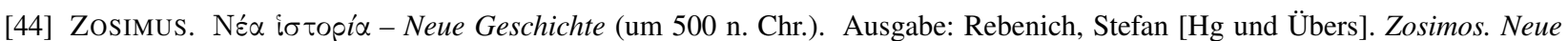
Geschichte. Stuttgart: Hirsemann, 1990. 


\section{Index}

Abbadon, siehe Teufel

Abel

- die Schuld an seinem Blut, 197

- einer der 24 Ältesten?, 51

Abendmahl, siehe Manna

Abgrund, 86, 87, 89, 90, 93, 101, 109, 127, 178, 183, 204, 205, 207, 213

Abraham (um 1875 v. Chr.), 20

- einer der 24 Ältesten, 50, 51

- von Sirach gelobt, 50

Abraham (um 1875 v. Chr.) (= Vater vieler Völker), 143

Abraham (um 1875 v. Chr.), 13, 28

- Abraham im Feueroffen (rabbinische Erzählung), 153

Abtreibung, siehe Giftmischerei

Acht, siehe Zahl

Achthundert, siehe Zahl

Achthundertachtundachtzig, siehe Zahl

Adler

- das vierte der vier Wesen, 46, 52-55, 66

- ruft den 4. Reiter herbei, 66

- Symbol der Gottheit Christi, 55

- Symbol für Gott, 116

- Symbol für eine Botschaft, 84, 124, 162

Adventisten

- Lehre über das Tausendjahr-Reich, 203

- ihre Deutung der Zahl 666 auf den Papst, 155, 156

- ihre Prophetin, Trägerin der Zahl 666, 156

Aetius, römischer General, Halbskythe (†454), kämpft gegen Attila, 169, 190

Agathias, Geschichtsschreiber (†582 oder 594), schreibt über Valerians Tod, 95

Ägypten, 69, 81, 106

- Auszug aus Ägypten, 162

- Erste Plage Ägyptens, 106

- Erstes gefallenes Reich, 185

- Marias Flucht nach Ägypten, 118, 119

- Siebte Plage Ägyptens, 82

- Symbolname für Rom, 101, 110

- Zehn Plagen Ägyptens, 108

Akiba, siehe Aqiba

Alamannen oder Alemannen, Germanenvolk

- gehören zu den zehn Hörnern, 188

- kämpfen im Heer des Radagais, 193

- von Rom mit Hilfe anderer Germanen bekämpft, 190

Alanen, asiatisches Volk

- fallen in Gallien ein, 189

- gehören zu den 10 Hörnern, 188

- gehören zu den zehn Hörnern, 188

- König Respendial, siehe Respendial

- kämpfen auf Seiten Roms, 190
- kämpfen im Heer des Radagais, 193

- überschwemmen das Reich, 173, 189, 190

Alarich, Westgotenkönig (382-410), 113, 167, 169, 175, 177, $189,190,193,195,239$

- belagert Rom, 193

- besiegt Rom, 191, 194

- einer der zehn Könige, 189

- erobert Rom, 196

- plündert Rom, 196

- römischer General, 190

- schont als Arianer die Kirchen Roms, 192

- schont die Kirchen Roms, 194

- sein Schlag gegen Rom wird mit einer Ernte verglichen, 168, 169, 238

- sein Sendungsbewusstsein, 191

- verbrennt Rom, 194

- vergießt weniger Blut als Attila, 169

Alboin, Langobardenkönig (565-573), 189

- Beitrag zur Zerstörung Roms, 197

- im Zusammenhang mit den zehn Königen, 189

Alcazar, Luis de, Kommentator $(† 1613$ )

- antik-geschichtliche Auslegung, 9

- Deutung der Edelsteine, 226

- Deutung der „tausend Jahre“, 205

Allo, Ernest-Bertrand, Kommentator († 1945)

- abstrakt-kirchengeschichtliche Auslegung, 9

- befürwortet Augustins Auslegung des Tausendjahr-Reichs, 204

- Deutung der „fünf Monate“, 91

- Deutung der ersten fünf Könige, 186

- Deutung des achten Königs, 187

- Deutung des dritten Edelsteins, 225

- Form des himmlischen Jerusalem, 223

- Johannes als Verfasser der Apokalypse, 7

Allwissenheit, siehe Vorsehung

Alpha und Omega, Erster und Letzter, Anfang und Ende

- bezieht sich auf Gott und Christus, 11, 13, 18, 44, 217 , $219,220,233,234$

Altar

- Altäre für Plotin und Porphyrius, 136

- Altar der Siegesgöttin Victoria, 193

- Beisetzung von Märtyrergebeinen, siehe Verehrung

- Bezeichnung für den Innenhof, 101, 102

- Bezeichnung für die Märtyrer, 173, 174

- Brand- und Rauchopferaltar, siehe Juden(tum), -Tempel

- im himmlischen und jüdischen Tempel, siehe Juden(tum), -Tempel

Älteste, die vierundzwanzig, siehe Heilige

Ambrosius, heiliger Bischof $(† 397), 193$

Amen, Bezeichnung Gottes und Christi, 43, 44 
Ammianus Marcellinus, heidnischer Schriftsteller, 140

Ammonius Sakkas († 242), Neuplatoniker, 135

Anastasius I. (399-401/2), heiliger Papst, 192

Anbetung, siehe Jesus; Verehrung

Andreas von Caesarea, Kommentator

- Kommentar zu den Feueraugen, 20

Andreas, König der Juden in Cyrene, 81

Anfang der Schöpfung Gottes

- Bezeichnung Christi, 43

Anfang und Ende, siehe Alpha und Omega

Angeln und Angelsachsen, Germanenvolk

- Bekehrung zum katholischen Christentum, 190

Angelus Silesius, Dichter, 158

Antichrist, letzter Gewaltherrscher, 9, 158

- Caligula als Antichrist, 149

- der Papst als Antichrist, 155, 156, 158

- Diktator „Gog“ von „Magog“, 155, 213

- Gedicht von Angelus Silesius, 158

- Herkunft aus Dan, 73

- Lichtbringer, 157

- Nero als Typus des Antichristen, 186

- nicht das Tier, 129

- nicht die Hure Babylon, 180, 181

- Papst als Antichrist, 156

- Teitan, 150

Antike, 71, 95, 114, 144, 153, 224, 239

- Untergang, 176, 177, 201

Antiochus III. der Große, König von Syrien (223-187 v. Chr.), 37,38

Antiochus IV. Epiphanes, König von Syrien (175-164 v. Chr.), $103,113,121$

Antipas, Märtyrer in Pergamon (um 94 v. Chr.), 31, 32

Antonius, heiliger Mönchsvater (250-356), 207

Anzahl der Menschen im römischen Reich, 103

Äon, 232

Aphrodisiaka, siehe Giftmischerei

Apokalyptische Reiter, siehe Reiter

Apollo, griech. Gott des Lichtes und des Verderbens

- erteilt Orakel, 140

- mit „Apollyon“ auf ihn angespielt?, 93

Apollonius von Tyana, Pythagoräer, Magier, falscher Messias († um 97), 136

Apollyon, siehe Apollo; Teufel

Apostel, siehe auch Johannes, Paulus, Petrus, Stern, 87, 159

Apostel, siehe auch Johannes, Paulus, Petrus, Stern, 27, 29, $40,49,50,62,70,83,87,88,118,119,148,180$, $196,199,208,217,221,224-228$

- falsche Apostel, 25-27

Aqiba (Akiba) ben Joseph, Rabbi (um 50-135), 83, 84

Aquila und Theodotion, jüdische Übersetzer der Hl. Schrift ins Griechische (2. Jh.), 84

Arbogast, 388-394 fränkischer Heerführer in römischen Diensten, 190

Arianer und Arius, Irrlehrer $(† 336), 192$

Arianer und Arius, Irrlehrer $(† 336)$, siehe auch Alarich, Geiserich, Gelimer, Hunnerich, Leovigild, Theodorich, Thrasamund, Zeugen Jehovas, 44, 64, 88, 89, 172, 174, 176, 190, 200, 202

Aristoteles, Philosoph († 322 v. Chr.), 135
Arkadius, oströmischer Kaiser (395-408), 174, 190, 193

Artemion, jüdischer Führer (um 115-117), 81

Ärzte in Laodizea, 43

Asklepios, griech. Gott der Heilkunst, 32

Asturier, Volk im Nordosten Spaniens, 173

Athanarich, Westgotenkönig $(† 381)$, Heide, verfolgt die Christen, 202

Attalus, weströmischer Kaiser (408/9-410), 177

- heidenfreundlich, 193

- seine Münzen, 194

Attila, Hunnenkönig (um 434-453), 169, 190

Beitrag zur Zerstörung Roms, 197

- das Blutbad, das er anrichtete, 169, 189

- die Zahl 666 ihm zugeschrieben, 158, 238

- einer der ,zehn“ Könige, 189

- sein Sendungsbewusstsein, 191

Außenhof, siehe Hof

Auferstehung und Auferweckung

- acht als Zahl der Auferstehung, 145

- Auferstehung der zwei Zeugen, 109, 111, 126, 209, 210

- Christi Auferstehung, 15, 17, 19, 23, 30, 36, 44, 45, 55-57, 59, 62, 70, 76, 139, 145, 225, 227

- erste und zweite Auferstehung, siehe auch Leben, 205, 209

- falsche Totenauferweckungen, 137

- im geistigen Sinn, 108, 123

- leibliche Totenauferstehung nach dem Weltgericht, 77, $79,166,215,216,222,230$

Aufgefressenwerden durch Tiere, siehe Tiere

Aufstand, siehe Juden, Erdbeben

Augen

- Augensalbe (Kollyrion), 43-45

- die Augen der vier Wesen, 46, 52-55

- die Feueraugen Jesu, 11, 20, 33, 34, 200

- die sieben Augen des Lammes, 16, 17, 47, 57

Augustinus, heiliger Bischof (354-430)

- Deutung der „tausend Jahre“, 203, 205

- Deutung der vier Wesen, 54

- Deutung des Untergangs Roms, 194

- Gottesstaat, 177

- lange Zeit bis zum Weltende, 63

- neuplatonischer Einfluss, 135

- Stellungnahme zum Diakon Nikolaus, 27

- „tauft“ den Neuplatonismus, 135

- Trauer über den Untergang Roms, 196

- über die Flucht aus Rom, 193

- über die Höllenstrafe, 164

Augustus, Kaiser (44 v. Chr. - 14 n. Chr.), 43, 150

- Erster der sieben Köpfe?, 185-187

Augustus, Titel, 132, 143, 148, 151

Auslegung, siehe Schriftauslegung

Ausspeiung aus Jesu Mund angedroht, 43, 44

Babylon

- Babylonische Gefangenschaft unter Nebukadnezar, 81, 105,111

- Babylonisches Reich, 82, 89, 185, 196

- Deckname für Rom, 181 
- Gründer Nimrod, 153

- Hure Babylon, die heidnische Stadt Rom, 145, 161, 178, 180-182, 192, 195, 198, 219, 221

- Symbolname für Rom, 153

Balak und Bileam, Verführer Israels (um 1410 v. Chr.), 32

Balak und Bileam, Verführer Israels (um 1410 v. Chr.), 31, $32,35,104,153$

. Bileams messianische Sternenprophezeiung, 83

Bald, siehe Kommen

Bär, siehe Galerius

Bar Kochba, falscher Messias ( $†$ 135)

- Führer im jüdischen Aufstand, 84

Bar Kochba, Simon, falscher Messias († 135); eigentlich Ben/Bar Koseba; auch Bar Koziba genannt

- Führer im jüdischen Aufstand, 80-83, 154, 238

- Träger der Zahl 666, 154

Bar Koseba, siehe Bar Kochba

Bar Koziba, siehe Bar Kochba

Barbaren

- dienen in römischen Heeren, 188, 190

- fallen ins römische Reich ein, 80, 93, 95, 169, 170, 173,175

- verfolgen die Christen und bekehren sich, 190

- zehn Hörner oder Könige, 120, 129, 130, 188-190

- zerstören antike Weltordnung, 71

- zerstören das römische Reich in der Völkerwanderung, $120,169,176,188$

Baum

- Bäume als Symbole für Familien, 82

- Symbol des Lebens, siehe Holz

Beda Venerabilis, Heiliger, Geschichtsschreiber, Kommentator $(\dagger 735)$

- Deutung der zwei Zeugen, 105

Beda Venerabilis, Heiliger, Geschichtsschreiber, Kommentator $(\dagger 735)$

- Aufschluss über die Notwendigkeit des Kennzeichens beim Kaufen und Verkaufen, 141

- Deutung des Gebets der Märtyrer, 68

Belisar, Feldherr Justinians $(† 565)$

- Beitrag zur Zerstörung Roms, 197

Ben Koseba, siehe Bar Kochba

Benedikt Gaetani, siehe Bonifaz VIII.

Benedikt XI., Papst (1303-1304)

- Träger der Zahl 666, 156

Berengaudus, Kommentator (9. Jh.)

- Deutung der zehn Könige, 188

- Kommentar zur Zahl 666, 158

Berg

- Berg Megiddo, 176

- Berg Sinai, 124

- Berg der Verklärung, 70

- Mt. Everest, 222

- Symbol für Feststehendes, 69

- Zion, 159, 160, 199

- „Feuerberg“ des Römischen Reiches, 79, 80, 82

- der „Stadtberg“ des Neuen Jerusalem, 10, 217, 221, 223, 228

Bevölkerungszahl
- im Römischen Reich, siehe Anzahl der Menschen im Römischen Reich

- in der Antike, siehe Weltbevölkerungszahl

Bewohner der Erde

- Vergleich zu ,auf der Erde Sitzende“, 163

- negativer Ausdruck, 39, 41, 84, 94, 101, 111, 124, 128, $133,137,159,163,178,181,183,230$

Bibel, siehe Schrift

Bihlmeyer, Karl, Historiker, 103

- Urteil über Bonifaz VIII., 156

Bild und Bilderverehrung, siehe Verehrung und Konzilien

Bilderverbot, siehe Gebote

Bileam, siehe Balak

Bischöfe

- Verehrung ihres Amtes, siehe Verehrung

- durch Sterne symbolisiert, siehe Stern

Bleich, siehe Grünbleich

Blitze, Stimmen, Donner, 82

- Erzeugung und Deutung von Blitzen, 137

- Satan fällt wie ein Blitz vom Himmel, 89

- furchterregende Gegenwart Gottes, 46, 51, 77, 78, 112, $114,176,177$

Blut, 63, 119, 131, 173, 180, 182, 193, 200, 201, 226, 238

- bis zu den Zügeln der Pferde, 162, 168

- Blut der Märtyrer, 67, 68, 174, 178, 180-182, 197, 225

- Blutbad Attilas, 169, 189

- Blutigwerden des Mondes, 69-71

- Blutvergießen, siehe Töten

- Blutzeugen, siehe Märtyrer

- Christenverfolgung, 119, 130-133, 152, 173, 185, 197

- Christus erlöst uns durch sein Blut, 11, 17, 47, 58, 74, $76,117,123$

- Einer der vier Körpersäfte, 53

- Ernte (Strafgericht), 168, 169, 201

- Julian wirft sein Blut in die Luft, 134

- Ort der Seele, siehe Seele

- Wasser wird zu Blut, 101, 106, 108, 173

- Wasser wird zu Blut, Lebewesen sterben, 82

Bonifaz VIII.

- Träger der Zahl 666, 156

Böses, von Gott zugelassen, siehe Zulassung

Bossuet, Bischof, Kommentator (1627-1704)

- antik-geschichtliche Auslegung, 9

- Auslegung der Zahl 666, 143

- Auslegung der kosmischen Katastrophen, 69

- Auslegung des achten Königs, 184

Brandopferaltar, siehe Juden(tum), -Tempel

Brustgürtung, priesterliches Zeichen, 20, 170

Bußprediger, siehe Zwei Zeugen

Buch

- Buch des Lebens und andere Bücher, 38

- Buch mit den sieben Siegeln, 46

- Johannes verschlingt ein Buch, siehe Zeichenhandlungen

Bundeslade, Schrein im jüdischen Tempel, 114, 170

Burgunder, Germanenvolk, siehe auch Gibika und Sigismund

- Bekehrung zum Christentum, 190

- gehören zu den zehn Hörnern, 188

- fallen in Gallien ein, 188, 189 
- fallen in Italien ein, 197

- gehören zu den zehn Hörnern, 189

- in römischen Diensten, 190

Caesar, Kaiser (45-44 v. Chr.)

- Erster der sieben Könige?, 185

Caesar, Titel, 143

Cajus, siehe Caligula

Caligula ( $=$ Cajus $=$ Gajus), Kaiser (37-41), 150, 185-187

- Erster der sieben Könige?, 187

- Träger der Zahl 666, 149

Calmet, Augustin, Kommentator (1672-1757)

- Antik-geschichtliche Auslegung, 9

- Auslegung der Zahl 666, 143

- Auslegung des achten Königs, 185

Cassius Dio, siehe Dio Cassius

Cerinth, Irrlehrer (um 100)

- sein extremer Milleniarismus, 203

Chararich, Suebenkönig (550-559), 190

Chiliasmus, 203

Chiliasten, siehe Tausendjähriges Reich

Chlodwig, Frankenkönig (481-511), 190

Christentum

- Befreiung, siehe Verfolgung

- Geschichtlicher Sieg, 99, 175-177

- Staatsreligion, siehe Theodosius

Christenverfolgung, siehe Verfolgung

Christi Wiederkehr, siehe Jesus Christus, -Wiederkehr; Kommen Christi

Christus, siehe Jesus Christus

Claudius II., Kaiser (268-270)

- sein Vorgehen gegen die Goten, 194

Claudius, Kaiser (41-54), 150, 185-187

- indirekter Christenverfolger und erster der sieben Könige?, 186

Computer, Hilfsmittel des Antichristen?, 155

Constans, siehe Konstans

Constantius Chlorus, Vater Konstantins, Kaiser (293-306), $102,109,130,184$

Constantius, öström. Kaiser, Vorgänger Julians (337-361), 131,132

Constantius, weström. Kaiser (407/8-411) zur Zeit der Dreiteilung, 177

Cornelius a Lapide, Kommentator (1567-1637), 8, 51

Crowley, Aleister, Satanist (1875-1947), 153

Dämonen, siehe Engel

Dänen, Germanenvolk

- gehören zu den ,übrigen“ Königen, 202

Daniel, Prophet (6. Jh. v.Chr.), 70

- einer der 24 Ältesten, 51

- erwähnt den Engel Michael, 122

- Menschensohn bei Daniel, 19

- Prophetie vom messianischen Reich, 99

- prophezeit eine Verfolgungsdauer von 3 1/2 Zeiten, 103

- vier Tiere und Winde bei Daniel, 72, 129

- Vision von Gott: Alter mit weißem Haar, 20
- Vorhersage der Verfolgung des Antiochus Epiphanes, 103,113

- musste seine Prophezeiung versiegeln, 234

Dante, Alighieri, Dichter (1265-1321), 156

David, König von Israel (1008-969 v.Chr.), siehe auch Goliath; Jonathan

- 42 als Zahl seines Namens, 104

- Christus als Davids Wurzel und Geschlecht, 47, 56, 219,236

- einer der 24 Ältesten, 50, 51

- Schlüssel Davids, 40

- von Sirach gelobt, 50

Decius, Kaiser (249-251), 31

- Christenverfolger, 31, 63, 108, 133

- Tod, 108, 133

Denar, durchschnittlicher Tageslohn, 64

Diakon

- die sieben ersten Diakone, 17, 27, 145

- Nikolaus, siehe Nikolaus von Antiochien

- Papylos, 31

- Pelagius (späterer Papst), 197

Dic Lux, antichristliches Wort?, 157

Dichter, siehe Angelus, Dante und Tolstoi

Dio Cassius, Geschichtsschreiber (3. Jh.)

- über den Bar-Kochba-Krieg, 81

Diokletian, Kaiser (284-305)

- befiehlt die Zerstörung der Gotteshäuser, 103

- Christenverfolger, 102, 103, 108-110, 124, 126, 129, $130,133,136,140,141,152,184,185$

- einer der fünf gefallenen Könige, 184

- einer der sieben Könige, 129

- Gefallener König, 184

- Gesetz über Kaufen und Verkaufen, 141

- Löwenmaul des Tieres, 129, 130

- Träger der Zahl 666, 141-143, 149, 152, 157, 185

- Verfolgung der Christen, 102

Dionysius, Bischof von Alexandrien $(† 264)$

- bestreitet die Abfassung der Apk durch den Apostel Johannes, 7

- über die Reich-Christi -Vorstellungen des Cerinth, 203

Dodekaeder (platonischer Körper), 49

Domitian, Kaiser (81-96), 185, 186

- Abfassung der Apokalypse unter Domitian, 8, 151, $183,186-188$

- befiehlt, den Weinbau aufzugeben, 64

- der achte König?, 186

- der sechste König?, 186-188

- Münze aus seinem 16. Jahr?, 151

- regierte kurzzeitig schon unter Vespasian, 187

- Träger der Zahl 666, 150-151

- zweiter Christenverfolger, 8, 18, 32, 63, 107, 149, 186

Donner

- Gottes Stimme, 98

- Gottes furchterregende Gegenwart, siehe Blitze

Drache

- Bezeichnung und Symbol für den Teufel, 115-122, 124-131, 135, 136, 145, 175, 204, 205

- das zweite Tier redet wie ein Drache, 128, 135, 136

Drei, siehe Zahl 
Dreißigjähriger Krieg, siehe Krieg

Dreieckszahlen, siehe Zahl

Dreieeinhalb (Zeiten/Jahre), siehe Zahl

Dreifaltigkeit, 12-16, 49, 160, 201

- Taufbefehl als Hinweis darauf, 232

Drittel, siehe Zahl, -ein Drittel

Drogen, siehe Giftmischerei

Dröhnen (der Heuschrecken)

- Symbol für leeres Gerede, 90

Ecclesia, siehe Kirche

Ecken der Erde als Himmelsrichtungen, 72

Edelsteine, 48, 221, 223-228

Edikt, siehe Gesetz

Edmundson, George, Kommentator (1848-1930), 187

Eisenpanzerbrust (der Heuschrecken)

- Symbol für Verhärtung, 90

Eiserner Stab, siehe Weiden

Elias oder Elija, Prophet (9. Jh.)

- Bußprediger, 106

- einer der Zwei Zeugen?, 106

- erscheint zusammen mit Moses, 106

- hielt den Regen zurück, 103, 108

- Himmelfahrt, 106

- ließ Feuer vom Himmel fallen, 106, 107

- von Sirach gelobt, 107

- von Sirach gelobt, 50

- Wiederkehr, 106

Elle (= 45,8 Zentimeter), 222

Ellen Gould White, Prophetin der Adventisten (1827-1915, siehe Adventisten

Empfängnisverhütung, künstliche, siehe Giftmischerei

Ende der Welt, siehe Endzeit

Endzeit

- am Ende hören Tod und Fegfeuer auf, 216

- beginnt anfanghaft schon nach Christi erstem Kommen, 63, 70, 234

- endet mit dem allgemeinen Weltgericht am Ende der Weltgeschichte, 214

- Endzeitkrieg, siehe Krieg

- Endzeitrede Jesu, siehe Krieg

- Gestalt (nicht die Substanz) des Kosmos vergeht durch den Weltenbrand, 214

- ist im engeren Sinn die Zeit kurz vor dem Ende der Weltgeschichte, 239

- Prophezeiungen über frühere Ereignisse werden oft eng mit solchen über die Endzeit verknüpft, 198

- Weltuntergang, siehe Weltuntergang

Engel

- Zeit des Weltendes ist ungewiss, 206-207

- Barachiel, 17

- Bezeichnung für Christus, 72, 98, 205

- Bezeichnung für einen Bischof, 23

- Botenengel, siehe auch Engel, - die sieben höchsten Botenengel, 17, 58

- Dämonen (böse Engel), siehe auch Teufel, 16, 87, 93 $96,115,120-122,141,145,175,176,179,192$, 205, 207
- Die sieben höchsten Botenengel, 15-17, 37, 51, 54, 57,58

- Die vier Wesen als höchste Engel, 52-54, 58

- drei unreine Geister in Froschgestalt, 175

- Engel der Winde, 174

- Engel der Winde (vier), 71

- Engel des Abgrundes, 90, 93

- Engel des Abgrunds, 90

- Engel des Drachen, 115, 121

- Engel des Feuers (Uriel), 168, 174

- Engel des Lichts (Lucifer), 158

- Engel des Todes (Abaddon, Apollyon), 93

- Engel des Todes und der Zerstörung (Satan), 119

- Engel des Wassers / der Gewässer, 173, 174

- Engel im engsten Sinn (untere Klasse), 54

- Engel vom Aufgang der Sonne (Christus?), 71, 72

- Engelfürstern, 17, 54, 120

- Engelmaß und Menschenmaß, siehe Maß

- Engelsturz, 120, 122, 123

- Fürbitte und Mittlerschaft von Engeln, siehe Heilige

- Gabriel, 16, 17

- gefesselte Engel am Euphrat (vier), 93-95

- Gemeinde-Engel, 23

- Höllenengel (Satan), 90

- Jehudiel, 17

- Kerubim, 52

- Kirchen-Engel, 23

- Michael, 16, 17, 98, 115, 121, 122, 126, 168, 205

- Priester als Engel des Herrn, 23

- Raphael, 15-17

- Sealtiel, 17

- Seraphim, 52, 54

- starker Engel mit dem Buch (Michael?), 97, 98

- Thronengel, 17, 48, 54, 58

- Uriel, 17

- Verehrung und Anbetung von Engeln, siehe Verehrung und Anbetung

- Zahl der Engel, 47, 58

Entfesselung Satans, siehe Teufel

Epiphanius, Bischof (ca. 315-403)

- Bericht über Montanus, 35

- Bericht über Theodot, 88

- Bericht über Theodotion, 84

- Stellungnahme zum Diakon Nikolaus, 27

Erdbeben

- beim Sieg Konstantins, 111

- in Laodizea, 43, 45

- in Philadelphia, 40, 42

- Symbol für Umstürze, 69, 70, 78, 114, 170, 177

- Symbol für die Umstürze der Völkerwanderungszeit, 177

Erde

- Bewohner der Erde, siehe Bewohner der Erde

- Könige der Erde, siehe Könige

- Symbol für Nation, 82

- Symbol für den „Untergrund“ politischer Aufwiegelung, 122

- Symbol für eine irdisch gewinnte Gesellschaft, 172

- Symbol für eine irdisch gewinnte Gesellschaft, 133 
Ernte

- Symbol für weltliche Mächte, 125

- Symbol für Gericht, 167-169

Erste Auferstehung, siehe Auferstehung, Leben

Erster Tod, siehe Tod

Erster und Letzter, siehe Alphe und Omega

Eucharistie, siehe Manna

Eunapius, heidnischer Geschichtsschreiber (um 348-414)

- schildert Julians Leben, 137

Euphrat, Fluss an der römisch-persischen Ostgrenze, 93-95, $175,176,181$

Eusebius, 203

Eusebius von Caesarea, Kirchengeschichtsschreiber (um 262339)

- bestreitet die Abfassung der Apk durch den Apostel Johannes, 7

- Nachrichten über Jakous den Gerechten, 227

- Nachrichten über Polykarp, 29, 31

- Nachrichten über Quadratus, 40

- Nachrichten über Theodot und seine Anhänger, 88

- Nachrichten über Verfasser und Abfassungszeit der Apk, 7, 8

- Nachrichten über den Diakon Nikolaus, 27

- Nachrichten über die Juden unter Trajan und Hadrian, 81

- Nachrichten über die Nikolaiten, 32

- seine Meinung zum Milleniarismus des Papias, 203

- Zeitzeuge der diokletianischen Christenverfolgung, 108, 111, 123, 124, 184

Eusebius, heiliger Papst (309), 102

Eusebius, Neuplatoniker (4. Jh.), Ratgeber Julians, 137

Eva, Stammmutter, 116

- Maria als neue Eva, 119

Evangelien oder Evangelisten

- dargestellt als vier Wesen, 52

- Joh ruft den 4. Reiter herbei, 66

- Lk ruft den 2. Reiter herbei, 63

- Mk ruft den 1. Reiter herbei, 62

- Mt ruft den 3. Reiter herbei, 65

- dargestellt als vier Wesen, 54

Evangelisten, siehe Evangelien oder Evangelisten

Evangelium

- Das Gericht als ewiges Evangelium, 162

- Protoevangelium, siehe Protoevangelium Ewigkeit

- der Höllenstrafe: lange Zeit oder Dauer ohne Ende?, 163,164

- ewige Herrschaft der Heiligen, 232

- Ewiges Evangelium, siehe Evangelium

- Gott überschaut die Ewigkeit in einem einzigen Moment, 68, 206

- Rom rühmt sich als ewige Stadt, 194

Exegeten, siehe Kommentatoren

Ezechiel, Prophet (6. Jh. v.Chr.)

- einer der 24 Ältesten, 51

- erwähnt Got im Land Magog, 155, 213

- lokalisiert das Paradies im Himmel, 27

- Prophetie vom Untergang der Stadt Tyrus, 70

- spricht von sterbender Seele, 173
- Tempelvision, 213

- Vision der Kerubim, 52

- Vision einer Totenauferstehung, 111

- Vision von der Versiegelung mit dem Tau, 72

- von Sirach gelobt, 50

Féret, Henri-Maria (1904-1992)

- Auslegung der ersten fünf Könige, 186

- Auslegung der tausend Jahre, 204-206

Fackeln, siehe Feuer

Falsche Götter, siehe Götter, falsche

Falscher Prophet, siehe Propheten

Farben, siehe Weiß, Schwarz, Rot, Grün, Grünbleich, Gold, Regenbogen

Fegfeuer

- Abteilung der Kirche (leidende Kirche), 60

- Abteilung des Hades, 28

- Anhaltspunkt für seine Existenz, 60, 230

- Durchgang zum Himmel, 210

- genaue Erklärung, 28

- hört nach dem Weltgericht auf, 28, 216

- Judas in die Hölle oder ins Fegfeuer?, 166

Feuer

- das Feuer in Hölle und Fegfeuer, 28, 163, 164, 220

- Feuer aus dem Mund der Zwei Zeugen, 107

- Feuer des Weltenbrandes, 214

- Feuer vernichtet Rom, 191, 194, 195

- Feuer, in dem die Märtyrer unter dem Alter als „Opfertiere" brennen, 78

- Feuerfackeln als Symbole für Engel, 17, 51

- Zweites Tier lässt Feuer vom Himmel fallen, 137

- feuerfarbene Metallrüstung und Feuer aus dem Mund der Pferde, 95, 96

Finsternis

- Plage der fünften Schale, 174, 175

- Verfinsterung von Gestirnen, 70

Firmung, siehe auch Siegel, 72-73, 90

Flavius, siehe Josephus; Severus

Flucht

- aus Babylon/Rom, siehe Babylon

- in der Christenverfolgung, siehe Wüste

Flügel

- Flügel von Engeln als Symbole ihrer Geisteskraft, 52

- der Heuschrecken, 90, 92

- der vier Wesen, 52-54

- des großen Adlers, 124

Fluss, Flüsse, siehe auch Wasser

- christenverfolgende Menschenmenge, 125

- Fluss im Neuen Jerusalem, 223, 230, 231

- innere Teile des Reiches, 174

- Teile des Volkes, 83

Franken, Germanenvolk

- Bekehrung zum katholischen Christentum, 190

- gehören zu den zehn Hörnern, 188, 190

- Heerführer Arbogast, siehe Arbogast

- König Chlodwig, siehe Chlodwig

- König Theudebert, siehe Theudebert

- kämpfen auf Seiten Roms, 190

Franziskus, Papst (ab 2013) 
- Träger der Zahl 666, 156

Frau, siehe Maria, - apokalyptische Frau

Frauenhaare, siehe Haare

Freiheit des Menschen, Gutes und Böses zu tun, 234

Freitag

- Tag der Kreuzigung Christi, 145, 146

Fridibald, Vandalenkönig (um 411)

- einer der zehn Könige, 189

Friesen, Germanenvolk

Frosch

- gehören zu den ,,übrigen“ Königen, 202

- drei unreine Geister in Froschgestalt, siehe Engel

Fünf, siehe Zahl

Fürbitte der Engel und Heiligen, siehe Heilige

Gabriel, Erzengel, siehe Engel

Gajus, siehe Caligula

Gajus, Kaiser (= Caligula), siehe Caligula

Galba, Kaiser, siehe Zwischenkaiser

Galenus, Claudius, Arzt ( $†$ um 199)

- schreibt über die „Augensalbe“, 43

Galerius, Kaiser (293-311)

- Bärenfüße, 130

- Christenverfolger, 102, 109, 124, 129, 130, 183, 184

- einer der fünf gefallenen Könige, 184

- einer der sieben Könige, 129

- Tod, 102, 124, 184

- Toleranzedikt, 102, 109, 122-124, 126, 183

Gebet, siehe Verehrung, Weihrauch

Gebote

- Anbetung und Verehrung, siehe Verehrung und Anbetung

- Bilderverbot, 137-140

- christliche Einstellung zu ihnen, 139

- Giftmischerei, siehe Giftmischerei

- Gnade und Werke, siehe Werke und Gnade

- Homosexualität, siehe Homosexualität

- Lüge, siehe Lüge

- Sabbat/Ruhetag, siehe Ruhetag

- Satan bekämpft das Festhalten an den Geboten, 126

- Schwören, siehe Schwören

- Töten, siehe Töten

Gegenpapast, siehe Natalis

Geheimnis Gottes: Die Kirche, 99

Geiserich, Arianer, Vandalenkönig (428-477)

- Beitrag zur Zerstörung Roms, 189

- einer der zehn Könige, 189

- plündert Rom, 196

- sein Sendungsbewusstsein, 191

- Träger der Zahl 666?, 158

- verfolgt katholische Christen, 202

- vergießt außerhalb Roms Blut, 169, 197

- vergießt außerhalb Roms Blut, 169

Geist, siehe Heiliger Geist, Engel

Gelimer, Arianer, Vandalenkönig (530-534)

- verfolgt die Christen, 202

Gemeinde, siehe Kirche

Genussmittel, siehe Wein, Öl

Gerechtigkeit, siehe Vergeltung, Waage
Gericht

- Endgericht, 10, 63, 66, 68, 70, 76, 91, 106, 113, 115, $164,210,212-216,219,234,239$

- Persönliches Gericht nach dem Tod, 68

- Strafgerichte inmitten der Geschichte, 61-203

Germanen, indogermanische Volksgruppe, siehe auch Alamannen, Angeln, Barbaren, Burgunder, Dänen, Franken, Friesen, Goten, Heruler, Langobarden, Sachsen, Skiren, Sueben, Vandalen

- Schlacht auf den Katalaunischen Feldern, 169

- überqueren den Rhein, 173

- zehn Hörner, 188

Gerste und Weizen, 64, 65, 82

Geschichtsschreiber, Quellen und Historiker, siehe Agathias, Ambrosius, Ammianus, Aristoteles, Basilius, Beda, Bihlmeyer, Dio Cassius, Drusius, Eunapius, Eusebius, Galenus, Gregor, Gregorovius, Hieronymus, Hippolyt, Irenäus, Isidor, Josephus, Justin, Laktanz, Lortz, Maier, Orosius, Philostorgius, Plinius, Procopius, Salvian, Schürer, Severus, Sokrates, Sozomenus, Strabo, Sueton, Tacitus, Theodoret, Zosimus

Geschlecht und Wurzel Davids, siehe David

Geschwür (Plage), 170, 172, 174, 239

- Tod des Galerius, 184

Gesetze

- Gesetze Gottes, siehe Gebote

- Gesetze der Kaiser, siehe Galerius, Diokletian, Julian, Konstantin, Maximinus, Trajan

Getreideernte und Traubenernte, 167-169, 201

Gewässer, siehe Fluss, Wasser

Gibika, Burgunderkönig († vor 411)

- einer der zehn Könige, 189

Giftmischerei, 94, 96, 197, 236

- Abtreibung, 96, 236

- Aphrodisiaka, 96

- Verhütung, künstliche, 96

Glasgold, siehe Gold und Glasgold

Gold und Glasgold, 224, 226, 228

Goliath, Riese, den David erschlug, 146

Goten, Germanenvolk

- Anführer der Goten, siehe Alarich, Athanarich, Leovigild, Radagais, Rekkared, Theodorich

- Bekehrung der Westgoten zum katholischen Christentum, 190

- Christenverfolger, 202

- Decius fällt im Kampf mit den Goten, 133

- fallen ins Römische Reich ein, 108

- gehören zu den zehn Hörnern, 188

- Hauptzerstörer Roms, 190

- kämpfen auf Seiten Roms, 190

- Krieg Justinians gegen die Ostgoten, 197

- plündern Rom, 196

- Teilnahme an der Völkerwanderung, 176

- überschwemmen das Römische Reich, 173

- unter Claudius II. getötet und als Sklaven verkauft, 194

- verbrennen Rom, 194

- verheeren zahlreiche Landstriche, 177, 189, 193 
- Zerstörung des Ostgotenreichs, 190

- gehören zu den zehn Hörnern, 188

Gott, siehe Allwissenheit, Dreifaltigkeit, Ewigkeit, Zulassung des Bösen

Götter, falsche, siehe Apollo, Asklepios, Attis, Serapis

Gottes Wort, siehe Wort Gottes

Gotteslästerung, siehe Lästern, Lästerungen

Gottesschau von Angesicht zu Angesicht, 53, 220, 232

Gottheit Christi, siehe auch Sonne; Adler, 13-15, 20, 22, 35, $37,40,41,44,57,59,64,70,87-89,174,211$, 220, 232, 234

Gottheit des Hl. Geistes, 14, 64

Gras

„Dichtes Gras lässt sich leichter mähen als dünnes“, 168

- Symbol der Jugend und Hoffnung, 80, 82, 90

Gregorovius, Ferdinand, Historiker (1821-1891)

- über Attila, 169

- über das Heidentum unter Theodosius, 193

Große Invasion der Barbaren, siehe Krieg

Grün, Farbe des Lebens, 48, 221, 224-228

Grünbleich, Farbe der Verwesung und Pest, 65

Grundnahrungsmittel, siehe Weizen und Gerste

Guntharich, Vandalenkönig (406-428)

- einer der zehn Könige, 189

Gürtung um die Brust, siehe Brustgürtung

Haare

- Frauenhaare der Heuschrecken, Symbol für Harmlosigkeit oder Verführung, 90

- weiße Haare, Symbol für Alter und Präexistenz, 20

Hades, 23, 27, 56, 60, 61, 66, 215, 216

- als Person, 66, 72

- genaue Erklärung, 27-28

- Hadesaufenthalt Jesu, 27, 28

- in den Feuersee gworfen, 216

- Tote kommen heraus, 215, 216

Hadrian, Kaiser (117-135)

- empfängt Verteidigungsschrift des Quadratus, 40

- schlägt jüdischen Bar-Kochba-Aufstand nieder, 81, 83

- Zeit von Aquila und Aqiba, 84

Hagel

- mit Feuer vermischt, 82

- zentnerschwerer Hagel, 177

Harfenspieler, 58, 159, 160, 171, 197

Harmagedon, siehe Krieg

Heiden, siehe auch Lästern, Neuplatoniker, Senatoren, Verfolgung

- Personen, siehe Ammianus, Apollonius, Aristoteles, Athanarich, Attalus, Dio Cassius, Eunapius, Galenus, Julian, Plinius, Radagais, Sueton, Symmachus, Tacitus, Tertullius

Heilige, siehe auch Himmel

- 144.000 jüdische Christen, 71-74

- 144.000 makellose Nachfolger Christi, 159-161

- Ambrosius, siehe Ambrosius

- Anastasius I., siehe Anastasius I.

- Apostel, siehe Aposte

- Augustinus, siehe Augustinus
- Basilius, siehe Basilius

- Beda Venerabilis, siehe Beda Venerabilis

- Beisetzung von Märtyrern in Altären, 67

- Fürbitte und Mittlerschaft der Engel und Heiligen im Himmel, 16, 58, 68, 77, 78, 211

- Gregor der Große, siehe Gregor der Große

- Große Schar aus allen Völkern, 74-77

- Heiligenverehrung, siehe Verehrung und Anbetung

- Hieronymus, siehe Hieronymus

- Innozenz I., siehe Innozenz I.

- Irenäus, siehe Irenäus

- Joseph, siehe Joseph

- Märtyrer, siehe Märtyrer

- Maria, siehe Maria

- Märtyrer nehmen am Gericht und Tausendahrreich teil, 204, 208

- Märtyrer sofort nach dem Tod belohnt, 30, 68

- Märtyrer unter dem Altar, 66-69, 78

- Nichtmärtyrer ebenso wie Märtyrer sofort nach dem Tod belohnt, 68, 162, 166, 204, 208, 209

- Paula, siehe Paula

- Vierundzwanzig Älteste, 46, 48-51

- Weiden (Regieren) mit eisernem Stab, siehe Weiden

- Zwei Zeugen, 101, 104-111

Heiliger Geist

- Deutung der 7 Engel als Hl. Geist, 15

- Deutung der Sieben Engel als Hl. Geist, 15-16

- Gottheit, siehe Gottheit des Hl. Geistes

- Quelle für das von Vater und Sohn ausgehende Wasser des Lebens, 77, 220

Heimtücke, Heimtückische Waffen, 90

Heiß, siehe Lauwarm, Heiß und Kalt

Hekate, Göttin der Magie, 137

Henoch, Urvater

- Bußprediger, 106

- einer der Zwei Zeugen?, 106

- einer der Zwei Zeugen?, 106

- Himmelfahrt, 106

- Prophezeiung des Endgerichts, 106

- von Sirach gelobt, 50

Herculius, siehe Maximianus Herculius

Hermerich, Suebenkönig (um 411) - einer der zehn Könige, 189

Herrentag, siehe Tag, Ruhetag

Herrschaft der Heiligen

- ,,auf der Erde herrschen“, 58, 229

- im tausendjährigen Reich, 208, 210, 228

- ,,in alle Ewigkeit“, 232

Heruler, Germanenvolk - gehören zu den zehn Hörnern, 188

- König Odoaker, siehe Odoaker

Herz und Nieren, Symbol für innere Gesinnung, 20, 34, 35

Hesekiel, siehe Echechiel

Heuschrecken, die Theodotianer, 86-93

Hierokles, Statthalter von Bithynien, später von Ägpten, Neuplatoniker (Anfang 4. Jh.), 136

- Gegner des Christentums, rät zur Christenverfolgung, 136

Hieronymus, Heiliger, Kirchenlehrer (347-420) 
- beschreibt Roms Untergang als Kosmos-Katastrophe, 177

- Deutung der vier Wesen, 54

- Nachrichten über Quadratus, 40

- Nachrichten über das Schicksal der Juden nach Bar Kochba, 81

- Stellungnahme zum Diakon Nikolaus, 27

- über die Flucht aus der Stadt Rom, 192

- über die Hungersnot im belagerten Rom, 194

- Zeitzeuge der Wirren der Völkerwanderungszeit, 173

- Zeitzeuge der Zerstörung Roms, 192, 194, 196

Himmel, siehe auch Paradies

- Dritter Himmel, 27, 225

- Eingehen der Heiligen in den Himmel sofort nach dem Tod, 30, 68, 76, 123, 162, 166, 196, 204, 209, 210

- Erster (diesseitiger) Himmel, 214, 217, 219

- genaue Erklärung, 27

- Himmel als einer der Lebensbereiche, 53

- leibfrei im Himmel befindliche Heilige, 76, 77

- Maß der Seligkeit verschieden groß, 223

- Mehrere diesseitige Himmel, 214

- Neuer Himmel, 215, 217, 219

- Sternhimmel, 53, 143

- Symbol für Seligkeit und Herrschaft, 28, 89

- Symbol für Zugehörigkeit zu Gott oder gottähnliche Macht, 122, 124

- Symbol für das am meisten Feststehende in der Welt, 70,71

- Symbolischer Ort Gottes, 46, 47

Himmelfahrt

- aller Christen, 123, 209

- Christi, 28, 60, 118-121, 209

- der vorchristlichen Gerechten, 28

- der zwei Zeugen, 101, 106, 111, 126, 208

- des Elias, 106

- des Henoch, 106

- des Paulus, 27, 225

- Mariens, 127

Himmlisches Jerusalem, siehe Neues Jerusalem

Hippolyt von Rom, zeitweise Gegenpapst, Heiliger, Kirchenvater, (um 170-235)

- Auslegung der Zahl 666, 158

Hippolyt von Rom, zeitweise Gegenpapst, Heiliger, Kirchenvater, (um 170-235)

- Nachrichten über Theodot, 88

- Stellungnahme zum Diakon Nikolaus, 27

Historiker, siehe Geschichtsschreiber

Hitler, Adolf, Reichskanzler (1933-1945)

- Art seines Kampfes gegen die Kirche, 132

- Judenverfolger, 81

- Träger der Zahl 666udenverfolger, 155

Hitze, siehe Sonne

Hof (Innen- und Außenhof des Tempels), 51, 67, 69, 102

Hölle, 28, 30, 60, 66, 75, 87, 90, 107, 156, 163-166, 202, $205,207,209,210,214,216,220$

- Abteilung des Hades, 28

- Ewigkeit, 164

- Feuersee, 28, 122, 200, 202, 210, 212, 216, 217

- genauere Erklärung, 28, 164-166
- Höllenmächte, 207

- Höllenrichter im ägyptischen Totenbuch, 104

- ,lebend“ zur Hölle, 202

- leiblicher Aspekt, 210, 216

- Qualen, 163, 166, 202

- schon vor dem jüngsten Tag, 214

- Verdammung sofort nach dem Tod, 28

- Wesen der Hölle, 28, 164

- Zweiter Tod, 29, 30, 107, 209, 210, 212, 216, 217

Holocaust, 81

Holz des Lebens, 231

Homosexulität oder Sodomie, 235-236

Honorius, Kaiser (395-423), 174, 177, 190, 193

Hörner

- Symbol der Macht, 57, 120, 188

- sieben Hörner des Lammes, 16, 17, 57

- vier Hörner des Altars, 94

- zehn Hörner des Drachen, 119, 120

- zehn Hörner des Tieres, 120, 129, 130, 182, 188, 191, 195, 200, 206, 239

- zwei Hörner des Zweiten Tieres, 135

Huldigung, siehe Verehrung

Hundert, siehe Zahl

Hundertjähriger Krieg, siehe Krieg

Hundertvierundvierzig, siehe Zahl

Hundertvierundvierzigtausend, siehe Zahl

Hunger und Pest, siehe auch Geschwür; Krankheit

- beim Fall Roms, 194

- der Schwarze Tod im Mittelalter, 35

- dritter und vierter apokalyptischer Reiter, 61, 63-66

- Im jüdischen Krieg unter Bar Kochba, 81

- während der römischen Christenverfolgungszeit, 108, 109,111

Hunnen, asiatisches Reitervolk, siehe auch Reiter

- Blutvergießen außerhalb Roms, 169, 189

- gehören zu den zehn Hörnern, 188

- kämpfen teils auf Seiten Roms, 190

- Könige der Hunnen, siehe Attila, Uldis

- lösen die Völkerwanderung aus, 173

- Mitvollstrecker des Gerichts am heidnischen Rom, 169

- Schlacht auf den Katalaunischen Feldern, 169

- Teilnahme an der Völkerwanderung, 176

- überschwemmen das Reich, 173

- verwüsten Italien, 197

Hunnerich, Arianer, Vandalenkönig (477-484)

- verfolgt katholische Christen, 202

Hure Babylon, siehe Babylon

Iannuzzi, Joseph OSJ, katholischer Theologe, 204

Ignatius von Antiochien, Märtyrer (um 107) - sein Brief an Polykarp, 29

Ikonen, siehe Verehrung, Konzilien

Immanuel, neuer Name Jesu, 42, 217, 220

Innenhof des Tempels, siehe Hof

Innozenz I, Heiliger, Papst (401-417), 192

Insel, Symbol für Feststehendes, 69, 70, 176, 177

Invasion, siehe Krieg

Irenäus von Lyon (um 135-202)

- Deutung der Zahl 666, 150, 158 
- Deutung der vier Wesen, 54

- kritisiert zwei jüdische Bibelübersetzungen, 84

- sein Milleniarismus, 203

- sein Millenniarismus, 204

- Stellungungahme zum Diakon Nikolaus, 27

- über Polykarps Einsetzung durch die Apostel, 29

- über den Apostel Johannes als Verfasser der Apk, 7

- über die Abfassungszeit der Apk, 8, 188

- zur Symbolik der Zahl sechs, 146

Irrlehrer und andere nichtkatholische Persönlichkeiten und Gemeischaften, siehe Adventisten, Aqiba, Aquila, Arius, Bar Kochba, Cerinth, Chiliasmus, Heuschrecken, Juden(tum), Konzilien, Luther und Protestantismus, Melchisedekianer, Montanus, Muhammad, Natalis, Paulus von Samosata, Theodot, Theodotion, Zeugen Jehovas

Isaak (um 1760 v.Chr.)

- einer der 24 Ältesten, 50

- von Sirach gelobt, 50

Isaurier, Volk in Kleinasien, 173

Isebel, Zauberin und Königin (9. Jh. v.Chr.) und ihre Nachahmerin, die Prophetin in Thyatira, 34

- Beziehung zum Satanismus, 36

Isidor, heiliger Bischof (um 560-636)

- schreibt über Edelsteine, 225-227

Islam, siehe Muhammad

Israel, siehe Juden

Jahr

- dreieinhalb Jahre, siehe Zahlen, -3 1/2

- Jahresanfang im Frühjahr, 91

- tausend Jahre, siehe Tausendjähriges Reich

Jahwe, Name Gottes, siehe Name

Jakob (um 1720 v.Chr.)

- ,ein Stern geht auf in Jakob“, 83

- einer der 24 Ältesten, 50

- Israels Stämme nach Jakobs Söhnen benannt, 73-74

- seine messianische Prophezeiung vom Löwen Juda, 56

- seine zwölf Söhne zu den 24 Ältesten zu rechnen?, 50

- von Sirach gelobt, 50

Jamblich (240/45-320/25), Neuplatoniker, von Julian als Gott verehrt, 136

Jeremia, Prophet (um 600 v.Chr.)

- drohte Babel das Gericht als eine Ernte an, 167, 168

- einer der 24 Ältesten, 51

- einer der Zwei Zeugen?, 106

- Gott prüft Herz und Nieren, 35

- Prophet für die Völker: Kommt er wieder?, 106

- Prophetie vom Neuen Bund, 99

- seine Worte sind Feuersglut, 106, 107

- von Sirach gelobt, 50

- Wasser als Symbol für eine Menschenmenge, 191

Jerusalem

- Modell der Stadt, 102

- Vertreibung der Juden aus Jerusalem, 70

- Zerstörung, 70

Jerusalem, Neues, siehe Neues Jerusalem

Jesaja, Prophet (um 720 v.Chr.)
- einer der 24 Ältesten, 51

- empfängt einen Auftrag von Jahwe und dem Hl. Geist, 14

- „Gott Amen“, 44

- Immanuelprophezeiung, 220

- Jahwe ist der Erste und der Letzte, 13

- lokalisiert das Paradies im Himmel, 27

- messianische Prophezeiungen, 56, 108

- Prophetie vom Heil auf für die Heiden, 99

- Prophetie vom Untergang Edoms, 70

- Prophetie von der gebärenden Jungfrau, 84

- sah die Serafim, 52, 54

- von Sirach gelobt, 50

- Wasser als Symbol für eine Menschenmenge, 191

- Zion wird Objekt kniefälliger Verehrung, 199

Jeschua, Hoherpriester (um 538-515 v.Chr.)

- Typus für einen der Zwei Zeugen, 105, 106

- von Sirach gelobt; einer der 24 Ältesten?, 50

Jesus Christus

- Alpha und Omega, Anfang und Ende, siehe Alpha und Omega

- „Amen“ als Christusbezeichnung, siehe Anfang und Ende

- Beziehung zum Vater und Hl. Geist, siehe Dreifaltigkeit

- Davids Wurzel und Geschlecht, siehe David

- Endzeitrede, siehe Krieg

- Engel, der für Christus steht, siehe Engel

- Gebete zu Christus dem Lamm, ihm dargebrachte Verehrung und Anbetung, 47, 58, 59, 232

- „Jahwe“ als Name Christi, siehe Name

- Kommen Christi, siehe Kommen Christi und Gottes

- Löwe als Christussymbol, siehe Löwe

- Lamm als Symbol der Menschheit Christi, siehe Lamm

- Lebendiger, siehe Lebendiger

- Menschensohn als Christusbezeichnung, siehe Menschensohn

- Morgenstern als Christussymbol, siehe Morgenstern

- Name „Jesus“ auf der Stirn, siehe Name

- nennt den Vater seinen Gott, 42

- Priester Christi im Himmel, siehe Priester

- regiert mit eisernem Stab, siehe Weiden mit eisernem Stab

- Reiterheer Christi; Christus als erster apokalyptischer Reiter, siehe Reiter

- sein Anklopfen an der Tür des Herzens, siehe Kommen Christi

- seine Menschennatur, siehe auch Lamm; Mantel, 12, $15-17,22,36,59,229$

- seine wahre göttliche Natur, siehe Gottheit Christi

- seine Macht über die Herzen, 41

- Sonne als Christussymbol, siehe Sonne

- Träger der Zahl 666?, 158

- Träger der Zahl 888, 145

- untrennbare Verbindung seiner beiden Naturen (Gottheit und Menschheit), 12, 38, 42

- Weltenrichter, 214

- Wiederkehr, 214, 234

- Wiederkehr Christi, 18, 203-205, 209, 215, 216 
- Wort Gottes als Christusbezeichnung, siehe Wort Gottes

- Wunder, 201

Jesus Sirach, Verfasser des Buches Sirach (um 190 v. Chr.), 50

Joel, Prophet (um 820 v.Chr.?)

- Posaune als Untermalung der Stimme Gottes, 77

- Strafgericht unter dem Bild einer Getreide- und Traubenernte, 167,169

- Voraussage einer Gestirnsverfinsterung, 70

Johannes der Täufer, Vorläufer Jesu

- einer der 24 Ältesten?, 51

Johannes Paul II., 165

Johannes, Apostel

- einer der 24 Ältesten?, 50

- hatte am Sonntag eine Christusvision, 8

- Himmelsvision von anderen Visionen überlagert, 62

- kehrt an den Strand von Patmos zurueck, 116, 127, 159

- Lieblingsjünger Jesu, 117

- nach Patmos verbannt, 8

- Paulus als Ersatzmann für Johannes, 50

- seine prophetischen Zeichenhandlungen, siehe Zeichenhandlungen

- Verfasser der Apokalypse, 7-8

- wird auf einen hohen Berg geführt, 221

- wird in den Hinmel entrückt, 47

- wird in die Wüste geführt, 182

- wirkte in Ephesus, 19, 26

Jonathan, Freund Davids, 146

Josef (Patriarch) und seine Brüder, 199

Josef, Pflegevater Jesu

- einer der 24 Ältesten?, 51

Josephus, Flavius, jüdischer Geschichtsschreiber (um 37-100)

- Zeitzeuge des Jüdischen Krieges, 64, 81

- zum Gewand des Hohepriesters, 20

Judas der Verräter, 27, 50, 165, 166, 227

Juden(tum)

- Christen als geistige Israeliten, 74, 160

- die zwölf Stämme Israels, 73-74

- erwähltes Volk, 208

- Gericht am Judentum, 238

- Juden aus Rom vertrieben wegen Christus, 186

- Katastrophen in der Geschichte des Judentums, 70$71,80-84,103,238$

- keine Alleinschuld am Tode Christi, 18

- Lästerungen gegen Polykarp, 30

- Mischna und Talmud, 84

- Nikolaiten jüdischer Abstammung als „Synagoge Satans", 41

- rabbinische Tradition über Abraham, siehe Abraham

- Tempel, Lade, Brand- und Rauchopferaltar, 67, 78, 94, $102,112,114,168$

- Versiegelung von 144.000 jüdischen Christen, 71-74

- Vorstellungen über den (Typus des) Antichristen, 149, 150

- Wiederkehr von Elias und Jeremia erwartet, 106

- Zeremonialvorschriften (nicht mehr bindend), 139

Judenverfolgung, siehe Juden(tum), Verfolgung
Julian der Abtrünnige, Kaiser (361-363), 166, 170, 172

- Christenverfolger und Erneuerer des Heidentums, 115, $130-132,135,138,171,173,185$

- Dauer seiner Herrschaft, 132

- der achte König, 185

- die 144.000 in seiner Zeit, 159

- Gesetz über Kaufen und Verkaufen, 141

- Heilung der Todeswunde des Tieres, 131, 183, 185

- Lästerungen, 132, 175

- Machtfülle, 133

- opferte täglich als Pontifex Maximus, 131

- Strafe für Nichtanbetung seines Bildes, 140

- Tod, 132-134, 140, 173, 175, 176

- Träger der Zahl 666, 152

- dargestellt ähnlich dem Gott Serapis, 138

- durch Neuplatoniker verführt, 135-137

- seine Entwicklung, 131-134

Julius Caesar, siehe Caesar

Julius Severus, siehe Severus

Jungfrau

- als Gegenbegriff zu „Hure“ Symbol für das wahre Christentum, 161

- Prophezeiung der Jungfrauengeburt, 84

Justin, Märtyrer der diokletianischen Verfolgung, 141

Justin, Philosoph und Märtyrer (ca. 100-165)

- älteste Nachricht über den Apostel Johannes als Verfasser der Apokalypse, 7

- sein Milleniarismus, 203, 204

Justinian, oströmischer Kaiser (527-565)

- bekämpft letzte Reste des Heidentums, 200

- sein Feldherr Belisar, 197

- sein Krieg gegen die Ostgoten, 197

Juvenal, Satirendichter(58/60-127/138)

- über Kaiser Domitian, 186

Kaiser

- Deutung der Zahl 666 auf eine Kaiserreihe, 150

- in der Auslegung der sieben bzw. acht Könige, 183188

- Tabelle der an der diokletianischen Verfolgung beteiligten Kaiser, 184

- Tabelle der ersten Kaiser, 150, 185

Kalender, antiker, 91

Kalt, siehe Lauwwarm, Heiß und Kalt

Karpos, Märtyrer in Pergamon $(† 155)$

- Bischof von Pergamon?, 31

- Bischof von Thyatira?, 34

Katalaunische Felder, siehe Krieg

Kataphrakten, persische Panzerreiter, 95

Katholisch, siehe Schriftauslegung, - Katholische Positionen

Kaufen und Verkaufen

- ohne das „Kennzeichen“ unmöglich, 141

Kelten, indogermanische Volksgruppe, siehe Pikten, Skoten

Keltertreten (großes Blutvergießen), 168-169, 201

Kennzeichen auf Hand und Stirn, siehe Name

Kerinth, siehe Cerinth

Kirche, siehe auch Geheimnis, Juden(tum), Maria, Mond, Neues Jerusalem

- die sieben Ortskirchen, siehe Briefe 
- „Kirche“, „Gemeinde“ und „Versammlung“ als Übersetzung von „Ekklesia“, 13

- Kirchenverfolgung, siehe Verfolgung

Kleid, Symbol für den Charakter der Seele, 38

Klemens von Alexandrien, Kirchenlehrer (um 150-215)

- Stellungnahme zum Diakon Nikolaus, 27

Komet, 83

Kommen Christi und Gottes, siehe auch Gericht; Tausendjähriges Reich

- Anklopfen an der Tür des Herzens, 17, 45

- Baldiges Kommen, 10, 31, 32, 39, 41, 79, 81, 87, 113, $218,219,233,234,238$

- Der da kommt als Gottestitel, 13, 113, 174

- Kommen als Strafgericht an der Ortskirche, 26

- Kommen als Zulassung einer Christenverfolgung, 41

- Kommen am Ende der römischen Verfolgung, 113

- Kommen im Zeitpunkt des Todes, 36

- Kommen mit den Wolken zum Endgericht, 11

- Kommen wie ein Dieb, 37, 38, 175, 176

- Kommen zum Gericht an den Nikolaiten, 31

- Kommen zum Gericht an den Tieren, 201

- Kommen zur Evangeliumsverkündigung, 62

- Kommen zur Schlacht von Harmagedon, 176

- Verschiedene Arten des Kommens, 176

Kommentatoren der Apk, siehe Adventisten, Alcazar, Allo, Andreas, Arius, Athanasius, Augustinus, Beda, Berengaudus, Bossuet, Calmet, Cornelius, Crowley, Feret, Gregor, Hieronymus, Justin, Irenäus, Luther, Papias, Scheeben, Victorin, Zeugen Jehovas

Kommunion, geistige und körperliche, siehe Manna

Kommunismus, siehe Marx

König(in)

- die sieben bzw. acht Könige (= Köpfe), 183-188

- die zehn Könige (= Hörner), 188-191

- Einzelpersonen, siehe Andreas, Antiochus, Balak, Barbaren, David, Isebel, Kaiser, Krösus, Kyros, Ludwig, Nebukadnezar, Salomon, Sapor, Xerxes

- Könige der Erde, negativer Ausdruck, 70

- Könige der Erde, positiver Ausdruck, 229

Konstans, weströmischer Kaiser (337-350), 140

Konstantin, Kaiser (306-337), siehe auch Verfolgung

- kein Christenverfolger, 184

- schenkt den Christen Freiheit, 110

- siedelt Vandalen in Pannonien an, 190

- verlegt seine Residenz nach Konstantinopel, 191

Konstantius, Name verschiedener Herrscher, siehe Constantius

Konzilien, 64-65

Köpfe

- sieben Köpfe des Drachen, 120

- sieben Köpfe des Tieres, 183-188

Körper

Körper und Seele, siehe Seele

- platonische Körper, siehe Platonische Körper

- toter Körper, siehe Leichnam

Koseba, siehe Bar Kochba

Koziba, siehe Bar Kochba

Krankheit

- als Strafe angedroht, 35
Kranz, Kränze, siehe Kronen

Krieg

- Bürgerkrieg während der diokletianischen Christeverfolgung, 108

- Barbaren gegen Rom (Aspekt von Harmagedon), 173177, 188-197

- Christenverfolgung im Römischen Reich bis Konstantin, 63, 101-126

- Christus besiegt die Barbaren (Aspekt von Harmagedon), 178, 201-203

- Christus besiegt die beiden Tiere, 200-203

- Decius gegen die Goten, 108

- Diokletianische Christenverfolgung, 109-112, 122126

- Endzeitkrieg Christus/Kirche gegen Satan/Gog, 212214

- Große Invasion der Barbaren, 189

- Harmagedon (Untergang des heidnischen Rom in der Völkerwanderung), 173-203

- Harmagedon (genaue Erklärung), 175-176

- Heuschreckenkrieg (frühchristliche Irrlehrer), 86-93

- in Jesu Endzeitrede, 63

- Julian gegen Persien, 115

- Justinians Krieg in Italien, verglichen mit dem DreiBigjährigen und Hundertjährigen Krieg, 197

- Krieg gegen Sardes (Lydien), 37

- Kriege nach Julians Tod, 173

- Maximinus gegen Armenien, 109

- Michael gegen Satan, 115-126

- Neuplatonisches Rom und Julian gegen die Christen, 131-141

- Perser gegen Rom, 93-96, 112

- Rom gegen die Juden, 80-83

- Satan gegen die Kirche, 116, 126

- Sieg Konstantins, 110-112, 131

- Völkerschlacht bei den Katalaunischen Feldern, 169

- Valerians Niederlage, 94, 103, 175

- Vernichtung der Nikolaiten, 32

- zweiter apokalyptischer Reiter, 61, 63, 64, 66

Kronen

- Zeichen des christlichen Sieges, 90

- Zeichen weltlicher Macht, 120, 130

Krösus, König von Lydien (560-546 v.Chr.), 37

Kyros II., König von Persien (um 555-530 v.Chr.), 37

Lactantius, siehe Laktanz

Lade, siehe Bundeslade, Juden(tum)

Laktanz, Lehrer unter Diokletian und später unter Konstantin (um 250-30)

- Aberglaube über Neros Wiederkehr, 186

- Bericht über Diokletian, 142

- Bericht über Galerius, 130

- Bericht über Valerians Tod, 95

Lamm

- Das zweite Tier als falsches Lamm, 135, 156, 158

- Geschlachtetes Lamm als Christussymbol, 57, 58

- Symbol für Christus als Mensch, 47, 57, 58, 158-161, $163,178,190,218,229,231,232$

Langobarden, Germanenvolk 
- gehören zu den zehn Hörnern, 188

- bekehren sich zum katholischen Christentum, 190

- fallen in Italien ein, 197

- König Alboin, siehe Alboin

Lasterkatalog, siehe auch Gebote, 96, 220, 235

Lästern, Lästerungen

- gegen Polykarp, 30

- Gotteslästerung Diokletians und seiner Mitkaiser, 129

- Lästerungen Julians, 132

- Lästerungen der Heiden vor und nach Roms Fall, 174 177, 193

Lauwarm, Heiß und Kalt, 43-44

Leben

- Auferstehung, siehe Auferstehung

- geistiges Zum-Leben-Kommen, 209

- Holz und Wasser des Lebens, siehe Holz, Wasser

Lebendiger, Christusbezeichnung der Lebendige, 12, 22

Lehramt, siehe Schrift, Tradition und Lehramt

Leib

- Leib und Seele, siehe Seele

- toter Leib, siehe Leichen, Leichnam

Leichen, Leichnam

- daas römische Reich gleicht einem toten Körper, 173

- Leichen der Zwei Zeugen liegen herum, 110

Lenin, siehe Marx

Leo I. der Große, Heiliger, Papst (440-461)

- beschützt Rom vor Attila und Geiserich, 169

Leovigild, Arianer, Westgotenkönig (568-586)

- verfolgt katholische Christen, 202

Lesart, siehe Schriftauslegung

Letzte Tage, siehe Endzeit

Leuchter

- im Tempel, 15

- Symbol für die sieben Ortskirchen, 12, 19, 23, 26

- Symbol für die zwei Zeugen, 105

Libanius, Neuplatoniker $(† 393)$

- Lobredner Julians, 136

Licinius, Kaiser (307-323), 102

- der siebte König, 131, 184

- einer der sieben Könige, 129

- mit Konstantin Befreier der Christen, 102, 110, 125

- späterer Christenverfolger, 102, 110, 131, 184

Liebe

Lied

- erster Liebe verloren, 26

- Lied des Mose und des Lammes, 171

- neues Lied, 58, 160

Limbus, 60

- Abteilung des Hades, 28

- genaue Erklärung, 28

- Limbusaufenthalt Jesu, 28

Literalsinn, siehe Schriftauslegung

Lortz, Joseph, Historiker (1887-1975)

Löwe

- Urteil über Neuplatonismus, 135

- Christusbezeichnung, 47, 55-57, 62

- Das erste der vier Wesen, 46, 52-54

- Engel brüllt wie ein Löwe, 97, 98

- Löwenköpfe der Pferde, 93, 95
- Löwenmaul des Tieres, 130

- Löwenmaul des Tieres (Diokletian), 128, 129

- Löwenzähne der Heuschrecken, 86, 90, 92

- ruft den 1. Reiter herbei, 62

- Symbol der Stärke, 55

- Symbol des Stammes Juda, 56

- Symbol für das Markusevangelium, 62

- Teufel brüllt wie ein Löwe, 207

- Tierkreissternbild, 53

Lucifer, siehe Morgenstern; Teufel

Ludwig XVI., König von Frankreich (1661-1715), 158

Luft

- Luft durch Rauch verschmutzt, 87

- Schale in die Luft geworfen, 177

Lüge

- Bezeichnung für geheime Sünde, 230

- Bezeichnung für jede Sünde, 236

- keine Lüge im Mund wahrer Christen, 161

- Lügner im Feuer- und Schwefelsee, 220

- Schwören und Lüge, 98

- Verschärfung des Verbots, 161

Luther, Martin (1483-1546) und Protestantismus

- Ablehnung der Heiligenproskynese, 199

- Anlehnung der Heiligenverehrung, 75

- Auslegung der Hure, 181

- freikirchlich-evangelikaler Milleniarismus, 203

- Mariologie, 127

- Schriftprinzip (allein die Schrift), 237

- Schwurverbot, 98

- Täufer in Münster, 203

- Werke und Gnade (Gnadenprinzip), 167

- Zahl 666 ihm zugeschrieben, 158

- konkret-geschichtliche Auslegung der Apk, 9

Lydien, Königreich, 37

Macht über die Völker, siehe auch Weiden, 36

Manna

- Symbol für das eucharistische Abendmahlsbrot, 33

Mantel Christi, Symbol seiner Menschennatur?, 200-202

Marcellus I., heiliger Papst (307-309), 102

Marcus Aurelius, siehe Mark Aurel

Maria, Mutter Christi

- apokalyptische Frau als Urbild der Kirche und als Braut, 116-127, 219, 221, 237

- als Stadt Gottes (Neues Jerusalem), 219, 223

- aus Davids Geschlecht, 236

- im Verhältnis zu den 24 Ältesten, 50

- verschiedene Lehren über Maria, 127

Mark Aurel, Kaiser(161-180)

- Christenverfolger, 63, 108

- Plagen zu seiner Zeit, 108

Märtyrer

- Doppelbedeutung des Wortes, 63, 105

- Einzelpersonen, siehe Antipas, Feuer, Heilige, Ignatius, Justin, Karpos, Polykarp

Marx (1818-1883) und Lenin (1870-1924), Väter des Kommunismus, 154

$\mathrm{Ma}$

- Essensration nach Maß abgewogen, 64 
- Maße des Neuen Jerusalem, 222-223

- Menschen- und Engelmaß, 222

$\mathrm{Maß}, 203$

Maxentius, Kaiser (306-312)

- Christenverfolger, 102, 111, 184

- einer der fünf gefallenen Könige, 184

- einer der sieben Könige, 129, 183

- ertrinkt im Tiber, 111, 184

- Johannes wird in seine Zeit versetzt, 183

- lässt Severus töten, 184

- letzter in Rom residierender Kaiser, 191

- Schreckensherrschaft, 109

- Sohn des Maximianus Herculius, 130

- von Konstantin besiegt, 102, 110, 111, 125, 131, 183, 184

Maximianus Herculius, Kaiser (285-305 und 306-308)

- achter König?, 184

- begeht Selbstmord, 184

- Christenverfolger, 109, 184

- einer der fünf gefallenen Könige, 184

- einer der sieben Könige, 129, 183

- Panther bzw. Leib des Tieres, 130, 184

- tritt 305 zurück, 109

Maximinus Daja, Kaiser (305-313)

- Christenverfolger, 102, 109-111, 124, 125, 129, 183, 184

- der sechste König, 184

- einer der sieben Könige, 129

- schlimmster Christenverfolger, 124

- sein Toleranzedikt, 183

- Tod, 184

- Todesstoß, 183

- Todeswunde, 131

Maximus von Ephesus, Neuplatoniker $(† 371)$

- verführt Kaiser Julian, 136-140

Medaillen, siehe Münzen

Meer

- als Gegensatz zum Feuerberg, siehe Berg

- Symbol für Menschenmenge, Volksmasse, 82, 173 , 191, 215

- Symbol für Menschheitsgeschichte im negativen Sinn (Abgrund, Unruhe), 127, 216, 219

- Symbol für die Taufe, 51

- von Babylon (= Rom) aus zu sehen, 196

- vor Gottes Thron, 51, 171

- wird zu Blut, 82, 173

Megiddo, siehe Harmagedon

Melchisedekianer, 89

Mensch

- Das dritte der vier Wesen, 52-54

- Menschengesichter als Symbol der Harmlosigkeit, 90

- Perioden im Leben des Menschen, siehe Zeitalter

- ruft den 3. Reiter herbei, 65

- das dritte der vier Wesen, 46

Menschensohn

- Christusbezeichnung, 19, 66, 88, 146, 162, 165, 167, 209

Messen und Zählen, siehe auch $\mathrm{Maß}$

- Ausmessen des Neuen Jerusalem, 222-223
- Symbol für Gottes Fürsorge, 102

Messias, der Gesalbte bzw. Christus

- falscher Messias, siehe Apollonius, Bar Kochba

- wahrer Messias, siehe Jesus Christus

Metall

- die sieben in der Antike bekannten Metalle, 144

- Metallrüstung der Panzerreiter, 95

Meteorit, 83

Michael, Erzengel, siehe Engel

Millenniarismus, 203, 204

Mischna, siehe Juden(tum)

Mittelalter, siehe Antike

Mittlerschaft der Engel und Heiligen, siehe Heilige

Mohammed, siehe Muhammad

Monat

- fünf Monate, 87, 91-92

- zweiundvierzig Monate, siehe Zahl, -42

Mond

- kein Mond mehr nötig, 229

- mit Sonne und Sternen Symbol für das Feststehende, 69,71

- Symbol für Veränderlichkeit, 118

- Symbol für die Kirche, 70, 83, 87

Montanus, Irrlehrer (2. Hälfte des 2. Jh.)

Seine- sein extremer Milleniarismus, 203

- sein krasser Milleniarismus, 204

- seine weissagenden Frauen, 35

Moral, siehe Gebote

Morgenstern

- Symbol für Christus, 34, 36, 219, 236

- Symbol für Satan, 89

Moses (um 1450 v. Chr.)

- bringt zehn Plagen über Ägypten, 108

- einer der 24 Ältesten, 51

- einer der Zwei Zeugen?, 106

- erscheint zusammen mit Elias, 106

- verwandelte Wasser in Blut, 106

- vollzieht vor seinem Schwiegervater eine Proskynese, 199

Münzen und Medaillen

- mit Namen laodizenischer Ärzte, 43

- Serapis-Medaillen Julians, 138

- unter Attalus mit Aufschrift Invicta Roma aeterna, 194

- unter Domitian zur Erklärung der 666, 150

Myriade (= 10.000), siehe Zahl

Nacht

- keine Nacht mehr, 229, 230, 232

- Tag und Nacht, d.h. ununterbrochen, 52, 76, 163

Nacktheit, 45

Nahrungsmittelknappheit, siehe Hunger

Name

- Bezeichnet das Wesen, 33

- Bezeichnet die Person, 37, 38

- Jahwe als Name Gottes, Christi und der Dreifaltigkeit, 13-14, 35, 232

- Name Jahwe auf der Stirn, 42, 159, 218, 231, 232

- Name des Lammes (Jesus) auf der Stirn, 159, 232

- Name des Tieres auf Hand und Stirn, 140-141 
- Name, den nur Christus versteht, 200

- Neuer Name Jesu, siehe Immanuel

- Neuer Name der Christen, 33

- Neuer Stadtname: Jahwe ist hier, 42

Napoleon, französischer Kaiser (1804-1814)

- Träger der Zahl 666?, 153

Narses, Feldherr Justinians $(† 568)$

- Beitrag zur Zerstörung Roms, 197

Natalis, erster Gegepapst (um 210?)

- von Theodots Anhängern aufgestellt, 88

Nationalsozialismus, siehe Hitler, Holocaust

Nebukadnezar, babylonischer König (605-562 v.Chr.)

- errichtet ein Standbild, 146

- zerstört Jerusalem samt dem Tempel und führt die Juden in die Gefangenschaft, 81

Nero, Kaiser (54-68), 150

- Erster Christenverfolger, 8, 25, 62, 63, 105, 107, 149, 152

- Erster, fünfter, sechster oder achter König?, 185-188

- Träger der Zahl 666, 149, 152, 157

Nerva, Kaiser (96-98), 185

- kein Christenverfolger, 151

- sechster König, zu dessen Zeit Johannes schrieb?, 187

- siebter König?, 187

- Träger der Zahl 666, 151

- unter ihm Timotheus gesteinigt, 25

Neues Jerusalem (bzw. Kirche)

- Anspielung auf die „Neue Kaiserstadt“, 42

- Ausmessen, siehe Messen

- Beschreibung des Endzustandes, 217-232

- die Stadtpyramide, 222-223

- durch Zion und Jerusalem symbolisiert, 160

- Identifizierung mit Maria, 223

- Symbolik der Länge, Breite und Höhe, 223

Neuplatoniker, siehe Ammonios, Hierokles, Jamblich, Julian, Libanius, Maximus, Pythagoräer, Plotin, Porphyrius

Neuplatonismus (zweites Tier), 134-141

- von Augustinus ,getauft“", 135

Neuzeit, siehe Antike

Nieren, siehe Herz

Nikolaiten, siehe auch Nikolaus

- ihre Eigenart, 25-27

- Prophezeiung ihres Untergangs, 31, 32

- Satanisten, 27, 34, 35, 41

- Träger der Zahl 666, 153

Nikolaus von Antiochia, Diakon (1.Jh.), siehe auch Nikolaiten, 27, 32

Nimrod, Gründer von Babylon (vor 2000 v.Chr.)

- soll Abraham in einen Feuerofen geworfen haben, 153

- Träger der Zahl 666, 153

Noah, Urvater

- einer der 24 Ältesten, 51

- sieben Paare reiner Tiere in seiner Arche, 145

- von Sirach gelobt, 50

Odoaker, Germane vom Stamm der Skiren, aber König der Heruler (476-489/90)

- Beitrag zum Fall Roms, 189, 197
- einer der zehn Könige, 189

- zuerst in römischen Diensten, 190

Öl

- Öl und Wein nicht beschädigt, 64, 65, 196

- Ölbäume als Symbole für die Zwei Zeugen, 105

Omega, siehe Alpha

Orosius, Paulus, Geschichtsschreiber (um 385-418)

- über das Heidentum in antiken Rom trotz der christlichen Kaiser, 193

- über den Verkauf von Goten als Sklaven, 194

- über die Christenverfolgung unter Bar Kochba, 81

- über die Flucht aus Rom, 192

- über Kaiser Valerian bei den Persern, 94

- über Kaiser Julians Plan einer blutigen Christenverfolgung, 132

- über Kaiser Julians Tod, 133

Ortskirchen, die sieben, siehe Kirche; Briefe

Otho, Kaiser (69), siehe Zwischnkaiser

Pachomius, heiliger Mönchsvater (um 290-347), 207

Pantheon, Tempel in Rom, wird in eine christliche Kirche verwandelt, 197

Panther, siehe Maximianus Herculius

Panzer(reiter), siehe Metall, Perser

Papias von Hierapolis, Märtyrerbischof (um 120)

- sein Milleniarismus, 203

- sein Millenniarismus, 204

Papst/Papsttum

- Antichrist und Träger der Zahl 666?, 155-156

- bibliche Grundlagen des Petrusamtes, 155-156, 181, 224-225

- Einzelpersonen, siehe Anastasius, Bonifaz, Benedikt, Gregor, Hippolyt, Innozenz, Leo, Natalis, Petrus, Pius XII., Victor

- Gegenpäpste, siehe Hippolyt, Natalis

- identisch mit der Hure Babylon?, 181

Paradies, 9, 25, 27, 116, 122, 203, 231

- genaue Erklärung, 27

- selige Gottesgemeinschaft, 27, 28

Paula, Heilige († 404), 192

Paulus Orosius, siehe Orosius

Paulus von Samosata, als Irrlehrer verurteilter Bischof (nach 272)

- letzter bedeutender Theodotianer, 89

Paulus, Apostel

- bezeugt das Fegfeuer, 28

- bezeugt Gottesdienste am Sonntag, 18

- Beziehung zum Edelsteinfundament, 225

- Paulus als Ersatzmann für Johannes?, 50

- dreizehnter Apostel, 50

- einer der Zwei Zeugen?, 105

- Engellehre, 48

- Lasterkatalog, 235

- leidet Geburtswehen, 117

- Märtyrertod unter Nero, 25

- nennt Christus den Ertgeborenen der Schöpfung, 44

- seine Himmelfahrt, 27, 225

- seine Timotheusbriefe, 25, 26

- setzt Timotheus als Bischof ein, 25 
- sieht Christen als geistige Israeliten, 74

- sofort nach dem Tod in den Himmel, 166

- über Christen als Gottestempel, 102

- über das Geheimnis Gottes, 99

- über das Gericht der Heiligen, 208

- über das persönliche Gericht, 68

- über den Antichristen, 213

- über den Selbstruhm (missvertanden als Äußerung zum Schriftprinzip), 237

- über die Auferstehung beim Endgericht, 215

- über die Herrlichkeit Gottes im Gesicht Christi, 20

- über die Kirche als Jungfrau, 161

- über die letzte Posaune, 79

- über die Rettung der Juden am Ende der Zeiten, 84

- über die Staatsgewalt, 134

- über die Verdammnis, 164

- über Feindesliebe, 107

- über fortschreitende Herrlichkeit der Gottesschau, 232

- über den geistigen Tod und geistige Auferstehung, 208, 209

- über Gnade, Werke und Lohn, 167, 223

- über Jesus als Spross aus der Wurzel Davids, 56

- über leuchtende Christen, 70

- über Schuldentilgung durch Christi Kreuzestod, 123

- vergleicht gewisse Irrlehrer mit Hunden, 235

- verkündigt Christus überall im römischen Reich, 62

- versteht das Paradies als himmlichen Ort, 27

- wird geopfert, 67

- wirkt in Ephesus, 26

- Worte Jahwes auf den H1. Geist übertragen, 14

Perser, Persien

- Angriff der Panzerreiter (Kataphrakten), 94-96

- greifen den Osten des Reiches an, 173

- Könige, siehe Kyros, Sapor, Xerxes

- sieben Ratgeber des persischen Königs, 17

- Teilnahme an der Zerstörung Roms, 188

Pest, siehe Hunger

Petrus, Apostel

- Alarichs Ehrfurcht vor dem Grab Petri in Rom, 192

- benutzt für Rom den Decknamen Babylon, 181

- einer der Zwei Zeugen?, 105

- ein Tag ist für Gott wie 1000 Jahre, 63

- Gnadenlehre, 167

- Märtyrertod in Rom, 105

- Märtyrertod unter Nero, 25

- Petrusamt, 155-156, 181, 224-225

- Prophetie des Weltuntergangs durch Feuer, 214

- Rede über Judas, 166

- sein Schwertschlag, 134

- spricht von den letzten Tagen, 70

- über die Arche, 145

- wehrt eine Anbetungsproskynese ab, 199

- vergleicht Apostaten mit Hunden, 235

Pferde

- Blut bis zu den Zügeln der Pferde, siehe Blut

- das weiße, rote, schwarze und bleiche, 61-66

- Heuschrecken als Kriegspferde, 90

- Pferdegespanne (rot, schwarz, weiß und gescheckt) bei Sacharja, 72
- Pferdeungeheuer, 95-96

Philostorgius, Geschichtsschreiber († nach 425)

- über den Tod Julians, 134

Pikten, keltischer Stamm

- gehören zu den ,übrigen“ Königen, 202

- verwüsten Britannien, 173

Pius XII., Papst, 1939-1958), 204

Plagen, siehe Ägypten, Erdbeben, Feuer, Finsternis, Geschwür, Hagel, Heuschrecken, Hölle, Hunger, Krankheit, Krieg, Pest, Posaunen, Reiter, Schalen, Siegel, Sonne, Tier, Verfolgung, Zwei Zeugen

Platonische Körper, 49

Plinius der Ältere (23/24-79)

- Hauptquelle für Bedeutung der Edelstein-Namen in der Antike, 224-227

Plinius der Jüngere (um 100) - über Kaiser Domitian, 186

Plotin, Gründer des Neuplatonismus (205-270), 135 - faszinierende philosophische Einsichten, 135 - man baute ihm Altäre, 136

Polykarp, Heiliger, Bischof (um 69-155)

- Bischof und Märtyrer in Smyrna, 29-31, 238

- Schüler des Apostels Johannes, 7

Pontifex Maximus (Julian), 131

Porphyrius, Neuplatoniker (um 233-303)

- Gegner des Christentums, 136

- Kaiser Julian eifert ihm nach, 136

- kommentiert Aristoteles, 135

- man baute ihm Altäre, 136

Posaunen

- die sieben Posaunen, 77-114

- Instrument der Gerichtsankündigung, 77

- letzte Posaune bei Paulus, 79

- Symbol für machtvolles Auftreten, 19

- Untermalung der Stimme Gottes, 77

Prä-Milleniarismus, 203

Priester

- heidnische, 135, 136, 140

- „Lateinischer Priesterkönig“, 155

- Priester Christi im Himmel, 205, 210, 211, 228

- Priesterliches Wirken der 24 Ältesten, 50, 67

- Priestertum Christi, 20, 55

- Priestertum aller Christen, 17, 47, 58

- Priestertum der Engel, 78, 172

. Priester als Engel des Herrn, 23

Privatoffenbarungen, 98

Procopius von Caesarea, Geschichtsschreiber (um 500-562)

- über das Bündnis der Barbaren mit Rom, 190

- über den Gotenkrieg, 190

- über die Dreiteilung des Westreichs, 177

- bedeutentster Geschichtsschreiber der Spätantike, 177

Procopius, Usurpator, öströmischer Kaiser (364-366)

- rebelliert gegen Kaiser Valens, 173

Prokopios, siehe Procopius von Caesarea; Procopius, Usurpator

Propheten

- alttestamentliche Propheten, siehe Daniel, Elias, Ezechiel, Jesaja, Jeremia, Joel, Sacharja, Samuel - andere „Propheten“, siehe Isebel, Montanus, White 
- falscher Prophet (= das zweite Tier), siehe auch Tier, 135, 175, 202

- Neuplatoniker als falsche Propheten, 135-140

Prophetie

- Warnung Jesu vor falschen Propheten, 207

- an welchem Punkt der Prophetie sind wir?, 239

- Apk macht konkrete Vorhersagen, 9

- der Geist der Weissagung ist das Zeugnis Jesu, 198

- ist nicht nur Zukunftsweissagung, 105, 135

- soll nicht versiegelt werden, 233

- Überblick über erfüllte Prophezeiungen, 238-239

- Zeit des Weltendes ist ungewiss, 206-207

Prophetische Perspektive, 113, 198

Prophezeiungen, siehe Prophetie

Proskynese, kniefällige Verehrung, siehe Verehrung und Anbetung

Protoevangelium, 116-118, 120, 121, 127

Pyramide, Form der Stadt Gottes, siehe Neues Jerusalem

Pythagoräer, siehe auch Apollonius

- aus ihnen gehen die Neuplatoniker hervor, 136

Quadratus, Apologet, Prophet (Anfang 2.Jh.)

- Bischof in Philadelphia?, 40

Qual, siehe Plagen

Quellen

- Geschichtsquellen, siehe Geschichtsschreiber

- Quellen(n) des Lebens, siehe Wasser

- Symbol für Stamm- und Mutterland, 83

- Symbol für das Innere des Reoches, 174

Quintus Aurelius Symmachus, siehe Symmachus

Rabbinische Tradition, siehe Abraham; Tradition

Rache, siehe Vergeltung

Radagais, Heide, Ostgotenführer (um 405)

- einer der zehn Könige, 189

- Gott überlässt ihm nicht die Zerstörung Roms, 194

- sein Ansturm gegen Rom, 193

- seine Niederlage, 193, 194

Raphael, siehe Engel

Rauch

- der Rauch ihrer Qual steigt auf, 28, 163

- rauchblaube Metallrüstungen und Rauch aus dem Mund der Pferde, 95-96

- Symbol für Gebete, siehe Weihrauch

- verhüllt Gott, 172

- verschmutzt die Luft, 87

Räucherwerk, siehe Weihrauch

Rauchopferaltar, siehe Juden(tum), -Tempel

Regen, Symbol für Gottes Wort

- von den Zwei Zeugen zurückgehalten, 108

Regenbogen, Symbol des Friedens

- auf dem Haupt eines Engels, 98

- Farben der Edelsteinfundamente des Neuen Jerusalem, 226-228

- seine sieben Farben, 144

- um Gottes Thron, 48

Reiter

- Christus als erster apokalyptischer Reiter, 61-62, 200 203
- die vier apokalyptischen Reiter, 61-66

- Reiterheer Christi, 201, 202

- Reiterheer der Hunnen, 168, 169

- Reiterheer der Perser, 95-96

Rekkared, Westgotenkönig (586-601), 190

Respendial, König der Alanen (um 406)

- einer der zehn Könige, 189

Richter, siehe Vergeltung, Kommen, Heilige, Gericht, Rot

Riese, siehe Goliath

Robinson, John Arthur Thomas, Kommentator (1919-1983), 187

Rot

- charakterisiert Gott als Richter, 48

- Farbe von Blut, Feuer und Wut, 63

- scharlachrot als Farbe der Könige, 182

Ruhetag vom Samstag auf den Sonntag verlegt, 19, 139

Sabbatgebot, siehe Ruhetag

Sacharja, Prophet (um 520 v.Chr.)

- vergleicht die Klage beim göttlichen Gericht mit der Klasse von Megiddo, 176

- Vision von vier Pferdegespannen, 72

- Vision von zwei Ölbäumen, 105

- Weissagung von Christi Durchbohrung, 8

Sachsen, Germanenvolk

- gehören zu den zehn Hörnern, 188

- kämpfen auf Seiten Roms, 190

Salomon, König von Israel (969-930 v.Chr.)

- sein Sündenfall, 146

- von Sirach mehr getadelt als gelobt, 50

Salvian von Marseille, Geschichtsschreiber (bis kurz vor 480) - über das Lästern der Heiden, 175

Samstag

- Ruhetag vom Sa auf den So verlegt, siehe Ruhetag

- Tag der Grabesruhe Christi, 145

Samuel, Prophet (ca. 1115-1010 v. Chr.)

- einer der 24 Ältesten?, 51

- von Sirach gelobt, 50

Sapor (Schapur) I., Perserkönig (240-270)

- lässt Kaiser Valerian töten, 95

- nimmt Kaiser Valerian gefangen, 94

Sarazenen, arabisches Volk, 188

Satan, siehe Teufel

- Gott dieser Zeit, 118

- Machthaber über den Tod, 127

Satanismus, siehe auch Crowley; Isebel; Nikolaiten, 27, 34, $36,153,155,206,213$

Säule - Synagoge Satans, 41

- an Säulen angebrachtes antichristliches Schreiben, 109

- des Wüstenheiligtums, 148

- Füße eines Engels wie Feuersäulen, 98

- wer siegt, wird eine Säule im Tempel Gottes sein, 42 Schalen

-die sieben Zornesschalen, 170-177

-gefüllt mit den Gebeten der Heiligen, 58

Schapur, siehe Sapor

Scharlachrot, siehe Rot

Scheeben, Matthias Joseph, Dogmatiker (1835-1888) 
- seine Auslegung der apokalyptischen Frau, 118 Schiffe

- ein Drittel der Schiffe zerstört, 82

- Schiffsbesitzer werden beklagt, 196

Schlacht, siehe Krieg

Schlagen der Völker, siehe Weiden

Schlange

- Bezeichnung und Symbol des Teufels, 32, 115-118, 120-122, 125-127, 147, 157, 204, 205

- Pferde mit Giftschlangenschwänzen, 93, 96

Schlüssel

- Symbol des Asklepios, 32

- Schlüssel Davids, siehe David

- Schlüssel des Todes und des Hades, 23

Schrift, Tradition und Lehramt, siehe auch Tradition, 237, 238

Schriftauslegung

- antik-geschichtliche Auslegung, 9, 10, 79

- endgeschichtliche Auslegung, 8-10, 79, 113, 114, 198, 212-235

- katholische Positionen, 44, 117, 127, 156, 165, 203 , 205,230

- kirchengeschichtliche Auslegung, 9, 10, 61-64, 66, 79,170

- Kommentatoren der Apk, siehe auch Adventisten, Alcazar, Allo, Andreas, Arius, Athanasius, Augustinus, Beda, Berengaudus, Bossuet, Calmet, Cornelius, Crowley, Edmundson, Feret, Hieronymus, Iannuzzi, Irenäus, Justin, Luther, (Papias), Pohl, Robinson, Scheeben, Zeugen Jehovas, 8-10, 240241

- Literalsinn und verborgene Sinne, 10

- mehrdimensionale Auslegung berechtigt, 10, 183

- mehrere Lesarten und Übersetzungsmöglichkeiten, 89 , 127, 133

- nicht jede Einzelheit muss unbedingt eine besondere Bedeutung haben, 82

- ungenaue Übersetzung, 68

Schürer, Historiker (1844-1910)

- über Aquila und Theodotion, 84

- über den Bar-Kochba-Krieg, 82, 83

Schwanz

- der Heuschrecken, siehe Skorpion

- der Pferdeungeheuer, siehe Schange

- des Teufelsdrachen, 120

Schwarz

- Farbe des Irrglaubens, 65

Schwefel

- Feuer und Schwefel in der Hölle, 163, 220

- Feuer- und Schwefelsee in der Hölle, 214

- schwefelfarbene Metallrüstungen und Schwefel aus dem Mund der Pferde, 95-96

Schwert

- Das mit dem Schwert erschlagene Tier, 128, 138

- Ein Schwert ging durch Marias Seele, 119

- Im Zusammenhang mit Tötung, 25, 35, 62, 65, 66, $128,133,134$

- Im Zusammenhng mit Tötung, Leid und Vernichtung, 29
- Symbol für Gottes Wort, 12, 20, 31, 32, 107, 200-202

Schwören, erlaubtes, 98

Sechs, siehe Zahl

Sechshundert, siehe Zahl

Sechshundertsechsundsechzig, siehe Zahl

Sechshundertsechzehn, siehe Zahl

Seele

- gegen die Seelenschlaf- und Seelentodtheorie, 30, 166, 196, 202

- inwiefern sterben Seelen?, 173

- vom Leib verschieden, 82, 196

- das Blut als „Ort“ der Seele, 67

- das Römische Reich als seelenloser Körper, 173

Sekten, siehe Irrlehrer

Senatoren

- heidnische Senatoren im christlichen Rom, 193

- von Barbaren zum Tod verurteilt, 191

Septimius Severus, siehe Severus

Serapis, ägyptischer Gott der Unterwelt

- auf Medaillen Julians, 138

Sertillanges, Antoin-Gilbert, Philosoph und geistlicher Schriftsteller (1863-1948)

- Meinung zum Tausendjahrreich, 206

Serubbabel, jüdischer Statthalter (um 538-515 v.Chr.)

- Typus für einen der Zwei Zeugen, 105, 106

- von Sirach gelobt; einer der 24 Ältesten?, 50

Severus (Flavius Severus), Kaiser (305-307), 102

- Christenverfolger, 109, 184

- einer der fünf gefallenen Könige, 184

- einer der sieben Könige, 129, 183

Severus (Julius Severus) Feldherr Hadrians (2. Jh.), 81

Severus (Septimius Severus), Kaiser (202-208)

- Christenverfolger, 63

Severus (Sulpicius Severus), Geschichtsschreiber (um 363425)

- über die Verfolgung des Licinius, 131

Sibylle von Thyatira, 34, 35

Sieben, siehe Zahl

Siebentausend, siehe Zahl

Siegel

- Buch mit den sieben Siegeln, 38

- Charakter und Sinn der Siegelvisionen, 61

- die sieben Siegelvisionen, 61-78

- Johannes soll die Apk nicht versiegeln wie einst Daniel sein Buch, 234

- Schutzwirkung des Siegels bei versiegelten 144.000 Israeliten, 73

- Schutzwirkung des Siegels auch bei versiegelten Nichtisraeliten, 90

- Symbol für Verborgenheit und Würde, 55

- Versiegelung als Symbol für die (durch die Firmung vollendete) Taufe, 72-73

- Versiegelung des Abgrunds, 207

Sigismund, Burgunderkönig (516-523), 190

Silesius, siehe Angelus Silesius

Simon Bar Kochba, siehe Bar Kochba

Sirach, siehe Jesus Sirach

Skiren, Germanenvolk

- gehören zu den zehn Hörnern, 188 
Skorpion

- Heuschrecken mit Skorpionschwänzen, 86, 90, 92, 93

- Skorpion-Monat Oktober/November, 91

- Tierkreissternbild, 53

Skoten, keltischer Stamm

- gehören zu den „übrigen“ Königen, 202

- verwüsten Britannien, 173

Sodom

- Deckname für Rom, 110, 192

- Sodom und Gomorrha, 165

- Sodomie, siehe Homosexualität

Sokrates, Kirchengeschichtsschreiber (um 380-440)

- über Neuplatoniker als Ratgeber Kaiser Julians, 136 Sonne

- Engel steht in der Sonne, 200, 202

- Engel vom Aufgang der Sonne, 71

- Keine Sonne mehr nötig, 218, 229, 232

- Sonne des Reiches, 170

- Sonnenglanz als Gnadenlicht, 97, 98, 115, 118

- Sonnengott Helios, 134

- Sonnengott Mithras, 132

- Sonnengott und Lichtgott Apollon, 158

- Sonnenhitze als Plage, 75, 76, 170

- Sonnenhitze als Plage der vierten Schale, 174

- Steht für Christus und seine Gottheit, 12, 21, 69-72, $83,87,115,118,174,227$

- Symbol für das Feststehende, 71

- Verfinsterung, 69-71, 83, 86, 87, 146

Sonntag, siehe Auferstehung, Tag, Ruhetag

Sozomenus, Kirchengeschichtsschreiber (um 400-450)

- über Alarichs Sendungsbewusstsein, 191

- über die Pest im belagerten Rom, 194

- über die Verschonung der Peterskirche durch Alarich, 192

- über ein Bild Kaiser Julians, 138, 140

- über heidnische Opfer im christlichen Rom, 193

Staatsreligion, siehe Theodosius

Stab, siehe Weiden

Stadion, antike Längeneinheit, 169, 222

Stämme Israels, siehe Juden(tum)

Stein, weißer

- Eintrittskrate und Freispruch-Symbol, 33

Sterben, siehe Tod

Sternbilder, 53, 91, 143

Sterne, siehe auch Sternbilder, 223, 225

- Apostel, 70, 87, 115, 118, 119

- Bar Kochba, 83, 154, 238

- Bischöfe (Gemeinde-Engel), 12, 20, 23, 25, 26, 36, $37,70,145$

- ein Stern geht auf in Jakob, 83

- Glaubenslehrer und Vorbilder, 69, 70, 83, 120

- Irrlehrer, 70, 79, 83, 87, 120

- mit Sonne und Mond Symbole für das Feststehende, $69,71,79$

- Morgenstern, 34, 36, 89, 219, 236

- Satan und Dämonen, 79, 86, 87, 89, 90, 115, 120

- Sternbilder, 53, 143, 144

- Theodot, 88

- Volk der Heiligen, 70
Stier

- Das zweite der vier Wesen, 46, 52-55

- ruft den 2. Reiter herbei, 63

- Symbol des Priestertums Christi, 55

- Tierkreissternbild, 53

Stilicho, römischer Feldherr, Sohn eines Vandalen und einer Römerin (um 362-408)

- kämpft gegen Radagais, 189

- unter ihm kämpfen Nichtrömer auf Seiten Roms, 190 Stimme

- Christi Stimme, 19, 101

- Gottes Stimme, siehe auch Donner, 172, 177, 192

- als furchterregendes Symbol Gottes, siehe Blitze

Strabo, Geograph (um 63 v.Chr. - nach 23 n.Chr.), 40

Stunde, siehe Tag

Sueben, Sueven, Schwaben, Germanenvolk

- gehören zu den zehn Hörnern, 188

Sueton, Geschichtsschreiber (um 79-122)

- über Claudius; erwähnt Christus, 186

Sulpicius Severus, siehe Severus

Sünden, siehe Laster; Gebote

Symmachus, Quintus Aurelius (um 342-402/3), heidnischer Stadtpräfekt von Rom, 193

Täufer in Münster, 203

Tag, siehe auch Freitag, Nacht, Ruhetag, Samstag, Sonntag

- 3 1/2 bzw. 1260 Tage, siehe Zahl

- Sonntag der Orthodoxie, 64

- Tag des Herrn = Herrentag = Sonntag, 18

- „Tag“ und „Stunde“ als Symbole für eine kurze Übergangszeit, 194

- „Tag“ und „Stunde“ als Symbole für eine kurze Übergangszeit, 190

- ,Tag und Stunde“ des Endgerichts kennt niemand, 207

Talent, Gewichts- und Währungseinheit; ca. $30 \mathrm{~kg}$ bzw. in etwa der Preis eines Segelschiffes, 64, 177

Talmud, siehe Juden(tum)

Taufe, siehe auch Siegel, 72-73

- Arche als Sinnbild der Taufe, 145

- durch den Namen auf der Stirn symbolisiert, 160

- Getaufte bleiben verschont, 80

- Münsteraner Täuferbewegung, 203

- Meer als Symbol für die Taufe, 51

- Taufe als „zum Leben kommen“, 209-210

- Taufbefehl als Beleg für die Dreifaltigkeitslehre, 232

- ,Taufe“ des Neuplatonismus, 135

- von Julian verhöhnt, 132

- weißes Kleid der Neugetauften, 38

Tausend, siehe Zahl

Tausendjähriges Reich, 10, 203-211

- Beginnt schon vor Christi Wiederkehr, 204

- Chiliasmus und (Prä-)Millen(n)iarismus, 203

Tausendsechshundert, siehe Zahl

Tausendzweihundertsechzig (Tage), siehe Zahl

Teitan oder Titan, Bezeichnung des Antichristen?, 150, 158

Tempel, siehe auch Judentum, -Tempel

- himmlischer und jüdischer Tempel, siehe Juden(tum)

- Innen- und Außenhof, siehe Hof

- kein Tempel mehr im Neuen Jerusalem, 229 
- Öffnung des himmlischen Tempels als Symbol für die Eröffnung des Strafgerichts, 172

- Öffnung des himmlischen Tempels als Symbol für einen neuen Zugang zu Gott, 114

- salomonischer Tempel, 51

- Symbol für die Kirche, 42, 102

- Umwandlung heidnischer Tempel in christliche Kirchen, 197

Tertullian, frühchristlicher Autor (nach 150-nach 220)

- bezeugt, dass Polykarp vom Apostel Johannes zum Bischof geweiht wurde, 29

- über Kaiser Domitian, 186

Tertullus, heidnischer Konsul im christlichen Rom (410), 193 Teufel

- Abaddon und Apollyon, 93

- bekämpft das Festhalten an den Geboten und am Zeugnis Jesu, 126

- böser Engel, 90, 158

- Diabolos = Verleumder, 122

- Drache, siehe Drache

- Engel des Lichts (Lucifer), 158

- Engelfürst dieser Welt, 120

- Fürst dieser Welt, 146

- geht wie ein brüllender Löwe umher, 207

- Gott dieser Zeit, 146

- hat böse Engel (Dämonen) auf seiner Seite, 87, 115, $117,120,121$

- Herrscher dieser Welt, 205

- kämpft gegen die Kirche, 116, 122-126

- Lucifer, 89, 158

- Morgenstern, 89

- Satan, 17, 31, 32, 87, 89, 90, 93, 115-127, 130, 146, 147, 203-208, 212, 213, 238

- Satan = Widersacher, Ankläger, 116, 122, 123

- Schlange, siehe Schange

- Schwanz des Teufels, 120

- seine Fesselung und Entfesselung, 203-214

- Stern, vom Himmel gefallen, siehe Stern

- Sturz aus dem Himmel, 89, 115, 116, 121, 122, 124 126

- Sturz aus der Position als Ankläger, 123

- Sturz in die Hölle, 214

- Thron Satans in Perganom, 31

- verführt die Völker, 208

Theodizee, siehe Zulassung des Bösen

Theodoret von Cyrus, Geschichtsschreiber und Kirchenlehrer (um 393-458)

- Stellungnahme zum Diakon Nikolaus, 27

- über Kaiser Julians Tod, 134

- wie Kaiser Julian die Christen dem Heidentum weihte, 141

Theodorich, Ostgotenkönig (471/474-526), Arianer, 189

- Beitrag zum Fall Roms, 197

- im Zusammenhang mit den zehn Königen, 189

- verfolgt (katholische) Christen, 202

Theodosius, Kaiser (379-395)

- Reichsteilung nach seinem Tod, 174

- erhebt das Christentum zur Staatsreligion, 174
Theodot aus Byzanz, der Schuster/Gerber, Irrlehrer (um 190), 195

- Träger der Zahl 666, 154

- vom Himmel gefallener Stern, 88-92

Theodot der Bankier/Geldwechsler (um 210), 89

Theodotion, siehe Aquila

Theudebert I., Frankenkönig (533-548), 189

- Beitrag zur Zerstörung Roms, 197

- im Zusammenhang mit den zehn Königen, 189

Theurgen, neuplatonische Wundertäter, 135

Thrasamund, Vandalenkönig (496-523), Arianer - verfolgt katholische Christen, 202

Thron, Throne

- Engelsklasse der „Throne“ (Thronengel), 48

- Gottes Thron im Himmel, 27, 48

- Thron Satans, siehe Teufel

- Thron des Endgerichts, 214

- Thron des Tieres, siehe Tier

- Throne der 24 Ältesten, 48

- Thronwagen Gottes, 52

Tier, siehe auch Drache, Lamm, Köpfe, Hörner, Prophet

- Aufgefressenwerden von Tieren, Symbol ehrlosen Untergangs, 66, 202

- Ruinen, nur noch von Tieren bewohnt, 192

- siebenköpfiges und zehnhörniges Tier, 129-133, 182191

- Thron des Tieres, 174

- zweihörniges Tier, 134-141

- zwei Tiere in die Hölle gestürzt, 202

Tierkreissternbilder, siehe Sternbider

Timotheus, Heiliger, Paulus-Schüler (Märtyrertod 97)

- Bischof von Ephesus, 25-26

- Paulus schreibt ihm über das Glaubensgeheimnis, 99

Titan, siehe Teitan

Titus, römischer Feldherr, später (79-81) Kaiser, 185

- belagert Jerusalem, 64

- schont Öl- und Weinpflanzungen, 64

- sein Sendungsbewusstsein, 191

- siebter König?, 186

- Träger der Zahl 666?, 150

- zerstört Jerusalem, 64, 81, 150, 191

Tod, Tote, Sterben

- Ende des „ersten Todes“, 216

- steht für die Pest, 66

- steht für eine tödliche Krankheit, 35

- Sterben als Versinken im Elend, 173

- Sterben der Seele, 173

- Tod der Christenverfolger, siehe Verfolgung

- Tote des Meeres, des Todes und des Hades, 215

Toleranzedikt, siehe Galerius, Konstantin, Maximinus Daja

Tolstoi, Leo, Schriftsteller (1828-1910)

- über Napoleon und die Zahl 666, 153

Tote, siehe Tod

Töten, Tötungsverbot

- das Tötungsverbot gilt nicht für Gott, 35

- Gilt für Christen ein absolutes Tötungsverbot?, 134

- inwiefern die „Zwei Zeugen“ töten, 107

- Tötungsabsicht als Töten gerechnet, 197

- Tod als Strafe für das Töten, 133-134 
- vier Engel töten 1/3 der Menschen, 95

Totila, Ostgotenkönig (541-552), 189

- Beitrag zur Zerstörung Roms, 197

- im Zusammenhang mit den zehn Königen, 189

- plündert Rom, 196

Tötungsverbot, siehe Töten

Tradition, siehe auch Schrift, Tradition und Lehramt

- Aqibas Traditionen als Grundstock der Mischna, 84

- Auslegungstradition über die Schlange, 32

- der Kirche von Smyrna über Polykarp, 29

- ehrbare Traditionen und Kulturleistungen der Völker in Gottes Stadt, 229

- fehlerhafte Tradition über Karpus, 31

- jüdisch-christliche Tradition über 3 1/2 Jahre als Typus einer Verfolgungszeit, 103

- rabbinische über Abraham und Nimrod, 153

- rabbinische in Mischna und Talmud, 84

- Teitan-Titus-Tradition?, 150

- über den Engel Uriel, 168

- über die Namen der sieben Engel, 17

- über feststehende Verdammnis abgefallener Engel, 165

- über Johannes, 7, 8, 19

- über Petrus, 181

- über Theodotion, 84

- über Timotheus, 25, 26

- von Papias empfangene ungeschreibene Tradition über das Tausendjahr-Reich?, 204

- von PAPIAS empfangene ungeschriebene Tradition über das Tausendjahr-Reich?, 203

Trajan, Kaiser (98-117), 185

- Der Achte König?, 187

- Dritter Christenverfolger, 41, 63, 151, 152

- Mitregent Nervas, 151

- Niederschlagung des jüdischen Aufstandes, 81

- Reichsweite Verfolgung, 107, 187, 238

- Träger der Zahl 666, 151-152

Traubenernte, siehe Getreideernte und Traubenernte

Trinität, siehe Dreifaltigkeit

Tür des Herzens, 17, 41, 45

Übersetzung(smöglichkeiten), siehe Schriftauslegung

Ubertino von Casale, Kommentator (um 1259-1330)

- bezieht die Zahl 666 auf einen Papst, 156

Überzeitlichkeit Gottes, 68, 133, 206

Uldis, Hunnenkönig (um 400-408)

- Verbündeter der Römer, 190

Umweltzerstörungen vorhergesagt, 114

Unendlich, siehe Zahl, unzählbar

Unzählbar, siehe Zahl, unzählbar

Uriel, Erzengel, siehe Engel

Valens, oströmischer Kaiser (364-378)

- lässt Goten ins Reich einwandern, 190

- wird von Procopius bekämpft, 173

Valentin Weigel, siehe Weigel

Valerian, Kaiser (253-260), Christenverfolger, 94, 95, 102, 103, 108, 112, 133, 195

Vandalen, Germanenvolk, siehe auch Verfolgung

- als Christenverfolger, 202
- berühmte Vandalen, siehe Geiserich, Guntharich, Fridibald, Stilicho

- dienten den Römern, 190

- fallen in Italien ein und plündern Rom, 169, 196, 197

- gehören zu den zehn Hörnern, 188

- kämpfen im Heer des Radagaie, 193

- überschwemmen das Reich, 173

- Vernichtung des Vandalenreiches, 190

Verdienst, siehe Werke

Verehrung und Anbetung

- abgewiesene Anbetung eines Engels, 180, 198, 218, 233

- Anbetung Christi, siehe Jesus Christus, - Gebete zu Christus, ihm dargebrachte Verehrung und Anbetung

- Anbetung des Drachen, 128, 131

- Anbetung des „Bildes des Tieres“, 140

- berechtigte Bilderverehrung, 139

- berechtigte Verehrung von Engeln und Heiligen (Heiligenproskynese), 199

- Jesu Haltung zum Kaiserbild, 138

- „Mein Herr“ als ehrfürchtige Anrede eines himmlischen Heiligen, 75

- Verehrung des Bischofsamtes (Proskynese), 41

Verfinsterung, siehe Finsternis

Verfolgung

- Befreiung durch Konstantin und Licinius, 102, 110113,125

- Caudius als erster Christenverfolger?, siehe Claudius

- Christenverfolgung durch die Juden unter Bar Kochba, 71,83

- Judenverfolgung unter Antiochus IV. als Muster für spätere Verfolgungen, 103, 121

- Judenverfolgungen, 81-83

- Letzte endzeitliche Verfolgung, 69, 74, 208, 212-214

- Plagen gegen die Christenverfolger, 108-112, 133134

- Todesart der Verfolger, 94-95, 133-134, 184

- Verfolgung und Toleranzedikt des Galerius, siehe Galerius

- Verfolgung unter Decius, siehe Decius

- Verfolgung unter Diokletian, siehe Diokletian

- Verfolgung unter Domitian, siehe Domitian

- Verfolgung unter Julian, siehe Julian

- Verfolgung unter Licinius, siehe Licinius

- Verfolgung unter Maximinus Daja, siehe Maximinus Daja

- Verfolgung unter Nero, siehe Nero

- Verfolgung unter Trajan, siehe Trajan

- Verfolgung unter Valerian, siehe Valerian

- Verfolgung vonseiten der Barbaren (vor allem Goten und Vandalen), 202

- Verfolgung, bei der Polykarp starb, 29-30

- Zehn römische Christenverfolgungen, 63

- unter Caligula Gefahr der Verfolgung des Volkes Gottes, siehe Caligula

Vergeltung

- Aufforderung zur Vergeltung an Rom, 194

- Bitte der Märtyrer um Vergeltung, 68-69 
- christlicher Racheverzicht, Verbot der Privatrache, 107, 134

- Christus vergilt jedem nach seinen Werken, 35, 234

- erlaubte Vergeltung durch den Staat, 134

- gerechte Vergeltung gepriesen, 174

- Vergeltung an den Christenverfolgern, 133

- Vergeltung beim Endgericht, 214

Verhütung, künstliche, siehe Giftmischerei

Versammlung, siehe Kirche

Versiegelung des Buches, der Getreuen und des Abgrundes, siehe Siegel

Vespasian, Kaiser (69-79), 185

- im Zusammenhang mit der Deutung der Zahl 666, 150

- sechster König; schrieb Johannes zu seinen Zeiten?, 186

Vestalinnen, heidnische Priesterinnen, 193

Victor, Heiliger, Papst (189-198/9)

- schließt Theodot aus der Kirche aus, 88

Victoria, Siegesgöttin, 193

Victorin von Pettau, Heiliger, Kommentator (um 230-303), erster lateinischer Exeget, 186

Vier, siehe Zahl

Vierundzwanzig, siehe Zahl

Vierzehn, siehe Zahl

Viktor, siehe Victor

Viktorin, siehe Victorin

Vitellius, römischer Kaiser (69), siehe Zwischenkaiser

Vogel, siehe Adler; Tier

Völkerschlacht bei den Katalaunischen Feldern, siehe Krieg

Völkerwanderung, siehe auch Hieronymus; Basilius; Barbaren, $71,95,173,176,177,188,189,197,201,239$

- nach dem Fall Roms, 239

Voraussagen, siehe Prophetie

Vorherwissen Gottes, siehe Buch; Überzeitlichkeit Gottes

Waage

- Symbol der (Schein-)Gerechtigkeit, 65

- Symbol der Lebensmittelrationierung, 64

Waffen, heimtückische, siehe Heimtücke

Wasser (Quelle, Quellen) des Lebens, 77, 220, 223, 230, 231, 237

Wasser als Symbol der Menschenmenge, siehe auch Meer, Flüsse, Quellen, 191

Weh, die drei, 9, 80

- 1 . Weh $=5$. Posaune, $86-93$

- 2. Weh $=6$. Posaune, 93-112

- 3. Weh $=7$. Posaune, $112-203$

- Anfang der Wehen, 63, 64

- Ankündigung durch einen Adler, 84

- Vorankündigung des 3. Weh, 124

- Zusammenfassung der drei Weh, 79, 112, 195, 238239

Weiden mit eisernem Staß und Zerschlagen von Tongefäßen, Symbol für machtvoll-fürsorgliche Regierung

- Christi, 201

- der Heiligen, 34, 36

Weihrauch

- Benutzung im Gottesdienst, 78

- Symbol für Gebete, 47, 58, 77, 78
Wein

- Wein und Öl nicht beschädigt, 64, 65, 196

- Zorneswein Gottes, 163, 176

- Zorneswein ihre Unzucht, 181

- Zorneswein ihrer Unzucht, 163

Weintraubenernte, siehe Traubenernte

Weiß, Farbe der Reinheit und des Lichts, siehe auch Haare, Kleider, Stein, 62

- Farbe Christi, 62

- Farbe des Thrones für den Weltenrichter, 214

Weissagung, siehe Prophetie

Weiße Haare, siehe Haare

Weiße Kleider, siehe Kleider

Weißer Stein, siehe Stein

Weizen und Gerste, 64, 65, 82

Weltbevölkerungszahl in der Antike, 95

Weltenbrand, 214

Weltende, siehe Endzeit

Weltuntergang, 127, 214

Weltwunder, die sieben, 26

Werke und Gnade, 166-167

Wesen, die vier, siehe Engel

White, Ellen Gould Harmon (1827-1915), „Prophetin“, siehe Adventismus

Wiederkehr

- Christi, siehe Jesus Christus, -Wiederkehr; Kommen Christi

- Elijas, 106

- Henochs, 106

- Jeremias, 106

- Neros, 186

Winde, die vier, 53, 61, 72

- bei Daniel, 72

- bei Sacharja, 72

- Engel der Winde, 54, 174

- Unheilsgestalten der vier ersten Siegelvisionen, 72

Witigis, Ostgotenkönig (536-540), 189

- Beitrag zur Zerstöung Roms, 197

- im Zusammenhang mit den zehn Königen, 189

Wolken

- Symbol der Zugehörigkeit zu Gott, 98

Wort Gottes

- Christusbezeichnung, 8, 55, 62, 200, 201, 223

- Durch das Schwert symbolisiert, 20, 201

Wunder

- Christi, 201

Würfel

- falscher Propheten, 135-137, 140

- das Neue Jerusalem hat nicht die Form eines Würfels, 222

- Platonischer- platonischer Körper, 49

- Symbol der Stabilität, 147

Wurzel und Geschlecht Davids, siehe David

Wüste

- Ort, wo Johannes die Hure sah, 182

- Wüste Sinai, 124

- Zufluchtsort verfolgter Christen, 118, 121, 124-126, 132 
Xerxes, Perserkönig (485-465 v.Chr.)

- stellt das größte Heer der Antike auf, 95

Zahl

- 1/10 (ein Zehntel), 111

- 1/3 (ein Drittel), 80-83, 93-96, 147

- 2/3 (zwei Drittel), 147

- 2 (zwei), 48

- 3 (drei), 48, 52, 177

- 3 1/2 (dreieinhalb) (Jahre, Tage oder Zeiten), 103, 110, 124,126

- 4 (vier), 48, 53, 59, 198

- 5 (fünf) (z.B. fünf Monate), 49, 81, 86, 87, 91-93

- 6 (sechs), 104, 143, 145-147

- 7 (sieben), 103, 104, 143-145

- 8 (acht), 145, 148

- 10 (zehn), 29, 30, 63, 108, 115, 147, 206

- 12 (zwölf), 49

- 14 (vierzehn), 104

- 24 (vierundzwanzig), 46, 48-50

- 42 (zweiundvierzig) (Monate), 103-104, 110, 126, 128, 132

- 100 (hundert), 206

- 144 (hundertvierundvierzig), 217, 222

- 600 (sechshundert), 146

- 616 (sechshundertsechzehn), 129, 141, 149, 151-152, 157

- 666 (sechshundertsechsundsechzig), 141-158

- 800 (achthundert), 145

- 888 (achthundertachtundachtzig), 145, 160

- 1000 (tausend), siehe auch Tausendjähriges Reich, 68, $73,111,147,169,206$

- 1260 (zwölfhundertsechzig) (Tage), 103-104, 106$107,110,115,121,126$

- 1600 (tausendsechshundert) (Stadien), 162, 168, 169

- 7000 (siebentausend), 111

- 10.000 (zehntausend) (Myriade), 93, 95

- 12.000 (zwölftausend), 222

- 144.000 (hundertvierundvierzigtausend), siehe auch Heilige, 73

- 200.000.000 (zweihundert Millionen), 95

- Anzahl der Menschen im Römischen Reich, 103

- Dreieckszahl, 147, 148

- magische Zahl, 147

- unzählbar, 74, 75, 165

- Weltbevölkerungszahl in der Antike, 95

- Zahl der Engel, 47, 58

- Zahl des Tieres, siehe 666

- Zahl eines Namens (666) auf der Stirn, 141, 160

- Zahlenwerte von Buchstaben, 142, 153, 154, 156

Zählen, siehe Messen und Zählen

Zehn, siehe Zahl

Zehntausend (Myriade), siehe Zahl

Zehntel, siehe Zahl

Zeichenhandlungen

- Ein Engel misst Jerusalem aus, 217

- Ein Engel wirft einen Stein ins Meer, 196

- Johannes misst den Tempel aus und zählt seine Anbeter, 101
- Johannes verschlingt ein Buch, 97

Zeitalter

- der Kirchengeschichte, 61-66

- Perioden im Leben des Menschen, 91, 144

Zeiten

- bestimmte Zeitangaben, siehe Zahl

- Endzeit, siehe Endzeit

Zeitprophezeiungen, siehe Prophetie

Zentner, siehe Hagel und Talent

Zeremonien, alttestamentlich-jüdische, siehe Juden(tum), -Zeremonialvorschriften

Zerschlagen der Völker, siehe Weiden

Zeugen Jehovas

- Auslegungung von Apk 3,14b, 44

- identifizieren sich mit den Heuschrecken, 89

- Lehre über das Tausendjahr-Reich, 203

Zeugen, zwei, siehe Zwei Zeugen

Zeugnis, die Gesetzestafeln, 172

Zorn Gottes

- inwiefern Gott zornig genannt wird, 163

- Zorneswein Gottes, siehe Wein

Zorobabel, siehe Serubbabel

Zosimus, heidnischer Geschichtsschreiber (um 500)

- über Alarichts Gras-Spruch, 168

- über die Pest im belagerten Rom, 194

- über Lebensmittelrationen in Rom bei der ersten Belagerung Alarichs, 194

Zulassung des Bösen durch Gott bzw. Christus, 62, 201, 234

Zwei, siehe Zahl

Zwei Zeugen, siehe auch Feuer; Regen; Töten, 104-112

Zweihundert Millionen, siehe Zahl

Zweite Auferstehung, siehe Auferstehungl

Zweiter Tod, siehe Tod

Zweiundvierzig (Monate), siehe Zahl

Zwischenkaiser des Jahres 69 (Galba,Otho, Vitellius)

- gehören sie zu den sieben Königen?, 186-187

- Teil einer Kaiserreihe, deren Anfangsbuchstaben die Zahl 666 ergeben?, 150

Zwölf, siehe Zahl

Zwölfhundertsechzig (Tage), siehe Zahl

Zwölftausend, siehe Zahl 